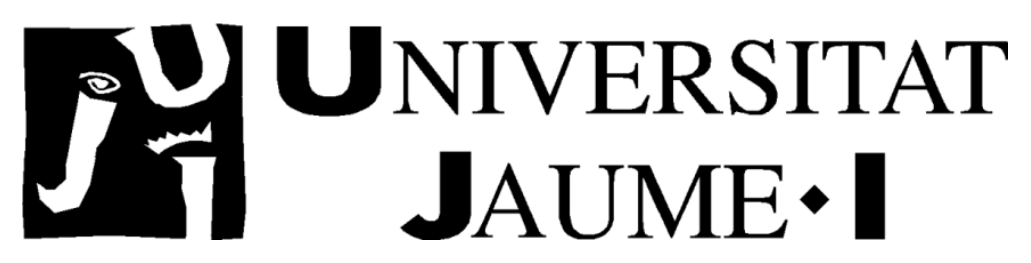

Facultad de Ciencias de la Salud

Departamento de Psicología Básica, Clínica y Psicobiología

\title{
Prevalencia, comorbilidad y correlatos psicológicos de la compulsividad sexual
}

TESIS DOCTORAL

Presentada por: Jesús Castro Calvo

Dirigida por: Rafael Ballester Arnal

María Dolores Gil Llario

Castellón de la Plana, 2017 

Esta tesis doctoral se ha realizado gracias a una ayuda predoctoral para la formación de personal investigador concedida por la Universitat Jaume I de Castellón (PREDOC/2012/51) y a un proyecto financiado por el Ministerio de Ciencia e Innovación (PSI2011-27992). 

De los millones de letras que integran las miles de palabras incluidas en los cientos de párrafos que dan cuerpo a esta tesis, las pocas que aquí vierto tienen para mí un significado especial. Su importancia no reside tanto en su contenido como en su intención; aquí me permito echar la vista atrás y rendir agradecimiento sincero a las personas que, de un modo u otro, han hecho posible la elaboración de esta tesis doctoral.

De entre todas ellas, me gustaría agradecer especialmente su dedicación y guía a los directores de este trabajo, la Dra. María Dolores Gil y el Dr. Rafael Ballester. A ellos quisiera agradecer el coraje de explorar la frontera donde la sexualidad linda con la psicopatología, la generosidad de hacerme partícipe de tan apasionante trabajo y la dirección y apoyo en la elaboración de este trabajo. Ha sido, es y será un privilegio crecer profesional y personalmente a vuestro lado. También me gustaría expresar mi agradecimiento a las personas que durante los últimos seis años han formado parte del equipo de investigación Salusex-Unisexsida, y en especial a Bea, Cris y Pedro. Primero, mentores; más tarde, compañeros; ahora, amigos. De vosotros no he echado nunca en falta palabras de apoyo y aliento.

En estas líneas no podía faltar mi familia, la que siempre me ha acompañado y la que entró en mi vida hace ya unos años, siempre presente conformando mi red de apoyo. A ellos les debo, entre otras muchas cosas, mi educación -la formal y sobre todo la de los valores-. De mi padre aprendí el valor del trabajo, la constancia y la responsabilidad, de mi madre el apasionamiento y de su conjunción, el equilibrio entre la acción y la reflexión.

A los ya mencionados he de sumar mi especial agradecimiento a la persona que me ha acompañado durante los últimos siete años, responsable en calidad de musa, amante y sostén de que hoy pueda estar escribiendo estas líneas. Lorena, tanto te debo que ni tan siquiera la escritura me permite su expresión, de modo que me limitaré a agradecerte que camines a mi lado en los buenos momentos, que tires de mí cuando las fuerzas flaquean y que me empujes hacia delante cuando crees -tú mejor que nadie- que todavía puedo dar más de mí.

No me gustaría terminar estos agradecimientos sin mencionar a los cientos de chicos y chicas que participaron en nuestra investigación. Ellos, leitmotiv del trabajo al que estas palabras dan apertura, compartieron con nosotros una parte muy importante de su intimidad y gracias a su colaboración, hoy nos acercamos un poco más a uno de nuestros objetivos más ambiciosos: mejorar el cuidado de todos aquellos pacientes cuya calidad de vida en general y sexual en particular se ve mermada por la dificultad para controlar sus impulsos sexuales. 

¿Eres tú aquel Virgilio, aquella fuente que derrama tan ancho raudal de elocuencia? iAh! iHonor y antorcha de los demás poetas! Válgame para contigo el prolongado estudio y el grande amor con que he leido $y$ meditado tu obra. Tú eres mi maestro y mi autor predilecto; tú solo eres aquel de quien he imitado el bello estilo que me ha dado tanto honor. Mira esa fiera que me obliga a retroceder; líbrame de ella, famoso sabio, porque a su aspecto se estremecen mis venas y late con precipitación mi pulso.

Dante a Virgilio, canto primero de la divina comedia, Infierno, edición de 1979. 



\section{ÍNDICE}

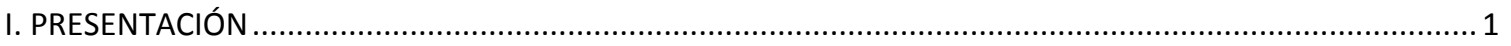

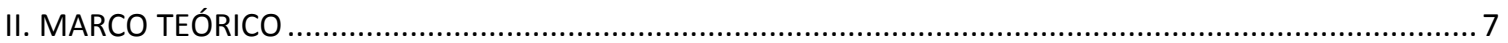

Capítulo 1. Concepto y descripción del cuadro clínico de compulsividad sexual .......................................9

1. Introducción al estudio de la conducta sexual excesiva ........................................................... 10

2. El problema de la terminología en el estudio de la compulsividad sexual .....................................15

3. Definiciones de la compulsividad sexual: visión categorial vs. dimensional ..................................... 16

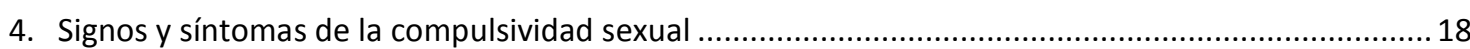

4.1 Síntomas conductuales: frecuencia sexual .............................................................. 19

4.2 Síntomas emocionales: uso del sexo como regulador emocional ................................... 22

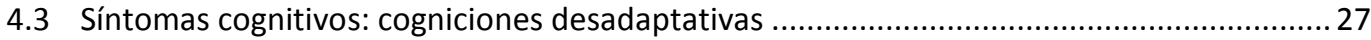

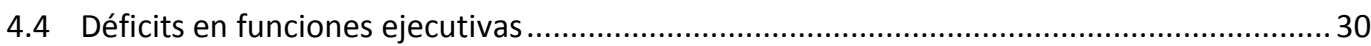

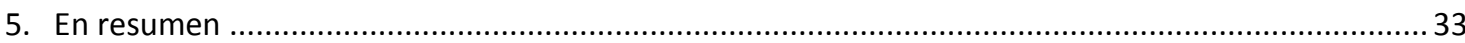

Capítulo 2. Evaluación, diagnóstico y clasificación de la compulsividad sexual ........................................35

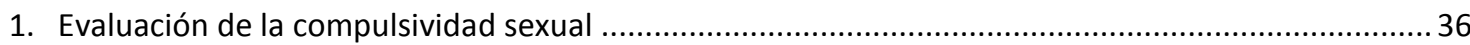

1.1 Introducción a la evaluación en CS ......................................................................... 36

1.2 Nivel 1: evaluación de la presencia y gravedad de los síntomas de CS..............................39

1.3 Nivel 2: descartando el origen orgánico de los síntomas de CS.......................................48

1.4 Nivel 3: descartando que los síntomas formen parte de un trastorno del Eje I o II ............ 49

2. El diagnóstico de la compulsividad sexual en los manuales DSM .................................................5 51

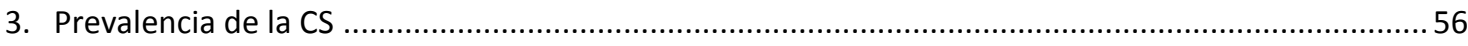

4. Comorbilidad psicopatológica: prevalencia de trastornos del Eje I y II en personas con CS...............60

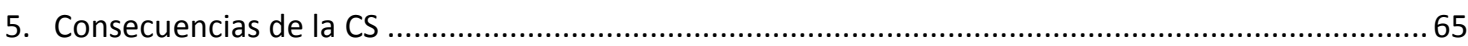

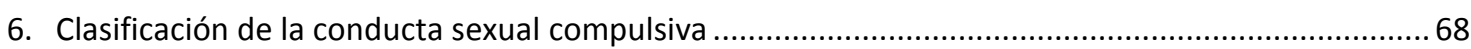

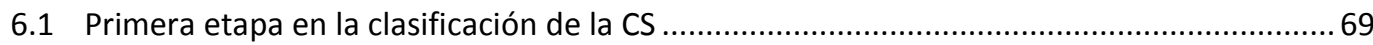

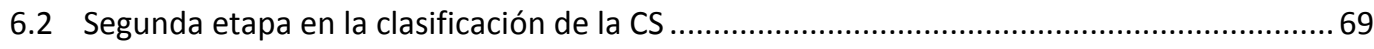

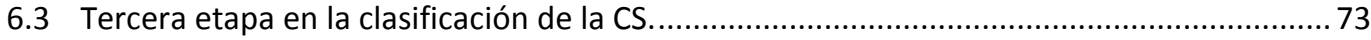

6.4 Análisis de propuestas de clasificación: ventajas, limitaciones y nuevos desarrollos .......... 79

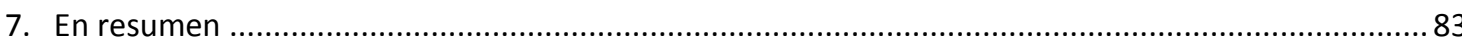




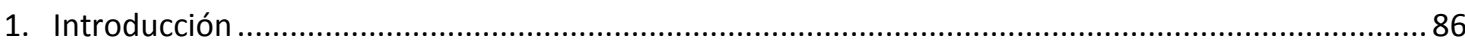

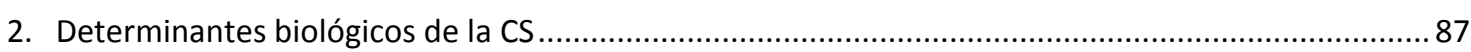

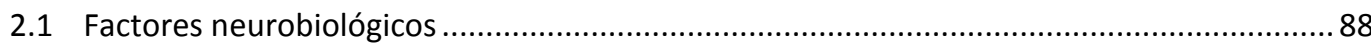

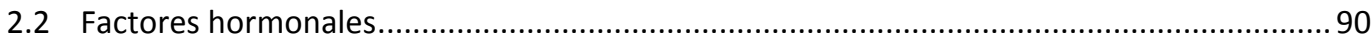

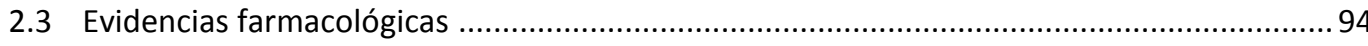

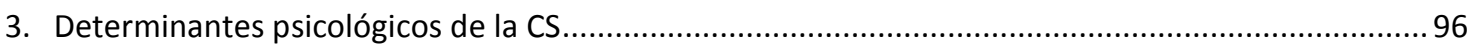

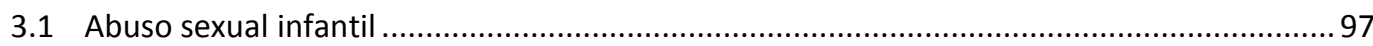

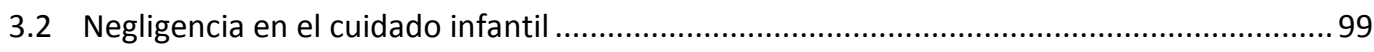

3.3 Estilos de apego y vinculación afectiva ...................................................................... 101

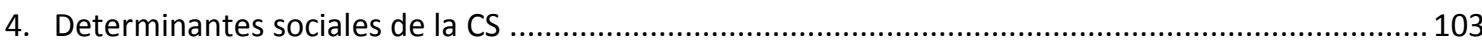

4.1 Entorno social y cultural como facilitador de la emergencia de la CS ................................ 104

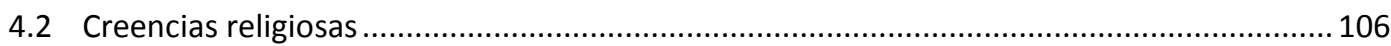

5. Modelos teóricos acerca de la entidad nosológica de la CS...................................................... 107

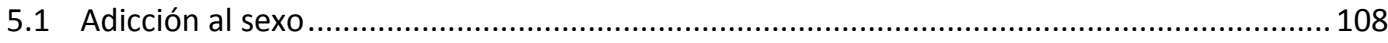

5.2 Control de los impulsos: conducta sexual compulsiva vs. impulsiva ................................. 113

5.3 Regulación del deseo sexual: hipersexualidad y modelo de control dual........................... 120

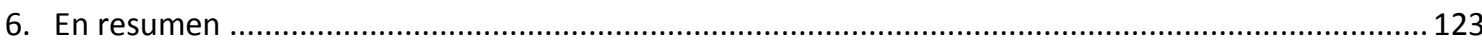

Capítulo 4. Variables moduladoras en compulsividad sexual: principales hallazgos ................................ 127

1. Variables sociodemográficas de interés en la manifestación y gravedad de la CS ..........................128

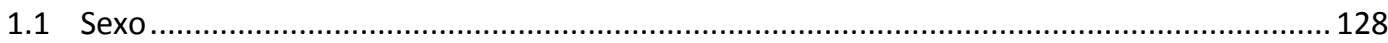

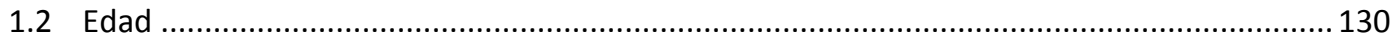

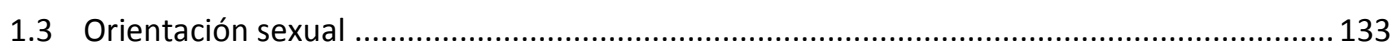

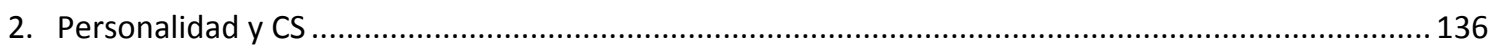

3. Historia sexual, comportamiento sexual y disposiciones sexuales ............................................... 143

3.1 Historia sexual y comportamiento sexual ................................................................. 143

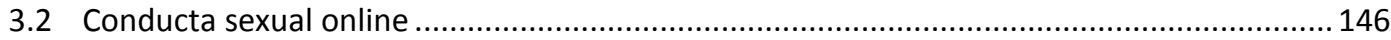

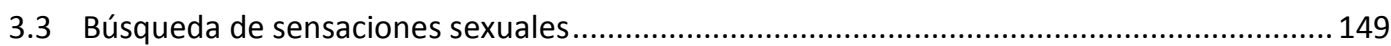

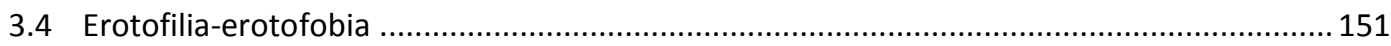

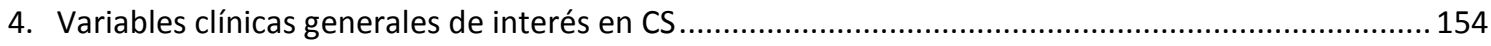

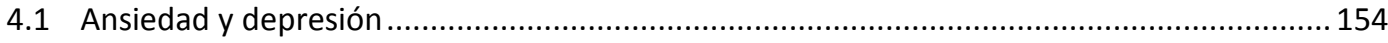

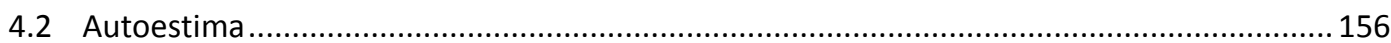

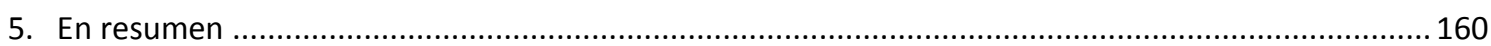

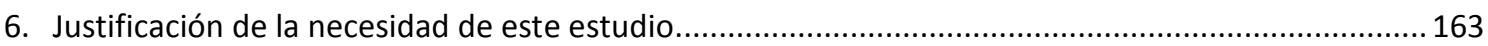




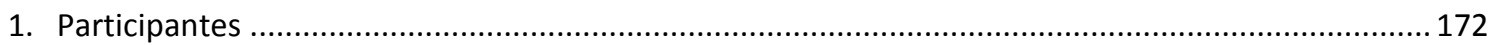

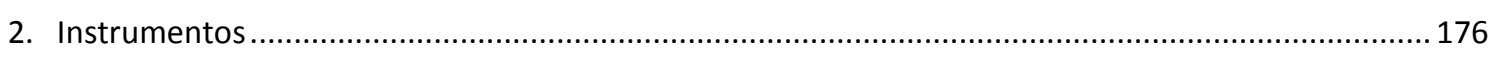

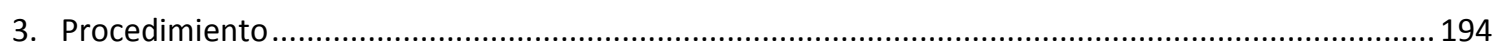

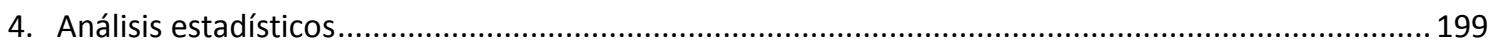

1. Screening de la CS: puntuación, prevalencia clínica e influencia de variables demográficas .............204

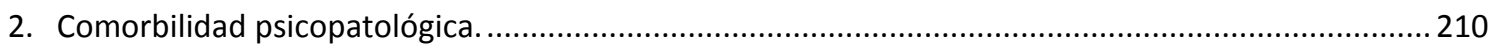

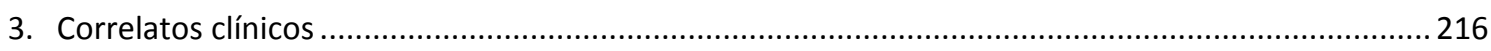

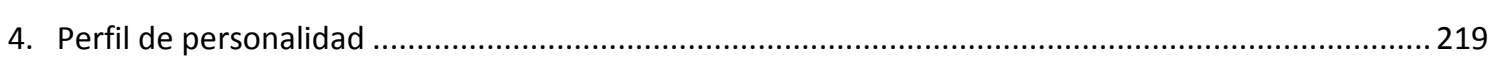

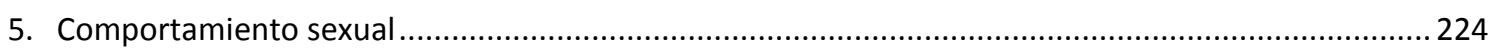

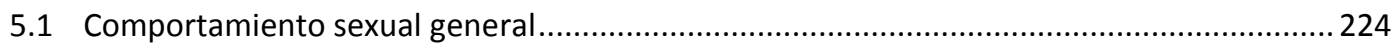

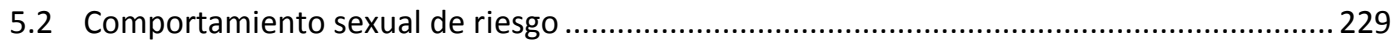

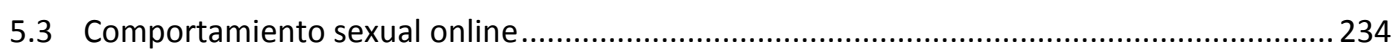

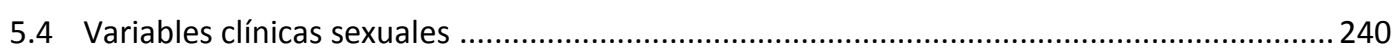

5.5 Evaluación hormonal: determinación del nivel de testosterona ........................................ 243

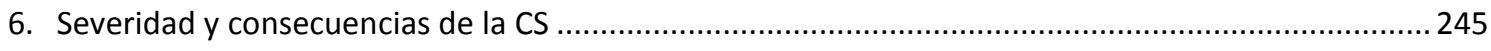

7. Capacidad predictiva de un modelo de regresión logística con interacción del sexo.........................249

8. Propuesta de un modelo de relaciones estructurales a través de metodología SEM ........................265

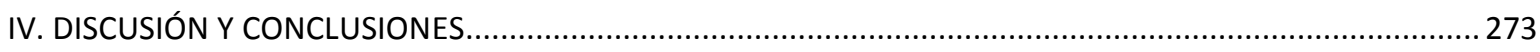

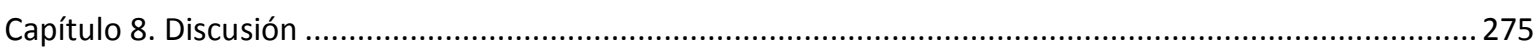

1. Fase I: características y prevalencia del cuadro clínico de CS en población joven ..............................278

2. Fase II: perfil biopsicosocial de jóvenes con puntuaciones subclínicas en CS .................................288

2.1 Comorbilidad psicopatológica con trastornos del Eje I y II. ..............................................290

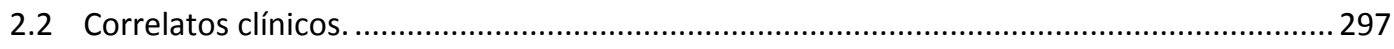

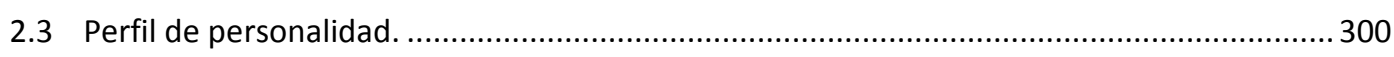

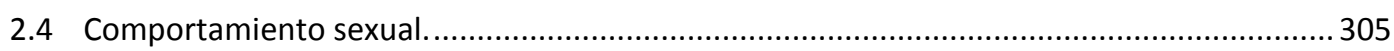

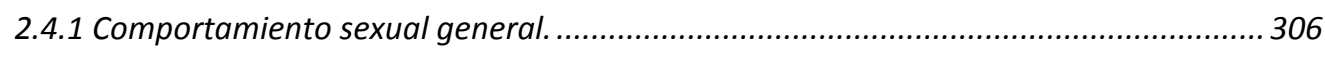

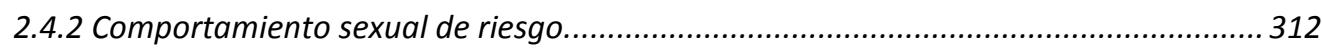




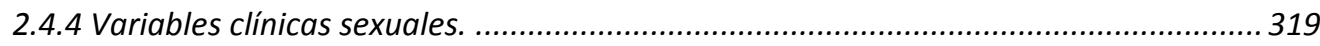

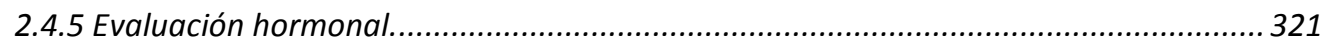

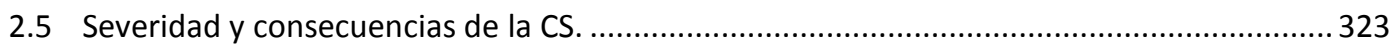

2.6 Modelos predictivos y explicativos del cuadro clínico de CS. .......................................... 326

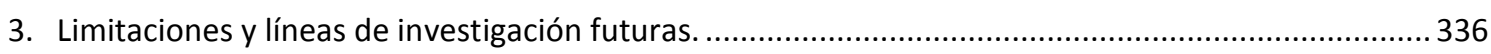

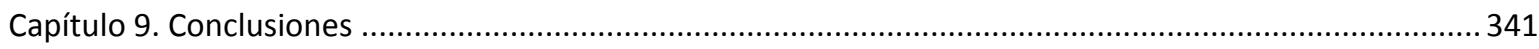

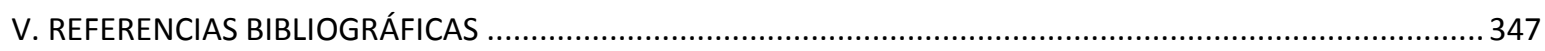

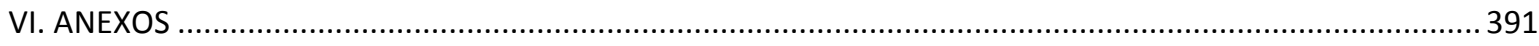




\section{ÍNDICE DE TABLAS}

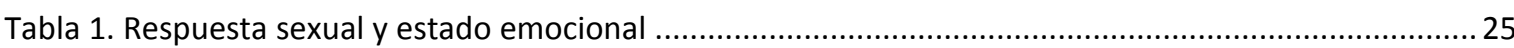

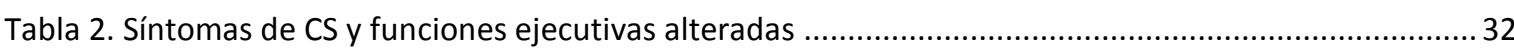

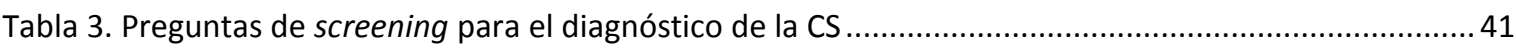

Tabla 4. Criterios diagnósticos para el trastorno por hipersexualidad propuestos para su inclusión en el DSM-V.

Tabla 5. Prevalencia de CS en población general y poblaciones especiales a partir de diferentes criterios diagnósticos.

Tabla 6. Comorbilidad entre compulsividad sexual-trastornos del Eje I (prevalencia a lo largo de la vida) .. 62

Tabla 7. Comorbilidad entre compulsividad sexual y trastornos del Eje II (prevalencia a lo largo de la vida)

Tabla 8. Consecuencias derivadas de la conducta sexual compulsiva 67

Tabla 9. Características de los participantes en la primera fase del estudio 172

Tabla 10. Características de los participantes en la segunda fase del estudio 175

Tabla 11. Distribución de los cuestionarios de la primera y segunda fase de la investigación 176

Tabla 12. Fiabilidad $(\alpha)$ de las escalas y subescalas en la primera y segunda fase de la investigación 193

Tabla 13. Estadísticos descriptivos y puntuaciones clínicas en las tres escalas de screening de la CS 204

Tabla 14. Estadísticos descriptivos y puntuaciones clínicas en función del sexo 206

Tabla 15. Estadísticos descriptivos y puntuaciones clínicas en función de la orientación sexual ..... 208

Tabla 16. Correlaciones ( $r$ ) entre la edad y las tres escalas de screening de la CS 208

Tabla 17. Puntuaciones clínicas en función de la edad 209

Tabla 18. Prevalencia de patologías del Eje I y II en chicos y chicas control y subclínicos 211

Tabla 19. Puntuación media en el cuestionario STAI, BDI y RSEI en chicos y chicas control y subclínicos..... 218

Tabla 20. Distribución de chicos y chicas control y subclínicos en categorías clínicas según el nivel de ansiedad (STAI), depresión (BDI) y autoestima (RSEI).

Tabla 21. Puntuaciones en las 5 dimensiones y 36 facetas del NEO PI-R en chicos y chicas control y subclínicos

Tabla 22. Comportamiento sexual en chicos y chicas control y subclínicos.

Tabla 23. Orientación del deseo sexual en chicos y chicas control y subclínicos 
Tabla 25. Puntuaciones en la escala de severidad percibida del VIH en chicos y chicas control y subclínicos

Tabla 26. Autoeficacia en el uso del preservativo en chicos y chicas control y subclínicos

Tabla 27. Prevalencia de diferentes comportamientos sexuales online en chicos y chicas control y subclínicos

Tabla 28. Puntuación media en las 5 dimensiones y la puntuación total del Cuestionario de Adicción al Cibersexo en chicos y chicas control y subclínicos

Tabla 29. Perfiles de consumo de cibersexo en chicos y chicas control y subclínicos.

Tabla 30. Variables clínicas sexuales en chicos y chicas control y subclínicos

Tabla 31. Niveles de testosterona en saliva en chicos y chicas control y subclínicos

Tabla 32. Puntuación media en la escala general y las subescalas del CSBI y el CBOSB en chicos y chicas subclínicos

Tabla 33. Prevalencia de consecuencias conductuales de la CS en chicos y chicas subclínicos

Tabla 34. Correlación entre severidad y consecuencias de la CS en chicos y chicas subclínicos 248

Tabla 35. Tabla de clasificación de valores observados y pronosticados por el modelo de regresión logística..... 250

Tabla 36. Variables incluidas en el modelo de regresión logística binaria jerárquica ..... 252

Tabla 37. Índices de bondad de ajuste para los distintos modelos 269

Tabla 38. Identificación de las variables contempladas en los 3 modelos SEM

Tabla 39. Tamaño muestral de la categorización a partir del perfil de puntuaciones, el sexo y la orientación sexual 


\section{ÍNDICE DE FIGURAS}

Figura 1. Síntomas conductuales, cognitivos y emocionales de la CS ............................................... 18

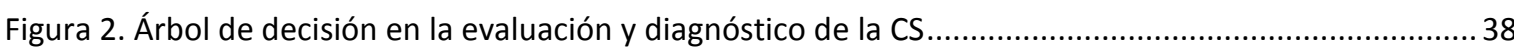

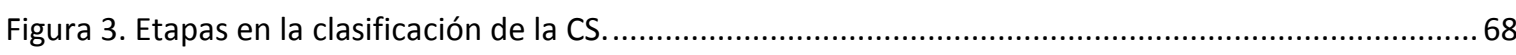

Figura 4. Síntesis de las tres principales clasificaciones de la CS..................................................... 82

Figura 5. Porcentaje de pacientes que afirmaron haberse visto afectos por distintas condiciones ............. 96

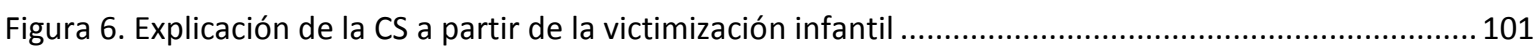

Figura 7. Distribución por edades de los participantes en la segunda fase del estudio............................174

Figura 8. Diagrama de flujo del procedimiento de reclutamiento de participantes .................................. 195

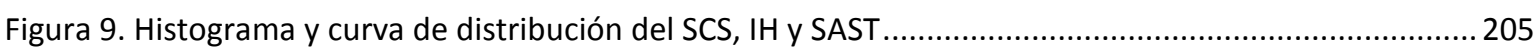

Figura 10. Representación gráfica del perfil de puntuaciones en el NEO PI-R de chicos y chicas control y subclínicos

Figura 11. Curva ROC de precisión diagnóstica de los valores predichos por el modelo de regresión logística.

Figura 12. Probabilidad de ser clasificado como subclínico en función del sexo y la edad.

Figura 13. Probabilidad de ser clasificado como subclínico en función de padecer o haber padecido abuso o dependencia del alcohol

Figura 14. Probabilidad de ser clasificado como subclínico en función de dos facetas de neuroticismo (vulnerabilidad e impulsividad).

Figura 15. Probabilidad de ser clasificado como subclínico en función de dos facetas de extraversión (gregarismo y emociones positivas).

Figura 16. Probabilidad de ser clasificado como subclínico en función de las faceta de estética (apertura) y sensibilidad (amabilidad)

Figura 17. Probabilidad de ser clasificado como subclínico en función de haber realizado o no masturbaciones mutuas.

Figura 18. Probabilidad de ser clasificado como subclínico en función de tener o no pareja estable y de haber realizado otro tipo de conductas sexuales

Figura 19. Probabilidad de ser clasificado como subclínico en función de la autoeficacia en el uso del preservativo

Figura 20. Probabilidad de ser clasificado como subclínico en función de la puntuación total en el cuestionario ISST 
Figura 21. Probabilidad de ser clasificado como subclínico en función de la puntuación en la escala de búsqueda de sensaciones sexuales (BSS)

Figura 22. Probabilidad de ser clasificado como subclínico en función del nivel de ansiedad-estado (STAI-

Estado) y depresión (BDI).

Figura 23. Representación gráfica de los tres modelos de ecuaciones estructurales propuestos

Figura 24. Variables que definen los perfiles de alto y bajo riesgo en función del sexo 


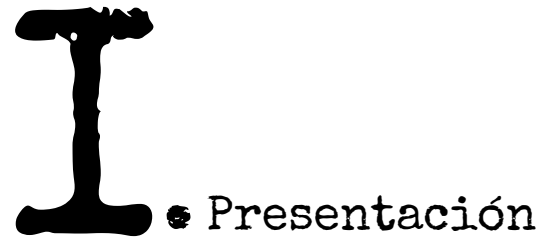



Durante los últimos años, el comportamiento sexual compulsivo ha atraído la atención de clínicos e investigadores. Utilizando una nomenclatura muy variada (satiriasis, hipersexualidad, compulsividad sexual, etc.), distintos autores han descrito un cuadro clínico caracterizado por "una preocupación intensa y repetitiva por fantasías sexuales, impulsos y conductas que llevan a la persona a experimentar consecuencias adversas y un malestar clínicamente significativo en áreas como el trabajo, el entorno social u otros aspectos de la vida de la persona" (Derbyshire \& Grant, 2015, p. 37). Este interés se ha traducido en un incremento exponencial del número de publicaciones que tratan de arrojar luz sobre las incógnitas que todavía planean sobre este fenómeno; tal ha sido su crecimiento que durante la última década se han publicado de forma periódica revisiones -e incluso metanálisis- que integran bajo un marco común estos avances (Gold \& Heffner, 1998; Kafka, 2010; McBride, Reece, \& Dodge, 2011; Mick \& Hollander, 2006).

Pero su reciente popularidad en el ámbito científico no significa que la conducta sexual compulsiva sea un problema contemporáneo. En el imaginario popular -en ocasiones reflejo de miedos atávicos que amenazan a todas las sociedades y épocas- se ha manejado con cierta frecuencia la idea de que para algunas personas, su deseo sexual desmedido y descontrolado puede suponer un problema; prueba de ello son los mitos clásicos sobre sátiros y ninfas incapaces de reprimir su impulso sexual o el personaje literario de Don Juan, atribuido a Tirso de Molina pero replicado en multitud de obras posteriores. A ellos les debemos términos como donjuanismo, satiriasis (sólo para hombres) o ninfomanía (mujeres), utilizados en ámbitos académicos para designar el cuadro clínico de compulsividad sexual.

La primera descripción clínica de un caso de compulsividad sexual data del año 1812. Ese año, el Doctor Benjamin Rush publica un manual sobre psiquiatría en el que dedica un capítulo a lo que denomina "estados mórbidos del apetito sexual"; ahí, Rush describe el caso de un hombre que "a pesar de sentirse repugnado por sus propensiones venéreas, es incapaz de resistirlas" (Rush, 1812, pp.348, citado en Finlayson et al., 2001). Durante el siglo XIX, pioneros del estudio de la sexualidad como Krafft-Ebing (1840-1902), Havelock Ellis (1859-1939) o Magnus Hirshfeld (1868-1935) publicaron trabajos en los que presentaban casos clínicos de hombres y mujeres cuyo apetito sexual resultaba desmedido y desadaptativo (Kafka, 2010). De entre ellos, el que describió con mayor precisión aspectos que posteriormente han resultado claves para definir la compulsividad sexual ha sido Krafft-Ebing (Finlayson et al., 2001). En su obra Psychopathia Sexualis (Krafft-Ebing, 1965), este autor analizaba el caso de un paciente cuyo apetito sexual era tan elevado que todos sus esfuerzos se dirigían exclusivamente a su satisfacción, sin que la sucesión de relaciones sexuales le supusiera finalmente disfrute alguno. 
En la actualidad, la compulsividad sexual acumula casi igual número de críticos y defensores. Uno de los principales argumentos en su contra está relacionado con la construcción social de la normalidad sexual. Como en cualquier tópico en sexualidad, los límites entre lo considerado normal y patológico dependen de la norma social dominante, determinada en gran medida por el contexto político, religioso, económico y cultural (Foucault, 1990; Gagnon \& Simon, 2009). Si convertimos este estándar social en criterio clínico, entonces es casi imposible distinguir una verdadera patología -aquella que interfiere en la calidad de vida del individuo- de lo que sólo se considera como tal por desviarse de la norma impuesta (Tiefer, 2004). Esta crítica resulta especialmente relevante habida cuenta del lastre que pesa hasta nuestros días a consecuencia de la aplicación radical de normas sociales y culturales a la conducta sexual: la consideración de la homosexualidad como enfermedad, la estigmatización de las mujeres que mantienen relaciones sexuales con parejas esporádicas, el tabú -y discriminación- en torno a las personas cuyo género no corresponde con su sexo biológico, etc.

Otros han centrado sus críticas sobre las consecuencias que puede suponer un diagnóstico de compulsividad sexual: Coleman (1995) advertía que terapeutas con tendencias o actitudes más conservadoras podrían encontrar en este diagnóstico la excusa para patologizar una conducta sexual que consideraran desviada -consideración fundamentada más en principios morales que clínicos-; por su parte, Giuglano (2004) apuntaba que el diagnóstico de compulsividad sexual respondía más a una necesidad de someter a control -y en algunos casos medicalizar- la conducta sexual que a un interés genuino en el cuidado de la salud y calidad de vida sexual.

Lo cierto es que se podrían enumerar muchos más ejemplos de investigadores que discuten las bondades y limitaciones de este diagnóstico, pero existe un caso paradigmático que resume las principales posiciones. En 2006, dos autores suecos con dilatada experiencia en el estudio de la sexualidad humana realizaron una investigación en la que trataban de responder a la pregunta de cuánto se consideraba demasiado sexo (Långström \& Hanson, 2006b). Estos investigadores concluían que la frecuencia sexual predecía la aparición de ciertas consecuencias adversas (menor salud en general y salud sexual en particular, problemas familiares, etc.) pero sólo si la actividad sexual se realizaba en solitario (masturbación) o con parejas esporádicas. Ese mismo año, Giles (2006) publicó una carta al editor de esa misma revista en la que criticaba que los autores se limitaban a estigmatizar unas prácticas sexuales con las que moralmente no estaban de acuerdo, equiparándolos en ciertos momentos con San Agustín de Hipona. En respuesta, Långström y Hanson zanjaban la cuestión de la siguiente manera: "estamos de acuerdo con que valores morales, entendidos de forma general, han determinado nuestro interés por realizar una investigación sobre conducta sexual (...). Pero más que motivados por 
una disconformidad moral con el sexo con parejas esporádicas, nuestra preocupación es para con el sufrimiento de las personas que buscan ayuda por el conjunto de problemas que se han llamado adicción al sexo, conducta sexual compulsiva o de forma más neutra, hipersexualidad" (Långström \& Hanson, 2006b, p. 643).

Como en el caso que se acaba de citar, los que defienden la importancia del reconocimiento de la conducta sexual compulsiva tienen como fin último mejorar la calidad de vida de las personas que viven con esta patología; tampoco es menos lícita la postura de sus detractores, que nos advierten de los riesgos reales que supone patologizar ciertos aspectos de la conducta sexual. Como apuntaban McBride, Reece y Dodge (2011), que se alcance el consenso depende de que seamos capaces de encontrar evidencias que asocien ciertos patrones disfuncionales de conducta sexual a la concurrencia de consecuencias negativas, y eso sólo se puede lograr avanzando en el estudio empírico de este fenómeno.

Partiendo de esta idea, la presente tesis doctoral busca explorar aquellos aspectos a los que el creciente número de publicaciones en este ámbito ha prestado menor atención. En concreto, sus principales objetivos son determinar la prevalencia de problemas en el control de impulsos sexuales en población joven e identificar el perfil biopsicosocial que caracteriza a los que presentan un riesgo mayor de desarrollar este cuadro clínico. El hecho de plantear un estudio empírico sobre comportamiento sexual compulsivo a nivel nacional ya supone una aportación a este campo habida cuenta de que en nuestro país, únicamente se han publicado trabajos de corte teórico como el de Echeburúa (2012). A eso se ha de sumar que este trabajo centra su atención en un sector habitualmente ignorado en este tipo de estudios (jóvenes con una manifestación de la compulsividad sexual por debajo del umbral para su diagnóstico), que lo hace atendiendo de forma integral al conjunto de factores biopsicosociales que afectan sobre su manifestación temprana y severidad y que además lo hace prestando especial atención a su estudio desde una perspectiva de género.

A tal fin, la presente tesis se divide en tres secciones principales. La primera (marco teórico) comprende cuatro capítulos a lo largo de los cuales se revisan exhaustivamente los principales antecedentes teóricos en el estudio del comportamiento sexual compulsivo. El primer capítulo se dedica a su conceptualización, y más concretamente a su ubicación en el continuo de deseo sexual, a la revisión de la terminología clásica y contemporánea empleada para su designación, la presentación de las principales perspectivas en cuanto a su definición y categorización y la enumeración de los signos y síntomas cardinales que lo caracterizan. El objetivo del segundo capítulo es ahondar en los aspectos relativos a su diagnóstico clínico, de modo que comienza con una revisión de las variables e instrumentos que se emplean con más frecuencia en su 
evaluación en contextos clínicos así como los criterios para su diagnóstico mediante los principales manuales diagnósticos al uso (DSM y CIE). A continuación se expone su prevalencia, las tasas de comorbilidad con otros cuadros psicopatológicos y sus graves consecuencias en distintos ámbitos (médico, legal, personal, familiar, etc.), para terminar enumerando distintas propuestas de clasificación de las manifestaciones de la conducta sexual compulsiva. En el tercer capítulo se ha tratado de responder a dos preguntas: ¿qué factores biopsicosociales influyen sobre el inicio y mantenimiento de la conducta sexual compulsiva y qué teorías se han propuesto a la hora de explicar su entidad clínica y nosológica? Por su parte, el cuarto capítulo se ha reservado con el fin de presentar los hallazgos que distintos estudios han realizado en torno a las principales variables consideradas en esta tesis: variables sociodemográficas (sexo, edad y orientación sexual), personalidad, historia, comportamiento y disposiciones sexuales y variables clínicas generales (ansiedad, depresión y autoestima).

En la segunda sección de la tesis doctoral (estudio empírico) se describen detalladamente los aspectos vinculados a la metodología empleada a la hora de desarrollar la investigación. Una de las características diferenciales que definen este estudio es que se ha llevado a cabo en dos fases, de modo que la exposición de los objetivos e hipótesis (quinto capítulo) y la descripción de la muestra, los instrumentos de evaluación, el procedimiento y los análisis de datos (sexto capítulo) se realiza atendiendo a esta particularidad. Para facilitar su exposición, los resultados (séptimo capítulo) se presentan clasificados en 8 epígrafes y subepígrafes que coinciden con los objetivos generales y específicos planteados para este trabajo. Así, un primer epígrafe corresponde a los resultados que se derivan del análisis de la prevalencia del cuadro clínico de compulsividad sexual en una cohorte de casi 1600 jóvenes de entre 18 y 27 años (primera fase) mientras que los 7 epígrafes restantes analizan el perfil diferencial de 200 jóvenes (100 chicos y 100 chicas) con problemas subclínicos en el control de impulsos sexuales y otros tantos sin esta característica en aspectos como: la prevalencia de patologías del Eje I y II, los correlatos con otras características y disposiciones clínicas (como el nivel de autoestima o la tendencia a experimentar ansiedad y depresión), el perfil de personalidad, varios aspectos relacionados con la actividad sexual y la severidad y consecuencias del comportamiento sexual compulsivo. Para terminar, en los 2 últimos epígrafes se exploran las variables que aumentan y disminuyen el riesgo de desarrollar este cuadro clínico (factores de riesgo y protección) y el modo en el que éstas se configuran a la hora de determinar aspectos como la severidad del cuadro clínico.

En la tercera sección (discusión y conclusiones) se exponen las conclusiones que se derivan de los resultados expuestos, se discuten a partir de la literatura científica previa y se exponen las principales limitaciones y líneas de investigación futuras (octavo y noveno capítulo). 


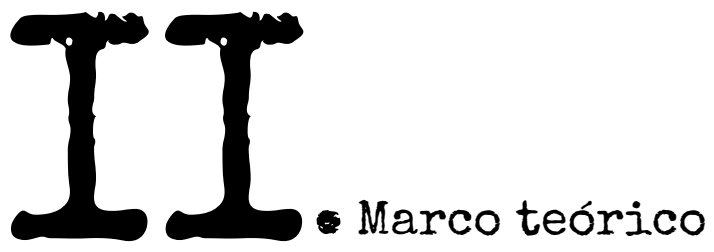





\section{Capítulo 1. concepto y descripción del cuadro clínico de compulsividad sexual}

1. Introducción al estudio de la conducta sexual excesiva

2. El problema de la terminología en el estudio de la compulsividad sexual

3. Definiciones de compulsividad sexual: visión categorial vs. dimensional

4. Signos y síntomas de la compulsividad sexual

4.1 Síntomas conductuales: frecuencia sexual

4.2 Síntomas emocionales: uso del sexo como regulador emocional

4.3 Síntomas cognitivos: cogniciones desadaptativas

4.4 Déficits en funciones ejecutivas

5. En resumen 


\section{Introducción al estudio de la conducta sexual excesiva}

Impulso sexual, libido o apetito sexual son algunos ejemplos de cómo a lo largo del tiempo nos hemos referido a lo que hoy entendemos por deseo sexual (Kandel, 1999). El deseo sexual, definido como "Ia suma de las fuerzas que nos inclinan hacia o nos alejan de la conducta sexual" (Levine, 2003, p. 280), es un constructo complejo en el que el criterio de clínicos e investigadores suele diferir bastante de la percepción que las personas tienen del mismo (King, Holt, \& Nazareth, 2007).

El deseo se manifiesta a través de múltiples formas de expresión. Una de las principales es la propia conducta sexual, más concretamente su frecuencia (Långström \& Hanson, 2006a). En este sentido, lo habitual es que las personas con mayor deseo mantengan relaciones sexuales con mayor frecuencia, hecho que efectivamente se ha demostrado a través de múltiples investigaciones (Bancroft \& Vukadinovic, 2004; Dodge, Reece, Cole, \& Sandfort, 2004). El vínculo entre ambos conceptos se ha considerado tan estrecho que en muchas ocasiones, deseo sexual y frecuencia sexual se han utilizado de forma indistinta para referirse al mismo concepto. Esta visión, si bien acertada, obvia algunas situaciones donde deseo y conducta no responden al estrecho vínculo que se les atribuye (Brotto, 2010): 1) personas que mantienen relaciones sexuales por cuestiones ajenas al mero deseo -como en el caso de los y las trabajadoras sexuales-, 2) situaciones en las que una persona experimenta deseo sexual sin que ello le lleve a iniciar ningún tipo de conducta sexual o 3) situaciones en las que el deseo sobreviene como consecuencia del inicio de la actividad sexual (especialmente en el caso de las mujeres) (Basson, 2007).

Estas excepciones, unidas al reconocimiento de las muchas otras facetas en las que se puede expresar el deseo sexual (Levine, 2002), han llevado a la adopción de una perspectiva más integradora. Desde esta nueva concepción, la frecuencia sexual constituye una de las principales formas de expresión del deseo (componente conductual), pero también lo serían la frecuencia y la intensidad de fantasías y pensamientos sexuales (componente cognitivo), la forma en la que respondemos al ver a una persona que nos resulta atractiva, al ser estimulados sexualmente $\mathrm{o}$ al ser expuestos a estímulos evocadores (componente reactivo) o incluso cuestiones más actitudinales como la importancia subjetiva que la persona otorga al hecho de estar sexualmente satisfecha (Brotto, Heiman, \& Tolman, 2009; Clayton et al., 2006; Rosen et al., 2000).

De acuerdo con Levine (2003), el deseo sexual sería un constructo dimensional y dinámico: dimensional porque las personas pueden variar entre sí en cuanto al grado e intensidad de su 
deseo sexual y dinámico porque en un mismo individuo, el deseo puede fluctuar a lo largo del tiempo. Según este mismo autor, estas diferencias y fluctuaciones se explicarían a partir de la interacción entre los tres principales determinantes del deseo sexual:

1) Impulso: componente del deseo determinado únicamente por factores biológicos y hormonales y que comparten todos los seres vivos con reproducción sexual. Este aspecto sería ajeno al control o la regulación voluntaria y establecería un nivel basal de interés sexual que asegura la reproducción y perpetuación de todas las especies.

2) Motivación: aspecto del deseo sexual en el que los factores psicológicos jugarían un papel esencial. El estado de ánimo, las relaciones interpersonales, la atracción, el afecto o el amor serían algunos de los factores que determinarían el grado en el que una persona experimentaría mayor o menor deseo sexual.

3) Disposición: componente del apetito sexual en el que los valores sociales y culturales tienen más peso. Estos aspectos pueden influir sobre cuestiones tan operativas como la frecuencia sexual considerada adecuada, cuál debe ser el objeto de nuestro deseo, etc. (es decir, sobre la forma socialmente aceptable de expresar nuestro apetito sexual).

Estos tres factores interactúan entre sí, provocando que las personas pasen por periodos donde prácticamente no experimentan deseo sexual (p.e., durante una convalecencia) o por periodos donde su deseo puede ser muy elevado (como pueden ser los primeros meses de relación con una nueva pareja). Estas fluctuaciones son relativamente habituales y no hacen sino reflejar el carácter dinámico del deseo sexual, pero cuando uno de sus extremos se mantiene en el tiempo -por un periodo superior a 6 meses-y adquiere la suficiente magnitud para provocar malestar, entonces se habla de patología del deseo sexual (American Psychiatric Association, 2014; Kleinplatz, 2011; Levine, 2003; Winters, Christoff, \& Gorzalka, 2010).

Los únicos trastornos del deseo sexual reconocidos hasta el momento por los principales manuales diagnósticos al uso son aquellos que se caracterizan por la disminución o ausencia de deseo, concretamente la aversión sexual y el deseo sexual hipoactivo -diagnósticos aplicables tanto a hombres (Maurice, 2007) como a mujeres (Basson, 2007) -. La nomenclatura para referirnos a este tipo de trastornos ha variado mucho a lo largo del tiempo, pero siempre ha perdurado un consenso entre expertos a la hora de reconocer la problemática y la interferencia que estas patologías generan (Kleinplatz, 2011). Este consenso es el resultado de múltiples investigaciones con grandes muestras de población general que dan buena cuenta de la frecuencia y del impacto que estas disfunciones sexuales provocan. En este sentido, Laumann, Gagnon, Michael y Michaels (1994) realizaron un estudio pionero en el que 
exploraban, entre otras muchas cuestiones, la relación entre frecuencia sexual y felicidad. Lo que estos autores encontraron tras entrevistar a 3432 estadounidenses de entre 18 y 59 años es que los que dijeron mantener una frecuencia sexual mensual de tres coitos o menos eran sensiblemente menos felices que los que mantenían una frecuencia sexual mayor. Ventegodt (1998), por su parte, se planteó la necesidad de estudiar el impacto que las disfunciones sexuales tenían sobre la calidad de vida. Para ello, evaluó una extensa muestra de población general ( 2460 ciudadanos daneses de entre 18 y 88 años), encontrando una alta prevalencia de distintos tipos de disfunciones sexuales (la más frecuente el bajo deseo sexual). El principal hallazgo de este estudio fue que la calidad de vida de las personas con este tipo de problemas era entre un 1.2-19.1\% menor que la de quienes no los padecían. Un año más tarde, FuglMeyer y Sjogren (1999) decidieron estudiar el impacto de las disfunciones sexuales sobre una dimensión mucho más concreta, la satisfacción sexual. Para ello evaluaron a 4781 suecos de entre 18 y 74 años, encontrando que el $47.5 \%$ de las mujeres y el $23 \%$ de los hombres habían experimentado algún tipo de disfunción sexual: la más frecuente nuevamente fue el bajo deseo sexual (33\% y $16 \%$ respectivamente). De entre los identificados con esta patología, tan sólo un $15-35 \%$ consideraban satisfactoria su vida sexual.

Mientras que los trastornos caracterizados por la ausencia o inhibición del deseo sexual están sobradamente establecidos y reconocidos desde 1952 (la primera versión del DSM ya incluía los trastornos de impotencia y frigidez) (Kleinplatz, 2011), en la actualidad estamos asistiendo a un complejo e intenso debate en torno al reconocimiento de la existencia de un trastorno en el extremo opuesto. La evidencia científica actual justifica sobradamente el reconocimiento de un cuadro clínico caracterizado principalmente por un deseo sexual excesivo; sin embargo, los esfuerzos por su reconocimiento han sido en vano y el comité de garantías éticas de la Asociación Americana de Psiquiatría (APA) ha rechazado recientemente la inclusión en su manual diagnóstico de este trastorno (APA, 2014; Kafka, 2014). Todas estas cuestiones se tratarán de forma mucho más pormenorizada a lo largo de la exposición del presente marco teórico, pero resulta importante destacar que existe una clara oposición al reconocimiento de los trastornos relacionados con la incapacidad para controlar los impulsos sexuales (Halpern, 2011; Moser, 2011).

El principal argumento de los que rechazan reconocer esta patología es que las investigaciones realizadas hasta el momento no permiten establecer con claridad que un mayor deseo sexual pueda acarrear consecuencia negativa alguna. Además, no es suficiente tomar un subconjunto de población con alta frecuencia sexual (ese trabajo ya se había realizado en investigaciones precedentes con muestra clínica); debían demostrar la relación entre frecuencia sexual y 
consecuencias negativas en población general. Långström y Hanson (2006a) se dieron cuenta y su oportunidad surgió gracias al Swedish Sexuality and Health Project, que era un estudio nacional en el que además de explorar múltiples cuestiones relacionadas con la conducta sexual, se aplicaban medidas de bienestar y salud física y psicológica. Valiéndose de los datos obtenidos a través de este estudio, en el que participaron 1279 hombres y 1171 mujeres de entre 18 y 60 años, se plantearon un doble objetivo: por un lado, querían comprobar si una mayor frecuencia sexual correlacionaba negativamente con indicadores de salud física y mental; por otro lado, querían comprobar si la relación negativa entre deseo sexual y salud se daba únicamente en lo que los autores denominaban "sexo impersonal" (masturbación, múltiples parejas sexuales, sexo en grupo, sexo con trabajadores/as sexuales, etc. ) o también en el "sexo personal" (sexo en el contexto de una relación estable monógama). Utilizando como indicador de deseo sexual la frecuencia sexual mensual (uno de los indicadores más fiables y de fácil registro a nivel empírico), estos investigadores realizaron dos importantes hallazgos: en primer lugar, demostraron que la frecuencia sexual se relacionaba negativamente con múltiples indicadores de salud (a mayor frecuencia, menor satisfacción con la vida en general y con la vida sexual en concreto) pero sólo cuando se medía frecuencia de sexo impersonal; por el contrario, una alta frecuencia de sexo personal se relacionaba positivamente con estos dos indicadores y con otros, como la percepción de salud física y psicológica. El segundo hallazgo encontrado fue que las personas con las tasas más altas de sexo impersonal tenían más probabilidad de haber sido separados de sus padres durante la infancia, haberse iniciado antes en el sexo y además de forma más variada, haber mantenido relaciones sexuales con personas del mismo sexo, haber pagado por sexo, mostrar indicios de ciertas parafilias, haber tenido problemas durante sus relaciones estables, haber padecido una o varias Infecciones de Transmisión Sexual (ITS), ser fumadores y beber grandes cantidades de alcohol, abusar de drogas ilegales y jugar a tragaperras. Además, estas personas informaban de una menor satisfacción con su salud física, mental, sexual y con la vida en general.

Con este estudio, Långström y Hanson (2006a) desmontaban uno de los principales argumentos en contra del reconocimiento de un cuadro clínico asociado a un exceso de deseo sexual. Sin embargo, todavía estaba por determinar si esta patología representaba únicamente la expresión de un gran deseo sexual -como algunos autores sugerían (Dodge et al., 2004)- o más bien surgía cuando a un apetito sexual excesivo se le sumaba la incapacidad para controlar dichos impulsos (lo que habitualmente se ha llamado "compulsividad sexual"). Demostrarlo daría validez y entidad diagnóstica propia a un trastorno con estas características y ese fue el objetivo con el que Winters et al. (2010) plantearon su investigación. Estos autores 
reclutaron a través de Internet una muestra de 14396 personas ( $55.1 \%$ mujeres y $44.9 \%$ hombres) con edades comprendidas entre los 18 y los 94 años (edad media de 28 años), la gran mayoría (91.7\%) estadounidenses. A todos ellos les aplicaron diversas escalas e instrumentos, entre ellas algunas que medían deseo sexual y otra que evaluaba compulsividad sexual. Al analizar los resultados, encontraron que 107 hombres y 69 mujeres dijeron haber buscado tratamiento por problemas relacionados con el control de los impulsos sexuales: en comparación con los que no lo habían hecho, el grupo que había buscado tratamiento obtuvo puntuaciones mayores en las escalas de deseo sexual (tanto solitario como en pareja), en la escala de excitación sexual y en la de compulsividad sexual, mientras que las puntuaciones en la escala de inhibición sexual eran menores. Estas personas indicaron a su vez una edad de inicio sexual más temprana, mayor consumo de pornografía, una mayor presencia de síntomas psicológicos y una menor satisfacción sexual. A partir de estos hallazgos, los autores concluyeron que lo que determinaba en mayor medida la búsqueda de asistencia profesional no era únicamente un mayor deseo sexual -muchos evaluados obtuvieron altas puntuaciones en las dimensiones de deseo sin haberse planteado nunca la búsqueda de tratamiento-, sino la conjunción de este factor junto con la percepción subjetivo de incapacidad para controlar los pensamientos, impulsos o conductas sexuales generadas por dicho deseo sexual excesivo.

Los dos trabajos a los que hemos hecho referencia son ejemplos de las numerosas investigaciones realizadas en torno al fenómeno del deseo sexual excesivo. Su relevancia radica en que sus resultados y conclusiones fundamentan el reconocimiento de un cuadro clínico caracterizado por la suma de un alto deseo sexual y la incapacidad para controlar sus diversas manifestaciones. A partir de ahí, la polémica en torno a la nomenclatura de esta patología o de su clasificación diagnóstica pierde sentido, permitiendo que las nuevas investigaciones se centren más en aquellos aspectos que permitan mejorar la atención diagnóstica y terapéutica a personas con esta problemática. 


\section{El problema de la terminología en el estudio de la compulsividad sexual}

Las primeras fases del nacimiento de una nueva área de estudio se caracterizan por la proliferación de etiquetas y terminología dispar para conceptos equivalentes. Así, uno de los principales problemas a la hora de abordar este campo de estudio es que no existe una terminología común para referirnos a lo que hemos llamado deseo sexual excesivo. Bajo etiquetas tan variadas como adicción al sexo (Carnes, 1983), hiperfilia (Money, 1986), impulsividad sexual (Barth \& Kinder, 1987), conducta sexual compulsiva (Coleman, 1991, 1995), compulsividad sexual (Kalichman \& Rompa, 1995), deseo sexual hiperactivo (Bradford, 1999), sexualidad desregulada (Winters et al., 2010) o hipersexualidad (Kafka, 2010, 2014; Kaplan \& Krueger, 2010) se ha englobado a aquellas personas cuya conducta sexual no se ajustaba al estándar de normalidad o bien por su frecuencia o por sus características. Se han dedicado trabajos completos a debatir las bondades de una etiqueta diagnóstica frente a otra (Coleman, 2003; Gold \& Heffner, 1998; Goodman, 2001; McBride et al., 2011; Mick \& Hollander, 2006), sin que se haya alcanzado todavía una terminología común. En la reciente monografía que la Journal of Sexual Addiction \& Compulsivity ha dedicado a esta cuestión, expertos en el área pugnan para que términos como adicción al sexo (Kor, Fogel, Reid, \& Potenza, 2013), impulsividad-compulsividad sexual (Miner \& Coleman, 2013) o hipersexualidad (Kafka, 2013) prevalezcan sobre el resto, por lo que tampoco parece que el consenso vaya a llegar, al menos, en poco tiempo.

El debate en torno a la nomenclatura obedece principalmente a razones teóricas: nombrar a una patología de una determinada forma y no de otra implica aceptar los supuestos implícitos acerca de la etiopatogenia del trastorno (Kafka, 2010; Kaplan \& Krueger, 2010; McBride et al., 2011). De acuerdo con esto, los defensores del término "adicción al sexo" asumirían la existencia de una etiología común entre las adicciones tóxicas y conductuales, mientras que los defensores del término "impulsividad sexual" estarán equiparando este trastorno con otros como por ejemplo la piromanía (clasificado según el DSM-5 como un trastorno del control de los impulsos). A nivel clínico, este debate carece de importancia ya que como bien señala Reid (2013), "Ia descripción subjetiva de un paciente acerca de sus fantasías sexuales, impulsos y conductas, junto con su angustia personal, sensación de falta de control y consecuencias negativas, es más significativo de cara al tratamiento que la etiqueta que finalmente pongamos a estas características" (Reid, 2013, p. 5). 


\section{Definiciones de la compulsividad sexual: visión categorial vs. dimensional}

El excesivo deseo sexual ha sido objeto de múltiples definiciones: algunas de ellas reflejarían una visión categórica, una concepción de este constructo como una patología que una persona padece o no; otras, por el contrario, denotarían una visión dimensional, una variable que todas las personas tienen en mayor o menor medida y que puede influir sobre aspectos tan concretos como la frecuencia de la actividad sexual, la tendencia al sexo de riesgo, etc.

La primera de las definiciones categoriales fue propuesta por Carnes en 1983. Para este autor, el deseo sexual desmedido (que él denominaba adicción al sexo) constituye "un conjunto de síntomas caracterizado por una pérdida del control sobre la conducta sexual que normalmente se asocia con una alteración del estado de ánimo" (Carnes, 1983, p. 4). El conjunto de síntomas al que este autor se refiere es idéntico al que se plantea para la dependencia de substancias, pero adaptando su contenido a la adicción al sexo (Goodman, 1992): la persona cada vez necesita más sexo o de mayor intensidad para satisfacer sus impulsos (tolerancia); síntomas de abstinencia cuando la persona se ve privada de actividad sexual; progresivo aumento del tiempo dedicado al sexo; esfuerzos fallidos por detener o reducir la conducta sexual; reducción o abandono de otras actividades y; persistencia en la conducta sexual a pesar de experimentar consecuencias negativas.

Tiempo después, Goodman (1992) amplía esta definición afirmando: "la adicción al sexo no es una aberración. Tampoco una moda o una única alteración: la adicción al sexo es simplemente el proceso de cualquier adicción expresado a través del sexo, la dependencia compulsiva de cierto tipo de actividad sexual como un medio para regular los sentimientos y el autoconcepto" (Goodman, 1992, p. 312). Esta autora destacaría que en la adicción al sexo, la conducta sexual sirve tanto para lograr el placer como para escapar de un estado de malestar interno.

Ambas definiciones remarcan aspectos importantes en la fenomenología del excesivo deseo sexual, pero estarían muy sesgadas por su consideración de esta patología como una adicción. Un ejemplo de definición con menos implicaciones teóricas es la que aporta Kafka $(2010,2013)$ bajo la denominación de hipersexualidad. Para este autor, esta patología se caracteriza por una preocupación intensa y repetitiva por fantasías sexuales, impulsos y conductas que llevan a la persona a experimentar consecuencias adversas y un malestar clínicamente significativo en áreas como el trabajo, el entorno social u otros aspectos de la vida de la persona. Que esta definición siga una estructura muy similar a la que encontramos en los manuales DSM para las parafilias o cualquier otro trastorno sexual no es casual: su autor fue uno de los encargados de proponer los criterios del trastorno por hipersexualidad para el DSM-5. 
La visión dimensional del excesivo deseo sexual se la debemos a Kalichman y su equipo, uno de los más claros referentes durante el diseño de nuestra investigación. Kalichman y Cain (2004) sostienen que la compulsividad sexual (de ahora en adelante CS) (término acuñado por estos investigadores para referirse al deseo sexual desmedido) es un constructo psicológico heterogéneo que comprende una grave preocupación por deseos sexuales y conductas que suelen producir graves consecuencias en las relaciones sociales, en el entorno laboral o simplemente en el día a día. En ciertos momentos, estos autores se llegan a referir al constructo de compulsividad sexual como una dimensión más de la personalidad, una dimensión que podría resultar de la intersección entre la impulsividad, la erotofilia y la búsqueda de sensaciones. El aspecto más importante es que la compulsividad sexual determina "la propensión a experimentar cierta desinhibición sexual o impulsos y conductas sexuales descontroladas en ciertas situaciones" (Kalichman \& Cain, 2004, p. 239). Lo más interesante es que estudios recientes avalan la estructura taxométrica dimensional del constructo de compulsividad sexual. Estaríamos hablando de una dimensión donde el extremo superior representaría la patología, mientras que niveles inferiores darían cuenta de distintos grados de gravedad y de afectación personal (Walters, Knight, \& Långström, 2011).

Tal y como señalan muchos autores, únicamente la combinación de ambas perspectivas -la categorial y la dimensional- permite entender verdaderamente las distintas manifestaciones del fenómeno de la CS y de cómo puede afectar negativamente sobre distintos aspectos de la vida de la persona (Kalichman \& Cain, 2004; Långström \& Hanson, 2006a; Walters et al., 2011; Winters et al., 2010). Hasta el momento, hemos venido utilizando el término "deseo sexual excesivo" porque, además de no presuponer ninguna teoría etiológica concreta, hace referencia a uno de los principales componentes del cuadro clínico. El problema de este término es que obvia el segundo gran eje que vertebra esta patología: la incapacidad para controlar las múltiples expresiones del excesivo deseo sexual. Por este motivo, de ahora en adelante utilizaremos "compulsividad sexual" (CS en su forma abreviada) o "conducta sexual compulsiva” para hacer mención a este cuadro clínico. Los motivos para su elección frente a otros también válidos como el mencionado anteriormente o como el de hipersexualidad son los siguientes: 1) el término compulsividad sexual refleja ese componente del cuadro clínico que nos permite diferenciar entre una persona que simplemente tiene un alto deseo sexual y la persona con un deseo sexual excesivo y patológico; 2) el constructo de compulsividad sexual -medido principalmente a través del Cuestionario de Compulsividad Sexual de Kalichman y Rompa (Kalichman \& Rompa, 1995)- es uno de los ejes a partir de los cuales hemos vertebrado el estudio empírico de esta tesis doctoral; 3) la teoría que acompaña al término de 
compulsividad sexual es una de las pocas que han abogado por una concepción dimensional del constructo frente a una visión categórica, visión que abre la puerta al estudio de la compulsividad sexual no sólo en población clínica, sino también entre población subclínica y población normal.

En conclusión, de ahora en adelante emplearemos el término "compulsividad sexual" para referirnos al trastorno que padecen aquellas personas con graves dificultades a la hora de controlar su deseo sexual, con pensamientos sexuales frecuentes e intrusivos que les llevan a mantener conductas sexuales solitarias o con parejas de forma repetida y sin ningún control, y que finalmente experimentan consecuencias derivadas de la falta de control sobre sus impulsos sexuales (ITS, embarazos no deseados, problemas familiares, trastornos psicológicos, etc.) (Mick \& Hollander, 2006).

\section{Signos y síntomas de la compulsividad sexual}

Existe cierto consenso a la hora de afirmar que los síntomas de la compulsividad se expresan a través de tres niveles: el conductual, el cognitivo y el emocional (Kingston \& Firestone, 2008). En la figura 1 se incluye la recopilación que Gold y Heffner (1998) realizan de los principales síntomas a estos tres niveles. Además, recientemente se ha empezado a desarrollar una prometedora línea de investigación en torno al papel de las funciones ejecutivas en las diversas manifestaciones de la CS. Esta nueva perspectiva está teniendo un importante impacto en la forma de entender esta patología y como señala Reid (2013), "puede ser la clave para comprender la constelación de síntomas, características y mecanismos asociados a la conducta sexual compulsiva" (Reid, 2013, p. 12).

Figura 1. Síntomas conductuales, cognitivos y emocionales de la CS (elaborado a partir de Gold \& Heffner, 1998).

\section{Conductuales}

- Gran frecuencia de actividad sexual.

-Masturbación compulsiva.

-Búsqueda de parejas sexuales.

- Incapacidad de mantener relaciones estables y múltiples infidelidades.

-Esfuerzos fallidos por detener o reducir su conducta sexual.

-Múltiples encuentros sexuales en ausencia de deseo.

- Uso frecuente de pornografía.

\section{Cognitivos}

- Creencias erróneas en torno al sexo y la sexualidad.

- Pensamientos obsesivos acerca de la sexualidad o de encuentros sexuales. -Inversión de tiempo exagerada fantaseando con encuentros sexuales o pensamientos eróticos.

- Racionalización y minimización de las consecuencias de su conducta.

-Disociación cognitiva durante la práctica sexual.

\section{Emocionales}

- Necesidad de escapar de un estado emocional negativo mediante de su actividad sexual.

- Culpa y vergüenza por la excesiva conducta sexual.

- Soledad, aburrimiento o rabia por no controlar la conducta sexual.

-Depresión y baja autoestima.

-Vergüenza por su conducta sexual e intentos de mantenerla en secreto.

-Indiferencia emocional hacia parejas sexuales. 
De los signos y síntomas descritos en la figura 1, algunos se pueden considerar centrales en un cuadro clínico de CS -frecuencia sexual, uso del sexo como regulador de estados de ánimo disfóricos y presencia de creencias erróneas en torno al sexo- y por ello los expondremos a continuación con mayor profundidad. El resto tendrían un carácter más secundario o común a muchas patologías psicológicas, si bien cabe tenerlos en cuenta porque conforman las distintas manifestaciones a través de las cuales este cuadro clínico puede expresarse. También comentaremos en profundidad las aportaciones que desde la neuropsicología se están realizando a la comprensión de los síntomas de la CS a través del marco de las funciones ejecutivas. Las consecuencias de la CS -que según Gold y Heffner (1998) se podrían considerar como síntomas conductuales de la CS y que en la práctica constituyen uno de los principales indicadores de la presencia de esta patología- se comentarán más detenidamente durante el segundo capítulo del presente marco teórico.

\subsection{Síntomas conductuales: frecuencia sexual}

Entre los síntomas conductuales, uno de los más significativos es la frecuencia de actividad sexual. Autores como Kafka (1997) o Kafka y Hennen (2003) han retomado un concepto que Kinsey y su equipo acuñaron hace ya más de 60 años, el de Total Sexual Outlet (TSO, número medio de orgasmos por semana tanto en relaciones sexuales con parejas como mediante masturbación) (Kinsey, Pomeroy, \& Martin, 1948). Para ellos, se puede hablar de conducta sexual compulsiva cuando el TSO es igual o superior a 7 orgasmos semanales durante un periodo mínimo de 6 meses a partir de los 15 años de edad. A este criterio diagnóstico se le ha llamado la regla de oro (TSO $\geq 7)$, aunque tampoco se ha visto exento de críticas.

La elección de este criterio se basó en estimaciones estadísticas a partir de estudios clásicos. Las distintas investigaciones realizadas hasta el momento indicaban que tan sólo entre un 3$8 \%$ de la población mantenía una frecuencia sexual igual o mayor a 7 orgasmos semanales. Kinsey et al. (1948) evaluaron la actividad sexual de alrededor de 5300 hombres, desde adolescentes hasta personas de 85 años, encontrando que tan sólo un 7.6\% mantenía un TSO igual o superior a 7 orgasmos. La actividad sexual semanal media fue de unos 2 orgasmos. Tiempo más tarde, Atwood y Gagnon (1987) obtuvieron resultados algo menores al evaluar a 1077 chicos. Estos autores encontraron que un 5\% de los estudiantes de educación secundaria y un 3\% de estudiantes universitarios se masturbaban a diario, lo que equivale a un TSO de 7 orgasmos semanales. Otro estudio en el que Kafka y su equipo se fijó para determinar su regla fue el realizado por Laumann et al. (1994). Estos autores evaluaron a 1320 hombres de entre 18 y 59 años y determinaron que el 33.6\% de ellos se masturbaba una vez por semana, el $14.5 \%$ de 2 a 6 veces por semana, el $1.9 \%$ se masturbaba a diario y un 1.2\% más de una vez al 
día. Es decir, el 3.1\% de estos hombres era susceptible de recibir el diagnóstico de hipersexualidad basándonos únicamente en el criterio de frecuencia sexual (TSO $\geq 7$ ).

El equipo de Kafka sometió a evaluación este criterio en dos ocasiones. En una primera ocasión, se reclutó a una muestra de 65 pacientes con un diagnóstico de parafilia y a 35 con un diagnóstico de hipersexualidad (Kafka, 1997). En ambos casos, la frecuencia media de orgasmos semanales superaba el criterio para el diagnóstico de hipersexualidad (TSO grupo parafilias=7.4/ TSO grupo hipersexualidad=8), si bien no se encontraban diferencias entre ambos grupos. Tomada la muestra en conjunto, el 72\% mantuvo un TSO $\geq 7$ en alguna ocasión a lo largo de su vida y un 52\% lo cumplió durante más de 5 años. Tanto el grupo de pacientes con parafilias como los hipersexuales coincidieron en que el momento de mayor actividad sexual se situaba en torno a los 20 años, la duración media era de 9 años y dedicaban una media de entre 1 y 2 horas al día a sus fantasías, impulsos o conductas sexuales. Este estudio demostró la importancia del TSO como criterio diagnóstico, si bien no parecía resultar útil a la hora de discriminar entre un diagnóstico de parafilia o de hipersexualidad.

Seis años después, Kafka y Hennen (2003) replicaban esta investigación con resultados prácticamente idénticos. Tomando de nuevo dos muestras (88 pacientes parafílicos y 32 hipersexuales), se encontró que el $80 \%$ cumplió el criterio TSO $\geq 7$ en alguna ocasión a lo largo de su vida, la mayoría de ellos desarrollaba su alta frecuencia sexual durante la adolescencia o el principio de la edad adulta (entre los 15 y los 19 años) y su duración media era de unos 11 años. La novedad fue que los pacientes que acumularon mayor número de diagnósticos sexuales a lo largo de su vida (mayor número de periodos donde superaban el criterio para el diagnóstico de un trastorno por hipersexualidad) también informaban de un mayor número de delitos sexuales, mayor duración de los periodos de alta frecuencia sexual y mayor número de horas diarias preocupados por sus pensamientos, impulsos o conductas sexuales.

Estudios recientes también con muestra clínica demuestran la importancia del TSO como indicador de gravedad y peligro de reincidencia en delincuentes sexuales. En un estudio con 586 adultos agresores sexuales, Kingston y Bradford (2013) encuentran que el $12 \%$ cumplía el criterio de frecuencia de orgasmos semanales tal como lo contempla Kafka. Además, el TSO parece ser un predictor robusto de la reincidencia en delitos sexuales violentos y no violentos.

Una de las críticas generalizadas a estos estudios es que no comparan sus resultados con un grupo control, por lo que tampoco podemos saber hasta qué punto el TSO es un indicador fiable que nos permita discriminar entre población normal y personas con compulsividad sexual. Estudios recientes han abordado esta cuestión con resultados contradictorios. Winters 
et al. (2010) realizaron una investigación por medio de una plataforma virtual en la que evaluaron a un total de 14396 personas de entre 18 y 94 años. Esta muestra se dividió en dos grupos según si habían buscado o no en alguna ocasión ayuda profesional por un problema de adicción al sexo. Al comparar ambos grupos, se encontraron diferencias en medidas de autoinforme sobre compulsividad sexual, deseo sexual y excitación sexual, pero no se encontraron diferencias significativas al comparar la frecuencia media de orgasmos semanales. EI TSO para mujeres que habían buscado tratamiento era de 9.21 (frente al 5.56 de las que no habían buscado tratamiento); para hombres que buscaron tratamiento, el TSO era de 8.31 (7.68 los que no lo habían buscado). En todo caso, debemos tomar estos resultados con precaución porque no es frecuente encontrar un número medio de orgasmos semanales tan alto en población general.

En España, tras una revisión de la bibliografía, no hemos podido encontrar trabajos que estudien la frecuencia sexual por medio del TSO. Lo que es más habitual es el uso de escalas categoriales para la medida de conductas sexuales concretas (p.e., frecuencia de relaciones sexuales con pareja, frecuencia de masturbación, etc.). En 2008, en una encuesta realizada por el Centro de Investigaciones Sociológicas (CIS, 2008), se preguntó a 1485 españoles (722 hombres y 762 mujeres) de 18 años en adelante la frecuencia con la que mantenían relaciones sexuales. De todos ellos, tan sólo el 3.7\% mantenía relaciones sexuales a diario (TSO $\geq 7$ ). Por edad, la franja donde el porcentaje de población que mantenía relaciones sexuales diarias era mayor (el 7.3\%) se encontraba entre los 25 y 34 años, momento a partir del cual la cifra decae. Estos datos resultan similares a los tomados por Kafka a la hora de elaborar su regla estadística para el diagnóstico de hipersexualidad.

Cuando analizamos la frecuencia de masturbación los resultados cambian. En un estudio realizado con 764 adolescentes de entre 13 y 20 años, el $23 \%$ de los chicos y el $2.4 \%$ de las chicas afirmó masturbarse a diario (TSO $\geq 7)$. El grupo que admitía masturbarse a diario en mayor frecuencia fue el de chicos de entre 13 y 15 años (el 33.6\% de ellos se masturba diariamente) (López, Carcedo, Fernández-Rouco, Blázquez, \& Kilani, 2011).

En resumen, el TSO ha demostrado ser un indicador útil a la hora de evaluar la presencia y la gravedad de la CS, si bien no debe tomarse como único signo de presencia de patología. Entre sus inconvenientes, destaca: 1 ) es un indicador sensible a la presencia de CS pero muy poco específico (existen otras patologías -por ejemplo las parafilias- donde también se aprecia una importante frecuencia de actividad sexual); 2) dado que la estimación de los criterios para considerar cierta frecuencia sexual como excesiva se han obtenido a partir de estudios únicamente con muestra masculina, no podemos generalizar estas estimaciones a mujeres; 3 ) 
teniendo en cuenta las notables influencias sociales y culturales sobre la conducta sexual, es atrevido pensar que en países como por ejemplo España, la frecuencia sexual en CS debiera seguir una distribución similar a la obtenida en otros países.

Lo cierto es que la acumulación de evidencias a favor y en contra de este criterio para el diagnóstico de hipersexualidad han llevado al propio Kafka a revisar y reformular su modelo. En publicaciones posteriores, Kafka ya planteaba que "cualquier definición de deseo hipersexual no es más que una línea en la arena en el continuo de la frecuencia de conductas sexuales apetitivas: una alta frecuencia sexual per se no necesariamente designa una condición patológica, a no ser que implique un deterioro importante de su bienestar y de otras áreas de funcionamiento de la persona" (Kafka, 2008, p. 575). Poco tiempo después, este mismo autor planteará los distintos criterios propuestos para el diagnóstico del trastorno por hipersexualidad en el DSM-5 (Kafka, 2010).

4.2 Síntomas emocionales: uso del sexo como regulador emocional

Uno de los síntomas más frecuentes en la compulsividad sexual es el uso del sexo como medio para regular estados emocionales negativos (principalmente ansiedad y depresión). En este sentido, Adams y Robinson (2001) apuntaban: "en compulsivos sexuales, placer y orgasmo son un medio para calmar estados de disconfort interno. Las sensaciones sexuales se unen a la vergüenza, tristeza, rabia y soledad, que se convierten en desencadenantes del ciclo de la adicción. La adicción es la causa de la culpa y la desregulación emocional" (K. M. Adams \& Robinson, 2001, p. 25). A lo largo de los años, se ha atribuido tanta importancia al uso del sexo como regulador emocional en compulsividad sexual que en la propuesta de Kafka de criterios diagnósticos, éste único síntoma engloba 2 de los 5 criterios necesarios para el diagnóstico de hipersexualidad (Kafka, 2010).

Sin embargo, este síntoma contradice completamente lo que hasta el momento teníamos entendido acerca de la relación entre estado emocional y conducta sexual: se creía que estados emocionales adversos reducían o suprimían invariablemente el deseo sexual, lo que a su vez suponía un descenso significativo de su frecuencia y por supuesto de su calidad. En esta línea, pioneros de la terapia sexual como Masters y Johnson (1970) o Kaplan (1979) recalcaban la importancia de los factores psicológicos (principalmente la depresión y la ansiedad) en el inicio y el mantenimiento de distintas disfunciones sexuales.

La relación negativa entre depresión y apetito sexual ha sido ampliamente documentada. En uno de los primeros trabajos de Beck sobre depresión se informaba de que el $61 \%$ de los pacientes con depresión severa experimentaban una pérdida significativa del interés sexual 
frente al $27 \%$ de los pacientes control (A. T. Beck, 1967). En una reciente actualización de los datos psicométricos del cuestionario $\mathrm{BDI}$, de nuevo Beck obtiene más de 40 años después de su primera investigación que el $60 \%$ de los pacientes con depresión clínica experimentan un descenso en su actividad sexual (A. T. Beck, Steer, \& Brown, 2011). Schreiner-Engel y Schiavi (1986) hallan resultados similares pero desde la perspectiva inversa. Tomando a un grupo de pacientes con bajo deseo sexual, estos autores logran indentificar un patrón persistente de episodios depresivos recurrentes a lo largo de su vida. Otro ejemplo lo encontramos en un estudio longitudinal realizado en Suiza con personas de entre 20 y 35 años. De nuevo este estudio permitió documentar la estrecha relación entre depresión y bajo deseo sexual, si bien en este caso la reducción del apetito sexual era más notable en mujeres (Angst, 1998).

Por otra parte, el impacto negativo de la ansiedad sobre la conducta sexual no resulta tan claro como en el caso de la depresión, si bien encontramos también algunos ejemplos. Ware et al. (1996) compararon la prevalencia de disfunciones sexuales entre hombres y mujeres con un diagnóstico de trastorno de ansiedad frente a un grupo de sujetos control. Los pacientes con fobia social y trastorno de ansiedad generalizada mostraban un riesgo mayor de patología sexual en general, mientras que los pacientes con trastorno de pánico experimentaban sobre todo menor deseo sexual. Van Minnen y Kampman (2000), en un estudio realizado exclusivamente con mujeres, encontraron que las pacientes con trastorno de pánico reportaban niveles menores de apetito sexual y una muy baja frecuencia de actividad sexual. Concretamente, la prevalencia de patología sexual entre estas mujeres era del $44.4 \%$ frente al $17.6 \%$ en población normal. Los diagnósticos sexuales más frecuentes fueron los de deseo sexual hipoactivo y trastorno por aversión al sexo. Un año más tarde, Figueira, Possidente, Marques y Haves (2001) confirmaron lo que estudios anteriores parecían indicar: existe un perfil diferencial de patología sexual en función del trastorno de ansiedad concreto. Por ejemplo, se demostró que las personas con trastorno de pánico tenían más probabilidad de padecer aversión al sexo y deseo sexual hipoactivo, mientras que los fóbicos sociales solían presentar eyaculación precoz y trastorno de la erección.

A pesar de la solidez de algunos de estos resultados, de forma recurrente aparecían investigaciones que sugerían que podían darse ciertas situaciones donde esta correspondencia no siempre se cumplía. En 1982, en una investigación realizada con 57 hombres y mujeres con depresión, el 31\% decía haber perdido interés en el sexo mientras que un $22 \%$ afirmaba justo lo contrario -que su apetito sexual había aumentado- (Mathew \& Weinman, 1982). Angst (1998) también obtuvo resultados que contradecían la idea de que estados emocionales adversos conducen invariablemente a una reducción del apetito sexual: en un grupo de 
hombres deprimidos, el $25.7 \%$ dijeron experimentar un menor apetito sexual, mientras que el 23.3\% afirmaron lo contrario. Este porcentaje era menor en mujeres, donde tan sólo el $8.8 \%$ experimentaban un aumento del deseo durante episodios depresivos.

Estos estudios, sumado a su interés por validar un nuevo modelo teórico de respuesta sexual (Dual Control Model, Bancroft \& Janssen, 2000), llevaron a Bancroft y su equipo a realizar una serie de investigaciones que culminarían en 2003 con la publicación de dos artículos sobre el papel del estado de ánimo en la conducta sexual. El primero de ellos (Bancroft, Janssen, Strong, Carnes, et al., 2003) consistió en una investigación con 919 hombres heterosexuales estadounidenses de entre 16 y 84 años. Estos autores encontraron que en estados depresivos, el $9.4 \%$ de los hombres experimentaban un aumento de su apetito sexual y el $3.2 \%$ un aumento de su respuesta sexual. En ansiedad, estos porcentajes aumentaban hasta el $20.6 \%$ en el caso del incremento del apetito sexual y el $10.6 \%$ en el incremento de la respuesta sexual. En una entrevista posterior, se preguntó a los participantes el porqué del incremento de su apetito sexual, concluyendo lo siguiente. En depresión, el sexo puede ser una forma de lograr intimidad y conexión emocional con alguien o simplemente de lograr cierta regulación emocional, por lo que suele estar relacionado con encuentros sexuales con otras personas; en ansiedad, el sexo es más bien un medio para reducir la activación fisiológica, beneficiándose de la calma que sucede al orgasmo -por ello se relaciona más con la masturbación-.

El segundo de estos artículos (Bancroft, Janssen, Strong, \& Vukadinovic, 2003) era prácticamente una réplica de este primer trabajo pero con población homosexual (662 hombres homosexuales con edades comprendidas entre los 18 y los 80 años). En este caso, los autores encontraron que durante estados depresivos, el $16 \%$ y el $7.2 \%$ de los evaluados experimentaban un aumento de su apetito sexual y de su respuesta respectivamente. En ansiedad, estos porcentajes aumentaban hasta el $23.9 \%$ en el caso del deseo sexual y hasta el 14.1\% en respuesta sexual. También hallaron que un incremento del deseo sexual durante periodos de ansiedad o depresión correlacionaba positivamente con la frecuencia de sexo anal y de cualquier tipo de práctica sexual, así como con la frecuencia de masturbación.

Bancroft y su equipo se dieron cuenta del papel central que el sexo podría jugar en la regulación emocional de personas con CS, por lo que se plantearon comprobar su modelo en estos pacientes. Hasta ese momento, las únicas evidencias de la relación entre estado de ánimo negativo y compulsividad sexual se habían documentado a través de estudios de comorbilidad (Black, Kehrberg, Flumerfelt, \& Scholosser, 1997; Raviv, 1993). En 2004, estos autores publicaron un trabajo en el que ponían a prueba la relación entre estado de ánimo y apetito sexual en una muestra de 31 pacientes con compulsividad sexual tratados en un 
programa de 12 pasos de sexo-adictos anónimos (Bancroft \& Vukadinovic, 2004). A diferencia de lo encontrado en población normal, la mayoría de estos pacientes experimentaba un aumento de su apetito sexual durante episodios de depresión o ansiedad; en depresión, el $54.8 \%$ experimentaba un aumento del apetito sexual y un $34.5 \%$ un aumento de su respuesta sexual; en ansiedad, el $61.2 \%$ apreciaba un incremento del apetito sexual y el $34.5 \%$ de su respuesta sexual. La conducta sexual más problemática era la masturbación compulsiva. En la tabla 1 podemos apreciar mejor la relación entre estado de ánimo y respuesta sexual en hombres con CS cuando los comparamos con chicos heterosexuales u homosexuales.

Tabla 1. Respuesta sexual y estado emocional (elaboración propia a partir de Bancroft, Janssen, Strong, \& Vukadinovic, 2003; Bancroft \& Vukadinovic, 2004; Bancroft, Janssen, Strong, Carnes, et al., 2003)

\begin{tabular}{lccc}
\hline & Heterosexuales & Homosexuales & Pacientes con CS \\
\hline Aumento del deseo sexual durante ansiedad & $20.6 \%$ & $23.1 \%$ & $61.2 \%$ \\
Aumento de la respuesta sexual durante ansiedad & $10.6 \%$ & $14.1 \%$ & $34.5 \%$ \\
Aumento del deseo sexual durante depresión & $9.4 \%$ & $16 \%$ & $34.8 \%$ \\
Aumento de la respuesta sexual durante depresión & $3.2 \%$ & $7.2 \%$ & $34.5 \%$ \\
\hline
\end{tabular}

Hasta el momento, la principal conclusión que se extrae es que el sexo es utilizado por las personas con CS como regulador emocional de ciertos estados mórbidos (concretamente ansiedad y depresión). Sin embargo, los estudios más recientes van un paso más allá y postulan que el verdadero problema es que las personas con CS sufren ciertos déficits en el procesamiento emocional; estos déficits serían los responsables de que estas personas sufran con mayor probabilidad estados emocionales disfóricos y también explicarían el uso desadaptativo del sexo como regulador emocional. Es decir, una tercera variable -los déficits en el procesamiento emocional- sería responsable al mismo tiempo de la compulsividad sexual y de los problemas emocionales. Sucesivos estudios han ratificado esta hipótesis. En 2008, Reid, Carpenter, Spackman y Willes (2008) se propusieron comprobar si estos déficits podrían estar relacionados con una mayor dificultad a la hora de identificar y describir estados emocionales internos (alexitimia) junto con una mayor propensión al estrés y mayor inestabilidad emocional. Para comprobarlo, evaluaron la personalidad y el estado emocional de 120 pacientes que acudieron a una clínica para tratamiento ambulatorio por un problema de hipersexualidad. Lo que estos autores encontraron es que efectivamente, las puntuaciones en la escala SCS correlacionaban con indicadores de vulnerabilidad emocional (concretamente con la dimensión de personalidad de neuroticismo y con dos de sus facetas -depresión y vulnerabilidad-), de propensión al estrés y con déficits en la identificación de emociones. De los tres indicadores, el que mostró una relación más estrecha con la compulsividad sexual fue la vulnerabilidad emocional. Más tarde, Reid (2010) comparó el estado emocional de un grupo 
de 103 pacientes buscando ayuda por un problema de hipersexualidad con un grupo control, obteniendo que los pacientes con hipersexualidad experimentaban muchas menos emociones positivas (sobre todo alegría) y muchas más emociones negativas (tristeza, rabia, etc.), de nuevo predictoras de ciertos indicadores de CS.

A nivel clínico, una impresión que la mayoría de terapeutas que habían tratado a personas con CS compartían es que el disconfort emocional que se trataba de manejar o mitigar a través de la conducta sexual compulsiva era generado por emociones de culpa y vergüenza (K. M. Adams \& Robinson, 2001; S. J. Reed, 2001; Wilson, 2000). El problema es que la dificultad para concretar estas emociones tan complejas en un constructo capaz de ser medido a través de instrumentos psicométricos había impedido el desarrollo de estudios empíricos, por lo menos hasta que Reid, Harper y Anderson (2009) abordaron esta cuestión. Valiéndose de un cuestionario que medía las 4 principales estrategias de las que las personas nos valemos cuando experimentamos culpa y vergüenza (evitación emocional, ataque a uno mismo, ataque a otras personas y negación), los investigadores evaluaron a un grupo de 71 hombres de entre 19 y 54 años con un diagnóstico de hipersexualidad y los compararon con un grupo de 73 estudiantes equivalentes en cuanto a edad. Lo que se apreció es que efectivamente, los pacientes hipersexuales utilizaban con mucha mayor frecuencia 3 de las 4 estrategias de manejo de la culpa y la vergüenza (concretamente la evitación emocional, el ataque a uno mismo y el ataque a otras personas). Este estudio confirmaba que las personas con CS experimentaban con mayor frecuencia emociones como la culpa y la vergüenza, pero fallaba a la hora de establecer vínculo alguno entre estas emociones y la conducta sexual compulsiva. Dicho vínculo lo logran establecer con resultados muy significativos Gilliland, South, Carpenter y Hardy (2011). Evaluando a un grupo de 170 hombres de entre 18 y 73 años que estaban recibiendo tratamiento por consumo excesivo de pornografía, estos autores encontraron un vínculo opuesto entre culpa, vergüenza y CS: mientras que la vergüenza se relacionaba positivamente con la conducta sexual compulsiva, la culpa lo hacía a la inversa y además predecía una actitud más positiva hacia el cambio e incluso se relacionaba con una conducta proactiva hacia dicho cambio (p.e., tratar de reducir el consumo de pornografía evitando la conexión a internet). De esta forma, los autores proponen que las intervenciones emocionales en CS deberían buscar sustituir la vergüenza por la culpa, mucho más relacionada con variables de cambio terapéutico.

Para terminar de afianzar la hipótesis del sexo como regulador emocional en CS, se ha publicado recientemente un trabajo en el que se evidencia que el mindfulness -que a fin de cuentas, no es otra cosa que una técnica de regulación emocional- y la hipersexualidad se 
relacionan íntimamente (Reid, Bramen, Anderson, \& Cohen, 2014). En esta investigación, en la que se comparan a un grupo de 40 pacientes hipersexuales con 40 pacientes con otras patologías mentales menos severas, se encuentra que mayores capacidades mindfulness -es decir, de regulación y estabilidad emocional- predicen una menor gravedad de la compulsividad sexual. De hecho, las capacidades mindfulness permiten predecir el $12 \%$ de la varianza de las puntuaciones en una escala de hipersexualidad.

Las últimas investigaciones se están centrando más en identificar el momento exacto en el que la desregulación emocional da paso a la conducta sexual compulsiva, presumiblemente porque esto podría arrojar cierta luz sobre una de las grandes cuestiones que todavía quedan pendientes: ¿la vergüenza y la culpa son causa o consecuencia de la conducta sexual compulsiva? De momento la pregunta sigue sin respuesta, pero al menos sabemos que la desregulación emocional no se da durante la realización de la conducta sexual (Prause, Staley, \& Fong, 2013). Esta afirmación es el resultado de una investigación en la que se exponía a 120 personas (71 con adicción a la pornografía y 49 controles) a dos escenas: una de ellas neutra y la otra pornográfica. Durante la exposición, los participantes debían valorar su estado emocional mediante distintas escalas, lo cual permitiría determinar el grado en el que la vivencia emocional de la escena pornográfica se podría considerar equilibrada o emocionalmente desregulada. Lo que se encontró es que el procesamiento emocional de pacientes con adicción a la pornografía y controles era prácticamente idéntico, por lo que la desregulación propia de la CS sólo puede considerarse como antecedente o consecuente de la propia conducta sexual, no concurrente a la misma.

\subsection{Síntomas cognitivos: creencias erróneas en torno al sexo}

En comparación con los emocionales y sobre todo los conductuales, los síntomas cognitivos de la CS han pasado desapercibidos sobre todo desde el ámbito académico. Los pocos estudios que se han parado a explorar el papel de las cogniciones en CS se han limitado a su análisis a un nivel superficial: concretamente, a la descripción de la frecuencia de pensamientos y fantasías sexuales. Estos estudios han constatado que efectivamente, la frecuencia de pensamientos obsesivos y fantasías es mayor entre las personas con alta CS (Kafka, 1997; Kafka \& Hennen, 2003), pero este abordaje del papel de las cogniciones le ha permitido asumir únicamente un papel secundario: el de antecedente de la conducta sexual.

Más recientemente, esta perspectiva ha cambiado y los planteamientos actuales buscan entender el papel central que ciertos sistemas de creencias erróneas en torno al sexo juegan en el inicio y el mantenimiento de esta patología (Pachankis, Rendina, Ventuneac, Grov, \& 
Parsons, 2014). A este respecto, Pachankis et al. (2014) afirman que "existe una notable falta de literatura científica en torno al papel de las creencias erróneas sobre sexo en la compulsividad sexual, entendidas como un conjunto de pensamientos formados a lo largo del desarrollo que definen la forma rígida y disfuncional con la que una persona expresa sus actitudes, creencias y expectativas sobre el sexo, su significado y sus consecuencias" (Pachankis et al., 2014, p. 670).

Existen cada vez más evidencias que apoyarían la importancia de ciertos sistemas de creencias en el inicio y el mantenimiento de la CS. Por ejemplo, en la mayoría de patologías comórbidas a la CS (depresión, distimia, abuso de sustancias, juego patológico, ansiedad social, ansiedad generalizada, etc.), la presencia de creencias erróneas y pensamientos automáticos permite explicar la incapacidad de estas personas para valorar y juzgar las situaciones de manera correcta, tener expectativas acertadas y coherentes sobre las consecuencias de la propia conducta o bien diseñar planes de acción realistas que les permitan restablecer el control sobre su propia conducta (A. T. Beck, 1979; Kohn, 2006; Witkiewitz \& Marlatt, 2004).

El ámbito de la intervención clínica en CS es uno de los que más importancia ha otorgado a los síntomas cognitivos de esta patología. Si bien tradicionalmente se ha potenciado sobre todo el uso de intervenciones farmacológicas, conductuales o bien basadas en el modelo de los 12 pasos de sexo-adictos anónimos (Hook, Reid, Penberthy, Davis, \& Jennings, 2014; Rosenberg, Carnes, \& O'Connor, 2014), existen algunos estudios que sugieren la utilidad del abordaje cognitivo-conductual de esta patología. En este sentido, intervenir sobre la excesiva importancia que estas personas atribuyen a su necesidad de mantener relaciones sexuales, valorar objetivamente los recursos de los que disponen para controlar su propio impulso sexual o bien potenciar ciertas habilidades de afrontamiento y de regulación emocional se han identificado como estrategias eficaces para mejorar los resultados de las intervenciones (Shepherd, 2009; Weiss, 2004b). Este modelo terapéutico basado en la reducción de los sesgos cognitivos en CS es coherente con las aproximaciones actuales a la intervención en otros problemas sexuales relativamente afines, como por ejemplo las parafilias (para una revisión completa consultar Laws \& O’Donohue, 2008).

Por otra parte, resulta destacable el papel de ciertas emociones complejas como la vergüenza y la culpa a la hora de propiciar la conducta sexual compulsiva. De acuerdo con el modelo cognitivo clásico, la experiencia emocional positiva o negativa dependería principalmente de la interpretación que diéramos de los desencadenantes de dicha emoción a través de un sistema concreto de creencias (A. T. Beck, 1979). Desde esta visión, asumir la importancia de ciertas emociones en la comprensión y la expresión de la CS significa aceptar implícitamente el papel 
central de las cogniciones, que sería el elemento que daría cuenta de dicha emoción. Trabajando desde esta perspectiva, Paunovic y Hallberg (2014) han logrado identificar a partir de su experiencia en el tratamiento de pacientes con CS algunas de las cogniciones disfuncionales que podrían estar generando los estados emocionales típicos de este cuadro clínico: la creencia de que sólo una mala persona es capaz de tener ciertos pensamientos o conductas sexuales sería la que lleva a la persona a experimentar vergüenza, mientras que la creencia de que los pensamientos y conductas sexuales provocan daño a otras personas sería, por su parte, la que propiciaría los sentimientos de culpa. En ambos casos, una creencia errónea daría cuenta de la emoción negativa concurrente. En todo caso, en ocasiones la vergüenza y culpa se emplean con fines clínicos para mejorar el control de impulsos sexuales.

La única investigación que ha abordado de forma directa el vínculo entre creencias erróneas y CS ha sido la realizada por Pachankis et al. (2014). Estos autores se enfrentaban en su investigación a un doble reto: el primero consistía en identificar las creencias erróneas en torno al sexo y la sexualidad más comunes en personas con CS; una vez hecho esto, el segundo reto consistía en tratar de establecer un vínculo entre dichas creencias y alguno de los indicadores prototípicos de conducta sexual compulsiva. Para ello, tomaron a una muestra de 202 hombres homosexuales con una edad media de 37 años y muy activos sexualmente (como mínimo 9 parejas sexuales en los últimos 90 días, 2 de ellas en los últimos dos meses). Mediante entrevistas individuales, lograron identificar las principales creencias erróneas en torno al sexo, que luego reflejaron a través de un cuestionario de 17 ítems. Esta escala se administró a los participantes junto con una serie de instrumentos que permitían establecer la gravedad del diagnóstico de CS. A partir de esta metodología, estos autores encontraron que las principales creencias erróneas se podían clasificar en tres dominios: 1) magnificación de la necesidad de sexo ("necesito sexo para sentirme mejor conmigo mismo"), 2) minimización de los beneficios del sexo ("el sexo hace más mal que bien") y 3) minimización de la capacidad para controlar el impulso sexual ("sólo pensar en sexo ya me hace que tenga que ir a buscarlo sea como sea"). Además, estos tres dominios en conjunto permitían predecir el $45 \%$ de la varianza de las puntuaciones en una escala de CS.

A partir de estos hallazgos, Pachankis et al. (2014) proponen la forma en la que las creencias erróneas podrían explicar el inicio o cuanto menos el mantenimiento de la CS. Según estos autores, cuando una persona piensa que el sexo se asocia con más daños que beneficios y aun así lo sigue haciendo, entonces comienza a desarrollar una baja percepción de control sobre su propia conducta sexual -empieza a ver su conducta sexual más como un impulso impuesto que como una elección-. A su vez, esta percepción de incapacidad para el control del propio 
impulso sexual aumenta conforme la persona ve el sexo cada vez más necesario para sentirse bien y equilibrado durante su día a día (p.e., "lo necesito para verme bien"). Este ciclo se retroalimenta hasta que alcanza su máxima expresión en el cuadro clínico típico de la CS; de ahí la gran importancia que tiene la identificación de los síntomas cognitivos no sólo para el diagnóstico de esta condición, sino también para plantear intervenciones eficaces.

\subsection{Déficits en funciones ejecutivas}

Las funciones ejecutivas constituyen toda una constelación de procesos mentales asociados a la conducta motivada. Tal y como señala Funashashi (2001), "son el producto de la acción coordinada de varios procesos cognitivos que permiten alcanzar metas y objetivos de manera flexible" (Funahashi, 2001, p. 147). Algunos de los procesos cognitivos implicados serían: inhibición conductual, control de impulsos, memoria de trabajo verbal y no verbal, regulación afectiva y motivacional, activación conductual, planificación, organización, toma de decisiones, juicio guiado por evidencias, monitorización de actividades, atención, solución de problemas, generación de hipótesis, pensamiento abstracto y flexibilidad cognitiva (Homack, Lee, \& Riccio, 2005; Lezak, 2004; Spinella, 2005).

El funcionamiento ejecutivo depende de la integridad de distintas zonas y estructuras cerebrales, principalmente la corteza frontal y prefrontal, el tálamo y el Globus Pallidus. En la medida en que estas zonas cerebrales se ven afectadas o bien por circunstancias sobrevenidas (p.e., una enfermedad neurodegenerativa) o bien por ciertas anormalidades congénitas en su actividad y desarrollo, el funcionamiento ejecutivo pierde eficacia y la persona suele experimentar problemas en el control, organización y planificación de su conducta (Elliott, 2003). Estos problemas no se expresan a través de un único síntoma; por el contrario, el deterioro del funcionamiento ejecutivo acaba afectando a muy diversos aspectos de la conducta de la persona. Un ejemplo prototípico sería el del trastorno por déficit de atención con hiperactividad -TDAH-: en este caso, las funciones ejecutivas (especialmente la inhibición de respuesta, la atención y la memoria de trabajo) se verían mermadas en distinto grado por la conjunción de factores psicosociales, del desarrollo y por una activación anómala de ciertas áreas cerebrales. Esto no provoca un único síntoma ni se expresa de una única manera, sino que acaba afectando al conjunto del comportamiento de la persona con esta patología (Cardo \& Servera, 2008).

Recientemente, la hipótesis de que un deterioro en las funciones ejecutivas podría explicar gran parte del cuadro clínico típico de un paciente con compulsividad sexual ha empezado a ganar fuerza. El corpus de investigaciones al respecto todavía no puede validar completamente 
esta hipótesis, pero se van acumulando evidencias tanto directas como indirectas. Por ejemplo, se han documentado de forma recurrente casos de conducta sexual hipersexual en pacientes con daño cerebral en las zonas asociadas al control ejecutivo: casos de daño cerebral adquirido (Kobayashi, 2004; Spinella, 2004), patología neurodegenerativa (Higgins, Barker, \& Begley, 2004), epilepsia o síndrome Kluver-Bucy (Luef, 2008). También el efecto de ciertas medicaciones sobre dichas zonas cerebrales o bien algunos cambios en la regulación endocrina se pueden asociar con síntomas de CS (Voon \& Fox, 2007). Tanto es así que la patología orgánica asociada a daño cerebral se ha incluido como diagnóstico diferencial en la propuesta de criterios diagnósticos para la hipersexualidad (Kafka, 2014): hablaríamos de hipersexualidad secundaria cuando los síntomas aparecen en respuesta a una causa orgánica identificable (p.e., Alzheimer o esclerosis múltiple) y de hipersexualidad primaria en el resto de casos.

Otro punto importante lo encontramos al analizar el vínculo entre TDAH y CS. Ambas patologías comparten ciertos síntomas (p.e., dificultades en la inhibición conductual y control de impulsos) que podrían explicarse a partir del funcionamiento anómalo del control ejecutivo (Reid, Davtian, Lenartowicz, Torrevillas, \& Fong, 2013). De hecho, la comorbilidad entre ambos trastornos es bastante alta: concretamente, del $16.7-18.7 \%$ cuando analizamos los antecedentes de TDAH durante la infancia (Kafka, 1997) y del 21-26\% cuando analizamos la presencia de síntomas de TDAH en la actualidad (Blankenship \& Laarser, 2004; Reid, Carpenter, Gilliland, \& Karim, 2011). El subtipo más común de TDAH en CS es el inatento. La explicación más plausible para el vínculo entre estas dos patologías es la presencia de alteraciones comunes en el córtex prefrontal que provocarían una merma en las capacidades de control ejecutivo, lo cual deriva en una sintomatología que en algunos aspectos, comparten tanto la CS como el TDAH (Reid et al., 2013).

Como ya hemos comentado, el funcionamiento ejecutivo se asocia a ciertas zonas cerebrales: de ahí la importancia de los estudios de neuroimagen. En CS, por lo que sabemos, solamente se han realizado hasta el momento dos estudios de este tipo, pero ambos aportan información muy significativa. En el primero de ellos se comparó mediante resonancia magnética funcional a un grupo de 8 pacientes con CS y a 8 personas sanas (Miner, Raymond, Mueller, Lloyd, \& Lim, 2009): en comparación con los voluntarios sanos, los pacientes con CS mostraban déficits significativos en la difusión de los tejidos de la zona frontal superior (asociada generalmente al control de las funciones ejecutivas). En otro estudio más reciente, Voon et al. (2014) encuentran al comparar a un grupo de 30 pacientes hipersexuales y 30 controles sanos que los primeros muestran una hiperactivación de 3 zonas cerebrales (estriado ventral, cingulado dorsal anterior y amígdala) al ser expuestos a estímulos sexuales explícitos. 
A partir de estos hallazgos, algunos autores han empezado a considerar las funciones ejecutivas en su capacidad para agrupar las distintas expresiones y síntomas de la CS. Desde esta perspectiva, a cada síntoma le correspondería una función ejecutiva alterada (tabla 2):

Tabla 2. Síntomas de CS y funciones ejecutivas alteradas (tomada de Reid, Karim, McCrory, \& Carpenter, 2010)

\begin{tabular}{ll}
\hline \multicolumn{1}{c}{ Síntoma de CS } & \multicolumn{1}{c}{ Función ejecutiva alterada } \\
\hline Dificultades en el control de la conducta sexual & Inhibición y control de los impulsos \\
Déficits en la motivación para el cambio conductual & Motivación, iniciativa y atención \\
Alexitimia y desregulación emocional & Control emocional, flexibilidad cognitiva e inhibición \\
Persistencia a pesar de las consecuencias negativas & Toma de decisiones, inhibición, planificación y organización \\
& y control de impulsos \\
Preocupación excesiva en torno al sexo & Atención, inhibición y flexibilidad cognitiva \\
\hline
\end{tabular}

Algunas investigaciones avalan esta asociación. Reid et al. (2010) han sido los primeros en explorar de forma empírica el vínculo entre CS y funciones ejecutivas. Para ello, tomaron una muestra de 87 hombres de entre 18 y 59 años (edad media de 31.4) en tratamiento por problemas en el control de los impulsos sexuales y compararon su desempeño en tareas neuropsicológicas con el de 92 hombres control equivalentes en características demográficas. Estos autores encontraron que los pacientes con CS mostraban resultados significativamente peores que los controles sanos en 8 de los 9 procesos cognitivos explorados (peor automonitorización, planificación y organización, flexibilidad, iniciativa en la realización de actividades, regulación durante el desempeño de tareas, control emocional, memoria de trabajo y organización de materiales). Además, los déficits en estos procesos cognitivos permitían explicar el $46 \%$ de la varianza de las puntuaciones en una escala de hipersexualidad. En esta línea, Miner et al. (2009) encuentran que los pacientes con CS obtienen peores resultados en una tarea Go no Go de control ejecutivo y en la escala Barrat de impulsividad.

Si bien las evidencias hasta el momento apuntan invariablemente a la presencia de ciertos déficits en el funcionamiento ejecutivo de pacientes con CS, estudios más recientes han fallado a la hora de replicar hallazgos. Sería el caso del estudio de Reid, Garos, Carpenter y Coleman (2011). Estos autores se plantearon replicar con una metodología más rigurosa un estudio que ellos mismos realizaron 1 año antes (Reid et al., 2010). En lugar de emplear autoinformes para la evaluación de las funciones ejecutivas, estos investigadores recurrieron a tareas de evaluación neuropsicológica más fiables y válidas (escala Weschler de inteligencia, tarea de Stroop, torre de Hanoi, etc.). Valiéndose de estos instrumentos, compararon la ejecución de 30 pacientes con CS y de 30 controles, sin lograr identificar diferencias significativas en ninguna de las funciones ejecutivas exploradas. Los autores plantean tres hipótesis para explicar las diferencias respecto a los resultados obtenidos hasta el momento: 1) puede ser que 
efectivamente, no exista alteración alguna en las funciones ejecutivas de pacientes con CS, 2) que los problemas de control ejecutivo en CS no tengan la magnitud suficiente como para ser detectados por las medidas neuropsicológicas utilizadas o 3) que sólo los pacientes más graves $-y$ no una muestra general de pacientes- experimenten deterioro del control ejecutivo.

Sea como sea, queda sobradamente demostrada la importancia de la evaluación de las funciones ejecutivas subyacentes a cualquier caso clínico de CS. Posiblemente, en los próximos años la investigación se centre precisamente en este tópico (Reid, 2013), habida cuenta de su potencial a la hora de explicar algunos de los importantes déficits presentes en el cuadro clínico de esta patología.

\section{En resumen}

El deseo sexual se define como la apetencia o inclinación subjetiva hacia la actividad sexual y su manifestación se modula a partir de determinantes biológicos, psicológicos y sociales. Se ha considerado un constructo dimensional porque las personas varían entre sí en cuanto al grado e intensidad de su deseo y dinámico porque en un mismo individuo, el deseo fluctúa según la etapa vital. Estas fluctuaciones son relativamente frecuentes pero cuando una persona se sitúa en uno de sus extremos por más de 6 meses y experimenta malestar e interferencia, entonces podría ser diagnosticado de un trastorno del deseo sexual. Si la persona experimenta un apetito sexual por debajo de lo normal, el diagnóstico que le corresponde es el de "deseo sexual hipoactivo", una disfunción sexual reconocida desde 1952 por los manuales DSM. Si por contrario, experimenta un deseo sexual excesivo, estos manuales no permitirían su diagnóstico porque no reconocen la entidad de este cuadro clínico.

A pesar de eso, múltiples estudios demuestran que cuando una persona experimenta un deseo sexual muy alto y una incapacidad patológica para su control, su conducta sexual sobreviene un problema que provoca un importante impacto y malestar en múltiples aspectos de su vida. Esto es especialmente cierto cuando el problema se manifiesta a través de conductas sexuales impersonales, es decir, de actividades sexuales que no implican el establecimiento de vínculo emocional alguno (masturbación, sexo con parejas esporádicas, etc.).

Se han empleado distintos términos para designar este cuadro clínico que reflejarían dos concepciones contrapuestas acerca de su naturaleza. Por un lado, términos como "adicción al sexo" o "hipersexualidad" definen el cuadro clínico de forma categórica, una patología que una persona padecería o no en función de sus síntomas. Por otro lado, el término "compulsividad sexual" reflejaría una visión dimensional, es decir, una variable que las personas comparten en mayor o menor medida y que dependiendo de su manifestación y gravedad, influye de una 
manera u otra sobra aspectos como la frecuencia de actividad sexual, el tipo, la realización de conductas sexuales de riesgo, etc. Esta última perspectiva es la que ha recibido mayor aval empírico y la que se ha considerado durante la elaboración de esta tesis.

Desde esta perspectiva, la CS designaría el trastorno que padecen las personas con dificultades a la hora de controlar su deseo sexual, pensamientos sexuales frecuentes e intrusivos que les llevan a mantener conductas sexuales -solitarias o con parejas- de forma repetida y sin ningún control y que experimentan consecuencias negativas derivadas de su comportamiento sexual. Los principales signos del cuadro clínico son: 1) frecuencia sexual elevada (7 o más orgasmos a la semana); 2) uso del sexo como regulador emocional; 3) pensamientos obsesivos sobre sexo y presencia de distorsiones cognitivas (magnificación de la necesidad de sexo, minimización de sus beneficios e infravaloración de la capacidad de control sobre el comportamiento sexual) y; 4) presencia de síntomas que sugieren diversos problemas en el control ejecutivo. 


\section{Capítulo 2. Evaluación, diagnóstico y clasificación de la compulsividad sexual}

1. Evaluación de la compulsividad sexual

1.1 Introducción a la evaluación en CS

1.2 Nivel 1: evaluación de la presencia y gravedad de los síntomas de CS

1.3 Nivel 2: descartando el origen orgánico de los síntomas de CS

1.4 Nivel 3: descartando que los síntomas formen parte de un trastorno del Eje I o II

2. El diagnóstico de la compulsividad sexual en los manuales DSM

3. Prevalencia de la CS

4. Comorbilidad psicopatológica: prevalencia de trastornos del Eje I y II en personas con CS

5. Consecuencias de la CS

6. Clasificación de la conducta sexual compulsiva

6.1 Primera etapa en la clasificación de la CS

6.2 Segunda etapa en la clasificación de la CS

6.3 Tercera etapa en la clasificación de la CS.

6.4 Análisis de las propuestas de clasificación: ventajas, limitaciones y nuevos desarrollos

7. En resumen 


\section{Evaluación de la compulsividad sexual}

1.1 Introducción a la evaluación en CS

La complejidad de los síntomas que caracterizan a la CS así como sus consecuencias y el estigma social que le acompaña requieren de una evaluación exhaustiva. Esta tarea implica una especial habilidad de adaptación, ya que la forma en la que estos pacientes acceden a los sistemas de asistencia no suele seguir los cauces habituales.

En general, estos pacientes no acuden a consulta por iniciativa propia y cuando lo hacen, el motivo de consulta no suele ser su conducta sexual (Kafka, 2007). En su lugar, buscan asistencia por problemas asociados -sobre todo ansiedad, depresión o coadicción a sustancias tóxicas- y el cuadro clínico de CS sólo emerge tras una evaluación exhaustiva. No en vano, estamos hablando de una patología que en la mayoría de ocasiones, lleva aparejados sentimientos de vergüenza y de culpa que difícilmente les permite expresar abiertamente a un desconocido -sea éste o no un profesional de la salud mental- su situación (Reid, 2010; Reid, Bramen, et al., 2014; Reid et al., 2008). El estigma asociado a padecer este tipo de problemas sexuales es si cabe mayor en mujeres, a las que tradicionalmente se las ha considerado promiscuas, adúlteras o degeneradas. Así, la probabilidad de que mujeres con este cuadro clínico busquen ayuda terapéutica es si cabe menor a la de los hombres (McBride et al., 2011).

Son pacientes cuyo cuadro clínico se ha ido agravando progresivamente durante años, por lo que la evaluación se da en un contexto en el que la estabilidad personal y sobre todo familiar se suele haber visto seriamente dañada (Pollard, Hook, Corley, \& Schneider, 2014). Muchos de ellos acuden a consulta cuando su pareja descubre su conducta sexual: en estas situaciones, resulta habitual que se produzca una separación o que, en el mejor de los casos, se lance a los pacientes un ultimátum donde lo único que puede evitar la separación es el cambio de la conducta sexual (Steffens \& Rennie, 2006). En este sentido, es importante implicar a la pareja en el proceso de evaluación inicial ya que la terapia familiar y de pareja son cruciales, siendo el apoyo del entorno familiar uno de los principales predictores de la eficacia del tratamiento (Hook et al., 2014; Kafka, 2007).

En otros casos los pacientes acceden a evaluación a través de la derivación por parte de un servicio de atención primaria -normalmente médicos de familia- (M. M. Campbell \& Stein, 2014). Esto se debe principalmente al creciente interés de estos profesionales por formarse en el reconocimiento de las características de este cuadro clínico: trabajos como el de Borgermans et al. (2013), publicado en la International Journal of Family Medicine y donde se abordan las nociones básicas para el diagnóstico de CS, dan buena cuenta del interés que 
suscita esta patología entre los profesionales de atención primaria y también evidencia el importante papel que pueden jugar en la toma de contacto y derivación de estos pacientes. No podemos ignorar la posición privilegiada de estos profesionales a la hora de: 1) acceder al historial médico de los pacientes, lo que permite identificar algunos signos de CS como haber padecido múltiples ITS o embarazos no deseados; 2) conocer de primera mano no sólo al paciente sino también a todo el entorno familiar, pudiendo identificar más fácilmente situaciones familiares que sugieran la presencia de este cuadro clínico; 3) poder establecer, gracias al contacto frecuente, una relación de confianza en la que el paciente sea más receptivo a los consejos del médico (como el de recurrir a un profesional de la salud mental para que evalúe su situación). No debemos olvidar que el médico de familia puede ser el profesional de referencia a quien el paciente consulte por primera vez su problema sexual.

En las ocasiones en las que la conducta sexual compulsiva cursa con algún tipo de parafilia o de desviación sexual, el paciente puede acudir a terapia como medida de reducción de condena o para evitar la entrada en prisión (Laws \& O’Donohue, 2008; Marshall, 2014). En estos casos, la evaluación y el tratamiento encaran otro problema: el intento manifiesto de mentir acerca de la gravedad consecuencias de sus síntomas y la escasa adherencia a las medidas terapéuticas.

Aun cuando el paciente tiene cierta conciencia de que su conducta sexual puede resultar problemática y decide libre y voluntariamente buscar asesoramiento especializado, se suele encontrar con algunos problemas añadidos. Para empezar, los centros y recursos con terapeutas especializados son muy limitados y con un coste prácticamente inasumible: en todo EEUU hay tan sólo 23 centros especializados en evaluación y tratamiento de la compulsividad sexual, con un coste medio que oscila entre los 650 y los 6800 dólares semanales (Addiction Resource Guide, n.d.). Asimismo, el número de terapeutas habilitados en ese país por las agencias nacionales de certificación para el tratamiento de la CS es de 606 (Hagedorn, 2009b), lo cual es insuficiente teniendo dada la prevalencia de esta problemática.

Al parecer, la calidad de la formación de algunos de estos profesionales homologados no es muy elevada. En un reciente trabajo, Hagedorn (Hagedorn, 2009a) contactó con 174 de esos 606 terapeutas homologados para preguntarles acerca de su formación y desempeño en la evaluación y tratamiento de la CS. La mayoría de estos terapeutas (92.5\%) -que trataban una media semanal de 2 pacientes con CS- indicaron no haber recibido formación especializada; prácticamente todos (98.3\%) creían necesario recibir formación adicional, sobre todo a través de seminarios y cursos de especialización; finalmente, cuando se les preguntó acerca de su desempeño en la evaluación y tratamiento de este tipo de pacientes, un 35\% afirmó sentirse entre nada y poco competentes. 
Sin embargo, cada vez son más las herramientas (entrevistas, escalas, autoinformes, etc.) que posibilitan una evaluación exhaustiva de los síntomas de la CS. Muchos de estos instrumentos cuentan con puntuaciones normativas que facilitan que, aun cuando la formación del clínico haya sido nula o escasa su experiencia en el tratamiento de estos pacientes, la evaluación y el diagnóstico se realice con ciertas garantías (Hook, Hook, Davis, Worthington, \& Penberthy, 2010; Womack, Hook, Ramos, Davis, \& Penberthy, 2013). Asimismo, se han ido desarrollando protocolos que permiten realizar una evaluación completa siguiendo una serie de directrices y pasos muy definidos (Coleman-Kennedy \& Pendley, 2002; Finlayson, Sealy, \& Martin, 2001). Finlayson et al. (2001) realizan una propuesta simple e intuitiva. Estos autores propusieron hace ya 15 años diferentes niveles y síntomas a explorar ante un cuadro clínico de CS, así como los diagnósticos correspondientes a cada nivel (figura 2). La evaluación ha evolucionado desde entonces pero este modelo -que nosotros tomaremos como referencia para el desarrollo de los epígrafes sucesivos de evaluación- sigue teniendo plena vigencia en la actualidad:

Figura 2. Árbol de decisión en la evaluación y diagnóstico de la CS (Adaptado a partir de Finlayson et al., 2001).
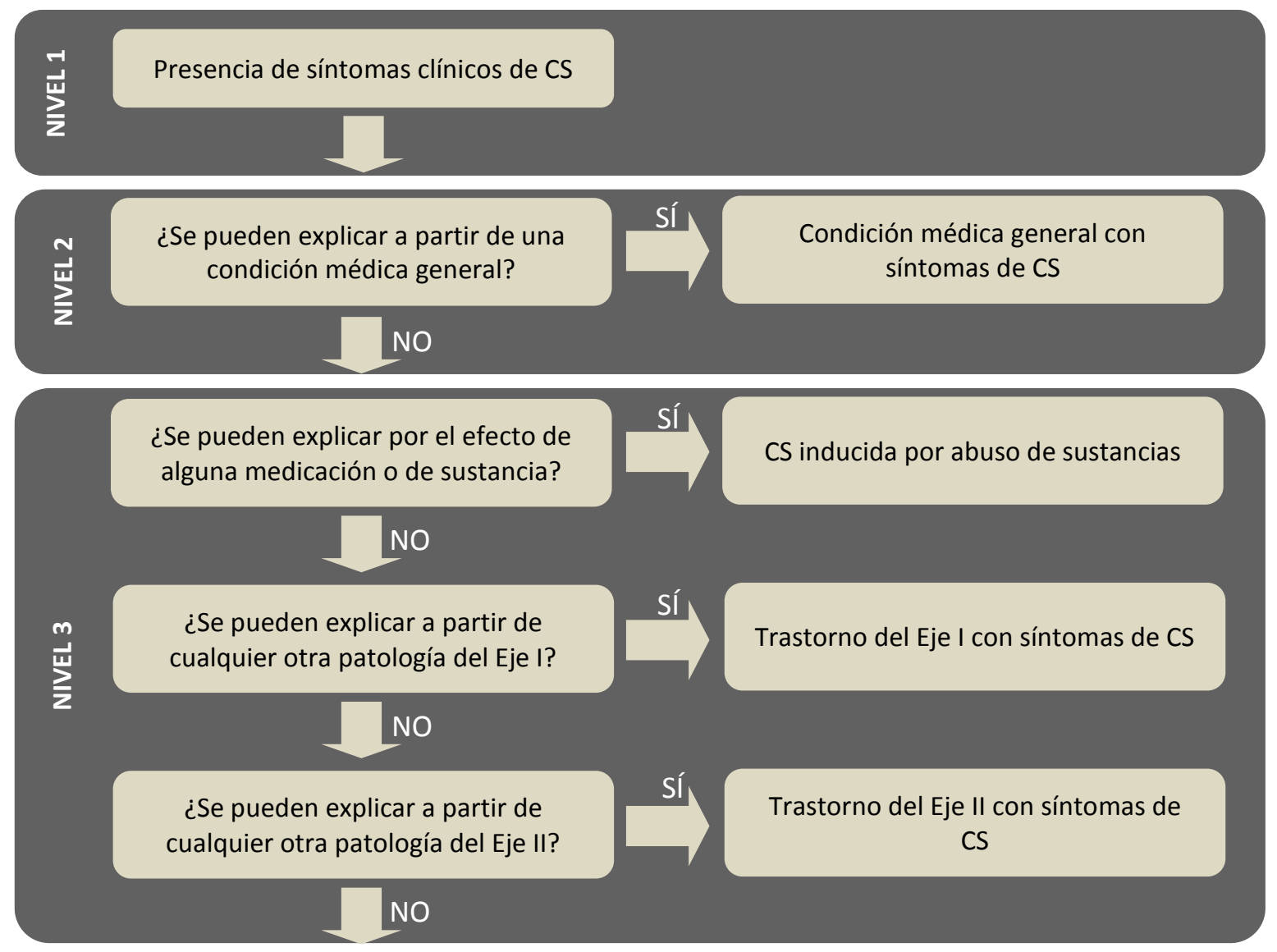

Cuadro clínico puro de CS 
Según este modelo, los primeros pasos de la evaluación deberían centrarse en comprobar si los síntomas que el paciente presenta corresponden o no a un cuadro clínico de CS y, en caso de corresponder, si alcanzarían la significación clínica -gravedad, interferencia, consecuencias negativas, etc.- necesaria para un diagnóstico en ese sentido (nivel 1). Una vez confirmado, se debe descartar que dichos síntomas se expliquen mejor a partir de la presencia de una enfermedad médica con un cuadro sintomático similar que pudiera confundir el diagnóstico (nivel 2). Descartada la explicación orgánica de los síntomas de CS, entonces se explora la posibilidad de que los síntomas se expliquen en el contexto de alguna patología del Eje I o del Eje II (nivel 3). Si tras la evaluación se desechan los posibles diagnósticos diferenciales, entonces se trataría de un cuadro puro de CS. Si, por el contrario, en alguno de los pasos anteriores se confirme la presencia de otra condición que explique mejor la sintomatología, entonces se debe valorar si la CS se puede considerar como parte de dicha patología (p.e., CS en el contexto de una enfermedad neurodegenerativa) o bien si resultaría más conveniente el diagnóstico de ambas condiciones comórbidas que se manifiestan de forma concurrente sin que la presencia de una explique por completo la de la otra (p.e., un cuadro clínico de CS diagnosticado junto con un episodio depresivo mayor).

A continuación se expondrá cómo evaluar cada uno de los niveles descritos, haciendo especial hincapié en los principios a tener en cuenta a la hora planificar y ejecutar una evaluación ante un caso de este tipo.

1.2 Nivel 1: evaluación de la presencia y gravedad de los síntomas de CS

En la evaluación de cualquier trastorno sexual, muchas veces el qué se pregunta no es tan importante como el cómo se pregunta: el generar un ambiente cómodo de evaluación a partir del rapport establecido entre paciente y terapeuta, dar seguridad acerca de la confidencialidad del proceso y de que los resultados de la evaluación no se utilizarán sino para el beneficio del paciente son algunas de las cuestiones que determinarán invariablemente que el proceso de evaluación llegue o no a buen puerto (S. Leiblum, 2006; Santamaría, 2010). Estos consejos son si cabe más significativos cuando hablamos de la evaluación de un paciente con un posible caso de conducta sexual compulsiva.

Kafka (2007) recomienda que las primeras entrevistas de evaluación se realicen con la presencia únicamente del paciente. En fases posteriores -sobre todo durante el tratamiento-, la inclusión de la pareja o personas significativas del entorno puede resultar muy importante, pero por norma general, el que otra persona esté presente durante el proceso de recopilación de información inicial y contraste de síntomas suele provocar inhibición y falta de veracidad en 
las respuestas a la evaluación. Incluso en casos excepcionales en los que el paciente confiesa el problema sexual a su pareja antes de acudir a tratamiento se debe proceder con cautela para evitar que la información obtenida durante la evaluación genere nuevos y serios conflictos. En todo caso, el apoyo de terceras personas puede emplearse como vehículo para que el paciente se muestre abierto y comprometido con la evaluación e incluso como fuente de información adicional -siempre con la autorización previa del paciente- (Coleman-Kennedy \& Pendley, 2002; Edwards, 2012).

Otro aspecto crucial antes de comenzar el proceso de evaluación de síntomas propiamente dicho es tomarse el tiempo necesario -en algunos casos pueden ser suficientes unos minutos y en otros serán necesarias sesiones completas- para generar el ambiente óptimo de evaluación: si comenzamos demasiado pronto a explorar la conducta sexual del paciente, es probable que éste no sea capaz de hablar abiertamente de su problema y esta inhibición perdure durante todo el proceso de evaluación, conduciendo a diagnósticos erróneos o poco precisos (Kafka, 2007). Algunos consejos útiles para establecer un vínculo terapéutico con este tipo de pacientes son: 1) explicar que cualquier información ofrecida al amparo del proceso de evaluación es objeto de total confidencialidad; 2) explicar que la sociedad suele juzgar la sexualidad a partir de criterios morales, pero que en este proceso nos valdremos únicamente de criterios científicos y de calidad de vida; 3 ) mantener una actitud abierta y conciliadora que permita que el paciente se involucre de manera activa en su proceso terapéutico, lo cual supone exponer los objetivos y áreas que se van a explorar durante la evaluación y mostrar disposición a modificarlos o retrasarlos si así lo prefiere. Resulta tan importante crear un vínculo sincero entre paciente y terapeuta que los modelos actuales de intervención en adicciones sexuales integran en sus protocolos técnicas como la entrevista motivacional -que consiste en reorientar la entrevista psicológica hacia las fortalezas que pueden motivar el cambio terapéutico en lugar de hacia las debilidades o problemas- (Lizarraga \& Ayarra, 2001; Orzack, Voluse, Wolf, \& Hennen, 2006).

Una vez generado el contexto apropiado, comienza la recogida de información de signos y síntomas de CS. Kafka (2007) propone que antes de comenzar con una evaluación más exhaustiva, se plantee al paciente 5 preguntas de screening (tabla 3) que justifican la aplicación de escalas e instrumentos más exhaustivos y que requieren una inversión de tiempo mayor. 
Tabla 3. Preguntas de screening para el diagnóstico de la CS (traducido de Kafka, 2007)

1. ¿Has tenido alguna vez problemas para controlar tu conducta sexual?

2. ¿Tu conducta sexual te ha provocado estrés personal o te ha supuesto consecuencias negativas significativas tales como la pérdida de una relación sentimental, problemas legales, laborales o consecuencias médicas (ITS, embarazos no deseados, etc.)?

3. ¿Has mantenido repetidas relaciones sexuales que has llevado en secreto porque te han provocado vergüenza o te han hecho sentir culpable?

4. ¿Alguna vez te has planteado o has tenido problemas por el tiempo que dedicas a fantasear con encuentros sexuales, a mantenerlos o bien a masturbarte?

5. ¿Alguna vez te has planteado que tu apetito sexual resultaba excesivo? Aclaración si el paciente lo requiere: incluyendo tanto la masturbación como las relaciones sexuales con parejas, ¿̇alguna vez has mantenido una frecuencia sexual de 7 o más orgasmos semanales durante un periodo de cómo mínimo 6 meses desde el final de la adolescencia?

Si el paciente contesta afirmativamente a una o más de estas 5 preguntas -seleccionadas de entre los principales síntomas de CS-, queda justificado explorar mediante procedimientos más exhaustivos la posibilidad de que presente un cuadro clínico de CS (Kafka, 2007). Durante esta primera fase del protocolo de evaluación se contempla normalmente una evaluación a dos niveles: en primer lugar, se recomienda explorar aspectos generales de la conducta sexual del paciente, para pasar posteriormente a evaluar los signos y síntomas particulares de CS (Kafka, 2007; Reid, 2013; Rosenberg et al., 2014). El objetivo es recoger información suficiente para identificar la presencia o no de un cuadro clínico de CS, sus características y, si corresponde, establecer su gravedad. En cuanto a los contenidos y áreas generales de la evaluación en CS, Edwards (2012) recomienda explorar:

1. Historial sexual del paciente: su objetivo es comprender la conducta sexual presente a través de la reconstrucción de la sexualidad durante etapas evolutivas pasadas -juegos sexuales durante la niñez y adolescencia, conducta sexual previa a la primera relación sexual, edad de inicio en las relaciones sexuales, masturbación durante la adolescencia y vida adulta, historial de problemas sexuales, etc.-. Puede resultar útil elaborar un cronograma de la conducta sexual del paciente donde se incluya el tipo de relaciones sexuales y su frecuencia desde la adolescencia hasta la actualidad.

2. Cultura, valores y estereotipos: no todas las culturas comparten los mismos valores con respecto al sexo y la sexualidad; aun dentro de un mismo grupo cultural, otra serie de características determinan muchas veces lo que resulta sexualmente aceptable o no. De ahí la importancia de conocer qué es lo que el paciente cree que se espera de él teniendo en cuenta sus características (edad, sexo, capacidades físicas, orientación 
sexual, religión, estatus socioeconómico, etc.) y sobre todo, el grado en el que finalmente su conducta sexual se ajusta o no a ese perfil.

3. Anatomía y función sexual: en tanto en cuanto los conocimientos sobre anatomía y función sexual se construyen normalmente a partir de la propia experiencia, conocer qué es lo que el paciente sabe en torno a temas como la respuesta sexual, sus fases y los cambios fisiológicos y subjetivos asociados a cada fase nos permitirá conocer mejor la conducta sexual actual del propio paciente. Por ejemplo, resulta habitual que pacientes con CS tengan dificultades a la hora de identificar diferencias entre las fases de deseo o excitación porque para ellos, ambas condiciones van siempre aparejadas.

4. Precauciones sexuales y sexo de riesgo: no interesa tanto saber si el paciente mantiene o no encuentros sexuales de riesgo como sus conocimientos en torno a las prácticas sexuales que puedan resultar perjudiciales. La explicación es sencilla: una persona que mantiene relaciones sexuales sin preservativo con múltiples parejas sexuales puede hacerlo porque es incapaz de controlar sus impulsos sexuales -lo que constituye un síntoma de CS- o bien porque desconoce que eso suponga riesgo alguno para la salud -en cuyo caso hablaríamos de un problema de educación sexual-.

5. Autoimagen corporal: especialmente relevante en algunas manifestaciones concretas de la CS como la adicción a la pornografía, donde se ha demostrado que una imagen negativa puede resultar un factor de riesgo que propicie el inicio y el mantenimiento de esta patología (Luder et al., 2011; Ross, Rosser, McCurdy, \& Feldman, 2007). En este sentido, se recomienda explorar la autoimagen general y también la percepción del paciente con respecto a sus genitales (tamaño, forma, olor, etc.).

6. Fantasías sexuales y masturbación: el análisis del tipo y frecuencia de fantasías sexuales permitirá conocer la naturaleza de los estímulos sexuales que despiertan el interés del paciente -estímulos que pueden ser normofílicos, parafílicos o una combinación-. La frecuencia de masturbación aporta información sobre la magnitud del apetito sexual.

7. Creencias sobre una sexualidad positiva: la valoración de este aspecto suele resultar más útil de cara a la planificación del tratamiento que para la evaluación. Si al explorar lo que el paciente considera como salud sexual comprobamos que cree que mantener el mayor número de relaciones sexuales posibles con el mayor número de parejas es ser sexualmente saludable, entonces podemos intuir que su percepción de gravedad con respecto a su patología será muy baja, así como su adherencia a las intervenciones terapéuticas que se le propongan. 
8. Intimidad y relaciones de pareja: el objetivo es conocer qué es lo que el paciente considera un vínculo de intimidad con una pareja. Muchos pacientes con CS confunden intimidad con actividad sexual, obviando las múltiples formas de alcanzarla sin recurrir al sexo. Resulta especialmente útil explorar este aspecto en pacientes cuya conducta sexual compulsiva responde a una necesidad por establecer relaciones de intimidad con otra persona, siendo el sexo la única estrategia que conocen para conseguirlo.

9. Valores y espiritualidad: este aspecto no resulta importante en todos los casos, pero para aquellas personas con fuertes valores espirituales y sobre todo religiosos, la CS puede ser una condición extremadamente incapacitante (Kwee, Domínguez, \& Ferrell, 2007). De ahí la importancia de evaluar el grado en el que la conducta sexual interfiere o va en contra de los valores espirituales y religiosos que profese.

No hay ningún instrumento diseñado ad hoc para la evaluación de estas 9 dimensiones. La estrategia habitual es explorarlas a través de entrevista abierta donde el terapeuta va guiando al paciente hasta lograr la información requerida (Edwards, 2012). Sin embargo, esto tiene el inconveniente de que no todos los terapeutas tienen las habilidades necesarias para realizar este tipo de entrevistas ni tampoco todos los pacientes se benefician de un formato de preguntas abiertas. En esos casos, se podría recurrir a una combinación de entrevistas y escalas que aborden cada una de estas dimensiones. Un buen ejemplo podría ser la entrevista sexual de Lo Piccolo y Heiman (1978): esta entrevista hace especial énfasis en la evaluación de los antecedentes tempranos de desarrollo sexual y de los primeros encuentros, así como de la evolución de la conducta sexual a lo largo de la adolescencia y de la edad adulta. También permite ahondar en aspectos como los valores en torno al sexo, los conocimientos sobre conductas sexuales de riesgo o la historia de relaciones íntimas y de pareja. Esto se podría complementar con otro tipo de medidas y cuestionarios como la versión en castellano de la escala Wilson de fantasías sexuales (Sierra, Ortega, \& Zubeidat, 2006) o bien la escala de insatisfacción corporal (Cooper, Taylor, Cooper, \& Fairbum, 1987).

Estos nueve aspectos permiten establecer el contexto general en el que la CS se desarrolla y aportan información útil sobre su evolución y los factores asociados a su origen y a su mantenimiento; sin embargo, no aporta información relativa a los síntomas concretos que constituyen el cuadro clínico de CS. Por ello, el siguiente paso consiste en llevar a cabo una evaluación concreta de los signos y síntomas de CS, que según Hook et al. (2010) y Womack et al. (2013) debería incluir el siguiente tipo de información:

1. Síntomas objetivos de CS: indicadores de CS directamente observables y cuantificables, como por ejemplo la frecuencia sexual, el número de parejas sexuales, 
el porcentaje de uso del preservativo durante las relaciones sexuales o bien el tipo de prácticas habituales. El Sexual Outlet Inventory (SOI; Kafka, 1991) es el mejor ejemplo de cuestionario de evaluación de síntomas objetivos: este cuestionario evalúa a través de 6 ítems la frecuencia de conductas sexuales durante una semana normal. Las preguntas se formulan en un formato que únicamente requiere del paciente que dé una respuesta concreta (p.e., “¿cuántos orgasmos has alcanzado durante la última semana masturbándote?" “¿y a través de encuentros sexuales con parejas?”).

2. Síntomas subjetivos de CS: indicadores de CS únicamente perceptibles por el propio paciente, como por ejemplo la percepción de control sobre su conducta sexual o bien la frecuencia y el tipo de fantasías sexuales y pensamientos sexuales intrusivos. Ítems como "siento que mis pensamientos y sensaciones sexuales son más fuertes que yo" o "uso el sexo como una forma de afrontar mis problemas", del Cuestionario de Compulsividad Sexual (Kalichman \& Rompa, 1995) y del Cuestionario de Screening de Adicción al Sexo (SAST; Carnes, 1983) respectivamente, serían buenos ejemplos de este tipo de síntomas.

3. Consecuencias de la CS: los perjuicios médicos, legales, personales o familiares de la CS son una de las dimensiones más importantes a evaluar, puesto que constituyen el mejor indicador para estimar la gravedad del cuadro clínico (Reid, 2013). Como en cualquier otro trastorno mental, la CS resulta problemática en tanto en cuanto genera consecuencias negativas para la vida de la persona. Como ejemplo de las áreas que normalmente se ven afectadas, el Cuestionario de Consecuencias Cognitivas y Conductuales de la Conducta Sexual (CBOSB; McBride, Reece, \& Sanders, 2008) -uno de los más utilizados para la evaluación de este tipo de síntomas- mide el grado en el que la CS afecta sobre las seis áreas siguientes: 1) perjuicios legales o laborales, 2) psicológicos o espirituales, 3) sociales, 4) físicos (heridas, hematomas, problemas genitales, etc.), 5) médicos (ITS, VIH, embarazos no deseados) y 6) económicos.

Para realizar una correcta evaluación, podemos centrarnos más en explorar uno u otro tipo de indicadores; sin embargo, al final resultará necesario contar con información sobre estos tres tipos de síntomas para hacer una descripción completa del cuadro clínico. No podemos fundamentar un diagnóstico de CS sin conocer de forma objetiva cómo es la conducta sexual del paciente, pero tampoco si no conocemos su percepción subjetiva con respecto a sus síntomas -por ejemplo, la sensación de control que tenga sobre su conducta sexual- o las consecuencias que este patrón de conducta le ha supuesto (Kafka, 2007; Reid, 2013; Rosenberg et al., 2014). 
En la actualidad, disponemos de múltiples herramientas para el diagnóstico de la CS: en una reciente revisión, Womack et al. (2013) identificaron 32 instrumentos de evaluación, muchos de ellos desarrollados durante los últimos tres años -justo después de que se propusieran los criterios para el diagnóstico por hipersexualidad en el DSM-V-. Todos ellos se diferencian en múltiples aspectos -síntomas que evalúan, formato, extensión, concepción teórica, etc.- y el clínico debe elegir uno u otro en función de su utilidad, fiabilidad y validez clínica (Hook et al., 2010; Womack et al., 2013).

La principal recomendación de la Society for the Advancement of Sexual Health (SASH) es que se utilicen únicamente instrumentos que cuenten con estudios psicométricos que avalen su fiabilidad y validez, sobre todo en el sector concreto de población al que dirijamos nuestra evaluación (Samenow, 2013). Esta idea es compartida por buena parte de los expertos en evaluación de la CS (Coleman-Kennedy \& Pendley, 2002; Kaplan \& Krueger, 2010; McBride et al., 2011; Samenow, 2011). En la actualidad, esto no supone un problema porque casi todos los instrumentos son sometidos a un proceso de evaluación previo a su publicación y difusión; sin embargo, muchos de los instrumentos más utilizados en evaluación de la CS no contaban con estudios psicométricos y se fundamentaban únicamente en su utilidad clínica aparente. El mejor ejemplo es el Cuestionario de Screening de Adicción al Sexo (SAST; Carnes, 1983): si bien este instrumento ha sido uno de los más utilizados en la evaluación clínica de la CS, no ha sido hasta 35 años después de su elaboración cuando se han publicado los primeros trabajos sobre sus propiedades psicométricas (Carnes, Green, \& Carnes, 2010; Nelson \& Oehlert, 2008).

Otro aspecto a tener en cuenta a la hora de elegir una herramienta es la definición que cada una hace de la CS, aspecto del que ya se ha hablado extensamente durante el capítulo anterior. Si bien es cierto que independientemente de su orientación teórica, todos estos cuestionarios describen un mismo cuadro clínico, el énfasis que hace por ejemplo el SCS en ciertos aspectos-sobre todo aquellos relacionados con la incapacidad para controlar la propia conducta sexual- no es el mismo que pueda hacer el Inventario de Hipersexualidad (IH; Reid, Garos, \& Carpenter, 2011), que se centraría más en aspectos como el uso del sexo como regulador emocional. Si bien esto debe ser tenido en cuenta, la solución es utilizar una combinación de varias herramientas que aseguren que la evaluación desde distintos puntos de vista converja en una descripción más enriquecedora de la problemática del paciente (Hook et al., 2010; Womack et al., 2013).

El último criterio a la hora de elegir un instrumento es su formato y extensión. Siguiendo a Hook et al. (2010) y Womack et al. (2013), podemos identificar tres tipos de instrumentos de evaluación de la CS con las siguientes ventajas e inconvenientes: 
- Entrevistas clínicas: aunque este tipo de instrumento se utiliza normalmente para evaluar síntomas objetivos, algunos incluyen preguntas sobre la experiencia subjetiva o los perjuicios derivados de la CS. La Entrevista Clínica para la Compulsividad Sexual (DISC; J Morgenstern, Muench, O'Leary, Parsons, \& Hollander, 2009) es un buen ejemplo. Esta entrevista se compone de 5 secciones que permiten explorar: 1) 7 tipos de síntomas de CS -tanto subjetivos como objetivos-, 2) tiempo que la persona lleva padeciendo estos síntomas, 3) percepción de interferencia y problemas generados, 4) edad de inicio del problema y 5) curso clínico. La aplicación lleva en torno a 60 minutos y diversos estudios psicométricos avalan su fiabilidad y validez, si bien únicamente se ha validado en muestra clínica homosexual.

Este formato de evaluación presenta muchas ventajas sobre otros tipos de evaluación, pero también algunos inconvenientes. Su aplicación requiere destrezas y habilidades de entrevista, así como conocimientos más sólidos sobre CS, manifestaciones y expresión clínica. También supone una inversión de tiempo mayor y algunos pacientes no se sienten cómodos narrando su problema directamente al terapeuta. Sin embargo, ofrece una información más pormenorizada de los principales síntomas del cuadro clínico. También se minimiza el sesgo provocado por la deseabilidad social y las preguntas que no quedan claras pueden ser reformuladas para que el paciente siempre responda con la mayor precisión posible. Finalmente, los terapeutas con experiencia en el manejo de entrevistas encuentran en este tipo de herramientas la flexibilidad de ahondar sólo en los aspectos más problemáticos y pasar por alto los que resulten menos significativos para el caso concreto.

- Auoinforme de síntomas: los hay de dos tipos, las escalas dimensionales y los checklist de verificación de síntomas. La diferencia radica en el formato de respuesta (dimensional vs. dicotómico). La mayoría evalúa únicamente síntomas subjetivos de la CS, por lo que deberemos recurrir a otro tipo de instrumentos para cubrir el resto de áreas de la evaluación. El Inventario de Conducta Sexual Compulsiva (CSBI; Coleman, Miner, Ohlerking, \& Raymond, 2001) es uno de los más completos. Esta escala de 28 ítems con formato de respuesta tipo Lickert permite evaluar el grado en que la conducta sexual está o no bajo el control del paciente, el grado en que dichos problemas pueden explicarse a través de una historia de abuso físico o sexual y si esa incapacidad para el control de los impulsos sexuales ha podido devenir en situaciones de violencia y agresión.

Entre las ventajas de los autoinformes, la principal es su brevedad: la mayoría de estas escalas se rellenan en menos de 10 minutos, por lo que son aplicables en contextos 
tanto clínicos como de investigación. La mayoría de ellas aportan puntos de corte clínicos a partir de los cuales establecer el diagnóstico, minimizando la posibilidad de sesgo debido a la inexperiencia o imprecisión del clínico. El problema es que si no se aplican junto con otro tipo de medidas más exhaustivas, los autoinformes de síntomas sólo tienen valor orientativo o de screening.

- Autoinforme de consecuencias: este tipo de instrumento se dirige exclusivamente a la evaluación de las consecuencias de la CS. El formato de respuesta puede ser también dimensional, dicotómico o combinar ambos formatos -como el CBOSB -. La mayoría no se consideran sensibles al cambio por no delimitar un espacio temporal, pero hay excepciones: la escala de consecuencias de la conducta sexual compulsiva (CS-BCS; Muench et al., 2007) ofrece dos versiones, una que evalúa las consecuencias a lo largo de la vida y otra que lo haría durante los últimos 90 días. Esta última es útil si se quiere evaluar el grado de cambio tras, por ejemplo, una intervención terapéutica.

La principal ventaja de este tipo de escalas es su brevedad, lo que las ha convertido en el complemento idóneo para su uso junto con una entrevista más extensa o una escala de síntomas de CS. Su uso como único elemento de valoración está contraindicado: no en vano, puede haber personas que por ejemplo hayan padecido una ITS sin que su conducta sexual se pueda considerar patológica y personas con una verdadera CS cuya vida por el momento no se haya visto especialmente afectada. Por eso, su utilidad se restringe a la estimación de la gravedad del cuadro clínico más que al propio diagnóstico. Asimismo, este tipo de cuestionarios pueden servir para que el paciente considere la gravedad de su situación e incremente su necesidad de cambio.

Womack et al. (2013) analizaron 32 escalas para la evaluación de la CS: el tipo de instrumento que medía un mayor número de criterios para el diagnóstico de la conducta sexual compulsiva es la entrevista diagnóstica (una media de 5.25 criterios), seguido de los autoinformes de síntomas (3.58) y los autoinformes de consecuencias (2). Cuando se cuantifica la profundidad con la que los instrumentos evalúan cada criterio, los resultados se invierten: los autoinformes de consecuencias dedican una media de 3.07 ítems a la evaluación de cada criterio clínico, los autoinformes de síntomas 2.35 ítems y las entrevistas 1.82. A partir de estos resultados, los autores concluyeron que la evaluación ideal debería contemplar la aplicación de una entrevista, una escala de síntomas y una escala de consecuencias de la CS. Otra combinación más breve podría ser la aplicación de un autoinforme de consecuencias junto con una escala de síntomas o una entrevista. Lo que se desaconseja es la aplicación de un solo tipo de medida -sobre todo si se trata sólo de autoinformes de consecuencias de la CS-. 
1.3 Nivel 2: descartando el origen orgánico de los síntomas de CS

Excluir las condiciones médicas asociadas a la hipersexualidad resulta relativamente sencillo ya que no suelen ser trastornos que pasen desapercibidos, sino enfermedades con un extenso abanico de síntomas. Las principales patologías en cuyos cuadros clínicos aparece este tipo de síntomas son: 1) patologías con afectación de zonas del córtex frontal y prefrontal -delirium, demencia, daño cerebral adquirido, etc.- (Kobayashi, 2004; Spinella, 2004), 2) enfermedades neurológicas y neurodegenerativas -Párkinson, Alzhéimer, enfermedad de Pick, Corea de Huntington, síndrome de Tourette, etc.- (Finlayson et al., 2001; Higgins et al., 2004), 3) algunos tipos de epilepsia (Luef, 2008) y 4) trastornos endocrinos caracterizados por un exceso de testosterona -hipertestosteronemia- (Voon \& Fox, 2007).

La frecuencia de síntomas de CS en este tipo de casos es relativamente baja. Por ejemplo, la relación entre daño cerebral adquirido y conducta sexual compulsiva se limita a un reducido número de casos clínicos (D. J. Stein, Hugo, Oosthuizen, Hawkridge, \& van Heerden, 2000) que no representa la norma en este tipo de afecciones. En Alzhéimer, la prevalencia informada de CS oscila entre el 2-30\% dependiendo de los criterios de evaluación utilizados por cada estudio (Wallace \& Safer, 2009). La prevalencia en demencia resultaría muy similar: un estudio realizado con 133 pacientes geriátricos con esta patología encontró que el 15\% de ellos mostraba conductas sexuales inapropiadas durante sus estancias hospitalarias o en su casa (S. J. Tsai, Hwang, Yang, Liu, \& Lirng, 1999). Donde mejor documentada está la prevalencia de síntomas de CS es en pacientes con Párkinson: en un estudio realizado por Singh, Kandimala, Dewey y O'Suilleabhain (2007) entre 300 pacientes con párkinson y tratamiento a base de agonistas de la dopamina, el $11 \%$ indicó haber experimentado síntomas de CS tras el diagnóstico de la enfermedad. Tan sólo uno de estos pacientes afirmó que los síntomas eran previos a la aparición del párkinson. En un estudio multicéntrico posterior realizado entre 267 pacientes también con párkinson pero donde no todos tomaban agonistas de la dopamina, tan sólo 7 (el 2.6\%) de los que eran tratados con medicaciones alternativas a los agonistas clásicos desarrollaron síntomas de CS; el porcentaje aumentaba hasta el $18.4 \%$ entre los pacientes que sí los tomaban (Bostwick, Hecksel, Stevens, Bower, \& Ahlskog, 2009).

En todos estos casos, la CS no constituye más que un síntoma dentro de un cuadro clínico mucho más amplio, de modo que el diagnóstico que prevalece es el de la condición médica general. Además, este tipo de pacientes rara vez llega a consultas generales de salud mental, por lo que la probabilidad de que un clínico se encuentre con este tipo de caso es remota. $\mathrm{Si}$ tras la estabilización del cuadro clínico -p.e., en epilepsias controladas a través de medicación o tras la normalización de los niveles de testosterona en la hipertestosteronemia- los síntomas 
de CS perduran, se debería considerar la posibilidad de que ambos problemas coexistan; sin embargo, ésta es una posibilidad muy remota y requeriría de una evaluación especialmente pormenorizada para establecer los límites entre una y otra patología.

1.3 Nivel 3: descartando que los síntomas formen parte de un trastorno del Eje I o II

La complejidad de la evaluación se acentúa cuando se debe descartar que el cuadro clínico se explique mejor por la presencia de cualquier otra patología del Eje I o II. La dificultad en los casos en los que los síntomas de CS se presentan de forma concurrente con los de cualquier otra patología mental es decidir si ambos corresponden a un mismo cuadro clínico (p.e., la típica conducta sexual promiscua e incontrolada durante episodios de manía) o si coexisten como condiciones comórbidas (como sería el caso relativamente frecuente de la coadicción entre sexo y sustancias químicas). (Coleman-Kennedy \& Pendley, 2002)

En ciertos trastornos mentales graves del Eje I (episodios afectivos [manía e hipomanía] y algunos tipos de esquizofrenia o de otros trastornos psicóticos) y del Eje II (principalmente en el trastorno límite de la personalidad), es relativamente frecuente que se dé un aumento del apetito sexual o de la frecuencia junto con ciertos problemas en el control de los impulsos sexuales, pudiendo estos síntomas confundirse con un cuadro clínico de CS. En esquizofrenia por ejemplo, muchas de las obsesiones y los delirios se centran en contenidos sexuales. Rudden, Sweeney, Frances y Gilmore (1983) encontraron que el $28 \%$ de una muestra de pacientes psicóticos hospitalizados tenía delirios de tipo sexual. En estos casos, los delirios u obsesiones suelen versar sobre fantasías sexuales heterosexuales, homosexuales, erotomanía sexual (creencia de que son los mejores amantes), infidelidad, cambio de sexo o embarazos ficticios (Thompson et al., 2010). Parece además que el riesgo de agresión sexual es mucho mayor en los pacientes con este tipo de delirios (Bjørkly, 2002), lo que vendría a ratificar los problemas en el control de los impulsos sexuales. Durante episodios maníacos o hipomaníacos, los síntomas sexuales son aún más frecuentes: se estima que entre el $21-72 \%$ de los pacientes experimenta un aumento muy significativo del apetito sexual durante este tipo de episodios afectivos (Cassidy, Murry, Forest, \& Carroll, 1998). Lo habitual es que mantengan relaciones sexuales con múltiples parejas sin importarles edad, características o simplemente si son o no conocidos. Por ejemplo, DelBello, Hanseman, Adler, Fleck y Strakowski (2007) describen el caso de una adolescente de 15 años que durante los dos meses previos a su ingreso hospitalario por un episodio maníaco grave, mantuvo relaciones sexuales sin preservativo con múltiples parejas. Además del riesgo de embarazo no deseado o ITS, la mayoría eran desconocidos mayores que ella, con el riesgo de victimización sexual que ello podría suponer. 
Al hablar de condiciones crónicas que en el mejor de los casos pueden ser controladas hasta el próximo periodo de inestabilidad, no se suele considerar la posibilidad de diagnosticar un cuadro de CS. Aun cuando el paciente está totalmente controlado y persisten los problemas en el control de los impulsos sexuales, es difícil valorar si debería realizarse un diagnóstico de CS comórbido al trastorno mental grave o si simplemente estos síntomas se pueden explicar por el efecto de alguno de los tratamientos médicos (p.e., el tratamiento médico con agonistas de la dopamina ha demostrado incrementar la libido y la frecuencia de pensamientos sexuales) (Bostwick et al., 2009). En cualquier caso, si el clínico intuye la posible presencia de alguno de estos trastornos, es importante centrarse primero en confirmar o no su presencia y actuar consecuentemente (Finlayson et al., 2001; Kafka, 2007).

Durante la evaluación, se debe explorar la presencia de un posible trastorno de ansiedad o episodio depresivo concurrente. Se estima que la comorbilidad entre CS y trastornos de ansiedad oscila entre el 37.5-42.9\%, mientras que en episodios depresivos mayores se estima entre el 33-71.8\% (Mick \& Hollander, 2006). Es tan habitual que un paciente con CS cumpla también criterios para uno de estos trastornos que la mayoría de procedimientos incluyen alguna herramienta de screening para evaluar la presencia de una de estas condiciones clínicas (Bancroft \& Vukadinovic, 2004; Reid, Carpenter, et al., 2012; Reid, Bramen, et al., 2014; Weiss, 2004a). En estos casos, la concurrencia de CS junto con episodios depresivos o trastornos de ansiedad suele relacionarse con cuadros de mayor gravedad; no en vano, uno de los criterios básicos para el diagnóstico de la conducta sexual compulsiva es precisamente el uso del sexo como regulador de estados de ánimo disfóricos (Kafka, 2010; Kaplan \& Krueger, 2010). Resulta útil especialmente de cara al tratamiento que durante la evaluación se explore si los episodios depresivos o de ansiedad aparecieron antes o después de los síntomas de CS. En los casos en los que la ansiedad o el estado de ánimo disfórico sea previo, el tratamiento concurrente de ambas condiciones es un buen predictor de eficacia terapéutica. Pero si los problemas emocionales surgieron como consecuencia de la CS -por ejemplo, por haber experimentado problemas legales o familiares-, el objetivo principal debería ser el tratamiento de los síntomas de CS ya que probablemente los síntomas emocionales remitan a medida que aumente el control sobre la conducta sexual (M. M. Campbell \& Stein, 2014).

El aspecto principal durante la evaluación de condiciones comórbidas a la CS es la exploración de la presencia o no de coadicción a una sustancia tóxica (Coleman-Kennedy \& Pendley, 2002; Kafka, 2007; Reid, 2013). El mecanismo que explica el vínculo entre ambas condiciones todavía se desconoce. Algunas sustancias -alcohol, cannabis y sobre todo ciertos psicoestimulantes y alucinógenos -, tomadas a dosis bajas y sin excesiva frecuencia, provocan un aumento de la 
activación fisiológica que algunas personas interpretan como un mayor vigor sexual y un aumento de la libido (Llópis, 2011); sin embargo, esas mismas sustancias tomadas de forma abusiva producen justamente el efecto contrario - una merma de las capacidades sexuales a lo largo de todas las fases de la respuesta sexual- (San Martín, 2011).De ahí que teorías que hablan de una predisposición a la CS que se expresa gracias a la desinhibición provocada por estas sustancias va ganando fuerza (Washton \& Boundy, 2000). Sea como sea, lo cierto es que los estudios sobre comorbilidad apuntan a que alrededor del $64 \%$ de los pacientes con CS presentan también un abuso o dependencia a una sustancia tóxica -la más habitual el alcohol- (Black et al., 1997). En última instancia, la relación entre CS y otras adicciones se ha encontrado también con las denominadas adicciones no tóxicas (juego patológico, alimentación compulsiva, abuso de Internet, etc.). Grant y Kim (2003) encontraron en una muestra de 96 jugadores patológicos una comorbilidad del 9.4\%, mientras que este mismo dato aumenta hasta el 11\% en el estudio de Black et al. (1997). En este último se encontró también una comorbilidad del $14 \%$ entre compras compulsivas, cleptomanía y CS.

\section{El diagnóstico de compulsividad sexual en los manuales DSM}

El Manual Diagnóstico y Estadístico de los Trastornos Mentales (DSM) es la herramienta de referencia a la hora de establecer cualquier diagnóstico en salud mental. Su uso en la práctica clínica ha sido objeto de muchas y muy variadas críticas, pero su empleo hoy día es ineludible (Blashfield, Keeley, \& Burgess, 2008). Junto con este manual, también sería frecuente el uso con este fin de la Clasificación Internacional de las Enfermedades (CIE) y más concretamente, de su sección dedicada a las enfermedades mentales y del comportamiento.

EI DSM permite definir y delimitar lo que debe o no considerarse como enfermedad mental (Phillips et al., 2012). El proceso para que un determinado cuadro clínico pase a ser considerado como una enfermedad mental es tremendamente exhaustivo: se requiere aval empírico suficiente para justificar su reconocimiento y también consenso acerca de su utilidad en el ámbito clínico. El problema es que en ciertas ocasiones, el criterio no depende únicamente de estándares científicos y en este proceso se entrometen intereses corporativos -como en el caso de las empresas farmacéuticas y sus grupos de presión-, políticos y sociales (Blashfield et al., 2008; Phillips et al., 2012; Reid \& Kafka, 2014). Esto es lo que hace del DSM un arma de doble filo: por un lado, sólo podemos presumir que los trastornos que allí aparecen cumplen con los más estrictos criterios para su reconocimiento como enfermedades mentales, al mismo tiempo que no podemos estar seguros de que los cuadros clínicos que no han sido reconocidos no constituyan también patologías mentales con entidad propia. Esto es lo que ha ocurrido con la compulsividad sexual. 
La forma en la que el DSM ha contemplado los trastornos sexuales -especialmente la CS- ha cambiado a lo largo del tiempo (Kafka, 2010). En la primera versión del DSM no se mencionaba la existencia de ninguna desviación sexual y no fue hasta la segunda (DSM-II) cuando se reconocieron. En esta segunda versión se recogían desviaciones sexuales parafílicas -incluidas en la categoría de trastornos de la personalidad- pero no se mencionaba ninguna desviación sexual no parafílica o ningún otro trastorno del deseo sexual. En 1980, el DSM-III estableció una categoría diagnóstica propia para las parafilias -desórdenes psicosexuales- e introdujo por primera vez un trastorno del deseo (el de "deseo sexual inhibido") (Brotto, 2010). En esta edición se reservó una categoría residual -la de desorden psicosexual no especificado- para el "estrés provocado por un patrón de repetidas conquistas sexuales que son vistas únicamente como objetos para ser utilizados (donjuanismo y ninfomanía)" (American Psychiatric Association, 1980, p.296, citado en Kafka, 2010). En la revisión del DSM-III, la categoría de "desorden psicosexual no especificado" se mantuvo, el diagnóstico de "deseo sexual inhibido" pasó a llamarse "deseo sexual hipoactivo" y se hizo un importante avance: se reconocía por primera vez el concepto de adicción sexual no parafílica. Posiblemente este fuera el momento en el que el DSM reconoció de forma más abierta la existencia de la compulsividad sexual, ya que en sus sucesivas versiones (DSM-IV y DSM-IV-TR) se eliminó el concepto de adicción sexual y pasó nuevamente a una categoría subsidiaria - "trastorno sexual no especificado"- (Kaplan \& Krueger, 2010). En la actualidad, el manual CIE-10 sí reconoce como entidad diagnóstica propia la categoría de "Impulso sexual excesivo". Sin embargo, es el único trastorno para el que no propone criterios diagnósticos específicos (únicamente una breve descripción) (Vroege, Gijs, \& Hengeveld, 1998).

El uso de categorías subsidiarias se mantuvo hasta que hace unos años, a propósito de la elaboración de la quinta edición del DSM, surgiera nuevamente la idea de incluir un diagnóstico con entidad propia que recogiera este cuadro clínico. El encargado de realizar tan ardua tarea fue Martin Kafka, miembro del grupo de trabajo del DSM-5 para la revisión de los trastornos sexuales y de la identidad de género. Su planteamiento original fue elaborar un diagnóstico basado en un único criterio, como los de los trastornos parafílicos; sin embargo, tras muchas discusiones con el resto de miembros del grupo de trabajo, se decidió elaborar un diagnóstico basado en un conjunto de criterios (Kafka, 2013). Tras una exhaustiva revisión, Kafka publicó su primera versión de criterios para el diagnóstico de hipersexualidad (Kafka, 2010). La tabla 4 corresponde a la última versión. Con respecto a su versión original, en ésta se han introducido dos cambios: se aumenta de 3 a 4 los síntomas del criterio A necesarios para poder realizar el diagnóstico y se incluye el criterio $\mathrm{D}$. 
Tabla 4. Criterios diagnósticos para el trastorno por hipersexualidad propuestos para su inclusión en el DSM-V (traducido de Reid, Carpenter, et al., 2012)

A. Durante un periodo de 6 meses, fantasías, impulsos o conductas sexuales recurrentes e intensas asociadas a 4 o más de los 5 criterios siguientes:

1. Inversión exagerada de tiempo en las fantasías e impulsos sexuales, así como en la planificación o el mantenimiento de la conducta sexual.

2. Fantasías, impulsos o conductas sexuales en respuesta a estados de ánimo disfóricos (ansiedad, depresión, aburrimiento, irritabilidad, etc.).

3. Fantasías, impulsos o conductas sexuales en respuesta a situaciones vitales estresantes.

4. Continuos pero infructuosos esfuerzos por controlar o reducir significativamente estas fantasías, impulsos o conductas sexuales.

5. Persistencia en la conducta sexual a pesar de los riesgos físicos o emocionales para uno mismo y para otras personas.

B. La frecuencia e intensidad de estas fantasías, impulsos o conductas sexuales provoca malestar personal clínicamente significativo o deterioro en las relaciones sociales, en el ámbito laboral o en otras áreas importantes del funcionamiento.

C. Estas fantasías, impulsos o conductas sexuales no son debidas al efecto fisiológico directo de una sustancia exógena (drogas de abuso o medicaciones), a la presencia de una condición médica general o a un episodio maníaco.

D. La persona tiene al menos 18 años.

Especificar si:

1. Masturbación

2. Pornografía

3. Conducta sexual consentida con adultos

4. Cibersexo

5. Sexo telefónico

6. Clubs de estriptis

7. Otros:

Los síntomas del criterio A -el que aporta la descripción general del cuadro clínico- dan un peso diferencial a los distintos grupos de síntomas de la CS. Posiblemente, la dimensión que se ve mejor reflejada sea la emocional: dos de los 5 síntomas del criterio A (el A2 y el A3) hacen referencia al uso del sexo como regulador emocional. El resto de síntomas serían resultado de la conjunción de aspectos conductuales, cognitivos y también neuropsicológicos. Otro aspecto a tener en cuenta del criterio $\mathrm{A}$ es el estricto punto de corte establecido para su cumplimiento: sólo los pacientes que cumplan 4 de los 5 criterios (el 80\%) son susceptibles de recibir el diagnóstico. Este punto de corte queda por encima del establecido para la mayoría de trastornos del Eje I y responde al interés por reducir la probabilidad de falsos positivos (Kafka, 2014). El resto de criterios son prácticamente idénticos a los de cualquier otro trastorno. 
El criterio $D$ fue la última modificación que se realizó de los criterios originales. Tras la publicación en la página web de la APA de la primera versión de criterios, el grupo de trabajo para la revisión de los trastornos sexuales recibió innumerables quejas en torno a una cuestión que preocupaba a clínicos e investigadores: "con estos criterios, estáis describiendo la conducta sexual de la mayoría de adolescentes americanos" (Kafka, 2013, p. 23). Si bien el criterio $B$ ya aseguraba que no se pudieran realizar diagnósticos en casos sin consecuencias adversas derivadas de la conducta sexual (como en el caso de los adolescentes), la inclusión de este criterio resultaba necesaria para evitar patologizar conductas sexuales que se deben entender en el contexto del proceso natural de maduración psicosexual.

Una vez propuestos los criterios, sometidos al juicio de la comunidad científica y refinados a partir de las críticas e indicaciones, quedaba todavía un último paso para sustentar la inclusión de este nuevo trastorno en el DSM: comprobar empíricamente su utilidad, fiabilidad y validez diagnóstica. Con este objetivo, Reid et al. (2012) pusieron en marcha el primer ensayo clínico para el trastorno por hipersexualidad. El objetivo del ensayo era recrear lo más fielmente posible el ambiente clínico donde habitualmente podría aparecer un paciente con esta patología y examinar la fiabilidad y validez de los criterios propuestos, la adecuación de los subtipos y finalmente el curso clínico y consecuencias del diagnóstico. Para que el ensayo fuera lo más similar posible al contexto clínico real (validez ecológica), la muestra se reclutó en centros especializados en el tratamiento de este tipo de problemas. A nivel empírico, se siguió una metodología muy rigurosa: cada nuevo paciente era sometido a un exhaustivo proceso de entrevista en el que, además del entrevistador que dirigía la sesión, estaba presente otro terapeuta. Éste último, que no interactuaba en ningún momento con el paciente, realizaba su propio diagnóstico. Durante esta primera sesión, el paciente se sometía a una entrevista diagnóstica de patologías del Eje I (MINI), una entrevista específica para los criterios de hipersexualidad (HD-DCl) y completaba una serie de escalas y autoinformes sobre gravedad, curso y tipo de conducta sexual compulsiva. Cada sesión de evaluación era grabada para que posteriormente, un tercer terapeuta emitiera un diagnóstico a partir de la primera entrevista. Dos semanas más tarde, un cuarto terapeuta evaluaba de nuevo al paciente presencialmente. Aparte de casos de hipersexualidad, en el estudio se incluyeron otro tipo de pacientes algunos con abuso/dependencia de sustancias y otros con patologías mentales diversas-; el entrevistador era ciego con respecto al tipo de paciente al que iba a someter a evaluación, así como a los resultados de la evaluación de los otros clínicos.

La principal conclusión obtenida es que los criterios propuestos para este nuevo diagnóstico cumplían sobradamente los estándares de fiabilidad, validez y sensibilidad diagnóstica para su 
inclusión en el DSM y su uso en el contexto clínico. La fiabilidad interjueces obtenida fue de .95 y la estabilidad diagnóstica tras dos semanas era de .82 . La sensibilidad diagnóstica fue de .88 (sólo hubo un $12 \%$ de falsos negativos) y la especificidad de .93 ( $7 \%$ de falsos positivos). En comparación, la sensibilidad y especificidad diagnóstica es muy similar a la de la resonancia magnética en la discriminación de tumores malignos y benignos de mama (García-Figueras, Padhani, Vilanova, Goh, \& Villalba-Martín, 2010). Con respecto a la validez diagnóstica, se encontraron correlaciones positivas y significativas entre el diagnóstico de hipersexualidad y múltiples medidas de síntomas y también de consecuencias de la compulsividad sexual.

El ensayo también encontró resultados significativos en cuanto al curso diagnóstico de la hipersexualidad. El 54\% de los pacientes desarrollaron los primeros síntomas (pródromo) antes de los 18 años, un 30\% entre los 18 y los 25 y el 16\% restante pasados los 25 años. El $82 \%$ describía una evolución progresiva a lo largo de meses o de años -raras veces se informaba de una aparición repentina-. La evolución una vez presente el cuadro clínico podía ser tanto continua como episódica: alrededor del 51\% hablaba de episodios independientes a lo largo de tiempo, mientras que el $49 \%$ reportó no haber estado libre de síntomas desde el inicio del problema. Finalmente, el cuadro clínico parecía ir ganando gravedad a lo largo del tiempo: tras episodios más leves, el tiempo dedicado a actividades sexuales, la intensidad de las mismas y otras manifestaciones de la patología y del riesgo asociado aumentaban.

Prácticamente hasta el último momento, parecía claro que la hipersexualidad pasaría a formar parte del DSM-5 como un diagnóstico con entidad propia dentro de la categoría de trastornos sexuales. Sin embargo, el comité de garantías éticas de la Asociación Americana de Psiquiatría (APA) rechazó poco tiempo antes de la publicación del borrador definitivo la inclusión de este nuevo trastorno (APA, 2014; Kafka, 2014). Reid y Kafka (2014) explican en un reciente artículo las razones que condujeron a esta decisión: 1) un ambiente poco propicio a la inclusión de cualquier nuevo trastorno en el DSM que pudiera conllevar un aumento del consumo de psicotrópicos; 2) el temor a que desde el ámbito forense, el trastorno por hipersexualidad se utilizara como atenuante en casos de agresión sexual, pedofilia, abuso, incesto, etc.; 3) la incapacidad de algunos críticos para ver el diagnóstico en su conjunto, prestando atención a los síntomas por separado y desvirtuando el conjunto del cuadro clínico; 4) la imposibilidad para identificar una etiología concreta para la hipersexualidad y; 5 ) la carencia de estudios que permitan establecer claramente su prevalencia.

A pesar del "fracaso" en el intento por el reconocimiento de este cuadro clínico, la elaboración y publicación de estos criterios ha servido para potenciar durante los últimos años la investigación en este campo de la salud mental; este esfuerzo se ha traducido en un 
importante avance tanto en el diagnóstico como el tratamiento de esta condición psiquiátrica. De momento, el DSM-5 relega el cuadro clínico de la compulsividad sexual nuevamente a una categoría residual (Reid \& Kafka, 2014). Si el objetivo es ajustar el diagnóstico a una categoría del DSM-5, la única alternativa posible es la del diagnóstico de un "Trastorno destructivo, del control de los impulsos y de la conducta, no especificado (312.9 [F91.9])", de la categoría de "Trastornos destructivos del control de los impulsos y de la conducta” (APA, 2014).

\section{Prevalencia de la CS}

Entre las limitaciones a la hora de establecer la prevalencia de CS, la más importante se relaciona con la escasa búsqueda de ayuda terapéutica. Muchos de los pacientes con este cuadro clínico sufren sus síntomas sin consultar a un especialista. De entre los que sí lo hacen, la mayoría son pacientes cuyo cuadro clínico alcanza una gravedad que les impide llevar una vida normal (Steffens \& Rennie, 2006), de modo que es posible que las estimaciones actuales de CS correspondan a los casos más graves y no a aquellas condiciones clínicas donde si bien la patología está presente, su intensidad, saliencia e interferencia es menor (Reid, 2013).

La ausencia de grandes estudios epidemiológicos es otra limitación. Al no ser una patología mental reconocida por los manuales diagnósticos al uso (DSM y CIE), carecemos de informes publicados desde los observatorios epidemiológicos de los Sistemas Nacionales de Salud -la principal fuente a la hora estimar la frecuencia de las diversas patologías mentales- (Kaplan \& Krueger, 2010). Este tipo de estudios, realizados a partir de datos recogidos en los dispositivos socio-sanitarios encargados del cuidado de la salud comunitaria, aportan una visión precisa de la tasa de incidencia y prevalencia así como del curso y evolución de la enfermedad: nuevos ingresos, información demográfica de los casos registrados, dispositivos a través de los cuáles reciben atención clínica, evolución, tipos de tratamiento, gravedad de los casos, reingresos, etc. (Beaglehole, Bonita, \& Kjellström, 2003).

La última limitación se relaciona con el criterio a partir del cual identificar la presencia de CS. EI principal requisito para establecer la prevalencia de una patología es disponer de un criterio sensible y específico que permita identificar la condición patológica y al mismo tiempo reducir la probabilidad de falsos positivos y verdaderos negativos. Scott (1958) identificó cuatro tipos de criterios diagnósticos empleados por los principales estudios epidemiológicos: 1) criterios de desadaptación social (indicadores de delincuencia, homicidio, suicido, divorcio, abuso, etc.), 2) de desadaptación personal (indicadores de malestar personal o reducción de la calidad de vida), 3) de identificación de síntomas a través de cuestionarios de screening y 4) criterios clínicos. De estos 4 criterios, el diagnóstico a partir de criterios de desadaptación social es 
inaplicable en la estimación de la prevalencia de CS: en algunos casos, la falta de control sobre los impulsos sexuales puede desembocar en, por ejemplo, agresiones sexuales o divorcios, pero estos casos representan un nimio porcentaje de todas las personas que pasan por estas situaciones. El resto de criterios sí se han utilizado con mayor o menor éxito.

A pesar de las limitaciones, se estima que la prevalencia de CS en población general oscila entre el 3-6\% según los estudios más fiables. Esto supone un total de entre 17 y 37 millones de personas afectadas tan sólo en EEUU (Hagedorn, 2009b). Diferentes parámetros pueden alterar esta estimación. En la tabla 5 se desglosa la prevalencia de CS atendiendo a criterios como el sexo, tipo de población objetivo del muestreo (población general vs. otras poblaciones) y el criterio diagnóstico utilizado.

A partir del criterio de frecuencia sexual -concretamente, una frecuencia de siete o más orgasmos semanales-, se determinó que la prevalencia de CS en población general oscilaba entre el 3 y el $7.6 \%$. Si bien estas cifras se consideraron fiables, lo cierto es que presentan inconvenientes: entre otros, no tienen en cuenta elementos esenciales en el diagnóstico de CS como el uso disfuncional del sexo como regulador emocional o su interferencia personal, social o familiar (Kafka, 2007). Además, los estudios siguiendo este criterio se realizaron con hombres, de modo que sus resultados no son generalizables a mujeres. En la actualidad, la frecuencia sexual no se toma como único criterio para establecer la prevalencia de CS.

Tres estudios han empleado criterios clínicos a la hora de estimar la prevalencia de CS en población general. El primero establecía la prevalencia a través de un conjunto de 7 indicadores diferentes según el sexo. En hombres, el haberse masturbado más de 15 veces durante el último mes, haber visto más de 31 veces pornografía durante el último año o el haber tenido más de 3 parejas sexuales por año sexualmente activo constituían los tres principales indicadores de CS. En mujeres, los criterios eran los mismos pero con puntos de corte inferiores. A partir de estos criterios, se estimó que el $12.1 \%$ de hombres y el $6.6 \%$ de las mujeres cumplía criterios para el diagnóstico de CS (Långström \& Hanson, 2006a). Tomando como criterio el haber acudido a asesoramiento profesional por problemas en el control de los impulsos sexuales, Winters, Christoff y Gorzalka (2010) redujeron hasta el 1.65\% en hombres y el $0.93 \%$ en mujeres el porcentaje de pacientes con CS en población general. Finalmente, los resultados obtenidos por Skegg, Nada-Raja, Dickson \& Paul (2010) dan buena cuenta de las diferencias entre las estimaciones anteriores. En este estudio, el $12.7 \%$ de los hombres y el $6.7 \%$ de las mujeres dijeron haber experimentado alguna vez a lo largo de su vida problemas en el control de sus impulsos, fantasías o conductas sexuales (porcentaje similar al obtenido por Långström y Hanson). De éstos, la prevalencia de los que percibieron la situación como 
interfiriente se redujo al 3.8\% en hombres y el 1.7\% en mujeres. Si atendemos a la percepción de necesidad de ayuda terapéutica, la prevalencia se limitó al 3\% en hombres y el $1.3 \%$ en mujeres mientras que si se les preguntaba si habían acudido a un especialista por estos problemas, entonces decrecía hasta el $0.2 \%$ y $0.9 \%$ respectivamente.

La prevalencia estimada a través de cuestionarios y escalas de screening oscilaría entre el 3$17.4 \%$ en hombres y entre el $1.2-32.2 \%$ en mujeres. De entre los cuatro trabajos donde se ha empleado este criterio, destacarían dos. El primero, realizado por Seegers (2003), identifica una prevalencia del $17.4 \%$ en hombres y del $32.2 \%$ en mujeres, que estaría muy por encima de estimaciones previas y donde además la prevalencia era mayor en mujeres que en hombres. Este estudio ha sido ampliamente criticado por establecer puntos de corte extremadamente laxos en la identificación de la CS. En el extremo contrario, el estudio Rettenberg et al. (2015) demuestra que se pueden conseguir estimaciones ajustadas empleando cuestionarios de screening -siempre que el procedimiento se ajuste a parámetros estrictos-. Valiéndose del IH (cuestionario que dispone de puntos de corte estimados a partir de muestra clínica), estos investigadores obtienen una tasa de prevalencia de CS del 6\% (en hombres y mujeres).

La estimación de la prevalencia de CS en poblaciones especiales aporta información adicional para entender la expresión clínica de la CS. En este sentido, las investigaciones realizadas en gais, lesbianas y población clínica demuestran que la prevalencia de CS en estos colectivos es superior a la documentada en población general. En una cohorte de pacientes con trastornos del estado de ánimo (la mayoría con episodio depresivo mayor o distimia), la prevalencia de CS alcanzó el 35.09\% en el caso de los hombres y el 8.33\% en mujeres (Nair, Pawar, Kalra, \& Shah, 2013). Estos porcentajes resultaban similares a los obtenidos en pacientes con abuso y dependencia a sustancias (31\% en hombres y $12.12 \%$ en mujeres) (Stavro et al., 2013); sin embargo, quedaría muy por encima del 4.4-4.9\% obtenido por Grant, Levine, Kim y Potenza (2005) en pacientes con diversa patología de Eje I, lo que sugiere que la sobrerrepresentación de la CS en muestra clínica se asocia únicamente a trastornos concretos.

De entre las investigaciones en poblaciones especiales, resulta destacable la realizada por Reid et al. (2008). Tomando una muestra de pacientes en tratamiento por problemas en el control de los impulsos sexuales a los que aplicaron el cuestionario SCS de compulsividad sexual, estos investigadores obtuvieron una prevalencia del $71 \%$. Esto significa que el $29 \%$ de sus pacientes en tratamiento o bien no eran detectados por los instrumentos clásicos de screening de CS o en realidad no eran realmente pacientes con esta problemática, de modo que todavía hacen falta más estudios para estimar con un grado de fiabilidad y validez aceptable la prevalencia de CS tanto en población general como en colectivos concretos. 
Tabla 5. Prevalencia de CS en población general y poblaciones especiales a partir de diferentes criterios diagnósticos (elaboración propia)

\begin{tabular}{|c|c|c|c|c|c|c|}
\hline & 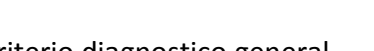 & Critorin dinanoction osnoúfice & Fctudin & A unetra & Preva & ncia \\
\hline & 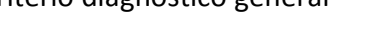 & - & Lstuuto & Tvicestra & Hombres & Mujeres \\
\hline & & & Kinsey, Pomeroy y Martin (1948) & 5700 hombres & $7.6 \%$ & \\
\hline & Frecuencia sexual & TSO $\geq 7$ (7 o más orgasmos semanales) & Atwood y Gagnon (1987) & $\begin{array}{l}1077 \text { chicos: } \\
\text { - Escolares }\end{array}$ & $5 \%$ & \\
\hline & & & & - Universitarios & $3 \%$ & \\
\hline & & & Laumann, Gagnon, Michael y Michaels (1994) & 1320 hombres & $3.1 \%$ & \\
\hline & & Conjunto de 7 criterios diagnósticos & Långström y Hanson (2006a) & 1279 hombres y 1171 mujeres & $12.1 \%$ & $6.8 \%$ \\
\hline 岀 & & Búsqueda de ayuda terapéutica & Winters, Christoff y Gorzalka (2010) & 6458 hombres y 7398 mujeres & $1.65 \%$ & $0.93 \%$ \\
\hline 岕 & & Fantasías, impulsos o conductas sexuales descontroladas & & & $12.7 \%$ & $6.7 \%$ \\
\hline$\frac{O}{y}$ & CIILerius cimilicus & Percepción de interferencia de la conducta sexual & 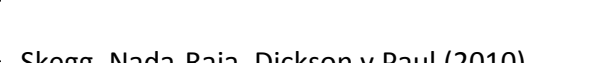 & 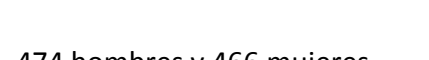 & $3.8 \%$ & $1.7 \%$ \\
\hline ठै & & Percepción de necesidad de ayuda terapéutica & Skegg, Nada-Kaja, Dickson y Paul ( 2010$)$ & 4/4 hombres y 466 mujeres & $3 \%$ & $1.3 \%$ \\
\hline & & Búsqueda de ayuda terapéutica & & & $0.2 \%$ & $0.9 \%$ \\
\hline & & Cuestionario de Adicción al Sexo (SAST) & Seegers (2003) & 69 hombres y 171 mujeres & $17.4 \%$ & $32.2 \%$ \\
\hline & & & Odlaug \& Grant (2010) & 254 hombres y 537 mujeres & $6.7 \%$ & $2.2 \%$ \\
\hline & Cuestionarios de screening & Minnesota Impulse Disorders Interview (MIDI) & Odlaug et al. (2013) & 762 hombres y 1075 mujeres & $3 \%$ & $1.2 \%$ \\
\hline & & Inventario de Hipersexualidad (IH) & Rettenberger, Klein y Briken (2015) & 750 hombres y 988 mujeres & & \\
\hline & Criterios clínicos & Criterios diagnósticos para trastorno por hipersexualidad & Nair, Pawar, Kalra y Shah (2013) & $\begin{array}{l}56 \text { hombres y } 37 \text { mujeres con } \\
\text { trastornos del estado de ánimo }\end{array}$ & $35.09 \%$ & $8.33 \%$ \\
\hline 悹 & & Minnesota Impulse Disorders Interview (MIDI) & Grant, Levine, Kim y Potenza (2005) & $\begin{array}{l}112 \text { mujeres y } 92 \text { hombres en } \\
\text { tratamiento por patologías Eje I }\end{array}$ & $4.4-$ & \\
\hline $\begin{array}{l}\tilde{w} \\
\text { w }\end{array}$ & & & Reid, Carpenter, Spackman y Willes (2008) & 120 pacientes (hombres) con CS & $71 \%$ & \\
\hline 岂 & Cuestionarios de screning & Escala de Compulsividad Sexual (SCS) & Kelly et al. (2009) & 1214 gais y 329 lesbianas & $30.47 \%$ & $18.59 \%$ \\
\hline 岁 & & & Grov, Parsons y Bimbi (2010) & 1324 gais & $30.5 \%$ & \\
\hline 잉 & & Cuestionario de Adicción al Sexo (SAST) & Stavro et al. (2013) & $\begin{array}{l}145 \text { hombres y } 66 \text { mujeres con } \\
\text { abuso de distintas sustancias }\end{array}$ & $31 \%$ & $12.12 \%$ \\
\hline
\end{tabular}




\section{Comorbilidad psicopatológica: prevalencia de trastornos del Eje I y II en personas con CS}

La comorbilidad, entendida como la "presencia concurrente de dos o más trastornos en la actualidad o a lo largo de la vida en un mismo paciente" (Kaplan \& Krueger, 2010, p. 187), es extremadamente frecuente en CS. Según algunos estudios, el 100\% de los pacientes con CS ha cumplido criterios a lo largo de su vida para algún otro trastorno del Eje I y el 50\% del Eje II (Raymond, Coleman, \& Miner, 2003).

Centrándonos en la comorbilidad con patología del Eje I, en la tabla 6 se resumen resultados de los principales estudios realizados hasta el momento. Para su elaboración, se han tomado únicamente en consideración trabajos realizados con pacientes con CS donde la patología en el Eje I se establecía a través de diagnósticos concretos -obviando los trabajos donde se habla de comorbilidad en términos de correlación entre rasgos, síntomas o disposiciones-.

Los trastornos del estado de ánimo son, junto con los de ansiedad, los que presentan las tasas más altas de comorbilidad con CS. Entre el $32.8 \%$ y el $80.8 \%$ de los pacientes con CS presentan al mismo tiempo algún trastorno del estado de ánimo. Los más frecuentes son la distimia y los episodios depresivos, dos cuadros clínicos que comparten sintomatología -ánimo depresivo- pero difieren en gravedad e intensidad (el trastorno distímico menos severo pero de larga duración y el trastorno depresivo mayor más grave pero episódico). Considerando que la prevalencia del trastorno depresivo mayor en población general se sitúa en torno al 6.6\% (Kessler et al., 2003) y que en personas con otras patologías del Eje I -p.e., pacientes con dependencia a sustancias- llega a alcanzar el 24\% (McNamara, 2002), una comorbilidad de entre el $28-58 \%$ en pacientes con CS resulta muy significativa. Las cifras de comorbilidad entre CS y episodios maníacos (2.6-14\%) deben ser tomadas con cautela: según el DSM-IV-TR, los episodios maníacos e hipomaníacos se pueden manifestar a través de una conducta sexual promiscua y un aumento del apetito sexual, síntomas que se pueden confundir con algunas manifestaciones del cuadro clínico de CS (Kafka, 2010).

La comorbilidad entre CS y trastornos de ansiedad oscila entre el 20.8-96\%, siendo la patología concurrente más frecuente la fobia social (FS, 8.2-46.2\%). La ansiedad generalizada (AG, 1415.6\%) y el trastorno por estrés postraumático (TEPT, 6.2-13\%) son también relativamente habituales, más de lo que lo es el trastorno obsesivo-compulsivo (TOC, 8-10\%). Que el TOC quede en al cuarto puesto en cuanto a comorbilidad con trastornos de ansiedad resulta significativo teniendo en cuenta que algunos autores han defendido que la CS se clasifique como un subtipo de este trastorno (Coleman, 1992). En este caso, el análisis de la comorbilidad 
resulta útil a la hora de refutar esta teoría: si la comorbilidad entre CS y TOC es más baja que con FS, AG o TEPT, entonces carece de fundamento la teoría que equipara ambos trastornos.

La comorbilidad entre CS y abuso de sustancias ha generado un considerable debate, sobre todo a partir de la publicación del estudio de Carnes, Murray y Charpentier (2005): estos investigadores encontraron una comorbilidad del $100 \%$ entre adicción al sexo y abuso de sustancias, mientras que investigaciones previas y posteriores situaron la comorbilidad entre CS y abuso de sustancias entre el $25 \%$ y el $71 \%$. La prevalencia de abuso de alcohol alcanza en algunos estudios el $63 \%$ y es más frecuente que el abuso de cualquier otra sustancia ilegal. Presumiblemente, la facilidad de acceso al alcohol frente a otras sustancias más penosas de conseguir -y que comportan riesgo penal- puede ser el factor que explica que la comorbilidad con sustancias ilegales se sitúe entre el 18.7-38\% (en el caso del abuso de marihuana).

Black et al (1997) evaluaron por primera vez la comorbilidad entre CS y trastornos del control de los impulsos (TCI), hallando un solapamiento de hasta el $14 \%$ con ciertas patologías (en concreto, con la cleptomanía y las compras compulsivas). Estudios posteriores realizados a través de otra metodología (cuestionarios en lugar de entrevistas) obtenían idénticos resultados (prevalencia de $\mathrm{TCl}$ entre el 15.5-15.6\%). Las cifras de prevalencia de $\mathrm{TCl}$ obtenidas por Raymond et al. (2003) son las únicas que se alejan de las halladas previamente, si bien la comorbilidad con trastornos concretos resultaba prácticamente equivalente: la explicación es que mientras que Black informaba de un notable solapamiento entre $\mathrm{TCls}$ (el mismo paciente cumplía criterios para varios de estos trastornos), esto no sucedía en el estudio de Raymond.

Los datos que apuntan a una comorbilidad del $46 \%$ con trastornos sexuales deben ser tomados con cierta cautela dado que sólo un estudio ha abordado esta comorbilidad (Raymond et al., 2003). De los trastornos sexuales explorados, las tasas más altas de comorbilidad se daban con el trastorno orgásmico femenino (50\%) y la disfunción eréctil (23\%). En ambos casos, no se aporta una explicación a cómo un paciente incapaz de mantener la respuesta sexual o de alcanzar el orgasmo presenta concurrentemente síntomas de un cuadro clínico caracterizado por un deseo sexual y una frecuencia sexual excesivas.

Habida cuenta de la comorbilidad entre CS y diferentes patologías del Eje I, Kafka (2007) recomienda: 1) que la evaluación de pacientes con CS incluya la exploración de síntomas de otras patologías del Eje I; 2 ) que cualquier paciente psiquiátrico sea evaluado de la presencia de un cuadro clínico de CS si se dan síntomas que lo sugieran y; 3) que el clínico considere el hallazgo de condiciones comórbidas a la CS como un indicador de severidad, estableciendo prioridades en el tratamiento de una u otra patología dependiendo de su interferencia. 
Tabla 6. Comorbilidad entre compulsividad sexual y trastornos del Eje I (prevalencia a lo largo de la vida) (elaboración propia)

\begin{tabular}{|c|c|c|c|c|c|c|c|}
\hline Estudio & Muestra & $\begin{array}{c}\text { Trastornos del estado de } \\
\text { ánimo (TEA) }\end{array}$ & Trastornos de ansiedad (TA) & Abuso de sustancias (AS) & $\begin{array}{c}\text { Trastornos del control de los } \\
\text { impulsos (TCl) }\end{array}$ & Trastornos sexuales (TS) & $\begin{array}{l}\text { Déficit de atención con } \\
\text { hiperactividad (TDAH) }\end{array}$ \\
\hline $\begin{array}{l}\text { Kafka y Prentky } \\
\text { (1994) }\end{array}$ & $\begin{array}{l}26 \text { hombres en } \\
\text { tratamiento por } \\
\text { hipersexualidad }\end{array}$ & $\begin{array}{l}\text { 80.8\% Algún TEA } \\
\text { 61.5\% Distimia }\end{array}$ & $\begin{array}{l}\text { 46.2\% Algún TA } \\
\text { 46.2\% Fobia social }\end{array}$ & $\begin{array}{l}\text { 46.2\% Algún AS } \\
\text { 40\% Abuso de alcohol }\end{array}$ & & & \\
\hline Black et al. (1997) & $\begin{array}{c}28 \text { hombres y } 8 \text { mujeres } \\
\text { autoidentificados como } \\
\text { compulsivos sexuales }\end{array}$ & $\begin{array}{l}\text { 39\% Algún TEA } \\
\text { 39\% Episodio depresivo } \\
\text { 14\% Episodio maníaco }\end{array}$ & $\begin{array}{l}\text { 50\% Algún TA } \\
\text { 42\% Fobia social } \\
\text { 14\% Ansiedad generalizada } \\
\text { 14\% Trastorno de angustia } \\
\text { 10\% Trno. Obsesivo Compulsivo }\end{array}$ & $\begin{array}{l}\text { 64\% Algún AS } \\
58 \% \text { Abuso de alcohol } \\
33 \% \text { Abuso de drogas }\end{array}$ & $\begin{array}{l}\text { 14\% Compras compulsivas } \\
14 \% \text { Cleptomanía } \\
11 \% \text { Juego patológico } \\
6 \% \text { Tricotilomanía }\end{array}$ & & \\
\hline $\begin{array}{l}\text { Kafka y Prentky } \\
\text { (1998) }\end{array}$ & $\begin{array}{l}18 \text { hombres en } \\
\text { tratamiento por } \\
\text { hipersexualidad }\end{array}$ & $\begin{array}{l}\text { 66.7\% Algún TEA } \\
\text { 61.1\% Distimia }\end{array}$ & $\begin{array}{l}\text { 42.9\% Algún TA } \\
\text { 25\% Fobia social }\end{array}$ & 25\% Algún AS & 15.6\% Algún TCl & & 16.7\% TDAH \\
\hline $\begin{array}{l}\text { Kafka y Hennen } \\
\text { (2002) }\end{array}$ & $\begin{array}{l}32 \text { hombres en } \\
\text { tratamiento por } \\
\text { hipersexualidad }\end{array}$ & $\begin{array}{l}\text { 71.8\% Algún TEA } \\
\text { 68.7\% Distimia } \\
\text { 41\% Episodio depresivo }\end{array}$ & $\begin{array}{l}\text { 37.5\% Algún TA } \\
\text { 25\% Fobia social } \\
\text { 15.6\% Ansiedad generalizada } \\
\text { 9.6\% Trastorno de angustia } \\
\text { 6.2\% Estrés postraumático }\end{array}$ & $\begin{array}{l}\text { 37.5\% Algún AS } \\
\text { 25\% Abuso de alcohol } \\
\text { 18.7\% Abuso de marihuana } \\
\text { 3.1\% Abuso de cocaína } \\
\text { 15.5\% Policonsumo de drogas }\end{array}$ & 15.5\% Algún TCI & & $\begin{array}{l}\text { 18.7\% TDAH } \\
\text { 3.1\% Combinado } \\
15.6 \% \text { Inatento }\end{array}$ \\
\hline $\begin{array}{l}\text { Raymond et al. } \\
\text { (2003) }\end{array}$ & $\begin{array}{l}23 \text { hombres y } 2 \text { mujeres } \\
\text { autoidentificados como } \\
\text { compulsivos sexuales }\end{array}$ & $\begin{array}{l}\text { 71\% Algún TEA } \\
\text { 8\% Distimia } \\
\text { 58\% Episodio depresivo } \\
\text { 8\% Episodio maníaco }\end{array}$ & $\begin{array}{l}\text { 96\% Algún TA } \\
\text { 21\% Fobia social } \\
\text { 17\% Ansiedad generalizada } \\
\text { 8\% Trno. Obsesivo Compulsivo } \\
\text { 13\% Estrés postraumático } \\
\text { 8\% Fobia específica }\end{array}$ & $\begin{array}{l}\text { 71\% Algún AS } \\
\text { 63\% Abuso de alcohol } \\
38 \% \text { Abuso de marihuana } \\
\text { 13\% Abuso de cocaína } \\
\text { 13\% Abuso de alucinógenos } \\
\text { 8\% Policonsumo de drogas }\end{array}$ & $\begin{array}{l}\text { 38\% Algún TCI } \\
\text { 13\% Cleptomanía } \\
\text { 4\% Juego patológico } \\
\text { 13\%Explosivo intermitente }\end{array}$ & $\begin{array}{l}\text { 46\% Algún TS } \\
\text { 23\% Disfunción eréctil } \\
5 \% \text { Anorgasmia (el) } \\
50 \% \text { Anorgasmia (ella) } \\
\text { 9\% Eyaculación precoz }\end{array}$ & \\
\hline Weiss (2004a) & $\begin{array}{l}220 \text { hombres adictos al } \\
\text { sexo }\end{array}$ & $28 \%$ Episodio depresivo & & & & & \\
\hline $\begin{array}{l}\text { Blankenship y } \\
\text { Laarser (2004) }\end{array}$ & $\begin{array}{l}70 \text { hombres adictos al } \\
\text { sexo en tratamiento }\end{array}$ & & & & & & $34 \%$ TDAH \\
\hline Reid (2007) & $\begin{array}{l}67 \text { pacientes en } \\
\text { tratamiento por } \\
\text { hipersexualidad }\end{array}$ & 59.7\% Algún TEA & 20.8\% Algún TA & & & & $\begin{array}{l}\text { 26.7\% TDAH } \\
\text { 96.4\% Inatento }\end{array}$ \\
\hline $\begin{array}{l}\text { Hartman et al. } \\
\qquad(2012)\end{array}$ & $\begin{array}{c}57 \text { hombres en } \\
\text { tratamiento por adicción } \\
\text { al sexo }\end{array}$ & & & $\begin{array}{l}\text { 63.2\% Algún AS } \\
\text { 7\% Abuso de alcohol } \\
5.26 \% \text { Abuso de cocaína } \\
50.8 \% \text { Policonsumo de drogas }\end{array}$ & & & \\
\hline $\begin{array}{l}\text { Morgenstern et } \\
\text { al. (2012) }\end{array}$ & $\begin{array}{l}183 \text { hombres gays y } \\
\text { bisexuales con } \\
\text { puntuaciones clínicas en } \\
\text { compulsividad sexual }\end{array}$ & $\begin{array}{l}\text { 32.8\% Algún TEA } \\
33 \% \text { Episodio depresivo } \\
2.6 \% \text { Episodio maníaco }\end{array}$ & $\begin{array}{l}\text { 35.2\% Algún TA } \\
\text { 8.2\% Fobia social } \\
\text { 14.8\% Ansiedad generalizada } \\
\text { 10.4\% Trastorno de angustia } \\
\text { 8.2\% Trno. Obsesivo Compulsivo } \\
\text { 15\% Fobia especifica }\end{array}$ & $\begin{array}{l}\text { 35\% Algún AS } \\
20.2 \% \text { Abuso de alcohol } \\
23 \% \text { Abuso de drogas }\end{array}$ & & & \\
\hline
\end{tabular}


En cuanto a la comorbilidad con patologías del Eje II, es previsible que el riesgo de padecer un trastorno de la personalidad en pacientes con CS sea cuanto menos un tanto mayor. No en vano, su prevalencia en población clínica -tanto de adultos como de adolescentes- es superior a la documentada en población general, que en adultos sería de alrededor del 10\% (Sansone \& Sansone, 2011) y en adolescentes del 14\% (J. G. Johnson et al., 2000). En este sentido, se considera a los trastornos de la personalidad como el caldo de cultivo ideal para la proliferación de trastornos del Eje I. Tanto es así que autores como Oldham et al. (1995) han hecho especial hincapié en su valor como elemento de prognosis: "Cuando está presente un trastorno de la personalidad, hay una alta probabilidad de que un trastorno del estado de ánimo, ansiedad, psicótico o alimentario agrave el cuadro clínico" (Oldham et al., 1995, p. 571). Los trastornos de personalidad que por sus características, están más ligados a la CS son los del Cluster B (narcisista, antisocial, límite e histriónico). Carnes (1991) sugería que los rasgos prototípicos de estas patologías coinciden con algunas manifestaciones de la CS. Asimismo, este autor planteaba un perfil diferencial para hombres y mujeres: los hombres con CS compartirían sintomatología sobre todo con el trastorno antisocial, mientras que las mujeres lo harían con un perfil histriónico, límite y narcisista. Montaldi (2002) planteaba que la CS podría ser una manifestación de un trastorno de la personalidad subyacente, identificando paralelismos entre esta patología y patrones de personalidad límite, histriónica, narcisista y obsesiva compulsiva. Rickards y Laaser (1999) concretaban aún más, señalando el trastorno límite de la personalidad como el de mayor peso en el cuadro clínico de la CS.

A nivel empírico, tres investigaciones aportan tasas de comorbilidad entre CS y trastornos de la personalidad. Sus resultados se resumen en la tabla 7. Los tres siguen una metodología similar: primero aplicaban el cuestionario de screening de trastornos de la personalidad de la SCID-II para comprobar la presencia de síntomas de trastorno de la personalidad pero sólo los diagnosticaban cuando se confirmaban a través de entrevista clínica.

A través del cuestionario de screening de trastornos de la personalidad, Black et al. (1997) encontraron que el $82 \%$ de los pacientes compulsivos sexuales que comprendía su muestra obtuvieron puntuaciones clínicas en al menos un trastorno de la personalidad y el $31 \%$ en más de uno. La comorbilidad estimada a partir de la entrevista clínica fue del $83 \%$, si bien el diagnóstico a través del cuestionario y de la entrevista únicamente coincidía en el $44 \%$ de los casos. En la tabla 7 figuran únicamente los diagnósticos de consenso -diagnósticos donde entrevista y cuestionario coinciden-. La prevalencia más alta es para el trastorno histriónico (21\%), seguido del obsesivo (15\%), paranoide (15\%), pasivo agresivo (12\%) y límite (9\%). 
Tabla 7. Comorbilidad entre compulsividad sexual y trastornos del Eje II (prevalencia a lo largo de la vida) (elaboración propia)

\begin{tabular}{|c|c|c|c|c|}
\hline & Estudio & Black et al. (1997) & Raymond et al. (2003) & Reid et al. (2013) \\
\hline & Muestra & $\begin{array}{l}28 \text { hombres y } 8 \text { mujeres } \\
\text { autoidentificados como } \\
\text { compulsivos sexuales }\end{array}$ & $\begin{array}{c}23 \text { hombres y } 2 \text { mujeres } \\
\text { autoidentificados como } \\
\text { compulsivos sexuales }\end{array}$ & $\begin{array}{l}123 \text { hombres que cumplían } \\
\text { criterios para el diagnóstico } \\
\text { por hipersexualidad DSM-5 }\end{array}$ \\
\hline \multicolumn{2}{|c|}{ Comorbilidad general } & $44 \%$ & $46 \%$ & $17 \%$ \\
\hline \multirow{3}{*}{ 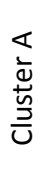 } & Paranoide & $15 \%$ & $20 \%$ & $1 \%$ \\
\hline & Esquizoide & $0 \%$ & $0 \%$ & $0 \%$ \\
\hline & Esquizotípico & $3 \%$ & $0 \%$ & $1 \%$ \\
\hline \multirow{4}{*}{ 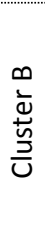 } & Narcisista & $6 \%$ & $18 \%$ & $8 \%$ \\
\hline & Antisocial & $6 \%$ & $11 \%$ & $3 \%$ \\
\hline & Límite & $9 \%$ & $5 \%$ & $0 \%$ \\
\hline & Histriónico & $21 \%$ & $0 \%$ & $0 \%$ \\
\hline \multirow{4}{*}{ 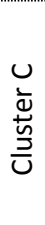 } & Evitativo & $6 \%$ & $15 \%$ & $2 \%$ \\
\hline & Dependiente & $3 \%$ & $0 \%$ & $0 \%$ \\
\hline & Obsesivo & $15 \%$ & $15 \%$ & $4 \%$ \\
\hline & Pasivo-agresivo & $12 \%$ & $20 \%$ & $1 \%$ \\
\hline
\end{tabular}

Raymond et al. (2003) obtienen una cifra de comorbilidad general similar a la anterior (46\%), si bien la prevalencia para trastornos concretos varía notablemente. En este caso, los trastornos de la personalidad más frecuentes son el pasivo-agresivo y el paranoide (20\%), seguido del narcisista (18\%), evitativo (15\%) y antisocial (11\%). La prevalencia para el trastorno histriónico (que resultó el más frecuente en la investigación anterior) fue del $0 \%$.

Reid et al. (2013) obtienen una comorbilidad un tanto mayor al analizar los resultados del cuestionario de screening de personalidad, si bien los resultados de la entrevista marcan distancia con los estudios precedentes. Según el cuestionario de screening, el 64\% de los 123 pacientes evaluados excedería el punto de corte para al menos 3 trastornos de la personalidad y el $29 \%$ lo haría para 6 o más. Sin embargo, tan sólo el 17\% de estos diagnósticos se confirma durante la entrevista. El trastorno narcisista es, con un $8 \%$, el diagnóstico más comórbido, seguido del obsesivo (4\%) y el antisocial (3\%). A partir de estos resultados, Reid y su equipo concluyeron: 1) que el único criterio diagnóstico válido cuando se explora la comorbilidad entre CS y un trastorno de personalidad es el obtenido a través de una entrevista diagnóstica; 2) que las teorías que hablan de la CS como expresión de un trastorno de personalidad carecen de aval empírico y; 3 ) que el riesgo de que un paciente con CS padezca un trastorno de la personalidad comórbido es equivalente al de cualquier paciente con otro trastorno del Eje I. 


\section{Consecuencias de la CS}

De entre los perjuicios personales y psicosociales que se derivan de la conducta sexual compulsiva, los sociosanitarios han suscitado mayor alarma. En este sentido, la alta frecuencia con la que estos pacientes mantienen relaciones sexuales con múltiples parejas sin utilizar los medios preventivos adecuados los sitúan en una posición de riesgo a la hora de contraer una ITS, el VIH o bien de provocar un embarazo no deseado (Kafka, 2010; Kaplan \& Krueger, 2010). De entre las investigaciones que confirman el riesgo sexual de las personas con esta patología, destaca la realizada por Parsons, Grov \& Golub (2012) en HSH, una población de especial riesgo. En este colectivo, uno de los pocos donde la prevalencia de VIH continúa incrementándose a pesar de los programas preventivos desarrollados (De Cock, Jaffe, \& Curran, 2012), se ha demostrado que la CS se relaciona de forma directa e indirecta con el riesgo de contraer VIH. Obtener puntuaciones clínicas en el cuestionario SCS aumenta en 2.25 puntos la probabilidad de realizar conductas sexuales de riesgo para la transmisión del VIH y en 2.05 puntos la probabilidad de ser $\mathrm{VIH}+$ (Parsons et al., 2012). Asimismo, cuando la CS se suma a otros factores de vulnerabilidad psicosocial (como por ejemplo el consumo de drogas o el bajo nivel socioeconómico), la probabilidad de contraer VIH aumenta exponencialmente. Respecto a la prevalencia de embarazos no deseados en pacientes con CS, Ferree (2001) estima que entre el $25-50 \%$ de sus pacientes con esta patología han cesado voluntariamente un embarazo que no deseaban cuanto menos en alguna ocasión.

Bien conocidas -aunque peor documentadas- son las consecuencias que la CS tiene sobre la vida familiar en general y de pareja en particular. Las parejas de pacientes con CS se enfrentan al hecho de que sus esfuerzos por satisfacer sexualmente a su pareja no son suficientes $y$, en algunos casos, a que éstos les hayan sido infieles. En un estudio realizado con 63 mujeres de pacientes con CS, la gran mayoría experimentó una fuerte reacción emocional al enterarse del problema sexual de sus parejas, que en muchos casos llevaba aparejado el haber sufrido una infidelidad (Steffens \& Rennie, 2006). La reacción emocional alcanzaba en algunos casos la sintomatología y severidad de un cuadro clínico de TEPT. Schneider y Corley (2002) encontraron tras evaluar a 80 pacientes en tratamiento por problemas de CS y sus respectivas parejas que el $41.8 \%$ de sus pacientes seguía ocultando a su pareja aspectos de su conducta sexual pasada a pesar de estar en tratamiento y que el 35.9\% lo hacía de su conducta sexual actual; el 52\% de las parejas de pacientes continuaba mostrándose desconfiadas después de perdonar la infidelidad; el $\mathbf{9 7 . 3 \%}$ de los pacientes y el $92.2 \%$ de sus parejas experimentó reacciones emocionales adversas cuando los problemas sexuales salieron a la luz, reacciones que en el $50 \%$ de los casos supusieron rupturas temporales o divorcios. Finalmente, la mayoría 
de las parejas y un porcentaje importante de pacientes reconocía que esta experiencia podía resultar perjudicial para el desarrollo emocional y psicológico de sus hijos.

Las restantes áreas donde la CS tiene implicaciones negativas han sido menos estudiadas. Concretamente, tres investigaciones han examinado las consecuencias negativas de la CS en un intento por elaborar escalas orientadas a su evaluación. La primera sería la Escala de Consecuencias de la Compulsividad Sexual (CSBSC, Muench et al., 2007), construida a partir de información extraída a un grupo de 28 pacientes homosexuales con problemas en el control de los impulsos sexuales. Los 21 ítems que comprende esta escala se clasifican en 3 áreas o dominios: 1) consecuencias personales (p.e., "El sexo me hace sentirme deprimido o ansioso" o "me ha impedido mi desarrollo personal"); 2) consecuencias interpersonales ("mis amistades se han visto dañadas" o "he perdido la oportunidad de tener pareja estable") y; 3) consecuencias médicas ("he tenido problemas médicos derivados de mi conducta sexual" o "he practicado sexo sin protección"). La crítica a este instrumento se ha centrado principalmente en su escasa especificidad y en que posiblemente las consecuencias que para el colectivo homosexual tiene la CS pudieran no ser las mismas que para el conjunto de la población (Reid, Garos, \& Fong, 2012).

La segunda sería la Escala de Consecuencias Cognitivas y Conductuales de la Compulsividad Sexual (CBOSBS, McBride et al., 2008). Este instrumento se planteó a partir de una revisión de estudios que sugerían distintas áreas donde la CS ejerce una influencia negativa. A partir de ahí, plantearon un instrumento que comprendía dos escalas: una de consecuencias cognitivas de la CS y otra de consecuencias conductuales. La escala de consecuencias cognitivas incluía preocupaciones que podían o no darse como consecuencia de una conducta sexual desmedida. Ejemplos de ítems de esta escala serían: "me preocupa que las cosas que he hecho sexualmente pudieran llevarme a problemas con mis amigos" o "pudieran hacerme perder el trabajo". La escala de consecuencias conductuales preguntaba por situaciones como por ejemplo: "he contraído el VIH" o "he tenido un embarazo no deseado". A partir de un estudio realizado con 390 estudiantes universitarios, se identificaron las 6 áreas más problemáticas: 1 ) problemas económicos; 2) legales; 3) físicos; 4) psicológicos; 5) espirituales y; 6) sociales.

El último es la Escala de Consecuencias de la Conducta Hipersexual (HBCS, Reid, Garos, et al., 2012), que comprendería 22 ítems con un formato de respuesta tipo Likert entre 1 (no me ha pasado nunca y veo poco probable que me pase) y 5 (me ha pasado muy frecuentemente). Sus autores se limitaron a integrar en una misma escala las fortalezas de las dos anteriores, por lo que no incluye ninguna novedad con respecto a las comentadas previamente. En este caso, la validación se realizó con una muestra de 137 pacientes en tratamiento por problemas en el 
control de los impulsos sexuales, obteniendo resultados que avalarían su uso tanto con fines clínicos como de investigación. En la tabla 8 se incluyen algunos de los resultados que estos investigadores obtuvieron y que ilustran de forma satisfactoria la frecuencia y el tipo de problemas habituales en personas con conducta sexual compulsiva.

Tabla 8. Consecuencias derivadas de la conducta sexual compulsiva (elaborado a partir de Reid, Garos, et al., 2012)

\begin{tabular}{|c|c|c|}
\hline “Mi conducta sexual desmedida... & $\begin{array}{c}\text { Me ha pasado } \\
\text { una o dos veces }\end{array}$ & $\begin{array}{c}\text { Me ha pasado muy } \\
\text { frecuentemente }\end{array}$ \\
\hline ...me ha hecho perder un trabajo" & $18.2 \%$ & $0 \%$ \\
\hline ...ha provocado la ruptura de una relación sentimental" & $33.6 \%$ & $38.7 \%$ \\
\hline ...me ha llevado a contagiarme con una ITS" & $5.8 \%$ & $22.6 \%$ \\
\hline ...me ha provocado problemas legales" & $16.8 \%$ & $1.5 \%$ \\
\hline ...me ha llevado a sacrificar cosas importantes en mi vida" & $25.5 \%$ & $48.9 \%$ \\
\hline ...me ha llevado a tener problemas económicos" & $24.1 \%$ & $32.1 \%$ \\
\hline ...me ha provocado daños emocionales" & $18.2 \%$ & $72.3 \%$ \\
\hline ...ha provocado que alguna de mis parejas desconfiara de mi" & $24.1 \%$ & $63.5 \%$ \\
\hline ...me ha hecho sentirme humillado y avergonzado" & $32.8 \%$ & $43.8 \%$ \\
\hline ...me ha llevado a que gente a la que cuido pierda el respeto hacia mi" & $32.1 \%$ & $40.1 \%$ \\
\hline ...ha afectado a mi salud mental" & $19.7 \%$ & $75.9 \%$ \\
\hline ...me ha aislado y alejado de personas significativas" & $13.9 \%$ & $70.8 \%$ \\
\hline ...ha amenazado mi confianza en mí mismo" & $9.5 \%$ & $87.6 \%$ \\
\hline ...ha interferido con mis creencias religiosas, espirituales o éticas" & $7.3 \%$ & $88.3 \%$ \\
\hline ...ha impedido que pudiera conectar emocionalmente con una pareja" & $11.7 \%$ & $83.2 \%$ \\
\hline
\end{tabular}

Como se aprecia tras analizar los porcentajes de la tabla 8, la mayoría de pacientes tratados por problemas en el control de impulsos sexuales experimentó en alguna ocasión problemas derivados de su comportamiento sexual y la mayoría los experimentó con mucha frecuencia. Entre los más habituales, se encontraban los problemas espirituales, éticos o religiosos, los problemas sociales (dificultad para conectar emocionalmente con otras personas) y personales (pérdida de la confianza en uno mismo), pero también serían frecuentes otras consecuencias con un impacto si cabe mayor como la ruptura de una relación, el haber experimentado problemas legales o bien haberse contagiado con una ITS. 


\section{Clasificación de la conducta sexual compulsiva}

Si la evaluación permite identificar una constelación de síntomas que cuadran con los criterios para el diagnóstico del trastorno por hipersexualidad, el siguiente paso es identificar la forma en la que el cuadro clínico se manifiesta. De igual modo que no todos los pacientes con CS comparten los mismos síntomas, sus manifestaciones pueden ser muy diferentes. De ahí su consideración de fenómeno único expresado a través de múltiples formas (Cantor et al., 2013).

Se han propuesto diversas clasificaciones para categorizar la CS a partir de varios criterios: gravedad del cuadro clínico y riesgo asociado (Carnes, 1983), tipo de tratamiento a aplicar (Cantor et al., 2013; Sutton, Stratton, Pytyck, Nathan, \& Cantor, 2014), grado en el que el paciente es o no consciente de la gravedad de su problema (Reid, 2007), etc. Sin embargo, el criterio más habitual ha sido su clasificación a partir de la descripción clínica de las conductas sexuales implicadas -presumiblemente por la facilidad para recoger este tipo de información y su importancia para estimar las consecuencias derivadas de cada caso- (Coleman, 1992; Coleman, Raymond, \& McBean, 2003; Kafka, 1997, 2010).

Clasificar la CS a partir de cómo se expresa la conducta sexual implica aclarar las conductas sexuales que pueden o no considerarse propias de este cuadro clínico. Así comenzó la discusión en torno a la consideración o no de las parafilias como una manifestación de la compulsividad sexual. En este sentido, se pueden identificar tres etapas donde situar las 6 principales clasificaciones para la CS (figura 3):

Figura 3. Etapas en la clasificación de la CS (elaboración propia).

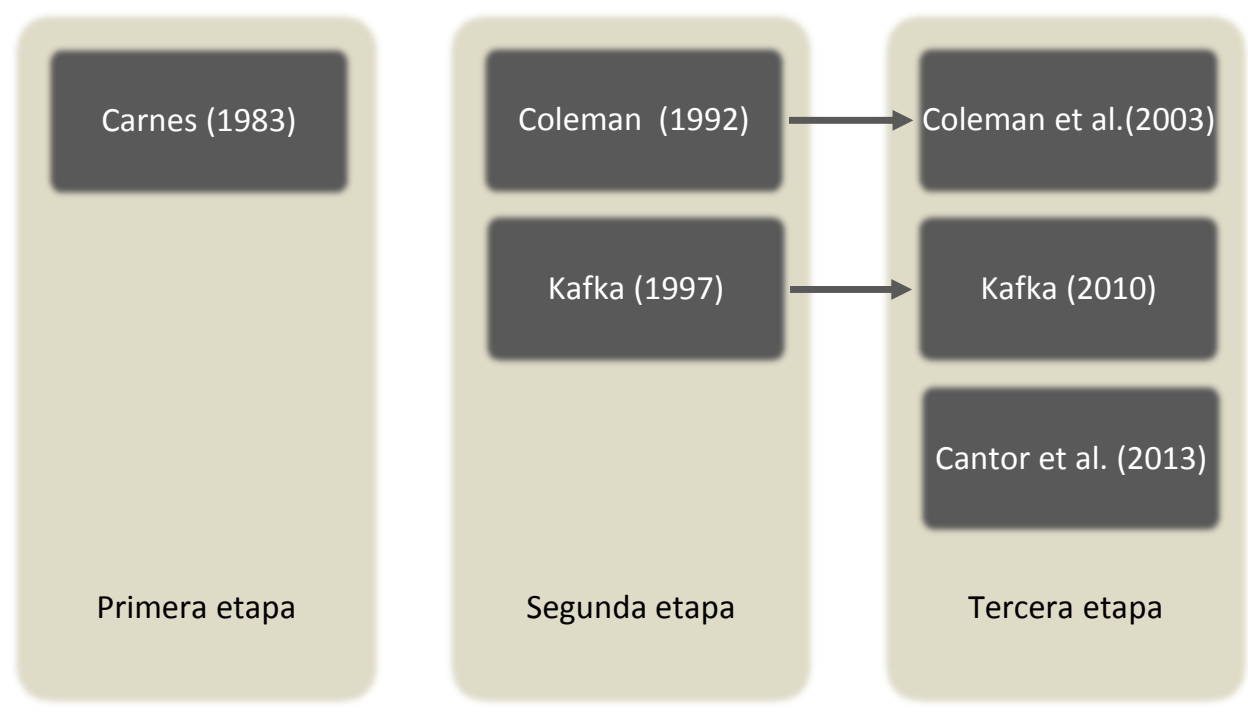




\subsection{Primera etapa en la clasificación de la CS}

Las clasificaciones surgidas durante esta primera etapa se caracterizan por no establecer una clara división entre CS y parafilias. El mejor ejemplo es la propuesta de Carnes (1983): este autor fue uno de los primeros en proponer que la CS se expresaba de múltiples formas y que además, estas distintas expresiones se podían clasificar en función de su grado de desviación de la conducta sexual normal. Este autor formuló tres niveles en los que ésta se podía manifestar: 1) en el primer nivel se situaban los pacientes cuya conducta sexual era normal en términos de objeto de deseo pero desviada en cuanto a su frecuencia (masturbación compulsiva, múltiples parejas sexuales, adicción a la pornografía, etc.); 2) en el segundo nivel se situaban los pacientes con intereses sexuales parafílicos que no implicaban victimización de terceros, al menos en cuanto a abuso físico (exhibicionismo, voyeurismo, escatología, fetichismo); 3) finalmente, en el tercer nivel se situaban aquellos compulsivos sexuales cuyos impulsos incontrolados se manifestaban a través del abuso y la victimización sexual (violación, coacción y abuso sexual, incesto, pedofilia, etc.).

Esta clasificación tiene el mérito de ser el primer intento por delimitar las distintas manifestaciones de la CS en un momento en el que este campo de estudio apenas comenzaba a desarrollarse. También resulta interesante la idea de clasificar la CS a partir de niveles de gravedad. Sin embargo, su utilidad a día de hoy es prácticamente nula, principalmente por su consideración de las parafilias como resultado de un cuadro agravado de CS. Según esta clasificación, la compulsividad sexual no sería sino un paso previo al desarrollo de una parafilia que, en el peor de los casos, implicaría la comisión de delitos contra la libertad sexual. No sólo eso, se asume implícitamente que el devenir natural de cualquier caso de CS es ganar gravedad hasta el desarrollo de una parafilia. Esta perspectiva es incompatible con las evidencias actuales sobre la etiología y curso de estos trastornos (Laws \& O’Donohue, 2008): efectivamente, la CS es considerada un factor que aumenta la probabilidad de desarrollar una parafilia, pero es incapaz de explicar por sí sola la presencia de un cuadro clínico de este tipo.

\subsection{Segunda etapa en la clasificación de la CS}

Posteriormente, surgen dos nuevas clasificaciones que permiten identificar una segunda etapa en cuanto a la consideración de las parafilias como manifestaciones de la CS. Ambas clasificaciones son bastante similares y comparten una misma base: tanto las parafilias como la CS tienen una etiología común, pero representarían dos formas distintas de expresión y por tanto, dos patologías independientes. 
Coleman (1992) defendía que la conducta sexual compulsiva se manifestaba de dos formas totalmente diferenciadas pero de etiología común: lo que este autor acertó a llamar "conducta sexual compulsiva Parafílica" y "conducta sexual compulsiva no Parafílica”. La primera suponía la expresión de la CS a través de intereses sexuales parafílicos mientras que la segunda abarcaba conductas sexuales normales que sobrevenían patológicas cuando se tornaban excesivas e incontroladas. Esta última categoría es la que respondería a la descripción de lo que entendemos ahora por compulsividad sexual. Concretamente, este autor identificaba 5 subtipos de conducta sexual compulsiva no parafílica: 1) múltiples parejas sexuales/cruising; 2) fijación compulsiva en una pareja inalcanzable; 3) masturbación compulsiva; 4) múltiples parejas románticas y; 5) conducta sexual compulsiva en el contexto de una relación estable.

La clasificación de Kafka (1997) es muy similar a la anterior. Se identifican también dos formas de manifestación de un fenómeno común, que en este caso recibía el nombre de trastorno por impulsividad sexual. Se propone que la etiología de este trastorno puede estar relacionada con un apetito sexual desproporcionado -debido posiblemente a alteraciones neurobiológicas- y se expresa nuevamente a través de dos vías: las parafilias y los trastornos relacionados con las parafilias. La primera categoría, como su propio nombre indica, englobaba las tradicionales desviaciones sexuales (sadismo/masoquismo sexual, fetichismo, etc.), mientras que para la segunda categoría se proponían 7 subtipos concretos: 1) masturbación compulsiva; 2) promiscuidad sexual; 3) dependencia de pornografía; 4) dependencia de sexo telefónico; 5) dependencia de accesorios -cocaína, pornografía, vibradores, etc.- para mantener relaciones sexuales satisfactorias $y$; 6) deseo sexual incompatible severo. Esta segunda categoría -trastornos relacionados con las parafilias- englobaría únicamente conductas sexuales normofílicas y sería la que posteriormente recibiría el nombre de trastorno por hipersexualidad (Kafka, 2001).

Las dos últimas clasificaciones son, a excepción de algunas categorías y de la nomenclatura, prácticamente idénticas. Sin embargo, la de Kafka (1997) obtuvo mayor trascendencia e impacto debido a que fue la primera en aplicarse a un grupo de pacientes clínicos. Este investigador tomó una muestra de 100 hombres (65 con parafilias y 35 con hipersexualidad) que acudieron a tratamiento a un centro especializado. Al explorar las principales manifestaciones de la CS en el grupo de pacientes hipersexuales obtuvo una interesante conclusión: era imposible encuadrarlos en una única categoría porque casi todos mostraban múltiples manifestaciones clínicas. La mayoría de los pacientes se podían clasificar como altamente promiscuos (80\%), pero también masturbadores compulsivos $(74.2 \%)$ y adictos a la pornografía (68.5\%). Las manifestaciones menos frecuentes eran la adicción al sexo telefónico 
(25.7\%), la incompatibilidad sexual severa (11.4\%) y la dependencia de accesorios sexuales (8.5\%). Dos años más tarde, Kafka y Hennen (1999) replicaron esta investigación con una muestra de 206 pacientes (63 hipersexuales y 143 parafílicos), obteniendo resultados prácticamente idénticos. Sin embargo, en este caso llegaron a una conclusión adicional: la dependencia de accesorios sexuales rara vez se producía en pacientes sin comorbilidad con parafilias (principalmente con fetichismo), por lo que decidieron eliminarla de su clasificación.

Estas dos investigaciones fueron también las primeras en aportar datos empíricos sobre la relación entre parafilias y CS. En la realizada en 1997 (Kafka, 1997) se encontró que a pesar de que algunos pacientes del grupo de hipersexuales mostraban ciertas tendencias parafílicas, ninguno había llegado a cumplir nunca los criterios necesarios para el diagnóstico de una parafilia; sin embargo, la gran mayoría de los pacientes parafílicos (el 86.1\%) sí habían cumplido cuanto menos en alguna ocasión criterios para el diagnóstico de hipersexualidad. De hecho, algunos aspectos de la conducta sexual que tradicionalmente se asociaban más con la compulsividad sexual como por ejemplo la frecuencia media de orgasmos semanales era superior en el grupo de pacientes parafílicos (16.9 orgasmos semanales frente a 14.3). En la investigación realizada dos años después se confirmaron los hallazgos anteriores y se encontró además que el cuadro clínico de los pacientes puros (los que sólo eran diagnosticados o con parafilias o con hipersexualidad) producía un impacto psicosocial menos severo que el de los pacientes con ambas condiciones (Kafka \& Hennen, 1999).

Estos mismos autores realizaron una tercera investigación comparando de nuevo pacientes parafílicos e hipersexuales (Kafka \& Hennen, 2003): el objetivo en este caso era explorar las diferencias en el riesgo de cometer abuso sexual entre un grupo de pacientes únicamente parafílicos, otro grupo de pacientes únicamente hipersexuales y un tercer grupo mixto (pacientes que cumplían criterios tanto de hipersexualidad como de parafilias). Como ya obtuvieron anteriormente, ambos grupos apenas diferían en cuanto a conducta sexual (frecuencia sexual, edad de inicio en la conducta sexual problemática, evolución clínica, etc.); sin embargo, sólo el grupo mixto o el de parafílicos puros se asociaba con un riesgo significativo de agresión sexual.

Por otra parte, Briken, Habermann, Kafka, Berner, \& Hill (2006) obtienen la misma conclusión pero a partir de una metodología totalmente opuesta: en lugar de evaluar el riesgo de abuso sexual en pacientes con parafilias, hipersexualidad o ambas condiciones, evaluaron la presencia de estas tres condiciones en convictos culpables de crímenes sexuales (homicidas sexuales). Concretamente, emplearon el historial médico, psiquiátrico y penal de 161 hombres que habían cometido homicidios sexuales para clasificarlos en 4 grupos: sin patología, 
parafílicos puros, hipersexuales puros y mixtos (con hipersexualidad y parafilias). Lo que encontraron es que nuevamente, el grupo combinado era el que presentaba el perfil más grave: estos convictos referían más problemas durante el desarrollo (abuso sexual y físico, enuresis, encopresis, TDAH), mayor frecuencia sexual tanto autoerótica como heteroerótica, tendencia a la masturbación con fantasías sádicas u homicidas y un mayor número de agresiones sexuales y de tiempo de encarcelación previo a la comisión del homicidio sexual. De hecho, el $34 \%$ de los convictos en este grupo eran reincidentes (ya habían cometido algún homicidio sexual previo). El siguiente grupo en riesgo de victimización y gravedad fue el de parafílicos puros, seguido por el de convictos sin patología e hipersexuales. Estos últimos solían presentar alta comorbilidad con consumo de alcohol, lo que en parte podría explicar la comisión del homicidio sexual. A partir de estos hallazgos y de los obtenidos por Kafka y Hennen (2003) se concluyó que la línea que separa a las parafilias de la CS no puede establecerse en términos cuantitativos, sino cualitativos: la CS constituye una condición sexual patológica por el disconfort interno que provoca y los problemas psicosociales que genera, pero no por suponer un especial riesgo de victimización a terceros.

A estos hallazgos hemos de sumarle finalmente los obtenidos por Rinehart y McCabe (1998). A diferencia de los anteriores, su estudio se centró en muestra subclínica. Concretamente, estos investigadores evaluaron la comorbilidad psicopatológica en un grupo de 156 estudiantes universitarios (69 hombres y 93 mujeres) que clasificaron en diferentes grupos según una serie de criterios: alto-bajo deseo sexual normofílico, alto-bajo deseo sexual parafílico, alta-baja frecuencia sexual normofílica y presencia-no presencia de conductas sexuales parafílicas. Su objetivo era explorar la comorbilidad psicopatológica asociada a estas 4 condiciones para tratar de trazar un perfil diferencial entre deseo normofílico y parafílico. Lo que estos investigadores encontraron es que un mayor deseo sexual parafílico se relacionaba con la presencia de síntomas de trastorno obsesivo compulsivo; a su vez, los evaluados que habían realizado algún tipo de conducta sexual parafílica (especialmente voyeurismo) mostraban niveles mayores de depresión que los que nunca lo habían hecho. Por el contrario, ni la alta frecuencia sexual ni el alto deseo normofílico se asociaban con mayor psicopatología. Estos hallazgos permitían establecer -en este caso a nivel subclínico- una clara diferencia entre la presencia de intereses sexuales parafílicos y normofílicos, apoyando nuevamente que ambas condiciones responden a un cuadro clínico distinto. 


\subsection{Tercera etapa en la clasificación de la CS}

Las investigaciones comentadas en el epígrafe anterior, junto con algunas publicadas posteriormente, han cambiado completamente la forma actual de entender la relación entre parafilias y CS. Kafka (2010) expresaba muy bien este cambio a la hora de plantear sus criterios diagnósticos para el trastorno por hipersexualidad: "el trastorno por hipersexualidad debe ser considerado en el DSM-5 como totalmente distinto al de las parafilias a pesar de que la comorbilidad entre ambas condiciones sea alta y que algunas manifestaciones de las parafilias se parezcan a ciertos síntomas del trastorno por hipersexualidad" (Kafka, 2010, p. 392). Por tanto, el criterio que ha marcado el desarrollo de las clasificaciones de la compulsividad sexual durante esta tercera etapa ha sido la desvinculación total entre ambos cuadros clínicos; no se obvia la relación en términos de comorbilidad o que compartan ciertos síntomas concretos (frecuencia sexual, edad de inicio en las prácticas sexuales, etc.), pero ya no se les atribuye una etiología común y además el diagnóstico de una y de otra condición es incompatible.

La primera clasificación surgida de esta perspectiva fue la de Coleman et al. (2003). Este equipo retomó la clasificación propuesta 10 años antes por uno de sus miembros (Coleman, 1992) e incluyeron dos modificaciones: eliminar cualquier mención a las parafilias y añadir 2 nuevas manifestaciones normofílicas de la CS. A continuación se detalla su propuesta:

1. Múltiples parejas sexuales/Cruising: pacientes cuya incapacidad para controlar sus impulsos sexuales se traduce en la búsqueda compulsiva de nuevas parejas sexuales. La relación que se establece con estas parejas es únicamente sexual -normalmente no se establece vínculo emocional alguno-. En algunos casos, como por ejemplo el cruising en parques o lugares públicos, esta conducta puede reportar problemas legales. Por otra parte, la conducta sexual promiscua es considerada un factor de riesgo para la transmisión de algunas ITS o de VIH caso que no se tomen las medidas profilácticas apropiadas (Mashegoane, Moalusi, Ngoepe, \& Peltzer, 2002).

2. Fijación compulsiva en una pareja inalcanzable: incapacidad para dejar de fantasear con una pareja determinada a pesar de que el interés sexual no sea recíproco. En estos casos, la CS se manifiesta a través de pensamientos intrusivos que provocan un importante malestar, si bien esta situación no suele desencadenar casos de acoso o asalto sexual -situación que sería más propia de ciertas parafilias-.

3. Masturbación compulsiva: incapacidad para controlar los impulsos autoestimulatorios. El orgasmo no se acompaña de una reducción de la libido; por el contrario, este tipo de pacientes sólo cesan por imposición contextual (encontrarse en lugares o junto a personas que impiden la masturbación) o por agotamiento. En ciertos 
casos, la masturbación compulsiva puede incluso llegar a provocar daños físicos en los genitales (Savaş, Efesoy, Cayan, \& Cayan, 2012; Swanson et al., 2014).

4. Múltiples parejas románticas: pacientes con una incesante necesidad por establecer nuevas relaciones románticas que, sin embargo, son incapaces de mantener. Suelen tener un trato insinuante y resulta muy habitual que cometan adulterio. El principal perjuicio de esta incapacidad para controlar sus impulsos sexuales suele darse en el contexto familiar y sobre todo de pareja.

5. Adictos a la pornografía: pacientes que dedican una ingente cantidad de tiempo al visionado de pornografía, acompañándolo en la mayoría de casos de masturbación. Se estima que este tipo de pacientes dedican una media semanal de 11 horas en adelante a la búsqueda de pornografía online (Cooper, Delmonico, \& Burg, 2000).

6. Usuarios compulsivos de cibersexo: similar a la categoría anterior pero en este caso, el interés es hacia la búsqueda de personas en Internet con las que mantener relaciones sexuales online (a través de webcam o chat). En algunos casos, el verdadero interés es acabar trasladando esta relación a la vida real (Craft, 2012).

7. Conducta sexual compulsiva en el contexto de una relación estable: personas con una incesante necesidad por mantener relaciones sexuales con sus parejas románticas. La negativa al coito suele provocar reacciones de ansiedad, depresión o incluso de ira (en algunas ocasiones estas personas pueden someter a sus parejas a cierta coerción o coacción sexual). Esta categoría es muy distinta a la incompatibilidad sexual, donde el problema no es que uno de los miembros de la pareja tenga un excesivo deseo sexual, sino más bien que el apetito sexual de un miembro es mucho menor del de la media para su edad y sexo y esto acaba generando problemas maritales.

El problema tanto de la clasificación original (Coleman, 1992) como de esta nueva (Coleman et al., 2003) es que apenas ha tenido repercusión en la evaluación de muestra clínica, por lo que no podemos estar seguros de la bondad de estas categorías a la hora de recoger las diversas expresiones clínicas de la CS. Es más, la descripción de alguna de ellas -sobre todo la de la fijación en una pareja inalcanzable- parece difícilmente operativizable, de modo que resulta complicado clasificar a pacientes con CS según estas categorías. El único estudio clínico donde se ha utilizado es el realizado por Raymond, Coleman y Miner (2003). Estos investigadores evaluaron a una muestra de 25 pacientes ( 23 hombres y 2 mujeres) que cumplían criterios para su identificación como compulsivos sexuales. Al explorar los subtipos de CS, los autores encontraron que el $100 \%$ podían clasificarse en dos de las 7 categorías propuestas: el $76 \%$ podían considerarse buscadores de múltiples parejas sexuales/cruisers y el $48 \%$ masturbadores 
compulsivos. Los autores no especifican la prevalencia del resto de categorías, pero señalan que prácticamente era inexistente y en caso de identificarse, no se daban nunca solas aparecían en combinación con alguna de las dos anteriores-. Posiblemente este sea el motivo por el que esta propuesta no haya alcanzado prácticamente trascendencia más allá de su mención en algunos trabajos teóricos (Mick \& Hollander, 2006).

La clasificación de Kafka (2010), también derivada de su propuesta original (Kafka, 1997), es la que hoy día se aplica en un mayor número de trabajos empíricos. Es presumible que también haya sido mayor su impacto a nivel clínico, puesto que corresponde con la propuesta de especificadores para el trastorno por hipersexualidad (Kaplan \& Krueger, 2010). Igual que la anterior, abandona cualquier mención a las parafilias como manifestación de la hipersexualidad y propone 6 posibles formas de expresión más 1 categoría abierta -otros- caso que un paciente concreto no encaje en alguna de las categorías anteriores. 4 de las 6 categorías que esta clasificación contempla (masturbación, pornografía, conducta sexual consentida con adultos [promiscuidad sexual] y cibersexo) son equivalentes a las del modelo de Coleman et al. (2003), por lo que no nos detendremos en volver a aportar una descripción de las mismas. Las dos restantes se describen a continuación:

1. Sexo telefónico: expresión de la CS a través de la necesidad compulsiva de llamar a líneas eróticas y mantener conversaciones sexuales con desconocidos. Suele ir acompañada de importantes problemas y perjuicios económicos; no en vano, estas líneas suelen cobrar importantes sumas de dinero por cada llamada, sobre todo de las de larga duración. En algunos casos, la llamada a líneas eróticas se sustituye por lo que se ha llamado "escatología telefónica": llamadas a desconocidos con los que se intenta mantener una conversación erótica (Dalby, 1988)

2. Clubs de estriptis: variante de la dependencia a pornografía ("pornografía en vivo") en tanto en cuanto el principio es muy similar en ambos casos: se puede mirar pero no tocar. A diferencia de la búsqueda compulsiva de pornografía en Internet, suele ir acompañado de problemas económicos. En algunos casos, este tipo de pacientes simplemente pasan un rato en estos establecimientos y se masturban al llegar a casa fantaseando con la situación; en otros, frecuentar estos establecimientos deriva en la contratación de trabajadoras sexuales. Kafka explica que este tipo de pacientes podrían clasificarse como masturbadores compulsivos o buscadores de múltiples parejas sexuales; sin embargo, las características diferenciales les hacen, a criterio del autor, merecedores de categoría propia. 
Como decíamos, esta clasificación ha sido utilizada en múltiples investigaciones empíricas con muestra clínica. La más relevante es sin duda el ensayo clínico de Reid et al. (2012), donde uno de los objetivos era precisamente evaluar la eficacia de estas 6 categorías a la hora de reflejar las distintas manifestaciones de la CS. Los resultados obtenidos se asemejan a los comentados previamente, con variaciones atribuibles al incremento en el uso de las Tecnologías de la Información y la Comunicación (TIC) frente a medios más tradicionales como las llamadas a teléfonos eróticos: de esta forma, la adicción a pornografía sobreviene el subtipo más frecuentemente diagnosticado (81.1\%), seguido muy de cerca por la masturbación compulsiva (78.3\%). El siguiente en prevalencia sería el sexo consentido con adultos -es decir, la promiscuidad sexual- (44.9\%), mientras que otras formas de manifestación como la adicción al cibersexo (18.1\%) o sobre todo los clubs de estriptis (9.4\%) y el sexo telefónico (7.9\%) serían mucho menos frecuentes. A partir de estos resultados, los autores sugieren la existencia de dos manifestaciones diferenciales: una de ellas implicaría conductas autoeróticas masturbación compulsiva y adicción a la pornografía- y sería el tipo más frecuente, mientras que el otro eje se referiría a conductas heteroeróticas (sexo con múltiples parejas sexuales) y sería mucho menos frecuente, presumiblemente por la dificultad añadida de encontrar parejas con las que mantener contactos sexuales. El resto de manifestaciones serían anecdóticas y no se suelen dar independientes de las ya comentadas.

La propuesta de clasificación de Cantor et al. (2013), aparte de ser la más reciente, es sin duda la que más difiere de todas las comentadas hasta el momento. Para empezar, pone en tela de juicio un principio común a todas las clasificaciones anteriores: el de que a pesar de que las manifestaciones de la CS puedan ser muy distintas, la causa que subyace a todas ellas es la misma. Según Cantor et al. (2013), este puede ser uno de los principales escollos que han impedido hasta el momento determinar la entidad nosológica de la CS así como diseñar tratamientos que adaptados a cada caso, puedan alcanzar altos niveles de eficacia terapéutica.

Otro punto de inflexión con respecto a clasificaciones anteriores es su objetivo: para ellos, establecer un diagnóstico preciso no es sólo una cuestión formal, sino que de ello depende la planificación de los tratamientos a aplicar. Del mismo modo que no creen que todas las manifestaciones de la CS tengan una causa común, tampoco piensan que los tratamientos sean aplicables indistintamente del perfil concreto del cuadro clínico. De modo que proponen personalizar los tratamientos para maximizar su eficacia y sobre todo, para abordar las idiosincrasias propias de las distintas manifestaciones de la CS. Partiendo de estas premisas y de su experiencia en el tratamiento de pacientes compulsivos sexuales en una unidad de salud sexual de un hospital de Canadá, estos autores proponen 6 categorías. 2 de ellas - 
masturbadores compulsivos y adúlteros crónicos- idénticas a las comentadas en clasificaciones anteriores, por lo que expondremos únicamente las 4 restantes:

1. Compulsivos sexuales parafílicos: lo central en estos casos no es el objeto de la atracción per se, sino la incapacidad para discriminar estímulos sexuales de los que no lo son. Este cuadro clínico difiere mucho del de una parafilia al uso: en este perfil de compulsivos sexuales se habla de intereses o tendencias parafílicas, no de parafilias per se-si fuera así, el diagnóstico apropiado sería el de una parafilia-. Mientras que los parafílicos puros muestran intereses sexuales muy concretos -púberes en el caso de los hebefílicos, el sometimiento y la humillación de la pareja en el de los sádicos, etc.- que muy raramente se solapan con otras parafilias, en el caso de los compulsivos sexuales parafílicos no hay un único interés restringido; a este perfil de pacientes les puede excitar desde jugar con la orina y las heces hasta la actividad sexual con animales. Parece que en estos casos las tendencias parafílicas no son primarias, sino secundarias a una incontrolable erotofilia. Entre este perfil de pacientes resulta frecuente la atracción sexual hacia personas con apariencia femenina pero con genitales masculinos, de modo que es relativamente habitual que recurran a la contratación de trabajadoras sexuales que cumplan estas características.

2. Sexualmente culpables: si bien este tipo de pacientes no constituyen un verdadero perfil de CS, son los que más frecuentemente solicitan evaluación en relación al control de los impulsos sexuales. De ahí su inclusión en esta clasificación. La conducta sexual de este tipo de personas, lejos de resultar excesiva o incontrolada, suele resultar totalmente normal en términos de frecuencia o tipo, pudiendo considerarse en algunos casos incluso escasa. Sin embargo, su visión extremadamente conservadora y moralista del sexo les lleva a valorar la posibilidad de padecer un problema sexual. Son personas que se creen incapaces de controlar sus impulsos sexuales por el mero hecho de masturbarse (aunque lo hagan siquiera una vez por semana) o porque en una ocasión fueron infieles a sus parejas. En estos casos, lejos de aplicar ningún tipo de tratamiento para el control de los impulsos sexuales, se deben establecer nociones básicas de educación sexual para, posteriormente, modificar los sistemas de creencias que les llevan a valorar su conducta sexual como disfuncional.

3. El paciente señalado: perfil que los autores incluyen por la frecuencia con la que aparecen en las consultas especializadas en atención sexual, no por ser una verdadera manifestación de la compulsividad sexual. De hecho, la conducta sexual de este tipo de pacientes resulta equiparable a la media y tras una evaluación exhaustiva, no se suele 
encontrar disfunción o patología alguna. Son, como en la categoría anterior, víctimas de una visión moralista e intolerante del sexo. La situación en este caso es todavía más grave que en el anterior: mientras que en el perfil de pacientes sexualmente culpables era el propio paciente el que se juzgaba enfermo, en este perfil es una persona significativa de su entorno (pareja, progenitores, amigos, asesor espiritual, etc.) y en algunos casos incluso personal sanitario no especializado el que le insta a la búsqueda de ayuda para controlar sus impulsos sexuales. Según los autores, este tipo de pacientes acaba reconociendo que su conducta sexual se aleja de la norma, lo cual les produce importantes sentimientos de culpa. En estos casos, aparte de las intervenciones aplicables a la categoría anterior de pacientes, se recomienda la intervención sobre el entorno que induce a la búsqueda de tratamiento.

4. Hipersexuales secundarios: pacientes que muestran rasgos típicos de compulsividad sexual que pueden entenderse en el contexto de otra enfermedad mental (principalmente manía, hipomanía y trastorno límite de la personalidad) o de una enfermedad física (como ciertos trastornos neurodegenerativos o endocrinos). No es que las clasificaciones anteriores no contemplen este perfil de pacientes, sino que en lugar de equipararlo al resto de manifestaciones de la CS como hace este modelo, lo contemplan como diagnóstico diferencial -la presencia de cualquier otra enfermedad mental o condición médica que explique los síntomas de la CS impide que se pueda realizar dicho diagnóstico-.

Esta clasificación cuenta también con un estudio empírico realizado para evaluar la bondad de estas categorías a la hora de reflejar las distintas manifestaciones de la CS. El estudio, realizado por Sutton et al. (2014), no sigue una metodología evaluativa directa: los datos se extrajeron de las historias clínicas de los pacientes que acudieron a un centro canadiense especializado en el tratamiento de trastornos sexuales. Mediante esta metodología, se recogieron datos de 115 hombres atendidos por problemas en el control de los impulsos sexuales por un periodo de tres años (entre 2009 y 2011). Para asegurar la representatividad de la muestra, se excluyó a los pacientes que acabaron recibiendo el diagnóstico de una parafilia. De todos los subtipos, el más frecuente fue el de hipersexuales parafílicos (28\%). Estos pacientes informaban una media de 3.49 intereses parafílicos (principalmente sadismo, masoquismo sexual y pedofilia) y mayor probabilidad de tener antecedentes de conducta criminal y abuso de sustancias. El $23.4 \%$ se clasificaba como masturbadores compulsivos, grupo que además solía experimentar más problemas de ansiedad y trastornos sexuales comórbidos (el más habitual la eyaculación retardada). El tercer grupo en frecuencia era el de los adúlteros crónicos (13\%). El 
solapamiento entre estas tres categorías era considerable, mientras que la prevalencia para la tres restantes era baja pero significativa: $10.4 \%$ clasificados como pacientes señalados, $9.5 \%$ como hipersexuales secundarios y $4.3 \%$ como sexualmente culpables. La evaluación del grupo de pacientes señalados y de pacientes sexualmente culpables confirmó que no padecían patología alguna ni en el control de los impulsos sexuales ni en su conducta sexual en general, y que el único problema era atribuible a un sistema de valores que afectaba negativamente sobre su visión del sexo y la salud sexual.

6.4 Análisis de las propuestas de clasificación: ventajas, limitaciones y nuevos desarrollos La utilidad del uso de sistemas de clasificación, taxonomías, especificadores o subtipos en la descripción de cualquier patología mental queda fuera de toda duda: como señalan Maser et al. (2009), permiten entre otras cosas "aumentar la especificidad diagnóstica, crear subgrupos homogéneos de pacientes con similares características, evaluar la gravedad de un cuadro clínico determinado, orientar en la elección del tratamiento a aplicar y aumentar la precisión de los pronósticos clínicos" (Maser et al., 2009, p. 30). La tendencia de los sistemas de clasificación actuales es la de generar una gran cantidad de especificadores y subtipos como medio para reflejar el carácter dimensional y heterogéneo de la gran mayoría de trastornos mentales (Regier, Kuhl, \& Kupfer, 2013). Desde el ámbito clínico se ha agradecido este esfuerzo que permite establecer diagnósticos que reflejan con mayor precisión la problemática de cada paciente y facilita la selección de tratamientos adaptados a las idiosincrasias de cada caso (Dailey, Gill, Karl, \& Barrio-Minton, 2014).

Sin embargo, mayor especificidad no es siempre sinónimo de mayor precisión diagnóstica o utilidad clínica, y esta es una crítica cada vez más generalizada (G. M. Reed, 2010). La tendencia a la sobreespecificación es uno de los principales factores asociados a la comisión de errores durante el proceso diagnóstico: no en vano, cuanta más información deba un clínico retener para un diagnóstico correcto -criterios diagnósticos, manifestaciones clínicas, etc.-, mayor es la probabilidad de que omita detalles que conduzcan un diagnóstico erróneo (Andrews, Anderson, Slade, \& Sunderland, 2008).

Encontrar el punto medio entre sobreespecificación y sobregeneralización es una cuestión todavía pendiente en cuanto a la clasificación de las distintas manifestaciones de la CS. Si tomamos de forma independiente las tres últimas clasificaciones comentadas -las que tienen vigencia en la actualidad-, las tres presentan importantes carencias que las hacen poco apropiadas para su uso en ámbitos clínicos o de investigación. El solapamiento entre categorías es tan alto que es raro que a un mismo paciente no se le puedan aplicar 2 o 3 
subtipos distintos de CS, menoscabando la utilidad del sistema de clasificación por categorías. Las tres clasificaciones incluyen además algunas manifestaciones de la CS que, al ser analizada su frecuencia, apenas si resulta anecdótica en el contexto actual (fijación compulsiva en una pareja inalcanzable, club de estriptis, etc.). La clasificación de Cantor et al. (2013) incluye como manifestación de CS a pacientes que, sorprendentemente, no cumplen ningún criterio objetivo para su diagnóstico (sexualmente culpables y pacientes señalados), mientras que la clasificación de Kafka (2010) propone dos subtipos -la masturbación compulsiva y la adicción a la pornografía- para un fenómeno que en realidad siempre va aparejado -como si hubiera pacientes que ven pornografía compulsivamente sin masturbarse concurrentemente-.

Quizás la comisión de estos errores se deba a lo que algunos expertos en psicodiagnóstico atribuyen a la sobreespecialización (Watson, 2003; Watson \& Clark, 2006). Los autores que proponen estas clasificaciones lo hacen porque a nivel empírico les permite contrastar teorías y obtener resultados sobre cuestiones concretas -etiología de los trastornos, respuesta a tratamientos sobre todo farmacológicos, etc.- que a nivel clínico solamente complican el proceso diagnóstico y aumentan la probabilidad de error. Esto se puede observar a simple vista cuando integramos las tres clasificaciones para la CS y los datos empíricos encontrados al respecto (figura 4). Como se aprecia en esta figura, hay manifestaciones de la CS presentes en una única clasificación, normalmente las menos frecuentes. Estas categorías muy raras veces aparecen independientes de otras como la masturbación compulsiva o el sexo con múltiples parejas sexuales (Kafka \& Hennen, 1999; Reid, Carpenter, et al., 2012; Sutton et al., 2014), de modo que cabría plantearse si vale la pena incluirlas o por el contrario, resultaría más eficaz agruparlas bajo categorías más amplias y descriptivas.

En el extremo opuesto estaría la masturbación compulsiva. Esta manifestación de la CS estaría presente en las tres clasificaciones y además, es una de las categorías más frecuentes de CS según la mayoría de estudios realizados con muestra clínica. Es una categoría que, como se desprende de distintos estudios de prevalencia, engloba a su vez otras categorías como la adicción a la pornografía o el sexo telefónico (Kafka \& Hennen, 2003; Reid, Carpenter, et al., 2012; Sutton et al., 2014) y que ofrece a nivel descriptivo mayores posibilidades, precisamente porque no entra a valorar el medio por el que se realiza esta conducta (si es fantaseando, mediante pornografía o cualquier otra vía). Finalmente, entre uno y otro extremo tendríamos 4 manifestaciones de la CS. La prevalencia de alguna de ellas, que en algunos casos alcanza hasta en el $84 \%$ de los casos de CS -múltiples parejas sexuales/cruising-, las hace dignas de consideración. Sin embargo, también es cierto que como hemos comentado ya, algunas de 
estas categorías (como la adicción a pornografía) quedan mejor englobadas en otras ya propuestas como la masturbación compulsiva.

Todo esto nos lleva a una conclusión que lejos de ser novedosa, ya se desprendía de la mayoría de estudios de prevalencia de manifestaciones de la CS: la CS se puede expresar a través de conductas autoeróticas (masturbación compulsiva) o heteroeróticas (sexo compulsivo con parejas sexuales) y ni tan siquiera estas dos categorías generales son mutuamente excluyentes, sino que convendría más bien hablar de preferencias - preferencia por actividades autoeróticas o heteroeróticas-. Dos simples categorías pero que permiten recoger con mayor fiabilidad y validez las múltiples expresiones de la CS. Desde esta perspectiva, la pornografía, los club de estriptis o las líneas eróticas no serían más que el medio elegido para facilitar la autoestimulación; la búsqueda de múltiples parejas sexuales, románticas o el sexo compulsivo con la pareja estable sería, por otra parte, el vehículo utilizado para saciar el impulso heteroerótico. Por supuesto, no se niega que las características del que se masturba mediante pornografía puedan ser bien distintas a las del que lo hace llamando a líneas eróticas o que el que es compulsivamente infiel no sea cualitativamente distinto al que necesita realizar el coito con su pareja 5 veces al día pero jamás ha buscado parejas sexuales alternativas; lo que se pretende resaltar es que a nivel de clasificación, estas dos categorías recogen con mayor bondad el cuadro clínico general que cualquiera de las clasificaciones propuestas. De hecho, este modelo de clasificación es uno de los que Reid (2013) aboga por desarrollar en los próximos años en detrimento de los complejos y poco aplicables modelos actuales: "Debemos empezar a considerar subtipos más generales basados en las manifestaciones de la compulsividad sexual, como el sexo solitario frente al sexo con una pareja" (Reid, 2013, p. 9).

Finalmente, alternativas a estos sistemas de clasificación basados en la conducta sexual podrían ser la clasificación a partir de la psicopatología comórbida (p.e., CS con o sin TDAH comórbido, con o sin episodio depresivo, etc.), facetas de personalidad (CS con alta o baja impulsividad, CS con alto o bajo neuroticismo, etc.), respuesta al tratamiento, severidad de las consecuencias, etc.(Reid, 2013). Sin embargo, la evidencia actual está todavía lejos de permitir establecer este tipo de clasificaciones. 


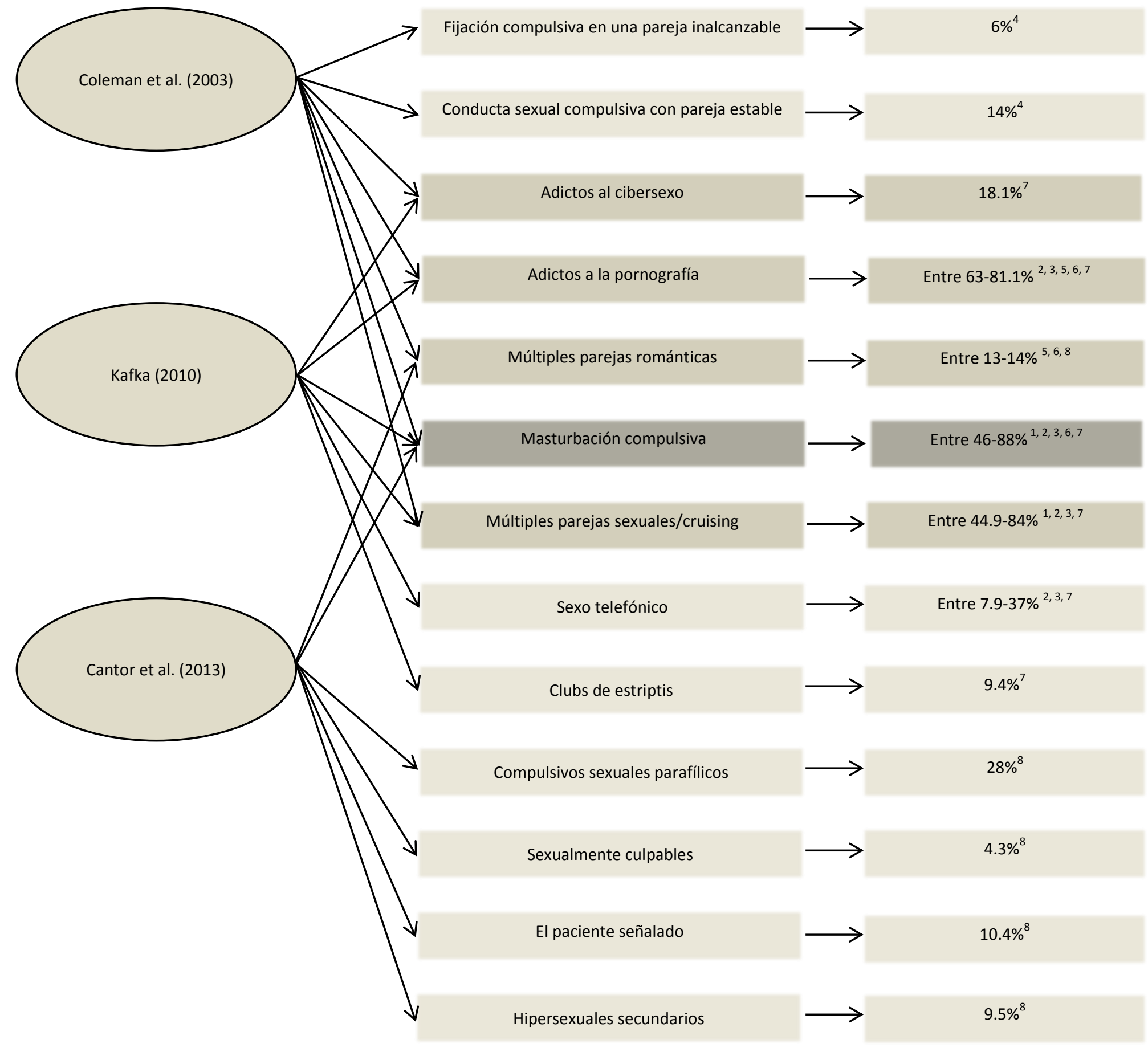

\section{Leyenda:}

Categoría presente en 1 clasificación

Categoría presente en 2 clasificaciones

Categoría presente en 3 clasificaciones

${ }^{1}$ Raymond, Coleman y Miner (2003)

2 Kafka (1997)

${ }^{3}$ Kafka y Hennen (1999)

${ }^{4}$ Black, Kehrberg, Flumerfelt y Schlosser (1997)

${ }^{5}$ Reid (2010)

${ }^{6}$ Reid, Carpenter, Spackman y Wiles (2008)

${ }^{7}$ Reid et al. (2012)

${ }^{8}$ Sutton, Stratton, Pytyck, Nathan y Cantor (2014) 


\section{En resumen}

Uno de los aspectos que complican la evaluación del cuadro clínico de compulsividad sexual es que ésta se realiza en circunstancias adversas. Para empezar, los pacientes sienten vergüenza a la hora de consultar con un profesional su problema y cuando lo hacen, suele ser por algún problema asociado (depresión, ansiedad, coadicciones, etc.). Los casos en los que el motivo de consulta es la propia conducta sexual suelen ser especialmente graves. La razón es que o bien acuden por recomendación/imposición de sus parejas (p.e., al descubrir una infidelidad) o bien como medida para atenuar una sanción legal. De cualquier modo, su motivación hacia la evaluación suele ser más bien limitada.

El primer paso en la evaluación consiste en explorar los principales síntomas del cuadro clínico. A la hora de valorar su presencia, es importante prestar atención al contexto de la evaluación (generar un ambiente cómodo, seguro y confidencial), a los aspectos concretos a evaluar (que incluirán tanto síntomas del cuadro clínico y sus consecuencias como aspectos más generales de la historia y del desarrollo psicosexual) y al tipo de instrumentos empleados con este fin (entrevistas clínicas, autoinformes de síntomas o autoinformes de consecuencias). Una vez hecho esto, se debe descartar el origen orgánico de los síntomas o que se expliquen mejor a partir de otra patología del Eje I o II.

A la hora de contrastar si los síntomas presentes en el cuadro clínico y su gravedad alcanzan suficiente significación como para ser diagnosticado se recomienda emplear los criterios propuestos para el diagnóstico de hipersexualidad del DSM-5. Esta propuesta contempla este trastorno cuando la conducta sexual del paciente cumple al menos 4 de 5 criterios siguientes: excesiva dedicación de tiempo y esfuerzo al comportamiento sexual, actividad sexual en respuesta a situaciones de estrés, en respuesta a situaciones de malestar emocional, intentos fallidos por controlar su manifestación y persistencia a pesar de su impacto en diversos ámbitos. Además, los síntomas deben provocar malestar o deterioro en el funcionamiento en diversas áreas, no se deben explicar mejor por el efecto de una sustancia, la presencia de una enfermedad médica o de otro trastorno mental y sólo si el paciente tiene 18 años o más. Las manifestaciones más frecuentes de CS son la masturbación compulsiva, la adicción a la pornografía y en menor medida, el sexo con múltiples parejas y la adicción al cibersexo.

En cuanto a las características del cuadro clínico de CS, las estimaciones más fiables sitúan su prevalencia en torno al 3-6\%. Este trastorno sería más prevalente en hombres que en mujeres, en personas con una orientación sexual alternativa a la heterosexual y en pacientes con otro tipo de problemas mentales. Así, su comorbilidad con otros diagnósticos del Eje I y II sería alta, 
especialmente con trastornos del estado del ánimo (distimia o el episodio depresivo mayor), de ansiedad (FS, AG y TEPT), de la personalidad y sobre todo con el abuso de sustancias (más concretamente el abuso y la dependencia del alcohol). Para terminar, en los casos más graves este trastorno aumenta la probabilidad de sufrir problemas médicos (contraer una ITS o sufrir un embarazo no deseado), psicológicos (depresión, baja autoestima, etc.), sociales (problemas de pareja o familiares), espirituales (crisis de fe, culpabilidad...), legales y económicos. 


\section{Capítulo 3. Hacia una etiología de la compulsividad sexual}

1. Introducción

2. Determinantes biológicos de la CS

2.1 Factores neurobiológicos

2.2 Factores hormonales

2.3 Evidencias farmacológicas

3. Determinantes psicológicos de la CS

3.1 Abuso sexual infantil

3.2 Negligencia en el cuidado infantil

3.3 Estilos de apego y vinculación afectiva

4. Determinantes sociales de la CS

4.1 Entorno social y cultural como facilitador de la emergencia de la CS

4.2 Creencias religiosas

5. Modelos teóricos acerca de la entidad nosológica de la CS

5.1 Adicción al sexo

5.2 Control de los impulsos: conducta sexual compulsiva vs. impulsiva

5.3 Regulación del deseo sexual: hipersexualidad y modelo de control dual

6. En resumen 


\section{Introducción}

Desde que en 1977 Engel publicara "The Need for a New Medical Model: A Challenge for Biomedicine" (Engel, 1977), el modelo biopsicosocial ha demostrado ser el marco teórico más eficaz para el análisis de la etiología de cualquier patología -física o mental-, así como de los factores que explican su mantenimiento y en muchos casos, su gravedad. Según este modelo, la presencia de cualquier proceso patológico se explicaría a partir de la interacción entre tres tipos de factores: biológicos, psicológicos y sociales. Los determinantes biológicos se centran en el impacto de factores de origen orgánico (factores anatómicos, estructurales, genéticos y moleculares) sobre el funcionamiento biológico del individuo; los determinantes psicológicos enfatizan el papel de aspectos como el desarrollo, la motivación o la personalidad sobre la génesis de la patología, además de resultar especialmente útiles a la hora de entender por qué cada persona vive y se enfrenta a su enfermedad de forma diferente; finalmente, los determinantes sociales explican la contribución de otros factores más distales como el entorno familiar, cultural, espiritual, social o ambiental en este proceso (W. Campbell \& Rohrbaugh, 2006; Engel, 1977).

El modelo biopsicosocial se ha aplicado con éxito en el análisis de múltiples patologías (para una revisión, Suls \& Rothman, 2004). Samenow (2010) ha sido el primero en aplicarlo en el ámbito de la CS. Según este autor, el análisis de su etiología a partir de este modelo ofrece ciertas ventajas con respecto a propuestas anteriores:

1) Al ser un modelo ecléctico (acepta evidencias de cualquier corriente de pensamiento siempre y cuando demuestren su fundamentación), permite integrar las aportaciones de distintas teorías que en la actualidad, pugnan por convertirse en paradigma científico.

2) Da a entender que la CS merece la misma consideración que cualquier otra enfermedad física o mental.

3) Permite mejorar la atención clínica a los pacientes abordando de forma unificada los diversos factores asociados a su presencia y gravedad.

Hasta el momento, el interés por explorar la etiología de la CS ha sido limitado (Reid, 2013). Como Bancroft (2009) señala, "la literatura sobre compulsividad sexual y adicción sexual se ha preocupado por cuestiones como su definición o correlatos y ha prestado muy poca atención a las explicaciones causales de porqué, en algunos casos, la conducta sexual sobreviene problemática" (Bancroft, 2009, p. 330). Además, los pocos intentos por conocer los factores que explican el inicio de la CS se han realizado desde una metodología poco rigurosa: en lugar de a través de estudios empíricos controlados, muchos de los factores que hoy consideramos 
asociados a la CS provienen de impresiones clínicas conformadas durante el tratamiento de este tipo de pacientes (Gold \& Heffner, 1998). En cualquier caso, las evidencias disponibles no permiten establecer bajo ningún concepto una relación causal entre un factor o conjunto de factores y el cuadro clínico de la CS (Kafka, 2010; Kaplan \& Krueger, 2010; McBride et al., 2011; Rosenberg et al., 2014) y tampoco es de esperar que esto suceda a corto-medio plazo (Reid, 2013; Samenow, 2013).

Como hizo Samenow (2010) y más tarde Hall $(2011,2013)$, a continuación se enumeran los factores biológicos, psicológicos y sociales que se han relacionado con el inicio, mantenimiento o gravedad de la CS. Muchas de las evidencias que revisaremos no provienen del estudio directo de la CS, sino que son generalizaciones de hallazgos obtenidos durante el estudio de otros trastornos íntimamente relacionados (p.e., parafilias, juego patológico, etc.). En ese caso, se deben mantener ciertas reservas en tanto en cuanto sólo podemos presumir -en ningún caso afirmar- que los resultados sean generalizables a la CS.

\section{Determinantes biológicos de la CS}

El grueso de las revisiones sobre etiología de la CS se han centrado precisamente en examinar exhaustivamente cómo ciertos mecanismos biológicos podrían explicar el inicio de este cuadro clínico (Kafka, 2010; Kaplan \& Krueger, 2010; Mick \& Hollander, 2006). Para Hall (2011), esta sería la mejor prueba de que persiste una visión médica y farmacológica de la conducta sexual anormal y de que "seguimos cayendo en la trampa del reduccionismo biológico" (Hall, 2011, p. 219), menoscabando la importancia de otros factores -sobre todo psicológicos- que sí habrían demostrado una vinculación sólida y directa con la CS. En el extremo contrario, Samenow (2010) defiende que "examinar los determinantes biológicos es crítico para que clínicos, pacientes y políticos asuman la necesidad del abordaje de esta problemática desde una perspectiva patológica" y que "centrar nuestra atención en la biología no supone menospreciar otras escuelas de pensamiento, sino legitimar el estudio de este fenómeno" (Samenow, 2010, p. 70). Sea como sea, es un hecho que nuestra conducta viene determinada en gran medida por mecanismos biológicos subyacentes y que a su vez, las experiencias y vivencias de la vida diaria dejan una impronta en esos mismos mecanismos (Bancroft, 2005); por tanto, sólo desde el abordaje integral de los distintos sistemas alcanzaremos una plena comprensión de los determinantes de la CS.

Tradicionalmente, en el análisis de los determinantes biológicos que contribuyen al inicio de la patología -tanto física como mental- se suelen revisar aspectos moleculares (que incluirían sistemas de neurotransmisión, estructuras neurológicas, regulación hormonal, etc.), genéticos 
(evidencias en torno a la heredabilidad de la patología), físicos (cualquier condición médica o fisiológica que contribuya al inicio o mantenimiento del estado patológico) y farmacológicos (hallazgos provenientes del estudio de los efectos de ciertos fármacos sobre el control de la patología) (W. Campbell \& Rohrbaugh, 2006; Engel, 1977; Suls \& Rothman, 2004). Sin embargo, todavía no contamos con evidencias suficientes como para establecer un nivel de análisis tan exhaustivo en el campo de la CS; de ahí que optemos por una estructura sintética centrada en torno a los tres tipos de evidencias que más fundamento y atención han recibido: 1) factores neurobiológicos asociados a la CS, 2) factores hormonales reguladores del deseo sexual y 3 ) evidencias provenientes de la farmacología de la CS.

\subsection{Factores neurobiológicos}

Las hipótesis actuales en torno al papel de las estructuras cerebrales y de neurotransmisión en el cuadro clínico de la CS provienen sobre todo de la generalización de los hallazgos para otros trastornos adictivos, del análisis de casos de pacientes con daño cerebral -sobre todo daño cerebral adquirido-, de algunos estudios de neuroimagen y de los hallazgos de investigaciones neuropsicológicas (Berlin, 2008). Con todo, se han propuesto 3 modelos -ninguno de ellos mutuamente excluyente- sobre factores neurobiológicos determinantes de la CS: el modelo $A B C$ de control de impulsos, la hipótesis de la neurotransmisión y la hipótesis de la desregulación de la dopamina.

1) El modelo $A B C$ de control de los impulsos es uno de los más prometedores en su aplicación a la CS (D. Stein, 2008), pero todavía no ha sido validado en muestra clínica. De las siglas que dan nombre a este modelo, la A correspondería a la amígdala, la B a la recompensa de la conducta (en su original en inglés, behavioral reward) y la $\mathrm{C}$ al control cognitivo. Según este modelo, lo que llevaría a los pacientes a experimentar esa incapacidad para controlar sus impulsos sexuales sería la suma de un funcionamiento anómalo de la amígdala que provocaría una importante desregulación emocional, la recompensa de la conducta compulsiva a través de estructuras cerebrales como el núcleo accumbens y los circuitos del estriado ventral, y un importante déficit en el control ejecutivo derivado de anomalías en el córtex prefrontal (Samenow, 2010).

Son muchas las evidencias que sustentan este modelo. A nivel clínico, efectivamente los pacientes con esta patología presentan una importante desregulación emocional que les lleva a experimentar excitación sexual ante situaciones de ansiedad o depresión en lugar de una inhibición sexual que sería lo más habitual (Bancroft \& Vukadinovic, 2004), síntoma atribuible a un funcionamiento anómalo de la amígdala. Estos pacientes suelen experimentar un fuerte alivio o una sensación de euforia (similar al "subidón" o high que 
se consigue tras el consumo de ciertas sustancias estupefacientes) durante la realización de la conducta sexual compulsiva (Kor et al., 2013), que correspondería a la liberación de dopamina realizada principalmente en zonas del estriado ventral y núcleo accumbens. Finalmente, la persistencia en la conducta sexual compulsiva a pesar de experimentar consecuencias negativas sería una prueba de los problemas ejecutivos asociados a anomalías en el córtex prefrontal (Kafka, 2010). Algunos estudios de neuroimagen apoyan la intervención de las áreas cerebrales antes mencionadas en la conducta sexual en general y en la CS en concreto. Hamman, Herman y Nolan (2004) demostraron a través de resonancia magnética funcional la hiperactivación de la amígdala durante la exposición a estímulos sexuales -sobre todo en hombres-. Por su parte, Miner, Raymond, Mueller, Lloyd y Lim (2009) encontraron tras comparar a 8 pacientes con CS y 8 pacientes control mediante técnicas de neuroimagen que los primeros mostraban déficits significativos en la difusión de los tejidos de la zona frontal superior (clásicamente asociada al control de las funciones ejecutivas). Finalmente Voon et al. (2014), valiéndose de nuevo de resonancia magnética funcional, demuestran al comparar a 30 pacientes hipersexuales y 30 control que los hipersexuales experimentan mayor activación de tres zonas (estriado ventral, amígdala y cingulado dorsal anterior) al ser expuestos a estímulos eróticos -dos de las tres zonas mencionadas por el modelo ABC-.

2) La hipótesis de la neurotransmisión sería otro de los modelos empleados para explicar la conducta sexual compulsiva (Kafka, 2010; Kaplan \& Krueger, 2010). Este modelo, aplicado tradicionalmente al estudio de las parafilias y validado en modelos animales, explica la CS a partir de la interacción entre neurotransmisores. Según este modelo, el incremento en los niveles de dopamina y el decremento de los de serotonina conformarían el sustrato biológico del apetito y la respuesta sexual desmedida (Kafka, 2010; Meston \& Frolich, 2000). La comorbilidad entre la CS y otros trastornos del Eje I -TDAH, trastorno bipolar, juego patológico, otras adicciones, etc.- donde sí se ha confirmado la intervención de estos neurotransmisores demostraría su importancia en la etiología de la CS. Asimismo, los estudios sobre fármacos que afectan a la transmisión de la serotonina en el control de la CS (que no comentaremos de momento ya que posteriormente dedicamos un epígrafe completo a su revisión) también apoyarían esta hipótesis.

3) La hipótesis de la desregulación de la dopamina es un derivado del modelo anterior donde el énfasis recae sobre ese neurotransmisor concreto (Hall, 2011). La dopamina es el denominador común a todas las adicciones -químicas o conductuales- (Robbins \& Everitt, 2010). Es la responsable de los sistemas de refuerzo y placer reguladores de la conducta y el aprendizaje humanos, así como de ciertos procesos cognitivos (memoria) y de algunos 
sesgos que en ellos pueden producirse (Berke \& Hyman, 2000). Su emisión se estimula de forma endógena (a través de la comida, bebida o actividad sexual) o exógena (mediante el consumo de sustancias). La hipótesis de la dopamina para las adicciones tóxicas defiende que el consumo exógeno continuado de ciertas sustancias aumentaría de forma anormal los niveles de dopamina, provocando la atrofia de los sistemas endógenos de producción. A partir de este momento, la persona necesita regular sus niveles de dopamina a través del consumo exógeno, momento en el que se establece la dependencia. No en vano, se documentan niveles de dopamina hasta 10 veces mayores en el cerebro de pacientes con adicción a la cocaína, la heroína o el LSD (Blum et al., 2000). Desde este modelo, la CS se explicaría a través del mismo principio: la actividad sexual serviría como estimulante endógeno de la liberación de dopamina que aumentaría notablemente los niveles basales de esta sustancia; una vez el cerebro se hubiera acostumbrado a estos niveles, el sexo perdería su función recreativa para convertirse en una verdadera dependencia a través de la cual se regularían los niveles de dopamina (Hall, 2011).

\subsection{Factores hormonales}

La influencia de las hormonas sexuales comienza mucho antes del propio nacimiento, concretamente durante las primeras semanas de gestación (Bancroft, 2005). Durante este periodo, cuando se inicia el proceso de dimorfismo sexual -fase del desarrollo en el que se conforma el sexo gonadal (Money \& Ehrhardt, 1986)-, una estricta cadena de eventos atribuibles exclusivamente a factores genéticos y hormonales determina los tres únicos resultados posibles: nacer hombre, nacer mujer o nacer con rasgos que impiden la identificación en alguna de estas categorías -como en el caso de la intersexualidad (Cespedes, Chahin, \& Coll, 2009)-. Tras el nacimiento, las hormonas sexuales (sobre todo estrógenos y testosterona) continúan determinando el desarrollo anatómico sexual pero durante etapas muy concretas del desarrollo: en la adolescencia se produce la última gran emisión hormonal -responsable del desarrollo de las características sexuales secundarias- tras la cual, los niveles se mantienen estables hasta su declive en la vejez (MacLaughlin \& Donahoe, 2004).

La estabilización de los niveles hormonales una vez pasada la adolescencia hacía pensar que su influencia sobre el conjunto del comportamiento sexual adulto era limitada o nula. Sin embargo, esta teoría ha ido perdiendo peso a la luz de nuevas evidencias. La entrada de técnicas de análisis cada vez más exhaustivas y precisas ha permitido conocer la importancia de ciertas hormonas sexuales -sobre todo la testosterona, el estradiol y ciertos péptidos- sobre el comportamiento sexual (Bancroft, 2005) y también cómo su efecto en hombres y mujeres resulta bien distinto. 
Los resultados en cuanto a la influencia de la testosterona en la conducta sexual masculina son los más claros. Los estudios de tratamiento hormonal sustitutivo en hombres con anomalías en la producción natural de testosterona han demostrado que niveles bajos de esta hormona influyen negativamente sobre el interés sexual así como sobre la propia respuesta genital: tras 3-5 semanas sin administración exógena de testosterona, los pacientes hipogonadales experimentan una reducción significativa del interés sexual tanto solitario como en pareja (Anderson et al., 1999) y si bien mantienen la capacidad eréctil, éstas perderían intensidad (rigidez) y duración (Carini, Granata, Bancroft, \& Marrama, 1995). Finalmente, experimentan una merma completa de las erecciones nocturnas propias de la fase REM del sueño (entre 4 y 6 por noche en hombres normales) (Parmeggiana \& Morrison, 1990). Un estudio realizado entre adolescentes sanos demostró que los niveles de testosterona libre en sangre predecían el nivel de interés sexual mejor que otros aspectos como la edad o el nivel de desarrollo (C. T. Halpern, Udry, Campbell, \& Suchindran, 1993) mientras que en hombres de entre 45 y 74 años, el decremento natural de testosterona se asocia con un menor deseo sexual (Schiavi, Schreiner-Engel, Mandeh, Schanzer, \& Cohen, 1990).

La influencia de la testosterona en la conducta sexual femenina resulta más compleja, presumiblemente porque los incesantes cambios hormonales asociados al ciclo menstrual, al embarazo, la lactancia o el climaterio hacen más difícil su abordaje empírico (Bancroft, 2005). En la mujer, el momento de mayor presencia de andrógenos es durante la pubertad (hasta el doble de los niveles habituales) y es en ese preciso momento donde el vínculo entre testosterona y conducta sexual es más claro. En un estudio entre mujeres de 13 a 15 años, Udry, Talbert y Morris (1986) encontraron una asociación directa entre niveles hormonales, deseo sexual y frecuencia de masturbación, si bien la asociación ya no resultaba significativa cuando se incluían en la muestra a chicas post-menarquía. Dentro de un mismo ciclo menstrual, los niveles de testosterona aumentan durante la fase folicular y declinan durante el final del periodo ovulatorio. En coherencia con esta perspectiva, muchas mujeres experimentan un mayor deseo sexual durante la fase folicular de la menstruación (cuando los niveles de testosterona son mayores), si bien este deseo suele decrecer antes de que lo haga el nivel de testosterona (Hedricks, 1994). El uso de anticonceptivos orales aporta también evidencias al respecto. Se ha documentado que ciertas combinaciones de anticonceptivos orales producen una merma en los niveles de testosterona libre en sangre. En mujeres con este tipo de tratamiento, Sanders, Graham, Bass y Bancroft (2001) encontraron que la principal causa de falta de adherencia era precisamente la percepción de una disminución del deseo sexual. Otra condición femenina donde se experimenta una reducción de los niveles de 
testosterona sería la lactancia: al comparar a mujeres que 6 meses después del embarazo alimentaban a sus hijos con biberón frente a mujeres que seguían con lactancia natural, las que mantenían lactancia natural experimentaban un menor deseo y frecuencia sexual (Hyde \& DeLamater, 2000). Además, el nivel de deseo entre las madres lactantes era proporcional a los niveles de testosterona en sangre (las lactantes que tenían niveles mayores de testosterona experimentaban una reducción del deseo sexual más discreta). Estas son algunas de las evidencias que apoyan el vínculo entre testosterona y sexualidad en la mujer, pero muchos otros estudios han fallado replicando estos hallazgos. En cualquier caso, en la sexualidad femenina más que en la masculina intervienen muchos otros factores más allá de la mera carga hormonal (motivación, estado de ánimo, energía y bienestar, etc.) que podrían estar jugando un papel importante a la hora de interpretar estos hallazgos (Bancroft, 2005).

El efecto del estradiol en la conducta sexual masculina resulta mucho más discreto; además dependería de su interacción con la testosterona (gran parte del estradiol se genera a partir del proceso de aromatización de la testosterona), por lo que no se puede establecer un vínculo directo entre estradiol y conducta sexual sin tener en cuenta su influencia sobre los niveles de testosterona (Lindzey \& Korach, 2003). En este caso, parece que mayor saturación de estradiol en sangre se relacionaría con un decremento en la cantidad y calidad de la actividad sexual. En el único estudio realizado en humanos -el resto se han realizado con modelos animales-, Bancroft, Tennent, Loucas y Cass (1974) exploraron el efecto de la administración exógena de etinil estradiol en 12 agresores sexuales en régimen de internamiento por delitos contra la libertad sexual encontrando que la aplicación del preparado provoca una reducción significativa del interés sexual, la frecuencia de masturbación y la respuesta de erección ante estímulos sexuales. De hecho, el estado fisiológico que resulta de la administración de estradiol es muy similar al que se podría encontrar entre pacientes hipogonádicos sin tratamiento. Sin embargo, la metodología fue duramente criticada y en la actualidad, no se utilizan ese tipo de preparados para el control farmacológico de estos pacientes.

La investigación en torno al papel del estradiol en la conducta sexual femenina ha dejado un hallazgo muy claro y es que el estradiol tiene un efecto fisiológico directo y negativo sobre la respuesta femenina de lubricación vaginal (Bancroft, 2005). En tanto en cuanto la lubricación es un elemento fundamental para el disfrute femenino de la sexualidad en pareja, el estradiol jugará un papel importante sobre el comportamiento sexual. Lo que ya no resulta tan claro es si aparte de su efecto a través de la lubricación, el estradiol se relaciona de alguna forma con el interés sexual en mujeres. En un estudio con 49 mujeres con menopausia inducida por cirugía, la administración de estradiol mejoró el interés sexual, el placer durante las relaciones 
sexuales, la frecuencia de orgasmos y el estado de ánimo en general (Dennerstein, Burrows, Wood, \& Hyman, 1980). Estudios posteriores matizan estos resultados y sugieren que el efecto depende de la dosis administrada: dosis moderadas pueden ser beneficiosas pero superado un umbral, el efecto sería el contrario (Sherwin, 1991).

Las últimas hormonas que la evidencia señala como relacionadas con la regulación de la conducta sexual son los péptidos: concretamente la oxitocina, $\beta$-Endorfinas y la prolactina (Bancroft, 2005). Los péptidos son sustancias que dependiendo de la zona, pueden actuar como cualquiera de las hormonas sexuales hasta ahora comentadas o bien como neurotransmisores. La oxitocina, hormona que multiplica su presencia durante el parto para facilitar las contracciones uterinas necesarias durante el alumbramiento, puede tener también un efecto sobre la conducta sexual humana. Los estudios demuestran que los niveles de oxitocina en hombres y mujeres entre 2-5 minutos después del orgasmo son mucho mayores que en estado de reposo (Krueger et al., 2003). Este incremento ha hecho que algunos investigadores la bauticen como la hormona de la saciación sexual (Caldwell, 2002), una hormona cuya presencia alerta al cuerpo de que ya se ha alcanzado la satisfacción sexual a través del orgasmo, reduciendo considerablemente la libido y la probabilidad de iniciar un nuevo coito. El efecto por su parte de las $\boldsymbol{\beta}$-Endorfinas parece ser al mismo tiempo inhibidor y activador. Dependiendo de la dosis, la administración exógena de un agonista de las $\beta$ Endorfinas puede estimular la actividad sexual de hombres y mujeres, mientras que dosis mayores inhiben tanto el deseo como la propia capacidad para mantener relaciones sexuales (Bancroft, 2005). La prolactina, asociada clásicamente a la lactancia materna, es la última hormona sexual que parece asociada a la conducta sexual motivada. Como la oxitocina, la prolactina se dispara tanto en hombres como en mujeres una vez alcanzado el orgasmo (Krueger et al., 2003), por lo que nuevamente parece desempeñar un papel importante en la reducción del apetito sexual post-orgásmico. Esta postura es coherente con algunos estudios que señalan una presencia mayor de prolactina en hombres y mujeres con bajo deseo sexual, así como en hombres con disfunción eréctil (Franks \& Jacobs, 1983).

Estas evidencias en torno al papel de las hormonas en la regulación de la conducta sexual sobre todo en cuanto a la capacidad de algunas de ellas para aumentar o disminuir el apetito sexual- ha llevado a los especialistas en CS a proponer que la regulación hormonal puede estar desempeñando un papel importante en el inicio y mantenimiento de la conducta sexual compulsiva (Hall, 2011). Desde la perspectiva etiológica, Samenow (2010) propone que la regulación hormonal puede tener tanto o más peso a la hora de explicar la conducta sexual compulsiva como la regulación de la neurotransmisión cerebral. Codispoti (2008) va un paso 
más allá y propone, desde el punto de vista terapéutico, el uso de antagonistas de la testosterona para el control de los impulsos sexuales en pacientes con CS -tal y como se hace en el tratamiento de las parafilias-. En una revisión de los últimos tratamientos disponibles, Rosenberg et al. (2014) también proponen la posibilidad de utilizar una combinación de ansiolíticos junto con antiandrógenos en el tratamiento de la CS habida cuenta de la capacidad de estos últimos para afectar negativamente sobre todas las fases de la respuesta sexual tanto masculina como femenina, si bien su uso quedaría restringido a casos donde el tratamiento psicológico no resulte efectivo. En cualquier caso, antes de la generalización del uso de antiandrógenos en el tratamiento de esta problemática o bien de señalar sin lugar a dudas que las hormonas sexuales pueden ser un factor etiológico más en la CS, hacen falta estudios empíricos que aborden directamente el vínculo entre ambas condiciones; como señala Reid (2013), esta es una de las líneas de investigación prioritarias para los próximos años, si bien de momento debemos mantener ciertas reservas hasta la publicación de sus resultados.

\subsection{Evidencias farmacológicas}

Las evidencias farmacológicas no tienen per se capacidad explicativa alguna en la etiología de la CS. Sin embargo, la eficacia de estos tratamientos permite fundamentar las hipótesis que se han planteado previamente. Concretamente, el tipo de fármacos que habitualmente se han utilizado para el control de los síntomas de la CS y que han demostrado su eficacia a través de distintos tipos de estudios - principalmente estudios de caso único pero algunos también con muestras grandes y una metodología más rigurosa- son los antiandrógenos, los inhibidores de la recaptación de la serotonina (SRI) y los antagonistas de la dopamina (Kafka, 2007).

El tratamiento de los síntomas de la CS a través de antiandrógenos es uno de los que se ha sometido a un estudio más exhaustivo y que ha logrado mejores resultados terapéuticos. Rosler y Witzlum (1998) fueron los primeros en someter a evaluación la aplicabilidad de este tipo de tratamientos en CS. En su estudio participaron 30 pacientes. Algunos de ellos fueron diagnosticados con una parafilia y otros con CS, pero todos tenían en común un "deseo sexual incontrolable" (Rosler \& Wiztum, 1998, p. 416). Todos los participantes fueron sometidos a un tratamiento de entre 8 y 42 meses a base de triptolerín, un fármaco que se había utilizado como tratamiento para el cáncer de próstata y que había demostrado ser un inhibidor eficaz de la secreción de andrógenos. El estudio no contaba con grupo control de comparación, pero todos los pacientes mostraron una reducción significativa de la frecuencia de fantasías y de deseo sexual, siendo los resultados evidentes a partir de los 3 meses de tratamiento. En 2009, los autores presentaron resultados similares pero con una muestra mayor (100 pacientes) (Rosler \& Wiztum, 2009). 
El estudio de Safarinejad (2009) utilizando también triptolerín es considerado uno de los más fiables en lo que a tratamiento farmacológico de la CS se refiere. Este investigador tomó a una muestra de 76 hombres iraníes diagnosticados exclusivamente de CS y los sometió a tratamiento durante un periodo de tiempo indefinido, evaluando su efecto sobre la frecuencia de actividad sexual. Después de 6 meses de tratamiento, la frecuencia sexual se había reducido significativamente y sus efectos se mantuvieron en evaluaciones posteriores a los 12 y 24 meses. Eso sí, los pacientes refirieron toda una variedad de efectos secundarios: fiebres, pérdida del vello facial y corporal, dolor en las zonas de administración de la medicación y lo que les supuso mayor interferencia, una total incapacidad para mantener la erección.

Estos estudios demuestran que efectivamente, las hormonas (en especial los andrógenos) desempeñan un papel crucial sobre la génesis y el mantenimiento de la CS. El problema de su uso como agentes terapéuticos es que su acción es inespecífica y acaba afectando al conjunto de la respuesta sexual, imposibilitando que estos pacientes puedan mantener una vida sexual normal. Asimismo, todos estos estudios se realizaron con hombres, por lo que desconocemos si la teoría de la acción de los andrógenos sobre la CS también se cumple en mujeres.

De los inhibidores de la recaptación de la serotonina (IRS), el más utilizado en el tratamiento de la CS es sin duda el citalopram. Su aplicación con esta finalidad fue testada por Wainberg et al. (2006) entre 28 hombres homosexuales sexualmente muy activos y que mantenían con frecuencia conductas sexuales de riesgo. La eficacia del tratamiento con citalopram (12 semanas con dosis diarias de entre $20-60 \mathrm{mg}$ ) se comparó con la de un tratamiento placebo. En ambos grupos se constató un descenso significativo en la frecuencia de conductas sexuales de riesgo así como en medidas específicas de CS (escala Yale-Brown de compulsividad sexual). Sin embargo, la única diferencia que se mantuvo en la comparación entre grupos fue el descenso en la percepción de deseo sexual (mayor en el grupo de tratamiento con citalopram). Aunque los hallazgos pueden ser discretos, parece que las teorías neurobiológicas que consideraban la serotonina como un elemento central en el desarrollo de la CS (a saber, la hipótesis de la neurotransmisión) encontrarían cierto apoyo en estos hallazgos.

Si bien las teorías neurobiológicas apuntan a la dopamina como uno de los neurotransmisores más relevantes en la manifestación de la CS, apenas hay estudios que avalen la aplicación de fármacos antagonistas de la dopamina para el control de los síntomas de esta patología. Esto puede deberse a que su acción farmacocinética resulta más compleja de gestionar o bien a que su efecto es más discreto. Kafka (2007), reconocido experto en el tratamiento farmacológico de la CS, afirma: "yo suelo prescribir estas medicaciones [antagonistas de la dopamina] sólo si los inhibidores de la recaptación de la serotonina han logrado reducir de forma efectiva la 
activación sexual o bien si por el contrario, su acción ha resultado totalmente ineficaz" (Kafka, 2007, p. 469). En esta línea, el único estudio donde se incluyó tratamiento farmacológico con este tipo de medicación (concretamente metilfenidato) reveló que su utilización puede ser útil en la reducción del apetito sexual en personas con CS pero sólo si se aplica como coadyuvante a un tratamiento a base de inhibidores de la recaptación de la serotonina (Kafka \& Hennen, 2000). Por tanto, a pesar de ser el neurotransmisor más relevante en la etiología de la CS según las principales teorías orgánicas, la dopamina no se considera herramienta terapéutica en el manejo de pacientes con esta patología.

\section{Determinantes psicológicos de la CS}

Desde el modelo biopsicosocial, entendemos por determinantes psicológicos aquellos factores del desarrollo, personalidad, estado emocional y cognitivo implicados en el inicio o el mantenimiento de la enfermedad (Campbell \& Rohrbaugh, 2006). En el caso de enfermedades físicas o enfermedades mentales graves (esquizofrenia, trastorno bipolar, etc.), estos factores permiten explicar sobre todo cómo las personas viven y se enfrentan a su enfermedad (estilos de afrontamiento, formas de manejo de la enfermedad, adherencia a los tratamientos, etc.). En el caso de enfermedades mentales menos severas, los factores psicológicos explican por sí solos una parte importante del cuadro clínico (Suls \& Rothman, 2004).

Los factores psicológicos asociados a la CS son diversos y van desde el abuso sexual infantil o la educación negligente hasta la exposición temprana a contenidos sexuales. Por supuesto, no todos ellos tienen el mismo peso o importancia sobre la génesis de la CS. Hall (2013) realizó una investigación en la que preguntó a 350 pacientes con CS si uno o más de los factores psicológicos que ella les proponía jugaron un papel importante o no a la hora de entender el origen de su problemática. En la figura 5 se exponen sus resultados:

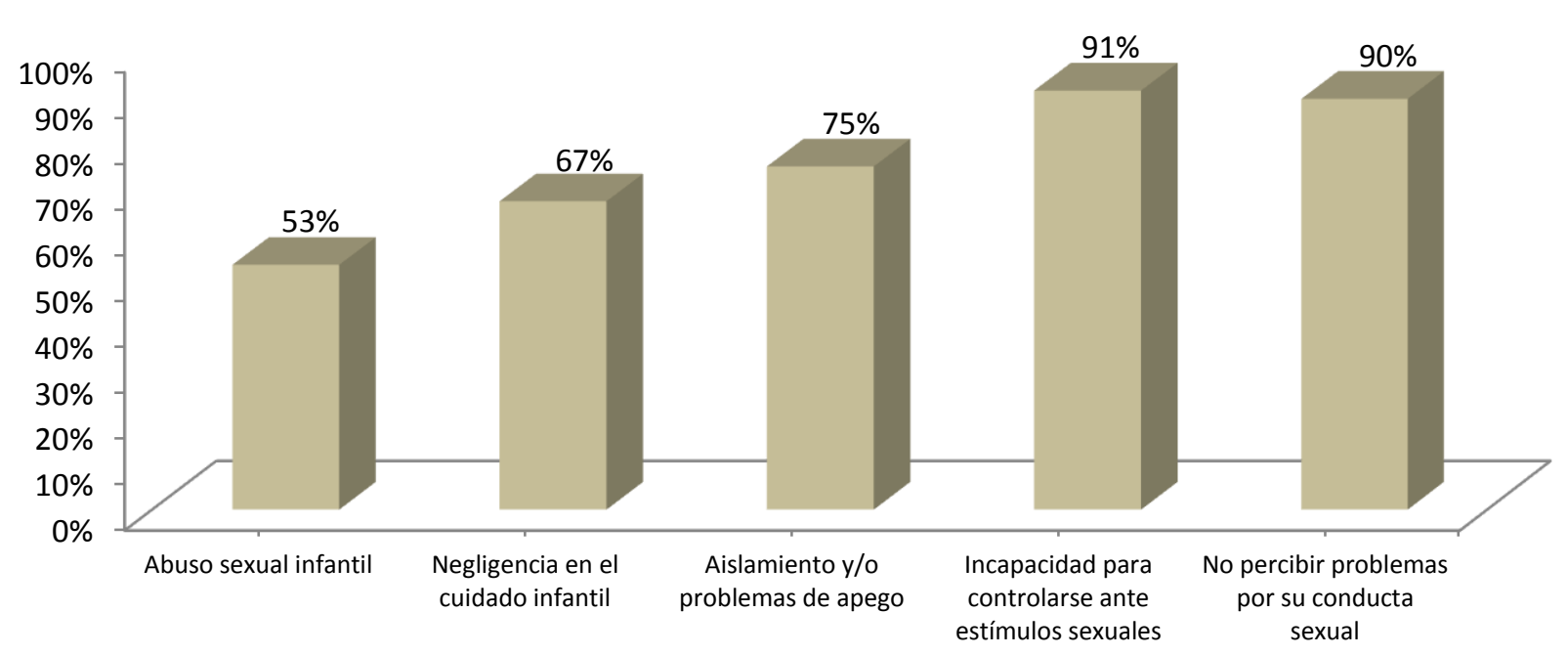

Figura 5. Porcentaje de pacientes que afirmaron haberse visto afectos por distintas condiciones (adaptado de Hall, 2013). 
Como se aprecia en la figura 5, en casi todos los casos uno o más de los factores psicológicos explorados desempeñaban un papel importante en la génesis del cuadro clínico -por lo menos así era como los pacientes lo percibían-. El factor que indicaron con menos frecuencia (pero como veremos a continuación, uno de los más sólidamente vinculados a la CS) fue el haber sufrido abuso sexual, seguido por la negligencia familiar en el cuidado infantil y los problemas de apego -tanto infantil como adulto-. Ninguno de estos factores debe interpretarse en términos absolutos: es cierto que el abuso sexual, la negligencia o los problemas de apego son comunes entre pacientes con CS; sin embargo, la mayoría de personas que viven o han vivido estas situaciones no desarrollan esta problemática. Expondremos más pormenorizadamente estos tres factores en sucesivos epígrafes.

La incapacidad para controlar la propia conducta sexual ante la exposición a estímulos evocadores o el no haberse dado cuenta de que su conducta sexual sobrevenía problemática serían los factores que los pacientes identifican en mayor frecuencia como asociados a su conducta sexual compulsiva. Si bien Hall (2013) los equipara con los factores anteriores, entre ellos habría una importante diferencia: los tres primeros se consideran antecedentes de la CS y estos dos últimos síntomas que se explican a partir de los problemas en el control ejecutivo de la conducta. Puesto que los déficits en el control ejecutivo ya se han expuesto en el primer capítulo, no se desarrollan nuevamente.

\subsection{Abuso sexual infantil}

Existe cierto consenso a la hora de identificar eventos o situaciones negativas ocurridas durante etapas tempranas del desarrollo como desencadenantes de ciertos trastornos durante la vida adulta, sobre todo cuando estas situaciones son tan graves y desestabilizadoras como el abuso sexual durante la niñez. El abuso sexual infantil se ha considerado un factor de riesgo de múltiples patologías psicológicas (Trickett, Noll, \& Putnam, 2011), y esto no es menos cierto cuando hablamos de la CS (Gold \& Heffner, 1998). Las evidencias que apoyan el vínculo entre abuso sexual infantil y conducta sexual compulsiva durante la edad adulta provienen de dos tipos de estudios: los que exploran la conducta sexual en víctimas de abuso durante su infancia y los que analizan antecedentes de abuso sexual en pacientes con problemas de CS.

Un total de 5 estudios han obtenido resultados significativos tras evaluar la conducta sexual de víctimas de abuso. Courtois (1979), tomando una muestra de hombres y mujeres que habían sufrido abuso sexual durante un periodo prolongado de su niñez por parte de miembros de su propia familia, encontró que la gran mayoría (concretamente el 80\%) experimentaron problemas sexuales durante la edad adulta -uno de los más frecuentes, el deseo compulsivo 
por mantener relaciones sexuales-. Herman (1981) encontró que el 35\% de su muestra compuesta también por víctimas de incesto mantenían una conducta sexual promiscua. Muchos de ellos afirmaron emplear el sexo como un medio para lograr seguridad y afecto. Tsai, Feldman-Summers y Edgar (1979) compararon la frecuencia sexual de víctimas de abuso sexual que buscaban ayuda terapéutica por problemas sexuales y de pacientes también con problemas sexuales pero sin historia de abuso. Lo que estos investigadores encontraron es que el $43 \%$ de los pacientes con historia de abuso habían mantenido relaciones sexuales con más de 15 personas frente a tan sólo el $9 \%$ de pacientes sin antecedentes de abuso. DeYoung (1982), definiendo el término promiscuidad sexual como "un patrón de conducta sexual indiscriminada que va más allá de la mera saciación del apetito sexual" (p.60), encontró que la conducta sexual del $15 \%$ de su muestra de víctimas de abuso sexual incestuoso se podía definir en estos términos. Finalmente, Vaillancourt-morel, Godbout y Labadie (2015) demuestran en un reciente estudio online que la puntuación en la Escala de Compulsividad Sexual de personas con antecedentes de abuso sexual es significativamente superior a la de personas sin historia de abuso; asimismo, las correlaciones entre esta escala y las medidas de evaluación del abuso resultan positivas y significativas.

Desde la perspectiva inversa -es decir, evaluando antecedentes de abuso sexual en personas con CS-, las evidencias señalan nuevamente un estrecho vínculo entre ambos fenómenos. En un estudio en el que se evaluaba a 233 hombres y 57 mujeres en tratamiento por adicción al sexo, prácticamente la totalidad de la muestra (concretamente el $82 \%$ ) informó haber sufrido abuso sexual durante la infancia (Carnes, 1991). Estudios posteriores obtienen resultados en esta misma línea pero un tanto más discretos. Långström y Hanson (2006b) encontraron tras evaluar a 1279 hombres y 1171 mujeres que aquellos que informaron de una alta frecuencia sexual con parejas esporádicas tenían más probabilidad de haber sufrido durante su infancia abuso sexual. Skegg, Nada-Raja, Dickson y Paul (2010) también encontraron sólidos indicios del vínculo entre CS y abuso sexual tras evaluar de forma longitudinal a 940 hombres y mujeres australianos. Estos investigadores encontraron que el $23.3 \%$ de los hombres y el $43.3 \%$ de las mujeres que cumplieron criterios para el diagnóstico de CS habían sufrido abuso sexual durante su infancia, ambos porcentajes muy superiores a los obtenidos en población general. Finalmente, Parsons, Grov, \& Golub (2012) encontraron tras administrar la Escala de Compulsividad Sexual (SCS) a 669 hombres gays y bisexuales que los que puntuaban más alto en dicha escala tenían hasta 2.2 veces más probabilidad de haber sufrido abuso sexual durante su infancia. 
Las teorías propuestas para explicar el vínculo entre CS y abuso sexual infantil son diversas, pero casi todas hacen referencia al uso del sexo como mecanismo de control. McCarthy (1994) proponía que la necesidad de control era una de las principales consecuencias del abuso sexual infantil, un mecanismo de compensación a la total ausencia de control al que estas personas se ven sometidas durante el tiempo que dura el abuso. Desde esta perspectiva, las personas que han sufrido abuso sexual desarrollarían durante su vida adulta estrategias de control de su entorno a través de uno de los principales reforzadores sociales de la conducta humana: el sexo. Una explicación compatible con la de McCarthy es la que aportan Timms y Conners (1992). Estos autores sugieren que "Ia conducta sexual promiscua es un intento inconsciente de controlar las emociones negativas asociadas al abuso sexual, una representación simbólica de que la víctima al final ha logrado el control sobre el abusador a través del sexo" (Timms \& Conners, 1992, p. 21). La explicación que contrasta más con las anteriores es la de Schwartz (1992). Este investigador establece un vínculo entre CS y abuso sexual a través de la noción de la revivencia (síntoma esencial del trastorno por estrés post-traumático). Según esta teoría, las personas que han sufrido abuso sexual y que no logran superar esta vivencia negativa encuentran en el sexo con múltiples parejas una forma de revivencia del trauma original. La nueva experiencia sexual resulta negativa por su similitud con el trauma original y aun así, se vería incapaz de evitarla. Esta teoría ha ganado posteriormente popularidad a través del concepto de revictimización, que sería la reformulación del concepto de revivencia aplicada al abuso sexual (Arata, 2000).

\subsection{Negligencia en el cuidado infantil}

Una experiencia extrema durante la infancia -el abuso sexual- puede predisponer al desarrollo de problemas en el control de los impulsos sexuales durante la edad adulta; sin embargo, no parece que sea necesario llegar a ese extremo para facilitar su aparición. Situaciones donde no se aprecia abuso físico o sexual pero sí negligencia por parte de los cuidadores primarios en la atención al niño -ambientes familiares poco estructurados donde las necesidades educativas, afectivas, higiénicas o alimentarias no están aseguradas- facilitan el aprendizaje de modelos de conducta y relacionales que fomentan durante la edad adulta la aparición de síntomas típicos de la CS (Coleman-Kennedy \& Pendley, 2002).

Earle y Crow (1998) propusieron por primera vez los ambientes familiares negligentes como un factor de riesgo para el desarrollo de la adicción al sexo. Estos clínicos identificaron a partir de su experiencia terapéutica con múltiples pacientes con esta problemática que un aspecto común en sus biografías era haber crecido en ambientes familiares poco estructurados. Estas situaciones provocan dos escenarios que aumentan la probabilidad de desarrollar una adicción 
sexual: por un lado, la ausencia de normas y en muchos casos, una escolarización deficiente o inconsistente, dificultarían el desarrollo de habilidades de regulación de la propia conducta (control de impulsos, intronspección, atención a las consecuencias de la conducta, conducta guiada hacia metas y objetivos); por otro lado, el contacto con iguales en ambientes desestructurados facilita el inicio del consumo de sustancias ilegales, un debut temprano y de riesgo de la actividad sexual y toda una serie de consecuencias negativas para el desarrollo psicosocial. La interacción entre ambos escenarios agravaría más si cabe la situación.

Basándose en la noción de que las actitudes sexuales disfuncionales se conforman a partir del contacto con el núcleo familiar y el grupo de iguales, Earle y Crow (1998) concluyeron que lo que explicaba el vínculo entre negligencia en el cuidado infantil y CS era el aprendizaje de mecanismos de regulación deficitarios socialmente reforzados: durante la adolescencia, estos pacientes encuentran en el sexo el reconocimiento de sus iguales, pero cuando su uso perdura y se generaliza entrada la edad adulta puede desembocar en un cuadro clínico de CS.

Kasl (1998) propuso un modelo alternativo sobre cómo las experiencias durante la infancia condicionan la aparición de problemas en el control de los impulsos sexuales durante la edad adulta. La base del modelo es la victimización infantil -entendida tanto en términos de negligencia como de abuso físico o sexual- y explica el desarrollo del cuadro clínico desde una perspectiva cognitivo-conductual (figura 6). Según este modelo, el nexo entre victimización infantil y desarrollo del cuadro clínico de CS está mediado por creencias disfuncionales a varios niveles. En un primer nivel, la victimización se interpreta a partir de la noción de culpa y falta de control. Esto es habitual en cualquier caso de abuso o negligencia, pero no en todos estos casos se desarrollan síntomas sexuales; ahí es donde interviene el filtro, que asume que una constelación de características personales evita que la mayoría de víctimas de situaciones de negligencia desarrollen problemas en el control de los impulsos sexuales. Si el filtro falla, se dan dos caminos independientes con un mismo final: el desarrollo del cuadro clínico de compulsividad sexual. El primero corresponde a los casos en los que la persona reacciona al abuso rechazando establecer relaciones íntimas: en estos casos, los pensamientos automáticos se relacionan con la idea de que la vida va mejor cuando no se tiene a nadie al lado y el sexo se configura únicamente como una medio para lograr control sobre otras personas. El segundo corresponde a casos en los que la persona reacciona con una necesidad extrema de que otra persona se encargue de su cuidado: en este caso, los pensamientos enfatizan la necesidad de encontrar a alguien que les quiera y les cuide y el sexo se convierte en el vehículo para lograr este objetivo (Kasl, 1998). 


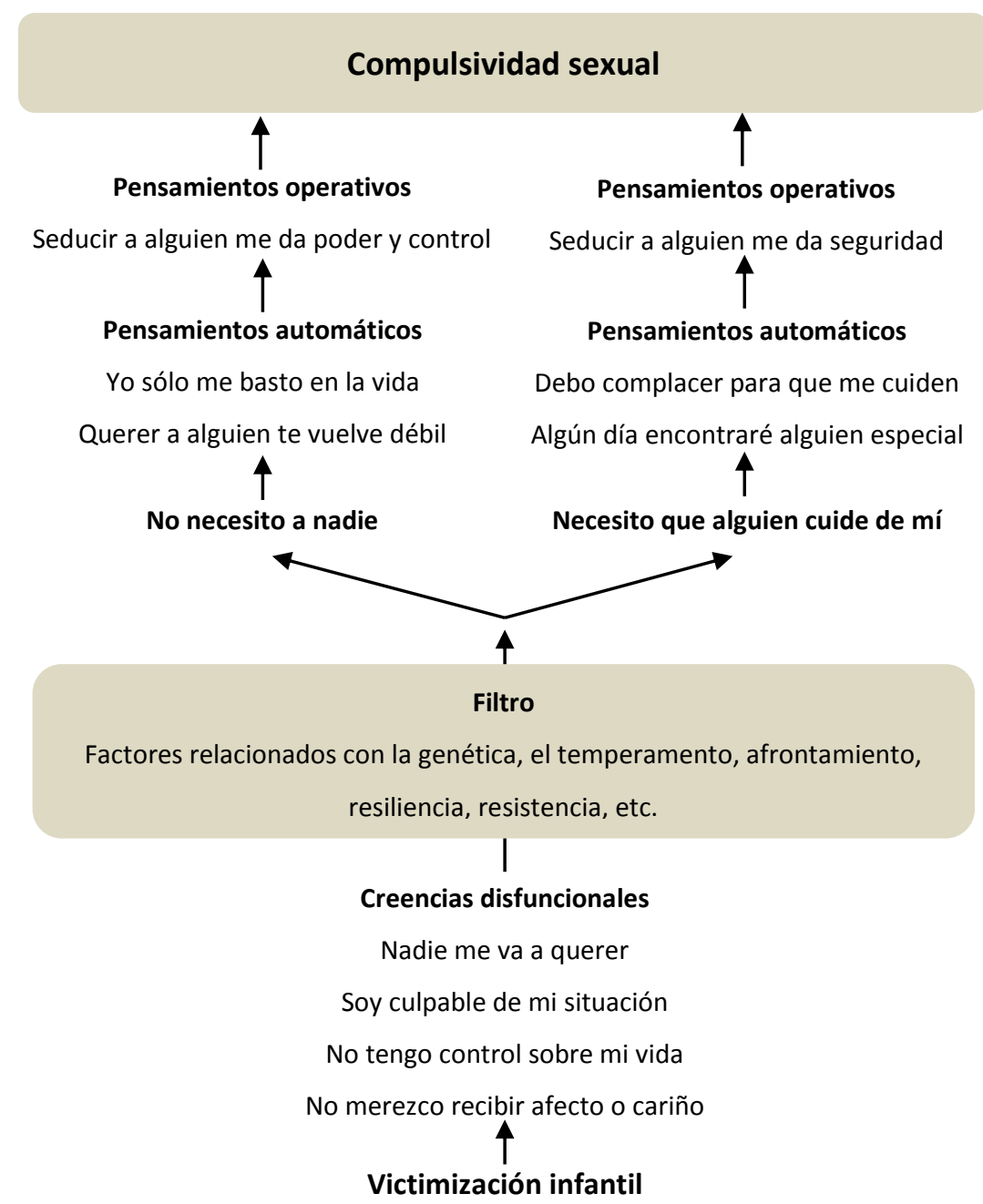

Figura 6. Explicación de la CS a partir de la victimización infantil (modificado a partir de Coleman-Kennedy \& Pendley, 2002)

\subsection{Estilos de apego y vinculación afectiva}

Que el tipo de apego establecido durante la infancia puede afectar positiva o negativamente sobre el desarrollo afectivo-social durante la edad adulta ha sido un tema de discusión desde que Bowlby (Bowlby, 1969, 1973, 1980) y más tarde Ainsworth (Ainsworth, Blehar, Eaters, \& Wall, 1978; Ainsworth \& Wittig, 1972) propusieran las primeras teorías sobre apego infantil. Según estas teorías, el tipo de relaciones que se establece con los cuidadores primarios durante las primeras etapas de la vida determinan la forma en la que los adultos se relacionan y establecen vínculos de intimidad emocional y sexual (Gilliland, Star, Hansen, \& Carpenter, 2015). Las personas criadas en entornos estables y afectivos desarrollan las habilidades necesarias para establecer vínculos basados en la confianza mutua y en la satisfacción de las necesidades de la pareja (apego seguro) (Obegi \& Berrant, 2009); por el contrario, las personas que crecen en familias con estilos de crianza inconsistentes, afectivamente distantes o negligentes no desarrollan estas habilidades y en consecuencia, sus relaciones adultas adolecen de problemas de vinculación afectiva (apego inseguro) (Sroufe, 2005). 
Distintas investigaciones han demostrado la utilidad de la teoría del apego para explicar satisfactoriamente ciertos aspectos de la conducta sexual adulta. En comparación con las personas que desarrollan un estilo de apego seguro, las que tienen estilos de apego inseguro tienden a mantener sus primeras relaciones sexuales de forma más temprana y con mayor riesgo, a tener más parejas sexuales a lo largo de la vida (la mayoría parejas esporádicas), a mantener relaciones sexuales con desconocidos y a ser infieles (Bogaert \& Sadava, 2002; Gentzler \& Kerns, 2004). Concretamente, se han propuesto tres estilos de apego inseguro: el preocupado, el evitativo y el desorganizado. Las personas con un estilo de apego preocupado requieren atención y aprobación constante por parte de su pareja o la persona con la que establecen el vínculo. Se suelen percibir a sí mismos en términos negativos (perdedores, incompetentes, poco atractivos, etc.) y tienden a describir a las personas de su entorno como insensibles, negligentes o poco afectivas (Hudson-Allez, 2009). Según Samenow (2010), sus necesidades emocionales les llevan a buscar incesantemente nuevas parejas, lo que se traduce en frecuentes infidelidades en caso de mantener una relación estable.

Las personas con un estilo de apego evitativo se caracterizan por minimizar su necesidad por establecer un vínculo. Son personas que rechazan cualquier tipo de intimidad emocional y ni siquiera la valoran como algo necesario. No en vano, suelen percibirse como autosuficientes y creen a los demás incapaces de satisfacer cualquiera de sus necesidades (Hudson-Allez, 2009). Estas personas suelen recurrir a actividades sexuales que no impliquen intercambio emocional (masturbación a través de pornografía, trabajadoras sexuales, etc.) (Samenow, 2010).

Finalmente, las personas con un estilo de apego desorganizado reúnen características de los dos estilos anteriores. En ocasiones muestran una excesiva necesidad de atención y afecto por parte de las personas de su entorno, mientras en otras pueden rechazar completamente cualquier tipo de contacto o intimidad (Obegi \& Berrant, 2009). Según Samenow (2010), este tipo de apego se relaciona en algunos casos con el desarrollo de intereses parafílicos.

A la luz de estos hallazgos, muchos investigadores comenzaron a valorar la posibilidad de que los estilos de apego (en particular los inseguros), además de explicar aspectos de la conducta sexual adulta, pudieran también relacionarse de alguna forma con la CS (Hall, 2011; Samenow, 2010). Leedes (1999) encontró tras evaluar una pequeña muestra compuesta por 22 pacientes con adicción al sexo que la mayoría (el 95\%) se podían clasificar como personas con apego inseguro. De éstos, el $68 \%$ mostraba un estilo de apego evitativo, el $27 \%$ preocupado y el $5 \%$ restante ambivalente. A partir de este y otros hallazgos, Leedes (2001) afirmó que "a pesar de que la incapacidad para establecer relaciones íntimas no es razón suficiente para explicar por sí sola la etiología de la CS, es componente central para desencadenar el cuadro clínico" (p.218). 
Zapf, Greiner y Carroll (2008) encontraron una distribución similar pero con una muestra de pacientes mayor (71 hombres en terapia por problemas de CS). Estos investigadores encontraron que tan sólo el $8 \%$ de sus pacientes se podían clasificar en la categoría de apego seguro, mientras que los porcentajes de pacientes con apego desorganizado, preocupado y evitativo fueron del $44 \%, 28 \%$ y $20 \%$ respectivamente. En un estudio online en el que se comparaban a 407 hombres y mujeres con puntuaciones clínicas en una escala de CS y a 214 sujetos control, nuevamente se encontró que la CS correlacionaba positiva y significativamente con los tres estilos de apego inseguros. Asimismo, la intensidad del vínculo entre apego inseguro y CS era más fuerte en mujeres (Faisandier, Taylor, \& Salisbury, 2011). Finalmente, en un estudio muy reciente en el que se aplicó una escala de apego a un total de 136 hombres entre 18 y 72 años en tratamiento por problemas de CS se encontró que mientras que un $23 \%$ se clasificaba como de apego seguro, el 77\% restante tenía algún tipo de apego inseguro (39\% apego evitativo, 20\% preocupado y $18 \%$ desorganizado) (Gilliland et al., 2015).

Hasta el momento, las evidencias demuestran que los estilos de apego desempeñan un papel importante en el cuadro clínico de la CS. Sin embargo, los estudios realizados no permiten establecer la naturaleza del vínculo. Puede ser que, como la interpretación más intuitiva sugiere, los estilos de apego inseguros sean un factor predisponente que aumenta el riesgo de padecer CS. Por otra parte, también es posible que los estilos de apego se modifiquen y sobrevengan inseguros como reacción a los síntomas de CS -como en el caso de las personas que se vuelven evitativas con sus parejas porque centran su tiempo y esfuerzo en mantener relaciones sexuales compulsivamente con otras parejas (Gilliland et al., 2015)-. En cualquier caso, convendría seguir valorando el papel de los estilos de apego como factores etiológicos porque quizá su modificación podría convertirse en objetivo terapéutico que mejore la eficacia de los tratamientos actuales para este trastorno.

\section{Determinantes sociales de la CS}

La identificación y cuantificación de los determinantes sociales que predisponen o facilitan el desarrollo de cualquier tipo de enfermedad suele ser compleja. Aspectos ambientales, políticos, sociales o culturales conforman un escenario que en ocasiones, tiene un impacto directo sobre la patología -p.e., la polución en las ciudades y el incremento en la proporción de enfermedades pulmonares- y en otras, tiene un impacto indirecto -como ciertas políticas asistenciales que haciendo énfasis en la prevención y la detección precoz, mejoran el pronóstico en enfermedades como el cáncer de colon, mama, próstata, etc.- (W. Campbell \& Rohrbaugh, 2006; Engel, 1977; Suls \& Rothman, 2004). Teniendo en cuenta que la CS es una línea de investigación emergente, todavía no contamos con estudios que demuestren una 
relación sistemática entre una serie de factores sociales y la emergencia de este trastorno. Sin embargo, algunos aspectos del entorno social, religioso y cultural -sobre todo los relacionados con las actitudes hacia el sexo y la sexualidad- sí parecen facilitar el inicio o cuanto menos la expresión de algunos rasgos y manifestaciones de la CS (Hall, 2011; Samenow, 2010).

\subsection{Entorno social y cultural como facilitador de la emergencia de la CS}

En relación con cómo la sociedad puede determinar los patrones de comportamiento sexual individual, existe una disciplina -la antropología sexual- dedicada por entero a explorar las diferencias en el comportamiento sexual de distintos pueblos y etnias (Choza, 1991; Nieto, 2003). Esta disciplina se sustenta sobre lo que se ha llamado "teoría de la construcción social del sexo": esta teoría sostiene que si la biología no permite explicar el infinito abanico de sexualidades posibles es porque otros factores -como la cultura y la sociedad- desempeñan un papel esencial (Rodríguez-Shadow \& López, 2009). A partir de esta y otras teorías como las defendidas por Foucault, Guasch (1993) afirmaba que "El sexo humano es cultural. La sociedad regula a través de la cultura el perpetuo estado de celo de nuestra especie" (p.118). Si como Guasch y muchos otros antes defienden, la sociedad regula a través de mecanismos como la cultura el estado de celo -es decir, el apetito sexual-, entonces empiezan a tener sentido las teorías que sostienen que los entornos sociales sexualmente más abiertos funcionan como facilitadores del inicio y la expresión de la CS (Hall, 2011; Samenow, 2010).

La aplicación de la teoría de la construcción social del sexo en la comprensión de las distintas manifestaciones de la CS se ha abordado desde dos perspectivas: la inter y la intracultural. La perspectiva intercultural, centrada en comparar el comportamiento sexual compulsivo en distintos pueblos y etnias, ha suscitado muchas críticas y su validez se ha puesto en duda sistemáticamente (para una revisión, ver Kaplan \& Krueger, 2010). Un ejemplo resulta clarificador: si a la consulta de un clínico acostumbrado a tratar personas con trastornos en el control de los impulsos sexuales acude una mujer que durante las semanas previas a su enlace matrimonial ha mantenido relaciones sexuales con todos los familiares varones de su marido, desde el más joven hasta el más mayor, probablemente pensaríamos que muestra claros síntomas de CS. Si además relata que ella ha sido la que por voluntad propia ha buscado esas relaciones sexuales para saciar un impulso sexual que ha sobrevenido desmedido, pocos clínicos dudarían a la hora de establecer el diagnóstico. Sin embargo, si aclaramos que esa mujer está cumpliendo con uno de los ritos matrimoniales tradicionales de ciertas etnias en Etiopía (Nieto, 2003), entonces carecería de cualquier sentido el diagnóstico establecido. Este ejemplo aclara que la visión de lo sano y lo patológico depende enteramente de las normas y límites que cada sociedad establece para con su sexualidad y el estudio de la CS no es una 
excepción. En esta línea, Levine y Troiden (1988) sostenían hace ya más de 25 años que "En cualquier sociedad, unos guiones sexuales concretos establecen el estándar de normalidad sexual. Por lo tanto, lo que una sociedad considera como una "conducta sexual incontrolada" puede no ser visto así por otra" (p.351). Es por eso que el análisis de la CS desde una perspectiva intercultural puede resultar interesante pero clínica y empíricamente inapropiado.

Además de variar entre culturas y etnias, la sexualidad tampoco es homogénea si se compara entre países de un mismo entorno cultural. Por ejemplo, la actitud hacia la homosexualidad en Europa varía desde la total aceptación en países como Suecia, Islandia o Dinamarca hasta el rechazo y la estigmatización en países como Ucrania, Rumanía o Lituania (Štulhofer \& Rimac, 2009) y lo mismo sucede en cuanto a las actitudes hacia el aborto, la contracepción, el sexo antes del matrimonio, la frecuencia sexual, etc. (Halman, Luijkx, \& Van Zundert, 2005). Por eso, la teoría de la construcción social del sexo se ha utilizado satisfactoriamente para analizar cómo dentro una misma cultura -la occidental, que es donde la definición de la conducta sexual compulsiva se ha consensuado y se aplica de forma más generalizada-, entornos sexuales más abiertos facilitan la expresión de esta patología (perspectiva intracultural).

En la cultura occidental, la sexualidad ha pasado por diferentes fases que han determinado la forma en la que se ha tratado más o menos abiertamente, cuestión que a su vez ha tenido un impacto directo sobre los patrones de relación y conducta sexual. En ocasiones, la transición entre estas etapas ha sido sutil y casi imperceptible, una serie de cambios actitudinales que han redundado en una vivencia más libre y completa de la sexualidad. En otros, los cambios han sido mucho más bruscos y su efecto sobre la conducta sexual muy evidentes -como en el caso de las sucesivas revoluciones sexuales- (Garton, 2004). Un buen ejemplo lo encontramos en los cambios que para la sexualidad supuso la aparición de los métodos anticonceptivos. Antes de la aparición de métodos eficaces para la prevención de embarazos, el sexo estaba inevitablemente ligado a la procreación. Sin embargo, la aparición primero del preservativo y más tarde de la píldora anticonceptiva supuso un verdadero cambio de paradigma ya que el fin reproductivo de la conducta sexual pasó de ser una imposición a una decisión que las parejas tomaban libremente. Este cambio, que analizado desde el punto de vista contemporáneo parece apenas trascendente, tuvo un impacto directo sobre la conducta sexual del conjunto de la población (Kafka, 2007). Para empezar, aumentó enormemente la frecuencia sexual con respecto a etapas anteriores, aumento que se dio tanto en el contexto de relaciones estables como de relaciones esporádicas. Otro gran cambio fue el sexo prematrimonial. Si hasta ese momento era la excepción, después de la aparición del preservativo y la píldora anticonceptiva pasó a convertirse en norma y hoy en día la mayoría de los que mantienen su virginidad hasta 
el matrimonio son jóvenes con profundas motivaciones religiosas -los que pueden, ya que la mayoría fracasan por el camino- (Edger, 2010; Kwee et al., 2007).

Como en toda revolución, no todo fueron luces y los cambios en el patrón de conducta sexual tuvieron un impacto negativo en ciertos ámbitos. Esta nueva forma de vivir la sexualidad contribuyó al aumento de la tasa de divorcios, resurgieron con inusitada intensidad las Infecciones de Transmisión Sexual (ITS) -con el perjuicio físico y emocional que por entonces acarreaba a las personas afectadas- y el VIH sobrevino una pandemia que todavía hoy no ha sido controlada (Garton, 2004).

Más recientemente, algunos investigadores han identificado nuevas formas de vivencia de la sexualidad relacionadas con el incremento en la proporción de pacientes con CS. Estamos hablando de lo que en EEUU se ha llamado Hookup Culture y que en nuestro contexto podemos entender como la actividad sexual con múltiples parejas esporádicas con las cuales no se mantiene vínculo emocional alguno y a las que, en muchos casos, apenas se acaba de conocer (B. McNair, 2002; Paul, McManus, \& Hayes, 2000). Este patrón de búsqueda de relaciones sexuales rápidas se lleva popularizando desde los últimos años y cada vez son más los jóvenes que prefieren este tipo de relaciones en detrimento de modelos más clásicos como las parejas estables monógamas. En este sentido, los estudios cada vez demuestran con mayor solidez que la CS y la cultura de múltiples relaciones sexuales esporádicas se relacionan íntimamente (Dodge et al., 2004). Hasta hace un tiempo, esta relación se entendía unidireccional -a mayor CS, mayor tendencia a buscar nuevas parejas sexuales- si bien cada vez parece más probable que igual que la CS incrementa la búsqueda de nuevas parejas, el mantener encuentros sexuales con múltiples parejas propicia una disminución del control sobre la conducta sexual y por tanto, un aumento de la probabilidad de padecer CS (Stupiansky et al., 2009). Esto es más cierto si cabe entre mujeres, donde el incremento en el porcentaje de las que afirman mantener este tipo de relaciones supera incluso al de hombres (Schneider \& Weiss, 2001).

\subsection{Creencias religiosas y CS}

Dados los estrictos estándares de conducta sexual establecidos en distintas religiones, en un principio se planteó que una fuerte convicción religiosa podría desempeñar un papel protector en el desarrollo de problemas en el control de los impulsos sexuales. No en vano, el tipo de relaciones que desde entornos religiosos se consideran adecuadas -relaciones heterosexuales, monógamas, tras el matrimonio y orientadas exclusivamente a la reproducción- representa la antítesis a la conducta sexual de un paciente con CS (Edger, 2010; Kwee et al., 2007). 
Pues bien, la investigación ha demostrado que nada más lejos de la realidad. En la actualidad hay contados estudios sobre esta cuestión, pero todos ellos apuntan precisamente a que el fundamentalismo religioso -la aplicación extrema de los principios de cualquier religión- se asociaría precisamente al malestar generado por la incapacidad para controlar los impulsos sexuales (Hall, 2011; Samenow, 2010). En algunos casos, las creencias religiosas extremas fomentan una visión distorsionada de la CS y hacen creer a personas sanas que padecen de una adicción sexual. Según Kwee et al. (2007), el 60\% de los jóvenes evangélicos que acuden a su consulta (estos investigadores trabajan en el centro de asesoramiento psicológico de una universidad evangélica) se identifican como adictos al sexo por el mero hecho de masturbarse -aunque no lo hagan ni tan siquiera una vez a la semana-. No obstante, no es de extrañar teniendo en cuenta que estos mismos investigadores afirman organizar grupos de terapia para "fomentar una sexualidad sana", que no sería otra cosa que una intervención para tratar que estos jóvenes logren la abstinencia sexual.

Sin embargo, el vínculo entre religión y CS no se limita a la mera exageración de la gravedad de la conducta sexual, sino que algunos estudios demuestran además una vinculación directa entre fundamentalismo y CS. Needell y Markowitz (2004) compararon la proporción de síntomas de CS en un grupo control y en otro de judíos jasídicos (una de las ramas más extremas del judaísmo), encontrando que una mayor proporción de éstos últimos mostraban síntomas de conducta sexual compulsiva. Por otra parte, Ross, Mansson y Daneback (Ross, Mansson, Daneback, Månsson, \& Daneback, 2012) encontraron que uno de los predictores más sólidos de adicción a la pornografía online era el grado de religiosidad (mayor riesgo a mayor religiosidad). La naturaleza del vínculo entre fundamentalismo religioso y CS resulta una incógnita. Tal vez en este vínculo medien mecanismos psicológicos de compensación al fundamentalismo extremo. Sea como sea, la investigación tiene todavía como tarea pendiente analizar a fondo este vínculo en tanto en cuanto esto pueda redundar sobre la mejora de la atención clínica a poblaciones muy concretas -como las minorías religiosas-.

\section{Modelos teóricos acerca de la entidad nosológica de la CS}

Hasta el momento, se han revisado pormenorizadamente los factores asociados en mayor o menor medida al inicio y el manteamiento de la CS. Estos factores conforman el muy discutido sustrato etiológico de este cuadro clínico pero en suma, no constituyen sino una serie de vínculos entre ciertos factores y la expresión clínica de un trastorno. Ante la incertidumbre que ha supuesto no encontrar una etiología clara para esta patología, se han propuesto toda una serie de modelos teóricos explicativos de este cuadro clínico. Cada uno de estos modelos ha otorgado un peso diferencial a los factores antes enumerados y a partir de ahí, ha tratado de 
dar respuesta a preguntas como: 1) ¿qué mecanismos permiten explicar la génesis del cuadro clínico de compulsividad sexual y su mantenimiento?; 2) ¿de qué hablamos cuando hablamos de CS? (entidad nosológica); 3) a partir de esta consideración de la CS, ¿cuál sería el término apropiado para designarla? A continuación presentaremos las teorías que han tratado de responder a estas preguntas.

\subsection{Adicción al sexo}

Los modelos que defienden la conducta sexual compulsiva como un trastorno adictivo caen en un error de partida: la nomenclatura. El término "adicción" no se ha contemplado nunca como categoría diagnóstica, por lo que hablar de adicción al sexo resulta impreciso; en su lugar, el uso de expresiones como dependencia sexual -terminología acorde a la clasificación DSM para los trastornos relacionados con sustancias (APA, 2002)- resultaría más adecuado. No es que hablar de adicción resulte incorrecto o poco comprensible; muy al contrario, es el término utilizado preferentemente en entornos divulgativos y el que suele manejar el conjunto de la sociedad para referirse a esta problemática. El problema es que esta expresión arrastra una serie de supuestos que han lastrado la investigación empírica en este tipo de patologías, de modo que la comunidad científica ha evitado sistemáticamente su utilización (O'Brien, 2011). Precisamente, la selección del término de "adicción sexual" frente a otros científicamente más precisos como el de dependencia sexual reflejaría una de las principales críticas a estos modelos: que tienen más vocación mediática y divulgativa que científica (Goodman, 2001).

Obviando de ahora en adelante el uso de una terminología inadecuada, Orford fue el primero en proponer que el excesivo apetito sexual y las conductas sexuales compulsivas podían entenderse como un trastorno adictivo en ausencia de una sustancia tóxica (Orford, 1978, 2001). Como clínico, sus afirmaciones se basaban en la similitud entre alguno de los síntomas que había observado mientras trataba a pacientes con adicciones tóxicas (alcohol, cocaína, etc.) y adicción al sexo. Goodman $(1992,2001)$ tomó y amplió las observaciones clínicas de Orford hasta identificar 9 aspectos comunes entre la adicción al sexo y la adicción a sustancias:

1) Curso clínico: el trastorno empieza habitualmente durante la adolescencia o la adultez temprana y sigue un curso crónico con remisiones y exacerbaciones episódicas.

2) Aspectos conductuales: el repertorio conductual queda limitado y el elemento central en el día a día es la satisfacción del impulso adictivo.

3) Experiencia subjetiva del ciclo adictivo: el paciente experimenta primero la necesidad de realizar la conducta adictiva (craving), excitación durante la preparación, satisfacción tras la ejecución y sensación de pérdida de control sobre la propia conducta a largo plazo. 
4) Evolución: la adicción evoluciona de forma insidiosa (si bien al principio parece inofensiva, la conducta sexual se torna incontrolable durante su evolución).

5) Tolerancia: las experiencias que antes lograban saciar el impulso adictivo resultan cada vez menos intensas, por lo que el paciente recurre a nuevas experiencias o experiencias de mayor intensidad para lograr la satisfacción inicial.

6) Abstinencia: los pacientes experimentan una intensa sensación de malestar físico o mental tras un periodo sin saciar el impulso adictivo.

7) Tendencia a la recaída: continuas recaídas tras periodos relativamente cortos donde pudiera parecer que el paciente ha empezado a recobrar cierto control sobre su conducta.

8) Interferencia: la conducta adictiva afecta de forma integral a las principales áreas de funcionamiento de la persona.

9) Otros fenómenos psicológicos: en la adicción al sexo, como en cualquier otra adicción, es habitual que el paciente padezca baja autoestima, conflictos familiares, negación de su situación, racionalización de los motivos que le han llevado a esta situación y exageración de la capacidad de control de la conducta sexual.

Si bien Orford sentó las bases teóricas de la consideración de la compulsividad sexual como un trastorno adictivo, su difusión se la debemos a Carnes. Desde la publicación en 1983 de la primera edición del libro Out of the Shadows: Understanding Sexual Addiction (Carnes, 1983), el fenómeno de la adicción al sexo ha ido ganando popularidad en parte gracias al interés de los medios por esta problemática (Gold \& Heffner, 1998; Kafka, 2010; Kingston \& Firestone, 2008; Kor et al., 2013). Se pueden identificar varios factores que explican el éxito de esta obra (reeditada en 3 ocasiones y manual de referencia para clínicos que se inician en el tratamiento de las adicciones sexuales): 1) lenguaje sencillo, divulgativo, con apenas referencias científicas que sustenten sus asertos; 2 ) simplificación de los mecanismos explicativos de la adicción al sexo y de sus abordajes terapéuticos, así como una sobregeneralización de las características de estos pacientes y; 3 ) datos de una supuesta investigación con más de 300 pacientes adictos al sexo (supuesta porque muchos autores han dudado de la veracidad de unos resultados que nunca han sido publicados a través de artículos peer-reviewed) (Gold \& Heffner, 1998). En resumen, una referencia aceptable cuando el conocimiento sobre la patología es incipiente pero una pobre referencia cuando se buscan aproximaciones basadas en la evidencia.

El elemento central en la formulación de Carnes es el uso disfuncional del sexo para regular estados de ánimo disfóricos (Carnes, 1983, 1991). La incapacidad para manejar emociones negativas llevaría a estos pacientes a instaurar patrones de comportamiento sexual disfuncionales como medio para suplir la carencia de mecanismos de afrontamiento positivos y 
adaptativos (tolerancia a la frustración, manejo de emociones negativas, etc.), lo que junto a otros fenómenos que se van generando concurrentemente a este patrón de conducta sexual compulsiva (tolerancia, aumento en la intensidad y frecuencia de la conducta sexual, conducta sexual de riesgo, síntomas de abstinencia, etc.) acaban explicando el cuadro clínico completo de la adicción al sexo.

Milkman y Sunderwirth (1987) desarrollaron un modelo alternativo de adicción al sexo que integra aspectos clínicos y conductuales con evidencias provenientes de la neurociencia. Si bien resulta más completo y fundamentado, apenas ha logrado impacto y difusión. Según estos autores, las adicciones -tanto tóxicas como conductuales- se podrían clasificar en tres categorías: adicciones relacionadas con el arousal-activación, con la saciación y con la evasión de la realidad. La saciación sería el componente central en la adicción al alcohol, la comida o los sedantes. La adicción al cannabis o las sustancias alucinógenas se clasificarían en la categoría de adicciones con evasión de la realidad. En la categoría de adicciones relacionadas con el arousal y la activación quedarían englobadas la adicción a la cocaína, las anfetaminas y el juego patológico. La adicción al sexo se considera una adicción propia de este último grupo pero relacionada también con la saciación y evasión de la realidad (Milkman \& Sunderwirth, 1987; Nakken, 2013). Por tanto, compartiría fenomenología y expresión clínica sobre todo con la adicción a la cocaína o el juego patológico pero también con otras como la adicción a la marihuana, el alcohol, etc.

A nivel clínico, el elemento central de esta formulación sería también la ausencia de recursos adaptativos para regular estados de ánimo disfóricos. Estos pacientes carecerían de estrategias de afrontamiento activo para el manejo de situaciones que provocan malestar, instaurándose patrones de comportamiento donde sólo el sexo -en algunas ocasiones combinado con el consumo de sustancias- permite lograr cierta regulación emocional. En un principio, una actividad sexual moderada -como la que puede darse en el contexto de cualquier relación estable- podría ser suficiente para la regulación emocional de estos pacientes pero pasado el tiempo, la tolerancia a niveles de actividad sexual moderados les obligaría a incrementar o bien su intensidad o su frecuencia, instaurándose un patrón de comportamiento incompatible con una vivencia sana de la sexualidad en pareja o del autoerotismo. Los problemas derivados de este patrón de comportamiento sexual compulsivo aumentan el malestar emocional, que sólo se calma a través de una conducta sexual cada vez más descontrolada. En ese momento se establece lo que se conoce como "ciclo de la adicción sexual" (Sbraga \& O’Donohue, 2004). Milkman y Sunderwirth (1987) aluden a mecanismos neurofisiológicos -más concretamente la hipótesis de la neurotransmisión- para sustentar sus impresiones clínicas. Según ellos, la 
hiperactivación del sistema de neurotransmisión resultado de la ingesta exógena de sustancias como por ejemplo la cocaína sería muy similar a la que se obtiene de forma endógena a través de la actividad sexual: en esta línea, "la gente no se volvería adicta a una droga o a una conducta concreta como tal, sino a sus efectos como reguladores del estado de ánimo y como potenciadores de sensaciones de euforia y de placer" (Coleman-Kennedy \& Pendley, 2002, p. 144). De acuerdo con esta perspectiva, la actividad sexual inicialmente incrementaría los niveles de ciertos neurotransmisores cerebrales -a saber, dopamina y serotonina-, provocando una sensación de euforia y bienestar similar al high de la heroína o la cocaína. La valencia positiva de la actividad sexual haría que se estableciera un patrón de conducta sexual repetitivo que provocaría que el umbral medio de neurotransmisores en el cerebro aumentara notablemente, dificultando cada vez más la homeostasis endógena. En este momento, la homeostasis fisiológica de los niveles de neurotransmisión ya dependería enteramente de la regulación a través de la conducta sexual compulsiva, que habría perdido su capacidad como reforzador positivo (euforia o high) y se habría transformado en reforzador negativo (evita la aparición de síntomas de abstinencia y craving).

La evidencia empírica en torno a la validez de estos modelos es discreta pero los resultados parecen refrendar algunas de las hipótesis que se manejan. Wines por ejemplo (1997) realizó una investigación en la que se propuso explorar en qué medida la síntomatología de la adicción al sexo se correspondía con los criterios propuestos por el DSM-IV-TR para el diagnóstico de la dependencia a sustancias. Para ello, evaluó la sintomatología de 53 pacientes con adicción al sexo ( 47 hombres y 7 mujeres) tratados en un programa de sexo-adictos anónimos. Este investigador encontró que la gran mayoría (98\%) informó haber tenido tres o más síntomas de abstinencia durante periodos sin realizar el impulso sexual, el $94 \%$ había fracasado al tratar de controlar o reducir su conducta sexual, el $94 \%$ invertía una cantidad exagerada de tiempo y esfuerzo en realizar la conducta sexual adictiva y el $92 \%$ admitió que su conducta sexual sobrepasaba lo que consideraban sexualmente adecuado. Estos resultados se interpretaron a favor de la teoría de que la adicción al sexo comparte sintomatología con cualquier otra adicción y por tanto debe ser considerada como tal, si bien deben ser tomados con cautela. Entre otras limitaciones, este estudio se realizó con una muestra de conveniencia compuesta por pacientes con experiencia en grupos de autoayuda de sexo-adictos anónimos, donde es habitual que durante las primeras sesiones se les instruya en interpretar sus síntomas a favor del paradigma de la adicción.

La validez de este modelo también se ha sustentado en resultados derivados de la aplicación de un cuestionario de referencia en la evaluación de la CS, el cuestionario de screening de la 
adicción al sexo (SAST; Carnes, 1983). Este instrumento, construido con un claro sesgo hacia la consideración de la CS como un trastorno adictivo, se ha aplicado con éxito en la evaluación de la sintomatología de compulsividad sexual en múltiples tipos de población. Es más, los estudios psicométricos realizados han obtenido una solución factorial de un único factor -a saber, la adicción al sexo- que permite explicar un porcentaje importante de la varianza de las puntuaciones en esta escala -entre el 33 y el 66\% dependiendo del tipo de población- (Carnes et al., 2010; Marshall \& Marshall, 2010). Nelson y Oehlert (2008) encontraron cuando trataban de validar el SAST en una muestra de veteranos de guerra con adicción a distintas sustancias un estrecho vínculo entre estas patologías y la adicción al sexo. De los veteranos de guerra diagnosticados con una dependencia de cocaína, el 20\% padecían además una adicción sexual comórbida; desde la perspectiva contraria, la mayoría de adictos al sexo (60\%) padecían dependencia de cocaína. Asimismo, las correlaciones entre el SAST y escalas de dependencia de alcohol por un lado y de dependencia de sustancias del Inventario Clínico Multiaxial Millon (MCMI-II) por otro, resultaron positivas y significativas (.355 y .433).

La concepción de la CS como un trastorno adictivo, tal vez por su condición de modelo mediático o quizás por no disponer del fundamento empírico suficiente para sustentar sus afirmaciones, ha sido objeto de múltiples críticas. Según Goodman (2001), las principales objeciones a este modelo giran en torno a: 1) el rechazo a considerar que una conducta, en contraposición a una sustancia tóxica, pueda sobrevenir adictiva; 2) la ausencia de evidencias empíricas suficientes que avalen la existencia de los dos principales fenómenos propios de cualquier adicción -tolerancia y abstinencia-; 3) el temor a que la adicción al sexo no sea sino una inventiva con una finalidad de control y regulación social de la conducta sexual y; 4) las reticencias a aceptar un diagnóstico que en entornos legales, podría ser utilizado como argucia para reducir o incluso evitar las condenas de prisión de agresores sexuales.

La primera de las críticas carece de fundamento tras la publicación de la última versión del Manual Diagnóstico y Estadístico de los Trastornos Mentales (DSM-5). En esta edición, el juego patológico se reconoce ya como un trastorno adictivo equiparable a cualquiera de los contemplados tradicionalmente. Es más, se abre la puerta a que otros trastornos de naturaleza conductual puedan formar parte de la categoría de trastornos relacionados con sustancias y trastornos adictivos en sucesivas ediciones, siempre y cuando fundamenten su naturaleza: "Además de los trastornos relacionados con sustancias, en este capítulo también se incluye el juego patológico, que refleja la prueba de que los comportamientos de juego activan sistemas de recompensa similares a los activados por las drogas, pues producen algunos síntomas 
comportamentales similares a los trastornos relacionados con el consumo de sustancias" (APA, 2014, p. 253).

La principal crítica que perdura y está lejos de solventarse es la que se refiere a los fenómenos de tolerancia y abstinencia. Para que se considere que cierta problemática responde a un patrón adictivo, deben identificarse claramente los fenómenos fisiológicos y conductuales de tolerancia y abstinencia. Sin embargo, la evidencia actual no permite afirmar taxativamente que éstos se den en la adicción al sexo (Mick \& Hollander, 2006). De ahí que modelos como los que consideran la CS como un trastorno del control de los impulsos, que también enfatizan el uso del sexo como regulador emocional pero obviando el papel central de la abstinencia o de la tolerancia en el cuadro clínico, hayan ganado fuerza.

5.2 Control de los impulsos: conducta sexual compulsiva vs. impulsiva

Es difícil establecer una clara distinción entre lo que consideramos una conducta compulsiva y una conducta impulsiva. De hecho, durante mucho tiempo, ambos términos se utilizaron de forma indistinta para referirse a un mismo fenómeno: la incapacidad para controlar los impulsos que nos empujan a realizar una determinada conducta (Kingston \& Firestone, 2008; Reid, Berlin, \& Kingston, 2015). En la actualidad, se considera que compulsividad e impulsividad comparten alteraciones en los mismos procesos cognitivos y un sustrato neurobiológico común, pero cuya expresión es opuesta (Fineberg et al., 2010).

La principal característica de las conductas impulsivas es que su objetivo es maximizar el placer o gratificación del que las realiza, independientemente de las consecuencias que para él o para otras personas pueda suponer (Claes, Nederkoorn, Vandereycken, Guerrieri, \& Vertommen, 2006; Moeller, Barratt, Dougherty, Schmitz, \& Swann, 2001). El ejemplo prototípico de conducta impulsiva es la del paciente cleptómano. Las personas con esta patología sienten un impulso irrefrenable por hurtar objetos que en realidad no necesitan, experimentan una importante sensación de tensión previa a la realización de la conducta que, una vez ejecutada, les supone un intenso placer (APA, 2014). En contraposición, las compulsivas tienen por objeto la reducción del malestar o ansiedad que genera resistir el impulso de realizar un determinado comportamiento (Claes et al., 2006). Además, este tipo de conductas se realiza de acuerdo a normas muy concretas, estereotipadas, que se establecen como hábito que la persona acaba realizando sin apenas ser consciente. Una forma habitual de comportamiento compulsivo es el que se da en pacientes con Trastorno Obsesivo Compulsivo (TOC). Un paciente con TOC (p.e., de limpieza y contaminación) experimentaría una serie de obsesiones intrusivas y altamente estresantes (a saber, "tocar un objeto que alguien ha tocado previamente puede transmitirme 
alguna enfermedad") que únicamente se verían mitigadas a través de ciertas conductas repetitivas que para él tienen el valor de contrarrestar esos pensamientos (suele ser común, por ejemplo, lavarse las manos compulsivamente).

De los anteriores ejemplos se deriva una de las grandes diferencias entre conductas impulsivas y compulsivas: el valor atribuido al comportamiento. Mientras que las conductas impulsivas tienen un carácter egosintónico (el paciente no valora su comportamiento como desviado o anormal y tampoco percibe malestar por su realización -al menos a corto plazo-), la ejecución de la conducta compulsiva se experimenta de forma muy negativa, intrusiva e interfiriente (egodistónica) (Pertusa et al., 2008).

Coleman (Coleman, 1987, 1990, 1992) fue el primero en defender que la conducta sexual excesiva debía entenderse como un tipo de conducta compulsiva, más concretamente como una expresión clínica del TOC. No en vano, este autor identifica en la CS los dos elementos esenciales en el diagnóstico del TOC: las obsesiones y las compulsiones. En la CS se manifiestan pensamientos obsesivos relacionados con el sexo y la sexualidad que los pacientes valoran como intrusivos, repetitivos y asociados a emociones negativas como la ansiedad y el estrés (egodistónicos). Estos pensamientos son extremadamente persistentes e interfirientes en tanto en cuanto los pacientes refieren ser incapaces de distraerse u ocupar de otra forma sus pensamientos (Black et al., 1997). Asimismo, la conducta concurrente a dichos pensamientos (la compulsión) sigue el patrón prototípico de las compulsiones en el TOC:

- La obsesión únicamente se mitiga a través de una conducta compulsiva, que en este caso suele ser el sexo tanto autoerótico como heteroerótico.

- El paciente trata de resistirse al impulso de ejecutar la compulsión al ser consciente de los perjuicios que puede ocasionarle pero aun así, es incapaz de lograrlo.

- El paciente acaba realizando un comportamiento compulsivo que en lugar de producirle placer, aumenta su emoción negativa y disconfort (Coleman, 1992; Raymond et al., 2003).

Efectivamente, la semejanza clínica entre TOC y CS sugeriría la posibilidad de considerar esta última como un subtipo del primero. Sin embargo, esto contraviene dos principios básicos. El primero de ellos tiene que ver con los criterios que el DSM contempla para el diagnóstico del TOC: este manual establece que "no pueden considerarse compulsiones [el comportamiento sexual, comer, dormir o consumir sustancias tóxicas] toda vez que la persona suele obtener placer a través de dichas actividades" (APA, 2002, p. 433). El segundo de ellos tiene que ver con la naturaleza de la compulsión: en el TOC, la compulsión constituye un acto físico o mental que representa una acción diametralmente opuesta a lo que su obsesión le impone (p.e., en 
un TOC de contaminación la compulsión típica se relaciona con la evitación de toda fuente de contaminación) (Schwartz \& Abramowitz, 2005). Sin embargo, la conducta compulsiva en los casos de deseo sexual excesivo no haría sino reafirmar el pensamiento obsesivo (replicar conductualmente -masturbarse o mantener relaciones sexuales- la obsesión mental). De ahí que los modelos que consideran la CS un subtipo de TOC fueran rápidamente desechados (Kingston \& Firestone, 2008; Schwartz \& Abramowitz, 2005).

Por otra parte, la consideración de la conducta sexual excesiva como un trastorno con un componente puramente impulsivo tampoco estaría exenta de problemas. Para empezar, existe una notable confusión en torno a la conceptualización y a la evaluación de la impulsividad, confusión posiblemente atribuible a que al mismo tiempo han convivido dos formas distintas de considerarla: la impulsividad como dimensión psicológica y como síntoma psicopatológico (Reid et al., 2015). Como dimensión, la impulsividad es un componente que refleja una tendencia a reaccionar a los estímulos internos o externos con respuestas rápidas y poco reflexivas (Moeller et al., 2001). Esto se traduce en una tendencia a actuar sin haber valorado previamente ni las alternativas ni las consecuencias de la conducta, en la preferencia por el pequeño refuerzo a corto plazo frente a los reforzadores de mayor magnitud a largo plazo y en la dificultad para terminar tareas que requieren de un mantenimiento sostenido de la atención (para una revisión, Reid et al., 2015). Como síntoma psicopatológico, la impulsividad es considerada elemento central en varios trastornos mentales (los denominados trastornos en el control de los impulsos) y síntoma transversal en multitud de patologías (abuso o dependencia del alcohol y otras sustancias, trastorno límite de la personalidad, trastorno bipolar, etc.). En el DSM-IV-TR, la sección de trastornos en el control de los impulsos incluía 6 cuadros clínicos: el trastorno explosivo intermitente, la cleptomanía, la piromanía, el juego patológico, la tricotilomanía y una categoría subsidiaria utilizada para el diagnóstico de otras condiciones afines pero menos prevalentes (p.e., la dermatilomanía, onicofagia, el abuso de Internet o las compras compulsivas) (APA, 2002). La reciente publicación del DSM-5 ha traído consigo grandes cambios como la sustitución del nombre clásico de esta categoría por el de trastornos destructivos del control de los impulsos y de la conducta. En esta nueva categoría se contempla únicamente el trastorno explosivo intermitente, la piromanía y la cleptomanía. Finalmente, el juego patológico (buque insignia de los trastornos del control de los impulsos) ha pasado a la categoría de trastornos relacionados con sustancias (APA, 2014).

Muchos han sido los investigadores que han propuesto que la CS, por su naturaleza y características, debería clasificarse como un trastorno en el control de los impulsos (Barth \& Kinder, 1987; Finlayson et al., 2001; Rinehart \& McCabe, 1998). De todos ellos, el modelo 
propuesto por Barth y Kinder (1987) es el más completo y el que mayor impacto ha supuesto. Estos investigadores se basan en dos elementos para proponer que el excesivo deseo sexual debe entenderse como un trastorno más del control de los impulsos: la comparación con otros trastornos de la misma categoría -en particular el juego patológico- y en algunos estudios con resultados que apoyan dicha hipótesis (Kingston \& Firestone, 2008). Según ellos, 7 de los 10 criterios propuestos por el DSM-IV para el diagnóstico de juego patológico resultan aplicables a la conducta sexual excesiva, cambiando únicamente la conducta objetivo (APA, 2002):

1. Preocupación por el sexo [en el original juego].

2. Necesidad de prácticas sexuales cada vez más intensas o frecuentes para lograr la excitación deseada.

3. Fracaso repetido de los esfuerzos para controlar, interrumpir o detener la conducta sexual excesiva.

4. Inquietud o irritabilidad cuando se intenta interrumpir o detener la conducta sexual.

5. El sexo se utiliza como estrategia para escapar de los problemas o para aliviar la disforia.

6. Se engaña a la familia, terapeuta u otras personas para ocultar el grado de implicación en la conducta sexual.

7. Se han arriesgado o perdido relaciones interpersonales significativas, trabajo $y$ oportunidades educativas o profesionales debido al sexo.

De acuerdo con Barth y Kinder (1987), los pacientes que cumplieran estos criterios serían susceptibles de recibir un diagnóstico de la categoría de trastornos en el control de los impulsos, más concretamente el trastorno del control de los impulsos no especificado siempre y cuando su interés sexual principal fuera normofílico-.

A nivel empírico, estos autores se basaron en el estudio de Quadland (1985) para fundamentar sus afirmaciones. Este investigador tomó una muestra de 30 hombres homosexuales y bisexuales que se autoidentificaban como adictos al sexo y que buscaron tratamiento para controlar sus impulsos sexuales y los comparó con una muestra equivalente de pacientes en psicoterapia por otros problemas psicológicos. Su objetivo era trazar un perfil diferencial entre ambos tipos de pacientes en cuanto a conducta sexual y a perfil psicopatológico. Al compararlos, se encontró que ambos grupos diferían únicamente en términos de parejas sexuales (los pacientes adictos al sexo informaban de una frecuencia sexual mensual con parejas esporádicas mucho mayor que el grupo control) pero no había diferencias en cuanto a tendencias o variables psicopatológicas. Tampoco se encontraron diferencias con respecto al número deseado de parejas sexuales (adictos al sexo y pacientes control deseaban una frecuencia sexual similar). Tanto Quadland (1985) como Barth y Kinder (1987) interpretaron 
estos hallazgos a favor de la teoría de la impulsividad sexual. Si lo que caracteriza a estos pacientes no es un deseo sexual desmedido, entonces el problema es que son incapaces de controlar voluntariamente su impulso sexual. La gran crítica a estas conclusiones es que no se exploraba la motivación para la realización de la conducta. Si la finalidad de la conducta sexual es maximizar el placer entonces hablaremos de impulsividad sexual pero no lo haremos si en realidad lo que se busca es mitigar la ansiedad o el estado de ánimo negativo, en cuyo caso hablaríamos de compulsividad sexual (Kingston \& Firestone, 2008).

Estudios posteriores donde sí se exploran las motivaciones que conducen a la conducta sexual excesiva evidencian la incapacidad de los modelos de impulsividad sexual y de compulsividad sexual para explicar por sí solos la fenomenología de la conducta sexual excesiva. Por ejemplo, Black et al. (1997) encontraron tras evaluar a 36 adictos al sexo ( 28 hombres y 8 mujeres) que escapar de un estado de ánimo disfórico resultaba la principal motivación para la realización de la conducta sexual. Asimismo, la actividad sexual no suponía una experiencia positiva ni maximizaba ningún tipo de placer, sino que muy al contrario provocaba una desagradable sensación de ausencia de control. En el extremo opuesto, Schwartz y Abramowitz (2003) encontraron que los pacientes hipersexuales realizaban la conducta sexual deliberadamente como medio para lograr emociones positivas, sensación de control y alivio. Parece pues que la conducta sexual excesiva pudiera tener en ocasiones un componente compulsivo y en otras impulsivo. A esta misma conclusión llegan Raymond, Coleman y Miner (2003) al encontrar que un tercio de su muestra de pacientes adictos al sexo valoraba sus pensamientos sexuales como intrusivos y que un $87 \%$ trataba de resistir los impulsos que de ellos se derivaban, síntomas que apoyarían la noción de compulsividad sexual. Al mismo tiempo, las puntuaciones de estos pacientes en escalas de impulsividad resultaron muy superiores a las de muestras normativas, lo que por otra parte indicaría que en este tipo de pacientes conviven rasgos tanto impulsivos y como compulsivos.

Durante los últimos años, varios estudios han venido a refrendar las conclusiones extraídas en los estudios anteriores: ni la hipótesis de la impulsividad sexual ni de la compulsividad sexual permiten explicar por sí solas la casuística de este tipo de pacientes, sino que debe entenderse en el contexto de la expresión concurrente de ambos tipos de comportamientos. Los últimos estudios realizados con muestra clínica evidencian una relación sistemática entre hipersexualidad y medidas de autoinforme de impulsividad general (Reid, Garos, \& Carpenter, 2011). Es más, la impulsividad nos permite explicar por sí sola (controlando otras variables de personalidad o psicopatológicas) una importante varianza en las puntaciones de un inventario de hipersexualidad (Reid, Stein, \& Carpenter, 2011). Sin embargo, sólo entre el 48\%-55.3\% de 
estos pacientes muestra niveles clínicos de impulsividad generalizada (Reid, Cyders, Moghaddam, \& Fong, 2014), lo que sugiere que en el porcentaje restante el componente compulsivo pudiera tener un peso más significativo.

Dos modelos teóricos superan la visión compartimentada del deseo sexual excesivo o bien como una conducta compulsiva o como una conducta impulsiva, integrando bajo un marco común las aportaciones de ambas propuestas. Se trata de modelos que se han agrupado bajo la etiqueta de "modelos de conducta sexual compulsiva-impulsiva" (en su versión original impulsive-compulsive sexual behavior models) (McBride et al., 2011; Mick \& Hollander, 2006; Miner et al., 2009). El primero de ellos y también el que mayor impacto ha supuesto es el de Kalichman y colaboradores, propuesta teórica que hemos tomado como eje vertebrador en la elaboración de la presente tesis doctoral. El interés primario del equipo de investigación de Kalichman no era per se el estudio de la compulsividad sexual como fenómeno clínico, sino más bien el estudio de factores de riesgo para la transmisión del VIH en diferentes colectivos. De hecho, su interés para con la conducta sexual fuera de control surgió como consecuencia de la necesidad de explorar algunas de las variables que pudieran explicar por qué a algunas personas que habitualmente realizaban conductas sexuales de riesgo les resultaba tan difícil adoptar estrategias preventivas -lo que se ha llamado "perfil resistente al cambio" - (Kalichman et al., 1994). De acuerdo con Kalichman y Cain (2004), la compulsividad sexual se define como "la propensión a experimentar cierta desinhibición sexual o impulsos y conductas sexuales descontroladas en ciertas situaciones" (Kalichman \& Cain, 2004, p. 239). Estos investigadores no asumen una única vía etiológica para la expresión de la CS, sino que entienden que este cuadro clínico puede ser consecuencia de una necesidad por controlar estados emocionales o pensamientos disfóricos (componente compulsivo), de un interés hedónico o de desinhibición para con un impulso que les resulta placentero (componente impulsivo) o constituir una mezcla de los dos casos anteriores (McBride et al., 2011).

Además, la propuesta de Kalichman es en esencia dimensional: huye de la visión clásica de la CS como una condición patológica, de modo que afirman explícitamente que su concepto se aleja de las etiquetas de adicción al sexo, hipersexualidad, etc. (Kalichman \& Cain, 2004). Sin embargo, dejan abierta la puerta a considerar que personas con una expresión extrema de una tendencia a la pérdida del control sobre su conducta sexual constituyan un grupo susceptible de recibir un diagnóstico en este sentido y atención clínica centrada en estos problemas (Benotsch, Kalichman, \& Kelly, 1999; Kalichman \& Cain, 2004; Kalichman \& Rompa, 1995; McBride et al., 2011). Estudios recientes avalan la concepción dimensional de la compulsividad sexual tal y como Kalichman y colaboradores proponen (Walters et al., 2011). 
El segundo de estos modelos es el propuesto recientemente por Reid et al. (2015). Estos investigadores asumen la existencia de un continuo (el espectro obsesivo-impulsivo) donde el elemento común sería la incapacidad para controlar los impulsos sexuales y cada uno de los extremos representaría las motivaciones que llevarían a dicha incapacidad. En el extremo compulsivo, la motivación sería la de la reducción del malestar asociado a no realizar la conducta compulsiva mientras que en el extremo impulsivo, la motivación sería maximizar el placer asociado a la realización de la conducta impulsiva. Los pacientes en el extremo compulsivo del espectro tienden a experimentar una sensación exagerada de vulnerabilidad y de amenaza por estímulos externos y la conducta compulsiva se convertiría en el vehículo para la reducción o neutralización de la amenaza. En el caso de la conducta sexual excesiva, los pacientes con este tipo de presentaciones son aquellos cuya principal motivación para la realización de la conducta sexual es la regulación de estados emocionales disfóricos o bien la neutralización de pensamientos sexuales persistentes e intrusivos. La realización de la conducta sexual en estos casos se percibiría como muy negativa y, por tanto, la conciencia de enfermedad sería muy alta. Para algunos de estos pacientes, la conducta sexual se llegaría a convertir en un ritual equivalente a las compulsiones de un paciente con TOC, si bien esta forma de presentación de la compulsividad sexual resulta minoritaria (Reid, 2007). Por otra parte, los pacientes en el extremo impulsivo del espectro tienden a subestimar o infravalorar las consecuencias de la conducta sexual excesiva. En algunos casos puede existir cierta conciencia de que la conducta sexual resulta exagerada y que puede suponerles consecuencias negativas graves (p.e., la ruptura de una pareja ante infidelidades recurrentes). Sin embargo, tendría más peso para ellos el beneficio de su realización (el placer que les reporta el acto sexual) que los riesgos o las consecuencias negativas.

Este modelo también da buena cuenta de cómo ambos extremos pueden interactuar y evolucionar hasta el establecimiento del cuadro clínico. Según Reid et al. (2015), la motivación inicial para la realización de la conducta sexual excesiva suele relacionarse con la maximización del placer y la omisión de los riesgos, conducta que se podría entender en el extremo impulsivo del espectro. Sin embargo, con el tiempo se establecería un patrón de conducta donde el placer inicial asociado a la actividad sexual se convierte en una necesidad que lejos de suponer placer alguno, acaba provocando un serio perjuicio en diferentes ámbitos de la vida del individuo. En ese momento el paciente ya es plenamente consciente de los perjuicios de su conducta y es cuando se establece el patrón compulsivo (Berlin \& Hollander, 2008). 
5.3 Regulación del deseo sexual: hipersexualidad y modelo de control dual

El nexo entre los dos últimos modelos es que ambos consideran que el elemento central del cuadro clínico es un excesivo deseo sexual. Por tanto, la categoría lógica y natural donde este trastorno debería integrarse es la de los trastornos sexuales (Bancroft, 2009; Kafka, 2013; Kaplan \& Krueger, 2010).

El modelo de hipersexualidad propuesto por Kafka (Kafka, 2010) y desarrollado en múltiples publicaciones posteriores (Kafka, 2013, 2014; Reid \& Kafka, 2014) parte de un único supuesto: la hipersexualidad es la expresión extrema y patológica de una pulsión biológica, innata y común a cualquier mamífero -no sólo a los humanos-, el deseo sexual. Según este autor, el deseo sexual sigue una distribución similar a la de la curva normal ya que la gran mayoría de las personas se aglutinan en valores intermedios de deseo -lo que en términos estadísticos llamaríamos la media y cuya equivalencia a nivel clínico es la normalidad-. Basándose en estudios clásicos como los de Kinsey, Pomeroy y Martin (1948) y también en otros más actuales, se estableció que la actividad sexual media de la gran mayoría de la población rondaba los dos orgasmos semanales. Sin embargo, un pequeño reducto de población se aleja de esta normalidad -estadística y clínica- y se sitúa en uno de sus extremos. Si la persona se localiza en el extremo inferior, entonces es susceptible de recibir el diagnóstico de deseo sexual hipoactivo mientras que en el extremo contrario, la persona con un excesivo deseo sexual recibe el diagnóstico de deseo sexual hiperactivo o, como es más frecuente, de hipersexualidad. Ni el DSM-IV-TR ni el DSM-5 consideran la frecuencia sexual como único indicador para el diagnóstico del deseo sexual hipoactivo -ni tampoco el más importante-, sino que junto con este criterio se contemplan otros aspectos como la frecuencia de fantasías sexuales o el deseo espontáneo por mantener relaciones (APA, 2002, 2014). En la misma línea, los criterios propuestos para el diagnóstico de hipersexualidad en el DSM-5 tampoco contemplan la frecuencia sexual como criterio inequívoco de presencia del cuadro clínico, si bien es cierto que el peso que en este caso se da a este indicador es mayor. Concretamente, una frecuencia media semanal de 7 o más orgasmos (lo que durante el primer capítulo presentábamos como la regla del TSO $\geq 7$ ) se considera indicador de la presencia de un cuadro clínico de hipersexualidad.

El modelo de hipersexualidad huye deliberadamente de cualquier explicación etiológica. No en vano, el objetivo de este modelo es "establecer una clasificación nosológica y diagnóstica neutral, abierta e inclusiva" (Kafka, 2010, p. 3) que permita integrar distintas aportaciones al estudio del deseo sexual excesivo independientemente de los mecanismos etiológicos que se le atribuya. Este intento por mantener posiciones más neutrales se hace patente también en la 
selección del término para su designación -a saber, hipersexualidad-, elegido a partir de criterios puramente etimológicos: "Cuando la conducta o el funcionamiento biológico muestra un desempeño por debajo de lo normal, el prefijo griego que se suele aplicar es el de hipo-. Por el contrario, el prefijo hiper- es consistente con la noción de un exceso o incremento en la conducta que conduce a una serie de consecuencias adversas [...]. De ahí el uso del término hipersexualidad" (Kafka, 2010, p. 2). En su intento por mantener esa neutralidad, este modelo se ha convertido más en un marco de referencia para la identificación y clasificación de la compulsividad sexual que en una teoría explicativa de su inicio o mantenimiento.

Un modelo alternativo y complementario es el modelo de control dual de la conducta sexual, desarrollado por investigadores del Instituto Kinsey para explicar las diferencias en el deseo y el comportamiento sexual y con implicaciones directas sobre la comprensión de la CS (Kafka, 2010; Kaplan \& Krueger, 2010). Este modelo postula que la respuesta sexual y el ciclo de deseo y excitación dependen de la interacción entre dos sistemas -ambos ubicados en zonas cerebrales todavía pendientes de identificar-: el sistema de activación/excitación sexual y el sistema de inhibición sexual. Estos dos sistemas de respuesta actúan de forma independiente y su combinación determina que las personas muestren mayor o menor apetito sexual así como más o menos habilidades para el control de la conducta sexual (Bancroft, 1999, 2009; Bancroft, Graham, Janssen, \& Sanders, 2009; Bancroft \& Janssen, 2000).

Para cuantificar la acción de cada uno de estos sistemas, se desarrolló un cuestionario compuesto por tres escalas: dos de ellas (la escala de inhibición sexual por miedo a fallos durante la actividad erótica y la escala de inhibición sexual por miedo a las consecuencias de la actividad erótica) dirigidas a la evaluación de la acción del sistema de inhibición sexual y la tercera (la escala de excitación sexual) orientada a la evaluación del sistema restante (Janssen, Vorst, Finn, \& Bancroft, 2002). La aplicación de estas escalas a diferentes tipos de población permitió identificar patrones y combinaciones consistentes de estos tres componentes que explicaban en buena medida distintos cuadros clínicos.

El perfil más frecuente se caracteriza por puntuaciones medias en las tres escalas y se corresponde con una capacidad normal para el control de la conducta sexual. Por otra parte, las personas con un bajo deseo sexual se caracterizan por puntuaciones sistemáticamente bajas en la escala de excitación sexual y un patrón de altas puntaciones en las dos escalas de inhibición sexual. Este es el patrón que encontraron Prause y Graham (2007) al evaluar a través de una plataforma de evaluación online a 41 pacientes asexuales -personas que voluntariamente habían rechazado mantener una vida sexual activa-. En el extremo contrario, las personas con una combinación de bajas puntuaciones en las escalas de inhibición sexual - 
sobre todo la de inhibición sexual por miedo a las consecuencias de la actividad erótica- y altas puntaciones en la escala de excitación sexual suelen experimentar problemas en el control de la conducta erótica, lo que se traduce en un perfil de personas con tendencia a la actividad sexual de riesgo y a la promiscuidad sexual. En un estudio en el que se comparaba a 31 pacientes adictos al sexo y una muestra control, Bancroft y Vukadinovic (2004) encontraron entre los primeros puntuaciones significativamente superiores en la escala de excitación sexual, así como puntuaciones menores en las escalas de inhibición sexual. A resultados similares llegaron Winters, Christoff y Gorzalka (2010) tras evaluar a 107 hombres y 69 mujeres que dijeron haber buscado tratamiento por problemas en el control de los impulsos sexuales. Nuevamente estos pacientes obtuvieron puntaciones significativamente mayores en la escala de excitación sexual y menores en las dos escalas de inhibición sexual. Además, esta combinación de puntaciones correlacionaba significativamente con la Escala de Compulsividad Sexual (SCS), es más, todas estas variables constituían un único factor que permitía explicar buena parte de la varianza del cuadro clínico de compulsividad sexual de estos pacientes.

El estudio más reciente que arroja luz sobre esta cuestión es el realizado por Muise, Milhausen, Cole y Graham (2013). El interés de estos investigadores era seguir explorando la relación entre CS y excitación/inhibición sexual pero en población subclínica. Además, querían comprobar si cada uno de estos componentes tiene un peso diferencial a la hora de predecir las variaciones en CS, así como los componentes concretos que pueden estar interviniendo en esta relación. Para ello, tomaron una muestra de 240 mujeres y 1061 hombres heterosexuales casados a los que aplicaron la escala de compulsividad sexual (SCS) y una versión alternativa del cuestionario de Janssen de excitación e inhibición sexual. Esta nueva escala permite medir la tendencia a la excitación ante una gran variedad de situaciones (excitabilidad), la inhibición debido a preocupaciones sexuales (p.e., la preocupación porque la pareja descubra la actividad sexual) y la inhibición por la importancia de la pareja (es decir, la tendencia a frenar encuentros o situaciones sexuales con otras personas para evitar cometer una infidelidad). Estos investigadores encontraron que las puntuaciones en la escala de compulsividad sexual se relacionan tanto en hombres como en mujeres con una mayor excitabilidad y con una menor inhibición por mantener una relación estable. De hecho, estas dos escalas logran predecir hasta el $27 \%$ de la varianza de las puntuaciones en la escala SCS. Estos resultados vienen a refrendar las conclusiones extraídas en los dos estudios anteriores y además realizan un hallazgo que hasta el momento había pasado desapercibido. En hombres, la CS también se relaciona positivamente con la inhibición debida a preocupaciones sexuales. Este hallazgo que pudiera parecer contradictorio es interpretado por los autores como una suerte de mecanismo 
de defensa ya que si tenemos en cuenta que los hombres evaluados en esta investigación eran personas casadas, la inhibición sexual podría estar ejerciendo una especie de mecanismo de compensación a una alta tendencia a la excitación -el que tengan más preocupaciones sexuales es el mecanismo de defensa que se activaría para evitar que estos hombres acaben cometiendo adulterio-. De no activarse este mecanismo, estos hombres tal vez podrían acabar experimentando problemas en el control de sus impulsos sexuales.

Un hallazgo complementario a lo comentado y crucial a la hora de entender la expresión clínica de la CS es el de la relación paradójica entre estado de ánimo y conducta sexual (Kaplan \& Krueger, 2010). En las personas con un funcionamiento sexual normal, situaciones de estrés, ansiedad o depresión (es decir, situaciones donde predomina un estado de ánimo disfórico) suelen provocar una preponderancia del sistema de inhibición sexual. Esto es, el sistema de excitación sexual perdería intensidad y ganaría protagonismo el sistema de inhibición sexual. Esta es la configuración que se da habitualmente en pacientes con deseo sexual hipoactivo, si bien en este caso tendría una clara función adaptativa: priorizar los recursos de los que la persona dispone para mejorar el estado de ánimo (Bancroft et al., 2009). Sin embargo, en las personas con problemas de CS se daría una reacción diametralmente opuesta ya que el estado de ánimo disfórico dispara el sistema de excitación sexual, que trasciende la capacidad inhibitoria del sistema opuesto y provoca un aumento del deseo sexual. No se sabe a ciencia cierta el motivo de esta relación paradójica, pero algunos estudios cualitativos con este tipo de pacientes revelan que el sexo en estos casos pudiera estar usándose como distractor (sobre todo cuando la conducta sexual principal es la masturbación) o como medio para lograr intimidad emocional caso que la conducta sexual principal sea con parejas sexuales (Bancroft \& Vukadinovic, 2004). En cualquier caso, lo cierto es que el $61 \%$ de los pacientes con CS experimentan un aumento del deseo sexual durante episodios de ansiedad y un 55\% durante episodios depresivos (Bancroft \& Vukadinovic, 2004) frente al $20 \%$ y el $9.4 \%$ en población normal (Bancroft, Janssen, Strong, Carnes, et al., 2003).

\section{En resumen}

Las teorías contemporáneas explican el inicio y mantenimiento del cuadro clínico de CS a partir de una perspectiva biopsicosocial. Entre los determinantes biológicos que predisponen el inicio e incrementan la gravedad del comportamiento sexual compulsivo destacan los factores neurobiológicos (funcionamiento anómalo de la amígdala y el córtex prefrontal, alteración del sistema de recompensa asociado a déficits en el núcleo accumbens y el estriado ventral y desregulación de los sistemas de neurotransmisión de dopamina y serotonina) y hormonales (incremento de los niveles de testosterona y decremento de los de estradiol). Por otra parte, 
los principales factores psicológicos asociados a este cuadro clínico serían haber sido víctima de abuso sexual infantil, haber sido criado en entornos negligentes y experimentar problemas de vinculación (apego inseguro). Finalmente, determinantes sociales como la aperturacerrazón hacia el sexo en culturas y grupos de población concretos o el seguimiento de ciertos preceptos morales o religiosos parecerían jugar cierto papel en la etiología de este cuadro clínico.

De estos tres factores, los psicológicos acumulan mayor aval empírico a su favor. Así, múltiples estudios demuestran su papel como predisponentes en el desarrollo de problemas de control de los impulsos sexuales. El papel del entorno social y cultural en la regulación de la conducta sexual es indiscutible, si bien su impacto directo sobre el desarrollo del cuadro clínico de CS es cuestionable. Finalmente, las evidencias en torno al sustrato biológico de la CS se consideran todavía preliminares en tanto en cuanto se derivan de investigaciones con modelos animales o de estudios de farmacología de la conducta sexual compulsiva.

Se han propuesto 3 modelos teóricos para explicar el inicio y el mantenimiento de la conducta sexual compulsiva. El primero de ellos (modelo de "adicción al sexo") equipara esta patología a cualquier otro problema de abuso o dependencia de sustancias, haciendo énfasis en síntomas comunes como la tolerancia, la abstinencia o la tendencia a la recaída. Esta teoría se encuadra en el movimiento de las llamadas "adicciones no tóxicas". Una de sus principales aportaciones es el llamado "ciclo de la adicción". Este concepto se ha empleado a la hora de explicar el inicio y el mantenimiento de la conducta sexual compulsiva. Según esta teoría, una actividad sexual moderada permitiría inicialmente regular el estado de malestar emocional de estos pacientes; habida cuenta de su eficacia, estos pacientes instaurarían esta conducta como mecanismo de afrontamiento, desarrollando cierta tolerancia que le obligaría a aumentar la intensidad para lograr el alivio inicial del malestar; cuando aparece la tolerancia, la conducta sexual pasa de ser un reforzador positivo (fuente de placer) a convertirse en reforzador negativo (conducta que se realiza para evitar los síntomas de abstinencia o craving).

El segundo (modelo de "control de impulsos") haría énfasis en los conceptos de impulsividad y compulsividad a la hora de explicar la conducta sexual excesiva. Las conductas impulsivas son aquellas que se realizan para lograr una sensación de placer a muy corto plazo (como el hurto de un objeto innecesario en la cleptomanía) mientras que las compulsivas se hacen para aliviar el malestar que genera resistir el impulso (como los rituales en el TOC). Las personas con CS transitan entre ambos tipos de conducta durante el desarrollo del cuadro clínico: los pacientes en el extremo impulsivo del continuo realizarían la conducta sexual porque les supondría una sensación positiva a muy corto plazo (presumiblemente por el efecto fisiológico del orgasmo) y 
tendrían una muy baja conciencia de enfermedad. Este sería el perfil típico del paciente con tendencia a la infidelidad y el sexo con múltiples parejas. Por el contrario, los pacientes en el extremo compulsivo tenderían a experimentar malestar y una sensación de vulnerabilidad que sólo se mitiga a través de una conducta sexual que ellos mismos considerarían exagerada. Estos pacientes sí experimentan una alta conciencia de enfermedad.

El tercer y último modelo (el de "regulación del deseo sexual") integraría las aportaciones de las teorías de la hipersexualidad y del control dual de la conducta sexual. Ambas comparten su visión de la CS como consecuencia de un deseo sexual desmedido; sin embargo, discrepan en cuanto a mecanismos explicativos. La teoría de la hipersexualidad huye de tratar de dar explicación etiológica alguna y concluye que la conducta sexual compulsiva es el resultado única y exclusivamente de un desmedido impulso sexual. El modelo de control dual parte de este mismo supuesto pero propone la interacción de dos sistemas independientes (el sistema de excitación sexual y el de inhibición sexual) a la hora de explicar este cuadro clínico. En las personas con un deseo sexual, ambos sistemas tendrían una influencia similar; en personas con un deseo sexual hipoactivo, el sistema de inhibición sexual se impondría sobre el de excitación; en personas con un cuadro clínico de compulsividad sexual, sucedería justo al contrario (el de excitación sexual superaría con creces las capacidades inhibitorias del sistema contrario). 



\section{Capítulo 4. variables moduladorass en compulsividad sexual principales hallazgos}

1. Variables sociodemográficas de interés en la manifestación y gravedad de la CS

1.1 Sexo

1.2 Edad

1.3 Orientación sexual

2. Personalidad y CS

3. Historia sexual, comportamiento sexual y disposiciones sexuales

3.1 Historia sexual y comportamiento sexual

3.2 Conducta sexual online

3.3 Búsqueda de sensaciones sexuales

3.4 Erotofilia-erotofobia

4. Variables clínicas generales de interés en CS

4.1 Ansiedad y depresión

4.2 Autoestima

5. En resumen

6. Justificación de la necesidad de este estudio 


\section{Variables sociodemográficas de interés en la manifestación y gravedad de la CS}

\subsection{Sexo}

La literatura científica en torno a la CS tiene un vacío importante en lo que a diferencias entre hombres y mujeres se refiere. La visión actual de la CS y del deseo sexual excesivo se ha construido a partir de una concepción masculina de la sexualidad, principalmente porque la mayoría de las investigaciones se han encontrado con serias dificultades a la hora de reclutar a mujeres con esta patología: tan sólo 8 de los 36 pacientes (el 22\%) evaluados por Black et al. (1997) eran mujeres, porcentaje que disminuía al 13.6\% (12 mujeres) y el 8\% (2 mujeres) en la investigación de Raymond et al. (2003) y de Schneider \& Schneider (1996) respectivamente. Por otra parte, en una encuesta enviada a los miembros de la Sociedad Alemana de Sexología, se encontró que de los 97 pacientes con sintomatología de CS tratados por alguno de estos profesionales, tan sólo 19 (20\%) fueron mujeres (Briken, Habermann, Berner, \& Hill, 2007).

Ante la escasez de resultados empíricos, han proliferado toda una serie de actitudes, mitos y falsas creencias que menoscaban la concreción de las características propias y diferenciales del cuadro clínico de la CS en mujeres. Como señala McKeague (2014), muchos investigadores asumen que la etiología, curso clínico, manifestaciones y tratamiento de la CS es equivalente en hombres y en mujeres, sobregeneralizando a ambos sexos los conocimientos actuales sobre este cuadro clínico. Por su parte, Ferree (2001) identifica 6 mitos muy extendidos que menoscaban la atención clínica a mujeres con esta patología: 1) "las mujeres no pueden ser adictas al sexo"; 2) "las mujeres con síntomas de CS en realidad no son adictas al sexo, sino adictas al amor"; 3) "lo que le pasa a una mujer con CS es que necesita afecto"; 4) "la manifestación de la CS en mujeres es idéntica a la de los hombres"; 5) "las consecuencias de la compulsividad sexual en hombres y mujeres son iguales" y; 6) "los instrumentos diagnósticos de la CS que utilizamos habitualmente con hombres son también útiles con mujeres". A algunos de estos mitos subyace una visión paternalista y patriarcal de la sexualidad femenina, prefiriendo verlas como mujeres enamoradizas que como compulsivas sexuales.

En una exhaustiva revisión de la escasa bibliografía existente, Mckeague (2014) señala las 3 principales áreas donde hombres y mujeres muestran un perfil diferencial en cuanto a manifestación de la CS: 1) etiología; 2) manifestaciones clínicas y; 3) consecuencias de la CS.

En cuanto a etiología, la evidencia disponible parece indicar que el vínculo entre abuso sexual infantil, problemas de apego y CS es más sólido en mujeres que en hombres. Tedesco y Bola (1997) encontraron una prevalencia similar de casos de abuso sexual infantil entre 24 hombres y 21 mujeres con problemas en el control de los impulsos sexuales, si bien su frecuencia y 
severidad fue mayor en mujeres. Probablemente fruto de la gravedad del abuso, también resulta más frecuente que las mujeres con CS y antecedentes de abuso sexual infantil tengan más probabilidad de padecer un trastorno por estrés postraumático $(52.4 \%$ de las mujeres frente al 31.6\% de los hombres) (Schneider \& Schneider, 1996).

Por su parte, Opitz, Tsytsarev y Froh (2009) evaluaron la relación entre abuso infantil, entorno familiar, cuidados paternos y CS en 99 mujeres que asistían o habían asistido a grupos de autoayuda para adictos al sexo (hasta la fecha, el estudio con mayor muestra clínica femenina). Entre otros hallazgos, se documentaron correlaciones positivas y significativas entre las puntuaciones en el cuestionario SAST de adicción al sexo y 5 tipos de abuso infantil: abuso sexual, físico, emocional, rechazo al contacto físico y rechazo al contacto emocional. Al contrario, las puntuaciones en el SAST correlacionaban inversamente con medidas de cohesión y adaptación familiar ( $r=-0.413)$ : entornos familiares más desestructurados y negligentes predecían una mayor tendencia a la CS. Por lo que respecta a la relación entre adicción al sexo y estilo educativo paterno, se encontró que estilos educativos paternos extremos -tanto sobreprotectores como negligentes- se asociaban a mayores dificultades en el control de los impulsos sexuales durante la edad adulta.

A nivel clínico, las creencias y pensamientos automáticos típicos en un paciente con CS presentan mayor gravedad en el caso de las mujeres debido a que a la culpabilidad y vergüenza de no ser capaces de controlar su propia conducta sexual se le suma la sanción social que supone ser sexualmente activa en una sociedad donde el rol sexual atribuido a la mujer es pasivo y supeditado a la voluntad masculina (McDaniel, 2008). En este sentido, es habitual que el sistema de creencias de las pacientes con CS se conforme con afirmaciones como: 1) el amor sólo se obtiene a través del sexo; 2) una mujer sólo está "completa" junto a un hombre; 3) una pareja resuelve cualquier problema de una mujer; 4) la intimidad y cercanía emocional sólo se consigue a través de una relación sexual y 5) el sexo es lo único que permite captar la atención de un hombre (Ferree, 2001).

Langström y Hanson (2006a) encontraron que en comparación con los hombres con altos niveles de hipersexualidad, las mujeres eran más jóvenes, habían sido separadas de sus familias de origen en mayor frecuencia (30\% frente al $25 \%$ de los hombres), habían sido víctimas de una agresión antes y después de los 18 años, habían tenido más problemas de pareja, un mayor porcentaje había mantenido relaciones sexuales con personas del mismo sexo (13.8\% frente al $7 \%$ ) y usaban frecuentemente el dolor -tanto infligido como padecido- durante sus relaciones sexuales. Además, el $40 \%$ de estas mujeres habían buscado alguna vez ayuda especializada por sus problemas sexuales frente al $14 \%$ de los hombres, lo 
que contradice el mito de que las mujeres con esta problemática raramente buscan atención clínica especializada.

Por lo que se refiere a su comportamiento sexual, la idea que se desprende de los estudios realizados hasta el momento es que el elemento diferencial entre hombres y mujeres no es la frecuencia sexual, sino el medio a través del cual mantiene la actividad sexual. En hombres, la actividad sexual más frecuente sería la masturbación mientras que en mujeres lo sería el coito. Skegg et al. (2010) encontraron que un mayor porcentaje de mujeres con CS que de hombres dijeron haber tenido más de 10 parejas sexuales durante los últimos años (26\% frente al $20 \%$ en hombres), haber sido infieles a sus parejas estables (52\% frente al $38 \%$ ), estar menos satisfechas sexual y emocionalmente con sus parejas estables, haber mantenido relaciones sexuales con una persona a la que habían conocido por internet ( $10 \%$ frente al $5 \%$ ) y haber mantenido relaciones sexuales con personas de su mismo sexo. En esta misma línea, Winters et al. (2010) encontraron al comparar a hombres y mujeres que habían buscado tratamiento por problemas en el control de impulsos sexuales que la frecuencia semanal de masturbación en el caso de los hombres (6.71 veces) y el número de horas semanales viendo pornografía (7 horas) superaba con creces a la obtenida en el grupo de mujeres (3.29 masturbaciones por semana y alrededor de hora y media viendo pornografía). Por el contrario, las mujeres superaban a los hombres en actividad sexual en pareja durante los últimos 3 meses (59.1 coitos en mujeres frente al 35.27 en hombres). Finalmente, la frecuencia de orgasmos semanales resultó muy similar en hombres (8.31 orgasmos) y en mujeres (9.21).

Por lo que se refiere a las consecuencias de la CS en hombres y mujeres, las áreas afectadas por este cuadro clínico (familia, pareja, salud, trabajo, estabilidad personal, etc.) no difieren, pero varía su gravedad y severidad. Las mujeres con esta problemática se enfrentan al problema principal de su patología y al problema añadido del juicio moral y social, aspecto que menoscaba aún más las principales áreas de su vida. Además, las mujeres se enfrentan a un problema adicional derivado de su actividad sexual compulsiva: la posibilidad de un embarazo no deseado. Ferree (2001) estima que entre el $25 \%$ y el $50 \%$ de sus pacientes ha cesado voluntariamente un embarazo que no deseaba cuanto menos en alguna ocasión.

\subsection{Edad}

Generalmente, la CS no se manifiesta durante la infancia o la adolescencia temprana. En la literatura se han descrito algunos casos de adolescentes cuya conducta sexual sugeriría la presencia de esta patología (El-Gabalawi \& Johnson, 2007), pero en la mayoría los síntomas se pueden explicar a partir de una enfermedad física o de un trastorno mental grave. No es 
infrecuente que niños y adolescentes en fases agudas de ciertos trastornos mentales graves muestren una conducta sexual exagerada o inapropiada: en una investigación realizada en niños ingresados en una unidad de salud mental infantil, la prevalencia de este tipo de problemas se situaba en torno al 40\% (J. Adams, McClellan, Douglass, McCurry, \& Storck, 1995). De entre aquellos que mostraban una conducta sexual inapropiada, las manifestaciones más frecuentes eran en el $20 \%$ de los casos exhibicionismo, abuso sexual de otros pacientes en un $40 \%$ y problemas en el control de los impulsos sexuales en el $40 \%$ restante.

Lo que sí resulta frecuente es que durante la infancia y adolescencia temprana se manifiesten rasgos o síntomas que preceden el desarrollo de un cuadro clínico de CS. El más común es la elevada frecuencia de masturbación. Los estudios retrospectivos revelan que durante su infancia, estos pacientes se suelen masturbar más que el resto de los jóvenes de su edad. Así, Briken, Habermann, Kafka, Berner y Hill (2006) encontraron que más de la mitad -el 58.6\%- de su muestra de pacientes hipersexuales se masturbaba con una frecuencia diaria durante la adolescencia y que el $13 \%$ lo hacía más de una vez al día. El porcentaje de los que lo hacían más de una vez al día ascendía hasta el $43.4 \%$ cuando además de la hipersexualidad, los pacientes desarrollaban una parafilia comórbida. En ambos casos, estas cifras superan el $4.5 \%$ de adultos sanos que durante su adolescencia se masturbaban más de una vez al día.

Estos primeros signos y síntomas tienden a empeorar entre los 16 y los 18 años, coincidiendo con el periodo en el que los jóvenes comienzan a iniciarse en mayor medida en la actividad sexual. Durante esta etapa, los jóvenes con rasgos compulsivos se caracterizan por iniciar su actividad sexual más tempranamente, con un mayor número de parejas sexuales y corriendo más riesgos durante la actividad sexual (Långström \& Hanson, 2006a). El 54\% de los pacientes que participaron en el estudio clínico de Reid, Carpenter, et al. (2012) identificaron el periodo de entre los 16 y los 18 años como el momento en el que comenzaron sus problemas sexuales.

El siguiente periodo crítico comprende los 18-25 años y corresponde al pródromo o periodo de manifestación subclínica de la patología. Durante este periodo, los síntomas empeoran de tres formas: se incrementa el tiempo dedicado a la actividad sexual, su frecuencia, su intensidad y sus manifestaciones y síntomas. Desde el momento en que aparecen los primeros síntomas hasta que el cuadro clínico se manifiesta por completo pueden transcurrir meses o incluso años, pudiéndose dar casos en que la patología remita espontáneamente. Estas remisiones pueden ser completas, si bien lo habitual es que después de un periodo de remisión el cuadro clínico retorne. Reid, Carpenter, et al. (2012) identifican un curso clínico episódico (alternancia de periodos de remisión y recaída) en el 50\% de los casos; por otra parte, Kafka (1997) encuentra que en los casos de curso episódico, la mayoría de pacientes (el 77\%) informa de 7 o 
más periodos de recaída por lo que la alternancia remisión-recaída parece ser muy rápida. En raras ocasiones (tan sólo en el $\mathbf{1 5 . 6 \%}$ de los casos) se desarrolla la CS si durante el periodo de los 18 a los 25 años no se han mostrado signos o síntomas (Reid, Carpenter, et al., 2012).

El periodo entre los 18-25 años coincide con el momento en el que los jóvenes comienzan a cursar estudios superiores, de modo que en muchos casos los problemas se manifiestan en el contexto de las relaciones sexuales entre universitarios (presumiblemente por las numerosas oportunidades de interacción que en este contexto se producen). En este sentido, se estima que más del $80 \%$ de los universitarios son sexualmente activos, que el frecuente consumo de alcohol durante las fiestas universitarias aumenta la probabilidad de mantener relaciones sexuales con desconocidos, que el $36 \%$ de los universitarios ha tenido encuentros sexuales de una noche y que el $29 \%$ los ha tenido con una persona a la que conocían desde hacía menos de 5 horas (Eshbaugh \& Gute, 2008; Goldstein, Barnett, Pedlow, \& Murphy, 2007). En este contexto, Stupiansky et al. (2009) demostraron que las jóvenes universitarias con mayores puntuaciones en el cuestionario SCS tenían un historial de parejas sexuales más extenso, era más probable que hubieran sido infieles a sus parejas y se mostraban más convencidas de querer seguir manteniendo relaciones sexuales con parejas a las que acabaran de conocer.

Existe cierto debate en torno a la relación entre la edad y la gravedad de la CS: algunos investigadores sostienen que dado que la CS evoluciona y gana gravedad de forma progresiva, los pacientes de 25 años en adelante (es decir, aquellos que han dispuesto de más tiempo para el empeoramiento de su cuadro clínico) serán los que exhiban una sintomatología de mayor gravedad. Otros investigadores defienden que al periodo de entre los $18-25$ años se le considera subclínico no tanto porque la intensidad de los síntomas sea menor que de 25 años en adelante, sino porque en esa etapa apenas experimentan consecuencias negativas. Desde esta perspectiva, mantener relaciones sexuales con múltiples parejas sexuales puede resultar irrelevante si estás soltero y tienes 23 años, pero no si tienes 40 años y estás casado. De ahí que el diagnóstico y búsqueda de ayuda terapéutica se dé más tardíamente. Con el objetivo de explorar esta relación, Reid, Garos y Fong (2012) tomaron una muestra de 137 pacientes con una edad de entre 18 y 71 años y les aplicaron el Inventario de Hipersexualidad IH y la Escala de Consecuencias de la Conducta Hipersexual (HBCS). Cuando correlacionaron la puntuación total en ambos cuestionarios con la edad de los pacientes, encontraron que la gravedad del cuadro clínico no se relacionaba con la edad ( $r=.07)$, pero que la edad sí correlacionaba con las consecuencias del cuadro clínico ( $r=.29$ ). A partir de estos resultados, estos investigadores confirmaron que el cuadro clínico de CS en jóvenes y adultos resultaba considerablemente similar y que la diferencia radicaba en que sus consecuencias se incrementaban con la edad. 


\subsection{Orientación sexual}

Las investigaciones han demostrado sistemáticamente que los hombres y mujeres con una orientación homosexual o bisexual muestran una mayor CS que los heterosexuales (Baum \& Fishman, 1994; Missildine, Feldstein, Punzalan, \& Parsons, 2005). En una reciente revisión, Muise et al. (2013) compararon la puntación media en la escala SCS de compulsividad sexual en investigaciones con diferentes tipos de población, encontrando que en muestras normativas -población general o muestras subclínicas-, la puntuación media de hombres heterosexuales oscilaba entre 14-18 puntos mientras que la de hombres homosexuales o bisexuales se sitúa entre 16.5-20 puntos. En mujeres sucedía algo similar, con un rango entre 11-14.3 para mujeres heterosexuales y entre 14-17.1 para mujeres homosexuales o bisexuales.

Asimismo, cuando analizamos la prevalencia diagnóstica de la CS, comprobamos que mientras que en población general no supera el $6 \%$, en mujeres y sobre todo hombres homosexuales o bisexuales esta cifra se multiplica por cinco. Kelly et al. (2009) realizaron una investigación en la que evaluaron a 1214 hombres entre 18-78 años y 329 mujeres entre 18-70 años miembros de diferentes colectivos LGTB (Lesbianas, Gais, Transexuales y Bisexuales). A todos ellos les aplicaron la escala SCS de compulsividad sexual, así como otras medidas de conducta sexual, consumo de sustancias, etc., encontrando que el $30.47 \%$ de los hombres y el $18.59 \%$ de las mujeres obtenían puntuaciones superiores a 24 en la escala de compulsividad sexual -punto de corte establecido a través de diversas investigaciones para el diagnóstico clínico de la CS-.

En esta línea, Morgenstern et al. (2012) reclutaron una muestra clínica de 183 hombres gays y bisexuales con problemas en el control de los impulsos sexuales tan sólo en la ciudad de Nueva York. La única investigación con una muestra clínica de tamaño similar (205 pacientes) fue el estudio clínico para el trastorno por hipersexualidad del DSM-5, donde se tuvo que recurrir a un diseño experimental multicéntrico que incluía clínicas repartidas por todo EEUU (California, Utah, Texas y Pennsylvania) para lograr la captación de un volumen de pacientes similar (Reid, Carpenter, et al., 2012). La facilidad para encontrar muestra clínica entre gais y bisexuales frente a la lentitud y complejidad del reclutamiento en población heterosexual da buena cuenta de la distribución irregular de pacientes en ambos tipos de población.

Una particularidad de la expresión clínica de la CS en población homosexual y bisexual es su vinculación con el consumo de alcohol y drogas. En comparación con población general, gais, lesbianas y bisexuales informan de altas tasas de abuso tanto de alcohol como de drogas (Cochran, Ackerman, Mays, \& Ross, 2004; Stall et al., 2001), así como un uso frecuente de estas sustancias con fines sexuales. Nanin y Parson (2006) identificaron un nuevo tipo de 
actividad especialmente frecuente entre hombres gais que consistía en quedar con el objetivo explícito de consumir drogas y mantener relaciones sexuales con múltiples parejas (lo que denominaban "Party 'n Play"). En el estudio de Kelly et al. (2009) ya citado se documentó también un estrecho vínculo entre orientación sexual, consumo de drogas y CS. En particular, se encontró que el $45.2 \%$ de los gais y lesbianas con puntuaciones clínicas en el SCS afirmaban consumir alcohol habitualmente antes de iniciar la actividad sexual frente al $38 \%$ de los participantes control; el porcentaje de los que dijeron consumir algún tipo de droga (cocaína, metanfetamina, crack, poppers, etc.) previa a la actividad sexual era también notablemente superior en el grupo clínico respecto al resto de participantes (37.2\% frente al $27 \%$ ) (Kelly et al., 2009).

Lo más preocupante del vínculo entre CS y consumo de drogas en hombres gais y bisexuales es la multiplicación del riesgo de mantener relaciones sexuales sin protección en un colectivo que en 2006 acaparaba el $48.1 \%$ de los nuevos casos de transmisión de VIH en EEUU (Centers for Disease Control Prevention, 2008) y que constituye hoy día uno de los pocos reductos donde el número de nuevos diagnósticos sigue incrementándose (Centro Nacional de Epidemiología, 2014). Diversas investigaciones han encontrado un vínculo directo entre CS y diversas prácticas sexuales de riesgo. Así, el estudio de Grov, Parsons y Bimbi (2010) con 1214 hombres gais y bisexuales permitió demostrar que mayores puntuaciones en CS se relacionaban con un incremento en la probabilidad de ser $\mathrm{VIH+}$, haber practicado sexo anal sin protección (tanto insertivo como receptivo) con una pareja sexual serodiscordante, haber mantenido relaciones sexuales con un mayor número de parejas, rechazar activamente el uso del preservativo en cualquier práctica sexual (barebacking) y haber realizado conductas sexuales alternativas a las mayoritarias (fisting, lluvia dorada, intercambio de semen con la boca, sexo en grupo, bondage y dominación, etc.). Resulta especialmente significativo el hallazgo de que los participantes que puntuaban 38 en el SCS tenían hasta un $237 \%$ más de probabilidad de haber practicado sexo sin preservativo que los que puntuaron 18 . Si a este vínculo directo le sumamos el hecho de que mantener relaciones sexuales bajo el efecto de ciertas sustancias provoca desinhibición y una relajación de los estándares de seguridad durante las relaciones sexuales, entonces nos encontramos ante una población con un riesgo sociosanitario notable (Carey et al., 2008).

No se sabe con certeza porqué la CS es más prevalente en gais, lesbianas y bisexuales, si bien se manejan varias hipótesis. En primer lugar, la frecuencia y el número de parejas sexuales en este colectivo es significativamente superior a la media de la población general (Oswalt \& Wyatt, 2013), lo que ha facilitado que los investigadores que equiparan CS y frecuencia sexual los señalen como colectivo de alto riesgo. La posibilidad y los medios para encontrar parejas 
dispuestas a mantener relaciones sexuales (cuartos oscuros, saunas, chats y foros, clubs y bares de ambiente, aplicaciones móviles, etc.) son mayores que para población heterosexual, de modo que hombres y mujeres con cierta predisposición a la pérdida del control sobre la conducta sexual encuentran en el ambiente sexual que les rodea facilidades para ello (Parsons, 2005). Otro de los factores propuestos tiene que ver con la dinámica de relaciones que se han impuesto en el colectivo LGTB: el conflicto social y la ansiedad que para estas personas supone mantener una relación estable en una sociedad donde todavía perdura gran homofobia tanto sutil como manifiesta hace más fácil instaurar dinámicas que impliquen la sucesión de parejas utilizadas casi exclusivamente con fines sexuales que mantener una relación estable con alguien del mismo sexo (Muench \& Parsons, 2004).

A través de entrevistas a miembros del colectivo gay, Parsons et al. (2008) identificaron dos explicaciones distintas a la incapacidad para controlar los impulsos sexuales: las intrínsecas y las extrínsecas. Algunos chicos gais (en torno al 56\%) atribuían su conducta sexual compulsiva a rasgos o predisposiciones personales o propias del colectivo LGTB. Destacan algunas como que los gais tienen un mayor deseo sexual (una mayor predisposición biológica), que tienden a compensar la falta de afecto por parte de su entorno con el sexo con múltiples parejas y que tratan de aumentar la autoestima y disminuir la ansiedad y depresión a través del sexo. Por otra parte, el $24 \%$ recurría a explicaciones extrínsecas, con argumentos relacionados con la vida en pareja (decían mantener una conducta sexual controlada cuando tenían pareja que se tornaba compulsiva al estar solteros) o con la facilidad para encontrar nuevas parejas sexuales. Una de las limitaciones de los estudios citados es su consideración de la orientación sexual: en estas investigaciones, la orientación sexual se considera una categoría estanca (heterosexual, bisexual u homosexual), ignorando que en realidad se debería considerar un continuo donde una persona se sitúa dependiendo de la medida en que sienta atracción hacia uno u otro sexo y teniendo en cuenta su carácter dinámico (las personas no siempre nos sentimos atraídos de igual manera hacia el nuestro o hacia el otro sexo, sino que variamos en la intensidad de la atracción) (Savin-Williams, 2014). De este modo, queda todavía pendiente analizar la relación entre orientación sexual -entendida como un continuo de atracción- y compulsividad sexual, así como la repercusión en los niveles y la expresión de este cuadro clínico en etapas de la vida donde la atracción hacia uno u otro sexo varíe. 


\section{Personalidad y CS}

La personalidad se define como "la constelación de dimensiones y facetas que determina la forma en la que las personas pensamos, sentimos y actuamos" (McCrae \& Costa, 2003, p. 23). Múltiples teorías han tratado de identificar los principales rasgos y dimensiones que la conforman. Muchas de ellas se solapan y superponen: "la psicología de la personalidad se ha visto desbordada por la abundancia de constructos y dimensiones que en muchas ocasiones, han recibido nombres distintos aun midiendo el mismo elemento y que en muchas otras, han recibido el mismo nombre cuando en realidad medían elementos opuestos" (Funder, 2001, p. 200). Ante esta abundancia de teorías de la personalidad, una en concreto ha permitido integrar las aportaciones de las precedentes: la Teoría de los Cinco Factores de la Personalidad (también Ilamada Teoría de los Cinco Grandes en referencia a las 5 dimensiones de personalidad que la conforman).

La teoría de los cinco factores (de ahora en adelante FFM por su denominación original -Five Factor Model-) propone que la personalidad se compone de 5 grandes dimensiones (neuroticismo, extraversión, apertura a la experiencia, amabilidad y responsabilidad) compuestas a su vez por 6 facetas (Costa \& McCrae, 2002). Cada una de estas 5 dimensiones y 36 facetas representa un continuo donde una persona se sitúa dependiendo de su propensión a pensar, sentir o actuar de acuerdo a unas características determinadas. Las diferencias en la personalidad entre individuos vendrían determinadas por la fuerza con la que se expresan cada uno de estos rasgos. Lo habitual es que las diferencias en la expresión de los rasgos de personalidad oscilen dentro de un rango de valores medios, pero en algunos casos su manifestación sobreviene extrema (Widiger \& Costa, 2012). Estas expresiones extremas lo pueden ser tanto por exceso como por defecto: la competencia (faceta de la dimensión de responsabilidad) es un rasgo beneficioso cuando se expresa de forma adaptativa o moderada, pero cuando la persona muestra un exceso de competencia (una valoración exagerada de sus capacidades y recursos) o una muy escasa competencia (muy baja opinión acerca de las propias capacidades), entonces este mismo rasgo sobreviene desadaptativo y acaba interfiriendo en múltiples aspectos de la vida del individuo (Widiger, 2001). Según McCrae, Löckenhoff y Costa (2005), ciertas dimensiones y facetas de personalidad como el neuroticismo se prestan más a una interpretación negativa que otras propuestas en sentido positivo como la amabilidad o la responsabilidad, si bien cualquiera de ellas repercute negativamente cuando se manifiesta en alguno de sus extremos.

El FFM cuenta con un importante aval empírico. Se han identificado los correlatos genéticos y neuroanatómicos de las principales dimensiones de personalidad de este modelo, así como el 
peso diferencial de los componentes ambientales y biológicos en cada una de ellas (Widiger \& Costa, 2012). Se ha demostrado también que la personalidad varía durante los primeros años del desarrollo -sobre todo durante el periodo en el que se conforma el temperamento- pero que se estabiliza alcanzada la madurez (Soto, John, Gosling, \& Potter, 2011). Finalmente, se han encontrado evidencias en torno a la universalidad de las 5 dimensiones de personalidad propuestas. En este sentido, McCrae et al. (2005) evaluaron la personalidad de alrededor de 11985 personas en un total de 50 países con habla, costumbres y estructura social diferente, encontrando que si bien la expresión varía, las dimensiones de personalidad del FFM son comunes en todos ellos.

La repercusión de este modelo se debe en parte a que su desarrollo ha transcurrido paralelo al diseño y validación de un cuestionario (el NEO PI-R) que ha permitido su aplicación a múltiples campos de estudio. Así, el FFM y las dimensiones que lo conforman han demostrado su utilidad a la hora de predecir un buen número de fenómenos individuales, tanto en sentido positivo como negativo. Concretamente, determinadas configuraciones de personalidad se han demostrado predictores robustos de aspectos como el bienestar subjetivo, la aceptación social, los conflictos maritales y la satisfacción con la relación de pareja, el triunfo o fracaso académico, la criminalidad, el desempleo, la satisfacción laboral, la salud mental, la salud física o incluso la mortalidad (para una revisión, Widiger \& Costa, 2012).

Uno de los ámbitos donde las aportaciones del FFM resultan más sólidas es en el estudio de la conducta sexual. Las primeras investigaciones tenían el objetivo de explorar qué dimensiones y facetas de personalidad permitían predecir un aspecto concreto de la conducta sexual: las conductas sexuales de riesgo. Con este objetivo, Trobst, Herbst, Masters y Costa (2002) evaluaron a 201 hombres y mujeres afroamericanos a los que clasificaron en tres grupos dependiendo de su perfil de riesgo sexual (bajo riesgo, riesgo medio y riesgo alto). A través del NEO PI-R se comparó el perfil de personalidad de estos tres grupos, encontrando que el de alto riesgo se caracterizaba por puntuaciones significativamente mayores en la dimensión de neuroticismo y menores en las dimensiones de responsabilidad y amabilidad. Los autores concluyeron que determinadas configuraciones de personalidad facilitaban asumir estándares de prevención sexual más laxos. Concretamente, las personas con mayor inestabilidad emocional, menor capacidad de afrontamiento y mayor tendencia a la ansiedad (más neuróticas), con una menor motivación para persistir en sus planes y objetivos, peor consideración de sus propias capacidades y mayor tendencia a actuar sin tener en cuenta las consecuencias (menos responsables) y las menos hábiles en el ámbito de las relaciones sociales (menos amables), eran más propensas a realizar conductas sexuales de riesgo para la 
transmisión del VIH. Asimismo, dos estudios recientes entre jóvenes españoles demostraron que la personalidad (en concreto, la apertura a la experiencia, amabilidad y responsabilidad) permitían predecir el uso inconsistente del preservativo en distintas prácticas sexuales y la realización o no de las pruebas de detección de anticuerpos del VIH (Ballester-Arnal, RuizPalomino, \& Gil-Llario, 2015; Ruiz-Palomino, Ballester-Arnal, \& Gil-Llario, 2015).

Miller et al. (2004) exploraron la relación entre las dimensiones y facetas del FFM y 6 aspectos del comportamiento sexual, alguno de ellos vinculado a conductas sexuales de riesgo y otros más generales: número de parejas sexuales, uso de alcohol y drogas antes o durante la actividad sexual, proporción de relaciones sexuales sin preservativo, embarazos durante la adolescencia, sexo con parejas esporádicas aun teniendo pareja estable y edad de inicio de la actividad sexual. Para ello, realizaron un estudio longitudinal con un total de 481 personas evaluadas durante un periodo de 5 años (una vez por año). En este caso, el neuroticismo no resultó un predictor eficaz de ninguno de los aspectos sexuales explorados, pero sí lo fueron la baja responsabilidad y amabilidad. Concretamente, estas dimensiones se asociaron a un debut sexual más temprano y con un mayor número de parejas sexuales, a la infidelidad hacia una pareja estable y al uso de alcohol o drogas en la actividad sexual. A su vez, dos dimensiones de personalidad que hasta el momento no habían aparecido vinculadas a la conducta sexual emergíeron como relevantes: la alta extraversión y apertura a la experiencia. La primera resultó ser el predictor más robusto del número de parejas sexuales (por delante de la baja amabilidad y responsabilidad) mientras que la segunda lo fue de los embarazos adolescentes.

La investigación de Schmitt y Buss (2000) aporta una visión más general de la relación entre personalidad y conducta sexual. Esta investigación se desarrolló en dos fases, para las que se contó con la participación de 574 jóvenes (331 mujeres y 243 hombres) con una edad media de 23 años. En una primera fase, se identificaron las principales áreas de la sexualidad humana, encontrando que 7 categorías (lo que ellos denominaron Sexy Seven) agrupaban la mayoría de aspectos relacionadas con la sexualidad: atractivo sexual, orientación sexual, fidelidad en una relación estable, contención sexual, vinculación emocional, tendencias erotofílicas y roles de género. En una segunda fase se exploró su relación con las 5 dimensiones de personalidad del FFM, encontrando que todas ellas se relacionaban de forma significativa con uno o más de estos rasgos. La extraversión por ejemplo correlacionaba con un mayor interés por el atractivo físico, una mayor tendencia a la infidelidad, muy baja contención sexual, mayor erotofilia y mayor vinculación emocional en las relaciones de pareja. La amabilidad y la responsabilidad se relacionaron de forma prácticamente idéntica con la mayoría de las dimensiones de conducta sexual: concretamente, una menor expresión de 
estas dimensiones correlacionaba con una mayor tendencia a la infidelidad, con el desarrollo de roles de género diferenciados entre hombres y mujeres, con una mayor disposición erotofílica y una menor inversión emocional durante las relaciones de pareja. La apertura a la experiencia únicamente mostró relación con la propensión a experimentar con orientaciones sexuales alternativas a la mayoritaria mientras que el neuroticismo no se relacionaba con ninguna dimensión de conducta sexual.

En una investigación posterior, este mismo autor comprobó la universalidad de los vínculos entre conducta sexual y personalidad a través de un estudio multicultural centrado en infidelidad y promiscuidad sexual (Schmitt, 2004). Schmitt y su equipo iniciaron un proyecto el International Sexuality Description Project- en el que participaron más de 100 investigadores y que, en conjunto, permitió la evaluación de 17837 personas repartidas en 56 países (10 regiones geográficas, 5 continentes, 13 islas y 28 idiomas). Estos investigadores encontraron que las personas infieles se caracterizaban por un pefil de personalidad marcadamente poco amable y poco responsable, perfil universal y común a cualquier región geográfica. La baja amabilidad y responsabilidad también resultaron rasgos cruciales en la comprensión de la promiscuidad sexual, donde además de esas dos dimensiones, la alta extraversión jugaba un papel central. Este vínculo entre extraversión y promiscuidad sexual no era universal: en países occidentales, una mayor extraversión sí resultaba predictor de un mayor número de parejas sexuales, mientras que en países de África o Asia la relación era débil o inexistente.

A pesar de la importancia de la personalidad en la comprensión de muy diversos aspectos de la conducta sexual, el interés por sus aportaciones al estudio de la CS ha sido relativo. Aun así, Reid, Dhuffar, Parhami y Fong (2012) resumen las ventajas de la aplicación del FFM al estudio de la CS: 1) ha aumentado los conocimientos acerca de la etiología, mantenimiento y tratamiento de la CS; 2) ha mejorado la comprensión de su comorbilidad con otros trastornos psicopatológicos del Eje I y especialmente del Eje II; 3) ha permitido identificar fortalezas que desarrolladas durante los tratamientos, mejoran la eficacia de las intervenciones terapéuticas; y 4) ha mejorado la comprensión de los factores que influyen en la construcción de las distorsiones cognitivas y los estilos de afrontamiento disfuncionales de pacientes con CS.

De entre las 5 dimensiones de personalidad del FFM, el neuroticismo es la más vinculada a la CS. Esta dimensión, que se relaciona con el malestar psicológico en general y más en concreto con desajustes emocionales, refleja la tendencia a manifestar ansiedad ante todo tipo de situaciones, la propensión a experimentar emociones negativas con o sin causa justificada, la dificultad para tolerar la frustración y el malestar generado por los estados emocionales disfóricos y la respuesta a través de mecanismos de afrontamiento desadaptativos (Costa \& 
McCrae, 2002). La correspondencia entre esta descripción y algunos síntomas del cuadro clínico de la CS motivó que los primeros estudios sobre personalidad en CS exploraran sobre todo esta dimensión. En el primero de ellos, Reid et al. (2008) investigaron la relación entre neuroticismo y CS en un grupo de 120 pacientes (116 hombres y 4 mujeres) en tratamiento por problemas en el control de los impulsos sexuales. A todos ellos se les aplicó el inventario de personalidad NEO PI-R así como la escala SCS de compulsividad sexual, encontrando una correlación de .49 entre neuroticismo y CS y de entre .31 y .48 con las 6 facetes que lo componen (sobre todo con la vulnerabilidad, impulsividad y depresión). En conjunto, el neuroticismo y sus facetas predecían el $34 \%$ de la varianza de las puntuaciones en CS.

Similares resultados obtuvieron Reid, Garos y Carpenter (2011) durante la validación del inventario IH de hipersexualidad. Tomando una muestra de 203 pacientes en tratamiento por problemas de CS, se encontró que las 6 facetas del neuroticismo correlacionaban con la puntuación general en el IH ( $r$ de entre .41 y .70) así como con las tres subescalas que lo componen. La correlación de mayor intensidad se dio con la subescala de consecuencias de la hipersexualidad, lo que los autores interpretaron como evidencia de la relación entre neuroticismo y gravedad del cuadro clínico.

Estos primeros estudios establecían un vínculo directo entre neuroticismo y CS. Sin embargo, estudios posteriores sugieren que además de una influencia directa, el neuroticismo es un mediador que multiplica o atenúa el impacto de otras variables. Esta es la conclusión a la que llegan Reid, Stein y Carpenter (2011). Estos investigadores demostraron que el neuroticismo se asociaba con la CS de forma directa pero también mediando en el vínculo entre mecanismos de afrontamiento de la vergüenza y la culpa y la CS. Concretamente, las personas con mayor tendencia a afrontar de forma desadaptativa la vergüenza y la culpa que además manifiestan rasgos neuróticos son más propensas a experimentar problemas en el control de los impulsos sexuales. A la inversa, el bajo neuroticismo resulta un factor protector. Por otra parte, Pinto, Carvalho y Nobre (2013) encontraron que el neuroticismo influía sobre el desarrollo de la CS a través de una tercera vía: propiciando otros trastornos psicopatológicos. Estos investigadores constataron que las personas más neuróticas eran a su vez más propensas a desarrollar ciertas patologías (principalmente trastornos del estado de ánimo y de ansiedad) que aumentan la probabilidad de manifestar síntomas de CS comórbidos a dichos estados psicopatológicos.

El vínculo entre neuroticismo y CS se muestra además estable en el tiempo. A través de un estudio longitudinal en el que se evaluaron 2 facetas de personalidad -impulsividad y vulnerabilidad- a los 26 años y la búsqueda de tratamiento por problemas en el control de los impulsos sexuales a los 32 , se encontró que los pacientes que acabaron desarrollando 
problemas sexuales se caracterizaban 6 años antes por puntuaciones mayores en ambas facetas del neuroticismo (Skegg et al., 2010). De modo que los autores concluyeron que el neuroticismo debía entenderse como un predisponente de la CS que se mantenía estable a lo largo de la edad adulta.

Tras el neuroticismo, el perfil de personalidad resultante de la combinación entre una baja amabilidad y una baja responsabilidad sería el más asociado a la CS. Dependiendo de la manifestación de uno u otro rasgo, esta combinación se expresa a través dos perfiles: el perfil de buscador de sensaciones impulsivo (Zuckerman \& Kuhlman, 2000) o el psicópata/antisocial (Paulhus \& Williams, 2002). El rasgo dominante en el perfil de buscador de sensaciones impulsivo sería la baja responsabilidad, lo que propicia una tendencia a actuar sin deliberar ni atender a las consecuencias de su conducta. La insensibilidad hacia los demás propia de la baja amabilidad sería la característica principal del perfil psicópata/antisocial, rasgo que manifiesta ignorando sistemáticamente las consecuencias que para otras personas pueda tener su comportamiento. Si bien ambos perfiles surgen de una misma configuración de personalidad, su expresión y consecuencias resultan bien distintas: mientras que el buscador de sensaciones impulsivo se caracteriza principalmente por mantener conductas sexuales de riesgo, el psicópata/antisocial suele ser promiscuo, propenso a la infidelidad y con cierta tendencia al desarrollo de parafilias (Brown, Dargis, Mattern, Tsonis, \& Newman, 2015).

Reid et al. (2012) identificaron por primera vez la presencia de esta combinación de personalidad en pacientes con CS. Estos investigadores exploraron la presencia de rasgos patológicos de personalidad en una muestra de 78 pacientes ( 47 hombres y 31 mujeres) en tratamiento por CS, encontrando que el 33.2\% obtenía puntuaciones clínicamente bajas en la faceta de confianza, el $38.51 \%$ en la de franqueza y el $29.4 \%$ en actitud conciliadora (las tres, facetas de la dimensión de amabilidad). El porcentaje de pacientes con puntuaciones clínicamente bajas fue del 33.75\% para la faceta de competencia, del $41.3 \%$ para el sentido del deber, del $32.7 \%$ para la necesidad del logro, $55.65 \%$ para autodisciplina y finalmente del $34.25 \%$ en deliberación ( 5 de las 6 facetas de la dimensión de responsabilidad). El sexo permitió establecer un perfil diferencial de personalidad: las mujeres en tratamiento por problemas de CS eran, en comparación con los hombres, sensiblemente menos amables y sobre todo menos responsables. A partir de estos resultados, los autores concluyeron que las personas -sobre todo las mujeres- con CS tendían a ser manipulativas e interesadas en sus relaciones con los demás, con estándares éticos y morales laxos, con cierta indiferencia por las consecuencias de sus actos para ellos mismos o personas de su entorno y con preferencia por la gratificación inmediata frente a la gratificación a largo plazo. 
Kastner \& Sellbom (2012) exploraron la vinculación entre el perfil del psicópata/antisocial y la CS. Las personas con este perfil de personalidad suelen manifestar dos patrones de comportamiento distintos: por un lado, los hay que parecen falsamente cálidos y encantadores y que son capaces de correr todo tipo de riesgos ignorando las consecuencias para ellos mismos o personas de su entorno (los dominantes) y los hay que tienden a ser agresivos, impulsivos, rudos y que utilizan a los otros sólo para su propio beneficio (antisociales). Para explorar el peso de cada uno de estos perfiles a la hora de predecir la CS, estos investigadores tomaron a una muestra de 482 estudiantes universitarios a los que evaluaron a través de un cuestionario de psicopatía y a través de una medida de CS (el cuestionario SCS). La correlación entre el perfil de personalidad dominante y la puntuación en el SCS fue de 0.11 y de 0.43 con el perfil antisocial. Asimismo, la presencia de uno u otro perfil de personalidad permitía predecir el $19 \%$ de la varianza de las puntuaciones en CS. Los autores concluyeron que si bien ambos perfiles estaban relacionados, el antisocial era el más vinculado a la expresión de la CS.

Menos se sabe del papel de las dos dimensiones de personalidad restantes en la comprensión de la CS. La apertura a la experiencia parece la menos relacionada con la CS habida cuenta de su escasa vinculación con aspectos más generales de la conducta sexual. Sí cabría esperar que la extraversión se vinculara con la conducta sexual compulsiva por su importancia en la comprensión de aspectos como la infidelidad y la promiscuidad sexual. Sin embargo, pocos estudios han abordado esta cuestión. El único estudio que conocemos que ha tenido en cuenta estas dos dimensiones de personalidad es el realizado por Rettenberger et al. (2015) entre 1749 estudiantes universitarios alemanes. Estos investigadores creían que la apertura no mostraría relación con la CS pero que sí lo haría la alta extraversión, hipótesis que se cumplió parcialmente. Efectivamente, la apertura a la experiencia no se relacionó con la CS mientras que al contrario de lo esperado, fue la baja extraversión la que se asoció a puntuaciones mayores en la escala IH de hipersexualidad. Estos investigadores explicaron este vínculo a partir del tipo de conducta sexual dominante: según ellos, extraversión y CS se relacionaban negativamente porque la principal conducta sexual en la muestra fue la masturbación. Si los pacientes se hubieran caracterizado por una gran promiscuidad sexual, los autores sugieren que extraversión y CS se habrían relacionado positivamente. 


\section{Historia sexual, comportamiento sexual y disposiciones sexuales}

3.1 Historia sexual y comportamiento sexual

La CS se manifiesta principalmente a través del comportamiento sexual, tanto del actual como del pasado. En concreto, se ha demostrado que las personas con altas puntuaciones en CS se diferencian del resto en: 1) edad de inicio en la actividad sexual, 2) número de parejas sexuales, 3) frecuencia sexual, 4) tipo de actividad sexual, 5) probabilidad de mantener relaciones sexuales con personas del mismo sexo -independientemente de su orientación sexual- y 6) número de parejas estables e historia de infidelidad.

Por lo que se refiere a la edad de inicio en la actividad sexual, los estudios demuestran que la CS se relaciona positiva y proporcionalmente con un debut sexual más temprano. En el estudio de Långström y Hanson (2006a), los hombres del grupo de alta CS mantenían sus primeras relaciones sexuales 2 años antes que los del grupo de baja CS (15.8 años frente a 17.8) y un año antes que los de moderada CS (16.7 años). De forma similar, en mujeres la diferencia entre las del grupo de alta y baja CS era también de dos años (15.7 años frente a 17.4) y de casi un año con respecto al grupo de moderada CS (debut sexual a los 16.5 años).

La vinculación positiva entre CS y número de parejas sexuales ha sido ampliamente documentada. Las personas con altas puntuaciones en CS -independientemente de si son susceptibles de recibir o no un diagnóstico al respecto- informan sistemáticamente de un mayor número de parejas tanto a lo largo de la vida como durante los últimos años. Esto es lo que encuentran Stupianksy et al. (2009) entre 170 universitarias estadounidenses de 18 a 25 años. Estos investigadores dividieron a las participantes en dos grupos dependiendo de sus puntuaciones en el cuestionario SCS de compulsividad sexual: el primero estaba compuesto por chicas con puntuaciones clínicas en esta escala y comprendía el $12.5 \%$ de la muestra (alta CS) mientras que el otro aglutinó a las participantes con puntuaciones normales (media-baja CS). Lo que encontraron fue que mientras que las chicas del grupo de alta CS informaban de una media de 7 parejas sexuales con las que habían mantenido sexo oral a lo largo de su vida y 5 con las que habían realizado sexo vaginal, el número de parejas en el grupo de media-baja CS apenas superaba las 3.5 tanto para sexo oral como vaginal.

La edad es un factor que inevitablemente modera esta asociación: a mayor edad, más han sido las oportunidades para mantener relaciones sexuales con distintas parejas a lo largo de la vida. Así, la diferencia entre personas con alta y baja compulsividad sexual se acentúa en población de mayor edad. En el estudio de Långström \& Hanson (2006a) con una muestra de pacientes más mayores (la edad media en el caso de los hombres fue de 34 años y de 30 en el grupo de 
mujeres), la media de nuevas parejas sexuales por año desde el inicio de la actividad sexual fue de 3 en el caso de los hombres y 2 en el caso de las mujeres. Esto se traduce en que un hombre de 30 años que se hubiera iniciado en la actividad sexual a los 15 habría tenido, de media, unas 45 parejas sexuales a lo largo de su vida. Resultados similares (tres nuevas parejas sexuales al año) obtienen Prause, Staley y Fong (2013) en una muestra de hombres y mujeres con problemas por consumo compulsivo de pornografía en Internet.

El número de parejas sexuales aumenta drásticamente entre los pacientes con problemas en el control de los impulsos sexuales que además se identifican como homosexuales o bisexuales. Parsons et al. (2008) evaluaron a 180 hombres homosexuales y bisexuales de entre 18 y 63 años con problemas en el control de los impulsos sexuales. A todos ellos se les administró una batería que incluía, entre otras preguntas, el número de parejas sexuales durante los últimos tres meses, encontrando que estos pacientes informaban de una media de 29.8 nuevas parejas sexuales durante los últimos tres meses (unas 10 nuevas parejas al mes). El sexo en grupo con desconocidos -práctica frecuente en este colectivo- explicaría en cierta medida estas cifras.

La CS se relaciona también con un aumento de la frecuencia sexual, independientemente de la práctica que consideremos. Si tomamos el número de orgasmos semanales (TSO) sin tener en cuenta si se han alcanzado a través de masturbación o de actividad sexual con una pareja, los pacientes con problemas en el control de los impulsos sexuales informan de una media de entre 8 (Kafka, 1997) y 8.3 orgasmos a la semana (Winters et al., 2010), mientras que la frecuencia en población normal no superaría los 3 orgasmos semanales (Kingston \& Bradford, 2013). En mujeres con CS, el número medio de orgasmos semanales alcanzaría los 9.21 , valor superior al documentado en el caso de los hombres. Esto pone de relieve que si bien son muchas menos las mujeres que cumplen los criterios para el diagnóstico de CS, las que lo hacen tienen cuadros clínicos de igual o mayor gravedad que los hombres.

Si nos centramos ahora en la frecuencia de masturbación, los pacientes hipersexuales lo harían una media de 6.71 veces por semana en el caso de los hombres y de 3.29 en el caso de las mujeres (Winters et al., 2010). Las cifras más altas se encuentran en pacientes compulsivos con una orientación homosexual o bisexual pues en estos casos, la frecuencia de masturbación media alcanza las 9 veces por semana (Parsons et al., 2008).

En el caso de la frecuencia de actividad sexual con parejas, en la medida en que su realización no depende únicamente de la propia voluntad sino también de la disponibilidad de una pareja, las diferencias en función del nivel de CS se disipan más que en el caso de la masturbación. Aun así, se aprecia claramente una mayor frecuencia de actividad sexual en pareja entre 
personas con alta CS. A nivel subclínico, los hombres con altas puntuaciones en CS presentarían una frecuencia de coitos mensuales de alrededor de 7.38 en comparación con los 5.28 de los hombres con puntuaciones bajas en esta dimensión (Långström \& Hanson, 2006a). En mujeres, la diferencia media de coitos mensuales entre las que presentan una alta y una baja CS ( 7.86 y 4.27 coitos respectivamente) es un tanto más acentuada (Långström \& Hanson, 2006a). En el estudio de Winters et al. (2010) con 178 pacientes hipersexuales (109 hombres y 69 mujeres) se encontró una frecuencia mensual de relaciones sexuales de 11.75 en el caso de los hombres y de 19.7 en el caso de las mujeres.

Tomando en conjunto los datos de frecuencia sexual, se encontraría un claro perfil diferencial en función del sexo. En chicos y chicas, la frecuencia de orgasmos semanales (TSO) es similar, pero varía la forma de alcanzarlos: los hombres con problemas en el control de los impulsos sexuales mantienen una moderada actividad sexual en pareja y una gran frecuencia de masturbación, mientras que en mujeres sucedería al contrario. Finalmente, se identifica un tercer perfil que corresponde a hombres homosexuales y bisexuales: entre estos pacientes, tanto la actividad sexual en pareja como la masturbación son extremadamente frecuentes.

La posibilidad de que la CS incremente la probabilidad de realizar distintos tipos de prácticas sexuales ha despertado cierto interés. Las primeras investigaciones confirmaron la hipótesis de que era más probable que los pacientes compulsivos hubieran realizado prácticas sexuales minoritarias en población general (como por ejemplo la práctica del sexo anal). Sin embargo, la tendencia cada vez más generalizada a experimentar con este tipo prácticas sexuales ha disipado esta relación, de modo que en la actualidad apenas se encuentran diferencias en el tipo de prácticas sexuales de personas con y sin problemas en el control de impulsos sexuales. Por ejemplo, Stupianksy et al. (Stupiansky et al., 2009) encuentran idéntico porcentaje de chicas con alta y baja CS que habían practicado sexo oral, vaginal o anal.

Donde sí se encontraría un perfil diferencial es en la atracción hacia actividades sexuales poco corrientes o que impliquen cierta desviación sexual. Grov et al. (2010) realizaron un estudio con 1214 hombres gais y bisexuales en el que encontraron puntuaciones significativamente mayores en la escala SCS de compulsividad sexual en aquellos que dijeron haber realizado prácticas sexuales con intercambio de orina (water sports), penetración anal con el puño (fisting), prácticas sexuales basadas en el dominio y la sumisión (bondage), exhibicionismo, asfixia erótica (hipofixiofilia) e intercambio de semen con la boca (snowballing). Por su parte, Rinehart y McCabe (1998) encontraron que los hipersexuales se excitaban más que el resto con estímulos sexuales pedófilos, de coerción sexual (violación y abuso sexual) y con la fantasía de espiar a desconocidos (voyeurismo) o exponerles sus genitales (exhibicionismo). 
Algunos investigadores han sugerido que debido en parte a su incapacidad para controlar un impulso sexual desmedido y al interés por experimentar distintos aspectos de la sexualidad, algunos pacientes heterosexuales con CS han podido mantener también relaciones sexuales con personas de su mismo sexo. Si bien no se ha confirmado la razón, efectivamente se ha constatado que la proporción de pacientes con CS que dicen haber mantenido relaciones sexuales con personas de su mismo sexo es notablemente superior a la de la población general, sobre todo en mujeres. Långström \& Hanson (2006a) encontraron que mientras que la proporción de hombres con baja CS que habían mantenido relaciones sexuales con personas de su mismo sexo era del 1.6\%, este porcentaje ascendía hasta el $7.3 \%$ en el caso de hombres con alta CS. En mujeres, la prevalencia de esta conducta sexual era del $0.5 \%$ en aquellas con baja CS frente al $13.8 \%$ de las que obtuvieron altas puntuaciones en CS. Estos porcentajes se situaron en el $6.7 \%$ en el caso de los hombres y en el $19.4 \%$ en el caso de las mujeres en el estudio de Skegg et al. (2010). Lo que estas investigaciones no exploran es si estos resultados pueden deberse más bien a una representación de personas homosexuales y bisexuales en el colectivo de pacientes con CS como sugieren múltiples investigaciones.

El último aspecto diferencial entre personas con y sin CS sería la proporción de los que mantienen una pareja estable y de los que han cometido una infidelidad. Al respecto, los estudios sugieren que la CS es un condicionante que disminuye la probabilidad de mantener una pareja estable y aumenta la de haber cometido una infidelidad. En el estudio de Långström \& Hanson (2006a), la proporción de pacientes con CS que afirmaban mantener una pareja estable era del $66 \%$ en el caso de las mujeres y del $65.8 \%$ en el caso de los hombres frente al $83.7 \%$ y el $85.4 \%$ de la muestra control. Respecto a la comisión de una infidelidad, el porcentaje de hombres y mujeres con problemas en el control de los impulsos sexuales que afirmaron haber sido infieles fue del $38.6 \%$ y del $51.6 \%$ respectivamente, porcentajes que se reducían hasta el $29 \%$ y el $15 \%$ en población general (Skegg et al., 2010).

\subsection{Conducta sexual online}

$\mathrm{Ni}$ todos los pacientes con CS acaban manifestando su problemática a través del sexo en Internet ni todos los adictos al cibersexo están predispuestos a desarrollar problemas en el control de los impulsos sexuales. Esa es la conclusión a la que llegaron Cooper, Delmonico y Burg (Cooper et al., 2000) tras evaluar a 9265 personas en uno de los más relevantes estudios realizados hasta el momento sobre el papel de la CS en la adicción al cibersexo. Eso sí, los pacientes que al mismo tiempo cumplen criterios para el diagnóstico de ambas condiciones son los que desarrollan cuadros clínicos de mayor gravedad. 
Estos investigadores lograron que una amplísima muestra (algo más de 13000 personas) completara una batería de cuestionarios online a través de uno de los portales Web de noticias más importantes en Norteamérica (MSNBC live). Entre otras, esta batería incluía la escala BSS de búsqueda de sensaciones sexuales, la escala SCS de compulsividad sexual y diversas medidas sobre consumo de cibersexo. La muestra comprendía a 7921 hombres y 1344 mujeres de entre 18 y 90 años con diferentes niveles de gravedad en el control de sus impulsos sexuales y en el consumo de sexo en Internet. Todos ellos se clasificaron en cuatro grupos dependiendo de su puntuación en la escala SCS de compulsividad sexual y del número de horas semanales que dedicaban a la práctica del cibersexo:

1. Grupo de CS baja: participantes con puntuaciones por debajo de 23.78 (1 Desviación Típica -DT- por encima de la media) en la escala SCS. El 83.5\% de la muestra se clasificó en este grupo.

2. Grupo de CS moderada: puntuaciones superiores a 23.78 en la escala SCS e inferiores a 29.3 (entre 1 y 2 D.T. por encima de la media). Representaba el $10.9 \%$ de la muestra.

3. Grupo de CS sin adicción al cibersexo: puntuación en el SCS superior a 29.3 (más de 2 D.T. por encima de la media) y consumo recreativo de cibersexo ( $<11$ horas semanales). El 4.6\% de los participantes se clasificaron en este grupo.

4. Grupo de CS adictos al cibersexo: puntuación por encima de 29.3 en el SCS (más de 2 D.T. por encima de la media) y que pasaban más de 11 horas semanales practicando cibersexo. Representaban tan sólo un $1 \%$ de los participantes.

Algunas de las conclusiones más importantes de este estudio se extrajeron de esta clasificación. Para empezar, estos investigadores encuentran una prevalencia de pacientes con CS del $5.6 \%$, de entre los cuales tan sólo un $1 \%$ manifestaba su problemática a través del sexo en Internet. En porcentajes relativos, tan sólo 18 de cada 100 pacientes con CS (el 18\%) acababa desarrollando una adicción al cibersexo comórbida, dato que contradecía la extendida idea de que todos los adictos al sexo recurren al cibersexo para saciar su apetito sexual. Desde la perspectiva inversa, tampoco resultó cierto que todos los adictos al cibersexo mostraran problemas previos en el control de sus impulsos sexuales. Estos investigadores encontraron que tan sólo 96 de los 734 participantes que cumplían el criterio de consumo problemático de cibersexo (dedicar más de 11 horas semanales al sexo en Internet) se clasificaban además en el grupo de CS. Es decir, tan sólo en el 13\% de los casos de pacientes con adicción al cibersexo su problemática se explicaba a partir de un cuadro clínico previo de CS. En el 87\% restante, la adicción al cibersexo se explicaba a través de otros factores. 
Además de estas primeras conclusiones, este estudio encontró que las mujeres estaban sobrerrepresentadas en el grupo de pacientes con CS y adicción al cibersexo. Si el 18\% de los pacientes con CS acababan desarrollando una adicción al cibersexo, este porcentaje ascendía hasta el $28 \%$ en el caso de las mujeres. Los autores explicaban este hallazgo a partir del estigma asociado a la sexualidad femenina: las mujeres que demuestran interés hacia el sexo o cuya conducta sexual resulta excesiva son tachadas con frecuencia de libertinas, lo que supone reprobación social a una conducta que se considera negativa en una mujer. En este contexto, el anonimato que Internet ofrece a la hora de expresar y satisfacer las necesidades sexuales podría ser el factor que determina que un mayor número de mujeres con CS encuentren en el cibersexo el medio más cómodo y también más seguro para manifestar su problema. También en relación con el sexo, en este estudio se encontró que las mujeres mostraban una clara preferencia por el uso de los chats sexuales frente a la pornografía, medio utilizado principalmente en el caso de los hombres.

El tiempo dedicado al uso de Internet en general (entre 35-45 horas semanales) y a la práctica del cibersexo en particular (entre 15-25) de los pacientes del grupo de CS adictos al cibersexo superó ampliamente al observado en el resto de grupos. Además, el $82.3 \%$ afirmó que el sexo en Internet había producido interferencia significativa en alguna dimensión importante de su vida (familia, pareja, trabajo, estudios, etc.).

Investigaciones posteriores no han hecho más que ratificar estos hallazgos y ampliarlos en diferentes colectivos. En el estudio de Odlaug et al. (2013) con 36 pacientes adictos al sexo se encontró que el $58.4 \%$ de ellos invertía más de una hora diaria a la práctica del cibersexo, llegando en algunos casos hasta las 25 horas semanales. Por su parte, Winters et al. (2010) encontraron un consumo medio de cibersexo de 6.83 horas semanales entre sus pacientes con $\mathrm{CS}$, tiempo que bajaba hasta las 1.69 horas en el caso de pacientes mujeres.

En ocasiones, Internet es utilizado por estos pacientes no tanto como un medio para saciar su impulso sexual sino como una forma de encontrar parejas sexuales con las que mantener relaciones sexuales en la vida real. Al respecto, la investigación de Skegg et al. (2010) demostró que el $6 \%$ de los hombres con problemas en el control de los impulsos sexuales y el $9.7 \%$ de las mujeres había mantenido relaciones sexuales con una persona a la que habían conocido a través de Internet. En este sentido y gracias en parte a la introducción de aplicaciones móviles que permiten identificar e incluso situar geográficamente a otras personas que buscan relaciones sexuales rápidas, Internet se dibuja como una herramienta eficaz para que personas con esta problemática encuentren a otras personas con los mismos intereses sexuales. 
Finalmente, se ha demostrado que los hallazgos sobre el vínculo entre CS y cibersexo pueden generalizarse también a personas con una orientación sexual alternativa a la heterosexual. Parsons et al. (2008) encontraron que sus pacientes gais y bisexuales adictos al sexo invertían una media de 12.3 horas a la semana chateando con fines sexuales, a lo que se sumarían 5 horas adicionales que dedicaban al visionado de pornografía. El uso de aplicaciones móviles para encontrar parejas sexuales en este colectivo es mayoritario, con porcentajes de hasta el 75.4\% de uso de este tipo de software (Rice et al., 2012).

\subsection{Búsqueda de sensaciones sexuales}

La búsqueda de sensaciones sexuales (BSS) es una variable que resulta de la aplicación del concepto más general de "búsqueda de sensaciones" al ámbito de la sexualidad. Acuñada por Kalichman y su equipo, la BSS se define como "la tendencia a alcanzar niveles óptimos de excitación sexual y a participar en actividades sexuales novedosas" (Kalichman et al., 1994, p. 387). Así, los buscadores de sensaciones sexuales son personas cuya necesidad por experimentar situaciones sexuales novedosas, variadas y cada vez de mayor intensidad les llevaría a realizar ciertas prácticas sexuales (relaciones con múltiples parejas sin preservativo, consumo de sustancias durante la actividad sexual, intercambio de parejas, etc.) que podrían suponer un riesgo para ellos o sus parejas (Gullette \& Lyons, 2005).

El sexo y la orientación sexual condicionan su expresión. Estudios como el de Flanders, Arakawa y Cardozo (2013) con 177 jóvenes hawaianos o el de Gaither y Sellbom (2003) con 546 estadounidenses demuestran que los hombres tienden a ser más buscadores de sensaciones sexuales que las mujeres, diferencia que explican a partir de razones socioculturales: las mujeres que viven de forma abierta y desinhibida la sexualidad son, en muchos casos, estigmatizadas y rechazadas, lo que fomenta la contención sexual frente a la desinhibición.

En cuanto a la orientación sexual, se creía que las personas homosexuales y bisexuales eran más buscadores de sensaciones que las heterosexuales. Sin embargo, sólo los resultados en hombres se ajustaban a esta hipótesis. McCoul y Haslam (2001) encontraron al comparar a 112 hombres heterosexuales y 104 homosexuales del área metropolitana de Nueva York que efectivamente, éstos últimos obtenían puntuaciones sistemáticamente mayores en la escala de BSS que los heterosexuales. Sin embargo, Hurlbert (1993) encontró al comparar a 34 mujeres heterosexuales y 34 homosexuales que las heterosexuales resultaban las más buscadoras de sensaciones sexuales. Estas discrepancias llevaron a plantear que el sexo desempeñaba un papel mediador entre la orientación sexual y la BSS, hipótesis que se 
demuestra en una reciente investigación realizada por Gil, Morell, Ballester, Giménez y Castro (2014). El objetivo de esta investigación era establecer cómo el sexo, la orientación sexual y sobre todo la interacción entre ambas variables influía sobre la expresión de la BSS. Para ello, 92 heterosexuales ( 50 hombres y 42 mujeres) y 90 homosexuales (50 hombres y 40 mujeres) completaron la escala BSS de búsqueda de sensaciones sexuales. De acuerdo con lo esperado, los hombres (indistintamente de su orientación sexual) obtuvieron puntuaciones superiores a las mujeres en la escala de BSS. Sin embargo, al analizar la BSS en función de la orientación sexual se encontró que mientras que las mujeres heterosexuales eran más buscadoras de sensaciones sexuales que las homosexuales, los hombres heterosexuales y homosexuales no diferían en cuanto a su puntuación en esta variable. Los autores concluyeron por tanto que la BSS se manifestaba más en hombres que en mujeres y más en mujeres heterosexuales que homosexuales - diferencia que no se daría en el caso de los hombres-.

Gran parte de los estudios sobre BSS se han centrado en cómo esta variable influye sobre la realización de conductas sexuales de riesgo para la transmisión del VIH o de una ITS. En este sentido, se han encontrado correlaciones significativas entre esta dimensión y múltiples indicadores de riesgo. Concretamente, se han documentado correlaciones de entre .23 y .28 entre BSS y número de parejas sexuales (Gullette \& Lyons, 2005; Kalichman et al., 1994), de .21 con la frecuencia de coito vaginal sin preservativo (McCoul \& Haslam, 2001), de entre .22 y .32 con la práctica de sexo anal sin preservativo (Kalichman et al., 1994; Kalichman, Heckman, \& Kelly, 1996), de entre .31 y .40 con la frecuencia de relaciones sexuales con parejas a las que se acaba de conocer (Gaither \& Sellbom, 2003) y de -.39 con la percepción de autoeficacia en el uso del preservativo (Gullette \& Lyons, 2006). Asimismo, estudios longitudinales concluyen que la influencia de la BSS sobre la realización de prácticas sexuales de riesgo se mantiene estable a lo largo del tiempo (Voisin, Hotton, Tan, \& Diclemente, 2013), considerándose esta variable como "sinónimo de conducta sexual de riesgo" (Gullette \& Lyons, 2005, p. 48).

Se han propuesto dos formas que explican por qué la BSS aumenta la probabilidad de realizar conductas sexuales de riesgo. La primera responde a un vínculo directo: las personas con mayor tendencia a la búsqueda de sensaciones sexuales experimentan atracción por situaciones sexuales donde el contacto físico y la espontaneidad de una relación sin preservativo desempeñan un papel principal y donde además ese riesgo actúa como excitador sexual. La otra forma responde a un vínculo indirecto: los buscadores de sensaciones sexuales serían más propensos a consumir alcohol o drogas durante las relaciones sexuales, lo que explicaría que disminuya su atención a la prevención durante la actividad sexual. Ambas vías resultan complementarias, hecho que se ha demostrado a través de varias investigaciones. 
Kalichman et al. (1996) demostraron a través de ecuaciones estructurales que la BSS se asociaba a la conducta sexual de riesgo (en este caso, sexo anal sin preservativo) a través de una vía directa y una vía mediada por el consumo de alcohol y drogas. El efecto directo de la BSS explicaba la gran mayoría del vínculo (el $80 \%$ ), mientras que la vía mediada a través del consumo de alcohol y de drogas predecía el $8 \%$ y el $12 \%$ respectivamente. Estudios posteriores han confirmado este vínculo, demostrando además que el modelo es igualmente aplicable a hombres y mujeres (Hendershot, Stoner, George, \& Norris, 2007). En estos estudios, la capacidad predictiva de la vía directa entre BSS y conducta sexual de riesgo era muy superior a la vía mediada a través del consumo de alcohol o drogas.

Los constructos de BSS y CS se han desarrollado paralelamente y su relación ha sido documentada a través de múltiples investigaciones. En la sucesión de estudios realizados por Kalichman, la correlación entre estas dos variables oscilaba entre .55 y .66 (Kalichman et al., 1994; Kalichman \& Rompa, 1995). Por su parte, Gullette y Lyons (2005) encontraron una correlación de .50 cuando exploraron estas dos variables en estudiantes americanos. Finalmente, estudios más recientes en jóvenes españoles encuentran una correlación de .44 entre BSS y CS (Ballester-Arnal, Gómez-Martínez, Gil-Llario, \& Salmerón-Sánchez, 2013). EI vínculo entre ambas variables responde a un origen teórico común, pero sobre todo a una vinculación clínica: en tanto en cuanto una persona sea incapaz de controlar sus impulsos sexuales, más probable resultará que su preferencia por actividades sexuales novedosas y cada vez de mayor intensidad les lleve a incurrir en prácticas sexuales de riesgo para la transmisión de ITS o VIH. De ahí la importancia del estudio de la BSS en la comprensión de las manifestaciones clínicas de la CS y sobre todo de su severidad y consecuencias.

\subsection{Erotofilia-erotofobia}

La erotofilia y la erotofobia constituyen los dos extremos de una misma dimensión psicológica cada vez más popular por su valor a la hora de explicar aspectos muy diversos de la conducta sexual (Fisher, White, Byrne, \& Kelley, 1988). Que una persona se sitúe en uno u otro extremo depende de su tendencia a acercarse o evitar situaciones y estímulos de contenido sexual: las personas que se sitúan en el extremo erotofílico del continuo suelen mostrarse abiertas y cercanas hacia todo aquello que les despierte interés sexual mientras que en el extremo contrario, las personas erotofóbicas rechazan y evitan todo lo relacionado con el sexo y la sexualidad (Macapagal \& Janssen, 2011). En cuanto a su topografía, se la considera a medio camino entre una actitud, una dimensión de personalidad y una creencia cognitiva profunda (Rye, Meaney, Yessis, \& Mckay, 2012). 
La erotofilia-erotofobia se conforma principalmente a través del aprendizaje temprano y la socialización sexual. Concretamente, las características del entorno familiar (en particular la apertura o cerrazón hacia temas sexuales) junto con la propia experiencia sexual temprana parecen ser los dos principales factores que explican que una persona se sitúe en uno u otro extremo de este continuo (Byrne, Fisher, Lamberth, \& Mitchell, 1974). Esta dimensión se ha demostrado universal y común a cualquier pueblo y sociedad, variando su manifestación. En las sociedades occidentales, la erotofilia es un rasgo propio de hombres jóvenes no religiosos mientras que en otros contextos y culturas -sobre todo sociedades matriarcales- apenas se aprecian diferencias entre hombres y mujeres (Fisher et al., 1988). Se ha demostrado que las tendencias erotofílicas-erotofóbicas varían paralelamente a los avances sociales en la consideración del sexo. En España, durante los últimos 30 años y especialmente en jóvenes, se ha producido un acercamiento generalizado hacia el extremo erotofílico del continuo, siendo ya pocos los que manifiestan una actitud negativa o de evitación hacia el sexo (López et al., 2011). Estos cambios han sido mayores en mujeres que en hombres -presumiblemente porque ellas partían de una mayor erotofobia-. Sin embargo, todavía hoy los hombres son más erotofílicos que las mujeres, lo que podría explicar al menos en parte las diferencias en el comportamiento sexual (Petersen \& Hyde, 2011).

Situarse en uno u otro extremo del continuo condiciona la forma en la que las personas se comportan sexualmente. Durante el principio de la adolescencia, la búsqueda de información y conocimientos sobre sexo y sexualidad es uno de los ámbitos donde esta dimensión muestra mayor influencia. Se ha demostrado que los adolescentes erotofílicos son más receptivos y abiertos a tratar y discutir los contenidos de los programas de educación sexual, mientras que los erotofóbicos evitan, en la medida de lo posible, participar activamente en estas iniciativas (Rye, 2013). Quizá por eso los adolescentes y adultos con actitudes erotofóbicas muestran, en general, peores conocimientos sobre temas relacionados con el sexo y la sexualidad (como por ejemplo, la contracepción o la prevención del VIH) (Herbenick, Reece, \& Hollub, 2009).

La erotofilia-erotofobia influye también sobre la historia y el desarrollo psicosexual. Los chicos y chicas erotofílicos tienden a iniciarse más tempranamente en la actividad sexual, hacerlo con un mayor número de parejas, mantener una frecuencia sexual mayor (tanto de masturbación como de sexo en pareja) e incluir entre su repertorio sexual mayor variedad de prácticas sexuales (para una revisión, Rye, 2013). Este patrón de conducta sexual, realizado sin emplear las medidas de prevención adecuadas, incrementa sensiblemente el riesgo de contraer una ITS o exponerse al VIH. Sin embargo, se constata que los erotofílicos muestran una actitud más positiva hacia el preservativo así como una mayor frecuencia de uso (Stephanie A Sanders et 
al., 2006), por lo que en realidad el riesgo de contraer una ITS o el VIH es mayor entre personas erotofóbicas.

Asimismo, esta dimensión influye sobre la vivencia de la sexualidad. Las personas erotofóbicas experimentan vergüenza y culpabilidad cuando mantienen relaciones sexuales, sobre todo cuando éstas se alejan de los cánones tradicionales (p.e., cuando mantienen relaciones sexuales con una persona a la que acaban de conocer), de modo que generalmente acaban desarrollando una peor autoestima sexual (Macapagal \& Janssen, 2011). Se ha demostrado también que las personas erotofílicas están más predispuestas a aceptar hábitos y prácticas sexuales alejadas de lo habitual (como por ejemplo el bondage), mientras que al contrario, las erotofóbicas raramente desarrollan este tipo de preferencias sexuales. Además, estos últimos juzgan con mayor dureza a las personas con este tipo de preferencias sexuales (Rye, Serafini, \& Bramberger, 2015). El panorama es similar cuando se analiza la vivencia del sexo con la pareja, ya que las inhibiciones propias de su evitación sexual les hacen disfrutar menos durante el coito y por tanto, experimentar una peor satisfacción sexual.

En el contexto de las distintas fases de la respuesta sexual, la erotofilia-erotofobia resulta especialmente significativa en la expresión del deseo y el interés sexual. En este sentido, Soleymani (1995, citado en Nobre et al., 2004) demostró que las mujeres erotofílicas mostraban mayor activación sexual subjetiva en respuesta a la exposición a estímulos sexuales, hallazgo que confirmaron 9 años más tarde Nobre et al. (2004) en este caso en hombres. El interés hacia el visionado de pornografía también se relaciona con esta dimensión: se ha demostrado que cuando a una persona se le muestra un estímulo de tipo sexual, el tiempo que pasa observándolo es proporcional a su grado de erotofília-erotofobia (Becker \& Byrne, 1985). Algo similar sucede con la frecuencia de pensamientos y fantasías sexuales: las mujeres con tendencias erotofílicas presentan una frecuencia de pensamientos sexuales sensiblemente superior a la de las mujeres erotofóbicas, diferencias que no se apreciarían en el caso de los hombres (Fisher, Moore, \& Pittenger, 2012).

A pesar de la importancia de esta dimensión a la hora de explicar múltiples aspectos del comportamiento sexual, su impacto en el campo de la CS ha sido más bien limitado. En este ámbito, se ha optado por emplear los conceptos de excitación e inhibición sexual, dos elementos básicos de la teoría de control dual de la conducta sexual cuya descripción se asemejaría bastante a la que Fisher hace de la dimensión de erotofilia-erotofobia (Bancroft et al., 2009). La principal diferencia entre ambas teorías es que ésta última no considera que la excitación y la inhibición sexual conformen los dos extremos de una misma dimensión (como en el caso de la erotofilia-erotofobia), sino que se trataría de dos dimensiones que funcionan 
independientes la una de la otra. Múltiples investigaciones han encontrado que determinadas configuraciones de estas dos dimensiones (principalmente una combinación de una alta excitación sexual y una baja inhibición) explicarían en parte el desarrollo de la CS, tanto en población subclínica (Muise et al., 2013) como en pacientes con problemas en el control de los impulsos sexuales (Rettenberger et al., 2015). Cabe, por tanto, esperar que la inclusión de la erotofilia-erotofobia en el ámbito de la CS permita mejorar la comprensión de este fenómeno clínico así como de sus consecuencias y manifestaciones.

\section{Variables clínicas de interés en CS}

\subsection{Ansiedad y depresión}

Como ya se comentó en un epígrafe anterior, la comorbilidad entre trastornos de ansiedad, del estado de ánimo y CS es muy elevada. En pacientes con problemas en el control de los impulsos sexuales, la presencia de estos cuadros clínicos provoca una respuesta paradójica: en lugar de producirse una pérdida del apetito sexual, estos pacientes experimentan un incremento de la libido concurrente a su aparición (presumiblemente por la capacidad del sexo para regular el estado emocional). Este patrón provoca inicialmente un cierto alivio del estado de ánimo disfórico que se agravaría a largo plazo como consecuencia del uso de estrategias disfuncionales de regulación emocional (Hook, Hook, \& Hines, 2008). Esto es congruente con la hipótesis de la automedicación en adicciones, que sostiene que las personas no se vuelven adictas a la ingesta de una sustancia (adicciones tóxicas) o a la realización de una conducta (adicciones no tóxicas), sino al alivio que éstas provocan a corto plazo sobre la regulación del afecto negativo (Kasten, 1999).

Demostrada la vinculación entre trastornos de ansiedad, del estado de ánimo y CS, se empieza a discutir si niveles subclínicos de ansiedad y depresión se relacionarían también con la presencia de síntomas y manifestaciones de la CS. Esta hipótesis defendería que no sólo los síntomas de ansiedad o depresión que acaban conformando un cuadro clínico aumentan la gravedad de la CS, sino que la intensidad del estado emocional disfórico correspondería con diferentes niveles de severidad de la CS (Schultz, Hook, Davis, Penberthy, \& Reid, 2014). En este epígrafe nos centramos en cómo la propensión a experimentar malestar en general y más en concreto ansiedad y depresión (lo que no significa la presencia de otro trastorno del Eje I) permite explicar un importante porcentaje del inicio y del mantenimiento de la CS.

Se han publicado múltiples investigaciones que demuestran el vínculo positivo y significativo entre niveles de depresión y CS. El metanálisis realizado por Schultz et al. (2014) -primer y único metanálisis en el ámbito de la CS- resume bien los principales hallazgos. El objetivo de 
estos investigadores era obtener una estimación de la magnitud de la relación entre depresión y CS, así como del posible papel moderador de variables como el sexo, la edad y la orientación sexual. Concretamente, estos investigadores planteaban que la relación entre nivel de depresión y gravedad de los síntomas de CS sería positiva y significativa, proponiendo además que esta vinculación sería más sólida en hombres que en mujeres, en homosexuales y bisexuales y en personas de 35 años en adelante. Para ello, sometieron a metodología metanalítica los resultados de 19 estudios que exploraban de forma dimensional la vinculación entre ambas variables, lo que sumaba una muestra de 3783 personas. En la línea de investigaciones anteriores, la mayoría de participantes fueron hombres (67\%), heterosexuales (72\%) y caucásicos (81\%), siendo la edad media de 33 años. Lo que estos investigadores encontraron es que la correlación entre depresión y CS oscilaba entre .11 y .67 según diferentes estudios y que, tomados en conjunto, la correlación entre ambas variables fue alta, positiva y significativa $(r=.34)$. Se descartó que el sexo, la edad o la orientación sexual jugaran papel modulador alguno sobre la relación entre depresión y CS.

A partir de estos resultados, Schultz et al. (2014) confirmaron la hipótesis del vínculo dimensional entre depresión y CS. La correlación y la varianza compartida entre ambas dimensiones (12\%) sugerían una relación donde la severidad de los síntomas de CS provocaría un empeoramiento del estado de ánimo y donde, a la inversa, mayores niveles de depresión mermarían en cierta medida la capacidad para el control de los impulsos sexuales. El hecho de que esta relación no se viera modulada por el sexo, la edad o la orientación sexual incrementa la solidez de estos hallazgos en la medida que sitúa el vínculo entre depresión y CS como un rasgo clínico central y transversal a cualquiera de las manifestaciones de esta patología.

No disponemos de un estudio que demuestre con tanta claridad la relación entre niveles de ansiedad y CS. Sin embargo, diferentes investigaciones apuntan hacia esta misma hipótesis. Los primeros en evaluar cómo diferentes niveles de ansiedad se relacionaban con la gravedad de la CS fueron Kalichman y Rompa (2001) y lo hicieron en un sector muy concreto de población: personas con VIH. Estos investigadores reclutaron a 197 hombres y 90 mujeres $\mathrm{VIH}+$ a los que aplicaron de forma concurrente el cuestionario de ansiedad estado-rasgo (STAl) y el cuestionario SCS de compulsividad sexual, encontrando una correlación entre ambas medidas de .42 en el caso de los hombres y de .19 en el caso de las mujeres. Si bien estos resultados confirman una relación dimensional entre ambas variables, la especificidad de la muestra impediría su generalización.

En 2009, Reid y su equipo publican dos estudios donde se confirman los hallazgos obtenidos por Kalichman y Rompa ocho años antes. En ambos estudios, la ansiedad se evaluó a través de 
escalas de síntomas psicopatológicos. En el primero, se encontró que la correlación entre la subescala de ansiedad del SCL-90 y la puntuación global en el IH era de .23. De entre las tres subescalas que conforman el IH, la de afrontamiento fue la que correlacionó de forma más intensa con la subescala de ansiedad $(r=.24)$, lo que confirmaría la importancia de la CS como regulador de la ansiedad (Reid, Carpenter, \& Lloyd, 2009). En el segundo estudio se encontró que la puntuación en la subescala de ansiedad del MMPI en un grupo de pacientes con altas puntuaciones en el IH fue muy superior a la puntuación normativa (Reid \& Carpenter, 2009).

Especialmente significativos resultan también los hallazgos realizados por Skegg et al. (2010). Estos investigadores hallaron diferencias en una escala de reacción al estrés cuando comparaban a hombres y mujeres con y sin problemas en el control de los impulsos sexuales. Tanto en el caso de los hombres como en el de las mujeres, los pacientes con rasgos de CS obtenían en esta variable puntuaciones significativamente superiores a las del grupo control ( 63.7 frente a 48.5 en el caso de las mujeres y 49.9 frente a 31 en el caso de los hombres).

Similares resultados se obtienen en tres investigaciones muy recientes. En la primera, Reid, Bramen, Anderson y Cohen (2014) administraron a un grupo de 80 personas (40 control y 40 pacientes con CS) una batería de cuestionarios que incluían, entre otros, el cuestionario STAI de ansiedad estado-rasgo y el inventario IH de hipersexualidad. La correlación entre ambas escalas fue de .48. En el estudio de Carvalho, Guerra, Neves y Nobre (2014) realizado con 235 mujeres de entre 18 y 39 años, la subescala de ansiedad del inventario breve de síntomas Derogatis permitía predecir, junto con algunas otras variables, el $16 \%$ de la varianza de las puntuaciones en la escala SCS de compulsividad sexual. Finalmente, Voon et al. (2014) encontraron importantes diferencias al comparar las puntuaciones medias en el cuestionario de ansiedad estado-rasgo (STAI) de un grupo de 19 pacientes con problemas en el control de los impulsos sexuales y 19 pacientes sanos. En concreto, los pacientes sanos obtuvieron puntuaciones significativamente menores tanto en la escala de ansiedad estado (36.5 frente a 44.1) como de ansiedad rasgo (37.1 frente a 49.4). A partir de estos hallazgos, se confirmaría que la relación entre ansiedad y CS no se limita a la mera comorbilidad entre estados psicopatológicos, sino que diferentes niveles de ansiedad se relacionan con distintos grados de severidad de la CS y viceversa.

\subsection{Autoestima}

La autoestima es una dimensión fundamental en la comprensión tanto de la salud psicosocial como de la patología mental. Su historia y evolución justifican su importancia. En la primera edición del manual Principios de la Psicología, William James la definió como "Ia razón entre 
los éxitos y los intentos" (James, 1890, citado en Sowislo \& Orth, 2013). De acuerdo con esta definición, la autoestima aumentaría acumulando éxitos y reduciendo fracasos o abandonando tareas en las que no seamos exitosos. En contraposición, otros han hecho énfasis en el componente social. Cooley (1902, citado en Sowislo \& Orth, 2013) creía que la autoestima positiva o negativa dependía de la forma en la que interpretáramos la información explícita e implícita que sobre nosotros transmitieran las personas de nuestro entorno. En la actualidad, tanto la valoración personal de nuestros logros y trayectorias como la opinión de las personas de nuestro entorno constituyen los principales determinantes de la autoestima. Junto con el autoconocimiento (cómo creo que soy) y la autoeficacia (cómo de eficaz percibo que soy), la autoestima (valoración positiva o negativa de mí mismo y de mis capacidades) conformaría el componente valorativo y emocional de una dimensión más general de autoconocimiento y autovaloración que se ha llamado autoconcepto (Leary \& Baumeister, 2000).

Existe cierto debate en torno a si considerar la autoestima como una dimensión general de valoración de uno mismo o considerarla dependiente del contexto (Swann \& Bosson, 2010). La primera defiende que la autoestima en cada uno de los ámbitos de la vida es equivalente, mientras que la segunda propone que la valoración de capacidades y recursos varía en ámbitos concretos -autoestima académica, física, social, etc.-. Lo que la investigación señala al respecto es que ambas perspectivas resultan complementarias y que dar prioridad a una u otra depende del nivel de análisis (Sowislo \& Orth, 2013). La autoestima general se relaciona con dimensiones y facetas globales (p.e., la satisfacción con la vida en general, la felicidad, la calidad en las relaciones sociales, etc.), mientras que la autoestima específica se ha demostrado un predictor fiable en niveles de análisis más concretos (por ejemplo, la autoestima intelectual resulta un predictor robusto del desempeño académico).

Cómo evoluciona y cuál es el impacto de una alta o baja autoestima son dos cuestiones que han suscitado mucho interés. Especialmente significativa resulta la investigación de Orth, Robins y Widaman (2012) para responder a estas preguntas. En este estudio longitudinal, un total de 1824 personas de entre 16 y 97 años fueron sometidas a 5 evaluaciones durante un periodo de 12 años. Sus hallazgos permitieron establecer la evolución temporal de la autoestima y sus implicaciones en diferentes ámbitos. Con respecto a la evolución, la autoestima mostraba una tendencia creciente desde la adolescencia hasta los 50 años, momento en el que ésta alcanzaba su máximo nivel. De ahí en adelante, el envejecimiento, la pérdida de salud física y la dependencia hacían que la autoestima decrecería lentamente hasta quedar por debajo de los niveles durante la adolescencia. Otro hallazgo significativo era que la autoestima no aumentaba ni disminuía drásticamente debido a eventos vitales positivos o 
negativos. Al contrario, era la autoestima la que aumentaba o disminuía la probabilidad de que dichos eventos ocurrieran. Lo mismo sucede en la relación entre autoestima y estado de ánimo. La baja autoestima resulta ser un predictor muy robusto de la aparición de episodios depresivos recurrentes, mientras que la ocurrencia de un episodio depresivo no tiene apenas capacidad predictiva sobre la autoestima. Si bien no es una norma inequívoca, lo que este estudio señala es que la autoestima no es la consecuencia de una situación vital positiva o negativa, sino más bien la causa o, por lo menos, uno de sus precursores.

Coherentemente con esta perspectiva de la autoestima como causa y no como consecuencia de diferentes eventos y situaciones vitales, el anterior estudio encuentra toda una serie de áreas donde ésta tendría un impacto significativo. En concreto, la autoestima tendría un efecto medio sobre el estado de ánimo (positivo en el caso de la alta autoestima y negativo en el caso de la baja), medio-bajo sobre las relaciones sociales y la satisfacción laboral y bajo sobre la salud. Siguiendo una clasificación similar, Emler (2001) hace una revisión de las dimensiones donde un bajo nivel de autoestima podría tener un impacto significativo:

1) No tiene impacto sobre el desarrollo de conductas violentas o criminales, prejuicios raciales, sobre el inicio del hábito de fumar o sobre la probabilidad de ejercer maltrato infantil.

2) Tiene una impacto medio sobre el inicio en el consumo de alcohol y drogas, problemas en el desarrollo de relaciones con iguales e insatisfacción laboral.

3) Tiene un impacto directo y significativo sobre la realización de conductas sexuales de riesgo y la probabilidad de un embarazo no deseado, desarrollo de trastornos alimentarios, fracaso escolar y bajo nivel académico, estado de ánimo negativo (tanto ansiedad como depresión) y finalmente sobre el riesgo de suicidio.

El impacto de la baja autoestima sobre la conducta sexual (en especial, la conducta sexual de riesgo) es uno de los mejor documentados a través de diversos estudios e investigaciones. En este sentido, la baja autoestima correlaciona con una menor edad de inicio en las relaciones sexuales (McGee \& Williams, 2000), con una actitud más desfavorable hacia el uso de métodos anticonceptivos y una menor frecuencia de uso en diferentes prácticas sexuales (L. D. McNair, Carter, \& Williams, 1998) y con una mayor probabilidad de embarazo no deseado (Plotnick, 1992). Como explica Emler (2001), el vínculo entre baja autoestima y conducta sexual de riesgo se ha explicado principalmente a partir de aspectos como la autoeficacia y las habilidades sociales. Por un lado, el uso consistente del preservativo requiere que la persona reconozca sus habilidades y destrezas en su uso, lo cual difícilmente sucede cuando la persona no tiene una visión positiva y no reconoce sus habilidades sexuales (autoestima sexual). Aun cuando la 
persona tenga una actitud positiva hacia el preservativo y se valore eficaz en su utilización, existen situaciones donde es la pareja la que se opone a su uso. En esos casos, las habilidades de asertividad y de negociación resultan imprescindibles para evitar la conducta sexual de riesgo y reorientar la situación, habilidades sociales que también se ven seriamente afectadas en personas con baja autoestima. Por otra parte, Lucker (1975) y Kaplan (1980) explican el vínculo entre baja autoestima y conducta sexual de riesgo desde una perspectiva emocional y valorativa. Lucker defiende que las personas con baja autoestima rechazan el uso de métodos preventivos porque "no tienen nada que perder". Para una persona que no se valora positivamente en ningún ámbito, el riesgo de transmisión de una ITS/VIH o de un embarazo no deseado es tan sólo una remota posibilidad más de que su vida vaya aun peor. Kaplan aborda esta relación desde la perspectiva de la ganancia secundaria argumentando que para una persona con baja autoestima, el sexo es una forma de sentirse querido y el sexo de riesgo, un paso más para lograr aprobación y reconocimiento. Como señalaban Crockenberg y Soby, "el sexo es una de las mejores formas de sentirnos atractivos" (Crockenberg \& Soby, 1989, p. 131). Otro argumento se ha utilizado para explicar el vínculo entre autoestima y CS. Muchos clínicos con experiencia en el tratamiento de pacientes con problemas en el control de los impulsos sexuales señalan que es común que sus pacientes presenten problemas de autoestima y no sólo como consecuencia de su problema, sino desde mucho antes de desarrollar los primeros síntomas. En este sentido, se sugiere que la CS no sólo puede ser un regulador de estados de ánimo disfóricos, sino también una forma alternativa de mejorar la valoración de uno mismo a través del contacto sexual con otras personas (Parsons et al., 2008). En 1994 aparecen las primeras evidencias empíricas que fundamentan esta hipótesis. Como parte del procedimiento de validación de las escalas de búsqueda de sensaciones sexuales y de CS, Kalichman y su equipo correlacionaron ambas medidas con una batería de cuestionarios donde se incluyó la Escala de autoestima de Rosenberg (RSEI). Lo que encontraron fue que mientras que la correlación entre autoestima y BSS no resultó significativa $(r=.11)$, la relación con la escala SCS (-.32) y con una escala de percepción de control sexual (.40) sí lo fue (Kalichman et al., 1994). Esta fue la primera vez que se documentaba a nivel empírico una relación que algunos clínicos apuntaban muchos años atrás. Un año más tarde, Kalichman demostró la consistencia de esta relación al hallar una correlación de - .35 entre CS y autoestima en una muestra de hombres homosexuales y de -.32 entre hombres y mujeres en riesgo de exclusión social (Kalichman \& Rompa, 1995). Por su parte, Guigliamo (2006) documentó tras una serie de entrevistas a hombres con problemas de CS que el $64 \%$ de ellos experimentó problemas de autoestima previos y también concurrentes a la aparición del cuadro clínico. 
La relación entre autoestima y CS ha sido ampliamente estudiada entre hombres que tienen sexo con hombres (HSH). En este colectivo, es frecuente que el rechazo social a sus prácticas sexuales así como la interiorización del heterosexismo social dominante provoque emociones de vergüenza y culpa cuando expresan sus afectos, lo que sin duda deja una impronta negativa en su autoestima. En este contexto, la conducta sexual compulsiva sobreviene un regulador que permite mantener unos niveles de autoestima soportables, igual que para muchos otros pacientes el sexo sirve para controlar un estado de ánimo ansioso o depresivo (Parsons et al., 2008). En un reciente estudio realizado con $305 \mathrm{HSH}$, los autores encuentran que la autoestima baja es, junto con la soledad, los dos principales predictores de la CS en este colectivo, mucho más que otras variables como el estado serológico o el haber confesado la orientación sexual a su entorno (Chaney \& Burns, 2015). En conjunto, ambas variables permiten predecir el $14 \%$ de la varianza de las puntuaciones en la escala SCS. Según estos autores, el sexo compulsivo (sobre todo con múltiples parejas sexuales) permite a estos hombres experimentar una sensación pasajera de atracción y encanto así como un vínculo emocional con su pareja esporádica, lo cual produciría un alivio momentáneo de su sensación de soledad y de su percepción personal negativa.

Algunos estudios sugieren que la autoestima podría, en cierta medida, explicar la comorbilidad entre la CS y otras patologías. Sería el caso de la investigación de Reid, Carpenter, Gilliland y Karim (2011) sobre comorbilidad entre CS y TDAH. En este estudio se encontró que el predictor más robusto de CS en una muestra de pacientes con TDAH comórbido no eran los problemas en el control ejecutivo (hipótesis que se planteaba a priori), sino que lo que mejor explicaba la unión entre ambas patologías era la baja autoestima. A partir de estos resultados, los autores sugieren que a la hora de explicar la comorbilidad entre CS y otras patologías quizás se esté dando demasiada importancia a ciertas dimensiones en detrimento de otras -como por ejemplo la autoestima- que podrían enriquecer el abordaje terapéutico y mejorar los resultados de nuestras intervenciones.

\section{En resumen}

Las tres principales variables demográficas que influyen sobre la expresión de la compulsividad sexual son el sexo, la edad y la orientación sexual. En cuanto al sexo, las mujeres muestran un perfil de conducta sexual compulsiva que se diferencia del masculino en 3 aspectos: etiología, manifestaciones clínicas y consecuencias del cuadro clínico. En cuanto a la etiología, la CS en mujeres se asocia más intensamente a situaciones de negligencia en el cuidado infantil en general y a antecedentes de abuso físico, sexual o emocional en particular. A nivel clínico, las mujeres desarrollan la patología más tempranamente y su conducta sexual es cualitativamente 
distinta de la de los hombres: mientras que ellos expresan su problema sexual a través de la masturbación, ellas lo hacen a través del coito compulsivo con una pareja estable o múltiples parejas esporádicas. Finalmente, las consecuencias del comportamiento sexual suelen ser más graves en mujeres, presumiblemente por la sanción social derivada del hecho de ser mujer y sufrir de un deseo sexual desmedido.

En cuanto a su manifestación a lo largo del ciclo vital, los primeros síntomas aparecen durante la adolescencia y estarían relacionados con la frecuencia de masturbación. Concretamente, los adolescentes que posteriormente desarrollan problemas en el control de impulsos sexuales se masturban más frecuentemente que los que no. Asimismo, suelen debutar en el sexo de forma más temprana, con un mayor número de parejas sexuales y asumiendo más riesgos. La etapa entre los 18-25 años corresponde al periodo de pródromo o manifestación subclínica. Durante este intervalo, los jóvenes con rasgos compulsivos dedican cada vez más tiempo a su conducta sexual, incrementan su frecuencia e intensidad y comienzan a mostrar los primeros síntomas (pérdida del control sobre el inicio o la finalización de la actividad sexual, regulación emocional a través del sexo...). Así, en torno al $85 \%$ de los pacientes con problemas de CS durante su vida adulta lo desarrollaron durante este periodo. Con el tiempo, el cuadro clínico evoluciona hasta adquirir gravedad suficiente para ser considerado como tal. Esto sucede en torno a los 30 años y no porque el comportamiento sexual cambie cualitativamente, sino porque a partir de este momento sus consecuencias adquieren severidad e interfieren más en la vida de las personas.

En relación con la orientación sexual, la prevalencia y severidad de la CS es sistemáticamente mayor entre hombres y mujeres con una orientación sexual alternativa a la heterosexual. Entre otras, la facilidad para encontrar parejas dispuestas a mantener relaciones sexuales sería una de las razones que explicarían este incremento. Asimismo, la conducta sexual compulsiva en este colectivo se asocia a un mayor consumo de alcohol o drogas y a un incremento del riesgo de transmisión de una ITS o el VIH, de modo que su análisis pormenorizado resulta crucial.

Además de estas variables sociodemográficas, existen una serie de disposiciones personales que modularían la manifestación y severidad del cuadro clínico de compulsividad sexual. Una de las más importantes sería la personalidad. Empleando la teoría de personalidad de los cinco factores, se ha determinado que el perfil de personalidad de personas con rasgos compulsivos se caracteriza por un mayor neuroticismo (sobre todo en cuanto a vulnerabilidad emocional y propensión a la psicopatología) y una menor amabilidad y responsabilidad. Por otra parte, las dimensiones de apertura a la experiencia y de extraversión apenas se relacionan con el control de impulsos sexuales. 
Todos estos aspectos hacen que el comportamiento sexual de los pacientes con problemas en el control de impulsos sexuales sea cuantitativa y cualitativamente distinto del de las personas sin este problema. La biografía sexual de estos pacientes se caracteriza por un debut sexual más temprano (en torno a dos años antes) que se traduce en un mayor número de parejas a lo largo de la vida (alrededor de 2 o 3 nuevas parejas sexuales por año). Esto se acentúa entre los pacientes de mayor edad y los que informan de una orientación homosexual o bisexual. Entre estos pacientes también sería mayor la frecuencia sexual, sobre todo la de la masturbación (presumiblemente porque su realización no depende de la disponibilidad de una pareja). El tipo de prácticas sexuales apenas varía cuando se explora actividad sexual normofílica pero sí se aprecia un mayor interés hacia prácticas parafílicas o que suponen cierta desviación sexual. Esto parece incompatible con la vivencia de una vida de pareja estable, ya que la proporción de los que cometen una infidelidad es alta y al contrario, pocos los que conservan sus parejas. En cuanto a su comportamiento sexual online, alrededor del $18 \%$ de estos pacientes acaban desarrollando también una adicción al cibersexo (28\% en el caso de las chicas). En pacientes aquejados de una doble adicción, el tiempo dedicado al cibersexo y su interferencia fue mucho mayor. Finalmente, la expresión de variables y disposiciones sexuales como la búsqueda de sensaciones sexuales y la erotofilia tiende a ser mayor entre las personas con CS.

Para terminar, se han identificado tres variables clínicas que permiten comprender algunas de las expresiones del comportamiento sexual compulsivo: la tendencia a experimentar ansiedad, depresión y baja autoestima. Si bien hasta hace poco se asumía que la ansiedad y la depresión eran respuestas incompatibles con experimentar excitación y deseo sexual, estudios recientes demuestran que en pacientes con problemas en el control de impulsos sexuales, la tendencia al malestar emocional se relacionaría con una mayor actividad sexual. Este vínculo se aprecia sobre todo con la tendencia a experimentar un estado de ánimo deprimido, presumiblemente por la capacidad del sexo para regular el estado de ánimo. Algo muy similar sucede con la baja autoestima: la mayoría de pacientes con problemas de control de impulsos sexuales padecen de una baja autoestima antes y durante la aparición del cuadro clínico, lo que sugiere que en estos casos el sexo se emplea también por su ganancia secundaria (en este caso, su capacidad para hacernos sentir atractivos). 


\section{Justificación de la necesidad de este estudio}

La revisión de la literatura especializada en torno al comportamiento sexual compulsivo pone de manifiesto tres limitaciones que por el momento, ningún estudio ha solventado. La primera y más importante tiene que ver con el estudio del perfil biopsicosocial de las personas con una manifestación subclínica de este cuadro clínico, que es la condición que precede al desarrollo y agravamiento de los síntomas propios de la fase aguda de esta patología. En este momento, desconocemos qué factores y disposiciones nos permitirían identificar con garantías a aquellas personas con un riesgo significativamente mayor de desarrollar un cuadro clínico de CS. Se han desarrollado múltiples investigaciones que demuestran que ciertas variables psicosociales son más frecuentes entre pacientes con esta problemática pero seguimos sin conocer si esas mismas u otras disposiciones caracterizan también a estadios más leves del cuadro clínico. De hacerlo, contaríamos con un dibujo más certero del perfil de riesgo en el desarrollo de esta problemática y se podría empezar a plantear intervenciones primarias o secundarias centradas en población de riesgo que impidan el desarrollo de un cuadro clínico de graves consecuencias. Teniendo en cuenta que el periodo de pródromo de este cuadro clínico se sitúa alrededor de los 18-25 años y que es precisamente en este momento en el que en torno al $85 \%$ de los que lo acaban desarrollando experimentan sus primeros síntomas, los estudios deberían centrar sus esfuerzos en determinar las características y disposiciones que durante este periodo permiten discriminar entre jóvenes con y sin rasgos de CS. Sin embargo, no son tantos los estudios a tal efecto y en este momento no contamos con evidencias suficientes respecto a esta cuestión, sobre todo si hablamos de estudios realizados en nuestro país.

Para terminar, sabemos que la sexualidad masculina y femenina es distinta y que equipararla no lleva más que a errores de sobregeneralización. Esto no es menos cierto cuando hablamos del comportamiento sexual compulsivo; sin embargo, lo que en este momento asumimos como cierto en cuanto a la expresión de este cuadro clínico en mujeres no constituye más que generalizaciones engañosas de lo que se ha demostrado de esta patología en hombres. De ahí la importancia de elaborar un perfil diferencial que permita identificar las particularidades de su expresión en hombres y en mujeres y mejorar de esta forma su identificación, expresión y comprensión de sus consecuencias.

Considerando estas premisas, la presente investigación se ha planteado con un doble objetivo: estimar la prevalencia del cuadro clínico de CS en jóvenes españoles de entre 18-27 años e identificar qué características biopsicosociales les diferencian de otros sin esta problemática. 



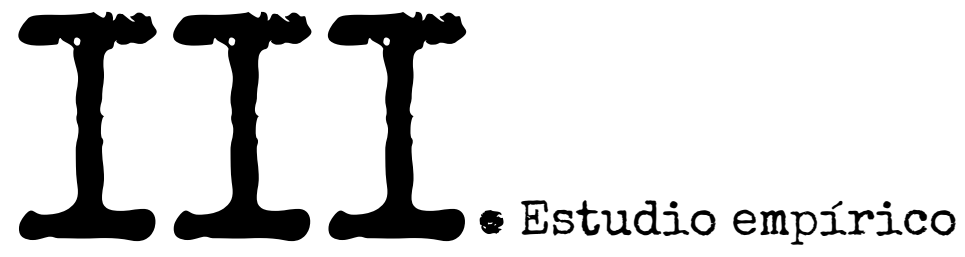



Capítulo 5. objetivos e hipotessis 
La presente tesis doctoral se divide en dos fases.

El objetivo general de la PRIMERA FASE era la estimación de la prevalencia de CS en población joven española, lo que se concreta en los siguientes objetivos específicos e hipótesis:

Objetivo específico 1: analizar el perfil de puntuaciones y estimar la prevalencia de CS en una muestra representativa de jóvenes a través de tres instrumentos de screening.

Hipótesis 1: la puntuación media en los cuestionarios de screening de CS se distribuirá de forma asimétrica, con un importante porcentaje de la muestra en valores inferiores del rango de puntuaciones y una densidad decreciente en valores superiores.

Hipótesis 2: la prevalencia de jóvenes con puntuaciones clínicas se situará entre el 3\%-7\%.

Objetivo específico 2: analizar la influencia del sexo, la edad y la orientación sexual en las puntuaciones y la prevalencia de CS.

Hipótesis 3: en función del sexo, los chicos obtendrán una puntuación media mayor en las escalas y subescalas de CS así como una prevalencia más alta de casos clínicos.

Hipótesis 4: en función de la orientación sexual, los bisexuales y sobre todo homosexuales obtendrán una puntuación media mayor en las escalas y subescalas de CS así como una prevalencia más alta de casos clínicos.

Hipótesis 5: no se encontrarán diferencias en la puntuación media o la prevalencia de CS en función de la edad.

Hipótesis 6: cuando se empleen criterios dinámicos para la estimación de la prevalencia de casos clínicos, ésta será equivalente independientemente del sexo y de la orientación.

El objetivo general de la SEGUNDA FASE era establecer un perfil diferencial entre jóvenes con puntuaciones subclínicas en CS y con puntuaciones normales. Para este objetivo general se plantean los siguientes objetivos específicos e hipótesis:

Objetivo específico 3: estimar y comparar la prevalencia de diferentes cuadros clínicos del Eje I y II en jóvenes con puntuaciones subclínicas en CS y jóvenes con puntuaciones normales.

Hipótesis 7: la prevalencia de patologías del Eje I y II será significativamente mayor en chicos y chicas del grupo de puntuaciones subclínicas en CS (alta comorbilidad psicopatológica), especialmente para trastornos del estado de ánimo, de ansiedad y abuso de sustancias. 
Objetivo específico 4: determinar la expresión diferencial de variables clínicas en jóvenes con puntuaciones subclínicas en CS y jóvenes con puntuaciones normales.

Hipótesis 8: los chicos y chicas del grupo de puntuaciones subclínicas en CS obtendrán puntuaciones mayores en depresión, ansiedad-estado y en ansiedad-rasgo. Al contrario, estos jóvenes obtendrán menores puntuaciones en autoestima.

Objetivo específico 4: identificar la presencia de un perfil de personalidad diferencial entre jóvenes con puntuaciones subclínicas en CS y jóvenes con puntuaciones normales.

Hipótesis 9: los chicos y chicas del grupo subclínico obtendrán mayores puntuaciones en la dimensión de personalidad de neuroticismo y sus 6 facetas (especialmente la de vulnerabilidad) y menores en las dimensiones de amabilidad y responsabilidad. No se encontrarán diferencias entre ambos grupos en las dimensiones de extraversión y apertura a la experiencia.

Objetivo específico 5: analizar el comportamiento sexual actual y pasado de jóvenes con puntuaciones subclínicas en CS y jóvenes con puntuaciones normales, así como la manifestación diferencial de algunas variables disposiciones sexuales y hormonales.

Hipótesis 10: las chicas y sobre todo los chicos del grupo de puntuaciones subclínicas mostrarán una conducta sexual más activa. Concretamente, se espera que estos participantes informen de una frecuencia sexual mayor, más parejas sexuales a lo largo de la vida, la realización de un mayor número de prácticas sexuales (sobre todo de las menos habituales como el sexo anal) y una mayor frecuencia de otros comportamientos como el haber sido infiel o el haber mantenido relaciones con personas del mismo sexo.

Hipótesis 11: las chicas y sobre todo los chicos con puntuaciones clínicas realizarán con mayor frecuencia conductas sexuales que supongan un riesgo para la transmisión del VIH o de una ITS. Sin embargo, se espera que no varíe su percepción de autoeficacia en el uso del preservativo o su valoración del riesgo del VIH.

Hipótesis 12: el uso de internet con fines sexuales (tanto el visionado de pornografía como el uso de chats sexuales) así como la severidad de su consumo será mayor en chicos subclínicos. También será mayor el porcentaje de adictos al cibersexo y de usuarios con un perfil de riesgo. Sin embargo, no se apreciarán diferencias en estos aspectos entre chicas control y subclínicas.

Hipótesis 13: se espera que los participantes subclínicos -chicos y chicas- obtengan puntuaciones mayores en búsqueda de sensaciones sexuales y en erotofilia. 
Hipótesis 14: el nivel de testosterona libre en saliva de los participantes del grupo subclínico será superior al nivel de los del grupo control.

Objetivo específico 7: explorar la severidad y las consecuencias de la conducta sexual en aquellos jóvenes con puntuaciones subclínicas en CS.

Hipótesis 15: la severidad del cuadro clínico será inferior a la encontrada en estudios previos con muestra clínica. Al comparar a chicos y chicas con puntuaciones subclínicas, la severidad del cuadro clínico será mayor en el caso de los chicos, sobre todo en cuanto a manifestaciones violentas o de incapacidad para controlar los impulsos sexuales.

Hipótesis 16: las consecuencias del cuadro clínico de CS serán más graves en chicos que en chicas. Asimismo, la proporción de jóvenes a los que su conducta sexual compulsiva les provoque malestar personal o familiar será alta, mientras que el porcentaje de los que informen de consecuencias negativas para su salud (contraer una ITS o el VIH), legales o monetarias será considerablemente inferior.

Hipótesis 17: la gravedad de las consecuencias del cuadro clínico de CS correlacionará con su severidad.

Objetivo específico 8: identificar la combinación de variables que mejor permita explicar la presencia de síntomas de CS en jóvenes.

Hipótesis 18: la combinación de algunas de las variables consideradas en este estudio permitirá predecir y clasificar correctamente a un alto porcentaje de participantes del grupo de puntuaciones subclínicas en CS (alta sensibilidad y especificidad), si bien el valor predictivo de las mismas variará notablemente. Así, variables como la búsqueda de sensaciones sexuales, la erotofilia o la adicción al cibersexo tendrán una importante capacidad predictiva sobre la variable dependiente, al menos superior a otras como el nivel de autoestima o depresión. Tampoco esperamos que todas las variables tengan una influencia directa sobre la CS, sino que algunas mostrarán una influencia mediada a través de otras variables. 


\section{Capítulo 6. Método}

1. Participantes

2. Instrumentos

3. Procedimiento

4. Análisis estadísticos 


\section{Participantes}

Un total de 1588 jóvenes españoles de entre 18 y 27 años participaron en la primera fase de la investigación, 384 de los cuales (el 24.18\%) formaron parte también de la segunda fase. En la tabla 9 se describen las características de los participantes del primer estudio y en la tabla 10 las de los participantes del segundo. En este último caso, los datos se muestran divididos por sexo y tipo de muestra (control o subclínica) para seguir la misma estructura que en la presentación de resultados. Se incluyen también análisis diferenciales para contrastar la equivalencia en las características de ambos grupos.

Tabla 9. Características de los participantes en la primera fase del estudio

\begin{tabular}{|c|c|}
\hline & $N(\%) \circ M(D T)$ \\
\hline \multicolumn{2}{|l|}{ Sexo } \\
\hline Hombre & $684(43.1 \%)$ \\
\hline Mujer & $904(56.9 \%)$ \\
\hline \multicolumn{2}{|l|}{ Edad } \\
\hline 18 & $262(16.5 \%)$ \\
\hline 19 & $344(21.7 \%)$ \\
\hline 20 & $291(18.3 \%)$ \\
\hline 21 & $243(15.3 \%)$ \\
\hline 22 & $174(11 \%)$ \\
\hline 23 & $106(6.7 \%)$ \\
\hline 24 & $59(3.7 \%)$ \\
\hline 25 & $42(2.6 \%)$ \\
\hline 26 & $40(2.5 \%)$ \\
\hline 27 & $27(1.7 \%)$ \\
\hline Media de edad & $20.58(2.17)$ \\
\hline \multicolumn{2}{|l|}{ Pareja estable } \\
\hline Sí & $830(52.2 \%)$ \\
\hline No & $758(47.8 \%)$ \\
\hline \multicolumn{2}{|l|}{ Orientación sexual } \\
\hline Heterosexual & $1461(92 \%)$ \\
\hline Bisexual & $52(3.3 \%)$ \\
\hline Homosexual & 75 (4.7\%) \\
\hline \multicolumn{2}{|l|}{ Creencias religiosas } \\
\hline Creyente practicante & $95(6 \%)$ \\
\hline Creyente no practicante & $615(38.7 \%)$ \\
\hline Ateo o agnóstico & $878(55.3 \%)$ \\
\hline \multicolumn{2}{|l|}{ Estudios } \\
\hline Preuniversitarios $^{a}$ & $53(3.3 \%)$ \\
\hline Licenciatura o grado en ciencias de la salud (CS) ${ }^{\mathrm{b}}$ & $239(15.1 \%)$ \\
\hline Licenciatura o grado en ciencias humanas y sociales $(\mathrm{CHS})^{c}$ & $488(30.7 \%)$ \\
\hline Licenciatura o grado en ciencias jurídicas y económicas $(\mathrm{CJE})^{\text {d }}$ & $329(20.7 \%)$ \\
\hline Licenciatura o grado en ciencias técnicas y experimentales (CTE) e & $352(22.2 \%)$ \\
\hline Máster y doctorado (sin indicar especialidad) & $24(1.5 \%)$ \\
\hline No se especifica & $103(6.5 \%)$ \\
\hline \multicolumn{2}{|c|}{$\begin{array}{l}\text { a = incluye educación básica, ciclos formativos y bachiller. } \\
\text { b= incluye medicina enfermería, psicología, farmacia y nutrición. } \\
c=\text { incluye traducción, magisterio, diversas filologías, historia, geografía, humanidades, periodismo, } \\
\text { publicidad y comunicación audiovisual. } \\
\text { d }=\text { incluye ciencias del trabajo, administración y dirección de empresas, contabilidad, turismo, } \\
\text { economía y derecho. } \\
\text { e }=\text { incluye ingenierías técnicas y superiores, diseño industrial, química, matemáticas e informática. }\end{array}$} \\
\hline
\end{tabular}


Como se aprecia en la tabla 9, la muestra de la primera fase del estudio estaba compuesta por un porcentaje ligeramente superior de mujeres que de hombres (56.9\% frente al $43.1 \%)$. La gran mayoría (71.8\%) tenían entre 18 y 21 años en el momento de la evaluación, decreciendo progresivamente el porcentaje de participantes con edades superiores. La media de edad fue de 20.58 años ( $D T=2.17)$. La distribución en función de si los participantes tenían o no pareja resultó prácticamente idéntica, con un porcentaje ligeramente mayor (52.2\%) que afirmaba sí mantener una relación estable. Respecto a la orientación sexual, la gran mayoría se autoidentificó como heterosexual (92\%), seguido muy de lejos por un $4.7 \%$ que afirmaba ser homosexual y un 3.3\% que se identificaba como bisexual. Tan solo una minoría (el 6\%) decía ser creyente practicante, mientras que el resto se repartía entre creyentes no practicantes (38.7\%) y sobre todo ateos o agnósticos (55.3\%). Un 6.5\% de los participantes no respondió a la pregunta sobre los estudios que cursaba. Excepto un 3.3\% que indicó estar cursando estudios preuniversitarios (principalmente bachillerato y ciclos formativos), el resto se encontraba cursando una titulación universitaria, muchos en alguna de las especialidades de la rama de ciencias humanas y sociales (30.7\%). El 22.2\% se encontraba cursando una titulación técnica, seguido del $20.7 \%$ que cursaba una titulación relacionada con las ciencias jurídicas o económicas y finalmente el $15.1 \%$ que cursaba una de la rama de ciencias de la salud.

La muestra de la segunda fase del estudio (tabla 10) comprendía a 384 participantes (187 hombres y 197 mujeres) clasificados en dos grupos: control y subclínicos. La asignación a uno u otro grupo dependía de su puntuación en la escala SCS: los que obtuvieron una puntuación centil superior a 80 (18 en chicos y 14 en chicas) fueron clasificados en el grupo subclínico y el resto en el grupo control. En el caso de los chicos, el grupo control estaba compuesto por 100 participantes con una edad media de 21.48 años ( $D T=2.43$ ) mientras que el grupo subclínico comprendía a 87 chicos con una edad media de 20.90 (DT=2.36). Si bien los subclínicos eran ligeramente más jóvenes, la diferencia no alcanzó la significación ( $t=1.66 ; p=.09 ; d=0.24)$. En el caso de las chicas, el grupo control comprendía a 99 participantes con una edad media de 20.64 (DT=1.92) y el subclínico a 98 con una edad media de 20.35 (DT=1.67). Nuevamente la edad resultó equivalente $(t=1.12 ; p=.26 ; d=0.16)$. En la figura 7 se presenta la distribución por edades: tanto en la muestra de hombres como de mujeres, la mayor parte se acumulaban en la franja de menor edad (entre los 18 y los 21 años), si bien en el caso de los chicos el porcentaje en edades superiores era un tanto mayor. La distribución de participantes control y subclínicos entre las diferentes edades era similar en la muestra masculina mientras que en el caso de las chicas se apreciaban ciertas discrepancias en algunos tramos de edad (por ejemplo el porcentaje de participantes control de 19 años era del $16.2 \%$ frente al $29.6 \%$ de subclínicas). 
$\square$ Control

Hombres $(N=187)$

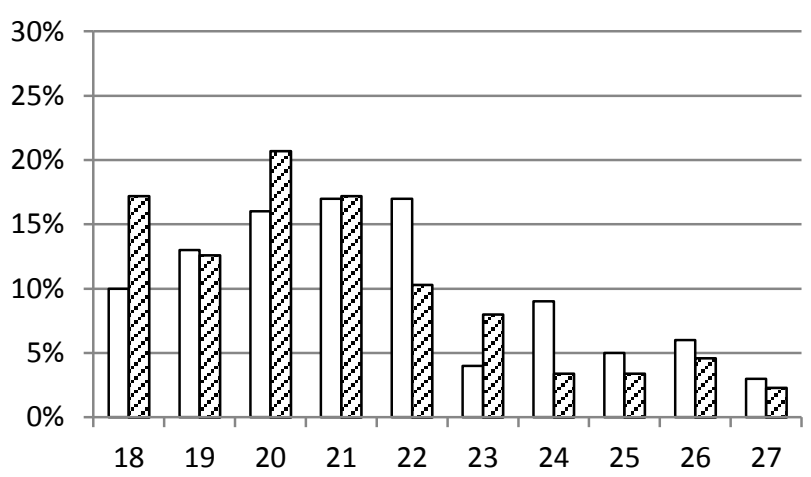

๒Subclínico

Mujeres ( $N=197)$

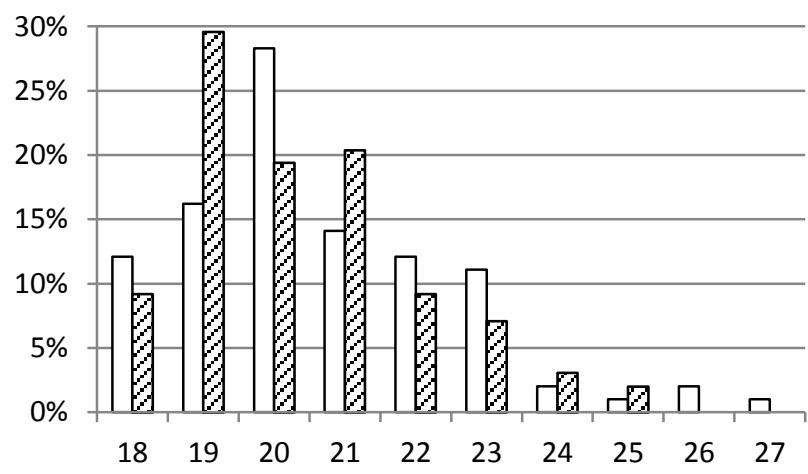

Figura 7. Distribución por edades de los participantes en la segunda fase del estudio

La mayoría de chicos control y subclínicos en la segunda fase del estudio se autoidentificaban como heterosexuales, ateos o agnósticos y cursaban una licenciatura o grado (principalmente de la rama de ciencias jurídicas y económicas en el caso de los participantes control y de la rama de ciencias técnicas en el caso de los subclínicos) (tabla 10). El porcentaje de los que afirmaban mantener una relación estable y de los que no fue prácticamente idéntico. Los contrastes estadísticos aplicados confirman la equivalencia entre chicos control y subclínicos en todas las variables sociodemográficas contempladas. Únicamente aparecen ciertas discrepancias que no alcanzan la significación estadística $\left(X^{2}=5.38 ; p=.06 ; V=0.17\right)$ en la distribución de participantes según la orientación sexual. En ese caso, el porcentaje de chicos autoidentificados como homosexuales en la muestra subclínica superaba sensiblemente el porcentaje en la muestra control (20.7\% frente al $9 \%)$.

En la muestra de chicas, el porcentaje de las que afirmaron mantener una relación estable (66.7\% en el grupo control y $58.2 \%$ en el clínico) era ligeramente mayor al de las que afirmaban lo contrario. Por lo demás, las características eran similares a las comentadas para la muestra masculina: la mayoría se autoidentificaban como heterosexuales, eran ateas o agnósticas y cursaban una licenciatura o grado en el momento de la evaluación. En este caso sí se encuentran diferencias significativas entre participantes control y subclínicas en cuanto a creencias religiosas $\left(X^{2}=8.51 ; p=.01 ; V=0.20\right)$ y sobre todo estudios $\left(X^{2}=28.65 ; p<.001 ; V=0.38\right)$. En el primer caso, el porcentaje de las participantes subclínicas que afirmaban ser ateas o agnósticas era un $18 \%$ superior al de las participantes control. Respecto a los estudios, más de la mitad de las chicas control (el 56.6\%) cursaba estudios de la rama de ciencias de la salud frente al 31.6\% de las participantes subclínicas. Al contrario, un mayor porcentaje de éstas cursaba estudios de la rama de ciencias humanas y sociales (32\% frente a $22 \%$ ) y sobre todo de la rama de ciencias técnicas (13\% frente a $1 \%)$. 
Tabla 10. Características de los participantes en la segunda fase del estudio

\begin{tabular}{|c|c|c|c|c|c|c|c|c|}
\hline & \multicolumn{4}{|c|}{ Hombres (N=187) } & \multicolumn{4}{|c|}{ Mujeres ( $N=197)$} \\
\hline & $\begin{array}{l}\text { Control }(n=100) \\
N(\%) \circ M(D T)\end{array}$ & $\begin{array}{c}\text { Subclínico }(n=87) \\
N(\%) \circ M(D T)\end{array}$ & $\begin{array}{c}\text { Estadístico de } \\
\text { contraste }\end{array}$ & $\begin{array}{c}\text { Tamaño } \\
\text { del efecto }\end{array}$ & $\begin{array}{l}\text { Control }(n=99) \\
N(\%) \circ M(D T)\end{array}$ & $\begin{array}{c}\text { Subclínico }(n=98) \\
N(\%) \circ M(D T) \\
\end{array}$ & $\begin{array}{c}\text { Estadístico de } \\
\text { contraste }\end{array}$ & $\begin{array}{l}\text { Tamaño } \\
\text { del efecto }\end{array}$ \\
\hline \multicolumn{9}{|l|}{ Edad } \\
\hline Edad media & $21.48(2.43)$ & $20.90(2.36)$ & $t=1.66(p=.09)$ & $d=0.24$ & $20.64(1.92)$ & 20.35 (1.67) & $t=1.12(p=.26)$ & $d=0.16$ \\
\hline \multicolumn{9}{|l|}{ Pareja estable } \\
\hline $\mathrm{Si}$ & $49(49 \%)$ & $42(48.3 \%)$ & \multirow{2}{*}{$X^{2}=0.01(p=.92)$} & \multirow{2}{*}{$V=0.01$} & $66(66.7 \%)$ & $57(58.2 \%)$ & \multirow{2}{*}{$X^{2}=1.51(p=.21)$} & \multirow{2}{*}{$V=0.08$} \\
\hline No & $51(51 \%)$ & 45 (51.7\%) & & & $33(33.3 \%)$ & 41 (41.8\%) & & \\
\hline \multicolumn{9}{|l|}{ Orientación sexual } \\
\hline Heterosexual & $87(87 \%)$ & $67(77 \%)$ & \multirow{3}{*}{$x^{2}=5.38(p=.06)$} & \multirow{3}{*}{$V=0.17$} & $96(97 \%)$ & $82(83.7 \%)$ & \multirow{3}{*}{$x^{2}=1.51(p=.21)$} & \multirow{3}{*}{$V=0.08$} \\
\hline Bisexual & $4(4 \%)$ & $2(2.3 \%)$ & & & $1(1 \%)$ & $11(11.2 \%)$ & & \\
\hline Homosexual & $9(9 \%)$ & $18(20.7 \%)$ & & & $2(2 \%)$ & $5(5.1 \%)$ & & \\
\hline \multicolumn{9}{|l|}{ Creencias religiosas } \\
\hline Creyente practicante & $5(5 \%)$ & $2(2.3 \%)$ & \multirow{3}{*}{$X^{2}=1.31(p=.51)$} & \multirow{3}{*}{$V=0.08$} & $13(13.1 \%)$ & $4(4.1 \%)$ & \multirow{3}{*}{$x^{2}=8.51(p=.01)$} & \multirow{3}{*}{$V=0.20$} \\
\hline Creyente no practicante & $23(23 \%)$ & $24(27.6 \%)$ & & & $36(36.4 \%)$ & $27(27.6 \%)$ & & \\
\hline Ateo o agnóstico & $72(72 \%)$ & $61(70.1 \%)$ & & & $50(50.5 \%)$ & $67(68.4 \%)$ & & \\
\hline \multicolumn{9}{|l|}{ Estudios } \\
\hline Preuniversitarios & $9(9 \%)$ & $10(11.5 \%)$ & \multirow{7}{*}{$X^{2}=4.11(p=.76)$} & \multirow{7}{*}{$V=0.14$} & $0(0 \%)$ & $0(0 \%)$ & \multirow{7}{*}{$X^{2}=28.65(p<0.001)$} & \multirow{7}{*}{$V=0.38$} \\
\hline Licenciatura o grado en CS & $18(18 \%)$ & 19 (21.8\%) & & & $56(56.6 \%)$ & $31(31.6 \%)$ & & \\
\hline Licenciatura o grado en CHS & $22(22 \%)$ & 19 (21.8\%) & & & $22(22.2 \%)$ & $32(32.7 \%)$ & & \\
\hline Licenciatura o grado en CJE & $25(25 \%)$ & 15 (17.2\%) & & & $15(15.2 \%)$ & $15(15.3 \%)$ & & \\
\hline Licenciatura o grado en CTE & $19(19 \%)$ & $21(24.1 \%)$ & & & $1(1 \%)$ & $13(13.3 \%)$ & & \\
\hline Máster y doctorado & $3(3 \%)$ & $1(1.1 \%)$ & & & $4(4 \%)$ & $0(0 \%)$ & & \\
\hline No se especifica & $4(4 \%)$ & $2(2.3 \%)$ & & & $1(1 \%)$ & $2(2 \%)$ & & \\
\hline
\end{tabular}




\section{Instrumentos}

Durante la primera fase de la investigación, todos los participantes completaron una misma batería de evaluación compuesta por un cuestionario $A d-H o c$ de información sociodemográfica y tres cuestionarios de screening de compulsividad sexual. La evaluación a través de esta primera batería llevaba una media de entre 15 y 20 minutos.

Los participantes en la segunda fase completaban una evaluación más extensa que incluía una entrevista clínica, una prueba de testosterona libre en saliva y hasta 12 escalas y cuestionarios distintos. En este caso, la administración de algunos cuestionarios dependía del grupo al que el participante era asignado. A los participantes del grupo subclínico se les administraron dos cuestionarios adicionales para determinar con mayor precisión la severidad y las consecuencias de sus problemas en el control de los impulsos sexuales. Por limitación de recursos, la prueba de testosterona se aplicó a un grupo de 80 participantes elegidos de entre los 4 grupos de la segunda fase del estudio (chicos y chicas control y subclínicos). Los participantes invertían una media de entre 2 horas y 2 horas y media en completar la segunda fase de la evaluación. En la tabla 11 se enumeran los cuestionarios y pruebas que formaron parte de las dos fases de la evaluación así como los grupos que completaron cada uno de ellos.

Tabla 11. Distribución de los cuestionarios de la primera y segunda fase de la investigación

\begin{tabular}{|c|c|c|c|}
\hline & \multirow{2}{*}{ Participantes fase I } & \multicolumn{2}{|c|}{ Participantes fase II } \\
\hline & & Grupo control & Grupo subclínico \\
\hline Cuestionario $\mathrm{Ad}$-Hoc de Información Sociodemográfica & $\mathrm{X}$ & $\mathrm{x}$ & $\mathrm{x}$ \\
\hline \multicolumn{4}{|l|}{ Evaluación de screening de la CS } \\
\hline Escala de Compulsividad Sexual & $\mathrm{x}$ & $\mathrm{X}$ & $\mathrm{X}$ \\
\hline Inventario de Hipersexualidad & $x$ & $x$ & $\mathrm{x}$ \\
\hline Cuestionario de Adicción al Sexo & $\mathrm{x}$ & $\mathrm{X}$ & $\mathrm{X}$ \\
\hline \multicolumn{4}{|l|}{ Evaluación de la comorbilidad psicopatológica } \\
\hline Entrevista Clínica Estructurada para los Trastornos del Eje I del DSM-IV & & $\mathrm{X}$ & $\mathrm{X}$ \\
\hline Entrevista Clínica Estructurada para los Trastornos del Eje II del DSM-IV & & $x$ & $\mathrm{x}$ \\
\hline \multicolumn{4}{|l|}{ Evaluación del perfil de personalidad } \\
\hline Inventario de Personalidad NEO Revisado & & $x$ & $x$ \\
\hline \multicolumn{4}{|l|}{ Evaluación del comportamiento sexual } \\
\hline Encuesta Sobre el SIDA (ENSI) & & $\mathrm{x}$ & $\mathrm{X}$ \\
\hline Cuestionario de Evaluación de la Orientación del Deseo Sexual & & $x$ & $x$ \\
\hline Batería de Exposición Involuntaria a Cibersexo & & $x$ & $x$ \\
\hline Cuestionario de Adicción al Cibersexo & & $x$ & $x$ \\
\hline Escala de Búsqueda de Sensaciones Sexuales & & $\mathrm{X}$ & $x$ \\
\hline Encuesta Revisada de Opinión Sexual & & $x$ & $x$ \\
\hline Testosterona libre en saliva $^{a}$ & & $x$ & $x$ \\
\hline \multicolumn{4}{|l|}{ Evaluación de correlatos clínicos y psicopatológicos } \\
\hline Cuestionario de Ansiedad Estado-Rasgo & & $\mathrm{x}$ & $\mathrm{x}$ \\
\hline Inventario de Depresión BDI & & $x$ & $\mathrm{X}$ \\
\hline Cuestionario de Autoestima de Rosenberg & & $\mathrm{x}$ & $\mathrm{x}$ \\
\hline \multicolumn{4}{|l|}{ Severidad y consecuencias de la CS } \\
\hline Inventario de Conducta Sexual Compulsiva & & & $\mathrm{x}$ \\
\hline Escala de Consecuencias Cognitivas y Conductuales de la Conducta Sexual & & & $x$ \\
\hline
\end{tabular}

${ }^{a}=$ realizado sobre a una selección aleatoria de 20 chicos y 20 chicas del grupo control y de 20 chicos y 20 chicas del grupo subclínico 
A continuación se describen pormenorizadamente cada uno de los instrumentos empleados durante la evaluación de los participantes.

1. Cuestionario Ad-Hoc de Información Sociodemográfica: las variables exploradas a través de este cuestionario fueron el sexo, la edad, la orientación sexual (heterosexual/bisexual/homosexual), si se tenía o no pareja estable, los estudios cursados en el momento de la evaluación (o los alcanzados si no estudiaba) y las creencias religiosas (creyente practicante/creyente no practicante/ateo o agnóstico). Aquellos que afirmaron ser creyentes (practicantes o no practicantes) debían indicar además la religión profesada.

2. Adaptación española de la Escala de Compulsividad Sexual (SCS, Ballester-Arnal et al., 2013): pensada originalmente para la identificación de pensamientos obsesivos hacia el sexo (Kalichman \& Rompa, 1995), el SCS es en la actualidad uno de los instrumentos más utilizados para el diagnóstico de problemas en el control de los impulsos sexuales. Esta escala consta de 10 ítems con 4 opciones de respuesta (1=Nada característico de mi/4=Muy característico de mi) cuya suma permite la obtención de una puntuación que oscila entre 10 y 40 . Según algunos estudios, puntuaciones por encima del percentil 80 para una determinada población indicarían posibles problemas en el control de impulsos sexuales (población clínica o subclínica) (Grov et al., 2010; Kelly et al., 2009).

La escala original contemplaba una única dimensión general de problemas en el control de los impulsos sexuales, si bien en la validación española la escala se divide en dos factores: un primer factor llamado "Interferencia" y compuesto por ítems que reflejan los problemas sociales y personales derivados de la falta de control sobre los impulsos sexuales ("Mi gran apetito sexual ha sido un obstáculo en mis relaciones" o "Mis deseos de tener sexo han afectado a mi vida cotidiana") y un segundo factor Ilamado "Problemas en el control" que haría énfasis en el malestar provocado por la incapacidad para controlar el comportamiento sexual ("A veces llego a ponerme tan caliente que podría perder el control" o "Siento que mis pensamientos y sensaciones sexuales son más fuertes que yo").

La versión original ha demostrado buena fiabilidad ( $\alpha$ entre .86 y .89) y estabilidad temporal (correlación test-retest de .80) en diferentes tipos población (para una revisión, Grov et al., 2010). En la validación española, la consistencia interna de la escala general en una muestra similar a la del presente estudio (estudiantes universitarios de entre 18 y 26 años) fue de .83 y la correlación test-retest de .72 . 
3. Inventario de Hipersexualidad (IH Reid, Garos, \& Carpenter, 2011): el IH se compone de 19 ítems con un formato de respuesta tipo Likert entre 1 (Nunca) y 5 (Muchas veces), con una puntuación total que oscila en un rango entre 19 y 95 . A diferencia del SCS, el IH sí se desarrolló con fines diagnósticos, de modo que el contenido de sus ítems refleja los principales síntomas propuestos para el diagnóstico del trastorno por hipersexualidad para el DSM-5. Según los autores, una puntuación $\geq 53$ indicaría una probable presencia de un cuadro clínico de hipersexualidad.

El IH se validó originalmente de forma preliminar en una muestra de 324 pacientes con problemas en el control de los impulsos sexuales y se confirmó posteriormente en una muestra de 203 nuevos pacientes. En ambos casos se obtuvo la misma estructura factorial de tres factores correlacionados. El primero, llamado "Afrontamiento", reflejaría el uso del sexo como medio para controlar estados emocionales negativos ("Recurro al sexo cuando experimento sentimientos desagradables"). El segundo factor, "Control", exploraría la presencia de déficits a la hora de controlar los pensamientos, impulsos o conductas sexuales ("Fracaso en mis intentos por cambiar mi conducta sexual"). El último, bautizado como "Consecuencias", exploraría la persistencia en la conducta sexual a pesar de las consecuencias negativas derivadas ("Mis actividades sexuales interfieren en aspectos de mi vida como el trabajo o los estudios").

La fiabilidad para la puntuación total así como para cada una de las tres subescalas oscilaba entre 0.89 y 0.95 . Una segunda administración del IH dos semanas después de la aplicación inicial confirmaba su estabilidad temporal (correlaciones test-retest entre .88 y .91$)$.

4. Cuestionario de Adicción al Sexo (SAST, Carnes, 1983): el SAST fue uno de los primeros cuestionarios desarrollados para evaluar los síntomas de adicción al sexo. Se compone de 25 ítems con un formato de respuesta dicotómico (Sí/No) cuya suma permite la obtención de una puntuación que oscila entre 0 y 25. Una puntuación superior a 13 sugeriría la presencia de un cuadro clínico de adicción al sexo. Este punto de corte permitía identificar al $96.5 \%$ de los pacientes con un diagnóstico de adicción al sexo.

En la validación original se encontró que un único factor explicaba aproximadamente el $50 \%$ de la varianza del SAST, si bien esta estructura factorial no se ha replicado. Ninguno de los estudios realizados posteriormente ha coincidido en una misma propuesta de factores o de distribución de ítems por cada factor (Carnes et al., 2012; Marshall \& Marshall, 2010; Nelson \& Oehlert, 2008), de modo que a falta de datos más 
sólidos, en este estudio se ha tomado únicamente su puntuación total. La fiabilidad de esta escala en población general fue alta ( $\alpha=.892$ ) (Carnes et al., 2010).

5. Entrevista Clínica Estructurada para los Trastornos del Eje I del DSM-IV (SCID-I, First, Spitzer, Gibbon, \& Williams, 1999): la SCID-I es una entrevista semiestructurada diseñada para identificar los principales diagnósticos del Eje I del DSM-IV. Su objetivo es mejorar la fiabilidad y validez diagnóstica a través de un procedimiento de evaluación estandarizado, protocolizado y adaptado para su uso en contextos clínicos. Para ello, el entrevistador dispone de un cuaderno de aplicación donde se proponen una o más preguntas por cada síntoma. Estas preguntas son suficiente para que el entrevistador determine si el paciente padece o no el síntoma y el cuadro clínico en su conjunto, si bien se contempla la posibilidad de que se planteen preguntas adicionales. El entrevistador dispone además de una plantilla de respuesta donde anotar la presencia (+) o ausencia (-) de cada síntoma, así como un espacio para anotaciones o comentarios. La principal característica de la SCID que la diferencia de un cuestionario de síntomas es que no prescinde del juicio clínico: las preguntas no tienen una respuesta correcta o incorrecta, sino que depende de la interpretación que el clínico haga de ellas el que se acepte o no la presencia de un determinado cuadro clínico.

La SCID-I consta de seis módulos que coinciden con las principales categorías diagnósticas del DSM-IV: 1) episodios afectivos, 2) síntomas psicóticos, 3) trastornos psicóticos, 4) trastornos del estado de ánimo, 5) trastornos relacionados con sustancias y 6) ansiedad y otros trastornos. Cada módulo evalúa una media de entre 6 y 15 diagnósticos, distinguiendo a su vez entre diagnósticos en la actualidad (el paciente cumple los síntomas en el momento de la evaluación) y a lo largo de la vida (el paciente cumple los síntomas en la actualidad o los ha cumplido en algún momento a lo largo de su vida). Los módulos están pensados para aplicarse de forma secuencial, si bien se puede prescindir de alguno de ellos para ajustarse a las necesidades de cada evaluación. En nuestro caso, padecer un trastorno mental grave se consideró un criterio de exclusión en la investigación, de modo que prescindimos de los módulos 2 y 3 (síntomas y trastornos psicóticos) de la SCID. Al contrario, se incluyó un módulo adicional Ad-Hoc (parafilias) para evaluar la presencia de los trastornos parafílicos contemplados por el DSM-IV. En su elaboración se siguió una estructura muy similar al del resto de la SCID-I, si bien las características de este tipo de patología hacían dudar de la validez de su evaluación a través de entrevista clínica.

Los datos de fiabilidad de la SCID-I de los que se dispone indican una gran fiabilidad interjueces (índices kappa superiores .70) que varía sensiblemente dependiendo del 
tipo de paciente y de las condiciones de evaluación. Una evaluación óptima implica la realización de la entrevista en una única sesión individual.

6. Entrevista Clínica Estructurada para los Trastornos del Eje II del DSM-IV (SCID-II, First, Gibbon, Spitzer, Williams, \& Benjamin, 1999): el procedimiento de aplicación y las características de la SCID-II son prácticamente iguales a las ya comentadas para la SCID-I con la diferencia de que en este caso se evalúan trastornos del Eje II del DSM-IV. En concreto, trastornos de la personalidad. Otra diferencia con respecto a la SCID-I es que mientras que en ésta se indica la presencia (+) o ausencia (-) de un determinado síntoma, en la SCID-II se indica la intensidad en una escala de 1 (ausencia del síntoma o característica) a 3 (el síntoma o característica se manifiesta clínicamente). Así, un determinado síntoma (p.e., "Comportamiento, intentos o amenazas suicidas recurrentes, o comportamiento de automutilación") se puntuaría con un 1 (ausente) cuando el paciente afirme no haberlo intentado nunca, con un 2 (subumbral) si lo ha hecho una vez y sin una clara intención autolítica y con un 3 (umbral o verdadera) cuando lo ha hecho en repetidas ocasiones y con intención manifiesta de causar daño. Sólo los síntomas puntuados con un 3 contarían para el diagnóstico del trastorno de la personalidad. Otra diferencia es que la SCID-II no contempla la distinción entre diagnóstico en la actualidad o a lo largo de la vida; no en vano, este tipo de trastornos suele presentar un curso crónico.

La SCID-II puede aplicarse íntegramente (evaluando los 10 trastornos de la personalidad del DSM-IV) o por secciones y precedida o no de un cuestionario previo. En nuestro caso, se aplicaron únicamente los módulos para la evaluación del trastorno obsesivo-compulsivo y del trastorno límite de la personalidad prescindiendo además del cuestionario inicial de screening. En el anexo I se enumeran los diagnósticos DSM contemplados por los módulos de la SCID-I y II empleados en esta investigación.

La fiabilidad interjueces de la SCID-II en un estudio multicéntrico con más de 280 pacientes osciló entre .24 para el trastorno obsesivo compulsivo de la personalidad y .74 para el histriónico, con un valor kappa promedio de .53. Estudios posteriores han obtenido valores kappa superiores a los encontrados en esta primera investigación, siendo la experiencia clínica del administrador uno de los factores que más aumentaría la fiabilidad de la entrevista (para una revisión, First, Gibbon, et al., 1999).

7. Inventario de Personalidad NEO Revisado (NEO PI-R, Costa \& McCrae, 2002): Este cuestionario, compuesto por 240 ítems que se contestan en una escala Likert de 5 puntos ( $0=$ Totalmente en desacuerdo/4=Totalmente de acuerdo), permite medir las 5 dimensiones del modelo de personalidad de Costa y McCrae así como cada una de las 
6 facetas que componen cada dimensión. Las puntuaciones directas se transforman a puntuaciones $T$ (escala típica con $M=50$ y $D T=10$ ) durante el proceso de corrección para facilitar su interpretación. Se considera que un determinado rasgo de personalidad se expresa normativamente cuando las puntuaciones oscilan entre $35 \mathrm{y}$ 65 , mientras que valores por debajo o superiores a esta franja indicarían que el rasgo se manifiesta en uno de sus extremos. A continuación se describen las 5 dimensiones y 30 facetas evaluadas a través de este cuestionario.

a. Neuroticismo (N): el $\mathrm{N}$ es una dimensión de propensión al malestar psicológico, de modo que su opuesto sería la estabilidad emocional. Las personas neuróticas experimentan más emociones negativas, tienen dificultades para tolerar la frustración, suelen ser poco realistas y tienen necesidades afectivas y materiales excesivas. Esta dimensión comprende las siguientes facetas:

- Ansiedad: las personas ansiosas suelen ser aprehensivas, miedosas y con tendencia a experimentar ansiedad. En el extremo contrario, las personas con bajas puntuaciones suelen ser calmados, relajados y despreocupados.

- Hostilidad: esta faceta representa la propensión a experimentar ira, enfado y frustración ante diversas situaciones. También se relaciona con la capacidad para tolerar el disconfort y la incomodidad sin alterarse (baja hostilidad).

- Depresión: explora la tendencia a experimentar afecto negativo (tristeza, culpa, desesperanza o soledad). Las personas depresivas suelen experimentar desazón y abatimiento ante el mínimo inconveniente. Al contrario, las personas menos depresivas afrontan los problemas sin que su estado de ánimo se vea afecto.

- Ansiedad social: esta faceta refleja la incomodidad ante situaciones de contacto social (alta ansiedad social) o al contrario, la seguridad o el aplomo durante la interacción con otras personas (baja ansiedad social). A esta faceta subyace una extrema sensibilidad al ridículo y sentimientos de inferioridad.

- Impulsividad: habilidad para controlar los impulsos y deseos. Las personas con altas puntuaciones experimentan dificultades para resistir cualquier deseo o impulso que experimenten (p.e., comida, bebida, sexo o bienes materiales), problemas que no experimentan los menos impulsivos.

- Vulnerabilidad: faceta relacionada con el afrontamiento de retos y el estrés. Las personas más vulnerables se sienten incapaces de afrontar situaciones de estrés, volviéndose vulnerables y dependientes de la ayuda de su entorno. Las personas que puntúan bajo se perciben capaces de manejar situaciones difíciles. 
b. Extraversión (E): La E es una dimensión de interacción social y búsqueda de emociones positiva. Su opuesto es la introversión. Las personas más extravertidas tienden a ser sociales, activas, habladoras, optimistas y buscadoras de emociones positivas. Al contrario, los más introvertidos tienden a ser reservados (no necesariamente hostiles o ariscos), sobrios, con poca necesidad de contacto y callados. La E comprende las siguientes facetas:

- Cordialidad: especialmente relevante para la intimidad personal, la cordialidad se refiere a la disposición a la vinculación emocional y el afecto con personas del entorno. Al contrario, las personas menos cordiales son fríos y emocionalmente distantes en sus relaciones.

- Gregarismo: el gregarismo representa la preferencia por estar en compañía de otras personas (alto gregarismo) o por la soledad y ascetismo (bajo gregarismo).

- Asertividad: las personas asertivas se caracterizan por su liderazgo, capacidad de influencia a nivel social y disposición a tomar la iniciativa. La baja asertividad indicaría preferencia por el anonimato y papeles secundarios en liderazgo social.

- Actividad: las personas más activas suelen tener un estilo de vida rápido, se muestran enérgicas en sus actividades diarias y les aburre la monotonía. Al contrario, las menos activas preferirían un estilo de vida pausado y reflexivo.

- Búsqueda de emociones: faceta que refleja la propensión a la búsqueda de estimulación y excitación. Los buscadores de emociones se caracterizarían por una constante necesidad de actividades intensas y variadas que les hagan experimentar nuevas sensaciones.

- Emociones positivas: explora la tendencia a experimentar sentimientos positivos como la alegría, la felicidad, el amor o la ilusión. Los que puntúan alto suelen ser personas optimistas que viven con intensidad emocional su vida diaria. Lo contrario se relacionaría con una mayor contención a la hora de experimentar sentimientos positivos.

c. Apertura a la experiencia (O): La $\mathrm{O}$ es la dimensión de la personalidad que describe la capacidad para aceptar todo lo que se aleja de lo convencional. Su opuesto sería la cerrazón a la experiencia. Las personas más abiertas a la experiencia suelen ser curiosas, imaginativas, creativas y dispuestas a experimentar y a vivir la vida fuera de los márgenes de lo convencional. Por el contrario, las personas más cerradas a la experiencia suelen ser dogmáticas, rígidas, convencionales en sus gustos y tradicionales. La O comprende las siguientes facetas: 
- Fantasía: las personas con altas puntuaciones disfrutan de su imaginación como forma de escapar del tedio. Son capaces de elaborar y desarrollar sus fantasías a través de una imaginación rica y creativa. Al contrario, las personas con bajas puntuaciones tienden a pensar de forma pragmática, operativa y previsible.

- Estética: la estética representa el aprecio por el arte y la belleza. Las personas más estéticas se conmueven con expresiones artísticas que les transmitan emociones, mientras que las menos estéticas aborrecen y se muestran insensibles ante la creación artística.

- Valores: en el extremo positivo de esta faceta se encontrarían las personas más capaces de desafiar las convenciones políticas, sociales, religiosas o morales, mientras que en el extremo negativo se encontrarían las que aceptan sin dudar las tradiciones impuestas.

- Sentimientos: las personas más sentimentales valoran la importancia de la vivencia emocional, tanto la positiva como la negativa, lo que les permite vivir más intensamente sus propias emociones. Los menos sentimentales no valoran su importancia y son menos capaces de reconocerlas.

- Acciones: esta faceta refleja la buena o mala disposición a probar cosas nuevas, poco usuales y que se alejan de la rutina. Altas puntuaciones suelen ir acompañadas de una buena actitud y aceptación hacia los cambios.

- Ideas: la faceta de ideas está íntimamente relacionada con la curiosidad intelectual. Las personas con altas puntuaciones disfrutan poniendo a prueba su intelecto, buscando nuevas formas de aprendizaje y conocimientos. Implica una mentalidad abierta a adquirir nuevos conocimientos e ideas.

d. Amabilidad (A): la A condiciona el modo en que una persona interacciona. En un extremo tendríamos a los más amables, que se suelen mostrar afables, cariñosos, bondadosos, confiados y empáticos en sus interacciones sociales y que tratan de vivir su vida con respeto hacia otras personas. En el extremo contrario se situarían las personas antagonistas, que tienden a ser cínicos, rudos, hostiles, poco cooperativos, vengativos e incluso manipulativos. Serían personas que pondrían su propio beneficio por delante del bien común. La A comprende las siguientes facetas:

- Confianza: las personas más confiadas tienden a creer que los demás son honrados y bien intencionados, mientras que los menos confiados son cínicos, escépticos y desconfían de las intenciones de los demás. 
- Franqueza: esta faceta refleja la disposición a la manipulación. Mientras que las personas francas se comportan de forma honrada, los menos francos tienden a engañar en su propio beneficio y a ocultar sus verdaderas intenciones.

- Altruismo: las personas altruistas ponen el beneficio de los demás delante del suyo propio, justo al contrario de lo que harían los menos altruistas. Asimismo, son sensibles a las necesidades de los demás y cooperan para la solución de problemas aunque no les supongan un perjuicio directo.

- Actitud conciliadora: representa la tendencia a evitar conflictos a través de la sumisión. Las personas conciliadoras siguen las directrices de los demás para evitar el enfrentamiento, lo que las hace de trato fácil. Las personas menos conciliadores compiten antes que cooperan y se defienden con agresividad.

- Modestia: las personas modestas describen sus éxitos con humildad y son capaces de reconocer los éxitos de los demás. Las personas poco modestas resultan engreídas, presumidas y arrogantes, creyendo sus éxitos muy por encima de los de los demás.

- Sensibilidad a los demás: explora la preocupación por las necesidades de los demás. Las personas con mayores puntuaciones son más sensibles a los problemas de otras personas y más comprometidos con su solución. Al contrario, los menos sensibles a los demás suelen ser más prácticos, dejando de lado la emocionalidad a la hora de tomar decisiones.

e. Responsabilidad (C): La dimensión de C refleja la forma en la que las personas orientan su conducta hacia metas concretas. Los que puntúan alto suelen ser organizados, fiables, meticulosos en sus tareas, ambiciosos y perseverantes. Por el contrario, los poco responsables suelen ser poco fiables, descuidados, tienden a ser perezosos, negligentes y hedonistas. Esta dimensión se compone de las siguientes facetas:

- Competencia: explora la valoración que las personas hacen de su desempeño. Así, las personas competentes se perciben a sí mismas como preparadas para afrontar retos o situaciones que pongan a prueba sus habilidades.

- Orden: las personas ordenadas suelen ser pulcras en el desempeño de sus tareas diarias. Al contrario, las personas poco ordenadas tienen serias dificultades para organizarse y ser metódicos en su trabajo y su vida en general.

- Sentido del deber: disposición a comportarse de acuerdo a normas y obligaciones sociales, morales o religiosas. Las personas con mayor sentido del 
deber cumplen estrictamente con lo que se espera de ellos, siendo altamente fiables y en cierto modo, previsibles. En el extremo contrario, las personas con poco sentido del deber serían informales en el afrontamiento de sus tareas.

- Necesidad de logro: tendencia a aspirar a grandes metas y objetivos (ambición). Las personas con alta necesidad de logro tienen metas en la vida y no dudan en trabajar duro para lograrlas. Su conducta suele estar altamente motivada hacia metas y raramente se desvían de sus planes y objetivos.

- Autodisciplina: capacidad para perseverar en las obligaciones por muy tediosas que resulten. Las personas autodisciplinadas dan prioridad al desempeño de sus deberes frente a actividades más divertidas y excitantes.

- Deliberación: tendencia a reflexionar antes de actuar. Las personas con este rasgo suelen ser prudentes a la hora de tomar decisiones, mientras que los que puntúan bajo actúan movidos por impulsos y sin pensar en las consecuencias.

EI NEO PI-R es, hoy por hoy, el instrumento más utilizado en la medida de la personalidad normal. Se han realizado estudios psicométricos que avalan su utilización en casi todo tipo de población (estudiantes universitarios, adultos, muestra clínica, personas con problemas de salud, etc.). Los índices de fiabilidad del instrumento en su versión española oscilan entre 0.85 y 0.91 para las 5 dimensiones y entre 0.55 y 0.78 para las 30 facetas. Múltiples estudios avalan también su estabilidad temporal y su validez en la medida de la personalidad normal.

8. Encuesta Sobre el SIDA (ENSI, Ballester-Arnal, Gil-Llario, Castro-Calvo, \& GiménezGarcía, 2016): El ENSI es un instrumento que permite explorar distintos aspectos del comportamiento sexual y de la conducta sexual de riesgo. 25 ítems con múltiples formatos de respuesta componen esta herramienta, que se divide en tres escalas: un índice de riesgo para la transmisión del VIH (HIV-Risk Index), una escala de severidad percibida del VIH y una escala de autoeficacia en el uso del preservativo.

De las tres escalas, el HIV-Risk Index sería la principal. A diferencia de otros índices de riesgo -la mayoría diseñados para colectivos de riesgo-, éste permite estimar el riesgo para la transmisión sexual del VIH en población general. Este índice incluiría 8 ítems sobre uso del preservativo en diferentes situaciones (con parejas estables, esporádicas, durante sexo anal, bajo el efecto del alcohol u otras drogas, etc.) que además se ponderan a través de dos variables (frecuencia sexual y número de parejas a lo largo de la vida). Aplicando una breve fórmula se obtendría un valor del riesgo por cada uno de los indicadores que componen el índice: 0 (no riesgo), 1 (riesgo medio), 1.25 (riesgo medio-alto) y 1.5 (alto riesgo). La suma de sus puntuaciones permitiría la 
obtención de un índice de riesgo general que oscila entre 0 (riesgo nulo de transmisión sexual del VIH) y 13.5 (riesgo alto de transmisión sexual del VIH).

La escala de severidad percibida del VIH incluiría 4 ítems con formato de respuesta dicotómica (Sí/No) que explorarían el riesgo atribuido a la infección por VIH y al SIDA. Un ejemplo de ítem de esta escala sería: “¿Dirías que actualmente el SIDA es una enfermedad que tiene curación?". La puntuación en la escala de severidad va de 0 a 4, con mayores puntuaciones indicando mayor atribución de severidad al VIH y al SIDA.

Finalmente, la escala de autoeficacia en el uso del preservativo se compone de 8 ítems con formato de respuesta tipo Likert que explorarían la capacidad para enfrentase con distintas barreras en el uso del preservativo. En la escala se incluyen ítems relativos a 3 tipos de situaciones: acceso a preservativos ("Me siento cómodo o seguro a la hora de comprar preservativos"), asertividad y negociación ("Si tengo que sugerir a una pareja que usemos el condón, tengo miedo a que me rechace") y autocontrol ("Estoy seguro de que podría parar en el momento de mayor excitación para ponerme el condón o ponérselo a mi pareja").

Estas tres escalas se validaron en una investigación con alrededor de 10.000 jóvenes de entre 18 y 30 años. La fiabilidad para el HIV-Risk Index, la escala de severidad percibida y la de autoeficacia en el uso del preservativo fue de $.79, .63$ y .65 respectivamente. La estructura factorial de estas escalas y su invarianza en función del sexo se confirmó a través de AFC. Asimismo, se demostró su validez convergente con diferentes tipos de medidas en una submuestra conformada por más de 380 jóvenes.

9. Cuestionario de Evaluación de la Orientación del Deseo Sexual (Ballester-Arnal, 2013): este cuestionario consta de 4 bloques de preguntas orientados a explorar el grado de atracción hacia uno u otro sexo. En el primer bloque (un único ítem) se pide al evaluado que se autoidentifique con una de las tres categorías clásicas de la orientación sexual (heterosexual, homosexual o bisexual). En un segundo bloque se explora el deseo, el haber fantaseado y el haber mantenido o no contacto sexual con personas del mismo o del otro sexo a través de 6 ítems de respuesta dicotómica (Sí/No). En el tercer bloque (un ítem) se pide a los evaluados que indiquen qué afirmación describe mejor su atracción sexual, ofreciendo 7 alternativas que van desde "Me siento atraído sólo hacia el otro sexo" hasta "Me siento atraído sólo hacia mi mismo sexo". Finalmente, en el cuarto bloque se emplea una escala analógica visual muy similar a la utilizada por Kinsey y su equipo para la evaluación de la orientación sexual. Esta escala consiste en una línea recta donde se ofrecen únicamente dos puntos de referencia: uno en el extremo izquierdo que corresponde con una 
orientación "exclusivamente heterosexual" y el otro en el extremo derecho que corresponde con una orientación "exclusivamente homosexual". El evaluado debe situarse en el punto que crea que refleja mejor su orientación sexual.

10. Batería de Exposición Involuntaria a Cibersexo (Castro-Calvo, Gómez-Martínez, GilJulià, Giménez-García, \& Ballester-Arnal, 2015): para la evaluación de la exposición involuntaria a material sexual en Internet (de ahora en adelante El) se aplicó un cuestionario de 12 ítems con múltiples formatos de respuesta (escalas tipo Likert, respuesta dicotómica, elección múltiple, etc.) que permite explorar las principales dimensiones implicadas en este fenómeno. Así, esta escala incluye: un ítem con 6 opciones de respuesta ( $0=$ Nunca/6=Muchísimas veces) y dos de respuesta abierta para la evaluación de la frecuencia de El, tres de elección múltiple para explorar las características de la exposición (tipo de materiales expuestos, en qué tipo de Webs, peticiones sexuales por parte de otros usuarios, etc.), dos de elección múltiple para comprobar la reacción conductual (qué hiciste) y emocional (cómo te sentiste) a la El y una lista de verificación de síntomas para analizar el impacto psicológico de dicha exposición. Asimismo, este cuestionario incluye tres ítems de respuesta dicotómica (Sí/No) para comprobar si la exposición se vivió como un hecho traumático o si por el contrario, se consideró una experiencia positiva para el desarrollo psicosexual.

11. Adaptación española del Cuestionario de Adicción al Cibersexo (Ballester-Arnal, GilLlario, Gómez-Martínez, \& Gil-Julià, 2010): este instrumento consta de 25 ítems de respuesta dicotómica (Verdadero/Falso) que evalúan el grado en que la conducta sexual online es o no problemática. La suma de las puntuaciones en cada ítem permite la obtención de un índice con valores entre 0 y 25. A partir de esta puntuación, Carnes, Delmonico y Griffin (2007) proponen clasificar a los usuarios como: 1) usuarios recreativos (puntuaciones $\leq 8$ ), 2) usuarios de riesgo (puntuaciones entre 9 y 18 ) y 3 ) usuarios patológicos o adictos al cibersexo (puntuaciones $\geq 19$ ).

Este cuestionario se divide a su vez en cinco escalas o factores. El primero, llamado "Compulsividad Sexual Online", explora el grado de control sobre la conducta sexual online y sería el indicador más importante de consumo patológico. El segundo, "Comportamiento Online Solitario No Compulsivo", analiza la realización de actividades sexuales en Internet que no requieren interactuar con otros usuarios (como masturbarse viendo pornografía). El tercero, "Comportamiento Online Social", rastrea el uso chats con fines sexuales y la posibilidad de llevar esa relación a la vida real. El cuarto, "Gasto Económico Online", evalúa la inversión económica durante la práctica del cibersexo. El quinto y último, bautizado como "Percepción de Gravedad 
del Propio Comportamiento Online", explora la percepción de gravedad del propio comportamiento sexual online.

Respecto a las características psicométricas, Ballester et al. (2010) informan de una fiabilidad $(\alpha)$ de .88 para la escala general y de entre .49 y .81 para las subescalas. La estabilidad temporal ( $r$ test-retest) pasadas unas semanas de la primera evaluación fue de .82 para la escala general y de entre .43 y .86 para las subescalas.

12. Escala de Búsqueda de Sensaciones Sexuales (Kalichman \& Rompa, 1995): esta escala se compone de 11 ítems con 4 opciones de respuesta que van de 1 (Nada característico de mi) a 4 (Muy característico de mi). Se emplea para evaluar la tendencia a experimentar con prácticas sexuales nuevas y variadas, independientemente del riesgo que supongan. Ítems como "Me gustan los encuentros sexuales salvajes y desinhibidos" o "Estoy interesado en probar nuevas experiencias sexuales" conformarían esta escala. La puntuación total, que oscila entre 11 y 44 , se obtendría a partir de la suma de las puntuaciones en cada ítem. Mayores puntuaciones corresponden a una mayor disposición a la búsqueda de sensaciones sexuales.

Las primeras versiones se validaron en población de riesgo. Kalichman et al. (1994) la aplicaron por primera vez en una muestra de 106 hombres gais sexualmente activos y un año más tarde replicaron el estudio con más muestra (296 hombres homosexuales) (Kalichman \& Rompa, 1995). La fiabilidad en estos dos estudios fue de .75 y .79 respectivamente y la estructura factorial reflejaba que los ítems se agrupaban bajo una única dimensión. Estudios posteriores como el de Beck, Thombs, Mahoney y Fingar (1995) o el de Gaither \& Sellbom (2003) obtuvieron una buena consistencia interna ( $\alpha$ de. 81 y de .83 respectivamente) y una estructura factorial equivalente al aplicar esta escala en población general masculina y femenina.

13. Encuesta Revisada de Opinión Sexual (EROS, Del Rio-Olvera, López-Vega, \& Santamaría, 2013): el EROS explora el continuo entre la tendencia al acercamiento hacia estímulos sexuales (erotofilia) y su evitación (erotofobia). Se compone de 20 ítems con 7 opciones de respuesta (1=Totalmente en desacuerdo/7=Totalmente de acuerdo) cuya suma permite la obtención de una puntuación con valores entre 20 y 140. Puntuaciones cercanas a 20 indicarían tendencias erotofóbicas, alrededor de los 80 representarían valores intermedios en el continuo de erotofilia-erotofobia mientras que puntuaciones cercanas a 140 indicarían una disposición altamente erotofílica. Las puntuaciones medias en esta escala suelen oscilar entre 75 y 85 .

La versión del EROS empleada en esta investigación soluciona alguno de los problemas de versiones anteriores, como por ejemplo el sesgo hacia la orientación sexual. 
Mientras que las versiones anteriores incluían ítems que discriminaban entre heterosexuales y homosexuales (p.e., "Bañarme desnudo con una persona del otro sexo podría ser una experiencia excitante"), modificaciones en la redacción de la nueva versión han solventado estos problemas (en su lugar, ese ítem ha pasado a "Bañarme desnudo con una persona del mismo u otro sexo podría ser una experiencia excitante"). De modo que independientemente de su orientación sexual, cualquier persona con tendencias erotofílicas contestará positivamente a esa afirmación.

La fiabilidad estimada a partir de un estudio con más de 300 participantes fue .851 . En este mismo estudio se encontró que los chicos, las personas con una orientación política de izquierdas y los homosexuales y bisexuales puntuaban más alto.

14. Testosterona libre en saliva: para la estimación de la concentración de testosterona libre en saliva se empleó el Kit Elisa para la Determinación Inmunoenzimática Directa de Testosterona en Saliva (ELISA). Este kit viene equipado con unos pequeños viales (2 $\mathrm{mL}$ de capacidad) y unas pajitas que se emplean para la recogida de la muestra. Un extremo de la pajita se introduce dentro del vial mientras que el otro se introduce en la boca del paciente; éste empuja su saliva hasta la pajita, que la canaliza hacia el vial. La cantidad mínima de saliva necesaria para la prueba es de $1 \mathrm{~mL}$ (medio vial). Una vez finalizado el examen, las muestras se almacenan en un congelador a temperaturas bajo cero para asegurar su conservación y se envían a un laboratorio para su análisis. Esta prueba permite la obtención de un índice de concentración de testosterona que se expresa en picogramos por mililitro $(\mathrm{pg} / \mathrm{mL})$. En hombres de entre 18 y 30 años, los valores normales oscilan entre 47.2 y 136.2 pg/mL mientras que en mujeres varían en un rango entre 7.9 y 50.4 pg/mL. Valores por encima o por debajo de estos umbrales indicarían un cuadro clínico alterado (hiper o hipogonadismo).

La precisión intraensayo de la prueba fue del 92\% (variabilidad $\leq 8 \%$ ) mientras que la exactitud en muestras de saliva enriquecidas fue del 98.97\%. La prueba es sensible a cambios $\geq 2 \mathrm{pg} / \mathrm{mL}$ y altamente específica (baja sensibilidad a otro tipo de hormonas). Finalmente, la correlación entre ELISA y otros kits comercial fue de .96.

15. Cuestionario de Ansiedad Estado-Rasgo (STAI, Spielberger, Gorsuch, \& Lushene, 2002): el cuestionario STAI se compone de dos escalas que miden dimensiones independientes de la ansiedad: la ansiedad como estado (STAI-Estado) y como rasgo (STAI-Rasgo). La escala STAI-Estado explora síntomas de ansiedad experimentados en la actualidad, de modo que resulta sensible a la hora de estimar la intensidad actual de las reacciones de ansiedad. Por su parte, la escala STAI-Rasgo explora la propensión general del individuo a experimentar ansiedad, de modo que resulta más apropiada 
cuando se pretende estimar la tendencia a experimentar ansiedad ante diversas situaciones. Cada una se compone de 20 ítems en sentido positivo y negativo con 4 opciones de respuesta $(0=\mathrm{Nada} / 3=$ Mucho). La suma de la puntuación en cada ítem permite la obtención de una puntuación directa por cada escala que se puede transformar a puntuación centil a través de los baremos que el cuestionario ofrece. La validación española del STAI obtuvo valores de fiabilidad de entre .90 y .93 para la ansiedad-estado y de entre .84 y .87 para la ansiedad-rasgo. La correlación entre ambas escalas ( $r$ entre .43 y .62) así como su relación con otras variables psicológicas y psicopatológicas justifican su validez y su empleo en entornos clínicos y empíricos.

16. Inventario de Depresión BDI-II (BDI-II, Beck, Steer, \& Brown, 2011): el BDI-II es uno de los instrumentos más utilizados en la evaluación del estado de ánimo. Este inventario plantea 21 síntomas típicos de un estado de ánimo deprimido que se valoran teniendo en cuenta únicamente las últimas dos semanas. Las respuestas varían para cada afirmación, pero todas oscilan entre 0 (ausencia del síntoma) y 3 (síntoma presente con intensidad). Así, las alternativas de respuesta para el síntoma de "Pérdida de interés por el sexo" serían: 0) no he notado ningún cambio en mi interés por el sexo, 1) estoy menos interesado por el sexo de lo que solía estar, 2) estoy mucho menos interesado por el sexo ahora y 3 ) He perdido completamente el interés por el sexo.

La suma de las puntuaciones por cada ítem permite la obtención de un índice general de depresión con valores entre 0 y 63 que se emplea para la clasificación en uno de los 4 grupos siguientes: 1) mínimamente deprimido (puntuaciones $\leq 13$ ), 2) ligeramente deprimido (puntuaciones entre 14 y 19), 3) moderadamente deprimido (puntuaciones entre 20 y 28) y 4) severamente deprimido (puntuaciones $\geq 29$ ). Tanto la versión original del BDI-II como su adaptación española han demostrado ser fiables, válidas y sensibles al cambio terapéutico en todo tipo de poblaciones.

17. Adaptación española del Cuestionario de Autoestima de Rosenberg (RSEI, MartínAlbo, Núñez, Navarro, \& Grijalvo, 2007): El RSEl es un instrumento compuesto por 10 ítems con formato de respuesta tipo Likert (4 opciones de respuesta que van de "Muy en desacuerdo" a "Muy de acuerdo") que permite evaluar la percepción global de una persona sobre sí misma y su desempeño. El cuestionario incluye ítems planteados en formato directo ("Soy capaz de hacer las cosas tan bien como la mayoría de la gente") e inverso ("A veces me siento realmente inútil"). Éstos últimos se invierten para el cálculo de la puntuación total. El sumatorio de las puntuaciones en cada ítem permite la obtención de una índice que oscila entre 10 y 40, indicando mayor autoestima las puntuaciones más cercanas al extremo superior de la escala. 
Los análisis psicométricos de la adaptación española obtienen una solución factorial unidimensional con buenos índices de fiabilidad $(\alpha=0.85)$ y de consistencia temporal 4 semanas después de la primera administración $\left(r_{\text {test-retest }}=0.84\right)$.

18. Inventario de Conducta Sexual Compulsiva (CSBI, Coleman et al., 2001): el CSBI es una escala empleada para valorar la gravedad de los síntomas de CS. A diferencia de otras como el SCS, el IH o el SAST, su carácter clínico impide su uso como instrumento de screening. Consta de 28 ítems en los que se indica la frecuencia con la que se han realizado diversas actividades sexuales en una escala entre 1 (Nunca) y 5 (Siempre). Sumados, los 28 ítems del CSBI permiten la obtención de una puntuación general de severidad de la CS que va de 28 (ausencia del cuadro clínico) a 140 (cuadro clínico de extrema gravedad). Su principal ventaja es que este inventario incluye síntomas omitidos en la mayoría de cuestionarios diagnósticos.

Los análisis factoriales realizados durante el estudio de validación original revelaron la presencia de tres subescalas que explicaban el $58 \%$ de la varianza del cuestionario: una a la que llamaron "Control" y exploraba la capacidad para regular voluntariamente la conducta sexual (“¿Te has sentido incapaz de controlar tu comportamiento sexual?" o “¿Con qué frecuencia has tenido relaciones sexuales o te has masturbado más de lo que querías?"); otra a la que llamaron "Abuso" y examinaba experiencias de abuso sexual infantil, de incesto y de comisión de delitos sexuales ("¿Has sufrido abusos sexuales en la infancia?” o “¿Has obligado a alguien a mantener relaciones sexuales en contra de su voluntad?"); y una última a la que llamaron "Violencia" y exploraba el uso de la coerción física y verbal durante la actividad sexual (“ ¿Has producido dolor físico por placer?" o “¿Has recibido dolor físico por placer?”). Los 6 ítems de la escala de violencia se eliminaron en versiones posteriores por no mostrar fundamento suficiente para su consideración como síntomas del cuadro clínico de CS (Miner, Coleman, Center, Ross, \& Rosser, 2007; Storholm, Fisher, Napper, Reynolds, \& Halkitis, 2011). Sin embargo, en nuestro estudio se empleó la versión que incluye esta escala por ser considerada información de interés acerca de la severidad del cuadro clínico.

La fiabilidad de la puntuación total $(\alpha=.94)$ así como de las subescalas de control $(\alpha=.96)$, abuso $(\alpha=.91)$ y violencia $(\alpha=.88)$ fueron altas. La estabilidad temporal una semana después de una primera administración fue de .86 . Asimismo, se demostró que las puntuaciones en el CSBI permitían discriminar entre pacientes control y pacientes con diferentes tipos de problemas en el control de los impulsos sexuales (compulsivos sexuales, pacientes parafílicos, etc.). 
19. Escala de Consecuencias Cognitivas y Conductuales de la Conducta Sexual (CBOSB, McBride et al., 2008): el CBOSB es un cuestionario compuesto por dos escalas, una de consecuencias cognitivas de la conducta sexual (CBOSB-Cognitivas) y otra de consecuencias conductuales (CBOSB-Conductuales). La primera se compone de 20 ítems con un formato de respuesta tipo Likert ( $0=\mathrm{Nunca} / 3=$ Siempre) que explora en qué medida el paciente considera (o le preocupa) que su conducta sexual compulsiva haya provocado problemas en diferentes ámbitos de su vida personal. Ejemplos de ítems de esta escala serían "Me preocupa que las cosas que he hecho sexualmente pudieran llevarme a problemas con mi pareja" o "Me preocupa que las cosas que he hecho sexualmente pudieran haberme puesto a mí o a mis parejas sexuales en riesgo de infección por el VIH". La segunda comprendería 16 ítems con un formato de respuesta dicotómica (Sí/No) que evalúa la presencia o no de ciertas consecuencias de la conducta sexual compulsiva. En este caso, los ítems seguirían el siguiente formato: "Contraje una infección de transmisión sexual" (Sí/No) o "Experimenté problemas económicos" (Sí/No).

El estudio de validación del CBOSB se realizó a partir de una muestra de 391 jóvenes. La fiabilidad obtenida en este estudio para la escala de consecuencias cognitivas fue de .89 mientras que para la escala de consecuencias conductuales fue de .75 .

En la tabla 12 se indica la fiabilidad $(\alpha)$ de los instrumentos que se aplicaron durante la primera y segunda fase de la investigación. Como se aprecia, la mayoría superaron el criterio de Henson de .70 para considerar fiable una escala (Henson, 2001), quedando únicamente 8 subescalas por debajo de este nivel de fiabilidad. Valores de consistencia interna por debajo de .70 no permiten asegurar que los resultados obtenidos a partir de dicha escala resulten completamente fiables, de modo que se estableció un criterio para decidir su empleo o no. El criterio fue desechar las escalas con valores por debajo de .50 y valorar individualmente la inclusión de las de valores $\alpha$ entre .50 y .70. A través de este criterio, se desestimó el uso de los resultados obtenidos a través de los factores 4 y 5 del ISST y se valoró individualmente el empleo de las siguientes escalas: factor 1 y 3 del ISST, escalas 2 y 3 del ENSI, factor 2 del CSBI y subescala CBOSB-Conductuales. Tras su análisis individual se decidió incluirlas todas o bien por ser escalas dicotómicas donde los niveles de fiabilidad tienden a ser más bajos que en escalas Likert (caso del factor 1 y 3 del ISST, de la escala 2 del ENSI y de la subescala CBOSBConductuales) o bien porque su valor de fiabilidad quedaba cercano al criterio de .70 . Al final de este trabajo se incluye una copia de los cuestionarios que conformaban la batería de evaluación de la fase I (anexo II) y II (anexo III) de esta investigación. 
Tabla 12. Fiabilidad $(\alpha)$ de las escalas y subescalas en la primera y segunda fase de la investigación

\begin{tabular}{|c|c|c|}
\hline & Fiabilidad $(\alpha)$ en fase I & Fiabilidad $(\alpha)$ en fase II \\
\hline Cuestionario $A d-H o c$ de Información Sociodemográfica & NA & NA \\
\hline \multicolumn{3}{|l|}{ Escala de Compulsividad Sexual } \\
\hline Puntuación total & .857 & .849 \\
\hline Factor 1. Interferencia & .755 & .738 \\
\hline Factor 2. Problemas en el control & .803 & .802 \\
\hline \multicolumn{3}{|l|}{ Inventario de Hipersexualidad } \\
\hline Puntuación total & .922 & .911 \\
\hline Factor 1. Afrontamiento & .882 & .879 \\
\hline Factor 2. Control & .837 & .838 \\
\hline Factor 3. Consecuencias & .783 & .766 \\
\hline \multicolumn{3}{|l|}{ Cuestionario de Adicción al Sexo } \\
\hline Puntuación total & .828 & .828 \\
\hline Entrevista Clínica Estructurada para los Trastornos del Eje I del DSM-IV & & NA \\
\hline Entrevista Clínica Estructurada para los Trastornos del Eje II del DSM-IV & & NA \\
\hline \multicolumn{3}{|l|}{ Inventario de Personalidad NEO Revisado } \\
\hline Neuroticismo & & .700 \\
\hline Extraversión & & .772 \\
\hline Apertura a la experiencia & & .714 \\
\hline Amabilidad & & .803 \\
\hline Responsabilidad & & .861 \\
\hline \multicolumn{3}{|l|}{ Encuesta Sobre el SIDA } \\
\hline Escala 1. HIV-Risk Index & & .764 \\
\hline Escala 2. Severidad percibida del VIH & & .542 \\
\hline Escala 3. Autoeficacia en el uso del preservativo & & .598 \\
\hline Cuestionario de Evaluación de la Orientación del Deseo Sexual & & NA \\
\hline Batería de Exposición Involuntaria a Cibersexo & & NA \\
\hline \multicolumn{3}{|l|}{ Cuestionario de Adicción al Cibersexo } \\
\hline Puntuación total & & .829 \\
\hline Factor 1. Compulsividad sexual online & & .677 \\
\hline Factor 2. Comportamiento Online Solitario no Compulsivo & & .780 \\
\hline Factor 3. Comportamiento Online Social & & .653 \\
\hline Factor 4. Gasto Económico Online & & .245 \\
\hline Factor 5. Percepción de Gravedad del Propio Comportamiento & & .273 \\
\hline \multicolumn{3}{|l|}{ Escala de Búsqueda de Sensaciones Sexuales } \\
\hline Puntuación total & & .832 \\
\hline \multicolumn{3}{|l|}{ Encuesta Revisada de Opinión Sexual } \\
\hline Puntuación total & & .828 \\
\hline Testosterona libre en saliva & & NA \\
\hline \multicolumn{3}{|l|}{ Cuestionario de Ansiedad Estado-Rasgo } \\
\hline STAI-Estado & & .907 \\
\hline STAI-Rasgo & & .884 \\
\hline \multicolumn{3}{|l|}{ Inventario de Depresión BDI } \\
\hline Puntuación total & & .891 \\
\hline \multicolumn{3}{|l|}{ Cuestionario de Autoestima de Rosenberg } \\
\hline Puntuación total & & .892 \\
\hline \multicolumn{3}{|l|}{ Inventario de Conducta Sexual Compulsiva } \\
\hline Puntuación total & & .849 \\
\hline Factor 1. Control & & .848 \\
\hline Factor 2. Abuso & & .606 \\
\hline Factor 3. Violencia & & .711 \\
\hline \multicolumn{3}{|l|}{ Escala de Consecuencias Cognitivas y Conductuales de la Conducta Sexual } \\
\hline CBOSB-Cognitivas & & .946 \\
\hline CBOSB-Conductuales & & .658 \\
\hline
\end{tabular}

$N A=$ no aplicable 


\section{Procedimiento}

La investigación comenzó con una búsqueda exhaustiva de los principales instrumentos de evaluación de la CS. Esta búsqueda permitió identificar alrededor de 10 cuestionarios utilizados previamente en la identificación de pacientes con problemas de CS. De estos 10, 4 fueron directamente desechados por no ajustarse a los objetivos de esta investigación, no cumplir requerimientos psicométricos básicos o no estar disponibles en su totalidad. De los 6 restantes, 3 se incluyeron en la primera fase de la investigación (SCS, IH y SAST) y los otros tres en la segunda (CSBI, CBOSB y Módulo de Conducta Sexual de la Entrevista Minnesota de Control de Impulsos). Del SCS disponíamos de una versión traducida al castellano y validada en población joven pero del resto contábamos únicamente con su original en inglés, de modo que fueron traducidos antes de su empleo durante la evaluación. En su traducción se siguieron las principales directrices para la adaptación de instrumentos psicométricos (Harkness, Penell, \& Schoua-Glusberg, 2004). Concretamente, cuatro miembros del equipo de investigación realizaron traducciones independientes que posteriormente se pusieron en común para consensuar una versión preliminar. Esta versión preliminar fue administrada a algunos jóvenes para comprobar que resultaba comprensible y no inducía a interpretaciones erróneas. En este momento se decidió desechar el Módulo de Conducta Sexual de la Entrevista Minnesota de Control de Impulsos ya que la mayoría de participantes durante la aplicación piloto mostraron serias dificultades a la hora de comprender su contenido. Tras realizar las mejoras sugeridas en el resto de cuestionarios, se dispuso de la versión final que se incluyó en la batería de evaluación.

El SCS y las traducciones del IH y del SAST conformaron, junto con un breve cuestionario $A d-$ Hoc de datos sociodemográficos, la batería de evaluación de la primera fase de investigación. El objetivo de esta primera fase era estimar la prevalencia de CS en población joven, de modo que en su elaboración se dio prioridad a la brevedad a cambio de lograr que un mayor número de participantes accediera a completarla. En una aplicación preliminar entre los propios miembros del grupo se comprobó que su cumplimentación no llevaba más de 20 minutos, un tiempo apropiado para su aplicación a gran escala.

En la batería de evaluación de la segunda fase, las traducciones del CSBI y del CBOSB se complementaron con una entrevista clínica, una prueba de testosterona en saliva y diversas medidas de evaluación autoaplicadas. El objetivo de esta segunda fase era establecer un perfil diferencial entre jóvenes con altas puntuaciones en CS y con puntuaciones normales, de modo que se sacrificó la brevedad a favor de una evaluación más exhaustiva. Se estimó que el tiempo para finalizar la segunda evaluación rondaba entre las 2 horas y las 2 horas y media. 
Una vez elaboradas las dos baterías de evaluación, comenzó el diseño del procedimiento de reclutamiento. El objetivo para la primera fase de la investigación era conseguir que al menos 1300 jóvenes (unos 600 chicos y 700 chicas) completaran la evaluación a través de la batería de screening de CS. Según cálculos previos considerando la prevalencia media del trastorno en la literatura, esto permitiría identificar a 100 chicos y 100 chicas con altas puntuaciones en CS y a otros tantos equiparables en edad y orientación sexual pero con puntuaciones normales. Estos 400 jóvenes se clasificarían en los cuatro grupos que posteriormente participarían en la segunda fase de la investigación. Es decir, se fijó un objetivo muestral para la segunda fase de evaluación de 100 chicos control, 100 subclínicos, 100 chicas control y 100 subclínicas. En la figura 8 se resumen los resultados del procedimiento de reclutamiento.

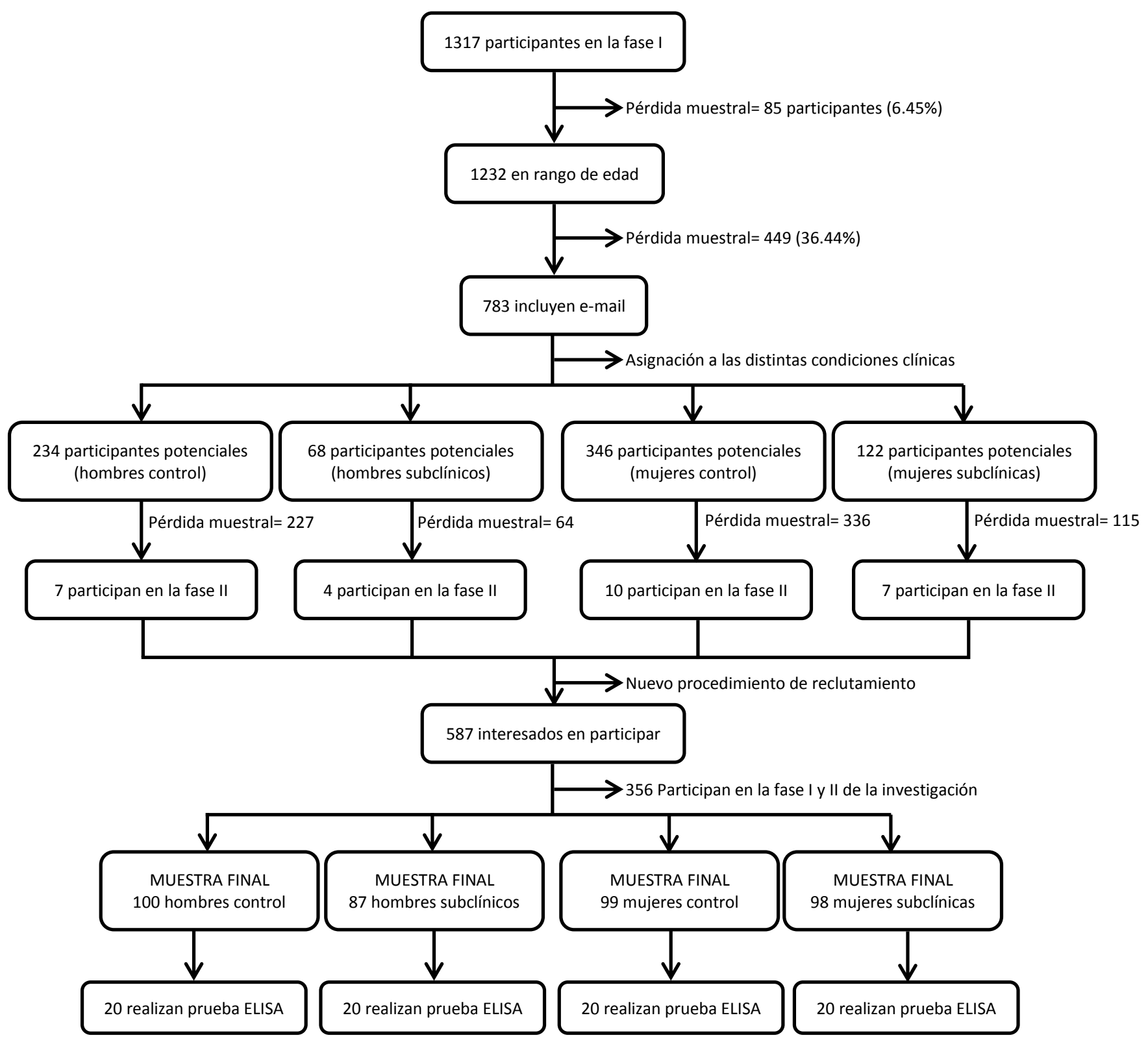

Figura 8. Diagrama de flujo del procedimiento de reclutamiento de participantes. 
Los participantes en la primera fase del estudio se reclutaron en el contexto de la comunidad universitaria a través de mesas informativas dispuestas en el hall de las distintas facultades y también de la biblioteca de la Universitat Jaume I. Se establecieron como mínimo dos días de recogida de datos por cada facultad, uno por la mañana y otro por la tarde para asegurar la participación de estudiantes de ambas franjas horarias. Los estudiantes que lo deseaban recibían información sobre adicción al sexo y se les ofrecía la posibilidad de colaborar de forma altruista en esta investigación. Los que accedían completaban un consentimiento informado y los instrumentos de evaluación en formato lápiz y papel. Para asegurar la confidencialidad y la intimidad durante su cumplimentación, las mesas se dispusieron de forma que permitieran una distancia entre participantes y no se les pidió ningún dato que pudiera facilitar su identificación. En la primera hoja de la batería de cuestionarios se explicaba que durante los meses siguientes se realizaría una investigación remunerada sobre comportamiento sexual (segunda fase del estudio). Los interesados en participar debían incluir un e-mail a través del cual se concertaría una cita para realizarla.

Durante los meses de abril y junio del 2012, 1317 jóvenes participaron en la primera fase de la investigación en alguna de las 10 mesas dispuestas en las distintas facultades. La Facultad donde más jóvenes participaron fue la de Ciencias Humanas y Sociales (38.1\%), seguida de la Escuela Superior de Tecnología y Ciencias Experimentales (23.8\%), la Facultad de Ciencias Jurídicas y Económicas (19.8\%) y finalmente la Biblioteca (16.1\%). Un 2.2\% de los cuestionarios se administraron durante una clase de la asignatura <<Psicología Clínica de la Salud >> (grado en psicología).

Durante el mes siguiente (julio de 2012) se procesaron los datos obtenidos para establecer los criterios de inclusión y exclusión en la segunda fase del estudio. El rango de edad de los participantes en esta primera fase oscilaba entre los 17 años y los 48 , si bien el grueso de la muestra se agrupaba en torno a los 18-27 años. Se decidió por tanto excluir de la segunda fase a los participantes con edades fuera de este rango para asegurar la representatividad de los resultados. De este modo, 85 participantes (el $6.45 \%$ de la muestra obtenida durante la fase I) quedaron excluidos y perdieron la oportunidad de participar en la segunda fase de la investigación. De los 1232 que sí se encontraban en el rango de edad, 783 indicaron un mail de contacto para participar en la segunda fase de investigación, lo que supuso una pérdida muestral para la segunda fase del $36.44 \%$.

Para asignar a los 783 participantes que incluyeron un e-mail a uno de los cuatro grupos de la fase II se siguieron dos criterios: el sexo y la puntuación en la escala SCS. Concretamente, los participantes con puntuaciones por encima del percentil 80 eran asignados al grupo subclínico 
mientras que el resto lo eran al grupo control. Este criterio resulta superior al empleo de un punto de corte unitario por dos motivos: es sensible a la población donde se aplica (no en vano, el percentil se calcula sobre la distribución objeto de estudio) y es sensible a las diferencias entre chicos y chicas en CS. A través del análisis de las puntuaciones en el SCS durante la fase I se estableció como punto de corte para la asignación al grupo subclínico la obtención de una puntuación $>18$ en el caso de los chicos y >14 en el caso de las chicas. Así, 234 de los 783 participantes con e-mail fueron asignados al grupo de chicos control, 68 al de chicos subclínicos, 346 al de chicas control y 122 al de chicas subclínicas.

Tras la asignación a uno de los 4 grupos, se envió un mail a cada uno de ellos para informarles del inicio de la segunda fase de investigación y para concertar una cita caso que todavía siguieran interesados en participar. Este contacto se realizó en octubre de 2012. En el anexo IV se incluye el modelo de correo electrónico que se empleó. En él se especificaba que su participación se remuneraba con 10 euros en metálico. Los que contestaron mostrando su interés fueron anotados en una lista de espera y citados bajo riguroso orden de inscripción. La evaluación se realizaba de forma individual en uno de nuestros laboratorios de investigación y se daba la oportunidad de completar toda la evaluación el mismo día o en dos días. La gran mayoría prefirió completar la evaluación el mismo día. Todas las evaluaciones comenzaban con la aplicación de la entrevista clínica y seguían con la cumplimentación de los cuestionarios. La entrevista era siempre realizada por el mismo evaluador para minimizar el sesgo de diferentes criterios y juicios clínicos. Cuando terminaba la entrevista, el evaluador explicaba el contenido de los cuestionarios y abandonaba la sala para permitir que el participante se sintiera más cómodo. Se sugería que acudiera a una sala anexa donde permanecía el responsable de la evaluación caso que tuviera dudas con alguno de los cuestionarios. Asimismo, el evaluador pasaba por la sala cada 15 minutos para comprobar que la cumplimentación era correcta. Cuando el participante finalizaba la evaluación, firmaba un justificante y recibía la remuneración en metálico.

Tan sólo 28 de los 783 participantes que incluyeron e-mail participaron finalmente en la fase II de la investigación. Se estimó por tanto una mortandad experimental del $96.4 \%$ en esta fase de la investigación. Entre otros, el tiempo transcurrido entre la fase I y II de la investigación (en algunos casos más de 6 meses), el inicio de un nuevo curso académico (con la movilidad estudiantil que eso supone) o que el e-mail de reclutamiento se tomara por SPAM pueden ser algunas de las razones que explican esta altísima mortandad. En todo caso, resultaba evidente que a través de este método no se lograrían los objetivos muestrales para la fase II de modo que se diseñó una nueva estrategia de reclutamiento. 
La nueva estrategia complementaba métodos clásicos y modernos de reclutamiento: por un lado, se empapelaron los tablones de anuncios de las facultades con carteles de la investigación y por otro, se emplearon redes sociales (concretamente Facebook) para dar difusión al estudio. En el anexo IV se incluye el cartel y una captura de pantalla de la difusión a través de redes sociales. Dado que el estudio era presencial, su difusión a través de redes sociales se limitó a páginas de estudiantes de esta universidad. Así, se emplearon grupos como "El informer de la UJI" o "Estudiantes de periodismo UJ" para acotar la difusión del estudio a la población objeto de interés. Los jóvenes que se interesaban en la investigación a través o bien de Facebook o de los carteles eran derivados a un enlace a una encuesta online (http://goo.gl/forms/uHohDIQGo3). En esta encuesta se les preguntaba por su nombre, edad, orientación sexual, número de teléfono, e-mail de contacto y disponibilidad. Asimismo se incluyó el cuestionario SCS para saber a qué grupo asignar a dichos participantes sin necesidad de que completaran la batería de evaluación de la fase I completa.

A través de estas vías, 587 jóvenes se interesaron en participar en la segunda fase. Si cumplían los requisitos (edad) se les incluía en 4 listas distintas (una por cada grupo clínico en fase II). Los chicos y chicas del grupo subclínico eran citados prioritariamente dada la dificultad para su identificación y captación, mientras que al resto se les citaba por orden de inscripción. La evaluación de estos participantes fue idéntica a la comentada previamente. La única diferencia es que a ellos se les administraba, además de todas las escalas y la entrevista de la segunda fase, los cuestionarios de screening de la primera de modo que tanto los reclutados a través del método pensado originalmente como éstos completaron los mismos instrumentos.

La segunda fase de la investigación terminó con la evaluación de 384 participantes. Los objetivos muestrales de esta fase se cumplieron casi al $100 \%$ en los grupos de chicos y chicas control y de chicas subclínicas, pero no en el caso de la muestra de chicos subclínicos ( $87 \%$ del objetivo muestral). La dificultad para encontrar participantes susceptibles de ser incluidos en ese grupo junto con las exigencias temporales del proyecto de investigación explicarían que no se alcanzara por completo el objetivo de participantes.

Para terminar, un mes después de la finalización de la evaluación se contactó de nuevo con 80 participantes (20 de cada condición clínica) para evaluar sus niveles de testosterona en saliva. Para asegurar su participación, esta prueba se remuneró con 10 euros adicionales. Estos 80 participantes acudieron en un mismo día a uno de los laboratorios de investigación del equipo para realizar la prueba ya que la conservación de las muestras y su análisis requería que la recogida se realizara en un corto periodo de tiempo. 


\section{Análisis estadísticos}

Los datos se analizaron mediante el paquete estadístico SPSS Versión 23.0, el software G*Power versión 3.1 (empleado para el cálculo del tamaño del efecto y la potencia estadística) y el programa de ecuaciones estructurales EQS versión 6.2. En primer lugar, se analizó el perfil de puntuaciones en los tres cuestionarios de screening de los participantes en la fase I ( $N=1588)$ a través de medidas de tendencia central y de dispersión. También se estimó el porcentaje de la muestra con puntuaciones clínicas en estas tres escalas a partir de los criterios establecidos para cada una de ellas. En el caso del SCS, se obtuvo la prevalencia para dos puntos de corte distintos.

Los mismos análisis se realizaron posteriormente en función de tres variables: sexo, edad y orientación sexual. El estadístico de contraste empleado para el análisis de las puntuaciones medias según el sexo fue el estadístico de contraste $t$ de Student. La magnitud de las diferencias en dicho contraste se estimó a partir de la $d$ de Cohen para el tamaño del efecto. En este caso, tamaños del efecto de alrededor de .20 fueron considerados pequeños, cercanos a .50 moderados y de .80 grandes (Cohen, 1988). Para el cálculo de las puntuaciones medias según la orientación sexual ( 3 grupos) se empleó la prueba ANOVA de un factor. El tamaño del efecto en este contraste se estimó a partir del índice $f$ : valores $f$ cercanos a .10 se consideraron pequeños, alrededor de .25 medios y en torno a .40 grandes (G*Power, 2014). La relación entre edad y CS se estimó a través de correlaciones bivariadas ( $r$ de Pearson). El estadístico de contraste empleado para el análisis de la prevalencia de CS según sexo, edad y orientación fue el Chi Cuadrado. La magnitud de las diferencias en dicho contraste se estimó mediante el cálculo de la $V$ de Cramer (que en tablas Chi Cuadrado $2 \times 2$ y 2xk como las utilizadas es equivalente al índice $W$ de Cohen para el tamaño del efecto) (Sheskin, 2007). Para la $V$ de Cramer, tamaños del efecto en torno a .10 son considerados pequeños, alrededor de .30 moderados y cercanos a .50 grandes (Ellis, 2010).

Los análisis realizados durante la segunda fase $(N=384)$ siguieron una estructura diferente. Chicos y chicas fueron analizados independientemente para evitar que las diferencias normales entre ambos grupos confundieran la interpretación de los efectos atribuibles a la variable independiente (tipo de grupo clínico). Así, los análisis se realizaron comparando independientemente chicos control y subclínicos y chicas control y subclínicas. En un primer bloque se analizó la prevalencia (\%) de patologías del Eje I y II del DSM-IV y las diferencias entre participantes control y subclínicos (Chi Cuadrado y $V$ de Cramer). En un segundo bloque se compararon las puntuaciones medias en las 5 dimensiones y 30 facetas del modelo de 5 factores de la personalidad en ambos grupos, empleando en este caso el estadístico de 
contraste $t$ de Student. En un tercer bloque se comparó el comportamiento sexual de chicos y chicas control y subclínicos. En este caso, los contrastes estadísticos variaron dependiendo del tipo de ítem: el estadístico de contraste escogido para variables categóricas (p.e., haber sido o no infiel) fue el Chi Cuadrado y la $V$ de Cramer, mientras que para variables continuas (p.e., puntuación en el BSS) se utilizó la prueba $t$ de Student de diferencia de medias y la $d$ de Cohen. En un cuarto bloque se analizaron las diferencias el perfil de puntuaciones en tres instrumentos psicopatológicos (el BDI, STAI y el RSEI) a través de pruebas $t$ de Student.

En el quinto bloque la organización de resultados varió de nuevo. Los cuestionarios empleados para el análisis de la severidad y las consecuencias del cuadro clínico se aplicaron únicamente a chicos y chicas del grupo subclínico ( $n$ de 87 y 98 respectivamente), de modo que en este bloque las comparaciones se realizaron entre estos dos grupos. La severidad se analizó a través de las puntuaciones medias en el CSBI y las diferencias entre los dos grupos a través de la prueba $t$ de Student y la $d$ de Cohen. La exploración de las consecuencias del cuadro clínico se abordó combinando las puntuaciones medias en la escala CBOSB y el porcentaje de participantes que afirmó haber experimentado diferentes consecuencias, de modo que dependiendo del nivel de análisis se emplearon contrastes estadísticos para variables continuas o categóricas. Finalmente, la relación entre severidad y consecuencias del cuadro clínico de CS se analizó a través de correlaciones bivariadas ( $r$ de Pearson).

En el sexto y último bloque se trató de integrar en un único modelo los resultados obtenidos durante los análisis previos a través de una regresión logística binaria por bloques. La variable dependiente del modelo fue el tipo de grupo (control o subclínico), mientras que las variables independientes variaron en función del bloque. En el primer bloque se incluyeron las variables que durante análisis previos demostraron su importancia para discriminar entre participantes control y subclínicos. Entre estas variables se incluían algunas continuas (p.e., las puntuaciones en el cuestionario de personalidad NEO PI-R) y otras categóricas (como la orientación sexual o el haber realizado o no ciertas prácticas sexuales). Para la introducción de estas últimas se empleó el método de codificación de variables Dummy (Rosel, Jara, \& Herrero, 2014). En el segundo bloque del modelo de regresión se incluyeron los términos de interacción entre las variables del primer bloque y el sexo. El método para la introducción de variables fue el de "introducir": este método permite elegir las variables incluidas en el modelo y se recomienda cuando se introducen términos de interacción entre variables (Hosmer \& Lemeshow, 2004). El ajuste se valoró a través de los índices de bondad de ajuste (Prueba de Hosmer-Lemeshow), de los valores de capacidad predictiva y significación ( $\beta$, E.T., $p, O R)$, del porcentaje de varianza explicada ( $R^{2}$ de Nagelkerke) y de su sensibilidad y especificidad clasificando participantes. 
A partir de los resultados de la regresión logística se realizó una ecuación estructural (SEM) para establecer el tipo de relación entre las variables contempladas en el modelo. En este caso, la variable dependiente no fue el grupo de pertenencia (variable dicotómica) sino la puntuación en la escala SCS (variable continua). Esta elección se debe principalmente a que el uso de variables dicotómicas en SEM está contraindicado. Los análisis se realizaron a través del programa de ecuaciones estructurales EQS (versión 6.2). Dada la distribución no normal de algunas de las variables incluidas en este modelo, el método empleado en la estimación de los parámetros fue el de Máxima Verosimilitud Robusto (método que permite obtener estadísticos que corrigen el efecto de la violación del principio de normalidad). Los índices de ajuste del modelo SEM incluyeron: el Chi Cuadrado de Satorra-Bentler $\left(X^{2}\right)$, el Chi Cuadrado Relativo ( $X^{2} /$ G.L.), la significación general del modelo $(p)$, el Estadístico de bondad de ajuste (GFI) y el de bondad de ajuste corregido (AGFI), la Raíz Cuadrada Media del Error de Aproximación (RMSEA) y los Índices de Ajuste Comparativo (CFI) e Incremental (IFI). Se consideró que el ajuste del modelo era correcto cuando el $X^{2}$ resultaba no significativo ( $p>05$ ), el $X^{2} /$ G.L. se situaba entre 1 y 2 , el CFI y el IFI eran $\geq .95$ y el RMSEA $\leq .05$ (Bagozzi \& Yi, 2011). Según criterios más laxos, valores entre 2 y 3 para el $X^{2} / G$.L., $\geq .90$ para el CFI y el IFI y $\leq .08$ para el RMSEA podrían considerarse también aceptables (Hooper, Coughlan, \& Mullen, 2008). Asimismo, se tuvo en cuenta a la hora de valorar el ajuste del modelo la significación del efecto directo e indirecto (mediado a través de otra variable) de cada variable independiente (Bentler, 2006), el porcentaje de varianza de la variable dependiente explicada $\left(R^{2}\right)$ y la sugerencia de relaciones latentes del Lagrange Multiplier Test (L.M. Test). Una vez planteado el modelo, se comprobó la invarianza de su configuración estructural a través de un análisis multigrupo comparando el ajuste del modelo en chicos y chicas. Tanto el método como los índices empleados para valorar el ajuste de este modelo fueron iguales a los ya comentados. 



\section{Capítulo 7. Resuttados}

1. Screening de la CS: puntuación, prevalencia clínica e influencia de variables demográficas

2. Comorbilidad psicopatológica.

3. Correlatos clínicos

4. Perfil de personalidad

5. Comportamiento sexual

5.1 Comportamiento sexual general

5.2 Comportamiento sexual de riesgo

5.3 Comportamiento sexual online

5.4 Variables clínicas sexuales

5.5 Evaluación hormonal: determinación del nivel de testosterona

6. Severidad y consecuencias de la CS

7. Capacidad predictiva de un modelo de regresión logística con interacción del sexo

8. Propuesta de un modelo de relaciones estructurales a través de metodología SEM 


\section{Screening de la CS: puntuación, prevalencia clínica e influencia de variables demográficas}

El perfil de puntuaciones y la prevalencia de CS se ha analizado a partir de tres cuestionarios de screening: la Escala de Compulsividad Sexual (SCS), el Inventario de Hipersexualidad (IH) y el Cuestionario de Adicción al Sexo (SAST). Los análisis se han realizado en primer lugar sobre el conjunto de la muestra (tabla 13) y posteriormente distinguiendo según sexo (tabla 14), orientación sexual (tabla 15) y edad (tabla 16 y tabla 17).

La asimetría y curtosis se han calculado solo para el conjunto de la muestra. La prevalencia en el cuestionario SCS se ha estimado a través de dos puntos de corte: uno al que hemos llamado $\mathrm{SCS}^{1}$ y establece un punto de corte fijo para identificar de puntuaciones clínicas (puntuación $\geq 24$ en la escala SCS) y otro al que se llama $\operatorname{SCS}^{2}$ y establece un punto de corte dependiente de la distribución de puntuaciones en poblaciones concretas (puntuación 2 DT por encima de la media). Este último se emplea para estimar la prevalencia de puntuaciones clínicas en el conjunto de la muestra y según sexo y orientación sexual pero no según edad. Posteriormente se explica en detalle el criterio que justifica esta omisión. En el IH se ha considerado como punto de corte la obtención de una puntuación $\geq 53$ (criterio $\mathrm{IH}^{3}$ ) y en el SAST la obtención de una puntuación $>13\left(\mathrm{SAST}^{4}\right)$. Los criterios $\mathrm{SCS}^{1}, \mathrm{IH}^{3}$ y $\mathrm{SAST}^{4}$ corresponden a la propuesta de corrección original de cada escala mientras que el $\mathrm{SCS}^{2}$ se extrajo de una investigación sobre adicción al cibersexo (Cooper et al. 2000).

Tabla 13. Estadísticos descriptivos y puntuaciones clínicas en las tres escalas de screening de la CS ( $N=1588)$

\begin{tabular}{|c|c|c|c|c|c|c|c|c|}
\hline & \multirow{2}{*}{ Rango } & \multirow{2}{*}{ Asimetria } & \multirow{2}{*}{ Curtosis } & \multirow{2}{*}{$M(D T)$} & \multicolumn{4}{|c|}{ \% Puntuaciones Clínicas } \\
\hline & & & & & $\operatorname{sCS}^{1}$ & $\mathrm{SCS}^{2}$ & $\mathrm{IH}^{3}$ & $\mathrm{SAST}^{4}$ \\
\hline \multicolumn{9}{|l|}{ Escala de Compulsividad Sexual (SCS) } \\
\hline Puntuación total & $10-40$ & 1.64 & 2.89 & $14.20(4.78)$ & $5.6 \%$ & $5.6 \%$ & & \\
\hline Factor 1. Interferencia & $5-20$ & 2.08 & 4.78 & $6.56(2.32)$ & & & & \\
\hline Factor 2. Problemas en el control & $5-20$ & 1.43 & 1.98 & $7.64(2.93)$ & & & & \\
\hline \multicolumn{9}{|l|}{ Inventario de Hipersexualidad (IH) } \\
\hline Puntuación total & $19-95$ & 1.50 & 2.47 & $30.59(11.28)$ & & & $6.3 \%$ & \\
\hline Factor 1. Afrontamiento & $8-40$ & 1.17 & 1.28 & $12.90(5.47)$ & & & & \\
\hline Factor 2. Control & $7-35$ & 1.84 & 3.86 & $8.98(3.85)$ & & & & \\
\hline Factor 3. Consecuencias & $4-20$ & 1.88 & 3.89 & $8.86(3.73)$ & & & & \\
\hline \multicolumn{9}{|l|}{ Cuestionario de Adicción al Sexo (SAST) } \\
\hline Puntuación total & $0-25$ & 1.38 & 1.84 & $3.53(3.64)$ & & & & $3.1 \%$ \\
\hline
\end{tabular}


Como se aprecia en la tabla 13, la puntuación total en los tres cuestionarios de screening y en los factores que los integran sigue una distribución positivamente asimétrica (valores de asimetría $\geq 1.17$ ) y leptocúrtica (índices de curtosis $\geq 1.28$ ). Así, en lugar de distribuirse siguiendo una curva normal -la mayoría de participantes con puntuaciones cercanas a los valores medios del rango de la escala-, la puntuaciones se agrupan en torno al extremo inferior del rango. Esta asimetría se hace más evidente cuando se analiza la curva de distribución de puntuaciones (figura 9). En las tres escalas, el punto más alto de la curva de distribución (que coindice con la puntuación media en cada escala) muestra una acentuada desviación hacia la izquierda, alejándose de valores centrales. De este modo, la puntuación media para la escala SCS fue de 14.20 (en una distribución con un rango de 10 a 40), de 30.59 en el IH (rango de 19 a 95) y de 3.53 en el SAST (rango entre 0 y 25). La asimetría y curtosis se acentúa sobre todo en aquellas subescalas que indican una mayor desviación psicopatológica, como el factor 1 del SCS (asimetría=2.08; curtosis=4.78) y el factor 2 (asimetría=1.84; curtosis=3.86) y 3 (asimetría=1.88; curtosis=3.89) del IH. Al contrario, se atenúa en dimensiones con menor significación clínica donde la distribución de puntuaciones a lo largo de la escala es un tanto más equivalente, como en el factor de afrontamiento del IH (asimetría=1.17; curtosis=1.28).
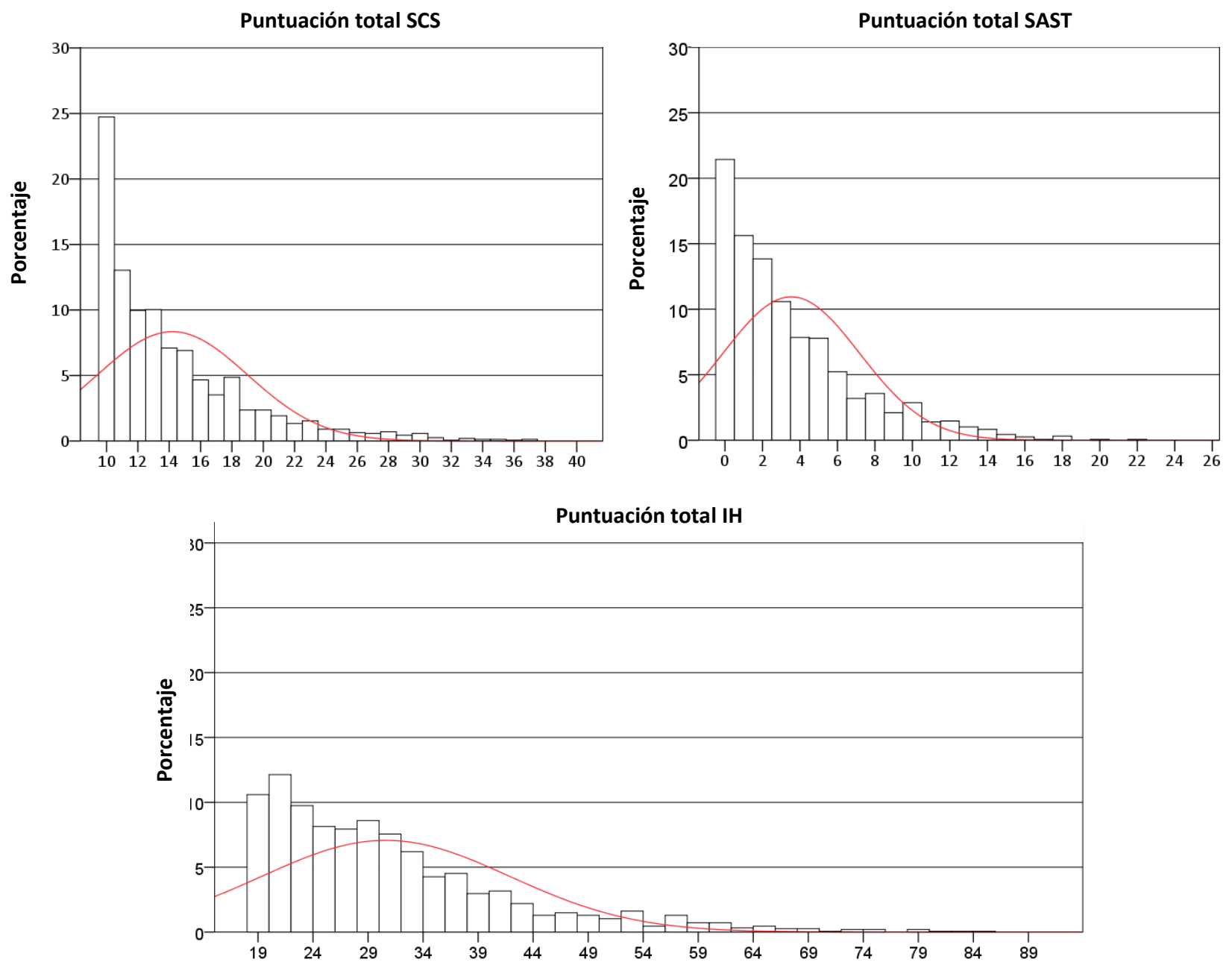

Figura 9. Histograma y curva de distribución del SCS, IH y SAST. 
Si atendemos a la prevalencia, el porcentaje de casos de CS identificados a través de los criterios SCS $^{1}$ y SCS ${ }^{2}$ fue del 5.6\% (tabla 13). La prevalencia según ambos criterios es la misma debido a que la suma de 2DT a la media de la distribución (criterio $\mathrm{SCS}^{2}$ para la identificación de casos clínicos) coincide con el punto de corte establecido por el criterio $\mathrm{SCS}^{1}$, lo que ya no sucede al estimar el $\operatorname{SCS}^{2}$ en función del sexo o la orientación sexual. La prevalencia estimada a través del IH es la que identifica un mayor porcentaje de casos clínicos (un 6.3\%). Al contrario, el SAST sería el que establece criterios diagnósticos más estrictos, con tan sólo un $3.1 \%$ de los participantes superando el criterio para la identificación de casos clínicos.

Tabla 14. Estadísticos descriptivos y puntuaciones clínicas en función del sexo

\begin{tabular}{|c|c|c|c|c|}
\hline & $\begin{array}{c}\text { Chicos }(n=684) \\
M(D T) \circ \%\end{array}$ & $\begin{array}{c}\text { Chicas }(n=904) \\
M(D T) \circ \%\end{array}$ & $\begin{array}{c}\text { Estadístico de } \\
\text { contraste }\end{array}$ & $\begin{array}{c}\text { Tamaño del } \\
\text { efecto }\end{array}$ \\
\hline \multicolumn{5}{|l|}{ Escala de Compulsividad Sexual (SCS) } \\
\hline Puntuación total & $15.95(5.30)$ & $12.87(3.84)$ & $t=13.30 * * *$ & $d=0.68$ \\
\hline Factor 1. Interferencia & $7.42(2.75)$ & $5.91(1.66)$ & $t=13.53 * * *$ & $d=0.68$ \\
\hline Factor 2. Problemas en el control & $8.52(3.07)$ & $6.96(2.62)$ & $t=10.84 * * *$ & $d=0.56$ \\
\hline Puntuaciones clínicas SCS ${ }^{1}$ & $9.9 \%$ & $2.5 \%$ & $x^{2}=39.42 * * *$ & $V=0.15$ \\
\hline Puntuaciones clínicas SCS ${ }^{2}$ & $5.9 \%$ & $5.7 \%$ & NA & NA \\
\hline \multicolumn{5}{|l|}{ Inventario de Hipersexualidad (IH) } \\
\hline Puntuación total & $33.96(12.43)$ & $28.06(9.58)$ & $t=10.54 * * *$ & $d=0.54$ \\
\hline Factor 1. Afrontamiento & $14.09(5.74)$ & $12.02(5.08)$ & $t=7.55^{* * *}$ & $d=0.38$ \\
\hline Factor 2. Control & $10.02(4.24)$ & $8.20(3.33)$ & $t=9.49 * * *$ & $d=0.48$ \\
\hline Factor 3. Consecuencias & $10(4.36)$ & $7.98(2.89)$ & $t=11.01 * * *$ & $d=0 . .56$ \\
\hline Puntuaciones clínicas $\mathrm{IH}^{3}$ & $9.9 \%$ & $3.6 \%$ & $X^{2}=25.45^{* * *}$ & $V=0.12$ \\
\hline \multicolumn{5}{|l|}{ Cuestionario de Adicción al Sexo (SAST) } \\
\hline Puntuación total & $4.60(3.80)$ & $2.73(3.29)$ & $t=10.39 * * *$ & $d=0.53$ \\
\hline Puntuaciones clínicas SAST ${ }^{4}$ & $4.6 \%$ & $1.9 \%$ & $x^{2}=9.42 * *$ & $V=0.07$ \\
\hline
\end{tabular}

Nota. SCS ${ }^{1}=$ Puntuación $\geq 24$ en la escala SCS

$\mathrm{SCS}^{2}=$ Puntuación 2 DT por encima de la media en la escala SCS distinguiendo según sexo (en chicos una puntuación $>26.55$ y en chicas $>20.55$ ).

$\mathrm{IH}^{3}=$ Puntuación $\geq 53$ en el inventario $\mathrm{IH}$

$\mathrm{SAST}^{4}=$ Puntuación $>13$ en el cuestionario SAST

$\mathrm{NA}=$ No aplicable

${ }^{*} p<0.05 ;{ }^{* *} p<0.01 ;{ }^{* * *} p<0.001$

Si analizamos el perfil de puntuaciones en función del sexo (tabla 14), se observa que los chicos obtienen puntuaciones superiores en todas las escalas y subescalas analizadas. La diferencia en la puntuación media de chicos y chicas alcanza la máxima significación estadística $(p<.001)$ en todas ellas, con tamaños del efecto superiores a 0.53 (entre moderados y grandes) en la puntuación total y los dos factores del SCS, en la puntuación total y el factor 3 del IH y en la puntuación total del SAST. 
También es mayor el porcentaje de chicos que supera los distintos puntos de corte clínicos. La prevalencia de puntuaciones clínicas según el $\operatorname{SCS}^{1}$ sería del 9.9\% en el caso de los chicos y del $2.5 \%$ en el de las chicas $\left(x^{2}=39.42 ; p<.001\right)$, diferencia que se consideraría entre pequeña y moderada $(V=0.15)$. La prevalencia en chicos según el $\mathrm{IH}^{3}$ sería exactamente igual $(9.9 \%)$ pero aumentaría ligeramente en chicas (3.6\%). Finalmente, el SAST ${ }^{4}$ sería el que identifica un menor porcentaje de participantes clínicos ( $4.6 \%$ de chicos y $1.9 \%$ de chicas) y donde las diferencias en función del sexo son más discretas $\left(x^{2}=9.42 ; p=.002 ; V=0.07\right)$. Empleando puntos de corte diferenciales en chicos y chicas (puntuación $>26.65$ y >20.55 respectivamente), la prevalencia estimada según el $\mathrm{SCS}^{2}$ sería del $5.9 \%$ y del 5.7\%.

La orientación sexual también se demuestra una variable importante en el análisis de las puntuaciones y la prevalencia de CS (tabla 15): a excepción del factor 2 del IH (donde los homosexuales puntúan más alto), los bisexuales obtienen una puntuación media mayor en todas las escalas y subescalas exploradas, seguidos en segundo lugar de homosexuales y finalmente de heterosexuales. En escalas como la puntuación total y el factor 3 del SCS, la puntuación total y el factor 2 del IH y la puntuación total del SAST, la puntuación media de bisexuales y homosexuales sería equivalente entre sí y mayor a la media obtenida por el grupo de heterosexuales (significación <.001 en los 5 casos). La diferencia en estos contrastes alcanzaría un tamaño del efecto que oscila entre 0.14 y 0.22 , de modo que en estos casos el efecto de la orientación sexual se considera entre pequeño y moderado. En otros casos, la media de homosexuales sería inferior a la de bisexuales e igual a la de heterosexuales (factor 1 del SCS), igual a la de heterosexuales y bisexuales (factor 3 del IH) o superior a la de heterosexuales (factor 2 del $\mathrm{IH}$ ).

Las diferencias en función de la orientación sexual son aún más acentuadas al estimar la prevalencia de puntuaciones clínicas. En este sentido, un $21.2 \%, 24 \%$ y $23.1 \%$ de los bisexuales obtiene puntuaciones clínicas en el $\mathrm{SCS}^{1}, \mathrm{IH}^{3}$ y $\mathrm{SAST}^{4}$ respectivamente, frente al $8.5 \%, 10 \%$ y $10 \%$ de los homosexuales y el $5 \%, 5.5 \%$ y $2 \%$ de los heterosexuales. La significación de estas diferencias es en los tres casos $<.001$, con un tamaño del efecto entre pequeño y moderado ( $V$ entre .13 y .23). En cambio, la prevalencia obtenida a través del $\mathrm{SCS}^{2}$ sería muy similar en heterosexuales (4.9\%), homosexuales (4.2\%) y bisexuales (5.8\%). Cabría considerar en todo caso que mientras una puntuación superior a 23.13 sería suficiente para la identificación de un participante clínico heterosexual según el $\mathrm{SCS}^{2}$, uno bisexual debería obtener una puntuación mayor a 32.51 para ser considerado como tal. 
Tabla 15. Estadísticos descriptivos y puntuaciones clínicas en función de la orientación sexual

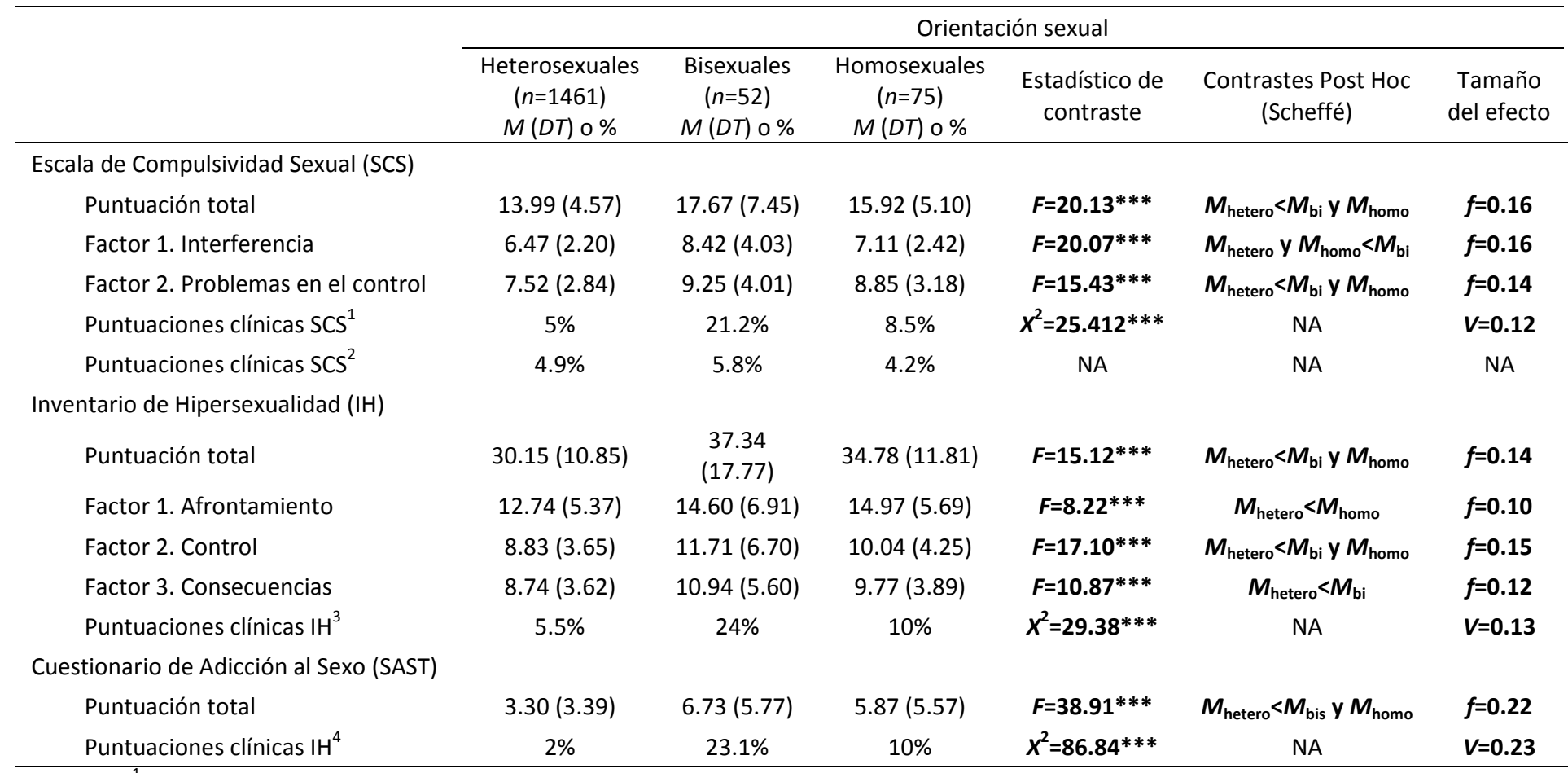

Nota. SCS ${ }^{1}=$ Puntuación $\geq 24$ en la escala SCS

$\mathrm{SCS}^{2}=$ Puntuación 2 DT por encima de la media en la escala SCS distinguiendo según orientación sexual (en heterosexuales una puntuación >23.13, en bisexuales $>32.51$ y en homosexuales $>26.12$ ).

$\mathrm{IH}^{3}=$ Puntuación $\geq 53$ en el inventario $\mathrm{IH}$

$\mathrm{SAST}^{4}=$ Puntuación $>13$ en el cuestionario SAST

NA $=$ No aplicable

${ }^{*} \mathrm{p}<0.05 ;{ }^{* *} \mathrm{p}<0.01 ; * * * \mathrm{p}<0.001$

Las correlaciones entre la edad y las tres escalas y subescalas de screening de CS (tabla 16) dan buena cuenta del escaso impacto de esta variable en la CS. De las 8 correlaciones estimadas, tan sólo la edad y el factor 2 del inventario IH correlacionaron pero muy tímidamente $(r=-.055$; $p=.02$ ). Ambas variables se relacionaban inversamente, de modo que la puntuación en la escala disminuía a medida que aumentaba la edad. El resto de correlaciones se situaron en un rango entre -.024 y .019 (en todos los casos muy lejos de la significación estadística).

Tabla 16. Correlaciones $(r)$ entre la edad y las tres escalas de screening de la CS ( $N=1588)$

\begin{tabular}{lc}
\hline & Edad \\
\hline Escala de Compulsividad Sexual (SCS) & .001 \\
Puntuación total & .019 \\
Factor 1. Interferencia & -.015 \\
Factor 2. Problemas en el control & \\
Inventario de Hipersexualidad (IH) & -.016 \\
Puntuación total & -.008 \\
Factor 1. Afrontamiento & .004 \\
Factor 2. Control & $-.055^{*}$ \\
Factor 3. Consecuencias & \\
Cuestionario de Adicción al Sexo (SAST) & -.024 \\
Puntuación total &
\end{tabular}

Nota. ${ }^{*} \mathrm{p}<0.05 ;{ }^{* *} \mathrm{p}<0.01 ; * * * \mathrm{p}<0.001$ 
Finalmente, la franja de edad donde se identifica mayor porcentaje de casos clínicos (tabla 17) a través del $\mathrm{SCS}^{1}$ sería a los 22 años (9.2\%). Según el $\mathrm{IH}^{3}$, la edad a la que se identifican más casos de CS sería a los 26 años (un 10\%) frente al 3.7\% que se identifica un año más tarde. Finalmente, el SAST ${ }^{4}$ estima un porcentaje mayor a los 27 años (el 7.4\%). En todo caso, no se encuentran diferencias significativas según la edad para ninguno de los tres criterios ( $p>05)$.

Tabla 17. Puntuaciones clínicas en función de la edad

\begin{tabular}{|c|c|c|c|}
\hline & Escala de Compulsividad Sexual & Inventario de Hipersexualidad & Cuestionario de Adicción al Sexo \\
\hline & Clínicos SCS ${ }^{1}(\%)$ & Clínicos IH ${ }^{3}(\%)$ & Clínicos SAST ${ }^{4}(\%)$ \\
\hline 18 años ( $n=262)$ & $5.8 \%$ & $8.4 \%$ & $4.7 \%$ \\
\hline 19 años ( $n=344)$ & $4.7 \%$ & $7.2 \%$ & $2.9 \%$ \\
\hline 20 años $(n=291)$ & $4.6 \%$ & $4.9 \%$ & $2.1 \%$ \\
\hline 21 años $(n=243)$ & $6.3 \%$ & $3.8 \%$ & $2.5 \%$ \\
\hline 22 años ( $n=174)$ & $9.2 \%$ & $5.3 \%$ & $2.3 \%$ \\
\hline 23 años $(n=106)$ & $4.9 \%$ & $6.9 \%$ & $4.8 \%$ \\
\hline 24 años $(n=59)$ & $6.8 \%$ & $8.5 \%$ & $1.7 \%$ \\
\hline 25 años $(n=42)$ & $2.4 \%$ & $9.5 \%$ & $2.4 \%$ \\
\hline 26 años $(n=40)$ & $5.1 \%$ & $10 \%$ & $2.5 \%$ \\
\hline 27 años $(n=27)$ & $7.4 \%$ & $3.7 \%$ & $7.4 \%$ \\
\hline Chi Cuadrado & 6.79 & 8.49 & 6.99 \\
\hline$V$ de Cramer & 0.06 & 0.07 & 0.06 \\
\hline
\end{tabular}

Nota. $\mathrm{SCS}^{1}=$ Puntuación $\geq 24$ en la escala SCS

$\mathrm{IH}^{3}=$ Puntuación $\geq 53$ en el inventario $\mathrm{IH}$

$\mathrm{SAST}^{4}=$ Puntuación $>13$ en el cuestionario SAST

$\mathrm{NA}=$ No aplicable

${ }^{*} \mathrm{p}<0.05 ;{ }^{* *} \mathrm{p}<0.01 ;{ }^{* * *} \mathrm{p}<0.001$

En resumen, la mayoría de participantes obtienen puntuaciones que les sitúan en la parte baja del rango en las tres escalas de screening de la CS y en sus subescalas. Esto se traduce en índices de asimetría y curtosis de una magnitud considerable, especialmente en las escalas con un carácter más clínico (como las de control de impulsos sexuales del SCS y del IH). Las variables demográficas que muestran influencia significativa sobre estas puntuaciones son el sexo y la orientación sexual, no sucediendo así con la edad. Concretamente, los chicos y las personas homosexuales y sobre todo bisexuales puntuarían significativamente más alto en las escalas de screening de CS analizadas. Respecto a la estimación de la prevalencia de casos clínicos, ésta oscilaría entre 3.1\%-6.3\% para el conjunto de la muestra y se situaría en rangos significativamente más altos en chicos (4.6\%-9.9\%) y en personas con una orientación sexual alternativa a la mayoritaria (8.5\%-10\% en homosexuales y $21.2 \%-24 \%$ en bisexuales). Cuando se emplea un punto de corte ajustado a la distribución, las diferencias en función del sexo o la orientación en la estimación de la prevalencia de casos clínicos desaparecen por completo. 


\section{Comorbilidad psicopatológica}

La prevalencia de patologías del Eje I y II en participantes control y subclínicos se comparó a través de los resultados de la entrevista clínica SCID I y II (tabla 18). Esta entrevista permite distinguir entre diagnósticos actuales y a lo largo de la vida: la diferencia entre ellos es que los primeros sólo se codifican positivamente cuando los síntomas están presentes en la actualidad mientras que los segundos se codifican positivamente tanto si están presentes en la actualidad como si lo han estado alguna vez a lo largo de la vida. Estos últimos son por tanto los más inclusivos y los que aportan mayor información durante su análisis, de modo que han sido los empleados para estimar la comorbilidad entre CS y trastornos del Eje I y II. Para simplificar el análisis y la presentación de resultados, alguno de los trastornos que en la versión original se codificaban como categorías independientes se han agrupado: así, el diagnóstico de trastorno bipolar I incluiría 7 trastornos que en la entrevista SCID se codificaban independientemente (trastorno bipolar I episodio más reciente hipomaníaco, episodio más reciente maníaco, etc.).

Como se aprecia en la tabla 18, la prevalencia de algunos trastornos del estado de ánimo en chicos (trastorno bipolar I, II y trastorno ciclotímico) es nula, independientemente del grupo clínico. Más frecuente sería el diagnóstico de otras patologías como el trastorno depresivo mayor (episodio único o recidivante) o el trastorno distímico. Éste último sería o habría sido padecido por un $3 \%$ y un $4.6 \%$ de los chicos control y subclínicos respectivamente. $\mathrm{Si}$ comparamos la prevalencia en función de la condición clínica, ésta tiende a ser superior en los chicos del grupo subclínico, si bien las diferencias alcanzan la significación estadística únicamente para el trastorno depresivo mayor episodio único $\left(X^{2}=5.66 ; p=.017\right)$. Más concretamente, el $24.1 \%$ de los chicos subclínicos habría padecido o padecería este trastorno frente al $11 \%$ de los control. En este caso, las diferencias en la prevalencia en función del grupo clínico se considerarían entre pequeñas y moderadas ( $V$ de 0.17 ). También se aprecia una prevalencia ligeramente superior de chicos subclínicos que recibieron un diagnóstico de trastorno depresivo mayor recidivante (9.2\% frente al 3\%), diferencia que se aproximaría mucho a la significación estadística ( $p$ de 0.07 ). Sería por tanto presumible que idénticos resultados en una muestra de mayor tamaño alcanzarían la significación estadística. Para someter a prueba esta hipótesis, se calculó a través de metodología bootstrap el intervalo de confianza para la $V$ de Cramer correspondiente al contraste entre la prevalencia de chicos control y subclínicos con un trastorno depresivo mayor recividante. A través de remuestreo bootstrap con 1000 muestras, se obtuvo un intervalo de confianza de 0.11-0.24, intervalo que incluiría valores para el tamaño del efecto entre pequeños-medios y que confirma la hipótesis de que las mismas diferencias con una muestra mayor pueden ser significativas. 


\begin{tabular}{|c|c|c|c|c|c|c|c|c|c|}
\hline & & \multicolumn{4}{|c|}{ Chicos $(N=187)$} & \multicolumn{4}{|c|}{ Chicas $(N=197)$} \\
\hline & & Control $(n=100)$ & Subclínicos $(n=87)$ & Chi Cuadrado & $V$ de Cramer & Control $(n=99)$ & Subclínicas ( $n=98)$ & Chi Cuadrado & $V$ de Cramer \\
\hline \multirow{9}{*}{$\begin{array}{l}\text { Trtnos. del estado de } \\
\text { ánimo }\end{array}$} & Trastorno bipolar I & $0 \%$ & $0 \%$ & NA & NA & $1 \%$ & $0 \%$ & 0.99 & 0.07 \\
\hline & Trastorno bipolar II & $0 \%$ & $0 \%$ & NA & NA & $0 \%$ & $0 \%$ & NA & NA \\
\hline & Trastorno ciclotímico & $0 \%$ & $0 \%$ & NA & NA & $0 \%$ & $0 \%$ & NA & NA \\
\hline & Trastorno depresivo mayor, episodio único & $11 \%$ & $24.1 \%$ & $5.66 * *$ & 0.17 & $14.1 \%$ & $28.6 \%$ & $6.11 * *$ & 0.17 \\
\hline & Trastorno depresivo mayor, recidivante & $3 \%$ & $9.2 \%$ & 3.22 & 0.13 & $5.1 \%$ & $9.2 \%$ & 1.27 & 0.08 \\
\hline & Trastorno distímico & $3 \%$ & $4.6 \%$ & 0.33 & 0.04 & $0 \%$ & $1 \%$ & 1.01 & 0.07 \\
\hline & Trastorno depresivo no especificado & $2 \%$ & $0 \%$ & 1.75 & 0.09 & $1 \%$ & $0 \%$ & 0.99 & 0.07 \\
\hline & Debido a enfermedad médica & $0 \%$ & $0 \%$ & NA & NA & $0 \%$ & $0 \%$ & NA & NA \\
\hline & Inducido por alcohol u otras sustancias & $0 \%$ & $1.1 \%$ & 1.15 & 0.07 & $1 \%$ & $0 \%$ & 0.99 & 0.07 \\
\hline \multirow{9}{*}{$\begin{array}{l}\text { Trtnos. relacionados } \\
\text { con sustancias }\end{array}$} & Abuso del alcohol & $24 \%$ & $49.4 \%$ & $13.08 * * *$ & 0.26 & $6.1 \%$ & $37.8 \%$ & $28.99 * * *$ & 0.38 \\
\hline & Dependencia del alcohol & $2 \%$ & $11.5 \%$ & $6.98 * *$ & 0.19 & $1 \%$ & $2 \%$ & 0.34 & 0.04 \\
\hline & Abuso o dependencia de alucinógenos & $1 \%$ & $0 \%$ & 0.87 & 0.06 & $0 \%$ & $0 \%$ & NA & NA \\
\hline & Abuso o dependencia de anfetaminas & $0 \%$ & $0 \%$ & NA & NA & $0 \%$ & $0 \%$ & NA & NA \\
\hline & Abuso o dependencia de cannabis & $15 \%$ & $19.5 \%$ & 0.67 & 0.06 & $2 \%$ & $16.5 \%$ & $12.30 * * *$ & 0.25 \\
\hline & Abuso o dependencia de cocaína & $0 \%$ & $3.4 \%$ & 3.50 & 0.13 & $1 \%$ & $0 \%$ & 0.99 & 0.07 \\
\hline & Abuso o dependencia de opiáceos & $0 \%$ & $0 \%$ & NA & NA & $0 \%$ & $0 \%$ & NA & NA \\
\hline & Abuso o dependencia de sedantes o hipnóticos & $0 \%$ & $0 \%$ & NA & NA & $0 \%$ & $0 \%$ & NA & NA \\
\hline & Abuso o dependencia de otras sustancias & $0 \%$ & $0 \%$ & NA & NA & $0 \%$ & $0 \%$ & NA & NA \\
\hline \multirow{10}{*}{ Trtnos. de ansiedad } & Trastorno de angustia (con y sin agorafobia) & $0 \%$ & $2.3 \%$ & 2.32 & 0.11 & $11.1 \%$ & $4.1 \%$ & 3.45 & 0.13 \\
\hline & Agorafobia sin historia de trastorno de angustia & $0 \%$ & $0 \%$ & NA & NA & $0 \%$ & $4.1 \%$ & $4.12 *$ & 0.14 \\
\hline & Fobia específica & $6 \%$ & $10.3 \%$ & 1.19 & 0.08 & $24.2 \%$ & $26.5 \%$ & 0.13 & 0.02 \\
\hline & Fobia social & $9 \%$ & $13.8 \%$ & 1.07 & 0.07 & $1 \%$ & $5.1 \%$ & 2.79 & 0.11 \\
\hline & Trastorno obsesivo-compulsivo & $3 \%$ & $5.7 \%$ & 0.85 & 0.06 & $1 \%$ & $3.1 \%$ & 1.04 & 0.07 \\
\hline & Trastorno por estrés postraumático & $3 \%$ & $1.1 \%$ & 0.76 & 0.06 & $2 \%$ & $7.1 \%$ & 2.96 & 0.12 \\
\hline & Trastorno de ansiedad generalizado & $0 \%$ & $0 \%$ & NA & NA & $1 \%$ & $0 \%$ & 0.99 & 0.07 \\
\hline & Trastorno de ansiedad no especificado & $0 \%$ & $0 \%$ & NA & NA & $0 \%$ & $0 \%$ & NA & NA \\
\hline & Debido a enfermedad médica & $0 \%$ & $0 \%$ & NA & NA & $0 \%$ & $0 \%$ & NA & NA \\
\hline & Inducido por alcohol u otras sustancias & $0 \%$ & $0 \%$ & NA & NA & $0 \%$ & $0 \%$ & NA & NA \\
\hline
\end{tabular}




\begin{tabular}{|c|c|c|c|c|c|c|c|c|c|}
\hline & & \multicolumn{4}{|c|}{ Chicos $(N=187)$} & \multicolumn{4}{|c|}{ Chicas $(N=197)$} \\
\hline & & Control $(n=100)$ & Subclínicos ( $n=87)$ & Chi Cuadrado & $V$ de Cramer & Control $(n=99)$ & Subclínicas $(n=98)$ & Chi Cuadrado & $V$ de Cramer \\
\hline \multirow{4}{*}{ Trtnos. Somatomorfos } & Trastorno de somatización & $0 \%$ & $0 \%$ & NA & NA & $0 \%$ & $1 \%$ & 1.01 & 0.07 \\
\hline & Trastorno somatomorfo indiferenciado & $0 \%$ & $0 \%$ & NA & NA & $0 \%$ & $0 \%$ & NA & NA \\
\hline & Hipocondría & $0 \%$ & $3.4 \%$ & 3.50 & 0.13 & $0 \%$ & $2 \%$ & 2.04 & 0.10 \\
\hline & Trastorno dismórfico corporal & $1 \%$ & $1.1 \%$ & 0.01 & 0.007 & $1 \%$ & $7.1 \%$ & $4.74 *$ & 0.15 \\
\hline \multirow{2}{*}{ Trtnos. alimentarios } & Anorexia nerviosa & $1 \%$ & $0 \%$ & 0.87 & 0.06 & $1 \%$ & $2 \%$ & 0.349 & 0.04 \\
\hline & Bulimia nerviosa & $0 \%$ & $1.1 \%$ & 1.15 & 0.07 & $3 \%$ & $3.1 \%$ & 0.001 & 0.001 \\
\hline \multirow{2}{*}{ Trtnos. adaptativos } & Trastorno adaptativo (todos los subtipos) & $6 \%$ & $11.5 \%$ & 1.79 & 0.09 & $7.1 \%$ & $14.3 \%$ & 2.69 & 0.11 \\
\hline & Trastorno adaptativo no especificado & $0 \%$ & $0 \%$ & NA & NA & $0 \%$ & $0 \%$ & NA & NA \\
\hline \multirow{8}{*}{ Trtnos. parafílicos } & Exhibicionismo & $0 \%$ & $1.1 \%$ & 1.15 & 0.07 & $0 \%$ & $0 \%$ & NA & NA \\
\hline & Fetichismo & $0 \%$ & $0 \%$ & NA & NA & $0 \%$ & $0 \%$ & NA & NA \\
\hline & Froteurismo & $0 \%$ & $0 \%$ & NA & NA & $0 \%$ & $0 \%$ & NA & NA \\
\hline & Pedofilia & $0 \%$ & $0 \%$ & NA & NA & $0 \%$ & $0 \%$ & NA & NA \\
\hline & Masoquismo sexual & $0 \%$ & $2.3 \%$ & 2.32 & 0.11 & $0 \%$ & $1 \%$ & 1.05 & 0.07 \\
\hline & Sadismo sexual & $0 \%$ & $0 \%$ & NA & NA & $0 \%$ & $0 \%$ & NA & NA \\
\hline & Fetichismo transvestista & $0 \%$ & $0 \%$ & NA & NA & $0 \%$ & $0 \%$ & NA & NA \\
\hline & Voyeurismo & $0 \%$ & $0 \%$ & NA & NA & $0 \%$ & $0 \%$ & NA & NA \\
\hline \multirow{2}{*}{ Trtnos. de personalidad } & Trtno obsesivo-compulsivo de la personalidad & $1 \%$ & $4.6 \%$ & 2.31 & 0.11 & $8.1 \%$ & $8.2 \%$ & 0.001 & 0.001 \\
\hline & Trastorno límite de la personalidad & $0 \%$ & $2.3 \%$ & 2.32 & 0.11 & $0 \%$ & $2 \%$ & 2.04 & 0.10 \\
\hline
\end{tabular}

Nota. NA=No aplicable

Trastorno límite de la personalidad

$1 \%$
$0 \%$

${ }^{*} p<0.05 ;{ }^{* *} p<0.01 ; * * * p<0.001$ 
El trastorno del estado de ánimo más prevalente en mujeres sería nuevamente el depresivo mayor episodio único, seguido del depresivo mayor recidivante. La prevalencia del primero en chicas subclínicas sería del 28.6\%, porcentaje que quedaría 14.5 puntos porcentuales por encima del observado en participantes control (14.1\%). La diferencia entre ambos porcentajes alcanzaría la significación estadística $\left(X^{2}=6.11 ; p=.013\right)$, con un tamaño del efecto atribuible a la condición clínica entre pequeño y moderado ( $V$ de 0.17 ). También se aprecia cierta diferencia entre participantes control y subclínicas en la incidencia del trastorno depresivo mayor recidivante: concretamente, la incidencia de esta patología en chicas subclínicas fue del 9.2\%, mientras que en chicas control apenas alcanzó el 5.1\%. En este caso las diferencias en función de la condición clínica tampoco alcanzan la magnitud suficiente como para que resulten significativas a nivel estadístico, de modo que nuevamente se calculó el intervalo de confianza para la $V$ de Cramer a través de remuestreo bootstrap con 1000 muestras. Los márgenes superior e inferior del intervalo de confianza para el tamaño del efecto en este contraste incluyeron nuevamente valores entre pequeños y moderados (0.06-0.21), de modo que no se puede descartar que las diferencias que a nivel muestral no resultan significativas, lo sean a nivel poblacional.

Con respecto a los trastornos relacionados con sustancias, en chicos los problemas más frecuentes tendrían que ver principalmente con el abuso o la dependencia del alcohol, cannabis y en menor frecuencia la cocaína. Más concretamente, el porcentaje de chicos subclínicos que abusaban o habían abusado del alcohol fue el doble del porcentaje de chicos control (49.4\% frente al $24 \%)$, diferencia que alcanzaba la máxima significación estadística $\left(X^{2}=13.08 ; p<.001\right)$. De los 46 cuadros clínicos explorados, en este sería donde las diferencias en función de la condición clínica fueron más abultadas, con un tamaño del efecto medio $(V=0.26)$. Aunque con menor intensidad $\left(X^{2}=6.98 ; p=.008 ; V=0.19\right)$, el porcentaje de chicos control y subclínicos dependientes del alcohol también difirió significativamente ( $2 \%$ y $11.5 \%$ respectivamente). Después del abuso y la dependencia del alcohol, el diagnóstico más frecuente en participantes control y subclínicos fue el de abuso o dependencia a cannabis (15\% y 19.5\%). Finalmente, ninguno de los chicos control recibió un diagnóstico de abuso o dependencia de cocaína pero sí lo recibieron el 3.4\% de los subclínicos.

En chicas, el trastorno relacionado con sustancias más frecuente fue nuevamente el abuso del alcohol, seguido en este caso del abuso o dependencia de cannabis. A diferencia de lo hallado en chicos, la prevalencia de dependencia del alcohol y sobre todo del abuso o la dependencia de cocaína fue prácticamente inexistente. En función de la condición clínica, el porcentaje de chicas subclínicas con un diagnóstico de abuso del alcohol a lo largo de la vida fue 6 veces 
superior al de las chicas control (37.8\% frente al 6.1\%), alcanzando la máxima significación estadística $\left(X^{2}=28.99 ; p<.001\right)$ y un tamaño del efecto grande $(V$ de 0.38$)$. También difería significativamente aunque con menor intensidad $\left(X^{2}=12.30 ; p<.001 ; V=0.25\right)$ el porcentaje de chicas control y subclínicas con un cuadro de abuso o dependencia de cannabis ( $2 \%$ frente al $16.5 \%)$.

En chicos, no se encuentran diferencias significativas en la prevalencia de trastornos de ansiedad en función de la condición clínica pero sí se aprecia que los del grupo subclínico mostrarían una incidencia ligeramente superior de estas patologías. Así, mientras el $13.8 \%$ de los chicos del grupo subclínico padecerían o habrían padecido una fobia social, la prevalencia en participantes control sería del 9\%. Algo similar sucede con la fobia específica y el trastorno obsesivo compulsivo: la prevalencia de estas patologías entre los integrantes del grupo subclínico $(10.3 \%$ y $5.7 \%)$ sería superior a la observada en participantes control pero no lo suficiente como para alcanzar la significación estadística. Una excepción sería el trastorno por estrés postraumático: al contrario que en el resto de cuadros clínicos, en este la incidencia sería ligeramente superior en chicos control (1.1\% frente al 3\%).

Con respecto a los chicos, las chicas mostrarían una prevalencia mayor de trastornos de ansiedad como por ejemplo el trastorno de angustia con o sin agorafobia, la agorafobia sin historia de trastorno de angustia y la fobia específica y menor de otros como la fobia social o el trastorno obsesivo-compulsivo. El único trastorno en el que la prevalencia en chicas control (11.1\%) supera la de chicas subclínicas (4.1\%) sería el de trastorno de angustia con o sin agorafobia, con una diferencia que quedaría cercana a la significación estadística $\left(X^{2}=3.45\right.$; $p=0.063 ; V=0.13)$. La incidencia del resto de trastornos de ansiedad sería superior en participantes subclínicas, sobre todo en la agorafobia sin historia de trastorno de angustia $\left(X^{2}=4.12 ; p=0.042 ; V=0.14\right)$ : concretamente, la prevalencia de esta patología sería del $4.1 \%$ en chicas subclínicas frente al $0 \%$ en control. La incidencia del trastorno por estrés postraumático sería 5.1 puntos porcentuales superior en chicas subclínicas, diferencias nuevamente cercanas a la significación estadística $(p=0.085)$. El intervalo de confianza para el tamaño del efecto en este contraste fue de entre 0.08 y 0.22 , intervalo que atribuiría valores de influencia entre baja y media para la condición clínica.

De los trastornos somatomorfos contemplados, dos de ellos -el de somatización y el somatomorfo indiferenciado- muestran una incidencia nula en chicos. De los dos restantes, el más frecuente sería la hipocondría (3.4\% en chicos subclínicos y $0 \%$ en control) seguido del trastorno dismórfico corporal (1.1\% frente al 1\%). En ninguno de los dos casos se aprecia una incidencia diferencial en función de la condición clínica. En chicas sería especialmente 
frecuente el trastorno dismórfico corporal, patología padecida por el 7.1\% de las participantes subclínicas y tan sólo por el 1\% de las control. Este sería el único trastorno de somatización en el que las diferencias en función de la condición clínica alcanzan la significación estadística $\left(X^{2}=4.74 ; p=.02\right)$, con un tamaño del efecto entre pequeño y moderado $(V=0.15)$

En lugar de la condición clínica, el factor que parece condicionar verdaderamente la prevalencia de trastornos alimentarios sería el sexo. Así, la incidencia de anorexia y bulimia nerviosa sería prácticamente nula en chicos, encontrándose tan solo uno afecto por cada una de estas patologías. El número de chicas con estas problemáticas sería ligeramente mayor, encontrándose una prevalencia prácticamente idéntica en participantes control y subclínicas: concretamente, un $1 \%$ y un $2 \%$ de las chicas control y subclínicas habría sido diagnosticada con una anorexia nerviosa y un 3\% y un 3.1\% respectivamente con bulimia nerviosa.

La pertenencia a una u otra condición clínica tampoco afectó de forma significativa sobre la prevalencia del resto de trastornos explorados, si bien se apreciaría una incidencia mayor de estos cuadros clínicos entre los y las participantes del grupo subclínico. Nuevamente el discreto tamaño muestral sumado a la baja prevalencia de estos diagnósticos en población general explicaría esta escasa significación, lo que por otro lado no significa que los hallazgos carezcan de repercusión a nivel clínico. Un ejemplo sería el diagnóstico de trastorno adaptativo: la prevalencia de este cuadro en chicos subclínicos sería del $11.5 \%$ y del $14.3 \%$ en chicas subclínicas ( $5.5 \%$ y $7.2 \%$ superior a la de chicos y chicas control). En ninguno de los dos casos se alcanzaría la significación estadística $\left(X^{2}\right.$ de 1.79 y $p=.18$ en chicos y $X^{2}$ de 2.69 y $p=.10$ en chicas); sin embargo, una diferencia de hasta 7 puntos porcentuales en función del grupo clínico en una patología cuya prevalencia en población general no supera el 3\% resulta más que significativo a nivel clínico. De manera similar, ninguno de los participantes control recibió un diagnóstico de trastorno parafílico pero sí lo recibieron algunos participantes subclínicos: más concretamente, un $1.1 \%$ de los chicos de este grupo fue diagnosticado de exhibicionismo y un $2.3 \%$ de los chicos y un $1 \%$ de las chicas recibieron el diagnóstico de masoquismo sexual. Si bien nuevamente a efectos estadísticos las diferencias en función de la condición clínica ni tan siquiera se aproximaban a la significación ( $p$ entre .12 y .25), a efectos clínicos estos resultados revelarían una tendencia con importantes implicaciones. Finalmente, la prevalencia de trastornos de la personalidad entre los chicos y chicas subclínicos fue del $4.6 \%$ y $8.2 \%$ respectivamente para el trastorno obsesivo compulsivo de la personalidad y del $2.3 \%$ y $2 \%$ para el trastorno límite, si bien en ningún caso la diferencia respecto a los participantes control alcanzó la significación estadística. 
En resumen, los principales trastornos comórbidos en participantes subclínicos serían los de la categoría de trastornos relacionados con sustancias: concretamente, el abuso/dependencia de marihuana (sólo en el caso de las chicas), la dependencia del alcohol (sólo en chicos) y sobre todo el abuso del alcohol (tanto en chicos como en chicas). También fue mayor el porcentaje de participantes subclínicos diagnosticados de un trastorno depresivo mayor. Respecto al resto de trastornos, tan sólo uno de la categoría de trastornos de ansiedad (la agorafobia sin historia de trastorno de angustia) y otro de la de trastornos somatomorfos (el trastorno dismórfico corporal) fueron más frecuentes en participantes subclínicos, concretamente en las chicas. Si bien en pocos casos las diferencias en función de la condición clínica alcanzan la significación, en casi todos los trastornos los participantes subclínicos muestran una prevalencia mayor.

\section{Correlatos clínicos}

La expresión diferencial de ciertas variables clínicas en participantes control y subclínicos se comparó a través de las puntuaciones medias en el Cuestionario de Ansiedad Estado-Rasgo (STAI), el Inventario de Depresión (BDI) y el Cuestionario de Autoestima de Rosenberg (RSEI) (tabla 19). Estas mismas puntuaciones se emplearon posteriormente para clasificar a los participantes en distintas categorías clínicas (tabla 20).

Si analizamos la puntuación media en el cuestionario STAI en función de la condición clínica (tabla 19), se aprecia que los participantes control tienden a experimentar un menor grado de ansiedad en sus diversas manifestaciones que los del grupo subclínico. Concretamente, los chicos de esta última condición puntúan significativamente por encima de los control en las escalas de ansiedad-estado ( $t=3.48 ; p=.001)$ y sobre todo de ansiedad-rasgo $(t=-3.70 ; p<.001)$, mientras que en las chicas únicamente se encuentran diferencias en la dimensión de ansiedadrasgo $(t=2.37 ; p=.01)$. El tamaño del efecto para los dos primeros contrastes se consideraría moderado $(d>0.50)$ y entre pequeño y moderado $(d=0.34)$ este último. Una tendencia similar se aprecia al analizar el porcentaje de participantes con niveles clínicos de ansiedad (tabla 20). En chicos, la diferencia entre el porcentaje de participantes control y subclínicos con puntuaciones por encima del percentil 85 es de 4.9 puntos porcentuales en la escala de ansiedad-estado (0\% frente al $4.9 \%$ ) y de 6.8 en la de ansiedad rasgo (6.1\% y $12.9 \%$ ). De estos dos contrastes, únicamente el primero alcanzaría la significación estadística $\left(x^{2}=4.93 ; p=.02\right)$, siendo el tamaño del efecto atribuible a la condición clínica pequeño $(V=16)$. Por su parte, la diferencia entre el porcentaje de chicas control y subclínicas con puntuaciones percentiles $\geq 85$ en la escala de ansiedad-estado y de ansiedad rasgo sería de 1.1 y de 3 puntos porcentuales, sin alcanzar en ningún caso la significación estadística. 
Algo similar sucede al explorar la puntuación media en el cuestionario BDI (tabla 19). En una escala con un rango de valores entre 0 y 60, los chicos subclínicos obtienen una puntuación media en depresión 2.01 puntos superior a la de los control ( $M$ de 6.66 y 8.67 respectivamente) mientras que en el caso de las chicas, la diferencia es de 4.94 puntos (6.03 frente a 10.97). En ambos casos la diferencia en la puntuación media resulta significativa ( $p$ de .03 y <.001) pero mientras el tamaño del efecto para el contraste en chicos es pequeño $(d=.31)$, en las chicas se consideraría entre moderado y grande $(d=.70)$. Cuando exploramos la distribución en función del nivel clínico de depresión (tabla 20), la mayoría de participantes (entre el $67.4 \%$ y el $88 \%$ ) son clasificados en la categoría de mínimamente deprimidos, decayendo el porcentaje a medida que aumenta la gravedad del cuadro clínico. En chicos, la condición clínica no influye sobre la distribución en las categorías de depresión $\left(x^{2}=4.45 ; p=.21\right.$ ) pero sí lo haría en las chicas ( $\left.x^{2}=10.39 ; p=.009\right)$. En este último caso, la mayoría de las control (el $84.5 \%$ ) se clasifican como mínimamente deprimidas y el $15.5 \%$ restante se reparte entre las categorías de ligera (12.4\%) y moderadamente deprimidas (3.1\%); por su parte, el porcentaje de chicas subclínicas en la categoría de mínimamente deprimidas es sensiblemente inferior (67.4\%) y aumenta el de las ligera (18.9\%), moderada (9.5\%) y severamente deprimidas (4.2\%).

El análisis de la puntuación media en el cuestionario RSEI (tabla 19) no revela diferencias en el nivel de autoestima en función de la condición clínica ( $p>05$ en ambos casos), si bien parece que ésta tiende a ser un tanto menor entre los chicos y chicas del grupo subclínico. En todo caso, el nivel general de autoestima -independientemente de la condición clínica- se sitúa en el extremo superior de la escala (puntuación por encima de los 30 puntos en una escala con un rango de valores entre 10 y 40). Cuando analizamos la distribución entre las tres categorías de autoestima en función de la condición clínica (tabla 20), ésta influye entre pequeña y moderadamente $(V=0.19)$ en chicos $\left(x^{2}=7.005 ; p=.03\right)$ pero no muestra significación alguna en la distribución de las chicas $\left(x^{2}=4.86 ; p=.08 ; V=0.15\right)$. La principal diferencia entre chicos control y subclínicos se da en la distribución de los participantes que quedan fuera de la categoría de autoestima normal (el $43.4 \%$ de los chicos control y el $28.7 \%$ de los subclínicos): mientras que los chicos subclínicos que quedan fuera de esta categoría se distribuyen a partes casi iguales entre los grupos de baja y alta autoestima ( $16.1 \%$ y $12.6 \%$ respectivamente), los participantes control acaban mayoritariamente en el grupo de alta autoestima ( $28.3 \%$ frente al $15.2 \%$ que es clasificado en el grupo de baja autoestima).

En resumen, los participantes control y subclínicos no difieren en cuanto a nivel de autoestima pero sí lo hacen en el grado de ansiedad y depresión: concretamente, éstos últimos muestran niveles mayores de ansiedad-estado (chicos), ansiedad-rasgo y depresión (chicos y chicas). 


\begin{tabular}{|c|c|c|c|c|c|c|c|c|c|}
\hline & \multirow[b]{2}{*}{ Rango } & \multicolumn{4}{|c|}{ Chicos $(N=187)$} & \multicolumn{4}{|c|}{ Chicas $(N=197)$} \\
\hline & & $\begin{array}{c}\text { Control }(n=100) \\
M(D T)\end{array}$ & $\begin{array}{c}\text { Subclínicos }(n=87) \\
M(D T)\end{array}$ & $t$ de Student & $d$ de Cohen & $\begin{array}{c}\text { Control }(n=99) \\
M(D T) \\
\end{array}$ & $\begin{array}{c}\text { Subclínicas }(n=98) \\
M(D T)\end{array}$ & $t$ de Student & $d$ de Cohen \\
\hline \multicolumn{10}{|l|}{ Cuestionario de Ansiedad Estado-Rasgo (STAI) } \\
\hline STAI-Estado & $0-60$ & $11.25(6.34)$ & $15.14(8.66)$ & $-3.48 * *$ & 0.53 & $10.94(7.65)$ & $12.67(8.26)$ & -1.49 & 0.21 \\
\hline STAI-Rasgo & $0-60$ & $16.23(8.07)$ & $20.95(9.19)$ & $-3.70 * * *$ & 0.55 & $17.53(8.67)$ & $20.63(9.48)$ & $-2.37^{*}$ & 0.34 \\
\hline Inventario de Depresión (BDI) & $0-63$ & $6.66(5.65)$ & $8.67(7.00)$ & $-2.15^{*}$ & 0.31 & $6.03(6.14)$ & $10.97(8.61)$ & $-4.58 * * *$ & 0.70 \\
\hline Cuestionario de Autoestima de Rosenberg (RSEI) & $10-40$ & $32.28(5.13)$ & $30.87(4.98)$ & 1.89 & 0.28 & $31.51(6.16)$ & $30.04(5.75)$ & 1.72 & 0.24 \\
\hline
\end{tabular}

Nota. ${ }^{*} p<0.05 ;{ }^{* *} p<0.01 ; * * * p<0.001$

Tabla 20. Distribución de chicos y chicas control y subclínicos en categorías clínicas según el nivel de ansiedad (STAI), depresión (BDI) y autoestima (RSEI).

\begin{tabular}{|c|c|c|c|c|c|c|c|c|}
\hline & \multicolumn{4}{|c|}{ Chicos $(N=187)$} & \multicolumn{4}{|c|}{ Chicas $(N=197)$} \\
\hline & Control $(n=100)$ & Subclínicos ( $n=87)$ & Chi Cuadrado & $V$ de Cramer & Control $(n=99)$ & Subclínicas $(n=98)$ & Chi Cuadrado & $V$ de Cramer \\
\hline \multicolumn{9}{|l|}{ Cuestionario de Ansiedad Estado-Rasgo (STAI) ${ }^{\text {a }}$} \\
\hline Ansiedad-estado clínicamente significativa (percentil $\geq 85$ ) & $0 \%$ & $4.9 \%$ & $4.93^{*}$ & 0.16 & $1 \%$ & $2.1 \%$ & 0.38 & 0.04 \\
\hline Ansiedad-rasgo clínicamente significativa (percentil $\geq 85$ ) & $6.1 \%$ & $12.9 \%$ & 2.58 & 0.11 & $4.2 \%$ & $7.2 \%$ & 0.83 & 0.06 \\
\hline \multicolumn{9}{|l|}{ Inventario de Depresión (BDI) ${ }^{\mathrm{b}}$} \\
\hline Mínimamente deprimido (puntuaciones $\leq 13$ ) & $88 \%$ & $78.8 \%$ & \multirow{4}{*}{4.45} & \multirow{4}{*}{0.15} & $84.5 \%$ & $67.4 \%$ & \multirow{4}{*}{$10.39 * *$} & \multirow{4}{*}{0.23} \\
\hline Ligeramente deprimido (puntuaciones entre 14 y 19) & $8 \%$ & $14.1 \%$ & & & $12.4 \%$ & $18.9 \%$ & & \\
\hline Moderadamente deprimido (puntuaciones entre 20 y 28) & $4 \%$ & $4.7 \%$ & & & $3.1 \%$ & $9.5 \%$ & & \\
\hline Severamente deprimido (puntuaciones $\geq 29$ ) & $0 \%$ & $2.4 \%$ & & & $0 \%$ & $4.2 \%$ & & \\
\hline \multicolumn{9}{|l|}{ Cuestionario de Autoestima de Rosenberg (RSEI) ${ }^{c}$} \\
\hline Baja autoestima (puntuaciones $\leq 27$ ) & $15.2 \%$ & $16.1 \%$ & \multirow{3}{*}{ 7.005* } & \multirow{3}{*}{0.19} & $22.2 \%$ & $26.5 \%$ & \multirow{3}{*}{4.86} & \multirow{3}{*}{0.15} \\
\hline Autoestima normal (puntuaciones entre 28 y 35 ) & $56.6 \%$ & $71.3 \%$ & & & $49.5 \%$ & $58.2 \%$ & & \\
\hline Alta autoestima (puntuaciones $\geq 36$ ) & $28.3 \%$ & $12.6 \%$ & & & $28.3 \%$ & $15.3 \%$ & & \\
\hline
\end{tabular}

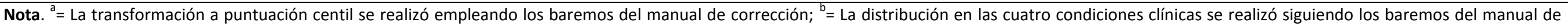

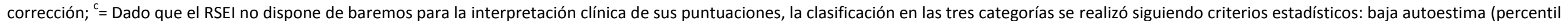
$\leq 15$ ), autoestima normal (percentil entre 26 y 84 ) y alta autoestima (percentil $\geq 85$ ).

${ }^{*} p<0.05 ; * * p<0.01 ;{ }^{* * *} p<0.001$ 


\section{Perfil de personalidad}

El perfil de personalidad de chicos y chicas control y subclínicos se comparó a través de las puntuaciones T en las 5 dimensiones y 30 facetas del cuestionario de personalidad NEO PI-R (tabla 21). Estas puntuaciones oscilan en un rango de entre 25 y 75 , con una media de 50 y una $D T$ de 10 . Se considera que los rasgos de personalidad se expresan de forma normativa cuando sus puntuaciones se sitúan entre 35 y 65, mientras que valores por encima o por debajo de este rango indicarían que el rasgo se manifiesta en uno de sus extremos. Para facilitar la interpretación de los hallazgos, en la figura 10 se representan las puntuaciones medias en las dimensiones y facetas de personalidad contempladas en función del grupo clínico.

Como se aprecia en la tabla 21 , el perfil general de personalidad de los chicos subclínicos se caracteriza por una mayor tendencia al neuroticismo $(t=-2.55 ; p=.01)$ y una menor amabilidad ( $t=3.07 ; p=.002)$ y responsabilidad $(t=3.57 ; p<.001)$. En los tres casos, las diferencias atribuibles a la condición clínica alcanzarían un tamaño del efecto entre pequeño y moderado. Explorando su perfil por facetas, los chicos subclínicos obtendrían puntuaciones mayores en tres de las seis facetas de la dimensión de neuroticismo: concretamente, en las facetas de hostilidad ( $t=-2.30$; $p=.02$ ), depresión ( $t=-2.23 ; p=.02$ ) e impulsividad ( $t=-2.43 ; p=.016)$. El tamaño del efecto para estas diferencias osciló entre .32 y .35 . No se encuentran diferencias significativas entre chicos control y subclínicos en ninguna de las facetas de la dimensión de extraversión pero sí en una de la de apertura: la faceta de estética $(t=-2.55 ; p=0.011)$. Concretamente, encontramos que el sentido estético sería un rasgo ligeramente más marcado en chicos subclínicos ( $d$ de 0.37 ). Las diferencias más importantes las encontramos en las facetas de las dimensiones de amabilidad y responsabilidad. Ordenando las diferencias en esta primera faceta de menor a mayor en función de su efecto, los chicos subclínicos serían menos conciliadores $(d=0.31)$, menos modestos $(d=0.35)$, menos altruistas $(d=0.44)$ y sobre todo menos francos $(d=0.52)$. Haciendo lo mismo con las de responsabilidad, los chicos subclínicos serían menos competentes $(d=0.40)$, tendrían menos sentido del deber y la responsabilidad $(d=0.41)$, serían menos autodisciplinados $(d=0.44)$ y deliberarían menos antes de tomar decisiones $(d=0.51)$.

Además de un mayor neuroticismo ( $t=-3.03 ; p=.003)$ y una menor amabilidad $(t=3.56 ; p<.001)$ y responsabilidad ( $t=3.88 ; p<.001$ ), el perfil general de personalidad de las chicas subclínicas se caracteriza por una mayor apertura a la experiencia $(t=-3.17 ; p=.002)$. En los 4 casos, las diferencias atribuibles a la condición clínica alcanzan tamaños del efecto moderados ( $d$ entre 0.43 y 0.55). Las diferencias entre participantes control y subclínicas en la dimensión de neuroticismo se agrupan principalmente en torno a la faceta de impulsividad, donde la puntuación media de chicas subclínicas $(M=61.87 ; D T=8.24)$ es significativamente superior a la 
de las chicas control ( $M=55.61 ; D T=9.61)$, con diferencias que en este caso alcanzan un tamaño del efecto grande $(V=0.69)$. A pesar de que chicas control y subclínicas no difieran en cuanto a puntuación general en la dimensión de extraversión, sí encontramos diferencias significativas en dos de sus facetas: la de actividad $(t=-2.42 ; p=.016)$ y la de búsqueda de emociones ( $t=-$ $3.95 ; p<.001)$. En ambos casos, las participantes subclínicas obtendrían puntuaciones mayores a las control, con diferencias entre pequeñas y moderadas ( $d$ de 0.34 para a faceta de actividad y de 0.57 para la de búsqueda de emociones). En cuanto a la dimensión de apertura a la experiencia, las chicas subclínicas obtuvieron puntuaciones significativamente superiores en 5 de las 6 facetas que la integran: más concretamente, en las facetas de fantasía ( $t=-2.71$; $p=.007)$, estética $(t=-2.53 ; p=.012)$, sentimientos $(t=-2.64 ; p=.009)$, acciones $(t=-2.15 ; p=.03) \mathrm{e}$ ideas $(t=-2.25 ; p=.02)$. Al contrario, las puntuaciones de las chicas subclínicas serían inferiores en 5 de las 6 facetas de amabilidad y en 4 de responsabilidad. Con tamaños del efecto entre pequeños y moderados ( $d$ entre 0.30 y 0.42 ), las chicas subclínicas serían menos confiadas $(t=2.75 ; p=.006)$, francas $(t=2.96 ; p=.003)$, altruistas $(t=2.23 ; p=.02)$, conciliadoras $(t=2.58$; $p=.01)$ y modestas $(t=2.11 ; p=.03)$. Con tamaños del efecto entre moderados y grandes ( $d$ entre 0.44 y 0.63 ), las participantes del grupo subclínico serían menos competentes ( $t=3.85 ; p<.001$ ), autodisciplinadas ( $t=3.11 ; p=.002)$, tenderían a la impulsividad y a la baja deliberación a la hora de tomar decisiones $(t=3.59 ; p<.001)$ y tendrían menor sentido del deber $(t=4.38 ; p<.001)$.

Si analizamos el perfil gráfico de puntuaciones NEO PI-R en chicos y chicas subclínicos (Figura 10), se aprecia que las diferencias en función de la condición clínica son más frecuentes y también de mayor magnitud en las chicas. En este grupo, las líneas que representan las puntuaciones en chicas control y subclínicas no coinciden en prácticamente ningún momento y en las facetas de la dimensión de neuroticismo y responsabilidad ni siquiera reproducen la misma tendencia. En cambio, las líneas que representan las puntuaciones de chicos control y subclínicos son prácticamente idénticas en las facetas de la dimensión de extraversión y apertura -salvo excepciones puntuales- y si bien difieren un tanto en las facetas de la dimensión de neuroticismo, amabilidad y responsabilidad, la tendencia en los tres casos sería prácticamente idéntica.

En resumen, los chicos y chicas subclínicos obtienen puntuaciones significativamente mayores en la dimensión de neuroticismo (especialmente en la faceta de impulsividad) y menores en las de amabilidad y responsabilidad. Asimismo, las chicas subclínicas puntuaron por encima de las control en la dimensión de apertura a la experiencia (sobre todo en las facetas de fantasía, de estética y sentimientos), no sucediendo así en los chicos de este grupo clínico. 
Tabla 21. Puntuaciones en las 5 dimensiones y 36 facetas del NEO PI-R en chicos y chicas control y subclínicos

\begin{tabular}{|c|c|c|c|c|c|c|c|c|c|}
\hline & & \multicolumn{4}{|c|}{ Chicos $(N=187)$} & \multicolumn{4}{|c|}{ Chicas (N=197) } \\
\hline & & $\begin{array}{c}\text { Control }(n=100) \\
M(D T)\end{array}$ & $\begin{array}{c}\text { Subclínicos }(n=87) \\
M(D T)\end{array}$ & $t$ de Student & $d$ de Cohen & $\begin{array}{c}\text { Control }(n=99) \\
M(D T)\end{array}$ & $\begin{array}{c}\text { Subclínicas }(n=98) \\
M(D T)\end{array}$ & $t$ de Student & $d$ de Cohen \\
\hline \multirow{5}{*}{ 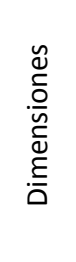 } & Neuroticismo & $56.27(8.40)$ & $59.28(7.59)$ & $-2.55^{*}$ & 0.37 & $58.09(8.84)$ & $61.72(7.93)$ & $-3.03 * *$ & 0.43 \\
\hline & Extraversión & $50.90(9.81)$ & $49.52(12.36)$ & 0.85 & 0.12 & $51.33(10.23)$ & 53.74 (11.03) & -1.59 & 0.22 \\
\hline & Apertura & $50.98(9.60)$ & 52.39 (9.87) & -0.98 & 0.16 & $52.84(9.66)$ & 57.15 (9.42) & $-3.17 * *$ & 0.45 \\
\hline & Amabilidad & $40.65(8.80)$ & $36.69(8.75)$ & $3.07^{* *}$ & 0.45 & 46.68 (9.72) & 41.49 (10.69) & $3.56^{* * *}$ & 0.45 \\
\hline & Responsabilidad & $38.77(7.06)$ & $35.11(6.85)$ & $3.57 * * *$ & 0.53 & $42.29(10.12)$ & $37.28(7.86)$ & $3.88 * * *$ & 0.55 \\
\hline \multirow{6}{*}{ 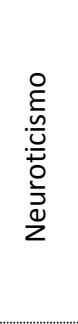 } & N1. Ansiedad & 50.55 (9.33) & $51.76(10.51)$ & -0.83 & 0.12 & $54.30(10.11)$ & $56.18(10.53)$ & -1.27 & 0.18 \\
\hline & N2. Hostilidad & $56.70(10.04)$ & $59.93(8.96)$ & $-2.30 *$ & 0.34 & 57.75 (9.59) & $64.21(33.07)$ & -1.86 & $0 . .32$ \\
\hline & N3. Depresión & $54.62(9.85)$ & $57.70(8.89)$ & $-2.23^{*}$ & 0.32 & $55.20(10.74)$ & $58.11(10.26)$ & -1.94 & 0.27 \\
\hline & N4. Ansiedad social & $56.21(9.07)$ & $57.75(9.55)$ & -1.12 & 0.16 & $57.23(9.97)$ & $58.42(9.21)$ & -0.86 & 0.12 \\
\hline & N5. Impulsividad & $56.04(7.95)$ & $59.15(9.49)$ & $-2.43^{*}$ & 0.35 & $55.61(9.61)$ & $61.87(8.24)$ & $-4.90 * * *$ & 0.69 \\
\hline & N6. Vulnerabilidad & $57.21(8.27)$ & $57.25(9.90)$ & -0.03 & 0.004 & $59.86(8.26)$ & $61.53(8.81)$ & -1.37 & 0.19 \\
\hline \multirow{6}{*}{ 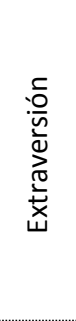 } & E1. Cordialidad & $46.62(9.23)$ & $44.32(11.63)$ & 1.50 & 0.23 & $50.77(10.07)$ & $49.16(10.88)$ & 1.07 & 0.15 \\
\hline & E2. Gregarismo & $44.75(8.63)$ & $44.86(11.28)$ & -0.07 & 0.01 & $49.96(10.48)$ & $48.88(10.85)$ & 0.71 & 0.10 \\
\hline & E3. Asertividad & $50.47(9.81)$ & $49.98(11.42)$ & 0.31 & 0.04 & $48.55(9.42)$ & $50.98(11.63)$ & -1.61 & 0.23 \\
\hline & E4. Actividad & $49.38(10.13)$ & $48.75(12.31)$ & 0.38 & 0.05 & $48.83(10.53)$ & $52.42(10.28)$ & $-2.42 *$ & 0.34 \\
\hline & E5. Búsqueda de emociones & $62.24(8.34)$ & $63.36(6.95)$ & -0.98 & 0.14 & $55.28(10.75)$ & $60.88(9.01)$ & $-3.95 * * *$ & 0.57 \\
\hline & E6. Emociones positivas & $49.84(10.28)$ & $47.71(11.69)$ & 1.32 & 0.19 & $53.05(10.95)$ & $53.03(11.78)$ & 0.01 & 0.001 \\
\hline \multirow{6}{*}{ 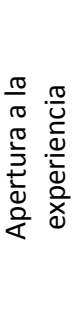 } & O1. Fantasía & $56.10(9.80)$ & $56.70(10.59)$ & -0.40 & 0.05 & $57.35(9.50)$ & $60.93(8.94)$ & $-2.71 * *$ & 0.38 \\
\hline & O2. Estética & $46.04(9.13)$ & $49.74(10.62)$ & $-2.55^{*}$ & 0.37 & $48.33(10.12)$ & $52.31(11.78)$ & $-2.53^{*}$ & 0.38 \\
\hline & O3. Sentimientos & $51.99(9.55)$ & 51.55 (11.19) & 0.28 & 0.04 & $53.73(9.27)$ & $57.07(8.44)$ & $-2.64 * *$ & 0.37 \\
\hline & O4. Acciones & $48.95(9.14)$ & $48.98(8.60)$ & -0.21 & 0.003 & $51.58(10.08)$ & $54.58(9.43)$ & $-2.15^{*}$ & 0.30 \\
\hline & 05. Ideas & $50.32(11.47)$ & $51.17(11.89)$ & -0.49 & 0.07 & $47.95(10.90)$ & $51.59(11.71)$ & $-2.25^{*}$ & 0.29 \\
\hline & O6. Valores & $51.72(9.11)$ & 51.84 (10.96) & -0.08 & 0.01 & $54.63(9.54)$ & 53.77 (10.67) & 0.59 & 0.27 \\
\hline
\end{tabular}


Tabla 21. Puntuaciones en las 5 dimensiones y 36 facetas del NEO PI-R en chicos y chicas control y subclínicos (continuación)

\begin{tabular}{|c|c|c|c|c|c|c|c|c|c|}
\hline & & \multicolumn{4}{|c|}{ Chicos $(N=187)$} & \multicolumn{4}{|c|}{ Chicas $(N=197)$} \\
\hline & & $\begin{array}{c}\text { Control }(n=100) \\
M(D T)\end{array}$ & $\begin{array}{c}\text { Subclínicos }(n=87) \\
M(D T)\end{array}$ & $t$ de Student & $d$ de Cohen & $\begin{array}{c}\text { Control }(n=99) \\
M(D T) \\
\end{array}$ & $\begin{array}{c}\text { Subclínicas }(n=98) \\
M(D T)\end{array}$ & $t$ de Student & $d$ de Cohen \\
\hline \multirow{6}{*}{$\begin{array}{l}\frac{0}{\pi} \\
\frac{\pi}{0} \\
\frac{0}{\overline{0}} \\
\frac{\pi}{\pi} \\
\frac{\xi}{4}\end{array}$} & A1. Confianza & $41.58(9.70)$ & $39.94(10.54)$ & 1.10 & 0.16 & $44.56(11.01)$ & $40.36(10.32)$ & $2.75 * *$ & 0.38 \\
\hline & A2. Franqueza & $42.10(8.56)$ & $37.78(7.98)$ & $3.54 * * *$ & 0.52 & $48.03(10.19)$ & $43.56(10.93)$ & $2.96 * *$ & 0.42 \\
\hline & A3. Altruismo & $45.88(9.09)$ & $41.72(9.84)$ & $3.00 * *$ & 0.44 & $50.17(9.71)$ & $46.86(11.10)$ & $2.23 *$ & 0.31 \\
\hline & A4. Actitud conciliadora & $40.27(8.23)$ & $37.67(8.31)$ & $2.14 *$ & 0.31 & $41.83(9.20)$ & $38.33(9.78)$ & $2.58 * *$ & 0.36 \\
\hline & A5. Modestia & $44.98(9.68)$ & $41.39(10.52)$ & $2.42 *$ & 0.35 & $51.51(9.25)$ & $48.51(10.59)$ & $2.11 *$ & 0.30 \\
\hline & A6. Sensibilidad a los demás & $46.81(9.40)$ & $46.14(11.16)$ & 0.44 & 0.06 & $51.47(10.66)$ & $48.73(10.45)$ & 1.82 & 0.26 \\
\hline \multirow{7}{*}{ 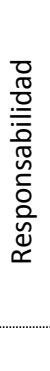 } & C1. Competencia & $41.38(8.13)$ & $38.07(8.35)$ & $2.74^{* *}$ & 0.40 & $44.49(9.95)$ & $39.42(8.45)$ & $3.85 * * *$ & 0.55 \\
\hline & C2. Orden & $41.80(9.95)$ & $39.16(10.01)$ & 1.80 & 0.24 & $45.37(12.39)$ & $42.69(13.34)$ & 1.46 & 0.20 \\
\hline & C3. Sentido del deber & $41.50(7.67)$ & $38.25(7.96)$ & $2.83 * *$ & 0.41 & $44.15(9.50)$ & $38.72(7.79)$ & $4.38 * * *$ & 0.63 \\
\hline & C4. Necesidad de logro & $39.59(8.96)$ & $37.72(9.06)$ & 1.41 & 0.20 & $42.86(10.72)$ & $40.36(9.60)$ & 1.72 & 0.25 \\
\hline & C5. Autodisciplina & $36.87(6.71)$ & $33.94(6.40)$ & $3.03 * *$ & 0.44 & $41.25(9.90)$ & $37.17(8.43)$ & $3.11 * *$ & 0.44 \\
\hline & C6. Deliberación & $42.29(7.47)$ & $38.28(8.12)$ & $3.51 * * *$ & 0.51 & $42.93(9.94)$ & $38.11(8.80)$ & $3.59 * * *$ & 0.52 \\
\hline & Deseabilidad social & $42.65(6.29)$ & $39.46(7.05)$ & $3.26 * * *$ & 0.47 & $45.19(7.88)$ & $42.49(7.62)$ & $2.44^{* *}$ & 0.35 \\
\hline
\end{tabular}

Nota. ${ }^{*} \mathrm{p}<0.05 ;{ }^{* *} \mathrm{p}<0.01 ;{ }^{* * *} \mathrm{p}<0.001$ 


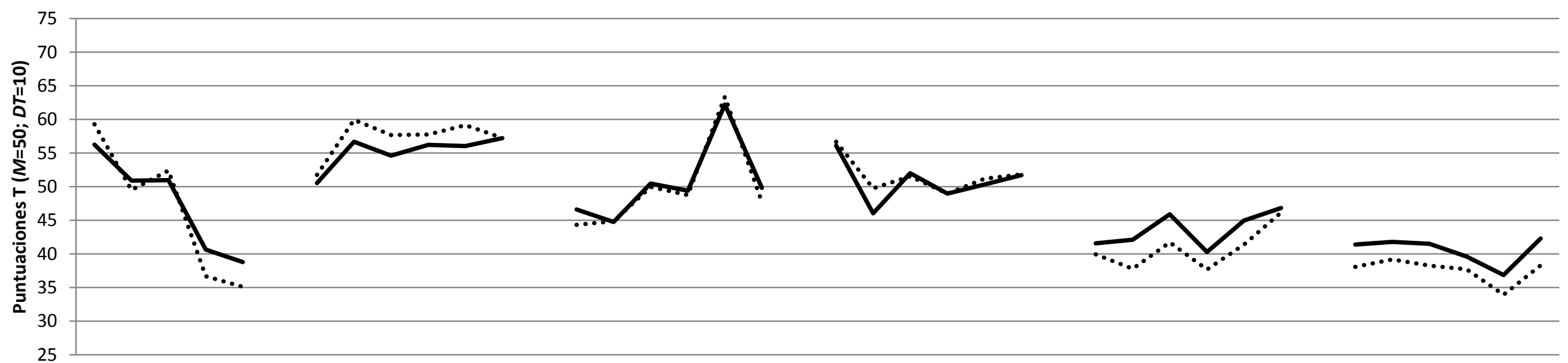

Chicas ( $\mathrm{N}=197)$

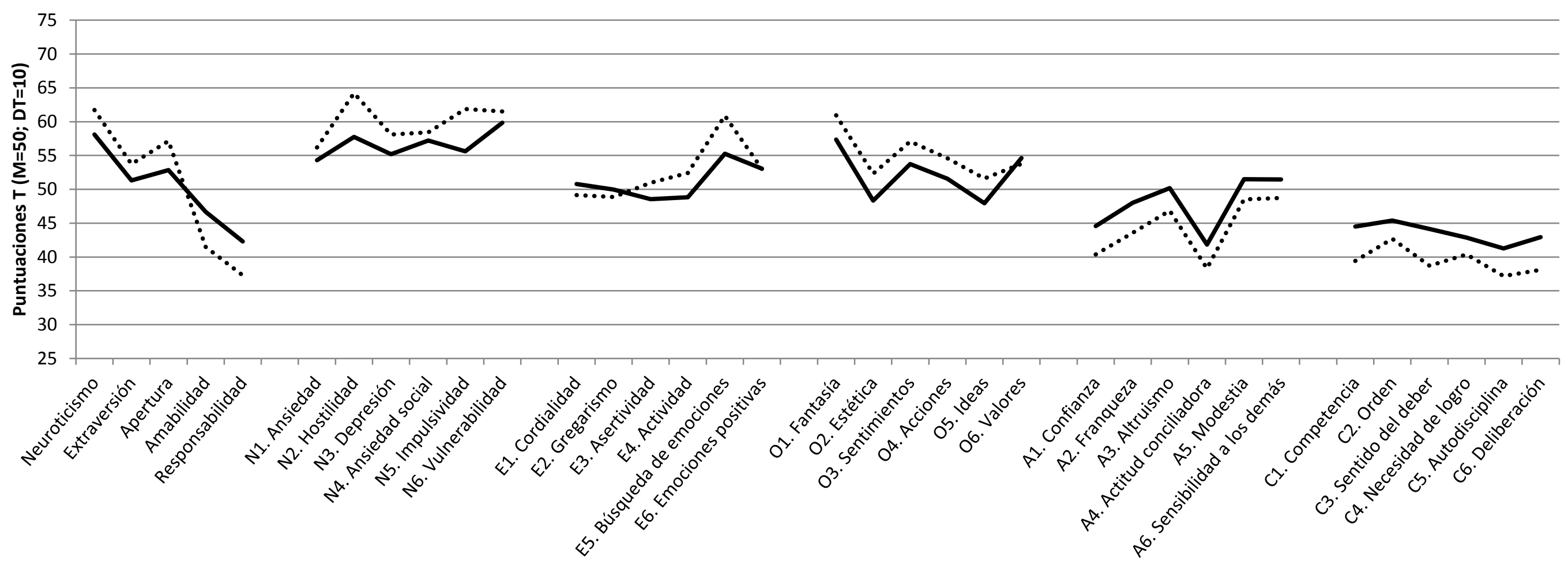




\section{Comportamiento sexual}

\subsection{Comportamiento sexual general}

El comportamiento sexual general de chicos y chicas control y subclínicos se comparó a través del análisis de algunos de los ítems de conducta sexual de la Encuesta Sobre el Sida (tabla 22) y del Cuestionario de Evaluación de la Orientación del Deseo Sexual (tabla 23).

Como se aprecia en la tabla 22, apenas existen diferencias entre el comportamiento sexual de chicos control y subclínicos en las variables analizadas en estos cuestionarios. El porcentaje de los que han mantenido relaciones sexuales con otra persona ( $95 \%$ de los chicos control y 97.7\% de los subclínicos), que en la actualidad o durante los últimos meses han mantenido una vida sexual activa ( $84 \%$ frente al $81.6 \%$ ) y que mantienen una relación estable (53\% frente al 51.7\%) es prácticamente idéntico en ambas condiciones clínicas. Entre los que sí afirmaron mantener una relación estable, el tiempo medio de duración fue ligeramente superior en el caso de los chicos control ( $M$ de 20.65 meses frente a 19 meses en chicos subclínicos), si bien esta diferencia ni tan siquiera se aproxima a la significación estadística $(t=0.47 ; p=.635)$. El porcentaje de chicos subclínicos que respondieron afirmativamente a la pregunta acerca de si habían sido infieles a una pareja estable (32.9\%) superó ligeramente al de participantes control (29\%), nuevamente sin que la magnitud de las diferencias alcance la significación $\left(x^{2}=0.33\right.$; $p=.56$ ). Donde las diferencias entre ambos grupos comienzan a ganar magnitud es durante el análisis del número de parejas sexuales a lo largo de la vida: mientras que los chicos control reportan una media de 9.28 parejas sexuales a lo largo de la vida, la media para los chicos del grupo subclínico es de 13.64 ( $t=1.03 ; p=.30$ ). Resulta significativo que la DT en el caso de los chicos subclínicos prácticamente triplique la obtenida por el grupo control (39.23 frente a 14.86), lo cual sugiere que el número medio de parejas sexuales en este primer grupo presenta una enorme variabilidad en comparación con el grupo control. Si atendemos a la frecuencia sexual, los porcentajes entre las distintas opciones de respuesta se reparten de forma equivalente en ambas condiciones clínicas $\left(x^{2}=2.13 ; p=.90\right)$, si bien parece que la densidad de muestra en las tres últimas categorías -las que indican una mayor frecuencia sexual- es un tanto superior en el caso de los chicos subclínicos: concretamente, un $69.5 \%$ de los chicos subclínicos mantendría una frecuencia sexual $\geq$ a 1 coito semanal frente al $61.1 \%$ de los chicos control. Finalmente, el porcentaje de chicos control y subclínicos que se han masturbado $199 \%$ y $99 \%$ respectivamente), han practicado masturbaciones mutuas ( $88 \%$ y $94.3 \%$ ), coito vaginal ( $87 \%$ y $80.5 \%$ ), sexo oral $(95 \%$ y $92 \%$ ) u otro tipo de prácticas sexuales (6\% y $4.6 \%$ ) es equivalente y ambos grupos tan sólo difieren significativamente en cuanto a práctica del sexo anal (35\% frente al 50.6\%). En todo caso, el tamaño del efecto sería pequeño ( $V=0.15$ ). 


\begin{tabular}{|c|c|c|c|c|c|c|c|c|}
\hline & \multicolumn{4}{|c|}{ Chicos $(N=187)$} & \multicolumn{4}{|c|}{ Chicas $(N=197)$} \\
\hline & $\begin{array}{l}\text { Control }(n=100) \\
M(D T) \circ \%\end{array}$ & $\begin{array}{l}\text { Subclínicos }(n=87) \\
\qquad M(D T) \circ \%\end{array}$ & $\begin{array}{l}\text { Estadístico de } \\
\text { contraste }\end{array}$ & $\begin{array}{c}\text { Tamaño del } \\
\text { efecto }\end{array}$ & $\begin{array}{l}\text { Control }(n=99) \\
M(D T) \circ \% \\
\end{array}$ & $\begin{array}{l}\text { Subclínicas }(n=98) \\
\qquad M(D T) \circ \%\end{array}$ & $\begin{array}{l}\text { Estadístico de } \\
\text { contraste }\end{array}$ & $\begin{array}{c}\text { Tamaño del } \\
\text { efecto }\end{array}$ \\
\hline $\begin{array}{l}\text { ¿Has mantenido relaciones sexuales de cualquier tipo con } \\
\text { otra persona? }\end{array}$ & $95 \%$ & $97.7 \%$ & $x^{2}=0.94$ & $V=0.07$ & $94.9 \%$ & $100 \%$ & $x^{2}=5.02 *$ & $V=0.16$ \\
\hline $\begin{array}{l}\text { ¿Mantienes o has mantenido en los últimos meses } \\
\text { relaciones sexuales? }\end{array}$ & $84 \%$ & $81.6 \%$ & $x^{2}=0.18$ & $V=0.03$ & $85.9 \%$ & $94.8 \%$ & $x^{2}=4.52^{*}$ & $V=0.15$ \\
\hline ¿Mantienes relaciones con una pareja estable? & $53 \%$ & $51.7 \%$ & $X^{2}=0.03$ & $V=0.01$ & $77.8 \%$ & $69.1 \%$ & $X^{2}=1.90$ & $V=0.09$ \\
\hline En caso afirmativo, tiempo de relación en meses & 20.65 (18.79) & 19 (15.19) & $t=0.47$ & $d=0.09$ & $33.80(24.07)$ & $24.73(19.85)$ & $t=2.43^{*}$ & $d=0.41$ \\
\hline ¿Alguna vez has sido infiel a una pareja estable? & $29 \%$ & $32.9 \%$ & $X^{2}=0.33$ & $V=0.04$ & $31.3 \%$ & $40.2 \%$ & $x^{2}=1.68$ & $V=0.09$ \\
\hline ¿Con cuántas personas has mantenido relaciones sexuales? & $9.28(14.86)$ & $13.64(39.23)$ & $t=-1.03$ & $d=0.17$ & $3.36(2.83)$ & $6.31(6.78)$ & $t=-3.97 * * *$ & $d=0.73$ \\
\hline \multicolumn{9}{|l|}{ Frecuencia sexual actual } \\
\hline$<6$ veces al año & $5.1 \%$ & $3.5 \%$ & & & $3.1 \%$ & $1.1 \%$ & & \\
\hline 5 o 6 veces al año & $8.2 \%$ & $5.9 \%$ & & & $2.1 \%$ & $4.2 \%$ & & \\
\hline 1 vez al mes & $10.2 \%$ & $7.1 \%$ & & & $10.4 \%$ & $1.1 \%$ & & \\
\hline 203 veces al mes & $15.3 \%$ & $14.1 \%$ & $X^{2}=2.13$ & $V=0.10$ & $16.7 \%$ & $20 \%$ & $X^{2}=13.99 *$ & $V=0.26$ \\
\hline 1 vez a la semana & $17.3 \%$ & $21.2 \%$ & & & $21.9 \%$ & $28.4 \%$ & & \\
\hline 3 veces a la semana & $22.4 \%$ & $21.2 \%$ & & & $31.3 \%$ & $22.1 \%$ & & \\
\hline$>3$ veces a la semana & $21.4 \%$ & $27.1 \%$ & & & $14.6 \%$ & $23.2 \%$ & & \\
\hline \multicolumn{9}{|l|}{ Tipo de prácticas sexuales realizadas } \\
\hline Masturbación & $99 \%$ & $99 \%$ & $x^{2}=0.01$ & $V=0.007$ & $65.7 \%$ & $85.6 \%$ & $x^{2}=10.50 * * *$ & $V=0.23$ \\
\hline Masturbaciones mutuas & $88 \%$ & $94.3 \%$ & $X^{2}=2.20$ & $V=0.10$ & $83.8 \%$ & $93.8 \%$ & $x^{2}=4.89 *$ & $V=0.15$ \\
\hline Coito vaginal & $87 \%$ & $80.5 \%$ & $x^{2}=1.47$ & $V=0.08$ & $97 \%$ & $97.9 \%$ & $x^{2}=0.18$ & $V=0.03$ \\
\hline Sexo oral & $95 \%$ & $92 \%$ & $x^{2}=0.71$ & $V=0.06$ & $79.8 \%$ & $94.8 \%$ & $x^{2}=9.96 * *$ & $V=0.22$ \\
\hline Coito anal & $35 \%$ & $50.6 \%$ & $x^{2}=4.62^{*}$ & $V=0.15$ & $23.2 \%$ & $38.1 \%$ & $x^{2}=5.12^{*}$ & $V=0.16$ \\
\hline Otras & $6 \%$ & $4.6 \%$ & $x^{2}=0.18$ & $V=0.03$ & $1 \%$ & $3.1 \%$ & $x^{2}=1.06$ & $V=0.07$ \\
\hline
\end{tabular}

Nota. ${ }^{*} p<0.05 ;{ }^{* *} p<0.01 ;{ }^{* * *} p<0.001$ 
Al contrario, el comportamiento sexual de chicas control y subclínicas sí presenta diferencias notables en la mayoría de variables exploradas (tabla 22). En primer lugar, todas las chicas del grupo subclínico dijeron haber mantenido relaciones sexuales con otra persona frente al $94.9 \%$ de las control $\left(x^{2}=5.02 ; p=.025\right)$, diferencias que alcanzarían un tamaño del efecto pequeño $(V=0.16)$. También pequeño $(V=0.15)$ sería el tamaño del efecto atribuible a las diferencias en el porcentaje de chicas control y subclínicas que mantienen o han mantenidos durante los últimos meses relaciones sexuales (85.9\% y $94.8 \%$ respectivamente). El porcentaje de chicas subclínicas que mantienen una relación estable (69.1\%) sería ligeramente inferior al de las participantes control (77.8\%), si bien en este caso las diferencias no alcanzaron la significación $\left(x^{2}=1.90 ; p=.16\right)$. Donde sí se aprecian diferencias de un tamaño del efecto medio $(d=0.41)$ es en el tiempo de duración de dichas relaciones: concretamente, la duración media de las relaciones de las chicas del grupo control $(M=33.80 ; D T=24.07)$ es significativamente superior al reportado por las chicas del grupo subclínico $(M=24.73 ; D T=24.07)$. La prevalencia de infidelidad es 9 puntos porcentuales superior en el grupo de chicas subclínicas (40.2\% frente al 31.3\% de participantes control), si bien la magnitud de estas diferencias no alcanza la significación estadística. Donde sí se alcanza la significación ( $t=3.97 ; p<0.001)$ y además con un gran tamaño del efecto $(d=0.73)$ es en el número de parejas sexuales a lo largo de la vida, donde la media en chicas subclínicas dobla la obtenida por las control (6.31 parejas sexuales frente a 3.36). Ambas condiciones clínicas difieren también en cuanto a frecuencia sexual $\left(x^{2}=13.99 ; p=.037\right)$ : concretamente, la densidad de muestra control en valores que indican una baja frecuencia sexual ( $<2$ coitos al mes) sería superior a la densidad en muestra clínica mientras que lo contrario sucede en valores que indican una frecuencia sexual mayor ( $\geq 1$ coito semanal). El tamaño del efecto para las diferencias en frecuencia sexual sería moderado $(V=0.26)$. Finalmente, el porcentaje de chicas subclínicas que se han masturbado (85.6\%), practicado masturbaciones con otra persona (93.8\%), realizado coito anal (38.1\%) o vaginal (97.9\%) sería superior al obtenido por las chicas control $(65.7 \%, 83.8 \%, 23.2 \%$ y $97 \%$ respectivamente), con tamaños del efecto entre pequeños y moderados ( $V$ entre $0.15-0.23$ ).

Si analizamos la orientación del deseo sexual en chicos control y subclínicos (tabla 23), se aprecia que el porcentaje de los que han deseado mantener relaciones sexuales con personas del mismo sexo varía en función de la condición clínica $\left(x^{2}=5.76 ; p=.016\right)$ : concretamente, el $35.6 \%$ de los chicos subclínicos respondió afirmativamente a esta pregunta frente al $19.8 \%$ de los control. Rozando la significación $\left(x^{2}=3.38 ; p=.06\right)$ quedaría también la diferencia en el porcentaje de chicos control y subclínicos que han mantenido relaciones sexuales con personas del mismo sexo ( $13.5 \%$ y $24.1 \%$ respectivamente). La distribución de los participantes 
en las tres categorías clásicas de la orientación sexual no varía en función del grupo clínico $\left(x^{2}=4.72 ; p=.09\right)$ pero sí se observan importantes diferencias como por ejemplo que el porcentaje de homosexuales en el grupo subclínico duplique el encontrado en chicos control (20.7\% frente al 9.4\%). Algo similar sucede en el análisis de la orientación sexual a través de 7 categorías de atracción sexual, donde si bien tampoco se aprecian diferencias en función del grupo clínico $\left(x^{2}=6.79 ; p=.34\right)$, el porcentaje de los participantes subclínicos que sienten casi siempre o siempre atracción hacia su propio sexo $(6.9 \%$ y $14.9 \%)$ es dos veces superior al porcentaje en chicos control (3.1\% y $7.3 \%$ respectivamente). Donde sí aparecen diferencias significativas aunque de pequeña magnitud $(d=0.33)$ es en la medida dimensional de la orientación sexual, donde los chicos subclínicos $(M=3.74 ; D T=5.48)$ mostrarían mayor atracción homosexual que los control $(M=2.12 ; D T=4.32)$.

Para finalizar, especialmente interesante resulta el análisis de la orientación del deseo sexual en chicas control y subclínicas. Más de la mitad de las chicas subclínicas ha deseado mantener relaciones sexuales con personas del mismo sexo y han tenido fantasías eróticas homosexuales para excitarse frente al $17.5 \%$ y el $21.3 \%$ de las chicas control. Asimismo, el $18.9 \%$ de éstas ha mantenido relaciones sexuales con personas de su mismo sexo frente a tan sólo el $3.8 \%$ de las control. Las diferencias en los tres casos alcanzan un tamaño del efecto moderado ( $V$ entre 0.23 y 0.36). También de un tamaño moderado $(V=0.24)$ serían las diferencias en la distribución de participantes control y subclínicas en una de las tres categorías clásicas de la orientación sexual: concretamente, el porcentaje de chicas control que autoinformaban de una orientación sexual alternativa a la heterosexual fue del $2.5 \%$ frente al $17.9 \%$ de las chicas subclínicas $\left(x^{2}=10.76 ; p=.005\right)$. En este último grupo, la orientación sexual más frecuente después de la heterosexual fue la bisexual (12.6\%) y finalmente la homosexual (5.3\%). Más abultadas son si cabe las diferencias cuando se analiza la orientación mediante las 7 categorías de atracción sexual $\left(x^{2}=28.86 ; p<.001\right)$. Mientras que la gran mayoría de chicas control expresan atracción únicamente hacia el otro sexo (el $81.3 \%$ ), este porcentaje se reduce a la mitad (44.2\%) en el grupo de participantes subclínicas. La preferencia sexual de estas últimas se centraría en torno a valores que reflejan una atracción prioritaria hacia el otro sexo pero con cierto interés hacia el suyo propio (como por ejemplo la categoría de "Siento casi siempre atracción hacia el otro sexo y raramente hacia el mío", que representa la opción escogida por casi el $40 \%$ de estas chicas). Coherente con lo comentado anteriormente, la puntuación media de las chicas subclínicas quedaría significativamente más próxima al extremo homosexual del continuo de orientación sexual que la de las chicas control $(t=4.63 ; p<.001)$. 


\begin{tabular}{|c|c|c|c|c|c|c|c|c|}
\hline & \multicolumn{4}{|c|}{ Chicos $(N=187)$} & \multicolumn{4}{|c|}{ Chicas $(N=197)$} \\
\hline & $\begin{array}{c}\text { Control }(n=100) \\
M(D T) \circ \%\end{array}$ & $\begin{array}{c}\text { Subclínicos }(n=87) \\
M(D T) \text { ० \% }\end{array}$ & $\begin{array}{l}\text { Estadístico de } \\
\text { contraste }\end{array}$ & $\begin{array}{l}\text { Tamaño } \\
\text { del efecto }\end{array}$ & $\begin{array}{c}\text { Control }(n=99) \\
M(D T) \circ \% \\
\end{array}$ & $\begin{array}{c}\text { Subclínicas }(n=98) \\
M(D T) \text { ० \% }\end{array}$ & $\begin{array}{l}\text { Estadístico de } \\
\text { contraste }\end{array}$ & $\begin{array}{l}\text { Tamaño } \\
\text { del efecto }\end{array}$ \\
\hline ¿Has deseado mantener relaciones sexuales con personas de tu mismo sexo? & $19.8 \%$ & $35.6 \%$ & $x^{2}=5.76 *$ & $V=0.17$ & $17.5 \%$ & $52.6 \%$ & $x^{2}=23.10 * * *$ & $V=0.36$ \\
\hline ¿Alguna vez te has excitado fantaseando con personas de tu mismo sexo? & $26 \%$ & $28.7 \%$ & $x^{2}=0.16$ & $V=0.03$ & $21.3 \%$ & $51.6 \%$ & $x^{2}=17.06 * * *$ & $V=0.31$ \\
\hline ¿Has mantenido relaciones sexuales con personas de tu mismo sexo? & $13.5 \%$ & $24.1 \%$ & $x^{2}=3.38$ & $V=0.13$ & $3.8 \%$ & $18.9 \%$ & $x^{2}=9.49 * *$ & $V=0.23$ \\
\hline \multicolumn{9}{|l|}{ En cuanto a tu orientación sexual, ¿̇te consideras... } \\
\hline ....Heterosexual? & $87.5 \%$ & $75.9 \%$ & & & $97.5 \%$ & $82.1 \%$ & & \\
\hline ...Bisexual? & $3.1 \%$ & $3.4 \%$ & $x^{2}=4.72$ & $V=0.16$ & $1.3 \%$ & $12.6 \%$ & $x^{2}=10.76 * *$ & $V=0.24$ \\
\hline ....Homosexual? & $9.4 \%$ & $20.7 \%$ & & & $1.3 \%$ & $5.3 \%$ & & \\
\hline \multicolumn{9}{|l|}{ ¿Qué afirmación describe mejor tu atracción sexual? } \\
\hline Siento atracción sólo hacia el otro sexo & $72.9 \%$ & $65.5 \%$ & & & $81.3 \%$ & $44.2 \%$ & & \\
\hline Siento casi siempre atracción hacia el otro sexo y raramente hacia el mío & $14.6 \%$ & $10.3 \%$ & & & $15 \%$ & $38.9 \%$ & & \\
\hline Siento atracción más hacia el otro sexo que hacia el mío & $0 \%$ & $1.1 \%$ & & & $1.3 \%$ & $5.3 \%$ & & \\
\hline Me siento igualmente atraído hacia los dos sexos & $1 \%$ & $0 \%$ & $x^{2}=6.79$ & $V=0.19$ & $1.3 \%$ & $0 \%$ & $X^{2}=28.86 * * *$ & $V=0.40$ \\
\hline Siento más atracción hacia mí mismo sexo que hacia el otro & $1 \%$ & $1.1 \%$ & & & $1.3 \%$ & $6.3 \%$ & & \\
\hline Siento casi siempre atracción hacia mi sexo y raramente hacia el otro & $3.1 \%$ & $6.9 \%$ & & & $0 \%$ & $4.2 \%$ & & \\
\hline Siento atracción sólo hacia mí mismo sexo & $7.3 \%$ & $14.9 \%$ & & & $0 \%$ & $1.1 \%$ & & \\
\hline Medida dimensional de la orientación sexual (rango de 0 a 15.40) ${ }^{\text {a }}$ & $2.12(4.32)$ & $3.74(5.48)$ & $t=-2.22^{*}$ & $d=0.33$ & $1.08(1.66)$ & $2.99(3.34)$ & $t=-4.63 * * *$ & $d=0.76$ \\
\hline
\end{tabular}

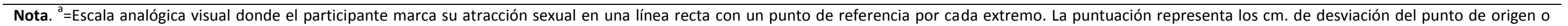

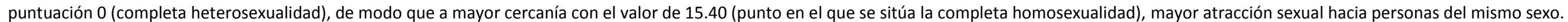

${ }^{*} p<0.05 ; * * p<0.01 ; * * * p<0.001$ 


\subsection{Comportamiento sexual de riesgo}

El comportamiento sexual de riesgo en participantes control y subclínicos se comparó a través del HIV-RI (tabla 24), de la escala de severidad percibida del VIH (tabla 25) y de la escala de autoeficacia en el uso del preservativo (tabla 26).

En la estimación del HIV-RI se tuvieron en cuenta 9 indicadores de riesgo, 6 relacionados con el uso del preservativo (indicadores directos de riesgo sexual) y los 3 restantes no directamente relacionados con la exposición a situaciones sexuales de riesgo pero cuya presencia aumenta la probabilidad de transmisión del VIH o de cualquier otra ITS (indicadores indirectos de riesgo sexual). Los ítems de la primera escala se respondían en un formato tipo Likert entre 1 (Nunca) y 4 (Siempre) y se dicotomizaron para reflejar el uso consistente e inconsistente del preservativo: así, se asignó una puntuación de 0 (no riesgo) a los que dijeron utilizar siempre el preservativo durante las situaciones sexuales evaluadas y de 1 (riesgo) a los que no lo utilizaron nunca, casi nunca o en algunas ocasiones. A los ítems de la escala de riesgos indirectos se les asignó el valor de 0 cuando no estaba presente el síntoma de riesgo y 1 cuando sí lo estaba (es decir, cuando la persona había sido infiel a una pareja estable, no conocía su estado serológico o no tenía la intención de utilizar el preservativo en el futuro).

Aplicando la corrección anterior se obtuvo por cada indicador un valor de riesgo entre 0 (no riesgo) y 1 (riesgo), al cual se le añadía un riesgo entre 0.25 y 0.5 adicional en función de dos parámetros de ponderación: la frecuencia sexual y el número de parejas sexuales por año sexualmente activo. Para ello, se aplicó la siguiente fórmula:

Riesgo $=$ Indicador de riesgo ( 0 [no riesgo] o 1 [riesgo]) $X$ frecuencia sexual (1 $[\leq 1$ coito semanal] - 1.225 [>1 coito semanal]) $X$ parejas sexuales (1 $[<1$ pareja sexual por año sexualmente activo] o 1.225 [ $\geq 1$ pareja sexual por año sexualmente activo]).

El resultado de esta fórmula se redondeó para obtener 4 valores de riesgo por cada indicador: 0 (no riesgo), 1 (riesgo medio), 1.25 (riesgo medio-alto) y 1.5 (riesgo alto). Su aplicación permitía reconocer que una alta frecuencia sexual o un gran número de parejas sexuales sólo era problemático cuando además estaba presente alguno de los indicadores de riesgo que conforman el índice. Así, una persona con alta frecuencia sexual y una nueva pareja cada poco tiempo obtenía el mismo riesgo que alguien que mantenía relaciones sexuales con una pareja estable si en ambos casos se hacía un uso consistente del preservativo. Al contrario, cuando se daba una conducta sexual de riesgo (p.e., uso inconsistente del preservativo durante coito vaginal), una alta frecuencia sexual y un extenso historial de parejas suponían un riesgo adicional en tanto en cuanto aumentaban la probabilidad de exposición al VIH y otras ITS. 
Si comenzamos analizando el perfil general de comportamiento sexual de riesgo (tabla 24), los participantes en este estudio (independientemente del sexo o condición clínica) no constituyen un grupo de especial riesgo para la transmisión del VIH o de cualquier otra ITS. Así, la puntuación media general en el HIV-RI fue de 5.11 en una escala con valores entre 0 (ausencia total de riesgo) y 13.5 (riesgo extremo). El riesgo mayor lo obtuvieron los chicos y chicas del grupo subclínico ( $M$ de 5.81 y 5.29 respectivamente), seguido por los chicos y chicas del grupo control ( $M$ de 5.11 y 4.32). Si se analiza el riesgo asociado a cada indicador, se aprecia que éste es muy bajo en alguno de ellos como la intención de no utilizar el preservativo en futuras relaciones ( $M$ de entre 0.13 y 0.26 en una escala entre 0 y 1.5 ), el haber sido infiel a una pareja estable ( $M$ entre 0.08 y 0.20 ) o el uso inconsistente del preservativo con parejas esporádicas en el caso particular de las chicas ( $M$ entre 0.12 y 0.31 ). Al contrario, el riesgo asociado a indicadores como el uso inconsistente del preservativo con parejas estables ( $M$ entre 0.76 y 1$)$, durante sexo vaginal ( $M$ entre 0.66 y 0.75 ) y sobre todo durante sexo oral ( $M$ entre 0.96 y 1.18) resultaría especialmente alto, presumiblemente por ser conductas más frecuentes en el contexto de las relaciones sexuales entre jóvenes.

Al comparar el comportamiento sexual de riesgo en chicos en función de la condición clínica, la puntuación de los participantes control y subclínicos en el HIV-RI resultó equivalente tanto a nivel de indicadores como de factores y puntuación total, de modo que no se puede afirmar que el riesgo para la transmisión del VIH u otras ITS sea mayor en uno u otro grupo. Sí se aprecia una tendencia generalizada aunque en ningún caso significativa a que sean los chicos del grupo subclínico lo que obtienen puntuaciones de riesgo mayores, sobre todo en los indicadores de riesgo debido al uso inconsistente del preservativo con parejas esporádicas ( $t=-$ $1.51 ; p=.13)$, cuando se ha tomado alcohol o drogas ( $t=-1.48$; $p=.13$ ) y sobre todo durante la práctica del coito anal ( $t=-1.81 ; p=.07)$. Del mismo modo, los chicos del grupo subclínico obtuvieron puntuaciones ligeramente mayores a los control en el factor 1 ( $t=-1.37 ; p=.17$ ), el factor 2 ( $t=-1.29$.; $p=.19$ ) y especialmente en la puntuación total en el HIV-RI ( $t=-1.52 ; p=.12$ ), no alcanzándose tampoco en estos casos la significación estadística.

Para comprobar si estos mismos resultados en una muestra de mayor tamaño alcanzarían la significación estadística, se calculó a través de metodología bootstrap el intervalo de confianza para la diferencia de medias en dichos contrastes. A través de remuestreo bootstrap con 1000 muestras, se obtuvo un intervalo de confianza para la diferencia de medias de entre -0.30 y 0.02 en el contraste entre chicos control y subclínicos en el riesgo debido al uso inconsistente del preservativo con parejas esporádicas, de entre -0.33 y 0.04 cuando se ha tomado alcohol o drogas y de entre -0.32 y 0.006 durante la práctica del coito anal. En los tres casos, el intervalo 
incluiría el valor 0 entre los valores más periféricos (valor que corresponde a la hipótesis de la igualdad de medias), de modo que no podemos descartar la hipótesis de que estos mismos resultados en muestras de un tamaño ligeramente superior arrojaran resultados significativos. De igual modo, los intervalos de confianza para la diferencia de medias en las comparaciones entre la puntuación de chicos control y subclínicos en el factor 1 ([-1.22; 0.20]), el 2 ([-0.49; .08]) y la puntuación total en el HIV-RI ([-1.60; 0.19]) incluirían de forma periférica el valor 0.

En chicas, la puntuación media en el HIV-RI de las participantes control y subclínicas sí difirió significativamente en varios de los indicadores de riesgo analizados, siendo las integrantes del grupo subclínico las que obtienen puntuaciones que sugieren un riesgo mayor de transmisión de VIH o de otras ITS. Más concretamente, las chicas del grupo subclínico obtuvieron un riesgo mayor debido al uso inconsistente del preservativo con sus parejas estables ( $t=-2.00 ; p=.04)$, al hecho de haber sido infieles $(t=-2.06 ; p=.04)$, al uso inconsistente del preservativo durante el sexo oral $(t=-2.47 ; p=.01)$ y al uso inconsistente del preservativo con parejas esporádicas ( $t=-$ 2.85; $p=.005)$. Las diferencias en dichos contrastes alcanzaron un tamaño del efecto entre pequeño y moderado ( $d$ entre 0.28 y 0.42 ). Agrupando los indicadores en factores, la puntuación media de las chicas subclínicas en el factor 1 ( $M=4.15 ; D T=2.39)$ superó al obtenido por las integrantes del grupo control $(M=3.32 ; D T=2.25)$, no sucediendo así en el factor 2 . Finalmente, la puntuación de las chicas subclínicas en el HIV-RI superó prácticamente por un punto (en una escala entre 0 y 13.5) a la obtenida por el grupo control, alcanzando dicha diferencia un tamaño del efecto entre pequeño y moderado $(d=0.34)$.

El siguiente aspecto del comportamiento sexual de riesgo que se exploró fue la severidad percibida del VIH (tabla 25). En general (sin distinguir por sexo o condición clínica), la mayoría de los participantes (el 79.6\%) reconocen que el VIH/SIDA es una enfermedad que no tiene curación y al $71.5 \%$ les produce mucho temor la idea de infectarse con el VIH. Sin embargo, tan sólo el $24.5 \%$ consideran que el SIDA es una enfermedad grave y sólo el $6 \%$ creería tener un alto riesgo de infectarse con el VIH. En chicos, estos porcentajes no varían en función de la condición clínica pero sí lo harían en chicas. Concretamente, un mayor porcentaje de chicas subclínicas experimentan mucho temor hacia la idea de infectarse con el VIH (79.6\% frente al $66.3 \%$ de chicas control). El porcentaje de las que creen tener un alto riesgo de infectarse con el VIH (4.1\% y $10.2 \%$ de las control y subclínicas) varía también en función de la condición clínica, quedando dichas diferencias cercanas a la significación estadística ( $X^{2}=2.70 ; p=.09$ ). Finalmente, la percepción general de severidad del VIH sería ligeramente superior en el caso de las chicas subclínicas $(t=1.96 ; p=0.05)$. 
Tabla 24. Puntuaciones en el HIV-RI en chicos y chicas control y subclínicos.

\begin{tabular}{|c|c|c|c|c|c|c|c|c|c|}
\hline \multirow[b]{2}{*}{ Riesgo de VIH debido a... } & \multirow[b]{2}{*}{ Rango } & \multicolumn{4}{|c|}{ Chicos $(N=187)$} & \multicolumn{4}{|c|}{ Chicas $(N=197)$} \\
\hline & & $\begin{array}{c}\text { Control }(n=100) \\
M(D T)\end{array}$ & $\begin{array}{c}\text { Subclínicos }(n=87) \\
\qquad M(D T)\end{array}$ & $t$ de Student & $d$ de Cohen & $\begin{array}{l}\text { Control }(n=99) \\
\qquad M(D T)\end{array}$ & $\begin{array}{c}\text { Subclínicas }(n=98) \\
\qquad M(D T)\end{array}$ & $t$ de Student & $d$ de Cohen \\
\hline ...uso inconsistente del preservativo durante sexo vaginal & $0-1.5$ & $0.73(0.66)$ & $0.66(0.66)$ & 0.679 & 0.10 & $0.67(0.62)$ & $0.75(0.65)$ & -0.88 & 0.12 \\
\hline ...uso inconsistente del preservativo durante sexo oral & $0-1.5$ & $1.18(0.34)$ & $1.16(0.44)$ & 0.273 & 0.04 & $0.96(0.50)$ & $1.13(0.42)$ & $-2.47 *$ & 0.37 \\
\hline ...uso inconsistente del preservativo durante sexo anal & $0-1.5$ & $0.36(0.58)$ & $0.52(0.66)$ & -1.81 & 0.25 & $0.35(0.57)$ & $0.49(0.64)$ & -1.60 & 0.22 \\
\hline ...uso inconsistente del preservativo con parejas estables & $0-1.5$ & $0.88(0.61)$ & $1.00(0.58)$ & -1.40 & 0.20 & $0.76(0.61)$ & $0.93(0.60)$ & $-2.00 *$ & 0.28 \\
\hline ... uso inconsistente del preservativo al tomar alcohol/drogas & $0-1.5$ & $0.36(0.60)$ & $0.5(0.66)$ & -1.51 & 0.22 & $0.44(0.59)$ & $0.52(0.62)$ & -0.92 & 0.13 \\
\hline ...uso inconsistente del preservativo con parejas esporádicas & $0-1.5$ & $0.54(0.64)$ & $0.68(0.67)$ & -1.48 & 0.21 & $0.12(0.36)$ & $0.31(0.55)$ & $-2.85 * *$ & 0.42 \\
\hline ...haber sido infiel a mi pareja estable & $0-1.5$ & $0.18(0.47)$ & $0.20(0.49)$ & -0.341 & 0.04 & $0.08(0.30)$ & $0.20(0.48)$ & $-2.06 *$ & 0.30 \\
\hline ...la intención de no utilizar el preservativo en el futuro & $0-1.5$ & $0.20(0.48)$ & $0.26(0.54)$ & -0.793 & 0.11 & $0.13(0.39)$ & $0.17(0.44)$ & -0.62 & 0.09 \\
\hline ...no conocer mi estado serológico & $0-1.5$ & $0.67(0.62)$ & $0.79(0.63)$ & -1.33 & 0.19 & $0.78(0.57)$ & $0.76(0.62)$ & 0.17 & 0.03 \\
\hline Factor 1. Indicadores directos de riesgo sexual (ítems 1-6) & $0-9$ & $4.06(2.30)$ & $4.55(2.59)$ & -1.37 & 0.20 & $3.32(2.25)$ & $4.15(2.39)$ & $-2.51 *$ & 0.36 \\
\hline Factor 2. Indicadores indirectos de riesgo sexual (ítems 7-9) & $0-4.5$ & $1.05(1.05)$ & $1.26(1.12)$ & -1.29 & 0.19 & $1.00(0.81)$ & $1.14(1.10)$ & -1.01 & 0.14 \\
\hline HIV Risk Index (HIV-RI) & $0-13.5$ & $5.11(2.98)$ & $5.81(3.27)$ & -1.52 & 0.22 & $4.32(2.65)$ & $5.29(2.97)$ & $-2.41 *$ & 0.34 \\
\hline
\end{tabular}

Nota. ${ }^{*} p<0.05 ;{ }^{* *} p<0.01 ;{ }^{* * *} p<0.001$ 
Tabla 25. Puntuaciones en la escala de severidad percibida del VIH en chicos y chicas control y subclínicos.

\begin{tabular}{|c|c|c|c|c|c|c|c|c|}
\hline \multirow[b]{2}{*}{ Severidad percibida del VIH } & \multicolumn{4}{|c|}{ Chicos $(N=187)$} & \multicolumn{4}{|c|}{ Chicas $(N=197)$} \\
\hline & $\begin{array}{c}\text { Control }(n=100) \\
M(D T) \circ \%\end{array}$ & $\begin{array}{c}\text { Subclínicos }(n=87) \\
M(D T) \circ \%\end{array}$ & $\begin{array}{c}\text { Estadístico de } \\
\text { contraste }\end{array}$ & $\begin{array}{c}\text { Tamaño del } \\
\text { efecto }\end{array}$ & $\begin{array}{c}\text { Control }(n=99) \\
M(D T) \circ \%\end{array}$ & $\begin{array}{c}\text { Subclínicas }(n=98) \\
M(D T) \circ \%\end{array}$ & $\begin{array}{c}\text { Estadístico de } \\
\text { contraste }\end{array}$ & $\begin{array}{c}\text { Tamaño del } \\
\text { efecto }\end{array}$ \\
\hline ¿Dirías que el SIDA es una enfermedad SIN curación? & $77 \%$ & $81.2 \%$ & $x^{2}=0.48$ & $V=0.05$ & $80.6 \%$ & $80 \%$ & $x^{2}=0.01$ & $V=0.008$ \\
\hline ¿Te produce mucho temor la idea de infectarte con el VIH? & $73 \%$ & $66.3 \%$ & $x^{2}=0.99$ & $V=0.07$ & $66.3 \%$ & $79.6 \%$ & $x^{2}=4.37^{*}$ & $V=0.14$ \\
\hline ¿Crees tener un alto riesgo de infectarte con el VIH? & $4 \%$ & $5.7 \%$ & $x^{2}=0.31$ & $V=0.04$ & $4.1 \%$ & $10.2 \%$ & $x^{2}=2.70$ & $V=0.11$ \\
\hline ¿Consideras que el SIDA es una enfermedad grave? & $18 \%$ & $25.3 \%$ & $x^{2}=1.46$ & $V=0.08$ & $27.6 \%$ & $27.6 \%$ & $x^{2}=0$ & $V=0$ \\
\hline
\end{tabular}

Nota. ${ }^{*} p<0.05 ;{ }^{* *} p<0.01 ;{ }^{* * *} p<0.001$

Tabla 26. Autoeficacia en el uso del preservativo en chicos y chicas control y subclínicos.

\begin{tabular}{|c|c|c|c|c|c|c|c|c|c|}
\hline \multirow[b]{2}{*}{ Autoeficacia en el uso del preservativo } & \multirow[b]{2}{*}{ Rango } & \multicolumn{4}{|c|}{ Chicos $(N=187)$} & \multicolumn{4}{|c|}{ Chicas $(N=197)$} \\
\hline & & $\begin{array}{c}\text { Control }(n=100) \\
M(D T)\end{array}$ & $\begin{array}{c}\text { Subclínicos }(n=87) \\
M(D T)\end{array}$ & $t$ de Student & $d$ de Cohen & $\begin{array}{c}\text { Control }(n=99) \\
M(D T)\end{array}$ & $\begin{array}{c}\text { Subclínicas }(n=98) \\
M(D T)\end{array}$ & $t$ de Student & $d$ de Cohen \\
\hline ¿Consideras fiable el preservativo en la prevención del SIDA? & $0-3$ & $2.68(2.00)$ & $2.60(0.53)$ & 1.09 & 0.06 & $2.69(0.48)$ & $2.67(0.55)$ & 0.27 & 0.04 \\
\hline Me siento cómodo a la hora de comprar condones & $0-3$ & $2.48(0.59)$ & $2.36(0.66)$ & 1.29 & 0.2 & $2.13(0.69)$ & $2.33(0.65)$ & $-2.03 *$ & 0.30 \\
\hline Estoy cómodo hablando del uso del condón con una nueva pareja & $0-3$ & $2.33(0.62)$ & $2.41(0.58)$ & -0.86 & 0.13 & $2.22(0.66)$ & $2.37(0.65)$ & -1.55 & 0.22 \\
\hline Me siento cómodo sugiriendo a una pareja que usemos condón & $0-3$ & $1.85(0.35)$ & $1.79(0.43)$ & 1.01 & 0.15 & $1.94(0.24)$ & $1.86(0.38)$ & 1.82 & 0.26 \\
\hline No pienso que si sugiero el uso del condón a una pareja se moleste & $0-3$ & $1.87(0.36)$ & $1.87(0.36)$ & -0.03 & 0 & $1.85(0.43)$ & $1.93(0.29)$ & -1.50 & 0.22 \\
\hline Recordaría usar el condón habiendo bebido o tomado drogas & $0-3$ & $2.34(0.59)$ & $2.22(0.65)$ & 1.30 & 0.19 & $2.32(0.65)$ & $2.37(0.65)$ & -0.58 & 0.07 \\
\hline Me siento cómodo poniéndome o poniendo a mi pareja el condón & $0-3$ & $1.48(0.74)$ & $1.55(0.62)$ & -0.65 & 0.10 & $1.55(0.69)$ & $1.55(0.72)$ & 0.04 & 0 \\
\hline Aun estando muy excitado podría parar para ponerme el condón & $0-3$ & $1.96(0.68)$ & $2.01(0.72)$ & -0.50 & 0.07 & $2.21(0.67)$ & $2.22(0.76)$ & -0.02 & 0.01 \\
\hline Puntuación total escala de autoeficacia en el uso del preservativo & $0-24$ & $16.99(2.00)$ & $16.80(2.12)$ & 0.62 & 0.09 & $16.91(2.00)$ & $17.29(2.25)$ & -1.24 & 0.17 \\
\hline
\end{tabular}

Nota. ${ }^{*} \mathrm{p}<0.05 ;{ }^{* *} \mathrm{p}<0.01 ;{ }^{* * *} \mathrm{p}<0.001$ 
El último aspecto del comportamiento sexual de riesgo que se exploró fue la percepción de autoeficacia en el uso del preservativo (tabla 26). Al respecto, la puntuación media en la mayoría de los indicadores de autoeficacia superó el valor de 2 en una escala entre 0 y 3 , siendo los ítems de consideración del preservativo como método fiable ( $M$ de 2.66), de comodidad a la hora de comprarlos ( $M$ de 2.33) y de hablar abiertamente de su utilización con nuevas parejas sexuales antes de iniciar el coito ( $M$ de 2.33 ) aquellos donde la percepción de autoeficacia fue mayor. Al contrario, la percepción de autoeficacia resultó un tanto inferior en los ítems de comodidad a la hora de ponerse o sobre todo poner a la pareja el preservativo ( $M$ de 1.53) o sugerir a una pareja su uso ( $M$ de 1.86). Con todo, la puntuación media en autoeficacia en una escala con valores entre 0 y 24 fue de 17. Esta puntuación apenas varió en función de la condición clínica, no encontrándose diferencias significativas ni en chicos ( $t=0.62$; $p=.53)$ ni en chicas $(t=-1.24 ; p=.21)$. En chicos tampoco se encontraron diferencias entre grupo control y subclínico en ninguno de los ítems de la escala de autoeficacia pero sí se encontraron en chicas: concretamente, las del grupo subclínico se sentían más cómodas a la hora de comprar preservativos $(t=-2.03 ; p=0.04)$. En todo caso, el tamaño del efecto para esta diferencia fue pequeño $(d=0.30)$.

En resumen, las chicas subclínicas muestran un riesgo significativamente mayor de transmisión del VIH o de una ITS asociado a diferentes aspectos de su conducta sexual (entre otras, algunas prácticas de alto riesgo como el uso inconsistente del preservativo con parejas esporádicas), no sucediendo así en chicos. En cuanto a la severidad percibida del VIH, todos los participantes comparten la percepción de que el VIH es una enfermedad grave pero fueron nuevamente las chicas subclínicas las que más valoraban que su conducta sexual suponía cierto riesgo de infección y también a las que más miedo les producía esta idea. Finalmente, la percepción de autoeficacia en el uso del preservativo para el conjunto de participantes fue alta, sobre todo a la hora de valorarlo como un método de prevención fiable y de sentirse cómodos a la hora de adquirirlos (especialmente en chicas subclínicas).

\subsection{Comportamiento sexual online}

El comportamiento sexual online de chicos y chicas control y subclínicos se comparó a través del Cuestionario de Adicción al Cibersexo. Concretamente, se analizó la prevalencia de los 25 ítems que conforman el cuestionario (tabla 27), la puntuación media en la escala general de adicción al cibersexo y en las 5 dimensiones que la integran (tabla 28) y la prevalencia de los principales perfiles de consumo de cibersexo (tabla 29). 
Las actividades sexuales online más frecuentes en chicos (tabla 27) son aquellas que no requieren interactuar con otros usuarios (factor 2), como la búsqueda de pornografía en Internet (realizado por el $82.8 \%$ de los chicos control y el $91.9 \%$ de los subclínicos) y la masturbación durante su visionado (92.9\% y 95.3\%). También es frecuente contar con sitios sexuales de referencia a la hora de buscar pornografía en Internet (69.7\% y $79.1 \%$ ) o el acceso a dichos contenidos desde distintos dispositivos (44.4\% y $54.7 \%$ ). En este factor, el único comportamiento sexual significativamente más frecuente en chicos subclínicos que control $\left(x^{2}=4.46 ; p=.03\right)$ sería el de permanecer despierto hasta altas horas por practicar cibersexo (57\% frente al $41.4 \%)$.

A estas conductas sexuales les siguen en frecuencia aquellas que sí requieren del contacto con otros usuarios (factor 3). Así, entre el 39.4-54.7\% (chicos control y subclínicos respectivamente) ha empleado insinuaciones sexuales mientras chatea con otros usuarios, entre el $27.3-39.5 \%$ ha participado en chats sexuales y entre el $24.2-46.5 \%$ ha utilizado Internet para conocer y quedar cara a cara con otra persona con fines románticos. La prevalencia en participantes subclínicos es mayor en 4 de los 6 comportamientos que integran este factor, con tamaños del efecto entre pequeños y moderados ( $V$ entre 0.15 y 0.23 ).

Si bien menos frecuentes, algunos de los comportamientos incluidos en el primer factor (indicadores de adicción al cibersexo) también alcanzan prevalencias relativamente altas: así, casi el $50 \%$ de los chicos subclínicos emplea internet para experimentar con distintos aspectos de su sexualidad (como por ejemplo las fantasías homosexuales en un varón heterosexual) frente al $32.3 \%$ de los chicos control $\left(x^{2}=4.54 ; p=.03\right)$. Junto con los ítems de experiencia de malestar cuando no se puede acceder a cibersexo $\left(x^{2}=5.17 ; p=.02\right)$ y sobre todo de valoración del propio consumo de cibersexo como adictivo $\left(x^{2}=10.12 ; p<.001\right)$, este es uno de los comportamientos donde la prevalencia en chicos subclínicos es significativamente superior a la obtenida en chicos control, con tamaños del efecto entre pequeños y moderados ( $V$ entre 0.16 y 0.23$)$.

La prevalencia de comportamientos que sugieren cierta percepción de gravedad del propio comportamiento (factor 5) como por ejemplo ocultar a otras personas las actividades sexuales que se realizan online ( $27.3 \%$ en chicos control y $26.7 \%$ en subclínicos) o el prometerse a uno mismo abandonar el cibersexo ( $17.2 \%$ y $19.8 \%$ respectivamente) es relativamente alta y en un ítem concreto varía en función de la condición clínica $\left(x^{2}=4.5 ; p=.03\right)$ : el $7 \%$ de los chicos subclínicos afirmó castigarse cuando practica cibersexo frente al $1 \%$ de los control $(V=0.15)$. Finalmente, la prevalencia de comportamientos que implican inversión económica durante la práctica del cibersexo (factor 4) es baja y sin variación en función de la condición clínica. 
Resultados similares se obtienen al analizar la puntuación media en las $\mathbf{5}$ dimensiones y la escala general de consumo de cibersexo en chicos (tabla 28). El factor del cuestionario donde la puntuación media es mayor es el de comportamiento online solitario no compulsivo, donde la puntuación en chicos control y subclínicos es de 4.04 (DT=1.31) y 4.62 (DT=1.65) respectivamente en un rango entre 0 y 6 . Considerablemente inferior sería la media en el factor de comportamiento online social (entre 1.41 y 2.25 ) y sobre todo en el de compulsividad sexual online ( $M$ entre 0.99 y 1.60 ) a pesar de que el primero mantiene el mismo rango de puntuaciones y el rango en el segundo es incluso mayor (entre 0 y 8). La puntuación media para el factor 5 ( 0.45 y 0.53 en un rango entre 0 y 3 ) y sobre todo el 4 ( 0.10 y 0.10 en un rango entre 0 y 2) sería muy baja. En función del sexo, los chicos subclínicos obtienen puntuaciones mayores en 4 de las 6 variables. Ordenadas de menor a mayor en función del tamaño del efecto, los participantes subclínicos obtienen comparativamente mayores puntuaciones en el factor $2(d=0.40)$, el $1(d=0.42)$, el $3(d=0.52)$ y la puntuación total del cuestionario $(d=0.78)$. En este último caso, las diferencias entre ambos grupos alcanzan un tamaño del efecto especialmente grande.

En cuanto a la prevalencia de los distintos perfiles de consumo de cibersexo en chicos (tabla 29), ésta varía significativamente en función de la condición clínica ( $\left.X^{2}=9.98 ; p=.007 ; V=0.23\right)$. La mayoría de los chicos control (el 69.7\%) obtiene puntuaciones propias de un perfil de consumo recreativo de cibersexo y el $30.3 \%$ restante es clasificado como usuario de riesgo. Por el contrario, menos de la mitad de los subclínicos (el $49.4 \%$ ) es clasificado como usuario recreativo y el porcentaje restante se reparte sobre todo entre usuarios de riesgo (47.1\%) y un pequeño porcentaje de adictos al cibersexo (3.5\%).

En chicas, la prevalencia de actividades sexuales online (tabla 27) es notablemente inferior a la documentada en chicos pero se mantienen algunos de los patrones antes comentados. Para empezar, en el factor 2 se agrupan los ítems de mayor prevalencia como por ejemplo ocultar el contenido de la pantalla a otras personas ( $15.2 \%$ en chicas control y $44.8 \%$ en subclínicas), buscar pornografía a través de Internet (36.4\% y 79.2\%) o masturbarse con dicho material (21.2\% y 59.4\%). En estos dos últimos ítems es donde la diferencia entre chicas control y subclínicos alcanza una magnitud mayor $(V>0.35)$, si bien las discrepancias entre grupos en los 6 comportamientos que comprende este factor alcanzarían la significación estadística. Les seguirían en frecuencia los comportamientos asociados al uso de Internet para contactar con otros usuarios (factor 2). Así, el $10.1 \%$ de las participantes control y el $24 \%$ de las subclínicas habría participado en chats sexuales, el $14.1 \%$ y el $30.2 \%$ habría quedado cara a cara con alguien conocido por Internet y entre el $5.1 \%$ y el $18.8 \%$ tendría un alias que utilizaría cuando 
navega por Internet con fines sexuales. Nuevamente la prevalencia en participantes subclínicas de los comportamientos contemplados en este factor es superior al de las control en todos los casos ( $V$ entre 0.14 y 0.24 ) excepto en tropezar con material sexual ilegal $\left(X^{2}=3.29 ; p=.06\right)$. Mucho más baja sería la prevalencia de los principales síntomas de adicción al cibersexo (factor 1), que en el grupo de chicas control es nula en prácticamente todos los casos. Las únicas excepciones son el uso de internet para explorar aspectos alternativos de la sexualidad y el uso del cibersexo como recompensa, afirmaciones a las que el $4 \%$ y el $1 \%$ de las chicas control responderían afirmativamente. En contraposición, un $8.3 \%$ de las chicas subclínicas afirma experimentar malestar cuando no puede acceder a contenidos sexuales $\left(X^{2}=8.60\right.$; $p=.003$ ), un $10.4 \%$ percibe que el sexo interfiere en aspectos importantes de su día a día $\left(X^{2}=10.87 ; p<.001\right)$ y un $4.2 \%$ valora su consumo como adictivo $\left(X^{2}=4.21 ; p=.04\right)$. Excepto para ocultar a otras personas lo que se hace en Internet (conducta realizada por el $12.1 \%$ de las chicas control y el $40.6 \%$ de las subclínicas), la prevalencia de los 5 comportamientos que integran los factores 4 y 5 del cuestionario de cibersexo es prácticamente nula en ambos grupos. En el grupo subclínico, un $14.6 \%$ de las chicas control habría adquirido productos sexuales a través de Internet y un $8.3 \%$ se habría prometido abandonar el cibersexo, porcentajes en ambos casos significativamente superiores a los encontrados en participantes control ( $V$ de 0.25 y 0.32 respectivamente).

La diferencia entre chicas control y subclínicas se acentúa al analizar la puntuación media en las 5 dimensiones y en la escala general del cuestionario de adicción al cibersexo (tabla 28), siendo la puntuación media de las subclínicas superior a la obtenida por las control en todos los casos ( $p<.001$ en los 6 contrastes). Excepto en el factor $4(d=0.46)$, la diferencia de medias entre ambos grupos alcanza un tamaño grande o muy grande en todos los contrastes: así, la puntuación media en chicas subclínicas supera en 0.35 puntos a la obtenida por las control en el factor $5(d=0.71)$, en 0.8 en el factor $3(d=0.80)$, en 0.51 en el factor 1 ( $d=1.02)$, en 1.64 en el factor $2(d=1.21)$ y en 3.45 en la puntuación total $(d=1.40)$.

Por último, encontramos también notables diferencias en la distribución de porcentajes entre los distintos perfiles de consumo de cibersexo en chicas (tabla 29). En chicas control, el 100\% obtuvo puntuaciones propias de un consumo recreativo de cibersexo mientras que este porcentaje bajaba hasta el $88.4 \%$ en el caso de las chicas del grupo subclínico. En este grupo, el $11.6 \%$ restante se clasificó como usuarias de riesgo, siendo nulo el porcentaje de participantes subclínicas adictas al cibersexo. Las diferencias en la distribución de porcentajes entre ambos grupos alcanzó la máxima significación estadística $\left(X^{2}=12.15 ; p<.001\right)$ y un tamaño del efecto entre pequeño y moderado $(V=0.25)$. 


\begin{tabular}{|c|c|c|c|c|c|c|c|c|c|}
\hline & & \multicolumn{4}{|c|}{ Chicos $(N=187)$} & \multicolumn{4}{|c|}{ Chicas $(N=197)$} \\
\hline & & Control $(n=100)$ & Subclínicos $(n=87)$ & Chi Cuadrado & $V$ de Cramer & Control $(n=99)$ & Subclínicas ( $n=98)$ & Chi Cuadrado & $V$ de Cramer \\
\hline \multirow{8}{*}{ Factor 1} & Pasar $>5$ horas semanales en Internet con fines sexuales & $10.1 \%$ & $17.4 \%$ & 2.12 & 0.10 & $0 \%$ & $2.1 \%$ & 2.08 & 0.10 \\
\hline & Gastar más dinero del planeado en sexo en Internet & $0 \%$ & $2.3 \%$ & 2.32 & 0.11 & $0 \%$ & $0 \%$ & NA & NA \\
\hline & El sexo en Internet interfiere en aspectos importantes & $15.2 \%$ & $25.6 \%$ & 3.12 & 0.13 & $0 \%$ & $10.4 \%$ & $10.87 * * *$ & 0.23 \\
\hline & Emplear Internet para experimentar sexualmente & $32.3 \%$ & $47.7 \%$ & $4.54^{*}$ & 0.16 & $4 \%$ & $25 \%$ & $17.41 * * *$ & 0.29 \\
\hline & Disponer de sitio web propio con material sexual & $4 \%$ & $3.5 \%$ & 0.03 & 0.01 & $0 \%$ & $2.1 \%$ & 2.08 & 0.10 \\
\hline & Emplear el sexo en Internet como recompensa & $17.2 \%$ & $20.9 \%$ & 0.42 & 0.04 & $1 \%$ & $4.2 \%$ & 1.94 & 0.10 \\
\hline & Experimentar malestar si no accede a cibersexo & $9.1 \%$ & $20.9 \%$ & $5.17 *$ & 0.16 & $0 \%$ & $8.3 \%$ & $8.60 * *$ & 0.21 \\
\hline & Valorar el consumo de cibersexo como adictivo & $6.1 \%$ & $22.1 \%$ & $10.12 * * *$ & 0.23 & $0 \%$ & $4.2 \%$ & $4.21 *$ & 0.14 \\
\hline \multirow{6}{*}{ Factor 2} & Tener sitios sexuales de referencia & $69.7 \%$ & $79.1 \%$ & 2.10 & 0.10 & $6.1 \%$ & $29.2 \%$ & $18.07 * * *$ & 0.30 \\
\hline & Buscar pornografía en Internet & $82.8 \%$ & $91.9 \%$ & 3.32 & 0.13 & $36.4 \%$ & $79.2 \%$ & $36.52 * * *$ & 0.43 \\
\hline & Masturbarse mientras se está conectado a Internet & $92.9 \%$ & $95.3 \%$ & 0.48 & 0.05 & $21.2 \%$ & $59.4 \%$ & $29.57 * * *$ & 0.38 \\
\hline & Acceder a pornografía desde distintos ordenadores & $44.4 \%$ & $54.7 \%$ & 1.19 & 0.10 & $3 \%$ & $16.7 \%$ & $10.30 * * *$ & 0.23 \\
\hline & Ocultar a otras personas lo que se tiene en la pantalla & $72.7 \%$ & $73.3 \%$ & 0.007 & 0.006 & $15.2 \%$ & $44.8 \%$ & $20.49 * * *$ & 0.32 \\
\hline & Permanecer despierto hasta tarde por practicar cibersexo & $41.4 \%$ & $57 \%$ & 4.46* & 0.15 & $6.1 \%$ & $19.8 \%$ & $8.22^{* *}$ & 0.20 \\
\hline \multirow{6}{*}{ Factor 3} & Participar en chats sexuales & $27.3 \%$ & $39.5 \%$ & 3.13 & 0.13 & $10.1 \%$ & $24 \%$ & $6.65 * *$ & 0.18 \\
\hline & Tener un nickname para navegar por Internet & $13.1 \%$ & $29.1 \%$ & $7.16 * *$ & 0.19 & $5.1 \%$ & $18.8 \%$ & $8.79 * *$ & 0.21 \\
\hline & Correr riesgos mientras se contacta con otros usuarios & $10.1 \%$ & $20.9 \%$ & $4.20 *$ & 0.15 & $3 \%$ & $10.4 \%$ & $4.27^{*}$ & 0.14 \\
\hline & Quedar cara a cara con alguien conocido en Internet & $24.2 \%$ & $46.5 \%$ & $10.08 * * *$ & 0.23 & $14.1 \%$ & $30.2 \%$ & $7.32 * *$ & 0.19 \\
\hline & Hacer insinuaciones sexuales a otros usuarios online & $39.4 \%$ & $54.7 \%$ & $4.30^{*}$ & 0.15 & $9.1 \%$ & $28.1 \%$ & $11.73 * * *$ & 0.24 \\
\hline & Tropezar con material sexual ilegal estando en Internet & $27.3 \%$ & $36 \%$ & 1.64 & 0.09 & $12.1 \%$ & $21.9 \%$ & 3.29 & 0.13 \\
\hline \multirow{2}{*}{ Factor 4} & Afiliarse a sitios sexuales para acceder a material sexual & $6.1 \%$ & $10.5 \%$ & 1.19 & 0.08 & $1 \%$ & $2.1 \%$ & 0.371 & 0.04 \\
\hline & Comprar productos sexuales a través de Internet & $4 \%$ & $7 \%$ & 0.77 & 0.06 & $1 \%$ & $14.6 \%$ & $12.64 * * *$ & 0.25 \\
\hline \multirow{3}{*}{ Factor 5} & Ocultar a otras personas lo que se hace en Internet & $27.3 \%$ & $26.7 \%$ & 0.007 & 0.006 & $12.1 \%$ & $40.6 \%$ & $20.50 * * *$ & 0.32 \\
\hline & Prometer a uno mismo abandonar el sexo en Internet & $17.2 \%$ & $19.8 \%$ & 0.207 & 0.03 & $1 \%$ & $8.3 \%$ & $5.95 *$ & 0.17 \\
\hline & Castigarse a uno mismo cuando se busca sexo en Internet & $1 \%$ & $7 \%$ & 4.5* & 0.15 & $0 \%$ & $0 \%$ & NA & NA \\
\hline
\end{tabular}

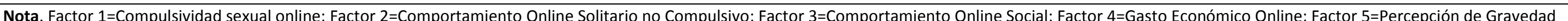
del Propio Comportamiento; NA=No aplicable.

${ }^{*} p<0.05 ;{ }^{* *} p<0.01 ; * * * p<0.001$ 
Tabla 28. Puntuación media en las 5 dimensiones y la puntuación total del Cuestionario de Adicción al Cibersexo en chicos y chicas control y subclínicos.

\begin{tabular}{|c|c|c|c|c|c|c|c|c|c|}
\hline & \multirow[b]{2}{*}{ Rango } & \multicolumn{4}{|c|}{ Chicos $(N=187)$} & \multicolumn{4}{|c|}{ Chicas $(N=197)$} \\
\hline & & $\begin{array}{c}\text { Control }(n=100) \\
M(D T)\end{array}$ & $\begin{array}{c}\text { Subclínicos }(n=87) \\
M(D T)\end{array}$ & $t$ de Student & $d$ de Cohen & $\begin{array}{c}\text { Control }(n=99) \\
M(D T)\end{array}$ & $\begin{array}{c}\text { Subclínicas }(n=98) \\
\qquad M(D T)\end{array}$ & $t$ de Student & $d$ de Cohen \\
\hline Factor 1. Compulsividad Sexual Online & $0-8$ & $0.99(1.10)$ & $1.60(1.73)$ & $-3.15 * *$ & 0.42 & $0.05(0.22)$ & $0.56(0.98)$ & b & 1.02 \\
\hline Factor 2. Comportamiento Online Solitario no Compulsivo & $0-6$ & $4.04(1.31)$ & $4.62(1.65)$ & $-2.68 * *$ & 0.40 & $0.87(1.23)$ & $2.51(1.57)$ & $-8.09 * * *$ & 1.21 \\
\hline Factor 3. Comportamiento Online Social & $0-6$ & $1.41(1.47)$ & $2.25(1.76)$ & $-3.53 * * *$ & 0.52 & $0.53(0.83)$ & $1.33(1.33)$ & $-5.01 * * *$ & 0.8 \\
\hline Factor 4. Gasto Económico Online & $0-2$ & $0.10(0.30)$ & $0.17(0.43)$ & -1.33 & 0.17 & $0.02(0.14)$ & $0.16(0.42)$ & $-3.23 * * *$ & 0.46 \\
\hline Factor 5. Percepción de Gravedad del Propio Comportamiento & $0-3$ & $0.45(0.65)$ & $0.53(0.74)$ & -0.77 & 0.11 & $0.13(0.33)$ & $0.48(0.59)$ & $-5.16 * * *$ & 0.71 \\
\hline Puntuación total Cuestionario de Adicción al Cibersexo & $0-24$ & $6.94(3.06)$ & $9.23(4.03)$ & $-4.36 * * *$ & 0.78 & $1.61(1.97)$ & $5.06(3.20)$ & $-9.06 * * *$ & 1.40 \\
\hline
\end{tabular}

Tabla 29. Perfiles de consumo de cibersexo en chicos y chicas control y subclínicos.

\begin{tabular}{|c|c|c|c|c|c|c|c|c|}
\hline & \multicolumn{4}{|c|}{ Chicos $(N=187)$} & \multicolumn{4}{|c|}{ Chicas ( $N=197)$} \\
\hline & Control $(n=100)$ & Subclínicos $(n=87)$ & Chi Cuadrado & $V$ de Cramer & Control ( $n=99)$ & Subclínicas ( $n=98$ ) & Chi Cuadrado & $V$ de Cramer \\
\hline Usuarios recreativos & $69.7 \%$ & $49.4 \%$ & & & $100 \%$ & $88.4 \%$ & & \\
\hline Usuarios de riesgo & $30.3 \%$ & $47.1 \%$ & $9.98 * *$ & 0.23 & $0 \%$ & $11.6 \%$ & $12.15 * * *$ & 0.25 \\
\hline Adictos al cibersexo & $0 \%$ & $3.5 \%$ & & & $0 \%$ & $0 \%$ & & \\
\hline
\end{tabular}

Nota. ${ }^{*} p<0.05 ;{ }^{* *} p<0.01 ; * * * p<0.001$ 
En definitiva, el consumo de cibersexo del conjunto de los participantes se caracterizó por una clara preferencia hacia actividades sexuales que se realizan en solitario (como el visionado de pornografía y la masturbación con dicho material) frente a otras que requieren del contacto con otros usuarios (como el uso del chat con fines sexuales). Asimismo, resultaron frecuentes algunos comportamientos que sugerirían la presencia de problemas de adicción al cibersexo, como por ejemplo experimentar malestar (ira, frustración, ansiedad, etc.) cuando no se logra acceder a contenidos sexuales en la red. Este mismo patrón se aplica tanto a chicos como a chicas, si bien la frecuencia de todos estos comportamientos sexuales online en este último grupo era inferior. Asimismo, la condición clínica desempeñaba un papel importante en la manifestación de la conducta sexual online: concretamente, los chicos y sobre todo las chicas subclínicas obtenían puntuaciones superiores a los participantes control en las dimensiones evaluadas (especialmente en las chicas). Esto se traduce en perfiles de consumo de cibersexo más severos y en porcentajes relativamente altos de participantes con puntuaciones que sugieren un uso problemático de cibersexo (sobre todo un perfil de consumo de riesgo).

\subsection{Variables clínicas sexuales}

La tendencia a la búsqueda de sensaciones sexuales y la disposición erotofílica-erotofóbica en participantes control y subclínicos se analizó a través de las puntuaciones en dos cuestionarios: la Escala de Búsqueda de Sensaciones Sexuales (BSS) y la Encuesta Revisada de Opinión Sexual (EROS) (tabla 30). Este último cuestionario se incluyó en la investigación tardíamente -una vez finalizada la evaluación de las participantes control-, de modo que no contamos con datos para chicas de esta condición clínica. Para aprovechar los datos de los que sí disponemos, se propone una metodología de análisis alternativa: comparar a través de una prueba T para una única muestra la puntuación media de las chicas subclínicas (de las que sí disponemos de datos) con la puntuación obtenida por 152 mujeres de alrededor de 29 años que participaron en el estudio de validación original del cuestionario (Del Rio-Olvera et al., 2013). Este último grupo equivaldría al grupo control. Sin duda, esta metodología es menos fiable que la que venimos empleando para el resto de análisis porque, entre otras cosas, implica asumir la comparabilidad de ambas muestras (la del estudio de validación original y nuestra investigación). Sin embargo, es la única alternativa para contrastar la disposición erotofílicaerotofóbica en chicas con puntuaciones subclínicas en CS y población normativa.

Si comenzamos analizando la puntuación media en la escala de búsqueda de sensaciones sexuales en función de la condición clínica (tabla 30), la puntuación media de los participantes subclínicos -tanto chicos como chicas- supera la obtenida por los jóvenes del grupo control. Más concretamente, la puntuación de chicos y chicas subclínicos es de 30.41 ( $D T=5.62)$ y 27.47 
$(D T=5.92)$ respectivamente en una escala con valores entre 11 y 44 , puntuación que les sitúa sobre todo en el caso de los chicos subclínicos- en el extremo superior del rango. Si bien la diferencia entre participantes control y subclínicos alcanza la máxima significación estadística $(p<.001)$ tanto en chicos como en chicas, la magnitud del tamaño del efecto revela que la diferencia entre condiciones es más acusada en el caso de las chicas ( $d$ de 1.31 frente a 0.75).

$\mathrm{Si}$ analizamos las puntuaciones en la dimensión de erotofilia-erotofobia (tabla 30), los 3 grupos de los que disponemos de datos propios (chicos control y chicos y chicas subclínicos) obtienen puntuaciones por encima de 100 en una escala con valores entre 20 y 140 , puntuación que les sitúa en el extremo erotofílico del continuo. En función de la condición clínica, el nivel de erotofilia en hombres control y subclínicos apenas varía ( $t=0.262 ; p=.79$ ) pero sí lo hace y mucho en mujeres $(t=6.49 ; p<.001)$. Más concretamente, la puntuación de las participantes subclínicas queda 32 puntos por encima de la obtenida por Del Rio-Olvera et al. (2013) en una muestra de 152 mujeres con una edad media de 29 años ( $M$ de 109.14 y 79.69 respectivamente), diferencia entre grupos que alcanzaría un tamaño del efecto muy grande $(d=1.47)$. A pesar de la robustez de los resultados, éstos deben ser tomados con cautela por las razones esgrimidas. Si bien el análisis empleado (prueba T para una única muestra) permite contrastar una media muestral (en este caso, la puntuación en la escala de erotofiliaerotofobia del grupo de chicas subclínicas) con una media de referencia o poblacional (la del estudio de Del Rio-Olvera et al.), esta prueba asume que la media del valor tomado como criterio de contraste tiene una varianza 0 . De modo que cuando la varianza de la variable criterio es baja, la precisión del contraste estadístico es muy alta mientras que cuando la varianza de la variable de contraste es alta -como en este caso-, el contraste pierde fiabilidad.

En resumen, los participantes subclínicos son más buscadores de sensaciones sexuales que los control, especialmente en el caso de las chicas. Estas últimas son además más erotofílicas, diferencia que no se aprecia en chicos porque tanto los control como los subclínicos se sitúan en el extremo superior de este continuo. 
Tabla 30. Variables clínicas sexuales en chicos y chicas control y subclínicos

\begin{tabular}{|c|c|c|c|c|c|c|c|c|c|}
\hline & \multirow{2}{*}{ Rango } & \multicolumn{4}{|c|}{ Chicos $(N=187)$} & \multicolumn{4}{|c|}{ Chicas $(N=197)$} \\
\hline & & $\begin{array}{c}\text { Control }(n=100) \\
M(D T)\end{array}$ & $\begin{array}{c}\text { Subclínicos }(n=87) \\
M(D T)\end{array}$ & $t$ de Student & $d$ de Cohen & $\begin{array}{c}\text { Control }(n=99) \\
M(D T)\end{array}$ & $\begin{array}{c}\text { Subclínicas }(n=98) \\
M(D T)\end{array}$ & $t$ de Student & $d$ de Cohen \\
\hline Escala de Búsqueda de Sensaciones Sexuales (BSS) & $11-44$ & $26.36(5.20)$ & $30.41(5.62)$ & $-5.02 * * *$ & 0.75 & $20.24(5.40)$ & $27.47(5.92)$ & $-8.85 * * *$ & 1.31 \\
\hline Encuesta Revisada de Opinión Sexual (EROS) & $20-140$ & $111.72(10.14)$ & $111.04(14.25)$ & 0.262 & 0.05 & $79.69(19.22)^{a}$ & $109.14(20.79)$ & $6.49 * * *$ & 1.47 \\
\hline
\end{tabular}

Nota. ${ }^{a}=$ datos obtenidos por Del Rio-Olvera et al. (2013) en una muestra de 152 mujeres sanas con una edad media de 29 años.

${ }^{*} p<0.05 ;{ }^{* *} p<0.01 ;{ }^{* * *} p<0.001$ 
5.5 Evaluación hormonal: determinación del nivel de testosterona

De los 384 participantes que completaron la segunda fase del estudio, 80 se sometieron a una evaluación complementaria para trazar su perfil hormonal a través de una prueba de concentración de testosterona en saliva. Para asegurar la representatividad de los resultados, en la selección de esta submuestra se tuvieron en cuenta dos criterios: el sexo y la condición clínica. De este modo, la submuestra quedó compuesta por 20 participantes de cada una de las 4 condiciones clínicas. Esta prueba permite la obtención de un índice de concentración de testosteriona que se expresa en picogramos por mililitro $(\mathrm{pg} / \mathrm{mL})$. En hombres de entre 18 y 30 años, los valores normales de concentración de testosterona oscilan entre 47.2 y $136.2 \mathrm{pg} / \mathrm{mL}$ mientras que en mujeres varían en un rango entre 7.9 y $50.4 \mathrm{pg} / \mathrm{mL}$. Valores por encima o por debajo de estos umbrales indicarían un cuadro clínico alterado (hiper o hipogonadismo). El perfil hormonal de chicos y chicas control y subclínicos se comparó a través de los niveles medios de concentración de testosterona en saliva $(\mathrm{pg} / \mathrm{mL})$ y del porcentaje de participantes con valores por encima y por debajo del rango normal (tabla 31).

Como se aprecia en la tabla 31, ninguna de las variables del perfil hormonal analizadas varía en función del grupo clínico. En chicos, el nivel medio de testosterona en saliva en participantes control y subclínicos resulta prácticamente idéntico $(t=-0.086 ; p=.93)$ y lo mismo sucede cuando se compara el porcentaje de participantes de ambos grupos con niveles que sugieren la presencia de hiper $\left(x^{2}=0.095 ; p=.75\right)$ o hipogonadismo $\left(x^{2}=0.122 ; p=.72\right)$. Si en lugar de analizar la significación de las diferencias analizamos las tendencias en cada medida, parece que los chicos subclínicos $(M=63.65 ; D T=26.77)$ tienden a mostrar niveles medios de testosterona ligeramente superiores a los chicos control $(M=62.91 ; D T=27.54)$, así como un mayor porcentaje de casos de hipergonadismo (21.8\% frente al $20 \%)$ y menor de hipogonadismo (5.7\% frente a $7 \%)$.

En chicas, la concentración media de testosterona $(t=-149 ; p=.88)$ y el porcentaje de casos de hipergonadismo $\left(x^{2}=0.029 ; p=.86\right)$ también resulta equivalente en ambos grupos clínicos. En este caso, ninguna obtuvo niveles de testosterona por debajo del rango normal (hipogonadismo). Los niveles medios de testosterona en chicas control $(M=38.12 ; D T=18.96)$ y subclínicas $(M=38.96 ; D T=16.48)$ son considerablemente más bajos que los obtenidos en chicos pero se replica la tendencia a que las participantes subclínicas obtengan niveles muy ligeramente superiores de concentración de testosterona. Esta tendencia se invierte al analizar el porcentaje de participantes con hipergonadismo, que sería casi un punto porcentual superior en el caso de las participantes control (15.2\% frente al $14.3 \%)$. 
Tabla 31. Niveles de testosterona en saliva en chicos y chicas control y subclínicos

\begin{tabular}{|c|c|c|c|c|c|c|c|c|}
\hline & \multicolumn{4}{|c|}{ Chicos $(N=40)$} & \multicolumn{4}{|c|}{ Chicas $(N=40)$} \\
\hline & $\begin{array}{c}\text { Control }(n=20) \\
M(D T) \circ \%\end{array}$ & $\begin{array}{c}\text { Subclínicos }(n=20) \\
M(D T) \text { ० \% }\end{array}$ & $\begin{array}{c}\text { Estadístico de } \\
\text { contraste }\end{array}$ & $\begin{array}{c}\text { Tamaño del } \\
\text { efecto }\end{array}$ & $\begin{array}{c}\text { Control }(n=20) \\
M(D T) \circ \% \\
\end{array}$ & $\begin{array}{c}\text { Subclínicas }(n=20) \\
M(D T) \circ \%\end{array}$ & $\begin{array}{c}\text { Estadístico de } \\
\text { contraste }\end{array}$ & $\begin{array}{c}\text { Tamaño del } \\
\text { efecto }\end{array}$ \\
\hline Concentración de testosterona en saliva $(\mathrm{pg} / \mathrm{mL})$ & $62.91(27.54)$ & $63.65(26.77)$ & $t=-0.086$ & $d=0.02$ & $38.12(18.96)$ & $38.96(16.48)$ & $t=-0.149$ & $d=0.04$ \\
\hline$\%$ con valores por encima del rango normal ${ }^{a}$ & $20 \%$ & $21.8 \%$ & $x^{2}=0.095$ & $V=0.02$ & $15.2 \%$ & $14.3 \%$ & $x^{2}=0.029$ & $V=0.01$ \\
\hline$\%$ con valores por debajo del rango normal ${ }^{b}$ & $7 \%$ & $5.7 \%$ & $x^{2}=0.727$ & $V=0.02$ & $0 \%$ & $0 \%$ & NA & NA \\
\hline
\end{tabular}

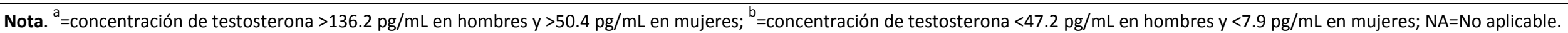

${ }^{*} p<0.05 ; * * p<0.01 ; * * p<0.001$ 


\section{Severidad y consecuencias de la CS}

La severidad y consecuencias del cuadro clínico de CS se evaluaron a través del Inventario de Conducta Sexual Compulsiva (CSBI) y de la Escala de Consecuencias Cognitivas y Conductuales de la Conducta Sexual (CBOSB). El carácter clínico y la especificidad de alguna de sus preguntas desaconsejan su empleo como instrumento de screening, de modo que estos cuestionarios se aplicaron únicamente a los participantes del grupo subclínico. Así, la severidad y consecuencias del cuadro clínico de CS se analizaron comparando las puntuaciones medias en el CSBI y el CBOSB de los 87 chicos y las 98 chicas que conformaban el grupo de participantes subclínicos (tabla 32) y comparando el porcentaje de participantes que experimentaron alguna de las consecuencias conductuales incluidas en el cuestionario CBOSB (tabla 33). Asimismo, se correlacionaron las subescalas que conforman estos dos instrumentos con el objetivo de explorar la relación entre severidad y consecuencias de la CS (tabla 34).

Como se aprecia en la tabla 32, la severidad del cuadro clínico de CS medida a través de la puntuación total y las subescalas del CSBI es baja. La puntuación total de los chicos y chicas subclínicos en la escala general (rango de 28 a 140) es de 46.81 (DT=10.08) y 43.52 (DT=10.25) respectivamente, puntuaciones que en ambos casos quedarían muy cerca del extremo inferior del rango y corresponden con una manifestación leve del cuadro clínico de CS. Si bien el uso de rangos de respuesta distintos dificulta la comparación entre factores, el primero (control) sería aquel en el que los y las participantes obtienen una puntación media mayor ( $M$ de 29.16 y 25.47 respectivamente en una escala con un rango entre 13 y 65), seguido del factor 3 de violencia ( $M$ de 9.12 y 9.19 y rango entre 7 y 30 ) y del factor 2 de abuso ( $M$ de 8.73 y 8.84 y rango entre 8 y 45). En función del sexo, los chicos experimentan una mayor severidad general del cuadro clínico ( $t=2.19 ; p=.03$ ) y en particular de aquellos síntomas que se agrupan en el primer factor y denotan una pérdida del control sobre la propia conducta sexual ( $t=3.05$; $p=.003)$. El efecto del sexo en el primer contraste sería entre pequeño y moderado $(d=0.32)$ y moderado en el segundo $(d=0.45)$.

Cuando analizamos la puntuación media en las dos subescalas que comprende el CBOSB (tabla 32), tampoco parece que las consecuencias del cuadro clínico de CS resulten especialmente notables para los chicos y chicas evaluados. Así, la puntuación media en la escala de consecuencias cognitivas de la CS es de $11.82(D T=16.14)$ y 11.21 (DT=13.08) en chicos y chicas respectivamente (rango entre 0 y 60$)$ y de $1.89(D T=1.86)$ y $1.39(D T=1.74)$ en la escala de consecuencias conductuales (rango de 0 a 16), puntuación media que en ambos casos se sitúa en el extremo más bajo del rango de puntuaciones. Si bien la puntuación media de los chicos es superior a la de las chicas en las dos subescalas -sobre todo en la de consecuencias 
conductuales-, en ningún caso éstas alcanzan la significación estadística. Si prestamos atención al porcentaje de participantes que experimentaron diferentes consecuencias conductuales de la CS (tabla 33), las más frecuentes tanto en chicos como en chicas fueron: la experimentación de sentimientos de culpabilidad ( $45.6 \%$ en chicos y $27.8 \%$ en chicas) y vergüenza ( $31.1 \%$ y 24.7\%) derivados de la conducta sexual, haber tenido problemas con una pareja estable (15.6\% y $8.2 \%$ ) o con amigos y familiares (11.1\% y $10.3 \%)$, haber contraído una ITS (11.1\% y 7.2\%) o haber experimentado malestar emocional (8.9\% y $12.4 \%)$. En chicos resulta también frecuente el haber causado daño a una pareja sexual (25.6\%) o el que una pareja sexual les haya causado daño (22.2\%) mientras que en chicas sucedería a la inversa (el 33\% informa haber sido víctima de daños físicos por parte de una pareja sexual y el $11.3 \%$ haber infligido daño). En función del sexo, únicamente se aprecian diferencias significativas en el porcentaje de participantes que dijeron haberse sentido culpable por su conducta sexual $\left(x^{2}=6.33 ; p=.01\right)$ y que causaron algún tipo de daño a una pareja sexual $\left(x^{2}=6.34 ; p=.012\right)$. En ambos casos, los chicos informan de una frecuencia mayor y el sexo influye de manera pequeña $(V=0.18)$.

Para terminar, las correlaciones entre la escala CSBI y la CBOSB (tabla 34) demuestran la existencia de una relación positiva y significativa entre la severidad del cuadro clínico de CS y la presencia de consecuencias negativas derivadas, relación que resultaría especialmente intensa en el caso de las chicas. Así, la puntuación total en el CSBI correlaciona de forma positiva y significativa con la puntuación de las chicas en la escala CBOSB-cognitivas ( $r=.316$; $p=.002)$ y con la de los chicos $(r=.313 ; p=.004)$ y las chicas $(r=.549 ; p<.001)$ en la escala CBOSBconductuales. De los factores que comprende el CSBI, el que mostró una relación más estrecha con las dos escalas de consecuencias de la CS fue el de control: concretamente, la correlación entre este factor y el de consecuencias cognitivas fue de .241 en chicos $(p=.02)$ y .321 en chicas ( $p=.002)$, mientras que la correlación con el de consecuencias conductuales fue de .215 ( $p=.04)$ y $.531(p<.001)$ respectivamente.

En resumen, ni la severidad del cuadro clínico de CS ni sus consecuencias -tanto cognitivas como conductuales- se considerarían especialmente graves entre los participantes subclínicos. En cualquier caso, la prevalencia de algunas consecuencias concretas como el sentirse culpable o avergonzado por el propio comportamiento sexual resultarían relativamente frecuentes. En función del sexo, la gravedad del cuadro clínico (especialmente de los problemas en el control de impulsos sexuales) sería un tanto mayor en el caso de los chicos. Finalmente, la severidad de los síntomas de CS correlacionaría positiva y significativamente con la presencia de consecuencias negativas derivadas del cuadro clínico, sobre todo entre las participantes subclínicas y en la escala de consecuencias conductuales. 


\begin{tabular}{|c|c|c|c|c|c|}
\hline & \multirow[b]{2}{*}{ Rango } & \multicolumn{4}{|c|}{ Subclínicos $(N=185)$} \\
\hline & & $\begin{array}{c}\text { Chicos }(n=87) \\
M(D T)\end{array}$ & $\begin{array}{c}\text { Chicas }(n=98) \\
M(D T)\end{array}$ & $t$ de Student & $d$ de Cohen \\
\hline \multicolumn{6}{|c|}{ Inventario de Conducta Sexual Compulsiva (CSBI) } \\
\hline Puntuación total & $28-140$ & $46.81(10.08)$ & $43.52(10.25)$ & $2.19 *$ & 0.32 \\
\hline Factor 1. Control & $13-65$ & $29.16(8.35)$ & $25.47(8.01)$ & $3.05 * *$ & 0.45 \\
\hline Factor 2. Abuso & $8-45$ & $8.73(1.33)$ & $8.84(1.65)$ & -0.48 & 0.07 \\
\hline Factor 3. Violencia & $7-30$ & $9.12(3.04)$ & $9.19(2.95)$ & -0.16 & 0.02 \\
\hline \multicolumn{6}{|c|}{ Escala de Consecuencias Cognitivas y Conductuales de la Conducta sexual (CBOSB) } \\
\hline CBOSB-Cognitivas & $0-60$ & $11.82(16.14)$ & $11.21(13.08)$ & 0.28 & 0.04 \\
\hline CBOSB-Conductuales & $0-16$ & $1.89(1.86)$ & 1.39 (1.74) & 1.89 & 0.27 \\
\hline
\end{tabular}

Nota. ${ }^{*} \mathrm{p}<0.05 ;{ }^{* *} \mathrm{p}<0.01 ;{ }^{* * *} \mathrm{p}<0.001$

Tabla 33. Prevalencia de consecuencias conductuales de la CS en chicos y chicas subclínicos

\begin{tabular}{|c|c|c|c|c|}
\hline \multirow{2}{*}{ Como consecuencia de mi conducta sexual... } & \multicolumn{4}{|c|}{ Subclínicos $(N=185)$} \\
\hline & Chicos $(n=87)$ & Chicas $(n=98)$ & Chi Cuadrado & $V$ de Cramer \\
\hline ...yo o alguna de mis parejas sexuales se ha quedado embarazada. & $1.1 \%$ & $1 \%$ & 0.003 & 0.004 \\
\hline ...he contraído una Infección de Transmisión Sexual (ITS). & $11.1 \%$ & $7.2 \%$ & 0.857 & 0.06 \\
\hline ...he contraído el VIH. & $0 \%$ & $0 \%$ & NA & NA \\
\hline ...he transmitido a alguien una Infección de Transmisión Sexual (ITS). & $5.6 \%$ & $1 \%$ & 3.12 & 0.13 \\
\hline ...he transmitido a alguien el VIH. & $0 \%$ & $0 \%$ & NA & NA \\
\hline ...me han causado dolor, lesiones u otros problemas físicos. & $22.2 \%$ & $33 \%$ & 2.69 & 0.12 \\
\hline ...he causado dolor, lesiones u otros problemas físicos a alguna de mis parejas sexuales. & $25.6 \%$ & $11.3 \%$ & $6.34^{*}$ & 0.18 \\
\hline ...mis relaciones con amigos o familiares se han visto perjudicadas. & $11.1 \%$ & $10.3 \%$ & 0.031 & 0.01 \\
\hline ...mi relación con una pareja estable se ha visto dañada. & $15.6 \%$ & $8.2 \%$ & 2.40 & 0.12 \\
\hline ...he sido arrestado/a. & $0 \%$ & $0 \%$ & NA & NA \\
\hline ...he experimentado problemas económicos. & $3.3 \%$ & $0 \%$ & 3.28 & 0.13 \\
\hline ... he experimentado problemas en la escuela. & $3.3 \%$ & $2.1 \%$ & 0.29 & 0.03 \\
\hline ...he experimentado problemas en el trabajo. & $1.1 \%$ & $0 \%$ & 1.08 & 0.07 \\
\hline ...he experimentado malestar espiritual. & $8.9 \%$ & $12.4 \%$ & 0.59 & 0.05 \\
\hline ...me he sentido avergonzado/a de mi mismo/a. & $31.1 \%$ & $24.7 \%$ & 0.94 & 0.07 \\
\hline ...me he sentido culpable. & $45.6 \%$ & $27.8 \%$ & $6.33^{*}$ & 0.18 \\
\hline
\end{tabular}

Nota. NA=No aplicable

${ }^{*} p<0.05 ;{ }^{* *} p<0.01 ;{ }^{* * *} p<0.001$ 
Tabla 34. Correlación entre severidad y consecuencias de la CS en chicos y chicas subclínicos

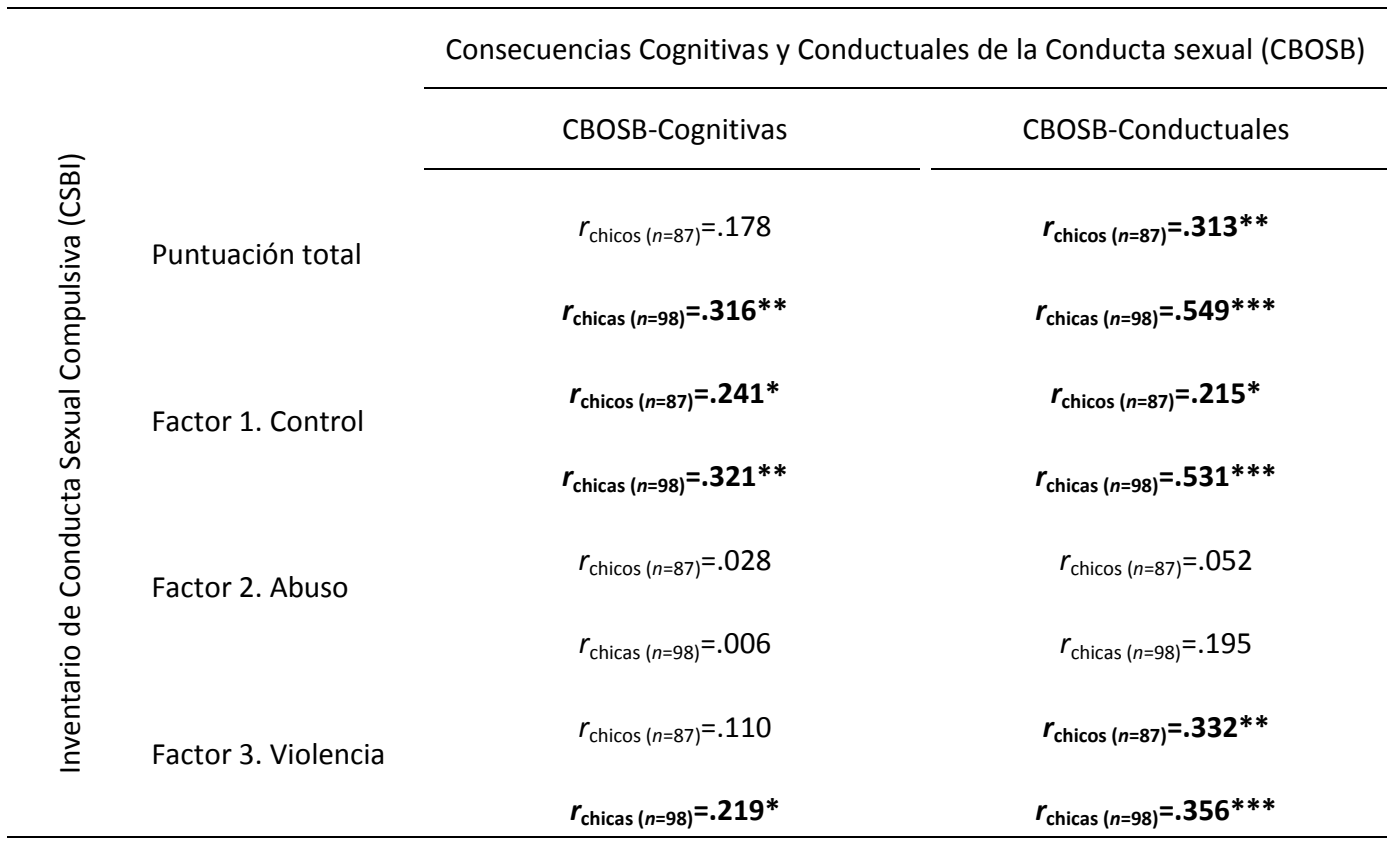

Nota. ${ }^{*} p<0.05 ;{ }^{* *} p<0.01 ;{ }^{* * *} p<0.001$ 


\section{Capacidad predictiva de un modelo de regresión logística con interacción del sexo}

Hasta el momento, los análisis que hemos realizado han considerado a chicos y chicas como grupos independientes. Esta metodología permite evitar que se atribuya a la condición clínica diferencias que se explican mejor a partir del sexo, pero impide comprobar si una misma variable se manifiesta de forma distinta en hombres y en mujeres (es decir, si el sexo interacciona potenciando o debilitando el efecto de ciertas variables). Así pues, se realizó una regresión logística binaria jerárquica para comprobar la capacidad predictiva de las principales variables del estudio a la hora de asignar a los participantes a una u otra condición clínica, teniendo en cuenta el posible efecto de interacción del sexo sobre esta relación. A continuación, se describen las especificaciones para la estimación del modelo de regresión:

1. Variable dependiente (de ahora en adelante VD): la VD -a predecir- por el modelo de regresión logística fue la condición clínica (grupo control o subclínico).

2. Variables independientes (de ahora en adelante VI): en la elección de las VI -predictorasdel modelo se siguieron diversos criterios. Uno de ellos fue el principio de parsimonia: este principio sostiene que los mejores modelos predictivos son aquellos que maximizan la potencia estadística con el menor número posible de variables (Raykov \& Marcoulides, 1999). Así, en lugar de tomar todas las variables contempladas en el estudio (más de 300), se seleccionaron únicamente aquellas que habían demostrado su significación a la hora de discriminar entre participantes control y subclínicos. Otro criterio seguido en la selección de las VI fue el de evitación de redundancias: algunos de los cuestionarios empleados permiten calcular una puntuación global y puntuaciones en distintos factores. La puntuación total se obtiene sumando las puntuaciones en cada una de las escalas de orden inferior, de modo que si se introducen juntas en el modelo de regresión se produciría una redundancia. Para evitarlo, se siguió la siguiente estrategia: por su mayor capacidad explicativa, prioritariamente se introdujeron en el modelo las puntuaciones globales de los cuestionarios, empleando la puntuación en sus subescalas únicamente cuando ésta carecía de capacidad predictiva significativa.

Atendiendo a estos dos criterios, se incluyeron en el modelo de regresión un total de 82 variables predictoras (164 si tenemos en cuenta los términos de interacción).

3. Codificación de variables categóricas: para la codificación de las variables categóricas del modelo se empleó el método de codificación de variables Dummy (Rosel et al., 2014). En variables dicotómicas (p.e., el sexo), esto equivale a asignar 0 o 1 a cada una de las opciones de respuesta. En variables categóricas con tres o más opciones de respuesta 
(p.e., orientación sexual), este método obliga a crear tantas variables como opciones de respuesta tenga el ítem menos una (en el caso de la orientación, dos variables Dummy).

4. Análisis de la interacción: para probar la hipótesis de la interacción, se calculó un término de interacción entre cada VI introducida en el modelo y el sexo. Las VI se introducían en un primer bloque de la regresión mientras que en el segundo bloque se introducían los términos de interacción. En la estimación de la interacción se respetó el principio de anidamiento, que sostiene que cuando un término de interacción resulta significativo, las variables de orden inferior que incluye la interacción deben permanecer en el modelo aunque no resulten significativas (Rosel et al., 2014).

5. Método de introducción de variables: el método escogido para la introducción de variables fue el de introducir. Este método permite que el investigador elija las variables incluidas en el modelo y es el recomendado cuando se introducen términos de interacción en el modelo de regresión (Hosmer \& Lemeshow, 2004).

6. Valores pronosticados: para facilitar la interpretación del efecto de las VI y sobre todo de los términos de interacción sobre la VD, se almacenaron las probabilidades pronosticadas por el modelo de regresión para su posterior representación gráfica.

Siguiendo estas especificaciones, se estimaron varios modelos de regresión. De todos ellos, se escogió aquel que obtuvo el mejor ajuste con un menor número de variables (concretamente, un modelo que incluía $25 \mathrm{VI}$ ). Los índices de bondad de ajuste general para el modelo fueron óptimos $\left(X^{2}=242.987 ;\right.$ G.L. $\left.=72 ; p=<.001\right)$ y sus 25 VI permitían predecir el $72.2 \%$ de la varianza de la VD. A continuación se incluyen sus índices de sensibilidad y especificidad (tabla 35):

Tabla 35. Tabla de clasificación de valores observados y pronosticados por el modelo de regresión logística

\begin{tabular}{ccccc}
\hline & & \multicolumn{2}{c}{ Valor pronosticado } & Porcentaje correcto \\
& & Control & Subclínicos & \\
\hline \multirow{2}{*}{ Valor observado } & Control & 146 & 17 & $89.6 \%$ \\
& Subclínicos & 21 & 128 & $85.9 \%$ \\
\hline
\end{tabular}

Como se aprecia en la tabla 35, la sensibilidad y especificidad diagnóstica del modelo de regresión fue del $85.9 \%$ y del $89.6 \%$ respectivamente, lo que supone un porcentaje general de acierto en la clasificación del $87.8 \%$. Desde la perspectiva inversa, el porcentaje de verdaderos negativos y de falsos positivos se limitó al $14.1 \%$ y $10.1 \%$ respectivamente. Si además se estima el Valor Predictivo Positivo y Negativo del modelo (probabilidad de ser subclínico o control si el modelo de regresión así lo predice), éste sería del $88.27 \%$ y del $87.42 \%$ respectivamente. En otras palabras, la probabilidad de que el modelo de regresión clasifique a un participante como control cuando en realidad es subclínico es del $12.57 \%$ y del $11.72 \%$ para la situación inversa. 
Para seguir explorando las características predictivas del modelo de regresión, se calculó su curva ROC tomando como variable de criterio (Golden Rule) la condición clínica observada y como variable a contrastar los valores de probabilidad predichos por el modelo de regresión. A través de estos análisis se encontró que el valor para el Área Bajo la Curva (AUC) bajo estos parámetros era de .94 (95\% IC .92-.97), lo que significa que los valores pronosticados por el modelo de regresión tienen un poder de discriminación del 94\% sobre la variable criterio. En la figura 11 se incluye la representación gráfica de la curva ROC con dichos parámetros. Como se aprecia, la curva que representa el modelo predictivo (curva azul) se aleja de la perpendicular que representaría la total ausencia de sensibilidad y especificidad (línea verde), lo que sugiere nuevamente que el modelo presenta una capacidad de discriminación muy positiva.

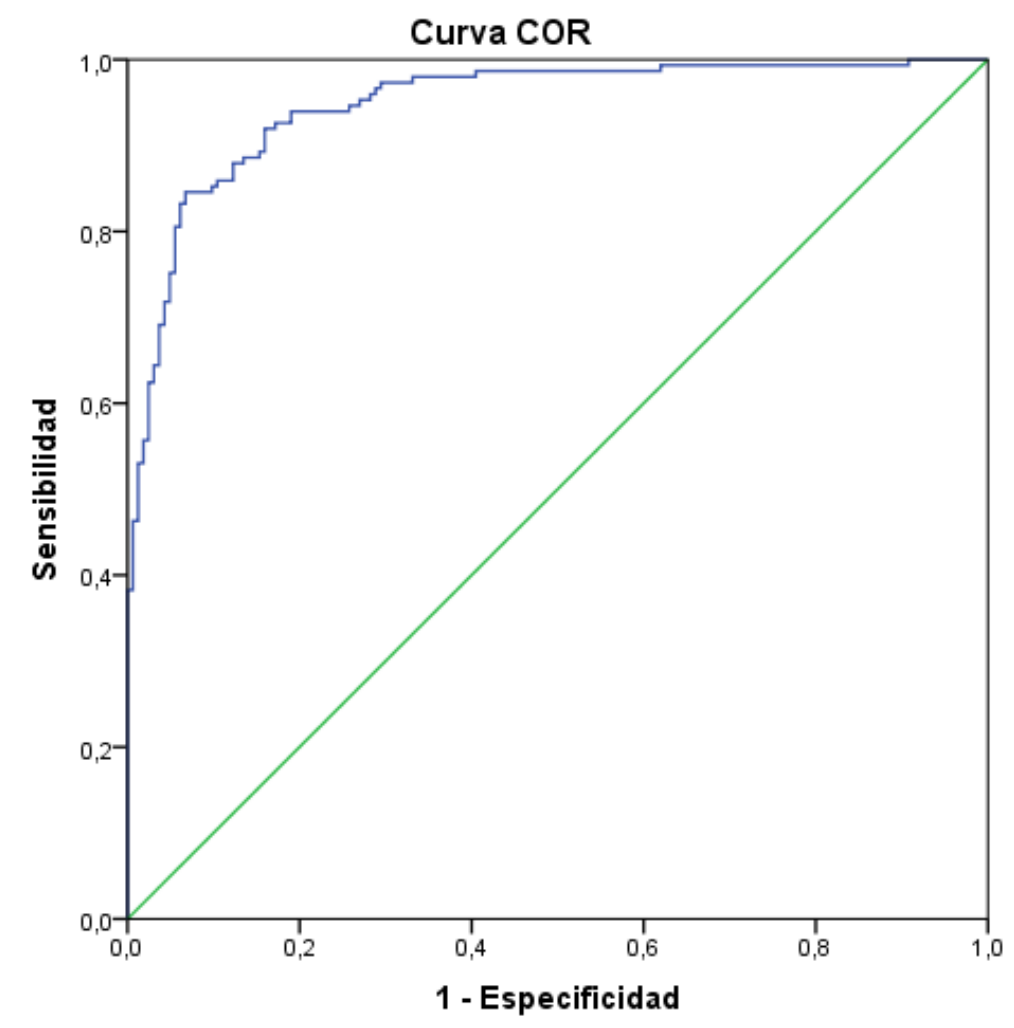

Figura 11. Curva ROC de precisión diagnóstica de los valores predichos por el modelo de regresión logística.

El valor de las $25 \mathrm{VI}$ contempladas en el modelo de regresión como factor de riesgo o protección a la hora de clasificar a los participantes como control o subclínicos se valoró a través de sus índices de capacidad predictiva $(B)$, significación estadística $(p)$ y Odds Ratio (OR) (tabla 36). Asimismo, las probabilidades pronosticadas por el modelo de regresión se representan gráficamente para facilitar la interpretación del efecto de las VI y los términos de interacción sobre la VD (figuras de la 12 a la 22). 


\begin{tabular}{|c|c|c|c|c|}
\hline & $B$ & E.T. & O.R. [95\% IC] & $p$ valor \\
\hline \multicolumn{5}{|l|}{ Variables demográficas } \\
\hline Sexo (mujer) & -14.117 & 6.032 & $0.016[0.000 ; 0.101]$ & .019 \\
\hline Edad & -0.239 & 0.106 & $0.788[0.639 ; 0.970]$ & .025 \\
\hline \multicolumn{5}{|l|}{ Comorbilidad psicopatológica } \\
\hline Abuso del alcohol & 2.237 & 0.582 & $9.362[2.992 ; 29.292]$ & $<.001$ \\
\hline Dependencia del alcohol & 2.752 & 1.444 & $15.680[0.924 ; 265.960]$ & .050 \\
\hline \multicolumn{5}{|l|}{ Perfil de personalidad } \\
\hline Impulsividad (neuroticismo) & 0.009 & 0.039 & $1.009[0.934 ; 1.1089]$ & .824 \\
\hline Impulsividad (neuroticismo) X Sexo (ser mujer) $¥$ & 0.123 & 0.061 & $1.131[1.002 ; 1.275]$ & .046 \\
\hline Vulnerabilidad (neuroticismo) & -0.072 & 0.034 & $0.931[0.870 ; 0.996]$ & .037 \\
\hline Gregarismo (extraversión) & 0.105 & 0.032 & $1.111[1.043 ; 1.184]$ & .001 \\
\hline Emociones positivas (extraversión) & -0.130 & 0.038 & $0.878[0.815 ; 0.946]$ & .001 \\
\hline Estética (apertura a la experiencia) & 0.097 & 0.029 & $1.101[1.040 ; 1.166]$ & .001 \\
\hline Sensibilidad (amabilidad) & 0.070 & 0.034 & $1.073[1.003 ; 1.148]$ & .040 \\
\hline Sensibilidad (amabilidad) X Sexo (ser mujer) $¥$ & -0.132 & 0.051 & $0.876[0.793 ; 0.969]$ & .010 \\
\hline \multicolumn{5}{|l|}{ Comportamiento sexual general } \\
\hline Tener pareja estable & 0.305 & 0.646 & $1.356[0.382 ; 4.816]$ & 637 \\
\hline Tener pareja estable X Sexo (ser mujer) $¥$ & -3.241 & 1.141 & $0.039[0.004 ; 0.366]$ & .005 \\
\hline Haber realizado masturbaciones mutuas & 1.406 & 0.878 & $4.082[0.730 ; 22.824]$ & .050 \\
\hline Haber realizado otro tipo de comportamientos sexuales & 0.464 & 1.179 & $1.590[1.590 ; 16.032]$ & 0.694 \\
\hline Haber realizado otro tipo de comportamientos sexuales X Sexo (ser mujer) $¥$ & 4.565 & 2.487 & $2.010[1.039 ; 2.364]$ & .048 \\
\hline \multicolumn{5}{|l|}{ Comportamiento sexual de riesgo } \\
\hline Autoeficacia en el uso del preservativo & -0.082 & 0.145 & $0.921[0.694 ; 1.224]$ & .572 \\
\hline Autoeficacia en el uso del preservativo X Sexo (ser mujer) $¥$ & 0.759 & 0.253 & $2.137[1.302 ; 3.509]$ & .003 \\
\hline \multicolumn{5}{|l|}{ Comportamiento sexual online } \\
\hline Puntuación total en el cuestionario ISST de adicción al cibersexo & 0.220 & 0.100 & $1.246[1.024 ; 1.517]$ & .028 \\
\hline Puntuación total en el cuestionario ISST de adicción al cibersexo X Sexo (ser mujer) ¥ & 1.098 & 0.295 & $2.999[1.683 ; 5.345]$ & $<.001$ \\
\hline \multicolumn{5}{|l|}{ Variables clínicas sexuales } \\
\hline Escala de Búsqueda de Sensaciones Sexuales (BSS) & 0.101 & 0.053 & $1.106[0.997 ; 1.228]$ & .050 \\
\hline \multicolumn{5}{|l|}{ Correlatos clínicos } \\
\hline STAI-Estado & 0.074 & 0.042 & $1.077[0.993 ; 1.169]$ & .047 \\
\hline Inventario de Depresión (BDI) & -0.051 & 0.054 & $0.950[0.854 ; 1.056]$ & .341 \\
\hline Inventario de Depresión (BDI) X Sexo (ser mujer) ¥ & 0.248 & 0.079 & $1.282[1.099 ; 1.495]$ & .002 \\
\hline
\end{tabular}

Nota. ¥=Interacción significativa entre la variable independiente y el sexo; $B=$ Beta; E.T.=Error Típico; O.R.=Odds Ratio u Oportunidad Relativa. 
De las variables sociodemográficas incluidas en el modelo (tabla 36), únicamente el sexo y la edad mostraron capacidad predictiva significativa sobre la VD. En el caso del sexo, el ser mujer reduciría notablemente la probabilidad de ser clasificado como participante clínico ( $B=-14.11$; $p=.019$ ) mientras que en el caso de la edad, la probabilidad sería menor a medida que ésta aumenta $(B=-0.23 ; p=.025)$. El efecto del sexo a la hora de reducir la probabilidad de ser clasificado como participante subclínico $(\mathrm{OR}=0.01)$ es mayor que el de la edad $(\mathrm{OR}=0.78)$, presumiblemente por ser una variable dicotómica donde el cambio por unidad de medida tiene mayor impacto que el cambio por unidad en una variable continua como la edad.

Como se aprecia en la figura 12, la probabilidad de que el modelo de regresión clasifique a un chico en el grupo subclínico es del $52 \%$ frente al $43.8 \%$ en el caso de las chicas. No obstante, es probable que la capacidad predictiva del sexo sobre la VD se deba a la inclusión de términos de interacción más que a un efecto puro e independiente de esta variable: en una evaluación a nivel poblacional, no cabría duda de que el ser mujer supondría un factor de protección a la hora de ser diagnosticado como CS (principalmente porque la prevalencia del cuadro clínico en mujeres es inferior); sin embargo, en la presente investigación el número de chicos y chicas en el grupo subclínico era casi idéntico, de modo que su efecto debería quedar maquillado por el tipo de muestro. Con respecto a la edad, la probabilidad de que un chico o una chica sea clasificado como subclínico oscilaría entre el 46.2-55.6\% entre los 18 y los 21 años, quedaría por debajo del $40 \%$ entre los 24 y 25 años y se reduciría al $20 \%$ con 27 años. De modo que la edad (concretamente, tener más de 24 años) parece desempeñar un cierto efecto protector a la hora de desarrollar un cuadro clínico de CS.
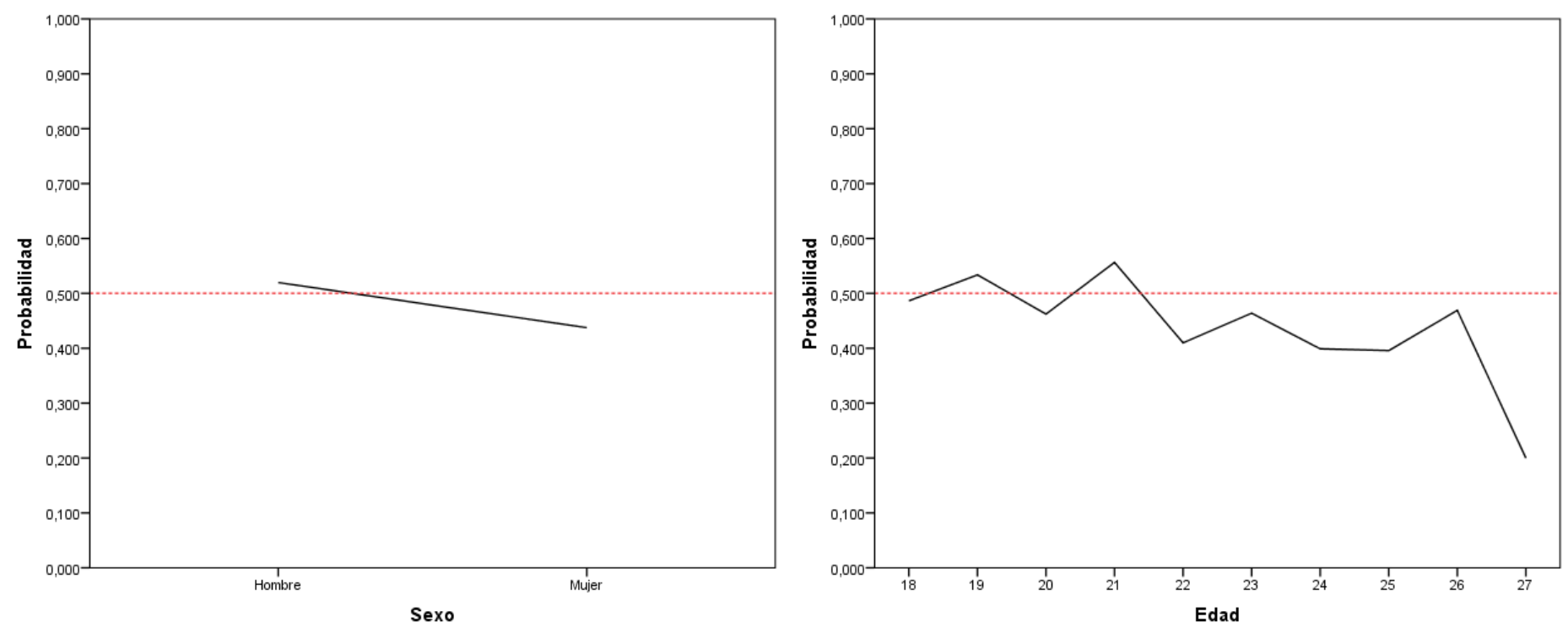

Figura 12. Probabilidad de ser clasificado como subclínico en función del sexo y la edad. 
De los cuadros clínicos explorados en el estudio (bloque de comorbilidad psicopatológica), los dos únicos que mostraron capacidad predictiva sobre la VD fueron el abuso $(B=2.23 ; p<0.001)$ y la dependencia del alcohol $(B=2.75 ; p=.050)$. En este sentido, la probabilidad de que alguien que sufra o hubiera sufrido abuso del alcohol sea clasificado como subclínico sería 9 veces superior a la de alguien que no hubiera padecido este problema $(O R=9.36)$ y 15 veces superior en el caso de la dependencia del alcohol $(O R=15.68)$. A pesar de la solidez de los hallazgos referidos a la dependencia del alcohol, la significación de su capacidad predictiva es inferior a la del cuadro de abuso del alcohol, presumiblemente porque el error asociado a su medición es notablemente superior (E.T. de 1.44 frente a 0.58 ).

Si atendemos ahora a la figuras 14 y 15, la probabilidad de que el modelo clasifique como subclínico a un participantes que abusa o es dependiente del alcohol sería del $72.2 \%$ y $81.8 \%$ respectivamente, frente al $37.8 \%$ y el $46.8 \%$ de los que no padecen estos cuadros clínicos. A tenor de estos porcentajes, el haber padecido alguna de estas patologías se dibuja como un importante factor de riesgo a la hora de desarrollar un problema en el control de los impulsos sexuales. Desde la perspectiva inversa, el no padecer o no haber padecido dependencia del alcohol no se consideraría un factor especialmente protector en el desarrollo de este tipo de problemas (la probabilidad de que personas sin esta patología desarrollen un cuadro de CS sería prácticamente del 50\%) pero sí lo sería el no haber sufrido un abuso del alcohol, donde la probabilidad de sufrir un problema en el control de los impulsos sexuales es menor al $40 \%$.
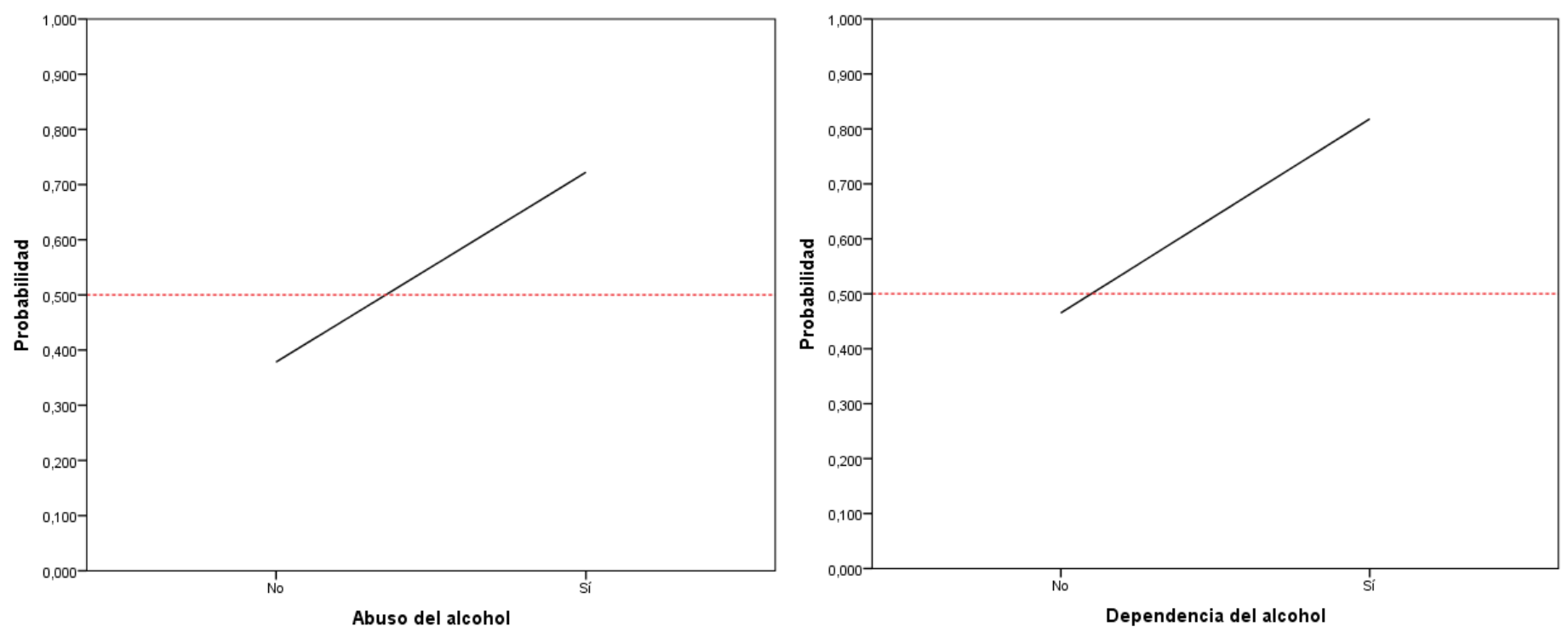

Figura 13. Probabilidad de ser clasificado como subclínico en función de padecer o haber padecido abuso o dependencia del alcohol. 
De las 30 facetas de personalidad del inventario NEO PI-R, 8 de ellas ( 6 VI y 2 términos de interacción) resultaron ser predictores significativos de la VD. De la dimensión de personalidad "neuroticismo", la interacción entre la faceta de impulsividad y el sexo se relacionó positivamente con el hecho de ser clasificado como participante subclínico ( $B=0.123 ; p=.046)$, no así la impulsividad tomada de forma aislada $(B=0.009 ; p=.824)$. Concretamente, un incremento de una unidad en la medida de la impulsividad en mujeres (no en hombres) se traduciría en un aumento del 1.131 en la probabilidad (OR) de ser clasificado por el modelo de regresión como participante subclínico. Al contrario sucedería con la faceta de vulnerabilidad, que se relacionaría en sentido inverso con la VD ( $B=-0.072 ; p=.037 ; \mathrm{OR}=0.931)$.

En cuanto a la distribución de probabilidad predicha por el modelo de regresión en función de estas facetas de neuroticismo (figura 14), los jóvenes con bajas puntuaciones en vulnerabilidad tendrían una probabilidad del $59.7 \%$ de ser clasificados como participantes subclínicos frente al $47.2 \%$ de los que obtienen puntuaciones medias y el $33.8 \%$ de los de altas puntuaciones. En cuanto a la faceta de impulsividad, la probabilidad en hombres apenas varía en los tres niveles propuestos (probabilidad entre el 38.6-46.2\%) pero sí lo hace en mujeres: concretamente, la probabilidad de que una mujer con baja o media impulsividad sea clasificada como participante subclínica sería del $24.3 \%$ y del $45.9 \%$ respectivamente frente al $66.3 \%$ de una que obtuviera altas puntuaciones en esta faceta. En este sentido, los dos extremos de esta faceta juegan un importante papel en el desarrollo del cuadro clínico de CS: mientras que una baja impulsividad en mujeres desempeña un papel protector, el extremo opuesto se dibuja como un importante factor de riesgo en la manifestación de este trastorno.
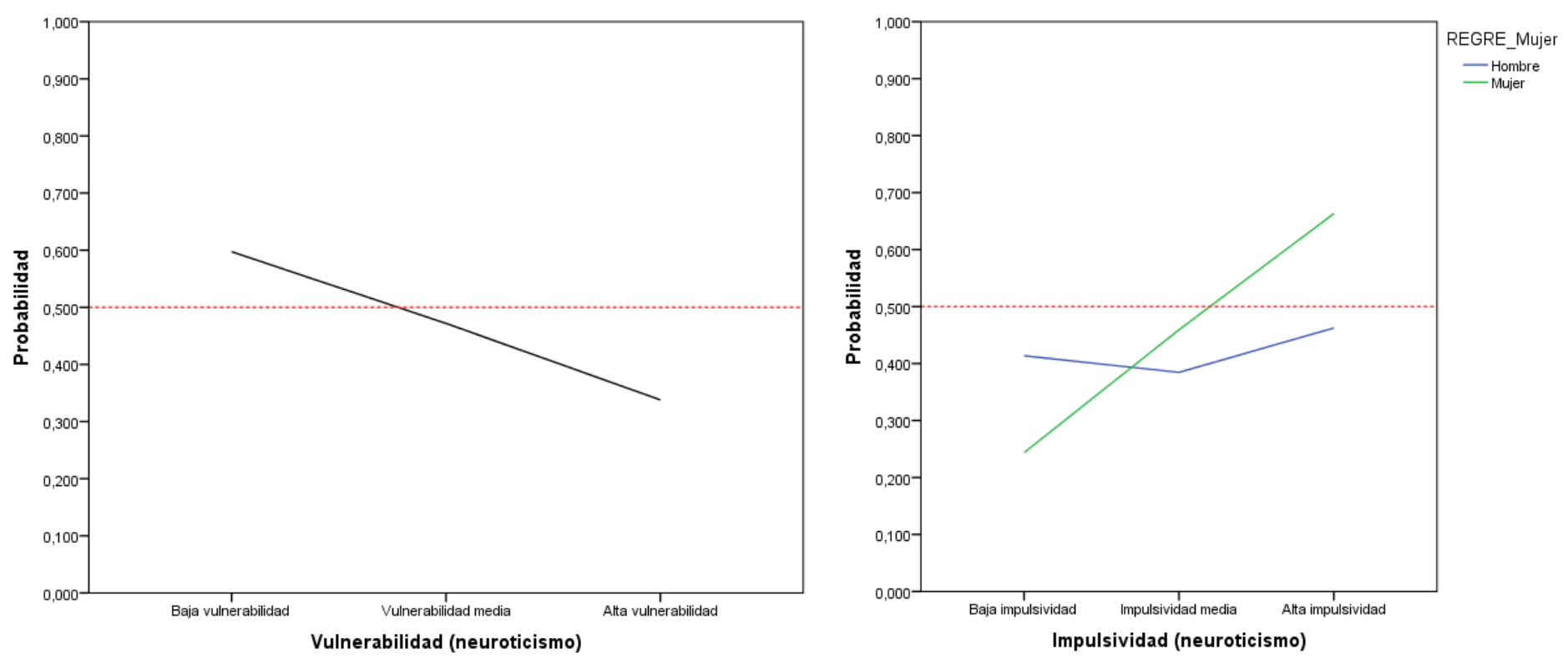

Figura 14. Probabilidad de ser clasificado como subclínico en función de dos facetas de neuroticismo (vulnerabilidad e impulsividad). 
Dos facetas de la dimensión de personalidad "extraversión" relacionadas de forma significativa con la clasificación en uno de los dos grupos clínicos serían el gregarismo y las emociones positivas: la primera se relacionaría positivamente con la VD $(B=0.105)$ mientras que la segunda lo haría de forma inversa $(B=-0.130)$. Si bien la significación de la capacidad predictiva es equivalente en ambos casos $(p=001)$, la capacidad de la primera para incrementar la probabilidad de ser clasificado como subclínico $(O R=1.111)$ es ligeramente más limitada que la capacidad de la segunda para reducirla $(\mathrm{OR}=0.878)$.

Recurriendo de nuevo a la representación gráfica de los valores predichos por el modelo de regresión (figura 15), la probabilidad de que un participante con bajo gregarismo sea asignado al grupo subclínico es del $34.1 \%$, frente al $49.9 \%$ y el $62.4 \%$ de los de puntuaciones medias y altas respectivamente. La tendencia inversa se aprecia en la faceta de emocionalidad positiva, donde el riesgo de que el modelo clasifique como subclínico a un participante con bajas puntuaciones es del $71.9 \%$, del $55.4 \%$ para los que obtienen puntuaciones medias y del $31 \%$ para las personas con alta emocionalidad positiva. Teniendo esto en cuenta, la obtención de un perfil de personalidad caracterizado por un bajo gregarismo y una alta emocionalidad positiva desempeñaría un papel protector a la hora de desarrollar un problema de CS mientras que la expresión opuesta de estas mismas facetas se identificaría como un claro factor de riesgo. En ambos casos, manifestaciones normales de estas dos facetas ni aumentarían ni disminuirían significativamente la probabilidad de manifestar este cuadro clínico.
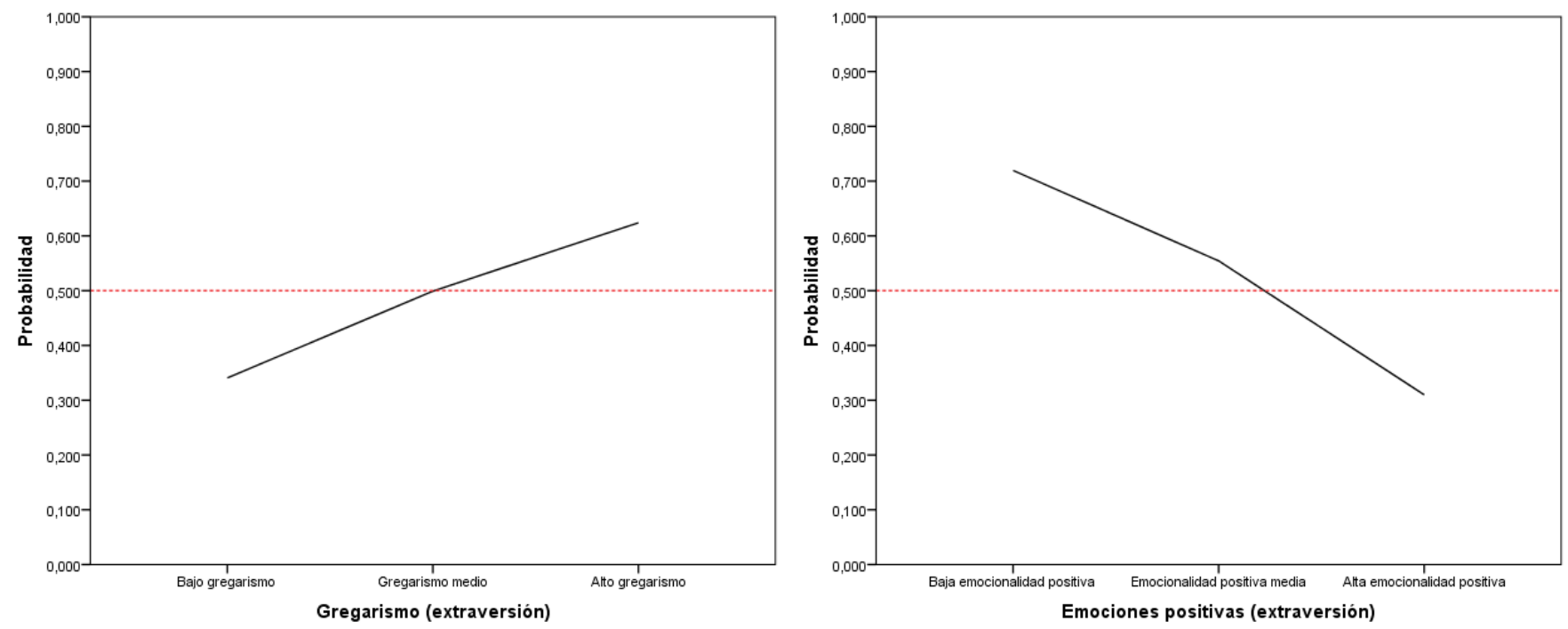

Figura 15. Probabilidad de ser clasificado como subclínico en función de dos facetas de extraversión (gregarismo y emociones positivas). 
Las dos últimas facetas de personalidad incluidas en el modelo son la de estética (dimensión de apertura a la experiencia) y la de sensibilidad (dimensión de amabilidad). La primera se relacionaría de forma positiva con la VD $(B=0.097 ; p=.001 ; \mathrm{OR}=1.101)$ mientras que la segunda lo haría tanto positiva como negativamente: sin tener en cuenta el sexo, la sensibilidad sería un predictor positivo de la VD ( $B=0.070 ; p=.040 ; O R=1.073)$. Sin embargo, si en su lugar tomamos el término de interacción entre sexo y sensibilidad, entonces el sentido de la relación se invierte $(B=-0.132 ; p=.010 ; \mathrm{OR}=.876)$. Esta contradicción se explica del siguiente modo: si tomamos la faceta de sensibilidad sin separar su efecto sobre la VD según el sexo, la relación entre ambas variables es positiva porque el efecto negativo de su manifestación en mujeres es más débil que el efecto positivo de su manifestación en hombres. Así, la media entre ambos efectos sería positiva aunque su influencia sea limitada $(p=0.040)$. Ahora bien, cuando se separa el efecto de esta variable según el sexo (en concreto, su efecto en mujeres), entonces la interacción resulta positiva y su capacidad predictiva aumenta considerablemente $(p=.010)$.

En este caso, la representación de probabilidades resulta especialmente útil sobre todo a la hora de interpretar el efecto de la interacción entre sexo y sensibilidad sobre la VD (figura 16). Como hemos visto en otras facetas, el extremo de bajas puntuaciones en la faceta de estética desempeña un papel protector frente a la manifestación de la CS (la probabilidad de que estas personas sean clasificadas como subclínicas es del 10.9\%) mientras que el extremo contrario se consideraría un factor de riesgo (61.80\%). Por su parte, la sensibilidad se manifiesta de forma contrapuesta en hombres y en mujeres: en hombres se aprecia un incremento del $19.2 \%$ en la probabilidad de ser clasificado como subclínico entre aquellos con bajas y altas puntuaciones en la faceta de estética mientras que en mujeres se produciría un decremento del $25.13 \%$.
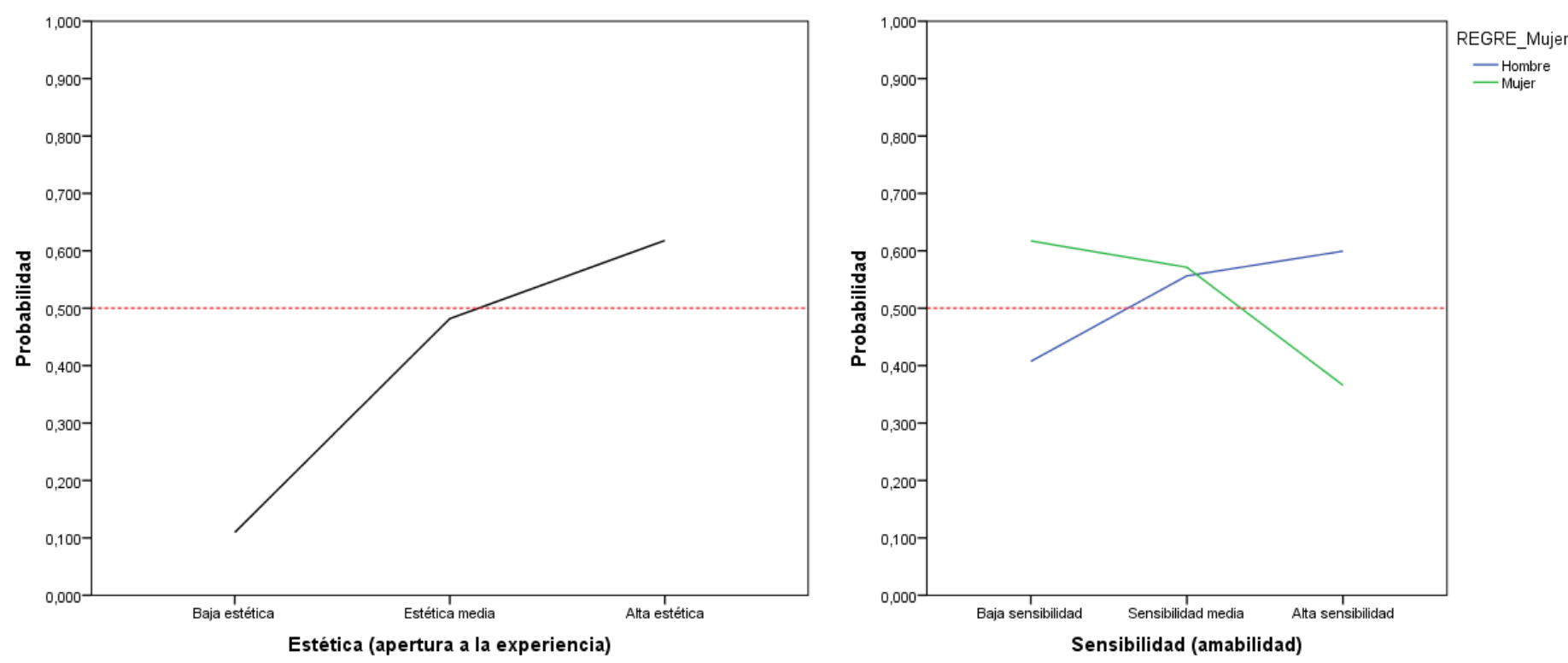

Figura 16. Probabilidad de ser clasificado como subclínico en función de las faceta de estética (apertura) y sensibilidad (amabilidad) 
De las variables de comportamiento sexual general incluidas en el modelo de regresión, una VI y dos términos de interacción resultaron ser predictores significativos de la VD. Aunque con una significación muy ajustada $(p=.050)$, el no haber realizado masturbaciones mutuas con una pareja resultó predecir la clasificación como participante subclínico $(B=1.406)$. En concreto, la probabilidad de que el modelo asigne al grupo de participantes subclínicos a una persona que no ha realizado nunca esta práctica sexual es 4 veces inferior $(\mathrm{OR}=4.082)$ a la probabilidad de que clasifique como tal a una persona que sí la haya hecho.

El análisis de la representación gráfica de probabilidades para esta variable (figura 17) permite apreciar que lejos de considerar esta conducta sexual como un factor de riesgo, el no haber realizado masturbaciones mutuas se dibuja más bien como un factor de protección que reduce hasta en un $21.5 \%$ el riesgo de ser clasificado como participante subclínico: en concreto, la probabilidad de ser clasificado como tal si no se ha llevado a cabo esta conducta sexual es del $28 \%$ frente al $49.5 \%$ de los que si la han practicado. Teniendo en cuenta que la frecuencia de esta actividad sexual en la población estudiada es del $89.9 \%$, lo que estos resultados vienen a señalar no es que los participantes que afirmaron haber realizado esta conducta sexual (la mayoría) tengan un riesgo mayor de ser clasificados como participantes subclínicos, sino que los que no lo hicieron tienen un riesgo significativamente menor de ser clasificados como tal.

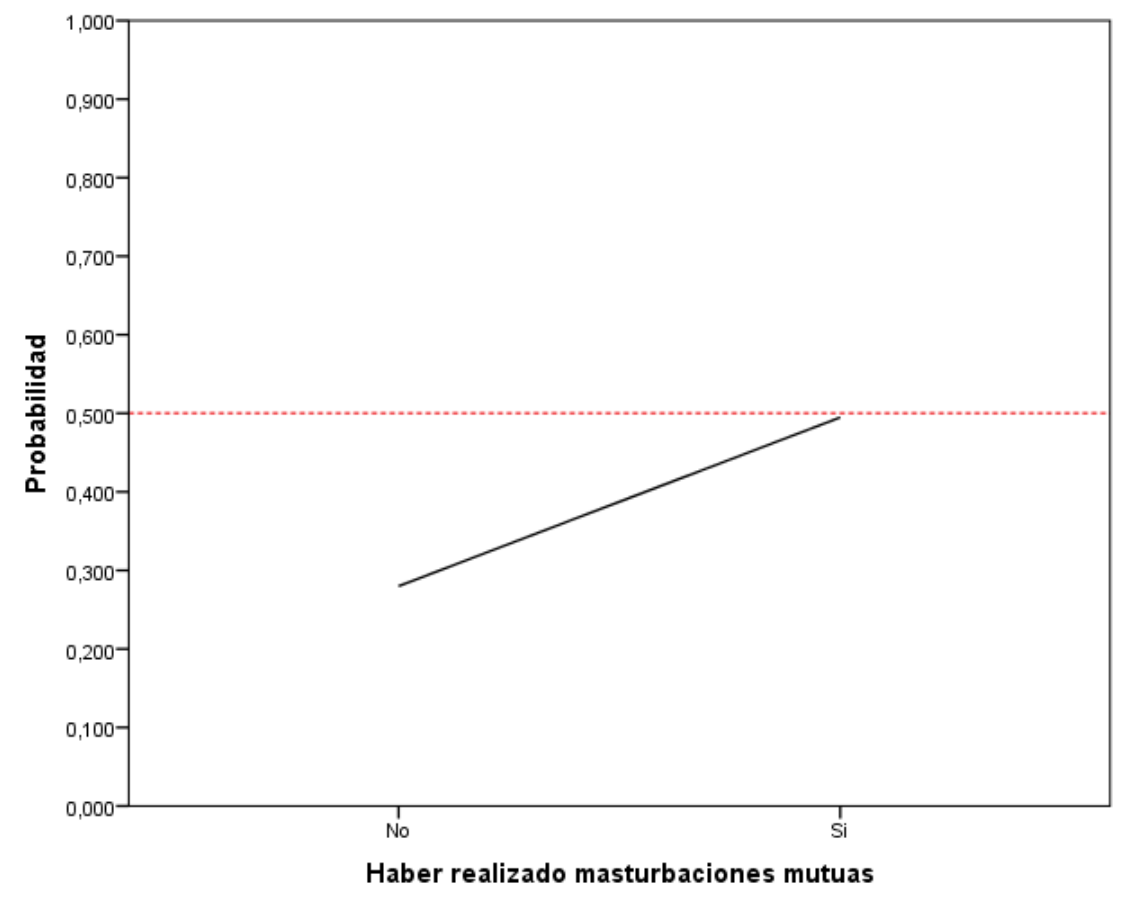

Figura 17. Probabilidad de ser clasificado como subclínico en función de haber realizado o no masturbaciones mutuas. 
Para terminar con el bloque de comportamiento sexual general, los términos de interacción que mostraron capacidad predictiva sobre la condición clínica fueron el tener pareja estable y el haber realizado cualquier conducta sexual distinta a la masturbación, masturbación con una pareja, sexo oral, coito vaginal y anal -es decir, cualquier comportamientos sexual alternativo a los mayoritarios-. En ambos casos, la VI sin tener en cuenta la interacción no mostraba capacidad predictiva alguna sobre la VD ( $p$ de.637 y .694), si bien se mantuvo en el modelo por respeto al principio de anidamiento de variables. En el caso de contemplar la interacción entre el sexo y estas mismas variables, tanto el tener pareja estable ( $B=-3.241 ; p=.005 ; O R=0.039$ ) como el haber realizado otro tipo de comportamientos sexuales ( $B=4.565 ; p=.048 ; \mathrm{OR}=2.137$ ) se relacionaron de forma significativa con la VD.

Con respecto a la distribución de probabilidad predicha por el modelo (figura 18), ser asignado al grupo subclínico en hombres es ligeramente más probable entre los que sí afirmaron tener pareja estable (probabilidad del $45.3 \%$ frente al $41.9 \%$ ) y los que no habían realizado otros comportamientos sexuales (44.1\% frente al 37.5\%). Al contrario, en mujeres es más probable que lo sean las que no tienen pareja y las que sí realizaron conductas sexuales alternativas a las mayoritarias (probabilidad del 61.5\% y el 75\% respectivamente). Así, mientras en hombres la diferencia en la probabilidad estimada entre categorías apenas oscila entre el $3.4-6.6 \%$ en función de tener pareja estable y haber realizado otras conductas sexuales, en mujeres lo haría entre el $12.8-23.6 \%$ respectivamente.
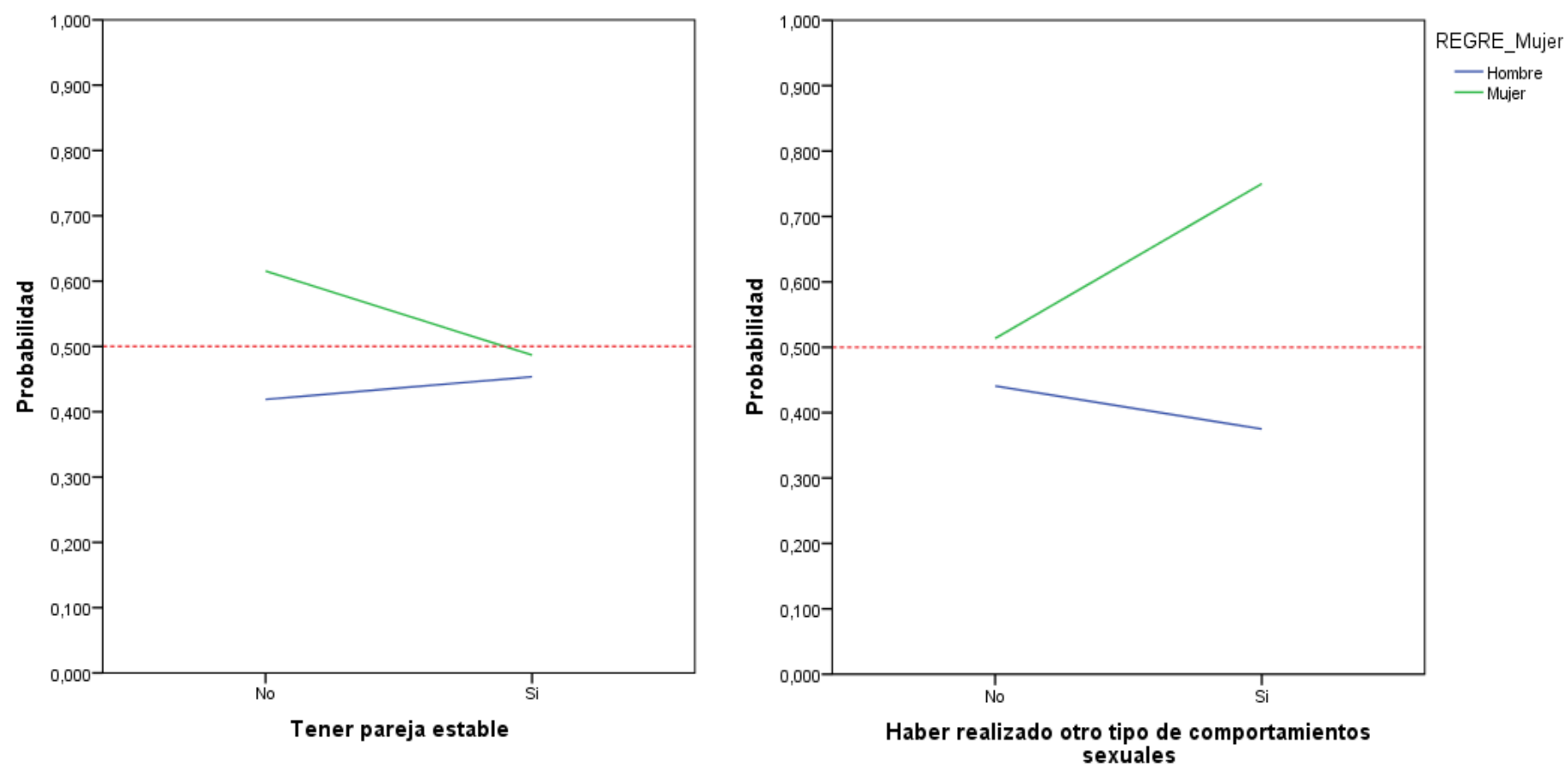

Figura 18. Probabilidad de ser clasificado como subclínico en función de tener o no pareja estable y de haber realizado otro tipo de conductas sexuales. 
De las variables de comportamiento sexual de riesgo incluidas, sólo la interacción entre sexo y nivel de autoeficacia en el uso del preservativo resultó ser un predictor significativo de la pertenencia a uno u otro grupo clínico ( $B=0.759 ; p=.003 ; \mathrm{OR}=2.137)$ : concretamente, las chicas experimentan un aumento del riesgo a medida que incrementa su nivel de autoeficacia en el uso del preservativo. Considerando que esta VI sin tener en cuenta su interacción con el sexo carece de cualquier tipo de capacidad predictiva sobre la VD $(B=-0.082 ; p=.572 ; O R=0.921)$, este incremento no sería significativo en hombres.

Estos resultados se confirman al analizar la representación de las probabilidades predichas por el modelo para la interacción entre el sexo y el nivel de autoeficacia en el uso del preservativo (figura 19). En hombres, la línea que representa la probabilidad de ser considerado subclínico resulta prácticamente perpendicular en los tres niveles de autoeficacia contemplados, con variaciones de apenas un $2 \%$ en la probabilidad dependiendo del nivel de autoeficacia. En mujeres, la probabilidad sería prácticamente igual en mujeres con baja y media autoeficacia percibida en el uso del preservativo (52.6\% y 51.6\% respectivamente) pero aumentaría mucho en aquellas con una alta percepción de autoeficacia (probabilidad del 64.6\%). Por tanto, un alto nivel de autoeficacia en el uso del preservativo podría considerarse un factor de riesgo a la hora de manifestar un cuadro clínico de CS en mujeres.

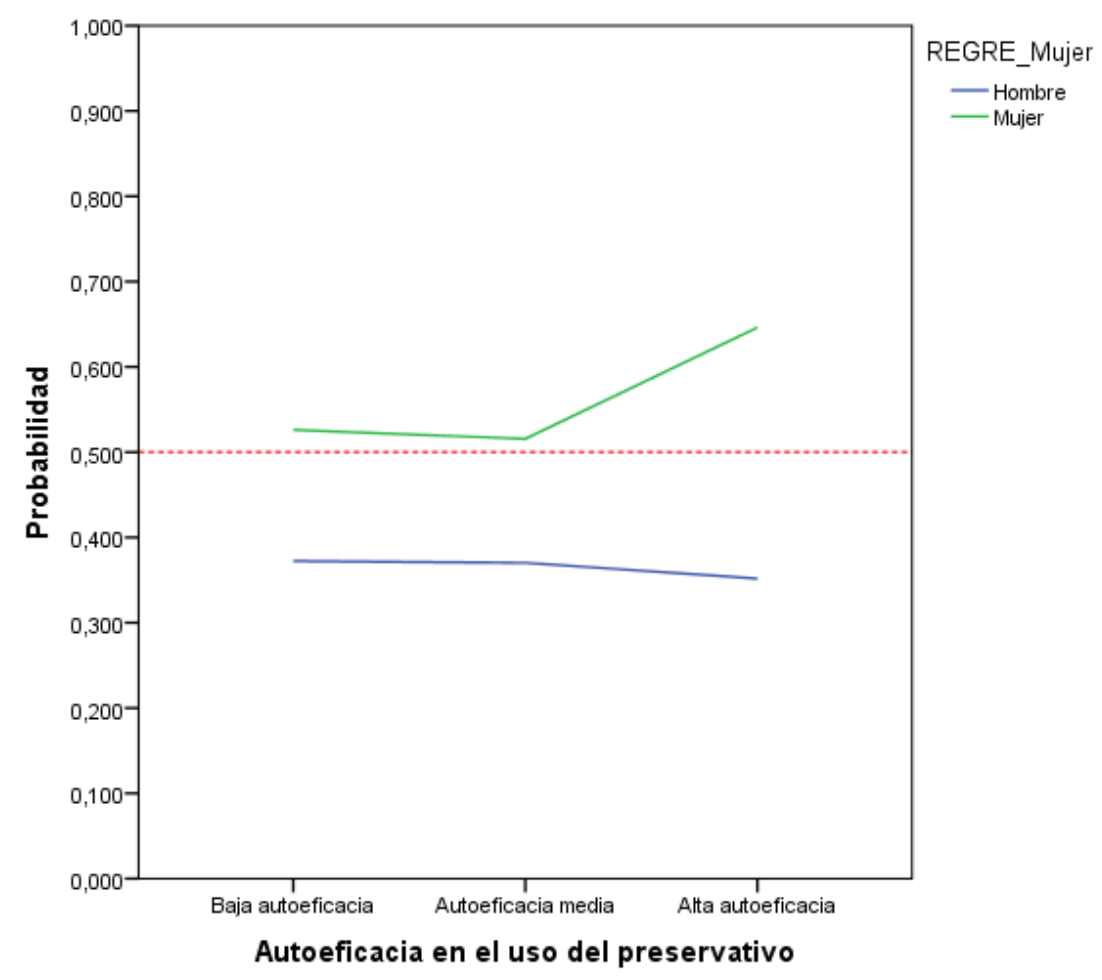

Figura 19. Probabilidad de ser clasificado como subclínico en función de la autoeficacia en el uso del preservativo 
Del bloque de variables de comportamiento sexual online, tanto la VI de puntuación total en el ISST $(B=0.220 ; p=.028)$ como su interacción con el sexo $(B=1.098 ; p<.001)$ muestran capacidad predictiva positiva sobre el ser o no clasificado como participante subclínico. En este sentido, el riesgo de que un participante -independientemente de su sexo- sea considerado subclínico aumenta en 1.246 puntos (OR) a medida que incrementa su puntuación en el ISST, a lo que debemos añadir un aumento adicional de 2.999 puntos en la probabilidad en chicas.

El efecto de la interacción entre el ISST y el sexo sobre la VD se aprecia más fácilmente a través de la representación de las curvas de probabilidad predichas (figura 20). Como se aprecia, ambas curvas siguen una tendencia ascendente continua a medida que aumenta la puntuación en el ISST; sin embargo, este incremento es notablemente más acentuado en mujeres que en hombres. Así, una mujer tan sólo tendría que obtener una puntuación $\geq 3$ para alcanzar una probabilidad del $50 \%$ mientras que un hombre debería obtener una $\geq 9$. Desde otra perspectiva, la probabilidad de que una mujer con una puntuación de 6 sea clasificada como subclínica es del $84 \%$ frente al $38 \%$ de un hombre con esa misma puntuación. Finalmente, cualquier mujer con una puntuación $>10$ sería clasificada invariablemente por el modelo como subclínica, cosa que no pasaría ni tan siquiera entre los hombres con las puntuaciones más altas en el cuestionario ISST.

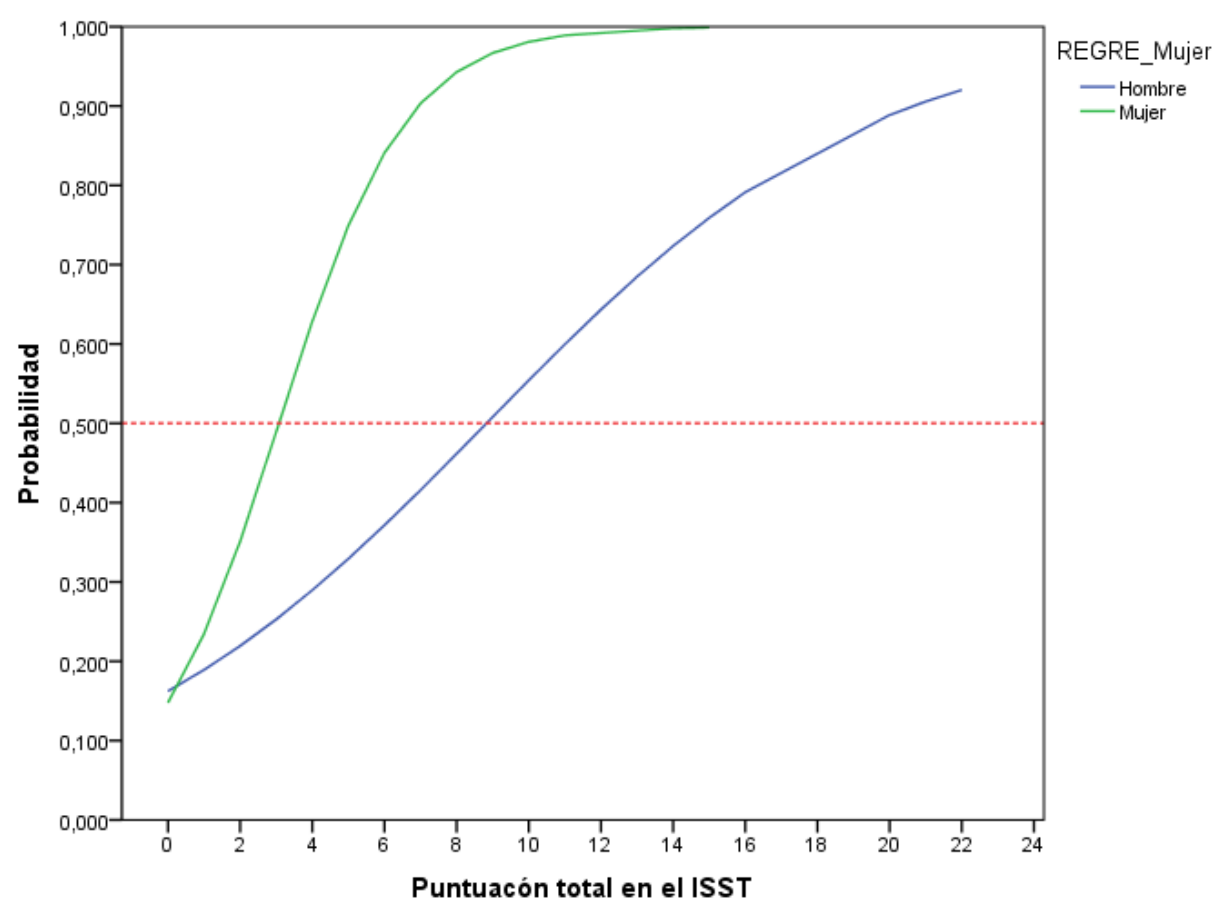

Figura 20. Probabilidad de ser clasificado como subclínico en función de la puntuación total en el cuestionario ISST 
Del bloque de variables clínicas sexuales, solo la VI de búsqueda de sensaciones sexuales (BSS) ha mostrado capacidad predictiva sobre la VD $(B=0.101)$. La significación estadística de la variable resulta ajustada $(p=.050)$ y su influencia sobre el incremento de la probabilidad de ser asignado por el modelo al grupo subclínico discreta (OR=1.106). De hecho, el intervalo de confianza para la OR incluye el 1 entre sus valores, de modo que aunque sea remota atendiendo al resto de índices, se debería tener en cuenta la posibilidad de que ni tan siquiera ejerza efecto alguno sobre la VD.

Si atendemos a la figura 21, la probabilidad predicha de ser clasificado como subclínico aumenta de forma lineal a medida que se incrementa la puntuación en la escala de búsqueda de sensaciones sexuales. Así, la probabilidad de ser clasificado como tal sería inferior al 30\% en puntuaciones $\leq 21$, del $50 \%$ con puntuaciones cercanas a 27 y mayor del $70 \%$ en puntuaciones 232. Se aprecia también que la probabilidad predicha para las puntuaciones del extremo superior del continuo -de 33 en adelante- no sigue una tendencia tan lineal como la de las puntuaciones anteriores (se observan pequeños picos que acompañan a cada incremento de probabilidad), lo que podría señalar en parte que la fiabilidad de estas estimaciones pueda ser un tanto inferior para este rango de puntuaciones.

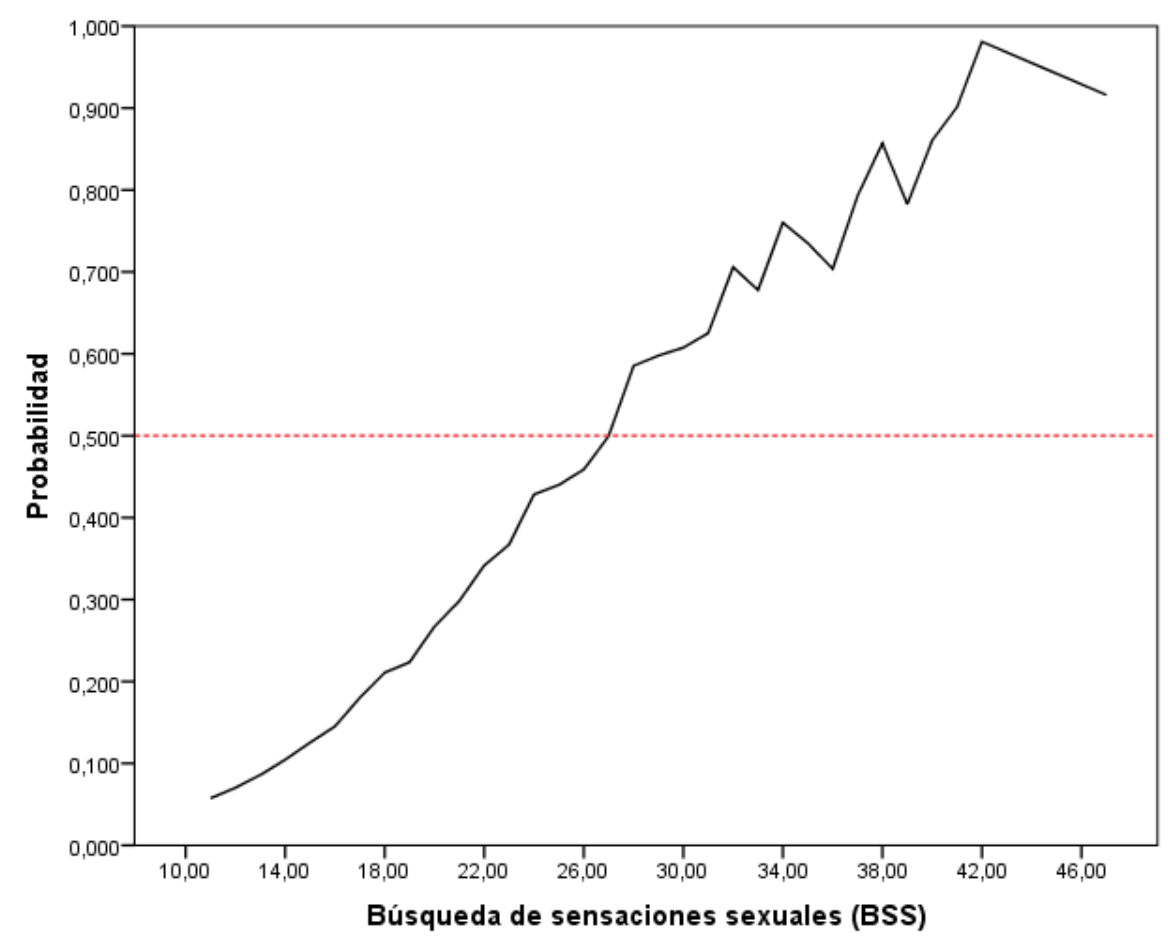

Figura 21. Probabilidad de ser clasificado como subclínico en función de la puntuación en la escala de búsqueda de sensaciones sexuales (BSS) 
Para terminar, en el modelo de regresión se incluyen dos variables clínicas que resultan predictoras de la VD: el nivel de ansiedad-estado $(B=0.074 ; p=.047)$ y la interacción entre sexo y nivel de depresión $(B=0.248 ; p=.002)$. En ambos casos, la probabilidad de ser clasificado como subclínico aumenta a medida que se incrementa el nivel de ansiedad-estado ( $O R=1.077)$ y, en mujeres, el nivel de depresión (OR=1.282).

Como se aprecia en la figura 22, la probabilidad de que un chico o una chica con bajos niveles de ansiedad-estado sea asignado por el modelo al grupo subclínico es muy remota ( $15.8 \%$ de probabilidad), se situaría en torno al $50 \%$ en personas con niveles normales de ansiedad y aumentaría hasta el $78.7 \%$ en personas que obtuvieran altas puntuaciones en esta dimensión. Por otra parte, en hombres apenas variaría entre el $44.3 \%$ y el $55.7 \%$ la probabilidad de ser clasificado como tal en función del nivel de depresión, pero sí lo haría en mujeres: más concretamente, la probabilidad de que una mujer con baja depresión sea clasificada subclínica sería del $29.5 \%$, ascendería hasta el $52.1 \%$ si tuviera niveles medios de depresión y alcanzaría el $76.2 \%$ cuando comenzara a experimentar problemas de depresión. Podríamos por tanto considerar que los dos extremos de la dimensión de ansiedad-estado desempeñan, tanto en hombres como en mujeres, un papel protector o potenciador del riesgo de manifestar CS y lo mismo se podría decir del nivel de depresión pero únicamente en el caso de las chicas.
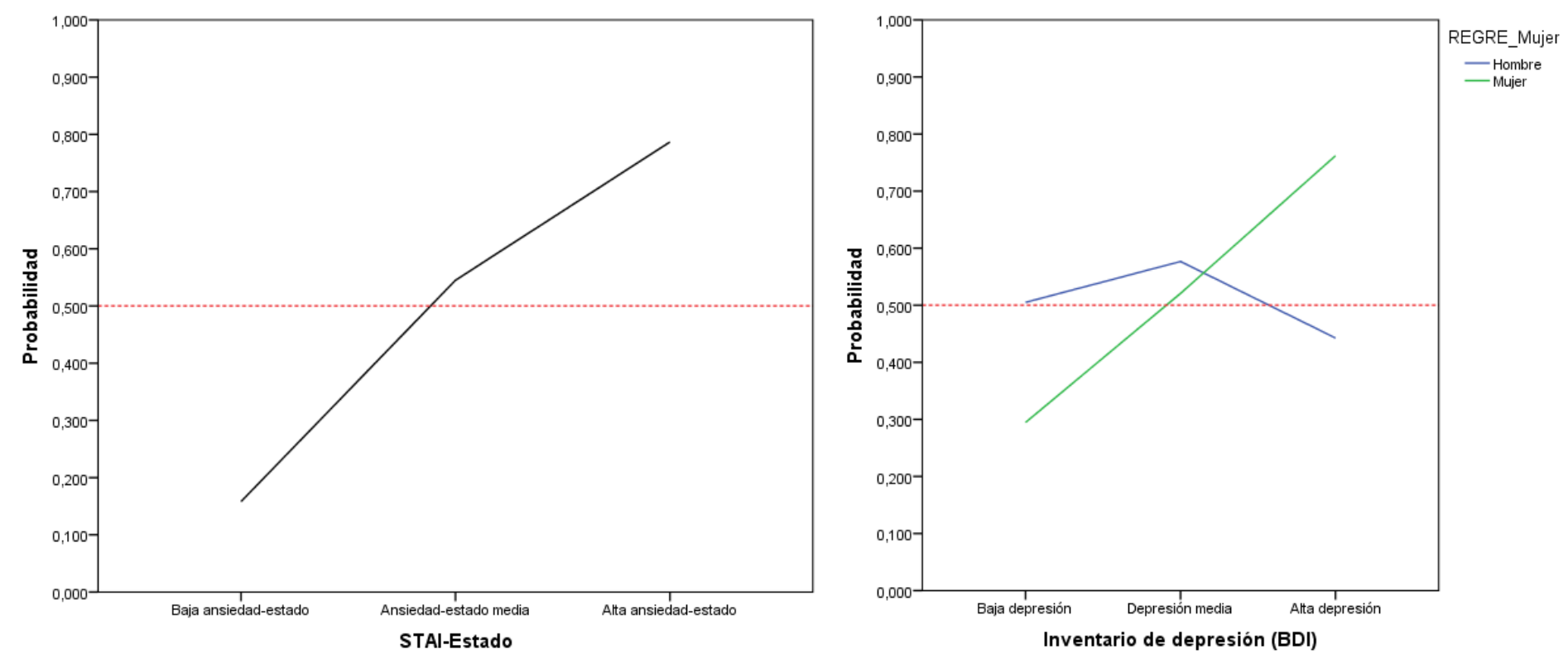

Figura 22. Probabilidad de ser clasificado como subclínico en función del nivel de ansiedad-estado (STAI-Estado) y depresión (BDI). 
A modo de resumen, el modelo de regresión logística expuesto permite que los participantes sean clasificados en una de las dos categorías clínicas (control o sublínicos) con un importante porcentaje de acierto (el $87.8 \%$ ). Sus índices de ajuste así como el porcentaje de varianza de la VD explicada (el 72.2\%) avalarían su adecuación. Este modelo contempla la influencia de un total de 25 variables (18 VI y 7 términos de interacción) sobre la variable dependiente. Según su efecto, estas variables se clasificarían como: factores de riesgo (si aumentan la probabilidad de ser clasificado en el grupo subclínico), de protección (si la disminuyan) o factores que dependiendo de su manifestación, desempeñan un papel u otro. Teniendo esta clasificación en cuenta, a continuación se desglosan las características que definirían a los participantes con mayor y menor riesgo de manifestar problemas en el control de impulsos sexuales:

- Perfil de alto riesgo: los participantes con mayor riesgo de CS se caracterizan por sufrir o haber sufrido abuso o dependencia del alcohol, ser más gregarios e impulsivos (sólo en mujeres), ser menos vulnerables, tener menos emociones positivas y más sentido estético, no mantener una relación estable (mujeres), haber realizado actividades sexuales alternativas a las mayoritarias (mujeres), percibirse más autoeficaces en el uso del preservativo (mujeres), consumir más cibersexo, ser más buscadores de sensaciones sexuales y experimentar más ansiedad-estado y depresión (mujeres). En el caso de los hombres, el ser más sensible aumentaría el riesgo mientras que en mujeres sucedería al contrario.

- Perfil de bajo riesgo: por el contrario, los participantes con menor riesgo de CS suelen ser mujeres, de mayor edad (>24 años), que no abusan o han abusado del alcohol, que son más vulnerables y menos impulsivas (mujeres), que tienden a ser poco gregarias y experimentar más emociones positivas, con menos sentido estético, que nunca han practicado masturbaciones mutuas, que tienen pareja (mujeres), que no realizan comportamientos sexuales alternativos a los mayoritarios, que experimentan menos ansiedad-estado y con menores niveles de depresión (mujeres). En el caso de los hombres, el ser menos sensible reduciría el riesgo mientras que en mujeres sucedería al contrario. 


\section{Propuesta de un modelo de relaciones estructurales a través de metodología SEM}

En este último bloque de resultados se proponen tres modelos teóricos que posteriormente se someten a evaluación empírica a través de metodología SEM (Structural Equation Modelling). Su objetivo es analizar cómo las variables exploradas se configuran a la hora de explicar las diversas manifestaciones de la CS, desde las formas más leves e incipientes hasta su expresión patológica. En el diseño de estos modelos se integran las evidencias empíricas obtenidas hasta el momento junto con las principales aportaciones teóricas en el campo de la CS de acuerdo a los siguientes criterios:

1- Construcción de la variable dependiente del modelo SEM: en SEM, el uso de variables dicotómicas está contraindicado (Bentler, 2006; Finney \& DiStefano, 2013) de modo que en lugar de la categoría clínica (control o subclínico), la principal VD del modelo se sustituyó por una variable continua. En un principio se consideró emplear como VD la puntuación total en la escala SCS pero esto supondría obviar aspectos importantes del cuadro clínico de CS que se ven pobremente reflejados en dicho cuestionario. De modo que en su lugar, se decidió construir un índice a partir de los principales factores que integran el SCS y el IH (los dos principales cuestionarios de screening de CS).

Después de valorar su contenido, se decidió incluir en este índice las dos escalas que integran el SCS ( 5 ítems que evalúan problemas en el control de los impulsos sexuales y 5 que analizan la interferencia de la conducta sexual) y una de las del IH (los 7 ítems de la escala de afrontamiento). Para comprobar que este nuevo índice admitía una solución factorial conjunta, se calculó en primer lugar el índice de Kaiser-Meyer-Olkin (KMO=.914) y la prueba de esfericidad de Bartlett $\left(x^{2}(136)=2742.202 ; p<.001\right)$. Ambas pruebas confirmaron que este índice cumplía adecuadamente los requerimientos psicométricos para su análisis factorial, de modo que se procedió a realizar un Análisis Factorial Exploratorio (AFE) que se confirmó mediante Análisis Factorial confirmatorio (AFC). El AFE (componentes principales y rotación oblicua) reveló una estructura de 3 factores que explicaba el $56.89 \%$ de la varianza de las puntuaciones en el cuestionario. Tal y como se esperaba, la asignación de los ítems a cada escala respetó la distribución original. A través de AFC se contrastaron dos modelos: el primero replicaba la estructura factorial del AFE (tres factores de primer orden correlacionados) mientras que el segundo proponía que los tres factores de primer orden se agrupaban bajo uno de segundo orden que explicaba la varianza compartida. De los dos, el segundo fue el que obtuvo un mejor ajuste $\left(X^{2}=134.15 ; p=.06 ; X^{2} / G . L .=1.38 ; G F I=.93 ; A G F I=.91 ;\right.$ RMSEA $=.03 ; \mathrm{CFI}=.85 ; \mathrm{IFI}=.86$ ) y el que finalmente se tomó como VD del modelo $\mathrm{SEM}$. 
2- Construcción y descripción del modelo SEM: a diferencia de los modelos clásicos de regresión, los construidos a partir de metodología SEM permiten someter a prueba un amplio abanico de relaciones estructurales que van más allá de la relación predictiva entre una o más VI y una única VD (Ruiz, Pardo, \& San Martín, 2010). La unidad básica de medida en SEM es el indicador (cualquier medición realizada sobre un sujeto) y se representa gráficamente a través de rectángulos. Cada indicador lleva asociado un término de error, que refleja la imprecisión de la medición. Finalmente, la agrupación de indicadores permite conformar variables latentes (dimensiones no directamente cuantificables pero que se extrapolan a partir de la conjunción de indicadores), que se representan a través de óvalos. Cualquier indicador o dimensión puede desempeñar el papel de variable exógena (variable que afecta a otra variable), endógena (variable que recibe el efecto de otra variable) o ambos al mismo tiempo. A partir de estas premisas y teniendo en cuenta aspectos como la inclusión únicamente de variables continuas, se construyeron los tres modelos SEM que se describen a continuación (figura 23). En la tabla 38 se incluye una leyenda de las variables incluidas en estos tres modelos:

- Modelo 1 (M1): modelo básico a partir del cual se conforman los modelos 2 y 3 . La principal variable endógena del modelo es la que recibe la etiqueta de CS: este factor de $2 .^{\circ}$ orden resulta de la unión de 3 factores de $1{ }^{\text {er }}$ orden que se construyen a su vez a partir de 5 (SCS-Interferencia y SCS-Control) y 7 indicadores (IH-afrontamiento). Esta dimensión representa la medición dimensional del cuadro clínico de CS y es la sección del modelo descrita en el apartado anterior (principal VD del modelo). Esta variable endógena recibe el efecto directo de 3 indicadores que representan distintos indicadores de desajuste psicopatológico (SCID- $\Sigma$ de trastornos, STAI-Estado y BDI), de otras tantas dimensiones de personalidad (NEO-Apertura, NEO-Amabilidad y NEOResponsabilidad) y de 2 variables de conducta sexual (BSS y Orientación). Asimismo, los indicadores de desajuste psicológico median en el efecto de otras 2 dimensiones de personalidad (NEO-Neuroticismo y NEO-Extraversión) sobre el factor de $2 .^{\circ}$ orden CS. Finalmente, entre las variables de personalidad se establece una relación de correlación o colinearidad que da cuenta del vínculo entre estas dimensiones.

- Modelo 2: la novedad de este modelo con respecto a su predecesor es que incluye dos nuevos indicadores endógenos (ISST y ENSI- $\Sigma$ prácticas sexuales) que recibirían efecto directo de regresión de la variable de $2 .^{\circ}$ orden CS. Así, ambos indicadores desempeñarían el papel de consecuentes de la medida dimensional de la CS en lugar de antecedentes (como se representaban en el modelo de regresión logística). 
- Modelo 3: este último modelo incluye 3 nuevos indicadores endógenos (CSBI, CBOSBCognitivas y CBOSB-Conductuales) que recibirían efecto directo de la variable de $2 .^{\circ}$ orden CS. Nuevamente estos indicadores se configuran como consecuentes de la medida dimensional de la CS. A pesar de que los modelos 2 y 3 son complementarios, se ha evitado integrarlos en una única ecuación estructural: la razón es que mientras los indicadores incluidos en el modelo 2 se evalúan sobre el conjunto de la muestra (384 participantes), los incluidos en el tercer modelo se evalúan únicamente en los participantes del grupo clínico (185 chicos y chicas). Así, de someter a prueba ambos modelos conjuntamente, los indicadores del modelo 2 se analizarían a partir de una muestra mucho más limitada (199 participantes control menos).

Por distintos motivos, estos tres modelos obvian algunas de las principales variables exploradas durante la investigación. Por su naturaleza, variables categóricas como el tener o no pareja, la orientación sexual medida a través de tres categorías o el haber realizado determinado comportamiento sexual no se han incluido en el modelo. En su lugar, se emplean variables alternativas que reflejan el mismo contenido (como la medida dimensional de la orientación sexual) o se han creado otras nuevas a partir de las originales que sí son admisibles en un modelo SEM (como las variables SCID- $\Sigma$ de trastornos o ENSI- $\Sigma$ de prácticas sexuales). Otras muchas (como la dimensión de erotofilia-erotofobia, el nivel de autoestima o la concentración de testosterona en saliva) se incluyeron en versiones originales del modelo 1 pero se extrajeron cuando se comprobó que su efecto sobre la VD carecía de significación. Así, los modelos aquí descritos son el resultado de un proceso previo de análisis de efectos directos e indirectos e incluyen únicamente variables que sí han demostrado ser importantes en la comprensión de la expresión dimensional de la CS.

3- Estimación del modelo SEM: dado que algunas de las variables incluidas en estos modelos no siguen una distribución normal, el método empleado para la estimación de parámetros fue el de Máxima Verosimilitud Robusto. Este método permite obtener estadísticos que corrigen la violación del principio de normalidad (en concreto, el $x^{2}$ de Satorra-Bentler), de modo que resulta apropiado para modelos que incluyen variables con índices de asimetría y curtosis elevados (como en este caso).

4- Invarianza estructural del modelo SEM: la hipótesis de la equivalencia estructural del modelo SEM se evaluó mediante análisis multigrupo en el que se comparaba el ajuste diferencial de los tres modelos en chicos y chicas. Dado que su objetivo era explorar la equivalencia de la estructura factorial y no la intensidad del vínculo entre variables (invarianza métrica), durante su estimación no se aplicó ninguna restricción. 
5- Índices de ajuste del modelo SEM: el ajuste de los 3 modelos SEM así como de los análisis multigrupo se valoró mediante los siguientes índices: Chi Cuadrado de SatorraBentler $\left(X^{2}\right)$, Chi Cuadrado Relativo $\left(X^{2} /\right.$ G.L.), significación general del modelo $(p)$, Estadístico de bondad de ajuste (GFI) y de bondad de ajuste corregido (AGFI), Raíz Cuadrada Media del Error de Aproximación (RMSEA) e Índices de Ajuste Comparativo (CFI) e Incremental (IFI). Se consideró que el ajuste del modelo era correcto cuando el $X^{2}$ resultaba no significativo ( $p>.05$ ), el $X^{2} /$ G.L. se situaba entre 1 y 2 , el CFI y el IFI eran $\geq .95$ y el RMSEA $\leq .05$ (Bagozzi \& Yi, 2011). Según criterios más laxos, valores entre 2 y 3 para el $X^{2} /$ G.L., $\geq .90$ para el CFI y el IFI y $\leq .08$ para el RMSEA podrían considerarse también aceptables (Hooper et al., 2008).

Como se aprecia en la tabla 37, el ajuste de los 3 modelos propuestos (en especial del tercero) fue satisfactorio. En los tres casos, la significación general del modelo $(p)$ superó el criterio de .05, alcanzando un valor de .57 en el modelo 3: así, se aceptaría la hipótesis nula de que la distribución estructural propuesta coincide con la distribución empírica real. Si atendemos al valor del $x^{2}$ relativo, éste se situó por debajo de 1 en el modelo $3\left(X^{2} / G . L .=0.98\right)$ y entre 1 y 2 en los modelos 1 y 2 ( $X^{2} /$ G.L.=1.10). Estos valores se sitúan dentro de los rangos más estrictos de ajuste estadístico. Por su parte, el valor del índice RMSEA se situó en 0.01 en los tres modelos (muy por debajo del criterio .05 para considerar el modelo ajustado). El CFI y el IFI mostraron un ajuste perfecto en el modelo 3; sin embargo, ni tan siquiera alcanzaron criterios de ajuste laxos en los modelos 1 ( $\mathrm{CFI}=0.80 ; \mathrm{IFI}=0.85)$ y $2(\mathrm{CFI}=0.78 ; \mathrm{IFI}=0.83)$. Lo mismo sucedería con los Estadísticos de bondad de ajuste (GFI) y de bondad de ajuste corregido (AGFI), que en los tres modelos se sitúan por debajo del criterio de 0.90 .

Al revisar ahora a los índices de ajuste de los modelos multigrupo (tabla 37), únicamente los valores para el estadístico $x^{2}$ relativo y el RMSEA se encontrarían en un rango aceptable de ajuste estadístico ( $x^{2}$ relativo entre 1 y 2 y RMSEA <.08). Por el contrario, el resto de índices ni tan siquiera se aproximarían a niveles de ajuste aceptables (especialmente el CFI y el IFI). En esta misma línea, la significación general $(p)$ de los tres modelos quedaría por debajo de .001, rechazando la hipótesis nula de que las relaciones estructurales entre las variables propuestas son equivalentes en hombres y en mujeres. De modo que atendiendo a estos criterios, no podría aceptarse la hipótesis de equivalencia factorial en función del sexo.

En cuanto al tipo e intensidad de la relación entre variables (figura 23), los tres indicadores de desajuste psicopatológico (SCID- $\Sigma$ de trastornos, STAI-Estado y BDI) propuestos en el modelo 1 predicen positivamente la medida dimensional de la CS (valores $B$ entre .09 y .22). A su vez, estos indicadores vendrían predichos por las dimensiones de personalidad de neuroticismo y 
extraversión (únicamente en el caso de la variable STAI-Estado), que permiten explicar entre el $6 \%$ y el $24 \%$ de su varianza. También positiva y significativamente se relaciona la dimensión de personalidad de apertura a la experiencia $(B=.02)$, la evaluación dimensional de la orientación sexual $(B=.11)$ y sobre todo la BSS $(B=.32)$ con la VD. Al contrario, la dimensión de personalidad de amabilidad $(B=-.09)$ y especialmente la de responsabilidad $(B=-.13)$ mostrarían capacidad predictiva negativa sobre el factor de $2{ }^{\circ}$ orden CS. Tomadas en conjunto, estas ocho variables permitirían predecir el 32\% de la varianza de la medición dimensional de la CS. En el modelo 2, el factor de $2 .^{\circ}$ orden CS permite predecir por sí solo el $19 \%$ de la varianza de las puntuaciones en la escala de adicción al cibersexo (ISST), con un valor $B$ de .43 (el mayor de todo el modelo). Con una intensidad sensiblemente inferior $(B=.07)$, la variable CS predice el $3 \%$ de la varianza del tipo de prácticas sexuales realizadas (ENSI- $\Sigma$ prácticas sexuales). Finalmente, en el modelo 3 el factor de $2 .^{\circ}$ orden CS predice con una intensidad .59 y de .36 y un porcentaje de varianza explicada del $34.6 \%$ y del $13 \%$ respectivamente la gravedad del cuadro clínico de CS (CSBI) y sus consecuencias conductuales (CBOSB-Conductuales). Sin embargo, esta dimensión apenas predeciría el 1\% de la varianza de las consecuencias cognitivas (CBOSB-Cognitivas).

En resumen, los tres modelos (en especial el tercero) se ajustan con exactitud a la distribución empírica real. Los tres resultan además complementarios y cada uno de ellos explora aspectos que permiten mejorar la comprensión de la manifestación y las consecuencias de la CS. En cualquier caso, ninguno de ellos se aplicaría de forma equivalente en chicos y chicas.

Tabla 37. Índices de bondad de ajuste para los distintos modelos

\begin{tabular}{lccccccccc}
\hline & $\chi^{2}$ & G.L. & $\mathrm{p}$ & $\chi^{2} / \mathrm{G} . \mathrm{L}$. & GFI & AGFI & RMSEA & CFI & IFI \\
\hline Modelo SEM & & & & & & & & & \\
Modelo 1 & 309.35 & 280 & .10 & 1.10 & 0.86 & 0.82 & 0.01 & 0.80 & 0.85 \\
Modelo 2 & 367.16 & 331 & .08 & 1.10 & 0.84 & 0.81 & 0.01 & 0.78 & 0.83 \\
Modelo 3 & 352.29 & 358 & .57 & 0.98 & 0.79 & 0.74 & 0.01 & 1 & 1 \\
$\begin{array}{l}\text { Invarianza estructural } \\
\text { Invarianza_Modelo 1 }\end{array}$ & 1054.56 & 560 & $<.001$ & 1.88 & 0.82 & 0.78 & 0.06 & 0.85 & 0.85 \\
Invarianza_Modelo 2 & 874.16 & 614 & $<.001$ & 1.42 & 0.83 & 0.79 & 0.04 & 0.56 & 0.62 \\
Invarianza_Modelo 3 & 909.47 & 616 & $<.001$ & 1.47 & 0.82 & 0.78 & 0.05 & 0.54 & 0.60 \\
\hline
\end{tabular}

Nota: $\chi^{2}=\chi^{2}$ de Satorra-Bentler; $\chi^{2} /$ G.L. $=\chi^{2}$ relativo; GFI= Estadístico de Bondad de Ajuste; AGFI= Estadístico de Bondad de Ajuste Corregido; RMSEA= Raíz Cuadrada Media del Error de Aproximación; CFI= Índice de Ajuste Comparativo; IFI= Índice de Ajuste Incremental. 


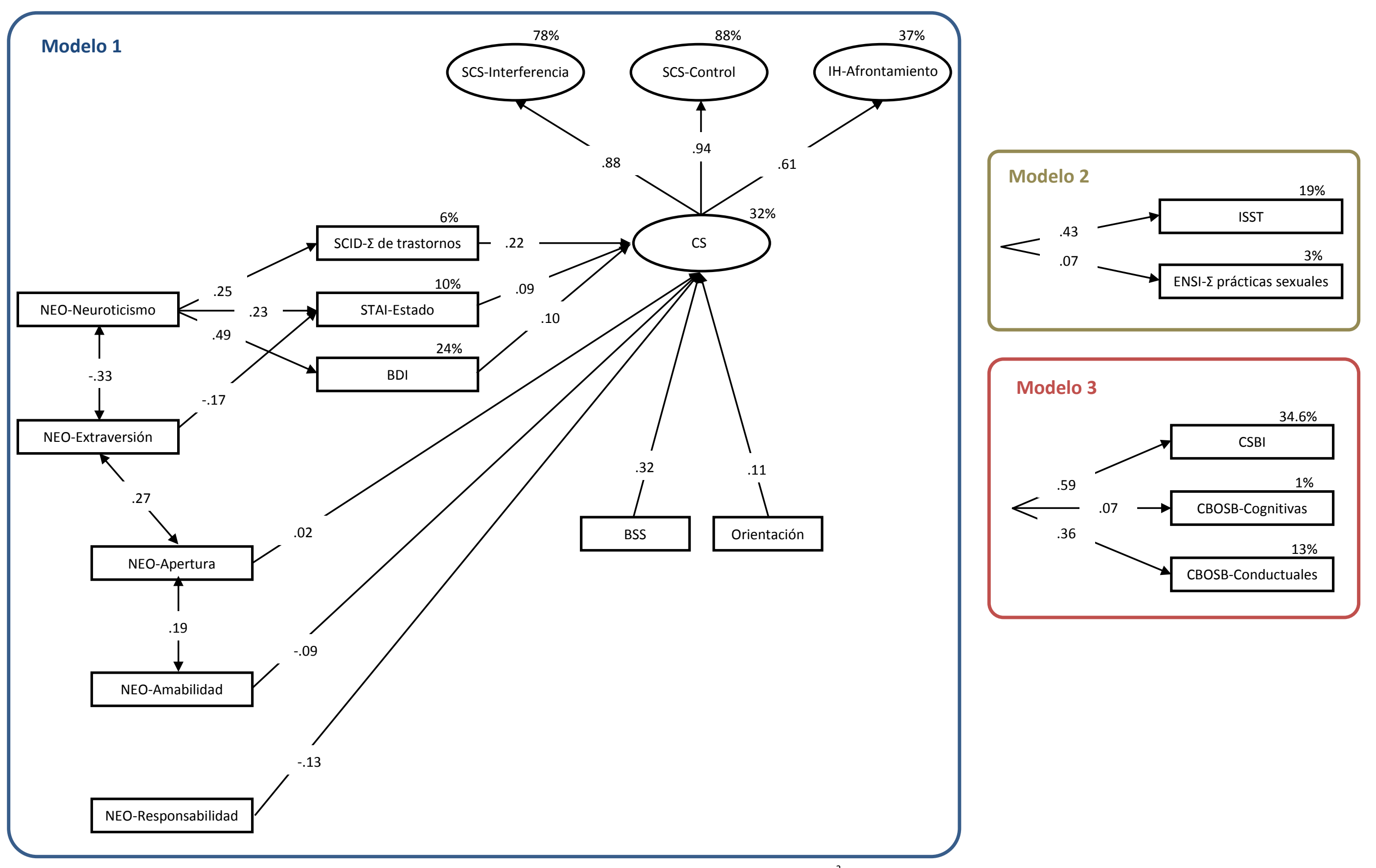

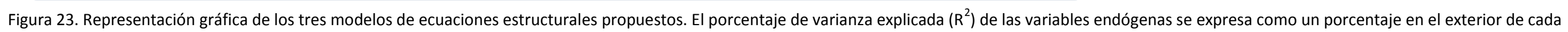

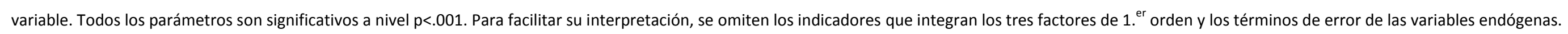


Tabla 38. Identificación de las variables contempladas en los 3 modelos SEM

\begin{tabular}{|c|c|c|c|}
\hline Etiqueta & Tipo de variable & Efecto de la variable & Identificación de la variable \\
\hline SCS-Interferencia & Factor de $1 .{ }^{\text {er }}$ orden & Endógena & Escala de Compulsividad Sexual (SCS): factor 1. Interferencia. \\
\hline SCS-Control & Factor de $1 .{ }^{\text {er }}$ orden & Endógena & Escala de Compulsividad Sexual (SCS): factor 2. .Problemas en el control. \\
\hline IH-Afrontamiento & Factor de $1 .{ }^{\text {er }}$ orden & Endógena & Inventario de Hipersexualidad (IH): factor 1. Afrontamiento. \\
\hline CS & Factor de $2 .^{\circ}$ orden & Exógena y endógena & Nuevo factor que integra las principales escalas del SCS y el IH. \\
\hline SCID- $\Sigma$ de trastornos & Indicador & Exógena y endógena & Entrevista Clínica Estructurada (SCID-I y II): $\Sigma$ del número de trastornos padecidos. \\
\hline STAI-Estado & Indicador & Exógena y endógena & Cuestionario de Ansiedad Estado-Rasgo (STAI): STAI-Estado. \\
\hline BDI & Indicador & Exógena y endógena & Inventario de Depresión BDI: Puntuación total. \\
\hline NEO-Neuroticismo & Indicador & Exógena & Inventario de Personalidad NEO Revisado: Neuroticismo \\
\hline NEO-Extraversión & Indicador & Exógena & Inventario de Personalidad NEO Revisado: Extraversión \\
\hline NEO-Apertura & Indicador & Exógena & Inventario de Personalidad NEO Revisado: Apertura a la experiencia \\
\hline NEO-Amabilidad & Indicador & Exógena & Inventario de Personalidad NEO Revisado: Amabilidad \\
\hline NEO-Responsabilidad & Indicador & Exógena & Inventario de Personalidad NEO Revisado: Responsabilidad \\
\hline BSS & Indicador & Exógena & Escala de Búsqueda de Sensaciones Sexuales (BSS): Puntuación total \\
\hline Orientación & Indicador & Exógena & Cuestionario de Evaluación de la Orientación Sexual: escala continua de orientación sexual. \\
\hline ISST & Indicador & Exógena & Cuestionario de Adicción al Cibersexo (ISST): Puntuación total \\
\hline ENSI- $\Sigma$ prácticas sexuales & Indicador & Endógena & Encuesta Sobre el SIDA (ENSI): $\Sigma$ del tipo de prácticas sexuales realizadas \\
\hline CSBI & Indicador & Endógena & Inventario de Conducta Sexual Compulsiva (CSBI): Puntuación total \\
\hline CBOSB-Cognitivas & Indicador & Endógena & Consecuencias Cognitivas y Conductuales de la Conducta Sexual (CBOSB): CBOSB-Cognitivas \\
\hline CBOSB-Conductuales & Indicador & Endógena & Consecuencias Cognitivas y Conductuales de la Conducta Sexual (CBOSB): CBOSB-Conductuales \\
\hline
\end{tabular}





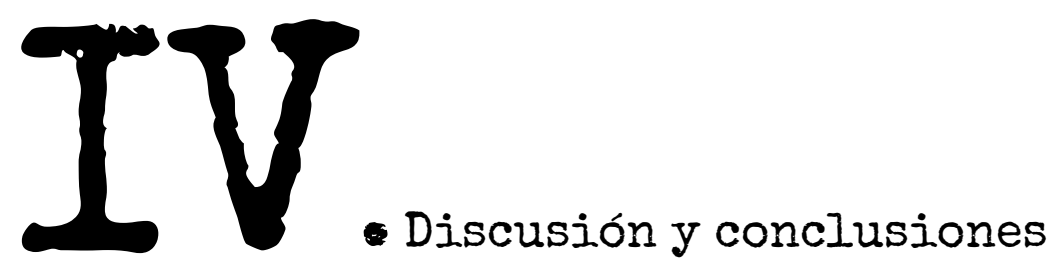





\section{Capítulo 8. Discusión}

1. Fase I: características y prevalencia del cuadro clínico de CS en población joven

2. Fase II: perfil biopsicosocial de jóvenes con puntuaciones subclínicas en CS

2.1 Comorbilidad psicopatológica con trastornos del Eje I y II.

2.2 Correlatos clínicos.

2.3 Perfil de personalidad.

2.4 Comportamiento sexual.

2.4.1 Comportamiento sexual general.

2.4.2 Comportamiento sexual de riesgo.

2.4.3 Comportamiento sexual online.

2.4.4 Variables clínicas sexuales.

2.4.5 Evaluación hormonal.

2.5 Severidad y consecuencias de la CS.

2.6 Modelos predictivos y explicativos del cuadro clínico de CS.

3. Limitaciones y líneas de investigación futuras. 
Las investigaciones en población general y clínica demuestran que la CS se distribuye de forma dimensional a lo largo de un continuo (Walters et al., 2011) y que sus primeras manifestaciones comienzan entre los 18 y los 25 años (Reid, Carpenter, et al., 2012). Durante este periodo crítico, considerado de pródromo o manifestación subclínica, los jóvenes en el extremo superior del continuo de CS comienzan a mostrar los primeros signos y síntomas del cuadro clínico: aumenta notablemente su frecuencia sexual, experimentan problemas para controlar sus pensamientos e impulsos sexuales, empiezan a utilizar el sexo como regulador emocional y no como fuente de placer y derivado de todo lo anterior, a experimentar algunos de los problemas físicos, sociales y emocionales típicos de este cuadro clínico (Kafka, 2013). En este periodo en el que la CS todavía no se manifiesta clínicamente, la identificación precoz de sus signos y síntomas y en particular de los factores que predisponen su desarrollo permitiría aplicar intervenciones preventivas eficaces que supondrían evitar el desarrollo de un cuadro clínico con graves implicaciones socio-sanitarias. Sin embargo, son muy pocos los estudios que se han detenido a analizar el perfil de riesgo para el desarrollo de la CS en este sector de población, de modo que no contamos con indicadores suficientes a la hora de identificar precozmente a aquellos jóvenes más susceptibles de desarrollar este cuadro clínico.

El periodo entre los 18-25 años coincide además con el momento en el que muchos jóvenes comienzan a cursar sus estudios superiores. Esto les ofrece múltiples y nuevas oportunidades de socialización (muchos viven por primera vez alejados de su hogar y por tanto sin control paterno), de modo que para muchas personas, este es el periodo de mayor actividad sexual de sus vidas (Eshbaugh \& Gute, 2008; Goldstein et al., 2007). En este contexto, algunos jóvenes con rasgos compulsivos encuentran el caldo de cultivo ideal en el que desarrollar una sexualidad que a largo plazo, les resultará extremadamente problemática (Stupiansky et al., 2009). Asimismo, la tarea de identificar un incipiente problema de CS se complica porque los signos y síntomas que denotan su presencia se confunden fácilmente con la conducta sexual prototípica de un joven universitario. Teniendo en cuenta estas carencias, esta tesis doctoral se planteó con un doble objetivo: estimar la prevalencia del cuadro clínico de CS en jóvenes españoles de entre 18-27 años e identificar qué características biopsicosociales les diferencian de otros jóvenes sin esta problemática.

Además de centrarse en un sector de población ignorado en el estudio empírico de la CS, esta tesis amplía en otros sentidos lo que hasta el momento sabíamos de este fenómeno. Que tengamos constancia, este es el primer estudio a gran escala sobre prevalencia y correlatos de la CS realizado en España. La experiencia en campos de estudio afines (principalmente la adicción al cibersexo) ha demostrado que en sexualidad, los hallazgos obtenidos en países con 
entornos socioculturales distintos (incluso aquellos con los que compartimos continente) no son fácilmente generalizables a nuestro contexto (Ballester-Arnal, Castro-Calvo, Gil-Llario, \& Gil-Julia, 2016; Ballester-Arnal, Giménez-García, Gil-Llario, \& Castro-Calvo, 2016; Castro-Calvo, Ballester-Arnal, Gil-Llario, \& Giménez-García, 2016). Así, resulta aventurado creer que lo que sabemos sobre CS a partir de estudios en otros países es generalizable al contexto español.

Otro aspecto que hasta el momento no se había tenido en cuenta en investigaciones precedentes y que sí se ha contemplado durante la elaboración de este trabajo ha sido la inclusión de variables biológicas en el estudio de la conducta sexual compulsiva. Existen infinidad de trabajos que demuestran la importancia de distintos indicadores hormonales (principalmente la testosterona) en la comprensión del deseo sexual normal e hipoactivo (Bancroft, 2005), pero no disponemos de estudios que lo exploraren en personas con una manifestación opuesta de esta dimensión. En su última revisión, Reid proponía la investigación hormonal como uno de los retos más prometedores en la comprensión integral de la CS (Reid, 2013) pero hasta este momento, nadie había tomado la iniciativa a la hora de desarrollar esta línea de investigación. De modo que aunque su inclusión en este estudio se deba considerar todavía tentativa, sin duda puede permitir ampliar el abanico de conocimientos de los que disponemos en la actualidad acerca de los correlatos biológicos de la CS.

Para terminar, una prioridad que ha condicionado el diseño y elaboración de esta investigación ha sido el análisis de la CS desde una perspectiva de género. En las investigaciones realizadas hasta el momento -en particular, con muestra clínica-, se aprecia un sesgo hacia el estudio de la conducta sexual compulsiva en hombres. Así, lo que sabemos actualmente acerca de sus signos, síntomas, manifestaciones, consecuencias o correlatos se ha construido a partir del análisis de la conducta sexual masculina y generalizado a las mujeres sin el debido aval empírico. Durante mucho tiempo se atribuyó esta escasez a su baja prevalencia, si bien parece que esto no resulta del todo preciso: efectivamente los estudios epidemiológicos constatan una prevalencia menor del cuadro clínico en mujeres pero también que el desconocimiento de su manifestación diferencial en función del sexo está llevando a su infraestimación (Mckeague, 2014). Si aplicamos los mismos criterios en el diagnóstico de la CS a ambos sexos -criterios elaborados a partir y para hombres-, efectivamente la prevalencia va a ser muy desigual, pero eso sería tan erróneo como afirmar que la sexualidad masculina y femenina es equivalente. El vacío en la literatura es especialmente grave en cuanto a identificación de predisponentes de la CS femenina, que es precisamente uno de los espacios más importantes que hemos tratado de abarcar durante la elaboración de esta tesis doctoral. 
Teniendo en cuenta estas premisas, a continuación se discuten los resultados de la presente tesis doctoral. En el capítulo se abordan los objetivos e hipótesis planteados, su cumplimiento -total o parcial- o refutación a partir de los resultados obtenidos y su discusión en el marco de la literatura científica sobre el tema. Su presentación se organiza en torno a dos bloques. El primer bloque corresponde a las conclusiones derivadas de la primera fase de la investigación, cuyo objetivo general fue estimar la prevalencia de CS en jóvenes (concretamente, chicos y chicas entre los 18 y los 27 años). El segundo bloque, dividido a su vez en 6 epígrafes, corresponde a las conclusiones extraídas de la segunda fase de la investigación. Su objetivo ha sido establecer las características biopsicosociales que identifican a los chicos y chicas con mayor probabilidad de desarrollar esta problemática.

\section{Fase I: características y prevalencia del cuadro clínico de CS en población joven}

Durante la primera fase de la investigación, 1588 jóvenes de entre 18 y 27 años completaron una batería de evaluación compuesta por un cuestionario Ad-Hoc de información sociodemográfica y tres cuestionarios de screening de compulsividad sexual: la Escala de Compulsividad Sexual (SCS), el Inventario de Hipersexualidad (IH) y el Cuestionario de Adicción al Sexo (SAST). El análisis de estas tres escalas y sus subescalas ha permitido abordar los dos primeros objetivos específicos de esta investigación: 1) analizar el perfil de puntuaciones y estimar la prevalencia de CS y 2) explorar la influencia del sexo, edad y orientación sexual en estos dos aspectos.

El análisis del perfil de puntuaciones en estos tres cuestionarios de screening reveló que el tipo de participantes en este estudio (jóvenes universitarios) no representa un grupo de especial riesgo en el desarrollo de problemas en el control de los impulsos sexuales. Si comenzamos analizando la principal medida de screening de compulsividad sexual (la escala SCS), la puntuación media fue de 14.20 en un rango que oscila entre 10 y 40 . Como se esperaba de una muestra de este tipo, esta puntuación queda muy por debajo de la documentada en estudios con grupos de alto riesgo (en particular, pacientes con distintos problemas en el control de los impulsos sexuales). En un estudio con 120 pacientes que cumplían criterios para el diagnóstico de hipersexualidad, Reid et al. (2008) reportaban una puntuación media en la escala SCS de 25.93 (más de 10 puntos por encima de la obtenida en nuestra investigación). Por otra parte, Winters et al. (2010) informaban de una puntuación de 24.3 y 20.4 en 107 hombres y 69 mujeres que dijeron haber buscado tratamiento por problemas de compulsividad sexual. Finalmente, Prause et al. (2013) hallaban una puntuación de 21.8 en pacientes adictos al cibersexo, más de 7 puntos por encima de la de nuestro estudio. 
Si por el contrario comparamos esta puntuación con estudios realizados en población general o en muestras equivalentes (estudiantes universitarios), los datos resultan prácticamente idénticos. En uno de los estudios citados anteriormente (Winters et al., 2010), la puntuación media en el SCS de los participantes control (7938 hombres y 6458 mujeres de entre 18-94 años) se situó en 15.45, apenas un punto por encima de la obtenida en nuestra investigación. Si analizamos algunos estudios con estudiantes universitarios, las cifras resultan todavía más similares: así, la puntuación media de los 899 estudiantes estadounidenses del estudio de Dodge et al. (2004) y de los 256 del estudio de Gullette y Lyons (2005) fue de 14.85 y 12.5 respectivamente. De modo que sin duda, las características de la muestra de nuestra investigación en cuanto a control de impulsos sexuales se asemejan a las que se pueden observar en cualquier otro estudio en población general aun cuando éstos hayan sido desarrollados en países con entornos socioculturales distintos al nuestro.

Esta misma tendencia se aprecia cuando analizamos las puntuaciones obtenidas en el IH o en el SAST. La puntuación media en esta primera escala fue de 30.59 (rango de 19-95), puntuación que quedaría 35.7 y 40.9 puntos por debajo de la obtenida en el estudio de validación original de la escala con 324 pacientes en tratamiento ambulatorio por problemas de hipersexualidad (Reid et al. 2011) y del estudio de Gilliland et al. (2015) con 136 pacientes en tratamiento por adicción a la pornografía. Por el contrario, se situaría tan sólo ligeramente por debajo de la puntuación de los participantes control del estudio de Reid (2010) y de Reid, Garos, Carpenter, et al. (2011), que fue de 37.9 y 32.93 respectivamente. Por su parte, la puntuación media obtenida en el SAST (3.53 en un rango entre 0-25 puntos) nuevamente se sitúa muy por debajo del 16.2 obtenido en un estudio con hombres y mujeres en tratamiento por adicción al sexo y tan sólo un poco por encima del 1.34 obtenido en población general (Carnes et al., 2010).

Al analizar los aspectos del comportamiento sexual compulsivo que más se manifiestan, los resultados no permiten establecer un claro patrón de síntomas que prevalezca sobre el resto. En el SCS, la puntuación en la escala de control supera la obtenida en la escala de interferencia. En la primera se agrupan síntomas que reflejan la incapacidad para manejar la conducta sexual (p.e., "tengo que luchar para controlar mis pensamientos y comportamientos sexuales") mientras que en la segunda se incluyen algunos de los problemas que se derivan de este tipo de síntomas ("mi gran apetito sexual ha sido un obstáculo en mis relaciones"). De modo que estos resultados son coherentes con los autores que sostienen que con relativa frecuencia, los jóvenes experimentan problemas a la hora de controlar su conducta sexual sin que ello les suponga interferencia alguna (Reid, Garos, et al., 2012). Esto se debería o bien a que su 
situación personal les permite mantener una conducta sexual en ocasiones excesiva (por ejemplo en cuanto a número de parejas cuando no tienen una relación estable) o a que los síntomas no alcanzan la severidad como para acarrear problemas significativos. Sin embargo, en el IH sucede justo al contrario: los síntomas de la escala de interferencia (p.e., "mi conducta sexual controla mi vida") son más frecuentes que los de control de la conducta sexual o los de afrontamiento (uso del sexo como regulador emocional). Así, parece que la manifestación de los distintos síntomas en población sin un problema clínico depende más de las características del cuestionario que de una verdadera preponderancia de unos u otros síntomas.

El análisis de la distribución de puntuaciones en estos cuestionarios de screening permite además extraer algunas conclusiones respecto a la taxonomía del constructo de CS. Algunas de las teorías con mayor aval empírico en este ámbito sostienen que la CS se distribuye de forma dimensional a lo largo de un continuo (Kalichman \& Cain, 2004). Esta visión se ha visto recientemente respaldada por estudios que avalan a nivel empírico la distribución dimensional de la CS: aplicando complejos métodos de evaluación taxométrica, Walters et al. (2011) demostraron primero en población general ( 2101 hombres y mujeres suecos de entre 18-60 años) y más tarde en agresores sexuales (716 hombres de entre 18-68 años encarcelados por distintos tipos de delito sexual) que el cuadro clínico de CS representa una manifestación patológica del continuo de deseo sexual, en cuyo extremo opuesto se situaría el deseo sexual hipoactivo. Sin embargo, nuestros resultados no apuntan en esta misma dirección. Como se esperaría de unos instrumentos destinados a la evaluación de un constructo categórico y no dimensional, la distribución de puntuaciones en el SCS, IH y SAST así como en sus subescalas fue positivamente asimétrica y leptocúrtica: en lugar de seguir una distribución normal, la mayoría de participantes obtuvo puntuaciones cercanas al extremo inferior de la escala, decreciendo abruptamente su frecuencia a medida que aumentan las puntuaciones. Existen varios motivos que permiten explicar esta discrepancia, si bien la hipótesis más plausible tiene que ver con las propiedades escalares de los cuestionarios. Tal y como se distribuyen las puntuaciones, es probable que estos cuestionarios tiendan a producir un cierto efecto suelo (McHorney \& Tarlov, 1995): es decir, la mayoría de personas sin un problema clínico de control de los impulsos sexuales tienden a puntuar en torno a las respuestas más bajas en las tres escalas, independientemente de su nivel de CS. Esto puede deberse a que el tipo de preguntas que conforman estas escalas están más orientadas a la evaluación de un cuadro clínico (síntomas) que a la estimación de una variable psicológica dimensional (rasgos o características). En todo caso, esta conclusión debe considerarse tentativa ya que para afirmar 
sin género de dudas que la CS es una variable categórica y no una dimensión se deberían haber realizado otro tipo de análisis estadísticos de orden superior.

Por tanto, nuestros resultados permiten confirmar en su totalidad la primera hipótesis planteada: "Ia puntuación media en los cuestionarios de screening de CS se distribuirá de forma asimétrica, con un importante porcentaje de la muestra en valores inferiores del rango de puntuaciones y una densidad decreciente en valores superiores".

Respecto a la estimación de la prevalencia de jóvenes con un posible cuadro clínico de CS, ésta se situó en un rango de entre el 3.1\%-6.3\%. La prevalencia más baja corresponde a la estimada a través del cuestionario SAST, que es el que establece criterios más estrictos; en el extremo contrario, el IH sería el que identifica una prevalencia mayor. Entre ambas estimaciones se sitúa la obtenida a partir de los puntos de corte propuestos en la corrección del SCS, que señala a un $5.6 \%$ de la muestra con un posible problema en el control de impulsos sexuales. Si además de la considerable prevalencia documentada tenemos en cuenta que muchos jóvenes desarrollan el cuadro clínico de forma tardía (Reid, Carpenter, et al., 2012), que el acceso cada vez más generalizado a contenidos sexuales en la red está incrementando la proporción de jóvenes con adicciones sexuales (Ross et al., 2012) y que el cuadro clínico de CS se acompaña de consecuencias severas para el que lo padece (Kafka, 2010; Parsons et al., 2012), entonces empezamos a comprender el calibre del problema socio-sanitario al que quizá debamos enfrentarnos durante los próximos años.

Estas cifras se acercarían mucho a las obtenidas en investigaciones anteriores sobre epidemiología de la conducta sexual compulsiva. En un reciente estudio en el que 1750 alemanes completaron el Inventario de Hipersexualidad a través de Internet, se obtuvo una prevalencia de casos clínicos del 6\% (apenas 3 décimas por debajo de la obtenida con este instrumento en nuestra investigación) (Rettenberger et al., 2015). Tasas muy similares se obtendrían a partir de otros métodos de estimación, como el TSO (Atwood \& Gagnon, 1987; Laumann et al., 1994), la aplicación de varios tipos de criterios clínicos (Skegg et al., 2010) o cuestionarios de screening distintos a los empleados en esta tesis (Odlaug et al., 2013). Un estudio criticado por sus polémicos resultados fue el realizado por Seegers (2003) con 240 estudiantes universitarios estadounidenses. Aplicando el Cuestionario de Adicción al Sexo (SAST), esta investigadora estimó que tan sólo el $73.9 \%$ de los chicos y el $54.4 \%$ de las chicas caían en la categoría de bajo riesgo, mientras que el $26.1 \%$ y el $45.6 \%$ restante tenían un riesgo entre medio y alto de padecer una adicción sexual. En concreto, Seegers estimó que la prevalencia de adictos al sexo en su muestra ascendía hasta el $17.4 \%$ en chicos y el $32.2 \%$ en chicas. En respuesta, muchos criticaron este cuestionario -hasta el momento, uno de los más 
populares en la evaluación clínica de la compulsividad Sexual (Hook et al., 2010; Womack et al., 2013)- por sobredimensionar su prevalencia, señalándolo ineficaz en el diagnóstico del cuadro clínico. A partir de ahí, su empleo se redujo drásticamente -sobre todo con fines empíricos-. Sin embargo, en este estudio queda demostrado que con un muestreo adecuado y aplicando criterios de corrección más estrictos, este instrumento resulta tan eficaz en la evaluación de la CS como lo pueda ser el SCS o el IH.

A la hora de valorar estos resultados debemos considerar dos limitaciones en el diagnóstico de la CS a través de instrumentos de screening. La primera estaría relacionada con su sensibilidad: en un estudio en el que la escala SCS se administró a 120 pacientes en tratamiento por problemas en el control de los impulsos sexuales, la tasa de diagnósticos positivos se situó en el 71\% (Reid et al., 2008). Es decir, a pesar de sido diagnosticados de hipersexualidad y de estar siento sometidos a tratamiento para este problema, el SCS resultó incapaz de detectar al $29 \%$ de los pacientes con este problema. De modo que resulta posible que las tasas de prevalencia identificadas en nuestro estudio estén infraestimadas por la baja sensibilidad diagnóstica de las escalas empleadas.

La segunda limitación tiene que ver con su congruencia diagnóstica (proporción de diagnósticos positivos compartidos entre distintos instrumentos). Con el objetivo de evaluar la convergencia diagnóstica entre los tres principales instrumentos de screening de la CS (el SCS, el IH y el SAST), Castro, Ballester y Gil (2015) realizaron un estudio en el que administraron estas escalas a una muestra de 600 jóvenes universitarios de entre 18-25 años (300 chicas y 300 chicos). Lo que estos investigadores encontraron fue que a pesar de que la correlación entre escalas era alta ( $r$ entre .529 y .732), la convergencia diagnóstica alcanzaba, en el mejor de los casos, el $46.3 \%$. Las tasas de convergencia diagnóstica fueron especialmente pobres en chicas: el mayor grado de acuerdo (40\%) se daba entre el IH y el SAST, mientras que bajaba hasta el $13.5 \%$ cuando se comparaba SCS e IH y hasta el $10.3 \%$ entre SCS y SAST. Tan sólo el 7.31\% de los casos clínicos según el SCS también lo fueron según el IH y el SAST. En nuestro caso, no se estimó la congruencia diagnóstica entre instrumentos pero es posible que el 3.1\% de casos clínicos identificados a través del SAST no coincida -o por lo menos no lo haga por completo- con el $5.6 \%$ estimado a través del SCS o con el 6.3\% del IH. De ahí la necesidad de tomar con cautela estos resultados, asumiendo que se necesita una evaluación pormenorizada de cada paciente para determinar si su sintomatología se adapta a lo que se esperaría de alguien con problemas en el control de los impulsos sexuales. 
A pesar de las limitaciones, nuestros hallazgos se ajustarían por completo a la segunda hipótesis planteada en relación a la prevalencia de jóvenes con puntuaciones clínicas: "la prevalencia de jóvenes con puntuaciones clínicas se situará entre el 3\%-7\%".

El último de los objetivos para esta primera fase de la investigación fue analizar el papel del sexo, la edad y la orientación sexual en la manifestación normal y patológica de la CS. En este sentido, los análisis realizados demuestran que la gravedad y prevalencia de problemas en el control de los impulsos sexuales estarían moduladas por el sexo y la orientación sexual pero no por la edad.

En función del sexo, los chicos obtienen puntuaciones sistemáticamente superiores a las chicas en los tres cuestionarios de screening empleados y en sus subescalas, con diferencias que en la mayoría de casos alcanzan un tamaño del efecto grande. Si nos centramos en la prevalencia de casos clínicos, el porcentaje de hombres posiblemente compulsivos sexuales superaría en un $2.9 \%$ al de mujeres según el cuestionario SAST ( $4.6 \%$ vs. $6.9 \%$ ), en un $6.3 \%$ según el IH (9.9\% vs. 3.6\%) y en un $7.4 \%$ si se aplica el punto de corte estático en ambos sexos en el SCS (9.9\% vs. $2.5 \%)$. Estos resultados coinciden con los obtenidos en la gran mayoría de investigaciones previas acerca de la epidemiología de la CS: a partir de un conjunto de 7 criterios clínicos, Långström y Hanson (2006a) hallaban una diferencia del 5.3\% en la tasa de hombres y mujeres con un posible problema de CS ( $12.1 \%$ y $6.8 \%$ respectivamente). A partir de otro criterio clínico -haber experimentado fantasías, impulsos o conductas sexuales descontroladas-, Skegg et al. (2010) documentaron una diferencia del $6 \%$ en la tasa de hombres y mujeres con este diagnóstico. Finalmente, Odlaug y Grant (2010) encontraban una diferencia del $4.5 \%$ a partir de un cuestionario de screening -el Minnesota Impulse Disorders Interview (MIDI)-. Las dos únicas excepciones a esta tendencia serían la ya citada investigación de Seegars (2003) en la que la tasa de mujeres con un posible problema de CS doblaba la obtenida en hombres (32.2\% vs. $17.4 \%$ ) y el estudio de Skegg et al. (2010). En este último, los investigadores demostraban que la prevalencia en mujeres superaba la de los hombres $(0.9 \%$ frente al $0.2 \%$ ) si se consideraba como criterio la búsqueda de asistencia terapéutica, lo que contradice la creencia de que las chicas buscan tratamiento con menor frecuencia.

Una crítica generalizada desde la perspectiva de género es que se han empleado sistemáticamente los mismos criterios en el diagnóstico de la conducta sexual compulsiva en hombres y en mujeres cuando sabemos que la sexualidad masculina y femenina dista mucho de ser equivalente, y esto no es menos cierto cuando hablamos de la CS (Ferree, 2001; Mckeague, 2014). En un reciente metanálisis en el que se analizaban los resultados de 834 estudios de sexualidad realizados entre 1993 y 2007 en más de 87 países (muestra de 
1.419.807 personas de entre 4 y 83 años), Petersen y Hyde (2010) hallaban diferencias de distinta magnitud en múltiples aspectos sexuales: las más pequeñas se encontraron en cuestiones actitudinales (los hombres mostraban una actitud más permisiva hacia el sexo) y las mayores en aspectos como la frecuencia de masturbación, de sexo con parejas esporádicas, la tasa de infidelidad o las tendencias erotofílicas. Estos aspectos en los que los hombres parecen mostrar una mayor predisposición son precisamente los que se evalúan más exhaustivamente en los principales instrumentos de screening de CS (Womack et al., 2013), de modo que el hecho de ser hombre ya supone cierta predisposición a contestar más positivamente que una mujer a algunas de las preguntas que plantean -independientemente de que existan o no diferencias en el control de los impulsos sexuales-. Si a esto le sumamos el hecho de que las manifestaciones más frecuentes de CS en mujeres -p.e., contar con un extenso historial de parejas sexuales (Skegg et al., 2010) o la frecuencia de actividad sexual con una pareja (Winters et al., 2010)- se exploran de forma superficial en los autoinformes de síntomas de CS (Hook et al., 2010; Womack et al., 2013), entonces resulta más que previsible que aspectos como la gravedad o la prevalencia de CS tiendan a ser siempre mayores en hombres. En todo caso, no podemos obviar que la magnitud de las diferencias apunta que más allá del método de evaluación, la CS se manifiesta de forma más prominente en hombres que en mujeres.

Así, nuestros resultados permiten confirmar en su totalidad la tercera hipótesis planteada: "en función del sexo, los chicos obtendrán una puntuación media mayor en las escalas y subescalas de CS así como una prevalencia más alta de casos clínicos".

Si nos centramos en la manifestación de la CS en función de la orientación sexual, se aprecia que la gravedad del cuadro clínico y su prevalencia es mayor en homosexuales y sobre todo bisexuales. En comparación con los participantes heterosexuales, los homosexuales obtuvieron puntuaciones más altas en las tres escalas de screening de CS (el SCS, el IH y el SAST) y en 4 de sus subescalas (las de problemas en el control de los impulsos sexuales del SCS y del IH, la de uso del sexo como mecanismo de afrontamiento del IH y la de interferencia del SCS). Por su parte, los participantes bisexuales puntuaban por encima de los heterosexuales en todas las escalas y por encima de los homosexuales en la subescala de interferencia del SCS. Este último hallazgo se entiende a partir del análisis de su comportamiento sexual: cuando una persona bisexual mantiene una pareja estable, inevitablemente reniega del $50 \%$ de su interés sexual (la atracción por el sexo contrario al de su pareja); esto, que puede resultar relativamente sencillo para una persona con un buen control de impulsos sexuales, se complica en las personas con problemas de CS. Así, sería más probable que personas bisexuales con problemas clínicos de CS cometan una infidelidad con una persona del sexo contrario al de su pareja estable. 
Estos resultados confirman y en algunos aspectos amplían los obtenidos en investigaciones precedentes. Rendina, Golub, Grov y Parsons (2012) encontraron en una muestra compuesta por 127 hombres homosexuales y bisexuales que su puntuación media en la escala SCS (17.3) superaba con creces la obtenida en población general. Esta puntuación sería tan sólo unas décimas menor a la obtenida en nuestra investigación por el grupo de bisexuales. Sin embargo, en este estudio no desagregaban las cifras por orientación sexual, de modo que no podemos saber si en un su caso la gravedad del cuadro clínico también tiende a ser mayor en bisexuales que en homosexuales. La investigación de Kelly et al. (2009) incluiría nuevamente en un mismo grupo a homosexuales y bisexuales pero en este caso comparando a hombres y mujeres. En este sentido, estos investigadores hallaron que la gravedad del cuadro clínico era mayor en homosexuales o bisexuales que en heterosexuales y que si se tenía en cuenta el sexo, el riesgo era especialmente alto en los hombres con una orientación sexual alternativa a la mayoritaria. Si generalizamos estos resultados a nuestra investigación, sería presumible que la distancia entre el riesgo de padecer un problema de CS de bisexuales y heterosexuales fuera mayor si además diferenciáramos a los hombres de a las mujeres, extremo que en nuestro caso no ha sido evaluado.

Las diferencias en la manifestación de la conducta sexual compulsiva en función de la orientación sexual se hacen especialmente evidentes si se analiza el porcentaje de posibles casos clínicos: en bisexuales, la prevalencia estimada a través del SCS, IH y SAST no bajó del $21.2 \%$ mientras que en homosexuales y heterosexuales oscilaba en un rango entre $8.5 \%-10 \%$ y $2 \%-5.5 \%$ respectivamente. A pesar de su magnitud, estos resultados quedan por muy debajo de los obtenidos por Kelly et al. (2009) entre miembros de la comunidad LGTB. Concretamente, estos investigadores estimaron que el $30.47 \%$ de los 1214 chicos gais evaluados y el $18.59 \%$ de las 329 chicas lesbianas obtenían puntuaciones que sugerían un posible problema de compulsividad sexual. Teniendo en cuenta que estos investigadores seguían el mismo criterio que el empleado en nuestra investigación para clasificar a sus participantes con un problema clínico (puntuación >24 en el SCS), entonces las diferencias entre ambos estudios se deben atribuir a otra cuestión. En este sentido, los autores referían haber reclutado su muestra entre los asistentes a un importante evento LGTB en Nueva York. Es posible que el perfil de gay o lesbiana que acude a este tipo de evento sea distinto del reclutado en nuestra investigación, lo que explicaría las importantes diferencias entre los datos obtenidos en el estudio de Kelly et al. (2009) y el nuestro. En todo caso, nuestros datos señalan que 2 de cada 10 bisexuales y 1 de cada 10 homosexuales muestran una conducta sexual que se ajusta a lo que hoy día entendemos por conducta sexual compulsiva. Si tenemos en cuenta 
que en este colectivo, permanentemente amenazado por el incremento de nuevos diagnósticos de VIH (Centro Nacional de Epidemiología, 2014), la CS se asocia a la realización de conductas sexuales de riesgo (Grov et al., 2010), entonces se evidencia la importancia de seguir explorando las razones que explican los resultados obtenidos.

Si bien no sabemos con certeza porqué la CS es más prevalente en gais, lesbianas y bisexuales, se han propuesto algunas hipótesis para explicarlo. La frecuencia y número de parejas sexuales en el colectivo LGTB es superior a la media en población general (Oswalt \& Wyatt, 2013), de modo que la posibilidad y los medios para encontrar parejas dispuestas a mantener relaciones sexuales (cuartos oscuros, saunas, chats, clubs y bares de ambiente, aplicaciones móviles, etc.) son mayores. Esto supone que hombres y mujeres con predisposición a la pérdida del control sobre la conducta sexual encuentren en el ambiente sexual que les rodea el caldo de cultivo ideal en el que desarrollar su conducta sexual problemática (Parsons, 2005). Este principio de disponibilidad explicaría además porque los bisexuales muestran una mayor predisposición al desarrollo de un comportamiento sexual compulsivo. Los jóvenes con esta orientación sexual tienen idénticas posibilidades de encontrar una pareja que cualquier heterosexual, a lo que se suma los espacios y recursos para encontrar además una pareja del mismo sexo.

Otra de las hipótesis tiene que ver con la dinámica de relaciones impuesta en el colectivo LGTB: el conflicto social y la ansiedad que para estas personas supone mantener una relación estable en una sociedad homófoba hace más fácil iniciar relaciones con parejas utilizadas exclusivamente con fines sexuales que mantener una relación estable con alguien del mismo sexo (Muench \& Parsons, 2004). Finalmente, Parsons et al. (2008) identificaron a través de entrevistas a gais con rasgos compulsivos que éstos atribuían su conducta sexual desmedida a que los gais tenían mayor deseo sexual (explicaciones intrínsecas) y a que les resultaba más sencillo encontrar nuevas parejas sexuales (explicaciones extrínsecas).

Los hallazgos discutidos acerca de la manifestación de la CS en función de la orientación sexual permiten confirmar parcialmente la cuarta hipótesis, que planteaba: "en función de la orientación sexual, los bisexuales y sobre todo homosexuales obtendrán una puntuación media mayor en las escalas y subescalas de CS así como una prevalencia más alta de casos clínicos". En efecto, homosexuales y bisexuales mostraron mayor severidad del cuadro clínico así como un incremento en la prevalencia de casos clínicos. Sin embargo, estos últimos serían los que realmente se desmarcan más del resto de participantes (y no a la inversa como planteaba la hipótesis). 
Por lo que se refiere a la manifestación de la CS en función de la edad, nuestros hallazgos sugieren que esta variable no desempeña papel alguno a la hora de modular la gravedad o prevalencia del cuadro clínico. La mayoría de correlaciones entre esta variable y las escalas y subescalas de screening de CS no resultaron significativas. La única excepción la constituye la correlación inversa entre la edad y la escala de control del $\mathrm{IH}$ : en este sentido, a medida que aumenta la edad parece que disminuyan los síntomas de pérdida de control sobre la conducta sexual. Sin embargo, la escasa significación de esta relación junto con el considerable tamaño muestral empleado para realizar estos cálculos hace pensar que este vínculo se debe más bien a un artefacto estadístico que a una verdadera relación clínica. Tampoco se apreciaron diferencias en la estimación de la prevalencia del cuadro clínico de CS en función de la edad. Estos resultados se ajustan a lo que se espera teniendo en cuenta que la horquilla de edad contemplada en la investigación (de 18 a 27 años) es limitada. Estos jóvenes constituyen un grupo que si bien resulta heterogéneo, comparte una característica común: la mayoría se ha iniciado en la actividad sexual pero su experiencia y el conocimiento de los propios gustos y preferencias sexuales es limitado (Eshbaugh \& Gute, 2008). En este sentido, muchos de ellos no consolidan su conducta sexual adulta hasta que llegan a los últimos años de este intervalo (a partir de los 24 o 25 años), de modo que su sexualidad puede variar notablemente durante este periodo. Asimismo, los estudios que exploran el inicio del cuadro clínico de CS remarcan que si bien se suele manifestar por primera vez durante el periodo de entre los 18 y los 25 , no es hasta un poco más tarde cuando se tiende a desarrollar y expresar con toda su gravedad y abanico de síntomas (Kafka \& Hennen, 1999; Reid, Carpenter, et al., 2012).

Estos hallazgos permiten confirmar el cumplimiento en su totalidad de la quinta hipótesis de esta investigación, que planteaba que: "no se encontrarán diferencias en la puntuación media o la prevalencia de CS en función de la edad".

Teniendo en cuenta los hallazgos expuestos, para que la evaluación de la CS resulte equitativa en hombres y mujeres y en heterosexuales, bisexuales y homosexuales deberíamos replantear la forma en la que en este momento se aborda el proceso diagnóstico. Esto, que a medio-largo plazo resulta la opción deseable, supondría cambiar casi por completo el paradigma diagnóstico actual. Sin embargo, disponemos ya en este momento de algunas alternativas para mejorar este proceso que no suponen reconstruir por completo los instrumentos y baterías de evaluación disponibles y que también fueron sometidas a evaluación en este trabajo. La alternativa consiste en adaptar los criterios de corrección de los instrumentos actuales al colectivo concreto en el que éste se aplique. Un ejemplo de esta estrategia es el uso de puntos de corte dinámicos en la corrección del SCS: en lugar de un punto de corte fijo para su 
corrección (puntuación $\geq 24$ ), se emplea un criterio que varíe adaptándose a la distribución de puntuaciones en poblaciones concretas (puntuación 2 DT por encima de la media). Cuando en nuestro estudio aplicábamos este criterio en la estimación de la prevalencia en función del sexo (5.9\% y $5.7 \%$ en hombres y mujeres) y la orientación ( $4.9 \%$ en heterosexuales, $5.8 \%$ en bisexuales y $4.2 \%$ en homosexuales), las diferencias que habíamos apreciado anteriormente se mitigaron por completo. Por supuesto, esta solución no está exenta de críticas, como la de que supone aplicar criterios estadísticos al diagnóstico de una condición clínica. Sin embargo, los estudios que optan por este tipo de solución muestran resultados satisfactorios (Cooper et al., 2000).

Los últimos hallazgos expuestos corresponden a la sexta hipótesis, que sostenía que: $<<c u a n d o$ se empleen criterios dinámicos para la estimación de la prevalencia de casos clínicos, ésta será equivalente independientemente del sexo y de la orientación>>. Analizándola ahora a partir de los resultados discutidos, podemos decir que ésta también se cumple en su totalidad.

\section{Fase II: perfil biopsicosocial de jóvenes con puntuaciones subclínicas en CS}

De los 1588 jóvenes que participaron en la primera fase de la investigación, 384 (187 chicos y 197 chicas) fueron seleccionados para participar también en la segunda. Su objetivo era identificar las características biopsicosociales que diferencian a jóvenes con y sin puntuaciones subclínicas en CS, de modo que se planteó una metodología que permitiera comparar ambos perfiles. En particular, a la hora de clasificar a los participantes como control o subclínicos se siguió el mismo criterio que habían empleado previamente Kelly et al. (2009) y Grov et al. (2010) con resultados satisfactorios: obtener una puntuación por encima del percentil 80 en la escala SCS. A través de este criterio, estos investigadores lograron identificar a personas que si bien no cumplían criterios para el diagnóstico de un problema en el control de los impulsos sexuales, sí mostraban rasgos que hacían muy probable su desarrollo en un corto espacio de tiempo.

La elección del SCS a la hora de cribar a los participantes en lugar de otras escalas como el IH o el SAST se realizó atendiendo a varios criterios. En primer lugar, el SCS era la única escala validada en población española en el momento que se inició la evaluación: actualmente, tanto el SAST (Castro-Calvo, Ballester-Arnal, Salmerón-Sánchez, \& Gil-Llario, 2016) como el IH (Castro-Calvo, Ballester-Arnal, \& Gil-Llario, 2017) cuentan con una validación preliminar que avala su empleo con fines clínicos y empíricos pero en los albores de esta investigación, el SCS era el único que ofrecía garantías de fiabilidad y validez en el proceso diagnóstico. Otra razón para su elección fue que según varios estudios, éste era uno de los instrumentos más fiables y 
precisos en el screening de la CS (Hook et al., 2010; Womack et al., 2013). Además, muchas de las publicaciones en este ámbito emplean el SCS en la evaluación del control de impulsos sexuales (Benotsch et al., 1999; Kalichman et al., 1994; Kalichman \& Cain, 2004; Kalichman \& Rompa, 1995), de modo que su elección aseguraba disponer de datos fiables con los que comparar los resultados obtenidos.

En nuestra investigación, el percentil 80 coincidió con una puntuación de 18 en chicos y de 14 en chicas, de modo que los que obtuvieron una puntuación superior a este punto de corte fueron asignados al grupo de participantes subclínicos y el resto al de participantes control. Asimismo, se dividió a los participantes por sexo para evitar comparar a chicos y chicas. Como ya se ha señalado, muchos estudios demuestran que hombres y mujeres con rasgos compulsivos se diferencian entre sí en cuanto a aspectos como la etiología del trastorno (Opitz et al., 2009; Tedesco \& Bola, 1997), pensamientos y creencias asociadas (Ferree, 2001), conducta sexual (Långström \& Hanson, 2006a; Skegg et al., 2010) y consecuencias de la CS (Ferree, 2001), de modo que tomar a chicos y chicas subclínicos como si se tratara de un grupo homogéneo habría supuesto pasar por alto algunas características de la CS sutiles pero significativas en un sexo y no en el otro. Esta precaución cobra especial relevancia a partir de los resultados obtenidos: como se verá, chicos y chicas subclínicos se diferencian entre sí y con respecto al grupo control en la mayoría de dimensiones contempladas en esta investigación. De haberlos tomado en conjunto, muchas de esas características que nos permiten trazar un perfil diferencial en función del sexo se habrían perdido.

De haber sido posible, a estas dos variables de agrupación (sexo y perfil de puntuaciones en el SCS) se habría sumado una tercera: la orientación sexual. En la sección anterior se demuestra que estas dos variables demográficas modulan la manifestación de la CS; la primera sí se contempla durante la segunda fase, no así en el caso de la orientación sexual. Su inclusión habría permitido indagar cómo la orientación sexual modula el perfil biopsicosocial de jóvenes con una manifestación subclínica de la CS pero por razones metodológicas se ha debido omitir: el limitado tamaño muestral de algunos de los 12 grupos que resultan del cruce de estas tres variables no permitiría establecer conclusiones con un nivel de confiabilidad aceptable. En la tabla 39 se indica el tamaño muestral de la agrupación a partir del cruce de las 3 variables:

Tabla 39. Tamaño muestral de la categorización a partir del perfil de puntuaciones, el sexo y la orientación sexual.

\begin{tabular}{|c|c|c|c|c|c|c|}
\hline & \multicolumn{3}{|c|}{ Chicos } & \multicolumn{3}{|c|}{ Chicas } \\
\hline & Heterosexuales & Bisexuales & Homosexuales & Heterosexuales & Bisexuales & Homosexuales \\
\hline Control & 87 & 4 & 9 & 96 & 1 & 2 \\
\hline Subclínicas & 67 & 2 & 18 & 82 & 11 & 5 \\
\hline
\end{tabular}




\subsection{Comorbilidad psicopatológica con trastornos del Eje I y II}

Según algunos estudios, el $100 \%$ de los pacientes con problemas en el control de impulsos sexuales ha cumplido criterios a lo largo de su vida para algún otro trastorno del Eje I y el 50\% para uno del Eje II (Raymond et al., 2003). Tanto es así que los protocolos de evaluación recomiendan incluir -por defecto- la exploración de otros síntomas del Eje I y II y en caso de hallar condiciones comórbidas, que éstas se tomen como indicadores de severidad del cuadro clínico (Kafka, 2007).

Considerando la importancia de analizar el patrón de comorbilidad de un determinado trastorno en la comprensión de su etiología y manifestación (Reid \& Meyer, 2016), el tercer objetivo específico planteado para esta investigación (primero de la segunda fase del estudio) consistió en estimar el perfil de comorbilidad en el Eje I y II de los jóvenes con puntuaciones subclínicas en CS.

Si comenzamos recapitulando el patrón general de comorbilidad, prácticamente todos los trastornos psicológicos contemplados son más prevalentes entre los participantes del grupo subclínico, si bien las diferencias respecto al grupo control varían en función del sexo y la categoría diagnóstica. Los trastornos más comórbidos son los de la categoría de trastornos relacionados con sustancias. En chicos subclínicos, prácticamente el 50\% había cumplido criterios a lo largo de su vida para un diagnóstico de abuso del alcohol y el 11.5\% para uno de dependencia. El abuso o dependencia de cannabis resultó también un trastorno muy frecuente en este grupo, si bien apenas se apreciaban diferencias con respecto al grupo control porque la prevalencia en este último también era alta (15\% frente al 19.5\%). En chicas, el 37.8\% cumplió criterios para abuso del alcohol y el $16.5 \%$ para abuso/dependencia de marihuana. La comorbilidad con el resto de trastornos fue prácticamente nula tanto en chicas control como subclínicas.

Estos resultados confirman y amplían los obtenidos en investigaciones precedentes. En un estudio de Kafka y Prentky (1994) con 26 hombres hipersexuales, el 40\% padecía o había padecido abuso de alcohol (porcentaje cercano al obtenido en mujeres y un $10 \%$ por debajo del documentado en hombres). Por su parte, Black et al. (1997) hallaron tasas de comorbilidad del $58 \%$ con el abuso de alcohol y del $33 \%$ con abuso de drogas en 36 pacientes compulsivos sexuales. No se especificaba el tipo de droga de la que estos pacientes abusaban pero sería presumible que igual que en nuestro estudio, la droga de la que más se abusara fuese la marihuana. Este extremo se confirmó a través de un estudio posterior, donde la prevalencia de abuso de marihuana (38\%) superaba holgadamente la de otras drogas como la cocaína (13\%) o 
los alucinógenos (13\%) (Raymond et al., 2003). Desde la perspectiva inversa, la prevalencia de problemas en el control de impulsos sexuales en pacientes con abuso o dependencia del alcohol fue del $53 \%$ frente al $34 \%$ de los que abusaban de la marihuana o el $13 \%$ de los de anfetaminas (Stavro et al., 2013).

Los estudios enumerados tienen en común con el nuestro que la prevalencia de problemas de abuso del alcohol supera la de cualquier otra droga. Sin embargo, no en todos los casos sucede así: en un estudio realizado entre 183 hombres gais y bisexuales con problemas de CS residentes en Nueva York, la tasa de abuso del alcohol (20.2\%) se situó ligeramente por debajo de la del abuso de otras drogas (23\%) (Jon Morgenstern et al., 2012). Analizados en conjunto, estos resultados sugieren que la CS se suele manifestar acompañada de un trastorno adictivo y que el cuadro clínico concreto depende de aspectos como por ejemplo los hábitos de consumo dominantes: en nuestro estudio, el abuso y la dependencia de alcohol es más frecuente que la de otras drogas porque ésta es una de las sustancias más consumidas y de fácil acceso entre jóvenes universitarios; en el colectivo LGTB, el consumo de drogas -en especial, alucinógenos y cocaína- es con frecuencia comparable al del alcohol (Cochran et al., 2004; Nanin \& Parsons, 2006), de modo que la tasa de abuso de ambas sustancias tiende a igualarse.

Existen varias teorías que explican el vínculo entre CS y abuso de sustancias. La primera haría énfasis en la desinhibición inducida por el consumo de sustancias (Reid \& Meyer, 2016): según esta teoría, los jóvenes con un consumo frecuente de alcohol u otras drogas tendrían más problemas para controlar sus pensamientos, impulsos y conductas sexuales porque la intoxicación inducida por estas sustancias entorpecería su capacidad de toma de decisiones sexuales. Esta teoría sería similar a la propuesta para explicar el vínculo entre consumo de drogas y conducta sexual de riesgo, que habría encontrado aval empírico en múltiples investigaciones (Benotsch et al., 1999). Esta idea presentaría una única salvedad: el consumo sostenido de alcohol o drogas se relaciona con un decremento tanto del deseo como de la respuesta sexual, de modo que resulta improbable que la CS se explique únicamente a partir de su efecto desinhibitorio. Teniendo esto en cuenta, han surgido otras teorías complementarias. Una de ellas sería la de la automedicación: desde esta teoría, el consumo excesivo de alcohol o drogas se considera un medio para mitigar las emociones negativas derivadas de la conducta sexual excesiva (Mckeague, 2014). El problema de la aplicación de esta teoría a nuestros resultados es que difícilmente el nivel de interferencia de la conducta sexual sea lo suficientemente significativo como para tener que recurrir al alcohol o las drogas para mitigarlo. De modo que cobra peso la teoría que sostiene que lo que explica la comorbilidad entre adicción al sexo y abuso de sustancias es la existencia de una etiología 
común a ambos tipos de trastornos. En este sentido, un reciente estudio realizado entre 312 adolescentes españoles de 14 a 16 años demuestra que el consumo de sustancias (en concreto, de tabaco, alcohol y drogas) comparte 2 vías etiológicas comunes con la adicción a Internet y al cibersexo: la tendencia a la conducta antisocial y las expectativas positivas hacia el consumo (Castro-Calvo, Ballester-Arnal, Gil-Llario, et al., 2016). En este sentido, parece que los jóvenes con una actitud más positiva hacia el consumo de sustancias (bien porque esperan que las drogas les ayuden a relacionarse o bien porque creen que les ayudará a divertirse) son también los que atribuyen un impacto más positivo al uso de Internet y del cibersexo, lo que explicaría que los problemas por el consumo excesivo de sustancias tóxicas se asocien a la manifestación de adicciones comportamentales. Si a esto añadimos que la adicción al sexo y a sustancias tóxicas comparten otro determinante tanto o más importante (la impulsividad) (Reid et al., 2013), entonces cobran sentido las altas tasas de comorbilidad halladas en nuestro estudios y en otros.

A los trastornos relacionados con sustancias les siguen en frecuencia los del estado de ánimo y más en particular el trastorno depresivo mayor: este trastorno sería o habría sido padecido por el $24.1 \%$ de los chicos subclínicos y por el $28.6 \%$ de las chicas, frente al $11 \%$ y al $14.1 \%$ de los chicos y chicas control. Habida cuenta de su gravedad, que 3 de cada 10 chicos y chicas con puntuaciones subclínicas padezcan además un trastorno depresivo -independientemente de su gravedad clínica- tendría importantes implicaciones, sobre todo teniendo en cuenta que en muchos casos la gravedad del cuadro clínico de CS se asocia al empleo del sexo como regulador emocional (Kafka, 2010; Reid, Bramen, et al., 2014).

Estas estimaciones superan ampliamente las cifras de prevalencia típicas de este trastorno, que en población general se sitúa cerca del 6.6\% (Kessler et al., 2003) y en pacientes con otras patologías - p.e., abuso de sustancias- alcanzaría el 24\% (McNamara, 2002). Sin embargo, quedan muy por debajo del $39 \%$ de prevalencia documentada en el estudio de Black et al. (1997) en pacientes con problemas en el control de impulsos sexuales, del $41 \%$ de Kafka y Hennen (2002) o del 58\% de Raymond et al. (2003). La explicación a estas diferencias debemos buscarla en el nivel de gravedad del cuadro clínico: en estos estudios participaban pacientes con un problema grave de CS mientras que los participantes en el nuestro constituyen un grupo clínico heterogéneo donde se incluyen desde jóvenes con ligeros rasgos compulsivos hasta pacientes que se ajustan por completo a la descripción clínica del trastorno. La excepción a los estudios citados sería el realizado por Weiss (2004a) entre 220 hombres adictos al sexo o el de Morgenstern et al. (2012) con 183 hombres gais y bisexuales con rasgos compulsivos, 
donde la prevalencia del cuadro clínico de depresión se situó en el $28 \%$ y $33 \%$ respectivamente (estimaciones que se aproximarían considerablemente a las obtenidas en nuestro estudio).

La prevalencia de comorbilidad entre CS y distimia en los estudios anteriormente citados se sitúa entre el $8 \%-68.7 \%$. Sin embargo, en nuestra investigación apenas el $4.6 \%$ y el $1 \%$ de los chicos y chicas subclínicos cumplió criterios para su diagnóstico. La explicación deberíamos buscarla en sus características: en comparación con el trastorno depresivo mayor, el cuadro clínico de distimia tiende a ser menos grave pero sostenido en el tiempo -para su diagnóstico se requiere cumplir los síntomas durante un periodo de al menos 2 años-. En muchos casos, la distimia surge a partir de la cronificación de un episodio depresivo mayor (Kupfer, Frank, \& Phillips, 2012), de modo que su propio curso clínico hace más probable su padecimiento en personas de una edad más avanzada. Este podría ser el factor que explique su baja prevalencia en nuestra investigación y su incremento en muestras clínicas de mayor edad.

Según la literatura, las tasas de comorbilidad entre CS y trastornos de ansiedad se sitúan entre el 20.8\%-96\% (Raymond et al., 2003; Reid, 2007), por encima de la de los trastornos del estado del ánimo o los trastornos relacionados con sustancias. Estas mismas investigaciones señalan que el trastorno de ansiedad más frecuente es la fobia social (8.2\%-46.2\%), seguido de la ansiedad generalizada (14\%-15.6\%), el trastorno por estrés postraumático (6.2\%-13\%) y finalmente el trastorno obsesivo-compulsivo (8\%-10\%). Sin embargo, en nuestro estudio la prevalencia de estos trastornos entre participantes subclínicos resultó equivalente a la obtenida en población control. La única excepción la constituye la agorafobia sin historia de trastorno de angustia, cuya prevalencia es ligeramente superior en el caso de las chicas subclínicas (4.1\% frente al $0 \%$ de las chicas control).

Para comprender estos resultados es necesario analizar en detalle los índices de comorbilidad. Si nos fijamos únicamente en la prevalencia de los distintos trastornos de ansiedad en participantes subclínicos, ésta es comparable a la obtenida en los estudios anteriormente citados: así, el $10.3 \%$ de los chicos y el $26.5 \%$ de las chicas de este grupo cumplió criterios para el diagnóstico de una fobia específica, porcentajes similares al $8 \%$ reportado por Raymond et al. (2003) o el $15 \%$ del estudio de Morgenstern et al. (2012). Lo mismo sucede con la comorbilidad con la fobia social, que entre los participantes subclínicos de nuestro estudio osciló entre el $5.1 \%$ y el $13.8 \%$ (porcentajes cercanos a algunas estimaciones con pacientes adictos al sexo). El problema es que en estos casos, la prevalencia en muestra control fue mayor a la esperada en una población de sus características (estudiantes universitarios), mitigando artefactualmente los efectos atribuibles a la condición clínica. En este sentido, no debemos olvidar que la entrevista SCID es una herramienta donde el juicio clínico del aplicador 
desempeña un papel esencial. Si durante el desarrollo de la investigación, el juicio clínico para el diagnóstico de determinadas condiciones resultó laxo, este hecho podría explicar que las diferencias entre participantes control y subclínicos en cuanto a prevalencia de condiciones comórbidas sean menores a las esperadas a priori. Otro aspecto a considerar es que la equivalencia estadística no siempre implica equivalencia clínica: así, una diferencia del $2 \%$ entre participantes control y subclínicos en la prevalencia de un trastorno puede no ser estadísticamente significativa (sobre todo teniendo en cuenta nuestro limitado tamaño muestral) pero sí serlo cuando se analiza desde la óptica clínica.

Del resto de trastornos explorados, el único en el que la prevalencia en participantes subclínicos superaría la de los control sería el trastorno dismórfico corporal: concretamente, el 7.1\% de las chicas de este grupo padecería o habría padecido este trastorno frente al $1 \%$ de las chicas control. Lamentablemente no disponemos de estudios con pacientes con problemas en el control de los impulsos sexuales donde se explore la comorbilidad con este trastorno; sin embargo, sabemos que su prevalencia en población general ronda el $1 \%-2 \%$ de modo que la tasa obtenida entre chicas subclínicas se podría considerar anormalmente alta (Koran, Abujaoude, Large, \& Serpe, 2008; Rief, Buhlmann, Wilhelm, Borkenhagen, \& Brähler, 2006). La característica definitoria de este cuadro clínico es una preocupación excesiva hacia un defecto corporal imaginario o que en caso de existir, provoca un malestar exagerado (Bjornsson, Didie, \& Phillips, 2010). Que tengamos constancia, esta es la primera ocasión en la que se documenta un vínculo sólido entre CS y este trastorno. No existen en la literatura argumentos para justificar este nexo, de modo que cabría explorar más a fondo esta cuestión con tal de aportar algo más de luz sobre sus determinantes.

Otro aspecto interesante de este estudio se deriva del análisis de la comorbilidad con trastornos parafílicos. A nivel diagnóstico, ambos trastornos se consideran incompatibles (uno de los criterios propuestos para el diagnóstico de la hipersexualidad en el DSM-5 es que la conducta sexual sea normofílica) (Kafka, 2010; Kaplan \& Krueger, 2010; Reid, Carpenter, et al., 2012). Sin embargo, sabemos que a nivel clínico ambos trastornos presentan un solapamiento considerable en cuanto a síntomas y manifestación: en una serie de investigaciones sucesivas con pacientes parafílicos e hipersexuales se demostró que tanto la frecuencia sexual como la severidad del cuadro clínico resultaban similares en ambos trastornos y que el $86.1 \%$ de los parafílicos había cumplido alguna vez criterios para el diagnóstico de un trastorno hipersexual (Kafka, 1997; Kafka \& Hennen, 2002; Kafka \& Prentky, 1998). De modo que la probabilidad de hallar pacientes con un trastorno parafílico cuando se exploran síntomas de CS resulta relativamente elevado. Sin embargo, en nuestro estudio apenas hallamos 4 jóvenes que 
cumplían o habían cumplido criterios para alguno de los trastornos parafílicos: uno de ellos fue diagnosticado de exhibicionismo mientras que los tres restantes ( 2 chicos y una chica) lo fueron de masoquismo sexual. En los 4 casos, los diagnósticos corresponden a participantes clasificados en la categoría de participantes subclínicos, lo que vendría a confirmar la hipótesis de que los síntomas de este tipo de trastornos suelen solaparse con los atribuidos a la conducta sexual compulsiva. Sin embargo, esperábamos una frecuencia un tanto mayor para este tipo de patologías.

Es probable que la baja prevalencia de trastornos parafílicos sea atribuible al método empleado para su diagnóstico: en nuestra investigación, la evaluación de parafilias se realizaba a partir de un módulo desarrollado ad hoc incluido como parte del protocolo de entrevista. Es decir, para recibir un diagnóstico de este tipo el participante debía confesar ante una persona a la que apenas conocía que experimentaba impulsos, deseos o conductas sexuales desviados -y en algunos casos ilegales-. Si bien es cierto que la evaluación de las desviaciones sexuales es siempre compleja y en algunos casos poco fiable (R. D. Laws, 2009; Laws \& O'Donohue, 2008; Thornton \& Laws, 2009), no es menos cierto que nuestro procedimiento de evaluación no solventa -y muy probablemente amplía- alguno de los problemas de los que este tipo de evaluación adolece. A esto hemos de añadir que la severidad de los problemas de control de impulsos sexuales en el grupo de participantes subclínicos no es ni tan siquiera cercana a la que pueda presentar un grupo de pacientes con un diagnóstico sólido, de modo que tampoco resultaría realista esperar tasas de comorbilidad completamente equivalentes.

Para terminar, la prevalencia de trastornos de la personalidad en participantes subclínicos osciló entre el 4.6\%-8.2\% para el trastorno obsesivo compulsivo de la personalidad y el $2 \%$ 2.3\% para el trastorno límite. Estas cifras se situarían un tanto por debajo de las obtenidas por Black et al. (1997) y Raymond et al. (2003), que fijaban una prevalencia del 15\% (obsesivocompulsivo) y de entre el 5\%-9\% (límite) para estos dos trastornos en pacientes compulsivos sexuales. Sin embargo, se acercan e incluso superan las reportadas por Reid et al. (2013) en un reciente estudio en el que aplicaron una metodología muy similar a la empleada en nuestra investigación. Concretamente, estos investigadores reclutaron una muestra de 132 hombres hipersexuales de entre 20 y 66 años a los que aplicaron la entrevista SCID-II para trastornos de la personalidad. A través de este procedimiento, los investigadores hallaron una tasa de comorbilidad del $4 \%$ para el trastorno obsesivo-compulsivo de la personalidad (prácticamente idéntica a la de los chicos subclínicos y un $4 \%$ inferior a la de chicas) y del $2 \%$ para el límite. Si a eso le sumamos que la prevalencia para estos trastornos en población general oscila entre 0.9\%-1.9\% (obsesivo-compulsivo de la personalidad) y $0.5-0.7 \%$ (límite) (Coid, Yang, Tyrer, 
Roberts, \& Ullrich, 2006; Samuels et al., 2002), entonces nuestros resultados resultan más que significativos.

Se han propuesto múltiples teorías para explicar el solapamiento entre los problemas en el control de impulsos sexuales y los trastornos de la personalidad, si bien ninguna de ellas se ha sometido a su validación empírica. Montaldi (2002) proponía que en muchos casos, la manifestación del comportamiento sexual compulsivo "replica patrones de comportamiento de un trastorno de la personalidad" (Montaldi, 2002, p. 3), trazando paralelismos entre ésta y otras patologías de la personalidad como el trastorno límite o el obsesivo compulsivo. Esta afirmación va en consonancia con el modelo de "diátesis común", que sostiene que los trastornos de la personalidad son, junto con el resto de trastornos del Eje I, manifestaciones distintas de procesos transdiagnósticos comunes (Fineberg, Reghunandanan, Kolli, \& Atmaca, 2014); la aplicación de estos principios a nuestros resultados explicaría que los jóvenes con una manifestación subclínica de la CS muestren mayor prevalencia tanto de trastornos de la personalidad (como el límite o el obsesivo-compulsivo) como de muchos otros trastornos del Eje I. El problema de este modelo es que no concreta cuál es la vulnerabilidad común a las distintas manifestaciones psicopatológicas, si bien se presume que la impulsividad podría ser clave para entender estas manifestaciones comórbidas (Reid et al., 2015). Para terminar, existe una teoría propuesta recientemente que podría ayudar a comprender mejor el nexo entre CS y los trastornos límite y obsesivo-compulsivo de la personalidad. Esta teoría, conocida como "modelo del tercer factor" (Starcevic \& Brakoulias, 2016), propone que la relación entre el trastorno límite de la personalidad, el obsesivo-compulsivo y los trastornos del espectro obsesivo-impulsivo -donde Reid et al. (2015) encuadran la hipersexualidad- se explica a partir de la desregulación emocional. La desregulación emocional constituye la característica principal del diagnóstico del trastorno límite de la personalidad mientras que el trastorno obsesivo-compulsivo y la conducta sexual compulsiva constituyen dos extremos opuestos a lo largo de los cuales se transita en el intento por manejar el malestar emocional: en ocasiones, un paciente expresa una tendencia excesiva al control para mitigar su malestar mientras que en otras, maneja sus emociones negativas mediante una conducta sexual compulsiva y descontrolada.

A la hora de interpretar estos últimos hallazgos debemos considerar ciertas limitaciones. Tal y como sucedía en los trastornos de ansiedad, la diferencia en la comorbilidad de los trastornos de la personalidad en participantes control y subclínicos no resultó significativa. La razón puede ser o bien que la prevalencia en participantes control fue excesivamente alta (como el 8.1\% de participantes control que cumplieron criterios para un trastorno obsesivo-compulsivo 
de la personalidad) o bien que el limitado tamaño muestral no permite que diferencias importantes a nivel clínico lo sean también a nivel estadístico. En cualquiera de los supuestos, estos resultados se consideran una valiosa fuente de información para comprender la manifestación de la CS en población subclínica.

Los hallazgos discutidos a lo largo de este epígrafe corresponden al tercer objetivo de este estudio, para el que se planteaba la séptima hipótesis: <<la prevalencia de patologías del Eje l y II será significativamente mayor en chicos y chicas del grupo de puntuaciones subclínicas en CS (alta comorbilidad psicopatológica), especialmente para trastornos del estado de ánimo, de ansiedad y abuso de sustancias $>$. Al respecto, los resultados expuestos permitirían confirmar parcialmente la hipótesis inicial así como ampliarla en distintos aspectos. Tal y como planteábamos, la prevalencia de los cuadros clínicos evaluados es sistemáticamente superior entre los participantes del grupo subclínico pero estas diferencias alcanzarían la significación estadística únicamente en 6 de los 46 diagnósticos explorados, con un claro perfil diferencial en chicos y chicas. En chicos subclínicos, se aprecia una prevalencia mayor del trastorno depresivo mayor, de la dependencia al alcohol y del abuso de esta misma sustancia. En chicas subclínicas, destaca la comorbilidad con la agorafobia sin historia de trastorno de angustia, el trastorno dismórfico corporal, el trastorno depresivo mayor, el abuso/dependencia de cannabis y el abuso del alcohol. A pesar de que las diferencias respecto al grupo control no alcanzan la significación, la prevalencia de trastornos de ansiedad o de la personalidad en participantes subclínicos superó con creces lo esperable en población normal, de modo que aunque a menor nivel, la expresión de la CS parece desempeñar también en estos casos un papel importante.

\subsection{Correlatos clínicos}

Una hipótesis que durante los últimos años ha ganado atención a la hora de explicar el inicio, mantenimiento y severidad del cuadro clínico de compulsividad sexual ha sido la de la regulación emocional (Hook et al., 2008; Kasten, 1999): desde esta perspectiva, las personas con problemas en el control de impulsos regularían a través del sexo (reforzador natural) su malestar emocional. A corto plazo, el comportamiento sexual provocaría un alivio del afecto negativo pero este patrón, sostenido en el tiempo, impediría el desarrollo de estrategias de regulación emocional efectivas y cronificaría el uso disfuncional del sexo como regulador emocional. Según esta teoría, el origen del malestar no sería un cuadro clínico alterado que ocurre en un momento determinado (como en un trastorno de ansiedad o episodio depresivo mayor) sino que se relacionaría con una disposición o tendencia a experimentar malestar, y más en concreto ansiedad y depresión. Asimismo, la manifestación de esta emocionalidad 
negativa podría estar parcialmente mediada por la baja autoestima, como sugieren algunos estudios recientes (Chaney \& Burns, 2015). Con el objetivo de someter a prueba esta hipótesis, se aplicó a los participantes tres instrumentos que permitían evaluar la depresión, ansiedad y autoestima de forma dimensional: el inventario de Depresión (BDI), el Cuestionario de Ansiedad Estado-Rasgo (STAI) y el Cuestionario de Autoestima de Rosenberg (RSEI).

A través de estas 3 escalas se constata que los chicos subclínicos manifiestan mayores niveles de depresión, de ansiedad-estado y sobre todo de ansiedad-rasgo, mientras que su nivel de autoestima apenas varía respecto al de los participantes control. Esto se traduce en porcentajes del $4.9 \%$ y $12.9 \%$ con puntuaciones clínicas en las dimensiones de ansiedad-estado y ansiedad-rasgo respectivamente. Si bien en ambos grupos la distribución de participantes en las distintas categorías de depresión es equivalente, en chicos subclínicos el porcentaje de los que se sitúan en niveles de depresión entre ligera y severa fue un tanto mayor ( $21.2 \%$ frente al 12\%). Para terminar, el porcentaje de participantes control con alta autoestima fue un $16 \%$ inferior al hallado en participantes control (28.3\% frente al $12.6 \%)$.

En cuanto al perfil clínico y psicopatológico de las chicas subclínicas, éste se caracteriza por unos niveles normales de ansiedad-estado y de autoestima y por un incremento significativo en el grado de ansiedad-rasgo y sobre todo de depresión. Así, alrededor del $21 \%$ obtuvo puntuaciones que sugerían la presencia de distintos grados de depresión (el 14.1\% ligeramente deprimidas, el $4.7 \%$ moderadamente deprimidas y el $2.4 \%$ severamente deprimidas). Por el contrario, no se aprecian diferencias con respecto a las chicas control en la distribución en categorías de autoestima o en el porcentaje con puntuaciones clínicas en las dos dimensiones de ansiedad. Respecto a este último aspecto, tan sólo el $2.1 \%$ obtuvo puntuaciones clínicas en la escala de ansiedad-estado, porcentaje que ascendía al 7.2\% en el caso de la ansiedad-rasgo.

Los resultados en cuanto a nivel de depresión en la manifestación subclínica de la CS confirman parcialmente los obtenidos en investigaciones precedentes. Tal y como evidenciaba el metanálisis de Schultz et al. (2014), se ha demostrado que el nivel de depresión -evaluado dimensionalmente o a través de categorías clínicas- es ligeramente mayor entre las personas con rasgos subclínicos de problemas en el control de los impulsos sexuales. A diferencia de los resultados obtenidos por estos investigadores, en nuestro estudio sí se aprecia que el sexo desempeña un papel importante a la hora de modular esta relación: en concreto, las chicas subclínicas manifiestan un peor estado de ánimo que los chicos. Considerando que el nivel de depresión comparte un $12 \%$ de varianza con la severidad de los síntomas de CS, esto explicaría al menos en parte que a lo largo de todo este trabajo las chicas obtengan un perfil clínico de mayor gravedad que el de los chicos. Esto resulta especialmente significativo si tenemos en 
cuenta que esta es la primera ocasión en la que se demuestra la significación de este vínculo en la manifestación subclínica de la CS.

Por lo que respecta al nivel de ansiedad, estos hallazgos sugieren que la dimensión de ansiedad-estado guarda una relación más limitada con la manifestación subclínica de la CS que la dimensión de ansiedad-rasgo. Existen múltiples estudios que documentan el vínculo positivo entre ansiedad general (medida a través de múltiples instrumentos) y severidad de los síntomas de CS (Carvalho et al., 2014; Reid, Bramen, et al., 2014; Skegg et al., 2010), pero sólo uno distingue entre síntomas de ansiedad actuales y propensión a la misma. En ese estudio, Voon et al (2014) reclutaron a 19 pacientes hipersexuales a los que aplicaron el cuestionario de ansiedad STAI. Lo que estos investigadores hallaron fue que si bien el nivel de ansiedad en ambas dimensiones era alto, la puntuación en la subescala de ansiedad-rasgo superaba ampliamente la de ansiedad-estado. En nuestro estudio, el nivel de ansiedad en el momento de la evaluación (ansiedad-estado) sólo permite discriminar entre chicos control y subclínicos mientras que la tendencia a experimentar ansiedad ante diversas situaciones (ansiedad-rasgo) es una característica propia de todos los participantes con una manifestación subclínica de la CS -indistintamente de su sexo-. Las implicaciones de este hallazgo son importantes ya que confirmaría la teoría de que el sexo no se emplea para regular estados de ánimo disfóricos originados por situaciones puntuales (si ese fuera el caso, el problema de CS desaparecería una vez superado el episodio de ansiedad) sino que permitiría manejar estados de ánimo crónicamente tendentes a la desregulación.

Para terminar, en nuestro estudio encontramos que la autoestima no desempeña papel alguno en la manifestación de los problemas en el control de impulsos sexuales, lo que contradice la teoría de que muchos pacientes con CS emplean el sexo para mejorar su valoración a través del contacto e intimidad con otras personas (Parsons et al., 2008). Esta teoría se sustenta sobre múltiples estudios que documentan el vínculo entre autoestima y CS. En este sentido, Kalichman y su equipo hallaron a través de una serie de investigaciones que la correlación entre CS y autoestima (medida a través del RSEI) oscilaba entre -.32 y -.35 (Kalichman et al., 1994; Kalichman \& Rompa, 1995). Más tarde, Guigliamo (2006) encontró mediante entrevistas clínicas con pacientes hipersexuales que el $64 \%$ de ellos experimentó baja autoestima antes y durante el transcurso de su problema. En hombres que tienen sexo con hombres (HSH), Chaney y Burns (2015) encontraron que la baja autoestima explicaba junto con la percepción de soledad el $14 \%$ de la varianza de las puntuaciones en la escala SCS de compulsividad sexual. Existen diversas hipótesis que permitirían explicar las diferencias entre nuestros resultados y los obtenidos en los estudios antes enumerados. Por un lado, es posible que nuestros 
resultados no concuerden porque los participantes en nuestro estudio sólo muestran ciertos rasgos de CS y no un cuadro clínico de una severidad importante. Quizá si tomásemos únicamente a los pacientes con manifestaciones más severas del cuadro clínico, el nivel de autoestima sería inferior. Por otro lado, un hallazgo recurrente en las investigaciones realizadas con el cuestionario RSEI es que esta escala tiende a producir un cierto efecto techo (Martín-Albo et al., 2007): es decir, la mayoría de personas tiende a puntuar en la parte alta del rango de autoestima independientemente de su autoconcepto. En todo caso, en las investigaciones de Kalichman y su equipo se empleó la misma escala y aun así se obtuvieron resultados significativos. Otra opción es que la CS no se relacione con la autoestima general sino con algún dominio específico (como por ejemplo la autoestima en el ámbito personal o sexual) (Swann \& Bosson, 2010). Para comprobarlo, sería recomendable la inclusión en futuras investigaciones de escalas que evalúen el nivel de autoestima por dominios.

Contrastando por tanto la octava hipótesis, nuestros resultados permiten su confirmación parcial. Según esta hipótesis: "Ios chicos y chicas del grupo de puntuaciones subclínicas en CS obtendrán puntuaciones mayores en depresión, ansiedad-estado y en ansiedad-rasgo. Al contrario, estos jóvenes obtendrán menores puntuaciones en autoestima". Efectivamente, el nivel de depresión y ansiedad-rasgo entre los participantes subclínicos fue mayor independientemente del sexo. En cambio, el nivel de ansiedad estado influyó únicamente en la manifestación masculina de la CS. Finalmente, no se apreciaban diferencias de ningún tipo entre la autoestima de los participantes control y subclínicos.

\subsection{Perfil de personalidad}

Otro de los objetivos específicos planteados para esta investigación consistió en explorar el perfil de personalidad en jóvenes con una manifestación subclínica de la CS. Con este fin, los participantes en la segunda fase del estudio completaron el cuestionario de personalidad NEO PI-R (Costa \& McCrae, 2002). En pacientes con problemas en el control de impulsos sexuales, éste se caracteriza por una marcada tendencia al neuroticismo y menores niveles de amabilidad y responsabilidad (Rettenberger et al., 2015). En población general, esta misma configuración se relaciona con aspectos como el debut en la actividad sexual, su frecuencia, el número de parejas a lo largo de la vida, la comisión de una infidelidad, el nivel de erotofilia o la realización de diversas conductas sexuales de riesgo (Miller et al., 2004; Schmitt, 2004). Que tengamos constancia, este es el primer estudio que explora el perfil de personalidad en jóvenes con una manifestación subclínica de la CS. 
Tras analizar el perfil de personalidad de los chicos con una manifestación subclínica de la CS, constatamos que éste se caracteriza principalmente por una mayor tendencia al neuroticismo y una menor amabilidad y responsabilidad. El neuroticismo es considerado una faceta que predispone al malestar psicológico en general y al desarrollo de trastornos psicológicos en particular, de modo que puntuaciones mayores en esta escala correlacionan con una mayor emocionalidad negativa, el establecimiento de metas poco realistas, con las dificultades para tolerar la frustración y el desarrollo de necesidades afectivas y materiales excesivas (Costa \& McCrae, 2002). Si analizamos pormenorizadamente la manifestación de esta dimensión, los chicos subclínicos se mostraron especialmente hostiles, depresivos y sobre todo impulsivos.

Estos resultados se ajustan completamente a los obtenidos previamente en muestra clínica. En una investigación en la que 120 pacientes hipersexuales completaron el SCS y el cuestionario NEO PI-R, la correlación entre CS y la dimensión de neuroticismo fue de .49 y de entre .33 y .48 con 6 de sus facetas (especialmente la de vulnerabilidad, impulsividad y depresión) (Reid et al., 2008). La única diferencia con nuestros resultados fue que en nuestro caso, la faceta de hostilidad resultó más significativa que la de vulnerabilidad. Un estudio posterior confirmó una correlación de entre .41 y .71 entre la dimensión de neuroticismo y sus 6 facetas y el cuestionario IH de hipersexualidad (Reid, Garos, \& Carpenter, 2011). Estos estudios establecen un vínculo directo entre este rasgo de personalidad y el control de impulsos sexuales, si bien parece que ambos se relacionan también de otros modos. Por ejemplo, Reid, Stein y Carpenter (2011) demostraban que además de un vínculo directo, el neuroticismo mediaba entre los mecanismos de afrontamiento de la vergüenza y la culpa: así, las personas más neuróticas experimentaban mayores problemas de CS cuando manejaban de forma desadaptativa estas dos emociones que las personas con menores niveles de neuroticismo. A esto se le suma una tercera vía a través de la cual el neuroticismo propicia un mayor nivel de CS: incrementando la probabilidad de padecer un trastorno del Eje I o II comórbido (Pinto et al., 2013). En este sentido, las personas más neuróticas serían a su vez más vulnerables a desarrollar distintas patologías del Eje I y II, que como hemos comprobado a lo largo del epígrafe anterior, se relacionan tanto con la manifestación clínica como subclínica de la CS.

Por otra parte, el perfil de personalidad resultante de la baja amabilidad y responsabilidad puede adoptar dos expresiones: la del buscador de sensaciones impulsivo (Zuckerman \& Kuhlman, 2000) o la del psicópata/antisocial (Paulhus \& Williams, 2002). El desarrollo del perfil particular depende de la dominancia de una u otra dimensión (Brown et al., 2015). En nuestra investigación, la baja responsabilidad se impuso sobre la baja amabilidad, lo que correspondería al perfil de buscador de sensaciones. Este tipo de personas tienden a actuar sin 
deliberar o atender a las consecuencias de sus actos, lo que les suele generar problemas y conflictos. Independientemente del perfil, cualquier persona antagonista (poco amable) tiende a ser cínica, poco cooperativa y manipulativa mientras que una persona poco responsable suele mostrarse descuidada, perezosa, poco fiable y un tanto negligente (Costa \& McCrae, 2002). Concretamente, los chicos subclínicos resultaron ser menos conciliadores, modestos, altruistas y francos que los del grupo control (antagonismo) así como menos competentes, con menos sentido del deber, menos autodisciplinados y con una muy baja capacidad para deliberar antes de tomar una decisión (baja responsabilidad).

Los resultados en cuanto a amabilidad y responsabilidad confirman en población subclínica los hallazgos obtenidos en investigaciones precedentes con muestra clínica. En una investigación en la que se exploraba la presencia de rasgos patológicos de personalidad en 78 pacientes en tratamiento por problemas en el control de impulsos sexuales, se encontró que el 33\% obtenía puntuaciones clínicamente bajas en confianza, el $38 \%$ en franqueza y el $29 \%$ en actitud conciliadora (Reid et al., 2012). Estas dos últimas facetas son, junto al altruismo y la modestia, las que diferencian a los chicos control y subclínicos de nuestra investigación en la dimensión de amabilidad. En la de responsabilidad, los investigadores hallaron que el $33 \%$ de los pacientes obtenían puntuaciones clínicas en competencia, el $41 \%$ en sentido del deber, el 32\% en necesidad de logro, el 55\% en autodisciplina y el $34 \%$ en deliberación. Excepto en la faceta de necesidad de logro, en las otras 4 los chicos subclínicos puntuaron significativamente por debajo de los del grupo control.

No existe una teoría específica que explique el vínculo entre estas dimensiones de personalidad y el control de impulsos sexuales pero sí se ha hablado mucho de su capacidad a la hora de modular la conducta sexual en población general. Se ha demostrado que la baja responsabilidad se asocia a la conducta sexual de riesgo porque las personas menos disciplinadas, con menor capacidad para actuar conforme se considera correcto (sentido del deber) y que deliberan menos antes de actuar son menos capaces de controlarse durante la actividad sexual (Trobst et al., 2002). Si este perfil de personalidad hace más probable la pérdida del control sobre la conducta sexual preventiva, es posible que también facilite una pérdida del control sobre el conjunto de la respuesta sexual. Por otro lado, la baja amabilidad se ha vinculado con la promiscuidad sexual y sobre todo la tendencia a cometer infidelidades porque las personas con esta disposición de personalidad son menos sensibles a las necesidades afectivas y emocionales de las personas de su entorno (Schmitt, 2004). Esto hace que en muchas ocasiones, sus relaciones se basen en la sucesión de distintas parejas con las 
que se mantiene relaciones sexuales sin apenas establecer ningún tipo de relación afectiva, que es precisamente una de las manifestaciones más destacadas de la CS.

El perfil de personalidad en chicas subclínicas comparte con el de los chicos una mayor tendencia al neuroticismo y menor a la amabilidad y la responsabilidad, si bien la importancia de sus facetas varía. Asimismo, las chicas subclínicas resultaron ser más abiertas a la experiencia que las del grupo control, no sucediendo así en hombres. Si centramos el análisis del perfil de personalidad en la dimensión de neuroticismo, las chicas subclínicas resultaron mucho más impulsivas que las del grupo control (con una diferencia que alcanzó un tamaño del efecto grande -por encima de cualquier otro-). Este hecho resulta especialmente significativo habida cuenta de la importancia de esta dimensión a la hora de explicar los problemas en el control de impulsos en general y de impulsos sexuales en particular (Charnigo et al., 2013; Reid et al., 2010). Las personas con un perfil de personalidad impulsivo experimentan problemas para resistir cualquier deseo o impulso a realizar una conducta placentera (comer, beber, comprar, etc.), lo que explicaría que también manifiesten problemas a la hora de controlar su conducta en el ámbito de la sexualidad.

En las facetas que comprende la dimensión de responsabilidad, las chicas subclínicas obtienen un perfil de personalidad exactamente igual que el de los chicos, si bien varía la intensidad de las diferencias con respecto al grupo control: concretamente, la diferencia entre chicas control y subclínicas en las facetas de competencia y de sentido del deber fue muy superior al observado en hombres. En cuanto a las facetas de la dimensión de amabilidad, la única diferencia es que además de menos francas, altruistas, conciliadoras y modestas, las chicas subclínicas son menos confiadas.

Estos resultados plantean una pequeña diferencia respecto a estudios precedentes relacionada con la manifestación diferencial de la amabilidad y la responsabilidad en función del sexo. En el estudio anteriormente citado de Reid et al. (2012), las mujeres en tratamiento por problemas de CS eran menos amables y sobre todo menos responsables que los pacientes masculinos. A partir de ahí, se concluyó que las mujeres con CS tendían a ser más manipulativas e interesadas que los hombres en sus relaciones con los demás, con estándares éticos y morales laxos, indiferentes a las consecuencias de sus actos y con preferencia por la gratificación inmediata frente a la gratificación a largo plazo. Sin embargo, nuestros resultados constatarían justo lo contrario: estos rasgos serían ligeramente más característicos en hombres que en mujeres. 
Para terminar, la principal diferencia entre el perfil de personalidad de chicos y chicas subclínicas la encontramos en la dimensión de apertura a la experiencia: concretamente, las chicas subclínicas se caracterizaron por ser más abiertas a la experiencia en general y en particular a mostrar una imaginación más rica y creativa (faceta de fantasía), disfrutar más con la belleza de las expresiones artísticas (faceta de estética), juzgar desde una visión crítica los dogmas y convenciones sociales (valores), vivir más intensamente e implicarse más en las experiencias emocionales (sentimientos) y disponer de una actitud más positiva hacia probar cosas nuevas y alejadas de lo usual (acciones). Estos resultados contradicen los obtenidos por Rettenberger et al. (2015) con una metodología similar a la empleada en nuestra investigación. Estos investigadores evaluaron a través de Internet a 1749 estudiantes universitarios a los que aplicaron toda una batería de medidas entre las que incluyeron el cuestionario $\mathrm{IH}$ y la versión abreviada del inventario de cinco factores (BFI-10). Lo que encontraron fue que la correlación entre apertura a la experiencia e hipersexualidad fue de apenas - .03 y que la puntuación media en esta dimensión no variaba entre los que sobrepasaron el punto de corte clínico en el IH y los control.

Si bien estos últimos resultados suponen una importante novedad con respecto a lo que sabíamos hasta ahora sobre la relación entre personalidad y CS, su explicación resulta sencilla si se analiza desde la perspectiva de la antropología sexual (Gagnon \& Simon, 2009; RodríguezShadow \& López, 2009). Tradicionalmente, el papel otorgado a la mujer en el ámbito del deseo sexual es secundario al del hombre: no se espera que una mujer experimente deseo sexual espontáneo, sino que aparezca en respuesta al cortejo y la insinuación masculina. En el otro extremo, a las mujeres que expresan su deseo e intención de mantener una vida sexual activa fuera del contexto de una relación estable se las ha sancionado socialmente, tachándolas -en el mejor de los casos- de casquivanas. Desde esta perspectiva, resulta comprensible que las chicas más abiertas a la experiencia (dimensión que expresa la tolerancia a las consecuencias de la lucha contra la norma social establecida) sean precisamente las que manifiestan mayor probabilidad de padecer problemas en el control de sus impulsos sexuales porque estos problemas se relacionan con una conducta sexual que en la actualidad, todavía es socialmente sancionada. Esto mismo explicaría por qué los chicos subclínicos y control no mostraron diferencias en esta dimensión: socialmente, un chico cuya conducta sexual se caracteriza por la sucesión de múltiples parejas o una alta frecuencia sexual (rasgos típicos del cuadro clínico de CS) no recibe sanción social alguna de modo que para realizar esta conducta, no se requiere de una especial predisposición a la hora de contravenir la norma social establecida (es decir, no se requiere de una mayor apertura a la experiencia). 
Finalmente, estos hallazgos permiten contrastar la novena hipótesis planteada para este objetivo: <<los chicos y chicas del grupo subclínico obtendrán mayores puntuaciones en la dimensión de personalidad de neuroticismo y sus 6 facetas (especialmente la de vulnerabilidad) y menores en las dimensiones de amabilidad y responsabilidad. No se encontrarán diferencias entre ambos grupos en las dimensiones de extraversión y apertura a la experiencia >>. Al respecto, podemos decir que ésta se cumple con matices en el caso de los chicos y tan sólo parcialmente en el de las chicas. Efectivamente, el perfil de personalidad de los chicos subclínicos se caracterizó por una mayor tendencia al neuroticismo pero en lugar de la vulnerabilidad, las facetas significativas fueron las de hostilidad, depresión e impulsividad. Sí se ajustarían a la hipótesis los resultados en cuanto a la baja amabilidad y responsabilidad de los chicos de este grupo clínico. Como plantea la hipótesis, el perfil de personalidad en chicas también se caracteriza por un mayor neuroticismo y una menor amabilidad y responsabilidad, a lo que cabría añadir en este caso una mayor apertura a la experiencia. Concretamente, las chicas subclínicas obtuvieron puntuaciones mayores a las del grupo control en 5 de 6 facetas de esta dimensión (fantasía, estética, sentimientos, acciones, ideas y valores). De nuevo, la faceta de neuroticismo más importante no fue la de vulnerabilidad sino la de impulsividad. Por otra parte, la faceta más significativa en la dimensión de amabilidad y responsabilidad fue la baja franqueza y el pobre sentido del deber respectivamente.

\subsection{Comportamiento sexual}

El comportamiento sexual es, al mismo tiempo, manifestación y consecuencia de los problemas en el control de los impulsos sexuales. Se ha demostrado sistemáticamente que la conducta sexual de este tipo de pacientes se diferencia cualitativa y cuantitativamente de la que manifiesta cualquier persona sin este tipo de problemas y que esto supone un importante impacto sobre su calidad de vida en general y su calidad de vida sexual en particular (Kafka, 2010; Kaplan \& Krueger, 2010; Reid, Carpenter, et al., 2012). Habida cuenta de su importancia, esta ha sido una de las áreas exploradas más exhaustivamente en esta tesis. Concretamente, los hallazgos al respecto se discuten en las 5 secciones siguientes: comportamiento sexual general, comportamiento sexual de riesgo, comportamiento sexual online, disposiciones sexuales y evaluación hormonal. 


\subsubsection{Comportamiento sexual general}

En la evaluación del comportamiento sexual general de chicos y chicas subclínicos se tuvieron en cuenta aspectos de la historia y del desarrollo sexual como: haber mantenido relaciones sexuales de cualquier tipo con otra persona; haberlo hecho durante los últimos meses; mantener o no una relación estable y en caso afirmativo, su duración; haber sido infiel; número de parejas sexuales a lo largo de la vida; frecuencia sexual actual; tipo de prácticas sexuales realizadas y; distintas preguntas sobre la orientación del deseo sexual.

El análisis del comportamiento sexual general de los chicos subclínicos revela que si bien su perfil se caracteriza por altos índices de actividad sexual, éste apenas varía en comparación con el de los participantes control. Concretamente, la práctica totalidad de chicos subclínicos (el $97.7 \%$ ) dijeron haber mantenido actividad sexual de cualquier tipo con otra persona y el 81.6\% haberlo hecho durante los últimos meses. Tan sólo la mitad de estos jóvenes tenía pareja estable, en cuyo caso el tiempo medio de relación fue de en torno al año y medio. Aproximadamente un tercio confesó haber sido infiel a una pareja estable y el número medio de parejas sexuales a lo largo de la vida se situó en torno a las 13 personas. En este sentido, se aprecia una gran variabilidad en el rango de respuestas, con participantes reportando cifras que superan con creces la tasa media. Alrededor del $70 \%$ declaraba una frecuencia sexual semanal mayor de 1 coito y el $27 \%$ mayor de 3 coitos. Lamentablemente no se preguntó acerca del número concreto de coitos semanales, de modo que en esta última categoría se incluyen desde personas con una frecuencia semanal de 4 coitos hasta otros que pueden triplicar o cuadruplicar esta cifra. La mayoría se había masturbado, masturbado con una pareja o practicado sexo oral (99\%, $94.3 \%$ y $92 \%$ respectivamente), mientras que el porcentaje se reducía al $80 \%$ cuando se preguntaba acerca de coito vaginal, al $50 \%$ en coito anal y al $4.6 \%$ en otras prácticas sexuales. La única diferencia entre chicos control y subclínicos la encontramos en el porcentaje de los que realizaron sexo anal, que entre estos últimos fue un $15 \%$ superior.

Respecto al perfil de atracción sexual hacia el propio y el otro sexo, el $35.6 \%$ de chicos subclínicos dijeron haber deseado mantener relaciones sexuales con personas de su propio sexo (frente al $20 \%$ de los control), el $28 \%$ haberse excitado con estas fantasías y un cuarto haber mantenido relaciones. Prácticamente el $25 \%$ informó de una orientación sexual alternativa a la heterosexual: concretamente, el $3.4 \%$ se declaraba bisexual y el $20.7 \%$ restante homosexual. En torno al $65 \%$ se declaró exclusivamente heterosexual y el porcentaje restante se distribuyó en distintos grados de atracción hacia el propio sexo. 
En cuanto al perfil de comportamiento sexual general de las chicas subclínicas, éste se caracterizó por niveles de actividad sexual si cabe mayores a los reportados por los chicos y con diferencias significativas respecto al de las participantes control en la mayoría de los ámbitos. Para empezar, el $100 \%$ de las chicas subclínicas había mantenido actividad sexual de cualquier tipo con otra persona (frente al $95 \%$ de las del grupo control) y la gran mayoría (95\%) durante los últimos tres meses. El porcentaje de las que mantenía pareja estable (69\%) era casi un $10 \%$ inferior al grupo control y significativamente menor su duración (33 frente a 24 meses). Poco menos de la mitad (el 40\%) afirmó haber cometido una infidelidad y el número de parejas sexuales a lo largo de la vida (6.31) duplicaba el reportado por las chicas control. Entre ambos grupos se hallaron también diferencias en cuanto a frecuencia sexual, siendo mucho más alta entre participantes subclínicas: concretamente, el 73.7\% de ellas mantenía una frecuencia sexual mayor de un coito semanal. Finalmente, se encontraron diferencias entre pequeñas y moderadas en cuanto a la realización de la mayoría de prácticas sexuales, en todos los casos a favor de las chicas subclínicas: prácticamente todas dijeron haber realizado sexo vaginal, oral o haber masturbado a una pareja ( $98 \%$, $95 \%$ y $94 \%$ respectivamente), el $85 \%$ dijo haberse masturbado ella misma y casi el $40 \%$ haber practicado sexo anal.

Si se analiza el comportamiento sexual de las chicas subclínicas en relación a su orientación sexual, más de la mitad dijo haber deseado mantener relaciones sexuales con personas de su mismo sexo y excitarse fantaseando con esta idea (el $52 \%$ y $51 \%$ respectivamente). Sin embargo, sólo el $18 \%$ había llegado a mantener relaciones sexuales con otra chica. El $82 \%$ se declaraba heterosexual y el $18 \%$ restante se repartía entre homosexuales (el $5.3 \%$ ) y sobre todo bisexuales (12.6\%). Cerca del $44 \%$ afirmó ser exclusivamente heterosexual, mientras que el resto varió en distintos grados de atracción hacia el propio sexo.

Comparando ambos perfiles, las chicas subclínicas demostraron una vida sexual mucho más activa que la de los chicos subclínicos en la gran mayoría de dimensiones exploradas y sus resultados se ajustan con pequeños matices a lo esperado en población con problemas subclínicos en el control de impulsos sexuales. No se puede decir lo mismo de los chicos subclínicos, que apenas muestran una conducta sexual más activa que los participantes control.

Si se analiza ahora en detalle cada uno de los aspectos del comportamiento sexual, prácticamente todos los jóvenes (especialmente los participantes de los grupos subclínicos) se habían iniciado en la actividad sexual en el momento de la evaluación. A pesar de ser previsible teniendo en cuenta que la edad media del debut sexual en España se sitúa en torno a los 15 años (Espada, Morales, \& Orgilés, 2013) -6 años por debajo de la edad media de la 
muestra-, este porcentaje supera el que se esperaría habida cuenta de los resultados obtenidos en otras investigaciones. Así, en un estudio con jóvenes de la misma franja de edad, Copen, Chandra y Febo-Vazquez (2016) hallaban que la tasa de los que ya se habían iniciado en la actividad sexual a esa edad se situaba en torno al $85 \%$ (entre un 10\%-15\% inferior a la obtenida en nuestra investigación). La razón para diferencias de esta magnitud reside probablemente en el tipo de muestreo: mientras que en la investigación citada la muestra se reclutó aleatoriamente y comprendía todo tipo de jóvenes, en nuestro estudio la muestra estaba compuesta exclusivamente por jóvenes universitarios, entre los que según se ha encontrado en algunos estudios, la actividad sexual podría ser mayor (Eshbaugh \& Gute, 2008; Goldstein et al., 2007).

Este y otros hallazgos que sugieren que el nivel de actividad sexual entre los participantes control es superior al esperable en población general deben tenerse muy presente durante la discusión de nuestros resultados: si el comportamiento sexual de los participantes subclínicos se comparase con participantes ajustados a parámetros habituales en población general en lugar de con jóvenes con un perfil sexualmente muy activo, es probable que alguno de los hallazgos que ahora no ha resultado significativo sí lo fuera.

Un aspecto donde normalmente discrepan las personas con y sin problemas de CS es en el tener o no pareja estable y en la probabilidad de haber cometido una infidelidad. Las investigaciones que abordan esta cuestión sugieren que la CS disminuye la probabilidad de tener una pareja estable y su duración, mientras que aumenta la de haber sido infiel (Långström \& Hanson, 2006a). No en vano, las personas con problemas en el control de impulsos sexuales rara vez resisten la tentación que les supone mantener una relación sexual con alguien que no sea su pareja, lo que a su vez conduce a la finalización temprana de dicha relación (Pollard et al., 2014). Respecto a este último aspecto, Skegg et al. (2010) hallaban un incremento del $10 \%$ en la tasa de infidelidad entre los hombres con problemas de compulsividad sexual y del 35\% entre las mujeres. En nuestro caso, los hallazgos constatan una tendencia similar pero con diferencias mucho más sutiles. Efectivamente, el porcentaje de participantes subclínicos con pareja estable era un tanto inferior y también era inferior el tiempo medio de duración; sin embargo, estas diferencias sólo alcanzan la significación en el caso de las chicas. En cuanto al porcentaje de los que afirmaron haber sido infieles, se halló un incremento de apenas el $4 \%$ entre chicos subclínicos y del $10 \%$ entre chicas en comparación con los participantes control, muy por debajo de los hallados en la investigación antes citada. En todo caso, habida cuenta del limitado tamaño muestral, es probable que estos resultados en una muestra de mayor tamaño sí alcanzaran la significación estadística. 
En cuanto al número de parejas sexuales a lo largo de la vida, diversas investigaciones en muestra clínica y población normal hallan que este aspecto se relaciona (en ocasiones proporcionalmente) con el nivel de CS. Siguiendo una metodología muy similar a la nuestra, Stupiansky et al. (Stupiansky et al., 2009) se plantearon analizar cómo el nivel de CS modulaba el número de parejas en chicas jóvenes. Para ello, tomaron una muestra de 170 estudiantes universitarias de 18 a 25 años a las que dividieron en dos grupos en función de su puntuación en la escala SCS. Así, estos investigadores estimaron que las chicas con problemas de CS habían tenido una media de 7 parejas sexuales a lo largo de su vida frente a 3.5 en chicas control. Estas cifras serían similares a las obtenidas en nuestro estudio. Cabría plantearse si este incremento en la frecuencia sexual se acompaña de un aumento del riesgo sexual para la transmisión del VIH o una ITS o bien del impacto negativo en otras áreas, que serían los únicos argumentos que justificarían la consideración negativa de este hallazgo.

Otro importante hallazgo es que entre los chicos subclínicos, el número de parejas sexuales dobló el de las chicas (13.64 frente a 6.31). La explicación podría estar en el porcentaje de homosexuales en la muestra. Se ha demostrado que la frecuencia sexual se dispara en personas que además de experimentar problemas en el control de impulsos sexuales, son homosexuales (Parsons et al., 2008). Si tenemos en cuenta que el $21 \%$ de los chicos subclínicos se declaraba homosexual frente al $5 \%$ de las chicas, se comprende que el número de parejas sexuales en el primer grupo doble el del segundo. Este extremo sería contrastable si además de, en función del sexo y del grupo clínico, se hubiera podido estimar la frecuencia sexual en función de la orientación sexual.

El análisis de la frecuencia sexual arroja también conclusiones interesantes. En población general, la frecuencia sexual tiende a situarse en torno a los 3 orgasmos semanales (Kingston \& Bradford, 2013) mientras que en pacientes con CS, ésta asciende hasta los 8 orgasmos semanales (Kafka, 1997). Tanto es así que durante mucho tiempo se consideró diagnosticar un problema en el control de los impulsos sexuales únicamente cuando la frecuencia sexual superara los 7 orgasmos semanales (TSO $\geq 7$ ). Si bien la forma en la que se midió la frecuencia sexual en esta investigación dificulta comparar sus resultados, es más que evidente que nuestros resultados se acercan más a los observables en población general que en muestra clínica. Si tomamos el porcentaje de chicos y chicas subclínicos con una frecuencia sexual semanal >3 (única categoría en la que se englobaría el criterio de $\mathrm{TSO} \geq 7$ propuesto para el diagnóstico de la hipersexualidad), éste fue de $27 \%$ y $23 \%$ respectivamente. Eso significa que el $73 \%$ y el $77 \%$ de los chicos y chicas que en nuestro estudio se consideran en riesgo de desarrollar un problema en el control de impulsos sexuales no cumplirían con el criterio básico 
de frecuencia sexual para ser clasificados como tal. Hay varias hipótesis que explicarían estos resultados. La primera y más evidente es que nuestra muestra subclínica ni tan siquiera se aproxima a la gravedad de los pacientes de las investigaciones anteriores, de modo que tampoco podemos esperar obtener tasas de frecuencia sexual similares. Otro aspecto a tener en cuenta es el cómo se registró la frecuencia sexual: cuando en nuestros cuestionarios se preguntó acerca de la frecuencia de actividad sexual, no se especificó que la masturbación se incluía en esta categoría, de modo que es muy posible que algunos participantes respondieran considerando únicamente la frecuencia de coitos semanales. En todo caso, en chicas sí queda demostrado que la frecuencia sexual de las participantes subclínicas supera la obtenida por las participantes control.

Respecto al tipo de prácticas sexuales realizadas, la literatura sugiere que no hay diferencias entre pacientes con y sin problemas de CS en la realización de las consideradas mayoritarias (como la masturbación, el sexo oral o vaginal o incluso el sexo anal) pero sí en conductas sexuales menos corrientes. Así, Stupiansky et al. (Stupiansky et al., 2009) encuentran idéntico porcentaje de chicas con alta y baja CS que habían practicado sexo oral, vaginal o anal mientras que Grov et al. (2010) demuestran que prácticas como el intercambio de orina, la penetración anal con el puño, las prácticas de dominio-sumisión, el exhibicionismo, la asfixia erótica o el intercambio de semen con la boca se manifiestan principalmente en personas con altas puntuaciones en CS. En nuestra investigación, un mayor porcentaje de chicos subclínicos dijo haber practicado sexo anal (50\% frente al 35\%) mientras que en chicas, todas las prácticas sexuales excepto el coito vaginal (que alcanzaba prácticamente el $100 \%$ en control y subclínicas) fueron más frecuentes en el grupo subclínico. Estos resultados contradicen las teorías recientes que defienden que la generalización de conductas sexuales que antes eran infrecuentes (como el sexo anal o si nos remontamos más atrás en el tiempo el sexo oral) han hecho que en la actualidad, su realización sea independiente de variables como la CS o la erotofilia. En este sentido, puede ser que esta afirmación sea cierta en hombres pero todavía se aprecia que casi entre un 10\%-20\% más de mujeres subclínicas dijeron haberse masturbado a sí mismas o a sus parejas y haber practicado sexo oral y anal. Como venimos discutiendo de forma recurrente a lo largo de esta sección, parece que la apertura sexual (en este caso hacia distintas prácticas sexuales) es una realidad generalizada en hombres pero para que lo sea para una mujer, deben mediar disposiciones individuales como por ejemplo una mayor tendencia a la CS.

Para terminar, el análisis de distintos aspectos relacionados con la orientación sexual revela que la CS desempeña un papel importante en su expresión únicamente en mujeres. Así, más 
de la mitad de las chicas subclínicas de este estudio deseaban o habían fantaseado con mantener relaciones con otras chicas y el 19\% había llegado a hacerlo. Este porcentaje supera holgadamente el $13.8 \%$ encontrado por Långström \& Hanson (2006a) entre mujeres con altas puntuaciones en CS y sería prácticamente idéntico al 19.4\% del estudio de Skegg et al. (2010). Asimismo, se documenta una gran diferencia entre chicos y chicas subclínicos en la distribución de porcentajes en orientaciones sexuales alternativas a la mayoritaria: mientras la mayoría de chicos que no eran heterosexuales se identificaban como homosexuales, en chicas el porcentaje de bisexuales superó ampliamente el de homosexuales. Un modo de explicar este hallazgo es acudir a la hipotesis de la experimentación sexual: desde esta perspectiva, el porcentaje de chicas subclínicas bisexuales sería mucho más alto que el de homosexuales porque éstas estarían más abiertas a la experimentación del placer sexual con otras chicas sin rechazar su atracción hacia personas del sexo contrario. Otra hipótesis tendría que ver con los esquemas de género y la rigidez en el reconocimiento de la orientación sexual: según esta hipótesis, cuando un hombre no se reconoce como heterosexual automáticamente se desplaza al extremo contrario del continuo, siendo más complicado que asuma posiciones intermedias; sin embargo, las chicas resultarían más flexibles en este sentido y experimentarían menos problemas a la hora de reconocer su atracción hacia ambos sexos. En todo caso, estas son tan sólo dos hipótesis que deberían contrastarse a través de estudios de naturaleza bien distinta al desarrollado en esta tesis (como grupos focales o de discusión).

Los hallazgos realizados permiten confirmar parcialmente la décima hipótesis acerca del comportamiento sexual de los participantes subclínicos, que planteaba: "las chicas y sobre todo los chicos del grupo de puntuaciones subclínicas mostrarán una conducta sexual más activa. Concretamente, se espera que estos participantes informen de una frecuencia sexual mayor, más parejas sexuales a lo largo de la vida, la realización de un mayor número de prácticas sexuales (sobre todo de las menos habituales como el sexo anal) y una mayor frecuencia de otros comportamientos como el haber sido infiel o el haber mantenido relaciones con personas del mismo sexo". En este sentido, tanto los chicos subclínicos como las chicas mostraron un perfil caracterizado por importantes índices de actividad sexual pero las diferencias con respecto a los participantes control en aspectos como la frecuencia sexual, el tipo de prácticas realizadas o bien la comisión de una infidelidad únicamente alcanzaron la significación estadística en chicas. Así, los resultados sugieren que el papel de la CS a la hora de modular la manifestación de la conducta sexual es importante sólo en este último caso. 


\subsubsection{Comportamiento sexual de riesgo}

Uno de los aspectos que más interés ha suscitado habida cuenta de los riesgos sociosanitarios que puede acarrear ha sido el papel de la CS en la realización de conductas sexuales de riesgo. El sexo es la principal vía de transmisión del $79.8 \%$ de los nuevos diagnósticos de VIH (Centro Nacional de Epidemiología, 2015), del 50\% de los de hepatitis B (Satterwhite et al., 2013) y la única en otras ITS como el Virus del Papiloma Humano (VPH), el herpes genital o la tricomoniasis. El riesgo de transmisión varía en función de aspectos como el tipo de práctica sexual, el rol durante la misma y su intensidad (más riesgo durante relaciones sexuales de alta intensidad que incluyen la práctica de coito anal o vaginal en rol receptivo) (Ballester-Arnal \& Gil-Llario, 2011), pero en todos los casos desaparece cuando se emplea el preservativo. En colectivos de alto riesgo - principalmente $\mathrm{HSH}$-, se ha demostrado que el nivel de CS se asocia a un uso inconsistente del preservativo y al incremento del riesgo de transmisión de estas patologías pero no está claro el papel que desempeña -si es que lo hace- en otros perfiles, especialmente entre personas con una manifestación subclínica de la CS. Considerando este importante vacío en la literatura, en este estudio se planteó el objetivo de analizar el riesgo sexual mediante un indicador directo de riesgo (el HIV-RI) y dos de riesgo indirecto (la escala de severidad percibida del VIH y la escala de autoeficacia en el uso del preservativo).

El HIV-Risk Index (HIV-RI, Ballester-Arnal, Gil-Llario, et al., 2016) es una escala desarrollada recientemente que a diferencia de muchas otras precedentes, permite estimar el riesgo de contraer VIH en población general. En su estimación se tiene en cuenta el riesgo directo del uso inconsistente del preservativo durante la actividad sexual y el riesgo indirecto derivado de aspectos como el ser infiel a una pareja estable o no tener intención de usar el preservativo en futuros encuentros sexuales. Asimismo, el riesgo en cada uno de estos indicadores se pondera atendiendo a dos criterios: la frecuencia sexual y el número de parejas. Así, este índice tiene en cuenta que el riesgo de contraer VIH es mayor en una persona que además de no usar el preservativo de forma consistente, mantiene una alta frecuencia sexual y cambia de pareja cada poco tiempo. Precisamente este aspecto convierte al HIV-RI en uno de los mejores instrumentos para estimar el riesgo sexual en personas con un problema en el control de impulsos sexuales.

Por otra parte, la severidad percibida del VIH y la autoeficacia en el uso del preservativo han sido considerados indicadores indirectos de riesgo en tanto en cuanto desempeñan un papel mediador en el uso del preservativo. Así, es más probable que emplee el preservativo durante su actividad sexual alguien que considere grave la infección por VIH (es decir, que le atribuya más severidad) (Zhao et al., 2012) y que tiene más habilidad para adquirir, usar o negociar con 
una pareja el empleo del preservativo (es decir, más autoeficaz en el uso del preservativo) (Widman, Noar, Choukas-Bradley, \& Francis, 2014).

Tras analizar mediante estos tres indicadores el nivel de riesgo sexual en chicos subclínicos, no parece que estos jóvenes se encuentren en una situación de especial riesgo a la hora contraer VIH o una ITS. Su puntuación en el HIV-RI fue de 5.81 en una escala con valores entre 0 (ausencia total de riesgo) y 13.5 (riesgo extremo), puntuación tan sólo 7 décimas por encima de la obtenida por los chicos control. Sin embargo, sí se aprecia una tendencia clínica pero no estadísticamente significativa que sugeriría que el riesgo asociado a ciertas prácticas sexuales (como el sexo anal, con parejas esporádicas o cuando se ha bebido o tomado drogas) es ligeramente mayor en este perfil de participantes. Este extremo se confirmó a través de análisis donde se determinaba que estas mismas diferencias en muestras de mayor tamaño alcanzarían la significación estadística, de modo que debemos tomar con cautela estos hallazgos. A esto debemos sumar que el riesgo de transmisión del VIH de los chicos tanto control como subclínicos medido a través de su puntuación en el HIV-RI dobla el obtenido por Ballester-Arnal et al. (2016) en el estudio de validación original de la escala con una muestra de 9477 estudiantes universitarios de entre 18-30 años (2.51).

Por otra parte, los hallazgos en las dos escalas restantes arrojan resultados contradictorios. En la de severidad percibida, el $81 \%$ consideraba el SIDA una enfermedad sin curación pero sólo un $25 \%$ creía que era grave; por otra parte, al $67 \%$ le producía temor infectarse con el VIH pero sólo un $5.7 \%$ creía tener riesgo de que eso pasara. Este último dato resulta especialmente destacable habida cuenta de que según estudios que contrastan distintos modelos de salud, la percepción de riesgo de infección por VIH es una de las variables con más peso explicativo sobre el uso del preservativo (Espada, Morales, Guillén-Riquelme, Ballester, \& Orgilés, 2016). En cuanto al nivel de autoeficacia percibida en el uso del preservativo, no se encontraron diferencias respecto al grupo de chicos control y en ambos casos la percepción de autoeficacia fue alta: así, la puntuación media en una escala con valores entre 0-24 fue de 16.8 para chicos subclínicos y de 17 para control. Los resultados más positivos se dieron en la consideración del preservativo como método fiable y en la comodidad a la hora de comprarlos o de hablar de su empleo con nuevas parejas sexuales; al contrario, la autoeficacia fue menor en la comodidad a la hora de ponérselo o ponerlo a la pareja y de sugerir a una pareja su uso.

En cuanto al riesgo sexual en chicas subclínicas, los resultados nuevamente no permiten afirmar que estas chicas tengan un especial riesgo de contraer una ITS o el VIH pero sí que tienen un riesgo significativamente mayor al de las chicas control: mientras que la puntuación de las primeras en el $H I V-R I$ fue de 5.3 (un valor de riesgo medio-bajo), la de las chicas control 
se situó casi un punto por debajo (riesgo bajo). Las mayores diferencias entre ambos grupos se dan en la escala de indicadores directos de riesgo sexual: concretamente, las chicas subclínicas mostraron mayor riesgo derivado del uso inconsistente del preservativo con una pareja estable, durante el sexo oral y sobre todo con una pareja esporádica. Este aspecto resulta especialmente preocupante habida cuenta del riesgo de no usar el preservativo con una pareja a la que apenas se acaba de conocer, sobre todo considerando que el número de pareja sexuales en chicas con este perfil tiende a ser más bien alto (Boyer et al., 2016).

Las diferencias entre chicas control y subclínicas se mitigan prácticamente por completo al analizar las escalas de riesgo indirecto, resultando equivalente en ambos grupos el nivel de autoeficacia en el uso del preservativo y apenas ligeramente mayor entre las subclínicas la severidad percibida del VIH. Como sucedía en los chicos, el porcentaje de las que se creen en riesgo de contraer el VIH (10\%) no es proporcional con el miedo que esa idea produce (80\%), igual que tampoco lo sería la creencia de que el SIDA no tiene curación (80\%) y su consideración como grave (28\%). En cuanto a la percepción de autoeficacia en el uso del preservativo, la única variable donde las chicas subclínicas se muestran más autoeficaces es en la comodidad a la hora de comprar preservativos.

Estos hallazgos permiten confirmar tan sólo en mujeres uno de los supuestos más extendidos en cuanto a consecuencias de la CS: que las personas en las que la CS se manifiesta más acentuada tienen mayor riesgo de contraer una ITS o el VIH (Kafka, 2010; Kaplan \& Krueger, 2010). De entre las investigaciones que exploran el riesgo sexual en personas con CS, destacaría la realizada por Grov et al. (2010). En un estudio con 1214 HSH de 18-78 años, estos investigadores hallaban que los que obtenían puntuaciones mayores en la escala SCS tenían más probabilidad de ser $\mathrm{VIH}+$, de haber realizado sexo anal con una pareja serodiscordante, de sentirse atraídos hacia el sexo sin condón y buscar parejas que quieran mantener este tipo de relaciones (Barebacking). Asimismo, estos investigadores demostraron que una persona con una puntuación de 38 en el SCS tenía 237\% más de probabilidad que una que puntuase 18 de haber practicado sexo sin preservativo. En una investigación posterior también en HSH, se encontró que la CS se relacionaba de forma directa e indirecta con el riesgo de contraer VIH: obtener puntuaciones clínicas en el cuestionario SCS aumentaba en 2.25 puntos la probabilidad de realizar conductas sexuales de riesgo para la transmisión del VIH y en 2.05 puntos la probabilidad de ser VIH+ (Parsons et al., 2012).

En nuestro caso, el riesgo de las chicas con una manifestación subclínica de la CS sería ligeramente mayor al encontrado en chicas sin este rasgo pero su gravedad no sería tan siquiera comparable a la de los estudios citados. La principal diferencia entre estos estudios y 
el nuestro corresponde a la muestra: en las investigaciones citadas, la muestra comprendía chicos gais o bisexuales -colectivo considerado de alto riesgo en la transmisión del $\mathrm{VIH}$ - mientras que en nuestro estudio participaron jóvenes estudiantes universitarios mucho menos vulnerables a la hora de contraer esta infección. A eso hemos de sumar que la gravedad clínica de los pacientes identificados como probablemente CS en los estudios anteriores es también superior a la del nuestro.

Otra hipótesis que permitiría explicar la ausencia de riesgo diferencial en chicos subclínicos y el discreto aumento en chicas se relacionaría con el nivel de educación sexual: los jóvenes reclutados en nuestra investigación proceden de un contexto -el universitario- en el que la educación en sexualidad se aborda de múltiples formas. Si bien es cierto que esta educación sexual no siempre alcanza una gran difusión, a lo largo de su carrera muchos de ellos reciben información sobre sexualidad (principalmente sobre sexo seguro) a través de acciones y campañas de sensibilización, mesas informativas o cursos (Giménez-García, Ballester-Arnal, Ruiz-Palomino, Salmerón-Sánchez, \& Castro-Calvo, 2016) y en otros casos incluso como parte de su currículum académico (Castro-Calvo, Ballester-Arnal, Giménez-García, et al., 2016). Si a eso le sumamos que recientemente se ha demostrado que las personas con mayor interés por el sexo son las que más se benefician de las acciones de educación sexual por la atención que estos temas les despierta (Herbenick et al., 2009; Rye, 2013), entonces se comprende por qué el riesgo sexual en los chicos subclínicos apenas varía con respecto a los control y por qué las diferencias en chicas son tan discretas.

Estos hallazgos refutan parcialmente la undécima hipótesis acerca del comportamiento sexual de riesgo en personas con una manifestación subclínica de la CS. Según esta hipótesis: "las chicas y sobre todo los chicos con puntuaciones clínicas realizarán con mayor frecuencia conductas sexuales que supongan un riesgo para la transmisión del VIH o de una ITS. Sin embargo, se espera que no varíe su percepción de autoeficacia en el uso del preservativo o su valoración del riesgo del VIH". De acuerdo con la hipótesis, las chicas subclínicas mostraron un riesgo ligeramente mayor (en ningún caso alto) para la transmisión del VIH o una ITS. Sin embargo, chicos control y subclínicos apenas diferían entre sí en riesgo asociado a su conducta sexual. Por otro lado, el grado de severidad percibida del VIH y la autoeficacia en el uso del preservativo no variaron entre hombres control y subclínicos mientras que entre las chicas, la percepción de severidad fue ligeramente mayor en las subclínicas. 


\subsubsection{Comportamiento sexual online}

Desde su nacimiento y especialmente durante los últimos años, Internet se ha convertido en uno de los principales espacios donde satisfacer la curiosidad y el deseo sexual. Entre los más jóvenes, Internet ha tomado el relevo a otros medios como el colegio o la familia a la hora de educar en sexualidad, universalizando el derecho a esta formación pero incrementando el riesgo derivado de delegar el cuidado de la maduración psicosexual de los más jóvenes (como el desarrollo de una visión poco realista de las relaciones sexuales) (Daneback, Månsson, Ross, \& Markham, 2012; Simon, Daneback, \& Ševčíková, 2015). Entre adolescentes y adultos jóvenes, el anonimato y el fácil acceso a cualquier tipo de contenido sexual ha hecho que cada vez sean más los que recurren a este medio para alcanzar el placer sexual en solitario (masturbándose mientras ven pornografía) o contactando con otros usuarios con los que mantener relaciones sexuales en persona o a través de chat o webcam. Tanto es así que algunos estudios apuntan una prevalencia de hasta el $76.5 \%$ y el $31 \%$ respectivamente para estas conductas (Döring, Daneback, Shaughnessy, Grov, \& Byers, 2015), que suelen ser especialmente frecuentes en chicos. En nuestro país, un reciente estudio en el que se analizaban los hábitos sexuales online de 1557 universitarios de entre 18-25 años encontró que el $35 \%$ afirmaba haber buscado pornografía en Internet (55\% en hombres y $24 \%$ en mujeres), el $30 \%$ haberse masturbado mientras lo hacía (59\% y $14.3 \%$ ) y el $12 \%$ haber participado en chats sexuales (20\% y 9\%) (Ballester-Arnal, Castro-Calvo, et al., 2016).

Uno de los riesgos asociados al uso de Internet con fines sexuales es el desarrollo de un cuadro clínico de adicción: se estima que entre el $1.7 \%$ y el $7.6 \%$ de los usuarios de cibersexo acaban desarrollando una dependencia (Ross et al., 2012) y el porcentaje es aún mayor si analizamos la proporción de usuarios con un perfil de riesgo, que en nuestro país representan el $8.6 \%$ de los que consumen cibersexo (Ballester-Arnal, Castro-Calvo, et al., 2016). En pacientes con problemas en el control de los impulsos sexuales, la prevalencia de adicción al cibersexo se dispara hasta el $18 \%$ (Cooper et al., 2000), de modo que esta variable desempeña un papel predisponente en el desarrollo de esta problemática. Sin embargo, todavía no se tiene claro hasta qué punto o en qué tipo de conductas sexuales online la falta de control de impulsos sexuales juega un papel más importante. Esto es especialmente cierto cuando hablamos de población con una manifestación subclínica de esta dimensión. Con el objetivo de paliar esta carencia, en el protocolo de evaluación de esta investigación se incluyó uno de los instrumentos más populares en la evaluación de la conducta sexual online y de la adicción al cibersexo: el cuestionario de adicción al cibersexo (ISST). 
A través de esta escala, se aprecia que el comportamiento sexual online de los chicos subclínicos se caracteriza por una clara preferencia por las actividades sexuales que no requieren interacción con otros usuarios como por ejemplo la búsqueda de pornografía a través de Internet (realizado por el 92\%) y la masturbación durante su visionado (95\%). Si bien estas prácticas tienden a ser más frecuentes entre participantes del grupo subclínico, apenas se aprecian diferencias con respecto a los chicos control principalmente porque su frecuencia en ambos grupos es muy alta. Donde sí se aprecian diferencias de una magnitud importante es en el empleo de Internet para interactuar sexualmente con otros usuarios: concretamente, un gran porcentaje de chicos subclínicos afirmó haberse insinuado sexualmente a través de Internet (55\%), participar en chats sexuales $(40 \%)$ o haber realizado conductas que pueden suponer cierto riesgo como por ejemplo quedar cara a cara con alguien a quien se había conocido por Internet (46\%). Asimismo, un importante porcentaje de chicos subclínicos afirmó haber sufrido algún síntoma de consumo compulsivo de cibersexo como por ejemplo experimentar malestar (ira, tristeza, frustración...) cuando no logra acceder a material sexual en Internet o considerarse adicto al cibersexo (22\%). Otro síntoma muy representativo de consumo patológico experimentado por el $7 \%$ de chicos subclínicos fue castigarse a ellos mismos cuando buscaban sexo online. Todo esto se traduce en un mayor nivel de gravedad en el consumo de cibersexo: así, los chicos subclínicos obtuvieron una puntuación de 9.23 en el ISST (rango 0-24) frente al 6.94 obtenido por los del grupo control. Finalmente, el $50 \%$ de participantes subclínicos obtuvo puntuaciones que sugerían un consumo recreativo de cibersexo mientras que el 50\% restante se repartió entre usuarios de riesgo (47.1\%) y adictos al cibersexo (3.5\%).

El comportamiento sexual online de las chicas subclínicas resultó ser muy similar al masculino, si bien en este caso casi todas las conductas y dimensiones de consumo de cibersexo exploradas fueron más frecuentes en participantes subclínicas. Las conductas sexuales online más prevalentes corresponden a actividades que se pueden realizar en solitario, como la búsqueda de pornografía (realizado por el $79 \%$ de las subclínicas frente al $36 \%$ de las control), la masturbación durante su visionado ( $59 \%$ frente al $21 \%$ ) o permanecer despierto hasta después de media noche para realizar estas actividades (20\% y 6\%). Le seguirían en frecuencia actividades que suponen el contacto con otras personas a través de Internet, como el hacer insinuaciones sexuales mientras se chatea con otros usuarios (28\% frente al $9 \%$ ) o participar en chats sexuales (24\% frente al 10\%). Por los riesgos que acarrea, resulta destacable que aproximadamente un 30\% de las chicas subclínicas haya visto en persona a alguien a quien había conocido en Internet. También un tanto preocupante resulta 
la frecuencia de algunos síntomas de consumo compulsivo de cibersexo como por ejemplo valorar que el cibersexo interfiere con algunos aspectos de su vida (10.4\% de chicas subclínicas frente al $0 \%$ de las control), emplear Internet para experimentar con distintos aspectos de su sexualidad ( $25 \%$ frente al $4 \%$ ) o sufrir cierto malestar cuando no se logra acceder a estos contenidos (8.3\% frente al $0 \%)$. Asimismo, el $4.2 \%$ de las chicas subclínicas valoró su consumo de cibersexo como problemático. Como consecuencia, la diferencia entre el grupo de chicas control y subclínicas en la gravedad del consumo de cibersexo (puntuación media en el ISST) fue de casi 4 puntos y mientras el 100\% de las control obtuvo una puntuación que sugería un consumo recreativo de cibersexo, el porcentaje bajó al $88.4 \%$ entre las subclínicas. El $11.6 \%$ restante correspondió a usuarias de riesgo.

Si comparamos nuestros hallazgos con los obtenidos por Ballester-Arnal, Castro-Calvo, et al. (2016) en una muestra equivalente y empleando el mismo instrumento de evaluación, destaca en primer lugar que la prevalencia de prácticamente todas las conductas sexuales online es mucho mayor en nuestra investigación -independientemente de la condición clínica-. Esto es especialmente cierto entre los chicos y chicas subclínicas, lo que confirma la importancia de la CS a la hora de modular el consumo de cibersexo. Otro aspecto importante tiene que ver con la diferencia entre hombres y mujeres en cuanto a manifestación del comportamiento sexual online: si bien en nuestro estudio los chicos todavía son los principales consumidores de sexo en Internet, las chicas comienzan a ganar protagonismo de modo que las diferencias que normalmente se aprecian en función del sexo se matizan ligeramente (Wright, Bae, \& Funk, 2013). Una hipótesis a la hora de explicar el incremento masculino y sobre todo femenino en el consumo de cibersexo tiene que ver con la fecha en la que se recogieron los datos: en un aspecto tan ligado al desarrollo tecnológico como lo es la adicción al cibersexo, una diferencia de uno o dos años entre estudios puede explicar el incremento notable en el consumo de material sexual online. La recogida de los datos analizados en esta tesis finalizó hace apenas un año (es decir, 2-3 años más tarde de los de la investigación antes citada). Esta brecha coincide además con el auge y proliferación de los llamados teléfonos inteligentes, que permiten que cualquier persona, desde cualquier lugar y en cualquier momento acceda a todo tipo de contenidos pornográficos. No en vano, estudios recientes hallan un crecimiento exponencial de este tipo de dispositivos a la hora de consultar contenidos eróticos en Internet (Kvalem, Træen, Lewin, \& Štulhofer, 2014).

Asimismo, se aprecia que la CS modula también la expresión patológica del consumo de cibersexo, sobre todo del consumo de riesgo de cibersexo. En nuestro estudio, la prevalencia de participantes subclínicos con este perfil fue del $47.1 \%$ en chicos y del $11.6 \%$ en chicas, 
porcentajes que superan holgadamente los obtenidos en investigaciones precedentes (Ballester-Arnal, Castro-Calvo, et al., 2016; Cooper et al., 2000; Ross et al., 2012). Este perfil se correspondería con una manifestación subclínica del cuadro clínico de adicción al cibersexo, de modo que estaríamos hablando de que aproximadamente la mitad de los chicos subclínicos y 1 de cada 10 chicas podría estar experimentando algunos problemas derivados del consumo abusivo de materiales sexuales online. En todo caso, habida cuenta del pequeño porcentaje de participantes subclínicos clasificados en la categoría de adictos al cibersexo (3.5\% de los chicos y $0 \%$ de las chicas), nuestros resultados no permiten considerar la CS como predisponente en el desarrollo del cuadro clínico.

En resumen, estos hallazgos confirman sólo parcialmente la hipótesis acerca del comportamiento sexual online de los participantes subclínicos: "el uso de internet con fines sexuales (tanto el visionado de pornografía como el uso de chats sexuales) así como la severidad de su consumo será mayor en chicos subclínicos. También será mayor el porcentaje de adictos al cibersexo y de usuarios con un perfil de riesgo. Sin embargo, no se apreciarán diferencias en estos aspectos entre chicas control y subclínicas". En efecto, el comportamiento sexual online de los chicos subclínicos se ajustaría completamente a la descripción planteada en esta hipótesis pero esta descripción es igualmente válido a la hora de hablar del consumo de cibersexo en chicas subclínicas.

\subsubsection{Variables clínicas sexuales}

Otro objetivo que se abordó durante la elaboración de este trabajo fue analizar qué papel juegan 2 dimensiones del comportamiento sexual (la búsqueda de sensaciones sexuales y las tendencias erotofílicas-erotofóbicas) en la manifestación subclínica de la CS. Ambas reflejan una actitud de apertura o cerrazón hacia temas relacionados con la sexualidad pero difieren en cuanto a concreción: la erotofilia se relaciona con aspectos generales de la conducta sexual como la búsqueda de información sobre sexo, la edad del debut sexual, frecuencia y variedad o la satisfacción sexual (Rye, 2013), mientras que la búsqueda de sensaciones sexuales se ha empleado para explicar principalmente la conducta sexual de riesgo (Voisin et al., 2013).

La importancia de comprender el papel de estas dos dimensiones en la manifestación subclínica de la CS se justifica a partir de su capacidad a la hora de predecir la severidad y consecuencias del cuadro clínico: si una persona que comienza a experimentar problemas en el control de sus impulsos sexuales muestra además tendencias erotofílicas y es un gran buscador de sensaciones sexuales, la probabilidad de que acabe realizando conductas sexuales que por su frecuencia, intensidad o naturaleza resulten riesgosas se multiplica. 
En nuestra investigación, los participantes subclínicos - chicos y chicas- se caracterizaron por mostrar una importante tendencia a la búsqueda de sensaciones sexuales y a la erotofilia. En el caso de los chicos, las diferencias respecto al grupo control son significativas en la búsqueda de sensaciones sexuales pero no en la de erotofilia-erotofobia mientras que en las chicas lo serían y además de una magnitud importante en ambos casos.

Nuestros resultados sugieren que la CS modula la expresión de la búsqueda de sensaciones sexuales pero no en todos los casos desempeña el mismo papel en la expresión de la erotofiliaerotofobia: en chicas, esta variable se expresa con más fuerza entre aquellas con rasgos que sugieren cierta pérdida del control sobre los impulsos sexuales mientras que en chicos, ambas variables se manifiestan de modo independiente. Este hallazgo resulta interesante: si bien el nivel de erotofilia-erotofobia evoluciona cada vez más paralelo en hombres y mujeres, ellos siguen siendo a día de hoy más erotofílicos (Petersen \& Hyde, 2010). En su caso, la erotofilia parece estar condicionada por factores como la apertura social y cultural hacia la sexualidad y no por disposiciones individuales, de modo que la actitud mayoritaria hacia el sexo tiende a ser de apertura y acercamiento (López et al., 2011); al contrario, la actitud más extendida entre mujeres de acercamiento discreto hacia el sexo y sólo las que presentan cierta predisposición (manifestada a través de la CS) transgreden este principio y se acercar al extremo erotofílico.

Esta última hipótesis tiene importantes implicaciones a la hora de interpretar algunos resultados obtenidos hasta el momento: así, sería posible que lo que determina que las chicas subclínicas manifiesten una conducta sexual más activa (mayor número de parejas sexuales, prácticas sexuales más variadas, etc.) no sea tanto la influencia directa de la CS sobre la conducta sexual como el papel mediador de la erotofilia en esta relación. Desde esta perspectiva, podría ser que las chicas con rasgos compulsivos que además muestran interés hacia lo relacionado con la sexualidad (es decir, más erotofílicas) tengan mayor probabilidad de perder el control sobre la conducta sexual que las que sólo manifiesten rasgos compulsivos. Parte de la importancia de este hallazgo reside en que esta es la primera ocasión en la que se demuestra un vínculo sólido entre esta dimensión y el control de impulsos sexuales.

A este respecto, inicialmente se planteó la siguiente hipótesis: "se espera que los participantes subclínicos -chicos y chicas- obtengan puntuaciones mayores en búsqueda de sensaciones sexuales y en erotofilia". A la luz de los resultados obtenidos, podríamos decir que esta hipótesis se cumple prácticamente en su totalidad, con la única salvedad de que los chicos control y subclínicos apenas variaron en cuanto a su grado de erotofilia-erotofobia. 


\subsubsection{Evaluación hormonal}

Uno de los objetivos más ambiciosos del presente trabajo fue analizar el papel de la testosterona en la manifestación subclínica de la compulsividad sexual. Las hormonas sexuales en general y la testosterona en particular desempeñan un papel central en el desarrollo y el comportamiento sexual. Reconociendo su importancia, Reid (2013) proponía que el nivel de testosterona podría explicar una parte importante del inicio y del mantenimiento del cuadro clínico de CS. Según esta hipótesis, una mayor concentración de testosterona determinaría la presencia de un exagerado deseo sexual mientras que problemas más generales en el control de impulsos impedirían su manejo efectivo. En esta línea, Codispoti (2008) y Rosenberg et al. (2014) propusieron el uso de antagonistas de la testosterona para el control de los síntomas de CS; el primero defendía su eficacia comparando su efecto con el del tratamiento de las parafilias mientras que los segundos restringían su empleo en casos donde la terapia psicológica (tratamiento de elección) resultara ineficaz. Hasta el momento, dos estudios han sometido a prueba la eficacia de este tipo de tratamientos. El primero demostró que la administración exógena de triptolerín (antagonista de la testosterona) reducía la frecuencia de fantasías y de deseo sexual en pacientes con parafilias y CS (Rosler \& Wiztum, 2009) mientras que el segundo encontró que si bien resultaban eficaces, estos tratamientos provocaban efectos iatrogénicos (desde pérdida del apetito, sueño o concentración hasta problemas más graves como fiebre, pérdida del vello facial o incapacidad para mantener la erección) (Safarinejad, 2009).

La eficacia documentada de los tratamiento a partir de antiandrógenos plantea 2 escenarios: o bien su administración reduce los síntomas de CS porque estos pacientes acumulan una mayor concentración de testosterona o bien porque como en el caso de las parafilias, estos fármacos afectan negativamente sobre el conjunto de la respuesta sexual. Si bien su contraste tiene importantes implicaciones a la hora de explicar el inicio y el mantenimiento del cuadro clínico, hasta la realización de este trabajo ningún otro estudio había abordado esta cuestión. Para explorar esta hipótesis, un subgrupo de 80 participantes (20 por cada condición clínica) fue sometido a una evaluación para determinar su concentración de testosterona en saliva.

Tras analizar los resultados de la prueba, se aprecia que el nivel de testosterona libre en saliva no guarda relación alguna con la manifestación subclínica de la CS. En este sentido, ni su concentración media ni el porcentaje de participantes con niveles por encima (hiper) o debajo (hipogonadismo) del rango de valores normales varía entre participantes control y subclínicos. 
Estos hallazgos tienen importantes implicaciones a la hora de comprender los determinantes del comportamiento sexual compulsivo y la eficacia de su tratamiento farmacológico. En primer lugar, estos resultados permiten refutar las teorías que defienden que el deseo sexual desmedido en pacientes hipersexuales se justifica a partir de un sustrato biológico (Hall, 2011; Reid, 2013) o al menos no por la presencia de un incremento en los niveles de testosterona. Teniendo en cuenta que el resto de hormonas sexuales desempeñan un papel limitado sobre el apetito sexual, la posibilidad de que sea otro andrógeno o estrógeno el que modula la CS es muy remota. Por otro lado, estos hallazgos cuestionan el empleo de antagonistas de la testosterona en el control de los impulsos sexuales. Si lo que justifica su empleo no es una acción directa sobre los mecanismos que mantienen el cuadro clínico sino su efecto negativo e irrestricto sobre el conjunto de la respuesta sexual, entonces cabe plantearse si sus beneficios compensan sus costes: es posible que este tipo de tratamientos reduzcan algunos de sus síntomas pero su administración provoca una merma en la calidad de vida en general y en particular de la calidad de vida sexual (les impide reorientar su actividad sexual de una forma que les resulte beneficiosa).

En todo caso, existen ciertas limitaciones a la hora de interpretar estos hallazgos. Para empezar, el limitado tamaño muestral a la hora de comparar entre los cuatro grupos obliga a considerar estos resultados provisionales. Por otro lado, los niveles de testosterona varían ligeramente a lo largo del día o bajo condiciones como la fase del ciclo menstrual en el que una mujer se encuentra (Hedricks, 1994). Dado que estos aspectos no se tuvieron en cuenta durante la recogida de muestras, puede ser que su influencia matice algunos de los resultados obtenidos. Finalmente, la estimación del nivel de testosterona a través de otros métodos más invasivos como por ejemplo a partir de análisis de sangre resultaría más fiable, de modo que en un futuro el método empleado podría complementarse o sustituirse por otro con un menor margen de error.

A los hallazgos comentados en este epígrafe les corresponde la decimocuarta hipótesis: $<<e l$ nivel de testosterona libre en saliva de los participantes del grupo subclínico será superior al nivel de los del grupo control»>. Contrastada a partir de los resultados obtenidos, esta hipótesis queda refutada en su totalidad: ni el nivel de testosterona libre en saliva ni tampoco el porcentaje de participantes con valores superiores (hiper) o inferiores (hipogonadismo) al rango normal presentaron la más mínima variación en función de la condición clínica. 


\subsection{Severidad y consecuencias de la CS}

En población clínica -especialmente en los casos más graves-, McBride et al. (2008) identifican 6 ámbitos en los que el comportamiento sexual compulsivo provoca un impacto negativo: 1) a nivel médico, las personas con una conducta sexual compulsiva tienen mayor probabilidad de contraer una ITS o el VIH (Parsons et al., 2012) y de sufrir un embarazo no deseado (Dhuffar \& Griffiths, 2016); 2) a nivel económico, algunos pacientes manifiestan su problema a través del consumo de servicios sexuales que suponen un gran desembolso económico (como llamadas a líneas eróticas, la contratación de trabajadores/as sexuales o el consumo de material sexual de pago online) (Kafka, 2013); 3) a nivel legal, estos pacientes pueden experimentar problemas caso que alguna de sus conductas sexuales trascienda los límites legales, que manifiesten una conducta sexual violenta o cometan abuso sexual -situaciones muy infrecuentes- (Coleman et al., 2001); 4) a nivel psicológico, estos pacientes manifiestan una constelación de síntomas que van desde pensamientos intrusivos y perturbadores (Kafka \& Hennen, 2003) hasta emociones negativas como la vergüenza, ira o culpa (Pachankis et al., 2014); 5) a nivel familiar, el impacto sobre la pareja puede derivarse de la incomprensión de la situación, de la insistencia por mantener relaciones sexuales con excesiva frecuencia o la comisión de una infidelidad (Pollard et al., 2014); 6) finalmente a nivel espiritual, los pacientes con fuertes convicciones religiosas tienden a experimentar un profundo malestar y en algunos casos "crisis de fe" motivadas por una conducta sexual que atenta contra los dogmas de la mayoría de confesiones (Edger, 2010). Estas consecuencias se dan en mayor o menor medida en un porcentaje importante de pacientes con problemas en el control de sus impulsos sexuales, sobre todo en los casos más severos (Kaplan \& Krueger, 2010). Sin embargo, poco sabemos del grado y severidad con que estos problemas se expresan en personas con una manifestación subclínica de esta problemática. De ahí que uno de los objetivos prioritarios de esta tesis a la hora de trazar el perfil biopsicosocial de los jóvenes con manifestación subclínica de la compulsividad sexual fuera explorar la severidad del cuadro clínico, identificar las consecuencias que se derivan de dicho comportamiento sexual y si la severidad y sus consecuencias se relacionan de forma lineal. Para contrastar esta hipótesis, los participantes del grupo subclínico completaron dos instrumentos: uno de ellos se empleó a la hora de evaluar la gravedad de los síntomas de CS (CSBI) y el otro para explorar la presencia de distintos tipos de consecuencias (CBOSB).

En cuanto a severidad del cuadro clínico, los chicos y chicas subclínicas obtienen puntuaciones que sugieren una muy baja gravedad en la manifestación de síntomas de CS: en concreto, su puntuación en una escala con valores entre 28 (ausencia del cuadro clínico) y 140 (cuadro clínico de extrema gravedad) fue de 46.8 y 43.5 en chicos y chicas respectivamente, en ambos 
casos situadas en la parte más baja del rango. Si las comparamos con las obtenidas en estudios con distintos tipos de población, estas puntuaciones quedarían en un punto medio entre las que se obtienen con pacientes clínicos o población de riesgo y las documentadas en población general. Así, la puntuación media en el CSBI en un estudio realizado entre más de 1000 HSH latinos sexualmente muy activos se situó 40 puntos por encima de la obtenida en esta tesis (Miner et al., 2007) y 20 puntos por encima en otra investigación donde se evaluó a través de esta misma escala a 8 pacientes en tratamiento por problemas en el control de impulsos sexuales (Miner et al., 2009). En el extremo contrario, la puntuación media de los 8 participantes control del estudio antes citado fue de 29 (14 puntos por debajo de la nuestra) y de 38 (6 puntos por debajo) en una investigación en la que 480 personas reclutadas aleatoriamente completaban este cuestionario (Storholm et al., 2011). Así, estos hallazgos sugieren que las personas con problemas subclínicos en el control de impulsos sexuales muestran un comportamiento sexual de mayor gravedad que el documentado en población general pero menos severo que el encontrado entre pacientes con un diagnóstico al respecto.

Cuando se analiza el perfil de severidad por escalas, el factor en el que se agrupan los síntomas más frecuentes es el de control, seguido a mucha distancia del de violencia y el de abuso. En esta primera escala -que oscilaba en un rango entre 13 y 65-, la puntuación media de los chicos fue un tanto superior a la de las chicas (29.2 frente a 24.5), si bien en ambos casos quedó nuevamente muy por debajo del 48.1 reportado por Reid, Garos, Carpenter, et al. (2011) en un estudio con 30 pacientes hipersexuales o del 54.6 que hallaban Hartman et al. (2012) en una investigación con 36 pacientes en seguimiento por un problema combinado de adicción al sexo y abuso de sustancias. La puntuación en las escalas de violencia y abuso (sobre todo en esta última) apenas se despegó del rango inferior de puntuaciones posibles, lo que sugiere que este tipo de síntomas apenas resultan significativos en la expresión subclínica de la CS. En este sentido, muchos de los estudios que emplean el CSBI con muestra clínica omiten emplear estas dos escalas habida cuenta de su limitada capacidad a la hora de explicar manifestación alguna de la CS (Hook et al., 2010), de modo que mostrar una conducta sexual violenta o tener cierta tendencia a cometer abuso sexual no estaría relacionado en modo alguno con la CS.

Los hallazgos expuestos acerca de la gravedad del cuadro clínico permiten confirmar casi en su totalidad la hipótesis planteada inicialmente: "Ia severidad del cuadro clínico será inferior a la encontrada en estudios previos con muestra clínica. Al comparar a chicos y chicas con puntuaciones subclínicas, la severidad del cuadro clínico será mayor en el caso de los chicos, sobre todo en cuanto a manifestaciones violentas o de incapacidad para controlar los impulsos sexuales". Efectivamente, la severidad del cuadro clínico entre los participantes subclínicos fue 
inferior a la hallada en estudios previos con pacientes con problemas en el control de impulsos sexuales. Asimismo, la severidad general y en particular en la escala de problemas en el control de impulsos sexuales fue ligeramente mayor entre los chicos subclínicos. Sin embargo, no se aprecian diferencias en función del sexo en cuanto a la manifestación de actitudes o comportamientos violentos asociados al cuadro clínico (principalmente porque estos síntomas no están presentes ni en chicos ni chicas).

En relación con las consecuencias del cuadro clínico, el análisis de las puntuaciones en la escala CBOSB revela que los participantes subclínicos apenas experimentan consecuencias cognitivas (preocupaciones acerca de cómo la conducta sexual afecta sobre distintos ámbitos de su vida) o conductuales (presencia de consecuencias manifiestas del comportamiento sexual compulsivo) derivadas de su conducta sexual. Así, las puntuaciones en la escala de consecuencias cognitivas (rango de 0 a 60) oscilaron entre 11.2-11.8 y entre 1.4-1.9 en la de consecuencias conductuales (rango de 0 a 16). Estas puntuaciones quedaron nuevamente muy por debajo de las documentadas en muestra clínica, que en la investigación de Prause et al. (2013) con 71 pacientes adictos al cibersexo se situaban en 33.6 (CBOSB-cognitivas) y 14 (CBOSB-conductuales).

Si se analiza la prevalencia de distintas consecuencias de acuerdo a la clasificación de McBride et al. (2008), las más frecuentes corresponden a la categoría de consecuencias psicológicas: concretamente, entre el $24 \%-31 \%$ y el $27 \%-45 \%$ de los participantes se sintió avergonzado y/o culpable por su conducta sexual desmedida. Este último aspecto sería ligeramente más prevalente en hombres. A las consecuencias psicológicas les siguen en frecuencia las médicas, y más concretamente el haber infligido (11\%-25\%) o haber sufrido (22\%-33\%) dolor durante la actividad sexual. También en esta misma dimensión, en torno al 11\% de los chicos y el $7.2 \%$ de las chicas dijo haber contraído una ITS. Con una frecuencia similar se posicionaron el malestar espiritual derivado de la actividad sexual (9\%-12\%) y algunas consecuencias familiares, como haber tenido problemas con la pareja ( $8 \%-15 \%)$ o con amigos o familiares $(10 \%-11 \%)$. Apenas ningún participante experimentó problemas económicos o legales. En comparación, todo estos porcentajes quedaron muy por debajo de los obtenidos por Reid, Garos et al. (2012) en una muestra de 137 pacientes en tratamiento por problemas de hipersexualdad, lo que confirma nuevamente que si bien las personas con una manifestación subclínica de la CS experimentan algunos problemas importantes derivados de su conducta sexual, su magnitud o extensión no es comparable a la de los pacientes clínicos.

Estos hallazgos permitirían refutar casi por completo la decimosexta hipótesis de este estudio, que plantea: "Respecto a las consecuencias del cuadro clínico, éstas serán más graves en chicos 
que en chicas. Asimismo, la proporción de jóvenes a los que su conducta sexual compulsiva les provoque malestar personal o familiar será alta, mientras que el porcentaje de los que informen de consecuencias negativas para su salud (contraer una ITS o el VIH), legales o monetarias será considerablemente inferior". En este sentido, los participantes subclínicos apenas experimentaron consecuencias derivadas de su conducta sexual independientemente de su sexo. Las más frecuentes fueron las que afectan al bienestar psicológico (como sentirse culpables o avergonzados), seguidas de algunas consecuencias físicas como el infligir o sufrir dolor durante la actividad sexual. Las consecuencias familiares no fueron tan frecuentes como esta hipótesis planteaba (sobre todo las que tienen que ver con los problemas de pareja) pero sí se confirmaría que las consecuencias legales o monetarias son prácticamente inexistentes.

Para terminar, nuestros resultados permiten confirmar el vínculo entre grado de severidad de la compulsividad sexual y la presencia de consecuencias negativas. Así, los participantes con una manifestación más grave de algunos síntomas de CS (especialmente de los de control de impulsos los sexuales) experimentan más consecuencias cognitivas y sobre todo conductuales derivadas de su comportamiento sexual. Asimismo, el vínculo positivo entre severidad del cuadro clínico y consecuencias parece ligeramente más fuerte en chicas, lo que confirmaría lo que algunos autores sugieren de que entre las mujeres, la manifestación de conductas sexuales que se apartan de lo considerado socialmente aceptable es objeto de mayor sanción y de más perjuicio que en el caso de los hombres (Dhuffar \& Griffiths, 2016; Mckeague, 2014).

De modo que estos hallazgos permiten confirmar por completo la hipótesis que plantea que: "La gravedad de las consecuencias del cuadro clínico de CS correlacionará con su severidad".

2.6 Modelos predictivos y explicativos del cuadro clínico de CS

Un aspecto importante del estudio de cualquier cuadro clínico -especialmente si hablamos de patologías emergentes como en el caso de la compulsividad sexual- es identificar las variables que predicen en mayor o menor medida su manifestación y severidad. Entre otras cosas, esto permite: 1) a corto plazo, identificar los perfiles de alto y bajo riesgo, mejorar el conocimiento acerca de la etiopatogenia del trastorno y ayudar a predecir su curso clínico; 2) a medio plazo, identificar las áreas hacia las que orientar la intervención terapéutica con el fin de mejorar su efectividad, eficacia y eficiencia y; 3) a largo plazo, focalizar las acciones de prevención primaria/secundaria en colectivos de alto riesgo, mejorando su impacto y ahorrando recursos.

En la literatura sobre comportamiento sexual compulsivo se identifican multitud de factores que han demostrado su importancia relativa en el inicio y mantenimiento de este cuadro clínico (Kafka, 2010; Kaplan \& Krueger, 2010; Mick \& Hollander, 2006). Su relevancia es 
indiscutible pero la mayoría adolecen de limitaciones que atentan de un modo u otro contra su generalizabilidad. Para empezar, muchos de los estudios realizados identifican los factores que predicen formas severas del cuadro clínico - casos en los que se busca ayuda terapéutica-, lo que obvia a una importante proporción de pacientes con manifestaciones más leves o sintomatología que no alcanzaría el umbral para el diagnóstico clínico. Estos estudios no permiten tener la certeza de que los factores predictores de las manifestaciones más graves sean los mismos que estarían presentes durante los periodos de pródromo o manifestación subclínica, de modo que carecen de valor a la hora de establecer un diagnóstico temprano. En otros casos, el impacto de los distintos factores de riesgo y protección se analiza de forma independiente, de modo que difícilmente sabremos si su relación está mediada por el efecto de otras variables (como se demuestra en nuestro estudio). Este análisis individualizado de los predictores de CS explica también que todavía no tengamos una imagen general del conjunto de factores biopsicosociales que explican su etiología. Para terminar, la mayoría de estudios exploran únicamente los factores que predicen la conducta sexual compulsiva masculina, obviando las particularidades de su manifestación en mujeres y sobre todo menospreciando el papel de esta variable a la hora de modular el impacto de otros factores.

Superar las limitaciones descritas y ofrecer una imagen nítida de los factores que intervienen en el inicio y mantenimiento del comportamiento sexual compulsivo constituye el último objetivo planteado para el presente trabajo. Así, una de sus principales aportaciones ha sido la de identificar un conjunto de variables cuya manifestación permite predecir el incremento (factores de riesgo) o la reducción (factores de protección) de la probabilidad de manifestar problemas subclínicos en el control de los impulsos sexuales. En este sentido, el modelo de regresión logística planteado en el epígrafe de resultados permite identificar 25 variables que por sí solas o en interacción con el sexo, clasifican correctamente al $87.8 \%$ de los participantes como control o subclínicos y que explican el $72.2 \%$ de su varianza.

De las variables sociodemográficas, el sexo y la edad desempeñan un papel protector a la hora de desarrollar problemas de compulsividad sexual. Concretamente, el riesgo de que una chica manifieste un perfil subclínico en el control de impulsos sexuales es un $10 \%$ inferior al de los chicos, lo que resulta coherente con los estudios que apuntan una ratio de al menos 2 a 1 en la prevalencia de este trastorno en hombres y mujeres (Kelly et al., 2009; Nair et al., 2013; Odlaug et al., 2013; Stavro et al., 2013). En todo caso, se debe tener presente que la selección de la muestra que participó en la segunda fase del estudio no fue aleatoria, de modo que en un contexto más ecológico es probable que el efecto del sexo (ser mujer) a la hora de prevenir el desarrollo de este cuadro clínico sea mucho mayor. Respecto a la edad, esta variable se 
relaciona inversamente con la probabilidad de manifestar problemas de CS, siendo los 21 y 27 años los momentos de mayor y menor riesgo de manifestar un perfil subclínico de CS (55\% y 20\%). Este hallazgo contradice lo que se esperaría teniendo en cuenta el curso clínico de esta patología. Según distintas investigaciones, la conducta sexual compulsiva se manifiesta por primera vez alrededor de los 18 años y a partir de ahí, gana gravedad progresivamente hasta manifestarse clínicamente en torno a los 30 (Kafka, 2007; Reid, Carpenter, et al., 2012). Si bien es cierto que durante ese periodo se pueden producir episodios de remisión espontánea, éstos suelen ir seguidos de recaídas de tanta o mayor gravedad de modo que eso no explica que los participantes de mayor edad experimenten un menor riesgo de ser clasificados como participantes subclínicos. Una explicación alternativa es que en realidad, los participantes del grupo subclínico no constituyen un grupo de especial riesgo en el desarrollo de problemas en el control de impulsos sexuales sino que más bien son jóvenes con una conducta sexual un tanto más activa. Esto explicaría que el riesgo de pertenecer a este grupo durante el periodo de entre los 18 y los 21 años (periodo caracterizado en muchos casos por una alta frecuencia sexual con múltiples parejas) sea mayor que entre los 25-27 años, momento en el que los jóvenes suelen estabilizar su comportamiento sexual en relaciones con parejas más estables.

En cuanto a comorbilidad psicopatológica, dos cuadros clínicos se dibujan como factores de riesgo en la manifestación de problemas de CS: el abuso y la dependencia del alcohol. En concreto, la probabilidad de que alguien que padece o ha padecido abuso del alcohol manifieste además problemas subclínicos en el control de sus impulsos sexuales es 9 veces mayor a la de alguien que no lo haya padecido $(O R=9.36)$ y 15 veces superior en el caso de la dependencia (OR=15.68). Esto concuerda con estudios que sostienen la existencia de procesos transdiagnósticos compartidos entre las adicciones tóxicas y comportamentales (Castro-Calvo, Ballester-Arnal, Gil-Llario, et al., 2016) y respalda la consideración nosológica de la conducta sexual compulsiva como adictivo (Rosenberg et al., 2014; Wines, 1997). En esta misma línea, muchos estudios acerca de las politoxicomanías en adicciones conductuales sostienen que el abuso y la dependencia del alcohol son dos de los cuadros clínicos más comórbidos con otras patologías como el juego patológico, la adicción al cibersexo o la adicción a Internet (Griffiths, Pontes, \& Kuss, 2015, 2016).

Por lo que se refiere al perfil de personalidad, 6 facetas del Five Factor Model resultan predictoras del riesgo de manifestar problemas en el control de impulsos sexuales. Tal y como suele suceder al analizar rasgos de personalidad, su papel como factor de riesgo o protección depende del extremo en el que la faceta se manifiesta (Widiger, 2001; Widiger \& Costa, 2012). Al contrario de lo que se esperaba, la vulnerabilidad (faceta de la dimensión de neuroticismo) 
resulta un factor protector frente al desarrollo de problemas de CS cuando se manifiesta en el extremo superior mientras que en el extremo contrario se consideraría un factor de riesgo. Así, el riesgo de ser clasificado con un posible problema de CS cuando se puntúa alto en esta faceta es del 33\% frente al 59\% cuando la puntuación es baja. Este hallazgo contradice los obtenidos en investigaciones previas (Reid, Garos, \& Carpenter, 2011; Reid, Stein, \& Carpenter, 2011) pero cobra sentido cuando se analiza detalladamente. La faceta de vulnerabilidad se relaciona con el afrontamiento de situaciones que generan malestar (sobre todo estrés, depresión o ansiedad); en estas situaciones, las personas más vulnerables se sienten incapaces de afrontar por sí solas la situación, de modo que no ponen en marcha estrategia alguna de afrontamiento (es decir, adoptan un estilo "laissez faire, laissez passer"). Al contrario, los pacientes compulsivos sí ponen en marcha estrategias para afrontar el malestar; su problema es que la estrategia que emplean (el uso del sexo como mecanismo de regulación emocional) es efectiva a corto plazo pero resulta disfuncional a medio y largo plazo -incrementa más si cabe su malestar inicial-.

Más coherente con las investigaciones precedentes son los resultados para la faceta impulsividad. En chicos, esta faceta ni aumenta ni disminuye el riesgo de manifestar problemas de CS pero sí lo haría en chicas: concretamente, la baja impulsividad reduce hasta el $24.3 \%$ el riesgo de que una chica desarrolle este cuadro clínico mientras que la alta impulsividad lo aumenta hasta el $66.3 \%$. Teniendo en cuenta que esta faceta se relaciona directamente con la capacidad para controlar impulsos y deseos apetitivos (Costa \& McCrae, 2002), los resultados se ajustan por completo a lo esperable en un cuadro clínico de este tipo.

En cuanto a la extraversión, dos de sus facetas (el gregarismo y las emociones positivas) modulan el riesgo de manifestar problemas de CS. Concretamente, el riesgo sería mucho mayor entre las personas más gregarias $(62.4 \%$ frente a $34.1 \%$ en personas con bajo gregarismo) y entre las que experimentan menos emociones positivas (71.9\% frente a $31 \%)$. Así pues, parece que los jóvenes más contenidos a la hora de experimentar emociones positivas (como alegría o amor) y que se sienten más desenvueltos durante sus interacciones sociales son los que tienen un riesgo mayor de desarrollar problemas en el control de impulsos sexuales, lo cual validaría tan sólo en parte los resultados obtenidos por Rettenberger et al. (2015) en cuanto a relación entre personalidad e hipersexualidad. Estos investigadores encontraron que extraversión y problemas en el control de impulsos sexuales se relacionaban inversamente, que sería el tipo de relación que en nuestro caso se ajusta para la faceta de emociones positivas; sin embargo, en nuestro estudio el gregarismo se relaciona de forma positiva con los problemas de CS. La principal diferencia entre esta investigación y la nuestra 
que explicaría al menos en parte estas contradicciones tiene que ver con el tipo de conducta sexual mayoritaria: mientras que Rettenberger et al. (2015) evaluaron a jóvenes cuya principal conducta sexual era la masturbación (un comportamiento sexual solitario), en el nuestro la gran mayoría dijeron haber mantenido relaciones sexuales con otras personas durante los últimos tres meses. Esto explicaría que en nuestro caso pero no en el suyo la alta extraversión se relacione con más problemas en el control de impulsos sexuales. Otra discrepancia con este estudio la encontramos al analizar la dimensión de personalidad de apertura a la experiencia, y más concretamente la faceta de estética. En nuestra investigación, el tener mayor sentido estético incrementaba el riesgo de ser clasificado en el grupo subclínico de CS (61.8\% frente a $10.9 \%$ de las personas con poco sentido estético) mientras que en el estudio de Rettenberger esta dimensión no mostró relación alguna con el control de impulsos sexuales.

La última faceta de personalidad que modula el riesgo de CS es la de sensibilidad (dimensión de amabilidad), que mostró una influencia inversa en función del sexo. En chicas, la probabilidad de manifestar problemas en el control de impulsos sexuales en las que puntuaban bajo en esta faceta es del $62 \%$ frente al $38 \%$ de las que puntúan alto, lo que se ajusta por completo a los trabajos que sugieren que las personas con menor amabilidad tienen mayor probabilidad de experimentar un comportamiento sexual compulsivo (Kastner \& Sellbom, 2012; Reid, Dhuffar, et al., 2012). Sin embargo, en chicos el factor que incrementa el riesgo $(60 \%)$ es precisamente puntuar alto en esta faceta. Teniendo en cuenta que la sensibilidad se relaciona con la preocupación por el bienestar ajeno, los hallazgos sugieren que los hombres más empáticos y las mujeres menos comprometidas con el bienestar de otras personas tienen un riesgo mayor de desarrollar el cuadro clínico de CS.

De las variables de comportamiento sexual general, tres mostraron capacidad predictiva sobre el riesgo de manifestar problemas en el control de impulsos sexuales. La primera de ellas (haber masturbado a una pareja) mostró un efecto independiente del sexo mientras que las dos restantes (tener pareja estable y haber realizado comportamientos sexuales alternativos a los mayoritarios) influían sobre el riesgo de CS sólo en mujeres. Más concretamente, el no haber masturbado a una pareja era factor protector a la hora de manifestar problemas subclínicos de CS (la probabilidad de ser clasificado como tal sin haber realizado esta conducta fue del $28 \%$ ). Si consideramos que la prevalencia de esta conducta sexual en la población estudiada es del $90 \%$, lo que estos resultados sugieren es que resulta muy poco probable que alguien que pertenezca a ese $10 \%$ de jóvenes que nunca ha realizado esta conducta sexual presente signos y síntomas de CS. En esta línea, muchos estudios demuestran que la realización de distintos tipos de prácticas sexuales no permite discriminar entre personas con y 
sin problemas sexuales porque en ambos casos, el patrón de actividades sexuales es similar (Stupiansky et al., 2009); sin embargo, el hecho de no haber realizado prácticas que sí son muy frecuentes en población general (como masturbar a una pareja) se consideraría un criterio para descartar la posible presencia de este tipo de problemas.

Respecto al efecto de las dos variables de comportamiento sexual general restantes, en mujeres el hecho de no mantener una pareja estable y haber realizado conductas sexuales alternativas a las mayoritarias aumentaría hasta el 61.5\%-75\% respectivamente el riesgo de manifestar problemas subclínicos de CS. Estos resultados se asemejan a los obtenidos en una investigación sobre el papel de tener o no pareja estable en la manifestación de la adicción al cibersexo (Ballester-Arnal, Castro-Calvo, Gil-Llario, \& Giménez-García, 2014) y refuerzan la hipótesis de que la falta de control de impulsos sexuales en ocasiones se traduce en una mayor tendencia a la búsqueda de materiales sexuales inusuales (Tripodi et al., 2015) y en la realización de actividades sexuales poco frecuentes (Grov et al., 2010).

Otro factor de riesgo en mujeres relacionado en este caso con el comportamiento sexual de riesgo es la percepción de autoeficacia en el uso del preservativo. En este sentido, las mujeres que se perciben muy autoeficaces tienen un riesgo en torno a un $13 \%$ mayor de manifestar un problema subclínico de CS que las que tienen un nivel de autoeficacia medio o bajo. Teniendo en cuenta que la autoeficacia percibida es uno de los principales predictores del uso del preservativo (Teng \& Mak, 2011) y que los pacientes con un perfil de comportamiento sexual compulsivo tienden al comportamiento sexual de riesgo (Parsons et al., 2012), esperábamos que nuestros resultados apuntasen justo en la dirección contraria. Sin embargo, este mismo vínculo positivo entre autoeficacia en el uso del preservativo y riesgo de CS podría explicar el perfil de bajo riesgo sexual documentado entre chicas del grupo subclínico en nuestro estudio (ver epígrafe 2.4.2.). Otro aspecto que explicaría este vínculo tiene que ver con la capacidad para hablar y discutir sobre temas sexuales. Uno de los principales ejes a la hora de evaluar la percepción de autoeficacia en el uso del preservativo es la capacidad para discutir abiertamente con una pareja acerca del uso del preservativo y convencerle caso que no quiera emplearlo; esto implica cierta capacidad para hablar y comunicar las preferencias e intereses sexuales, habilidad que debido al aprendizaje y exposición repetida a situaciones sexuales, se manifiesta sobre todo en personas con tendencias erotofílicas y compulsivas (Rye et al., 2015).

El comportamiento sexual online en general y más concretamente la puntuación en la escala de adicción al cibersexo es uno de los factores más íntimamente ligados a la manifestación subclínica del comportamiento sexual compulsivo. En este sentido, bajas puntuaciones en esta dimensión se considerarían un factor de protección mientras que en el extremo contrario, 
puntuaciones medias en adelante incrementarían el riesgo de manifestar problemas en el control de impulsos sexuales. Asimismo, el incremento del riesgo a medida que aumenta la severidad del consumo de cibersexo es cuantitativamente distinto en hombres y mujeres, siendo exponencialmente mayor entre estas últimas. Así, un chico que obtuviera una puntuación de 7 en la escala de adicción al cibersexo (rango de 0 a 25) tendría un riesgo inferior al $40 \%$ de manifestar problemas de CS, presentaría un riesgo del $60 \%$ caso que obtuviera una puntuación de 11 y alcanzaría el máximo riesgo (90\%) cuando obtuviera una puntuación de 22. En el caso de las chicas, tan sólo debería obtener una puntuación de 3 para alcanzar un $40 \%$ del riesgo, con tan sólo un punto más obtendría un riesgo del $60 \%$ y alcanzaría el $100 \%$ con una puntuación superior a 10 . Así, estos hallazgos no harían sino reafirmar la importancia de esta variable en la manifestación subclínica de la CS (Cooper et al., 2000).

Resultados similares se obtienen al analizar la influencia de la búsqueda de sensaciones sexuales sobre el riesgo de manifestar problemas de conducta sexual compulsiva. Esta variable desempeña un papel protector cuando se manifiesta más tímidamente, pierde influencia cuando se sitúa en un rango de valores intermedio y se dibuja como factor de riesgo cuando alcanza puntuaciones del rango superior de la escala de puntuaciones. Así, el riesgo de manifestar problemas subclínicos de comportamiento sexual compulsivo se situaba por debajo del $30 \%$ en puntuaciones $\leq 21$, en el $50 \%$ en puntuaciones intermedias de la escala y superaba el $70 \%$ en personas con manifestación clínica de esta dimensión. Estos resultados confirman la vinculación entre ambas variables encontrada en muchas otras investigaciones previas (Ballester-Arnal et al., 2013; Gullette \& Lyons, 2005).

Para terminar, dos variables clínicas (el nivel de ansiedad-estado y depresión) modulan el riesgo de manifestar problemas subclínicos de control de impulsos sexuales. La primera se consideraría factor protector cuando la persona muestra baja ansiedad-estado y de riesgo en el extremo opuesto; en el primer caso, la probabilidad de ser considerado subclínico se reduce hasta el $16 \%$ mientras que en el segundo, ésta asciende hasta el $79 \%$. El papel modulador de esta variable es equivalente en hombres y en mujeres. La relación entre riesgo de experimentar problemas de CS y nivel de depresión sería exactamente igual a la descrita en el caso de las chicas pero no en el de los chicos; así, las chicas con bajos niveles de depresión tienen un riesgo del $30 \%$ de mostrar un perfil compulsivo frente al $76 \%$ de las que se encontraban muy deprimidas. En este sentido, nuestros hallazgos confirmarían la importancia de comprender el comportamiento sexual compulsiva como estrategia de afrontamiento, compensación y regulación del malestar emocional (Schultz et al., 2014; Voon et al., 2014). 
A modo de resumen, en la siguiente figura se enumeran los factores que integran un perfil de alto y bajo riesgo de manifestar problemas subclínicos de CS en función del sexo (figura 24):

\section{Perfil de alto riesgo}

1. Historia de abuso y/o dependencia del alcohol.

2. Mayor necesidad de contacto social (gregarismo).

3. Más problemas en el control de impulsos (impulsividad).

4. Menos dificultades en el afrontamiento del estrés (vulnerabilidad)

5. Menor tendencia a experimentar emociones positivas.

6. Mayor aprecio por la belleza (sentido estético).

7. Menor preocupación por las necesidades ajenas (sensibilidad)

8. No mantener una relación estable.

9. Realizar actividades sexuales alternativas a las mayoritarias.

10. Mayor percepción de autoeficacia en el uso del preservativo.

11. Mayor severidad en el consumo de cibersexo.

12. Mayor tendencia a la búsqueda de sensaciones sexuales.

13. Mayores niveles de ansiedad-estado.

14. Mayores niveles de depresión.

\section{Perfil de bajo riesgo}

1. Mayor edad (24 años en adelante).

2. Sin historia de abuso y/o dependencia del alcohol.

3. Menor necesidad de contacto social (gregarismo).

4. Menos problemas en el control de impulsos (impulsividad).

5. Más dificultades en el afrontamiento del estrés (vulnerabilidad).

6. Más tendencia a experimentar emociones positivas.

7. Menor aprecio por la belleza (sentido estético).

8. Mayor preocupación por las necesidades ajenas (sensibilidad).

9. Que nunca han masturbado a una pareja.

10. Con pareja estable.

11. No realizan actividades sexuales alternativas a las mayoritarias.

12. Menor severidad en el consumo de cibersexo.

13. Menores niveles de ansiedad-estado.

14. Menores niveles de depresión.

\section{Perfil de alto riesgo}

1. Historia de abuso y/o dependencia del alcohol.

2. Mayor necesidad de contacto social (gregarismo).

3. Menos dificultades en el afrontamiento del estrés (vulnerabilidad)

4. Menor tendencia a experimentar emociones positivas.

5. Mayor aprecio por la belleza (sentido estético).

6. Más preocupación por las necesidades ajenas (sensibilidad)

7. Mayor severidad en el consumo de cibersexo.

8. Mayor tendencia a la búsqueda de sensaciones sexuales.

9. Mayores niveles de ansiedad-estado.

\section{Perfil de bajo riesgo}

1. Mayor edad (24 años en adelante).

2. Sin historia de abuso y/o dependencia del alcohol.

3. Menor necesidad de contacto social (gregarismo).

4. Más dificultades en el afrontamiento del estrés (vulnerabilidad)

5. Más tendencia a experimentar emociones positivas.

6. Menor aprecio por la belleza (sentido estético).

7. Menor preocupación por las necesidades ajenas (sensibilidad).

8. Que nunca han masturbado a una pareja.

9. Menor severidad en el consumo de cibersexo.

10. Menores niveles de ansiedad-estado.

Figura 24. Variables que definen los perfiles de alto y bajo riesgo en función del sexo.

Finalmente, se han propuestos tres modelos complementarios de ecuaciones estructurales que permiten mejorar la comprensión acerca del modo en el que estas y otras variables se configuran para explicar las distintas manifestaciones de la compulsividad sexual (figura 23). A través de estos modelos, se demuestra que las dimensiones de personalidad se relacionan con el nivel de CS a través de dos vías: una vía directa y otra indirecta. La vía directa comprendería las dimensiones de apertura a la experiencia (relacionada positivamente con la CS) y de amabilidad y responsabilidad (relacionadas de forma negativa). A excepción de la de apertura (que en los escasos estudios realizados nunca había resultado ser un predictor significativo del nivel de CS) (Rettenberger et al., 2015), las otras dos dimensiones se han relacionado sistemáticamente con el control de impulsos sexuales a través de múltiples investigaciones 
(Kastner \& Sellbom, 2012; Reid, Dhuffar, et al., 2012). La vía indirecta comprende las dimensiones de personalidad de neuroticismo y extraversión, que influirían sobre el nivel de CS potenciando tendencias psicopatológicas (ansiedad-estado y depresión) y facilitando la emergencia de distintos cuadros clínicos. Pinto et al. (2013) ya habían descrito esta vía indirecta en el caso de la dimensión de neuroticismo pero esta es la primera ocasión en la que se demuestra también para la dimensión de extraversión.

Siguiendo la explicación del modelo, tres indicadores psicopatológicos (el número total de trastornos diagnosticados a través de la SCID, la tendencia a experimentar altos niveles de ansiedad-estado y el nivel de depresión) mostraron una influencia positiva y directa sobre el nivel de CS. Esto apoya algunas teorías que sostienen que existen procesos transdiagnósticos que explican la comorbilidad entre los distintos cuadros psicopatológicos, que independientemente de su manifestación y sintomatología diferencial, son consecuencia de una vulnerabilidad común (Leventhal \& Zvolensky, 2015). De las 3 variables psicopatológicas, la que mostró mayor capacidad predictiva fue el número total de trastornos diagnosticados a través de la SCID, lo que demuestra la importancia de la comorbilidad psicopatológica en la comprensión de las manifestaciones de la CS (Kafka, 2007).

Finalmente, el nivel de búsqueda de sensaciones sexuales y la orientación sexual medida de forma dimensional resultaron también predictores positivos de la compulsividad sexual. Concretamente, el nivel de CS aumentaba a medida que la persona se situaba más cerca del extremo homosexual del continuo de orientación sexual. En ambos casos, los hallazgos van en la línea de los obtenidos en investigaciones precedentes (Ballester-Arnal et al., 2013; Parsons et al., 2012), si bien en este caso se demuestra además que la búsqueda de sensaciones sexuales es el principal predictor del nivel de CS. Concretamente, el conjunto de variables contempladas por el modelo de ecuaciones permiten predecir el $32 \%$ de la varianza de las puntuaciones de una medida continua de CS.

Asimismo, estos modelos permiten destacar la importancia del consumo de cibersexo y del tipo de prácticas sexuales no como predisponente en el desarrollo de la CS (que es como se contemplaban en el modelo de regresión) sino como una de sus manifestaciones. Así, el nivel de CS predecía el 19\% de la varianza de las puntuaciones en la escala de adicción al cibersexo y el $3 \%$ (un porcentaje discreto) en la variable que resultaba del sumatorio de los distintos tipos de prácticas sexuales realizadas. Que tengamos constancia, esta es la primera ocasión en la que se demuestra de forma empírica la naturaleza de las relaciones entre estas tres variables. 
Estos modelos demuestran también que el nivel de CS (estimado a partir de la unión de tres escalas que miden distintos síntomas básicos de la CS -capacidad de control de la conducta sexual, uso del sexo como regulador emocional e interferencia con distintos aspectos de la vida-) permite predecir el $35 \%$ de la varianza de la gravedad del cuadro clínico, el $13 \%$ de sus consecuencias conductuales (haber contraído una ITS, haberse sentido culpable o avergonzado de sí mismo, etc.) y un porcentaje muy pequeño (tan sólo el $1 \%$ ) de sus consecuencias cognitivas. De modo que en el cuadro clínico de CS, parece que la presencia de preocupaciones relacionadas con la conducta sexual (consecuencias cognitivas) queda en un segundo plano si se las compara con el hecho de haber sufrido distintos eventos negativos derivados de la conducta sexual (McBride et al., 2008). Este hallazgo restaría peso a las teorías que sostienen la presencia de distorsiones cognitivas que explicarían el inicio y la gravedad del cuadro clínico de compulsividad sexual (Pachankis et al., 2014; Paunović \& Hallberg, 2014).

Finalmente, el análisis de la invarianza estructural de los 3 modelos en función del sexo demuestra que la estructura de estas relaciones no es exactamente equivalente en hombres y en mujeres, evidencia que junto con el resto de las presentadas a lo largo de esta tesis doctoral, demuestra la importancia de seguir explorando en detalle el papel del género en la manifestación y severidad de la conducta sexual compulsiva.

Los hallazgos discutidos a lo largo del epígrafe corresponden al octavo y último objetivo de este estudio, para el que se planteaba la siguiente hipótesis: <<la combinación de algunas de las variables consideradas en este estudio permitirá predecir y clasificar correctamente a un alto porcentaje de participantes del grupo de puntuaciones subclínicas en CS (alta sensibilidad y especificidad), si bien el valor predictivo de las mismas variará notablemente. Así, variables como la búsqueda de sensaciones sexuales, la erotofilia o la adicción al cibersexo tendrán una importante capacidad predictiva sobre la variable dependiente, al menos superior a otras como el nivel de autoestima o depresión. Tampoco esperamos que todas las variables tengan una influencia directa sobre la CS, sino que algunas mostrarán una influencia mediada a través de otras variables $>$. Al respecto, los resultados expuestos permitirían confirmar parcialmente la hipótesis inicial así como ampliarla en distintos aspectos. 


\section{Limitaciones y líneas de investigación futuras}

Al reto que de por sí entraña cualquier proyecto científico, en la elaboración de la presente tesis se ha lidiado con otras dificultades. Una de ellas estaría relacionada con el propio objeto de estudio: aproximarse al análisis de la conducta sexual en una sociedad que enseña que el sexo pertenece al ámbito de lo privado y que todavía cuestiona su inclusión en el contexto educativo no es baladí, máxime cuando se pretende analizar la conducta sexual compulsiva. Afortunadamente, la actitud de los jóvenes hacia el sexo ha cambiado y cada vez son más los que comparten abiertamente su vivencia en este ámbito (López et al., 2011), lo que ha facilitado la realización de este trabajo.

No podemos obviar que este estudio adolece de limitaciones que podrían comprometer en cierta medida la generalizabilidad de sus hallazgos. Una de las más importantes tendría que ver con la tasa de mortalidad experimental. En el transcurso entre la primera y segunda fase del estudio, se produjo una mortandad experimental del 96\%. Entre otros, el tiempo entre evaluaciones (en algunos casos más de 6 meses), el inicio de un nuevo curso académico (y la movilidad estudiantil que supone) o que el e-mail de contacto se tomara por SPAM explicarían estas tasas. En cualquier caso, esto supuso modificar el procedimiento de reclutamiento para alcanzar el objetivo muestral propuesto inicialmente. En la planificación del nuevo procedimiento se prestó especial atención a captar el mismo perfil de participantes que completaron la primera fase del estudio (estudiantes de la Universitat Jaume I entre 18-27 años); sin embargo, no se debe obviar que los participantes reclutados online quizá no tengan el mismo perfil que los captados a través del método anterior (mesas informativas). En todo caso, creemos que el beneficio de este cambio de procedimiento en términos de objetivos muestrales supera los costes metodológicos que ha podido suponer.

Otra de las limitaciones de esta investigación tendría que ver con su generalizabilidad. La mayoría de participantes fueron jóvenes que se encontraban cursando estudios superiores en el momento de la evaluación; si bien la tasa de estudiantes universitarios en España supera holgadamente la media de la Unión Europea (Ministerio de Educación, 2016), hay indicios que nos llevan a pensar que tal vez no representan por completo al conjunto de población joven española, sobre todo en relación a su conducta sexual. En este sentido, las chicas y sobre todo los chicos del grupo control mostraron una conducta sexual más activa -en términos de frecuencia sexual, número de parejas, etc.- de lo que se esperaría de jóvenes en esa franja de edad. Así, algunas diferencias en el comportamiento sexual entre participantes control y subclínicos pudieron verse artefactualmente mitigadas por el proceso de muestreo empleado. 
En todo caso, lejos de menoscabar nuestros hallazgos, este hecho reforzaría la diferencia entre jóvenes con y sin problemas subclínicos de CS.

Otro aspecto -quizá el principal- que debe hacernos tomar con cautela los resultados derivados de esta investigación tiene que ver con el procedimiento empleado para clasificar a los participantes con y sin problemas subclínicos en el control de sus impulsos sexuales. A tal fin, se siguió el mismo procedimiento usado en investigaciones precedentes con resultados satisfactorios: clasificar como participantes subclínicos a aquellos que puntuaran por encima del percentil 80 en la escala SCS de compulsividad sexual (Cooper et al., 2000; Grov et al., 2010; Kelly et al., 2009). Se tomó la precaución de establecer puntos de corte diferenciales en hombres y mujeres, evitando que las diferencias en función del sexo en esta puntuación excluyeran a un número excesivo de mujeres. No obstante, este procedimiento supone juzgar un fenómeno clínico (presentar o no síntomas que sugieren la presencia de un cuadro clínico de compulsividad sexual por debajo del umbral diagnóstico) a partir de un criterio estadístico, lo cual no está exento de posibles críticas. El resultado es que probablemente, el grupo de participantes subclínicos constituía en realidad una amalgama de perfiles donde se agrupaban: pacientes con problemas en el control de sus impulsos sexuales con distinto grado de severidad, pacientes con una manifestación de estos síntomas por debajo del umbral diagnóstico (verdaderos "pacientes subclínicos") y jóvenes con una conducta sexual por encima de la media pero sin problema alguno en el control de sus impulsos sexuales.

Finalmente, es posible que uno de los instrumentos usados durante la evaluación haya sesgado en cierta medida los hallazgos obtenidos: concretamente, hablamos de la entrevista clínica SCID. Esta entrevista ofrece una guía manualizada que explora los criterios de distintas patologías del Eje I y II pero en última instancia, deja al criterio del evaluador el diagnóstico del cuadro clínico. Es más, el manual advierte que el principal predictor de su fiabilidad es la experiencia del entrevistador (First, Gibbon, et al., 1999), lo que plantea dos escenarios: 1) un mismo terapeuta no diagnosticará con igual precisión/criterio un cuadro clínico cuando comience a utilizar la entrevista y cuando cuente con mayor experiencia en su aplicación y 2) en función de su experiencia y juicio clínico, dos terapeutas no tienen por qué compartir umbrales diagnósticos equivalentes. En nuestro estudio, el segundo supuesto no sería una limitación ya que se tomó la cautela de que todas las entrevistas clínicas las realizara el mismo evaluador; sin embargo, es más que probable que después de 384 entrevistas, los umbrales diagnósticos del entrevistador cambiaran.

A pesar de estas limitaciones, consideramos que este estudio ha contribuido a arrojar luz sobre cuestiones que hasta el momento se habían explorado menos exhaustivamente en el ámbito 
del comportamiento sexual compulsivo. Que tengamos constancia, este es el primer estudio empírico realizado a gran escala en nuestro país, lo que nos sitúa como referencia a la hora de contrastar la validez de la aplicación a nuestro contexto de resultados empíricos obtenidos en otros países. Asimismo, este estudio se ha centrado en una población habitualmente ignorada en este tipo de estudios (población joven) y lo ha hecho desde una perspectiva de género, lo que suma validez a los resultados obtenidos y aumenta la aplicabilidad del amplio abanico de conocimientos de los que disponemos en la actualidad acerca del control de los impulsos sexuales. Finalmente, este trabajo ha permitido identificar el perfil de aquellos jóvenes con un riesgo mayor de desarrollar problemas en el control de impulsos sexuales, lo que permitirá diseñar programas de prevención ajustados a poblaciones concretas y donde se trabajen aquellas variables más íntimamente relacionadas con el desarrollo de este cuadro clínico.

Las limitaciones planteadas resultan un buen punto de partida a la hora de enumerar las líneas de investigación futuras en este ámbito. Para empezar, resultaría interesante ampliar el estudio para que además de jóvenes universitarios, abarcara otros sectores de población joven. Esto facilitaría la generalización de los hallazgos obtenidos y permitiría contrastar la hipótesis de si la prevalencia de este tipo de problemas es o no más alta entre jóvenes que cursan estudios superiores. Además, convendría ampliar la muestra para que incluyera también a colectivos de alto interés, como gais y lesbianas. Durante la primera fase de nuestro estudio, quedaba claro que la orientación sexual era, junto con el sexo, una de las variables sociodemográficas que más influía sobre la prevalencia y gravedad de la conducta sexual compulsiva. Sin embargo, obvias limitaciones muestrales derivadas de una prevalencia minoritaria de perfiles homosexuales y bisexuales en la población general impedían comprobar si esta misma variable modulaba también el perfil biopsicosocial de los jóvenes con una manifestación subclínica de la compulsividad sexual.

Teniendo en cuenta que una de las principales limitaciones de este estudio se deriva del método de cribado empleado para identificar a jóvenes con y sin problemas en el control de sus impulsos sexuales, sería recomendable que futuras investigaciones incluyeran escalas más exhaustivas en la identificación de estos perfiles. A tal fin, se podría emplear por ejemplo la Entrevista Clínica para el trastorno por Hipersexualidad (HD-DCI), que contrasta la presencia de los criterios propuestos para este trastorno a través de un conjunto de preguntas cerradas y ejemplos aclaratorios (Reid, Carpenter, et al., 2012). Esta entrevista permite diagnosticar esta condición clínica en la actualidad y a lo largo de la vida, identificar su curso clínico, especificar las conductas sexuales más problemáticas (masturbación, sexo con múltiples parejas esporádicas, pornografía...) y explorar la presencia de síntomas que no alcanzan el umbral 
diagnóstico (es decir, identificar manifestaciones subclínicas del cuadro clínico). Aprovechando la inclusión de nuevos instrumentos de evaluación, se podría plantear sustituir o complementar la entrevista clínica SCID con otros instrumentos de diagnóstico psicopatológico más objetivos, como la versión española del Symptom Checklist-90-R (Caparrós, Villar, Juan, \& Viñas, 2007) y del Inventario Clínico Multiaxial Millon-III (Cardenal \& Sánchez, 2007) para la evaluación de la comorbilidad en el Eje I y II respectivamente.

En última instancia, cabría plantearse la posibilidad de realizar estudios que hagan un seguimiento de la evolución y curso clínico de las personas con una manifestación subclínica de la CS. Con este objetivo, se podrían plantear dos tipos de estudios. El primero, más sencillo pero menos exhaustivo, consistiría en realizar un estudio transversal que incluyera una cohorte de edad más amplia (p.e., personas de entre 18-40 años). Esta metodología permitiría contrastar la prevalencia de los distintos perfiles de este cuadro clínico en distintos tramos de edad y comprobar si aumenta a medida que ésta avanza. El segundo, más sofisticado pero metodológica y estadísticamente más sólido, consistiría en realizar un seguimiento longitudinal de los jóvenes con un perfil subclínico de problemas en el control de sus impulsos sexuales y comprobar si los síntomas desaparecen, se mantienen o se agravan con el paso del tiempo. Esta sería la opción preferible ya que además de prestar especial atención a cómo distintos aspectos impactan sobre la evolución del cuadro clínico, permitiría establecer relaciones de causalidad entre las variables. Esta segunda opción fue por la que optamos cuando hace un tiempo, contactamos de nuevo con 200 de los 400 jóvenes que participaron en la segunda fase del estudio (50 por cada uno de los cuatro grupos clínicos) para realizar un seguimiento de su evolución un año después de la primera evaluación. Que tengamos constancia, este sería el primer intento de realizar una aproximación longitudinal (aunque limitada a un único año de seguimiento) al estudio de la evolución del control de impulsos sexuales. 

Capítulo 9. conclusiones 
A continuación, se exponen brevemente las principales conclusiones que se derivan de las 2 fases que integran el presente trabajo:

Primera fase: estimación de la prevalencia de CS en población joven española.

* Los jóvenes universitarios como colectivo no representan un grupo de riesgo en el desarrollo de problemas en el control de los impulsos sexuales.

* Los principales síntomas de CS tienen que ver con la incapacidad para regular voluntariamente la conducta sexual y con la interferencia derivada de esta incapacidad.

* La distribución asimétrica y leptocúrtica de las puntuaciones en el SCS, IH y SAST apoyaría una visión categórica del constructo de CS frente a su concepción más dimensional.

* La prevalencia de posibles casos clínicos de CS en jóvenes se situaría en el 3.1 y el 6.3\% en función del instrumento de evaluación empleado.

* La prevalencia y severidad de los problemas en el control de impulsos sexuales está modulada por el sexo y la orientación sexual pero no por la edad.

* Los hombres obtienen un mayor grado de severidad en todas las dimensiones de compulsividad sexual así como una mayor prevalencia de posibles casos clínicos (4.6\%-9.9\% en hombres frente al 1.9\%-3.6\% en mujeres).

* La severidad del cuadro clínico de CS es mayor en personas con una orientación sexual alternativa a la heterosexual (homosexuales y sobre todo bisexuales). En cuanto a la prevalencia, ésta se sitúa entre $21.2 \%-24 \%$ en bisexuales, $8.5 \%-10 \%$ en homosexuales y $2 \%-5.5 \%$ en heterosexuales.

* La severidad y la prevalencia del cuadro clínico de CS apenas varía en función de la edad, si bien se aprecia que los síntomas de pérdida del control sobre el propio comportamiento sexual disminuyen tímidamente a medida que ésta aumenta.

* Si en lugar de usar un punto de corte estático, la prevalencia de posibles casos de CS se estima a partir de criterios basados en la distribución muestral (p.e., puntuar 2 DT por encima de la media), entonces desaparecen las diferencias en función del sexo o la orientación sexual. Así, hombres y mujeres apenas difieren 2 décimas en la prevalencia de CS a partir de este criterio (5.9\% en chicos y $5.7 \%$ en chicas) mientras que la diferencia en función de la orientación sexual es del 1.6\% (5.8\% en bisexuales, $4.9 \%$ en homosexuales y $4.2 \%$ en heterosexuales). 
Segunda fase: identificación del perfil biopsicosocial de jóvenes con una manifestación subclínica de la CS.

* Los chicos y sobre todo las chicas con problemas subclínicos de CS tienden a mostrar una prevalencia mayor de la mayoría de los trastornos del Eje I y II.

* Los trastornos con mayores tasas de comorbilidad se agrupan en la categoría de trastornos relacionados con sustancias. En chicos, prácticamente el $50 \%$ cumplió criterios a lo largo de su vida para un diagnóstico de abuso de alcohol y el $11.5 \%$ para dependencia. En chicas, el $37.8 \%$ los cumplió para abuso del alcohol y el $16.5 \%$ para abuso o dependencia de marihuana

* Respecto a la comorbilidad con trastornos del estado del ánimo, el $24.1 \%$ de los chicos y el $28.6 \%$ de las chicas con problemas subclínicos de CS había padecido además un trastorno depresivo mayor comórbido.

* La prevalencia de algunos trastornos de ansiedad en participantes con problemas subclínicos de CS osciló entre el 10.3\%-26.5\% (fobia específica), 5.1\%-13.8\% (fobia social), 1.1\%-7.1\% (trastorno por estrés postraumático) y el 3.1\%-5.7\% (trastorno obsesivo-compulsivo).

* El 7.1\% de las participantes con problemas subclínicos de CS había padecido un trastorno dismórfico corporal frente al $1 \%$ de las chicas control.

* De los 384 participantes en la segunda fase, apenas cuatro cumplieron criterios para el diagnóstico de un trastorno parafílico. Los 4 (3 chicos y 1 chica) pertenecían al grupo de participantes subclínicos.

* En cuanto a la comorbilidad con trastornos de la personalidad, la prevalencia del trastorno obsesivocompulsivo y límite en participantes con problemas subclínicos de CS se situó entre el $4.6 \%-8.2 \%$ y el $2 \%-2.3 \%$ respectivamente.

* El perfil de personalidad de los chicos con problemas subclínicos de CS se caracterizó por una mayor tendencia al neuroticismo y una menor amabilidad y responsabilidad. Concretamente, estos jóvenes resultaron especialmente hostiles, depresivos y sobre todo impulsivos (alto neuroticismo), menos conciliadores, modestos, altruistas y francos (antagonismo) y menos competentes, con menos sentido del deber, menos disciplinados y con una baja capacidad para deliberar antes de tomar una decisión (baja responsabilidad).

* El perfil de personalidad de las chicas con problemas subclínicos de CS se caracterizó por un mayor neuroticismo y una menor amabilidad y responsabilidad, así como una tendencia hacia la apertura a la experiencia. Concretamente, estas chicas se caracterizaban por ser muy impulsivas (alto neuroticismo), mostrarse menos confiadas, francas, altruistas, conciliadoras y modestas (antagonismo) y por ser menos competentes, con menor sentido del deber, menos autodisciplinadas y con poca tendencia a deliberar (baja responsabildad). Asimismo, se mostraban más abiertas a la experiencia en general y en particular disponían de una imaginación más rica y creativa (fantasía), disfrutaban más con la belleza de las expresiones artísticas (estética), juzgaban desde una visión crítica los dogmas y convenciones sociales (valores), vivían más intensamente y se implicaban más en las experiencias emocionales (sentimientos) y disponían de una actitud más positiva hacia probar cosas nuevas y alejadas de lo usual (acciones). 
* El perfil de comportamiento sexual de los chicos con problemas subclínicos de CS se caracterizaba por altos niveles de actividad sexual, si bien apenas varió respecto a los participantes control. En concreto, la práctica totalidad (el $97.7 \%$ ) dijo haber mantenido actividad sexual de cualquier tipo con otra persona y el $81.6 \%$ haberlo hecho durante los últimos meses; la mitad tenía pareja estable (tiempo medio de relación de año y medio); un tercio dijo haber sido infiel y el número medio de parejas sexuales se situó en torno a las 13 personas; el 70\% afirmó mantener una frecuencia sexual mayor a 1 coito semanal y el 27\% mayor a 3 coitos; la mayoría se había masturbado, masturbado con una pareja o había practicado sexo oral (99\%, $94.3 \%$ y $92 \%$ respectivamente) y el porcentaje se reducía al $80 \%$ en coito vaginal, al $50 \%$ en coito anal y al $4.6 \%$ en otras prácticas sexuales.

* El perfil de comportamiento sexual de las chicas con problemas subclínicos de CS se caracterizaba nuevamente por altos niveles de actividad sexual que en este caso sí superaban holgadamente los observados en chicas control. Concretamente, el $100 \%$ de las chicas subclínicas había mantenido actividad sexual de cualquier tipo con otra persona y la mayoría (95\%) durante los últimos tres meses; el 69\% mantenía una pareja estable (duración media de 24 meses); menos de la mitad (el 40\%) afirmó haber sido infiel y el número de medio de parejas sexuales a lo largo de la vida fue de 6.31; el 73.7\% mantenía una frecuencia sexual mayor a 1 coito semanal; prácticamente todas dijeron haber realizado sexo vaginal, oral o masturbaciones mutuas (98\%, $95 \%$ y $94 \%$ respectivamente), el $85 \%$ dijo haberse masturbado y casi el $40 \%$ realizó sexo anal.

* La expresión de distintos aspectos relacionados con la orientación sexual en chicos con un posible problema subclínico de CS apenas varía en comparación con los chicos control: el 35.6\% dijeron haber deseado mantener relaciones sexuales con personas de su propio sexo, el $28 \%$ haberse excitado con estas fantasías y un cuarto haber mantenido relaciones; el 25\% informó de una orientación sexual alternativa a la heterosexual (3.4\% bisexual y el $20.7 \%$ homosexual); finalmente, el $65 \%$ se declaraba exclusivamente heterosexual.

* Las chicas con problemas subclínicos de CS mostraron un perfil mucho más abierto respecto a la orientación sexual que las control: más de la mitad dijo haber deseado mantener relaciones sexuales con personas de su mismo sexo y excitarse fantaseando con esta idea (el 52\% y 51\%), si bien sólo el 18\% habría llegado a mantener relaciones con otra chica. El $82 \%$ se declaraba heterosexual y el $18 \%$ restante se repartía entre homosexuales (5.3\%) y bisexuales (12.6\%). Cerca del $44 \%$ dijo ser exclusivamente heterosexual.

* El riesgo directo (asociado al uso inconsistente del preservativo) e indirecto (relacionado con a la severidad percibida del VIH y la autoeficacia en el uso del preservativo) de transmisión del VIH o de una ITS entre los chicos con un posible problema subclínico de CS fue bajo y equivalente al de los participantes control.

* Si bien nuevamente se consideró bajo, el riesgo de transmisión del VIH o de una ITS entre chicas con un problema subclínico de CS superaba clínica y estadísticamente el obtenido por las chicas control, sobre todo al considerar indicadores directos de riesgo. Concretamente, estas chicas mostraban mayor riesgo 
derivado del uso inconsistente del preservativo con una pareja estable, durante el sexo oral y sobre todo con una pareja esporádica.

* El comportamiento sexual online de los participantes con un problema subclínico de CS (chicas y sobre todo chicos) se caracterizaba por una altísima frecuencia de distintas actividades sexuales online y una preferencia por aquellas que no implicaban interacción con otros usuarios (como por ejemplo el visionado de pornografía) frente a otras como la participación en chats sexuales o el intercambio de mensajes eróticos. La prevalencia de ciertos signos y síntomas de consumo patológico entre estos participantes (p.e., experimentar malestar al no poder conectarse a Internet con fines sexuales o considerarse a ellos mismos adictos al cibersexo) era considerable, lo que se traducía en un incremento de la prevalencia de usuarios de riesgo y adictos al cibersexo así como una mayor gravedad de los cuadros clínicos.

* Los chicos y chicas con un posible problema subclínico de CS mostraban una gran tendencia a la búsqueda de sensaciones sexuales y a la erotofilia.

* El nivel de testosterona en saliva no guardaba relación con la manifestación de problemas subclínicos de CS.

* La severidad del cuadro clínico entre participantes con un problema subclínico de CS se situó a medio camino entre la que se observa habitualmente en pacientes sometidos a tratamiento por problemas en el control de impulsos sexuales y población general. En chicos, el nivel de severidad fue un tanto mayor. La severidad asociada al abuso o al ejercicio de la violencia durante la actividad sexual (sobre todo esta última) resultó inexistente.

* Los participantes subclínicos apenas experimentaban preocupación acerca de cómo su conducta sexual podría afectar en distintos ámbitos de su vida.

* La presencia de ciertas consecuencias manifiestas derivadas de la CS entre participantes con un problema subclínico resultan frecuentes: las más habituales corresponden a la categoría de consecuencias psicológicas (sentir vergüenza y/o culpabilidad por su conducta sexual desmedida), seguida de las médicas (haber infligido o sufrido dolor, contraído una ITS, etc.), espirituales (malestar espiritual derivado de la actividad sexual) y familiares (haber tenido problemas con la pareja o con amigos/ familiares). Apenas ninguno experimentó problemas económicos o legales.

* Los participantes con una manifestación más severa del cuadro clínico de CS experimentan más consecuencias cognitivas y sobre todo conductuales como consecuencia de su comportamiento sexual.

* Las personas con un mayor riesgo de desarrollar problemas subclínicos en el control de sus impulsos sexuales se caracterizan por sufrir o haber sufrido abuso o dependencia del alcohol, ser más gregarios e impulsivos (sólo en mujeres), ser menos vulnerables, ser más (hombres) o menos (mujeres) sensibles, tener menos emociones positivas y más sentido estético, no mantener una relación estable (mujeres), haber realizado actividades sexuales alternativas a las mayoritarias (mujeres), percibirse más autoeficaces en el uso del preservativo (mujeres), consumir más cibersexo, ser más buscadores de sensaciones sexuales y experimentar más ansiedad-estado y depresión (mujeres). 
* Las cinco dimensiones de personalidad del modelo de cinco factores (FFM) se relacionan con el nivel de CS a través de dos vías: una directa y otra indirecta. La vía directa comprendería las dimensiones de apertura a la experiencia (relacionada positivamente con la CS) y de amabilidad y responsabilidad (relacionadas de forma negativa). La vía indirecta comprende las dimensiones de personalidad de neuroticismo y extraversión, que influirían sobre el nivel de CS potenciando tendencias psicopatológicas (ansiedad-estado y depresión) y facilitando la emergencia de distintos cuadros clínicos.

* Tres indicadores de desviación psicopatológica (número total de trastornos diagnosticados a través de la SCID, tendencia a experimentar altos niveles de ansiedad-estado y nivel de depresión) mostraron una influencia positiva directa sobre el nivel de CS.

* El nivel de búsqueda de sensaciones sexuales y la orientación sexual medida de forma dimensional resultaron predictores positivos de la compulsividad sexual. Concretamente, el nivel de CS aumentaba a medida que la persona se situaba más cerca del extremo homosexual del continuo de orientación sexual.

* En lugar de como antecedentes, el consumo de cibersexo y el tipo de prácticas sexuales se consideran dos manifestaciones de la CS. Concretamente, esta variable permite predecir el 19\% de la varianza del consumo de cibersexo y el $3 \%$ de la realización de distintas prácticas sexuales.

* El nivel de CS predice el $35 \%$ de la varianza de la gravedad del cuadro clínico, el $13 \%$ de sus consecuencias conductuales y pequeño porcentaje de sus consecuencias cognitivas. 


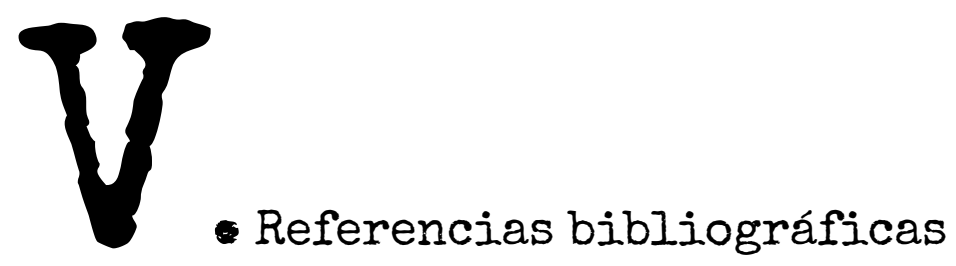


Adams, J., McClellan, J., Douglass, D., McCurry, C., \& Storck, M. (1995). Sexually inappropriate behaviors in seriously mentally ill children and adolescents. Child Abuse \& Neglect, 19(5), 555-68.

Adams, K. M., \& Robinson, D. W. (2001). Shame Reduction, Affect Regulation, and Sexual Boundary Development: Essential Building Blocks of Sexual Addiction Treatment. Sexual Addiction \& Compulsivity, 8(1), 23-44. http://doi.org/10.1080/10720160127559

Addiction Resource Guide. (n.d.). Addiction Resource Guide, Special populations: Sexual $\begin{array}{llll}\text { addiction. } & \text { Retrieved } & \text { 2015, } & \text { from }\end{array}$ http://www.addictionresourceguide.com/specpop/sexual.html

Ainsworth, M., Blehar, M., Eaters, E., \& Wall, S. (1978). Patterns of Attachment: a psychological study of the strange situation. Hillsdale, NJ: Lawrance Erlbaum.

Ainsworth, M., \& Wittig, B. A. (1972). Attachment and exploratory behaviour of one-year-olds in a strange situation. In B. M. Floss (Ed.), Determinants of Infant Behaviour (pp. 111136). London, UK: Wiley.

American Psychiatric Association. (2002). DSM-IV-TR: manual diagnóstico y estadístico de los trastornos mentales. Barcelona: Masson.

American Psychiatric Association. (2014). Manual diagnóstico y estadístico de los trastornos mentales ( $5^{a}$ edición). Washington, DC: American Psychiatric Publishing.

Anderson, R. A., Martin, C. W., Kung, A., Everington, D., Pun, T. C., Tan, K. C. B., ... Baird, D. T. (1999). 7?-Methyl-19-Nortestosterone (MENT) maintains sexual behavior and mood in hypogonadal men. Journal of Clinical Endocrinology and Metabolism, 84, 3556-3562.

Andrews, G., Anderson, T. M., Slade, T., \& Sunderland, M. (2008). Classification of anxiety and depressive disorders: problems and solutions. Depression and Anxiety, 25(4), 274-81. http://doi.org/10.1002/da.20489

Angst, J. (1998). Sexual problems in healthy and depressed persons. International Clinical Psychopharmacology, 13(6), 1-4.

Arata, C. M. (2000). From Child Victim to Adult Victim: A Model for Predicting Sexual Revictimization. Child Maltreatment, 5(1), 28-38.

Atwood, J. D., \& Gagnon, J. H. (1987). Masturbatory behavior in college youth. Journal of Sex Education \& Therapy, 13, 35-42.

Bagozzi, R. P., \& Yi, Y. (2011). Specification, evaluation, and interpretation of structural 
equation models. Journal of the Academy of Marketing Science, 40(1), 8-34. http://doi.org/10.1007/s11747-011-0278-x

Ballester-Arnal, R. (2013). Cuestionario de Evaluación de la Orientación del Deseo Sexual. Instrumento no publicado.

Ballester-Arnal, R., Castro-Calvo, J., Gil-Llario, M. D., \& Gil-Julia, B. (2016). Cybersex Addiction: A Study on Spanish College Students. Journal of Sex \& Marital Therapy, 1-19. http://doi.org/10.1080/0092623X.2016.1208700

Ballester-Arnal, R., Castro-Calvo, J., Gil-Llario, M. D., \& Giménez-García, C. (2014). Relationship status as an influence on cybersex activity: cybersex, youth, and steady partner. Journal of Sex \& Marital Therapy, 40(5), 444-56. http://doi.org/10.1080/0092623X.2013.772549

Ballester-Arnal, R., \& Gil-Llario, M. D. (2011). Infección por VIH y psicología: prevención e intervención. Madrid: Klinik.

Ballester-Arnal, R., Gil-Llario, M. D., Castro-Calvo, J., \& Giménez-García, C. (2016). HIV-Risk Index: development and validation of a brief risk index for Hispanic Young people. AIDS \& Behavior, 20(8), 1796-1807.

Ballester-Arnal, R., Gil-Llario, M. D., Gómez-Martínez, S., \& Gil-Julià, B. (2010). Psychometric properties of an instrument for assessing cyber-sex addiction. Psicothema, 22(4), 104853.

Ballester-Arnal, R., Giménez-García, C., Gil-Llario, M. D., \& Castro-Calvo, J. (2016). Cybersex in the "Net generation": Online sexual activities among Spanish adolescents. Computers in Human Behavior, 57, 261-266. http://doi.org/10.1016/j.chb.2015.12.036

Ballester-Arnal, R., Gómez-Martínez, S., Gil-Llario, M. D., \& Salmerón-Sánchez, P. (2013). Sexual compulsivity scale: adaptation and validation in the spanish population. Journal of Sex \& Marital Therapy, 39(6), 526-40. http://doi.org/10.1080/0092623X.2012.665816

Bancroft, J. (1999). Central inhibition of sexual response in the male: a theoretical perspective. Neuroscience and Biobehavioral Reviews, 23(6), 763-84.

Bancroft, J. (2005). The endocrinology of sexual arousal. Journal of Endocrinology, 186, 411427. http://doi.org/10.1677/joe.1.06233

Bancroft, J. (2009). Human sexuality and its problems (3rd editio). New York, NY: Elsevier.

Bancroft, J., Graham, C. A., Janssen, E., \& Sanders, S. A. (2009). The dual control model: current status and future directions. Journal of Sex Research, 46(2-3), 121-42. 


\section{http://doi.org/10.1080/00224490902747222}

Bancroft, J., \& Janssen, E. (2000). The dual control model of male sexual response: a theoretical approach to centrally mediated erectile dysfunction. Neuroscience and Biobehavioral Reviews, 24(5), 571-9.

Bancroft, J., Janssen, E., Strong, D., Carnes, L., Vukadinovic, Z., \& Long, J. S. (2003). The relation between mood and sexuality in heterosexual men. Archives of Sexual Behavior, 32(3), 217-230.

Bancroft, J., Janssen, E., Strong, D., \& Vukadinovic, Z. (2003). The relation between mood and sexuality in gay men. Archives of Sexual Behavior, 32(3), 231-242.

Bancroft, J., Tennent, G., Loucas, K., \& Cass, J. (1974). Thecontrol of deviant sexual behaviour by drugs: 1 . Behavioural changes following oestrogens and anti-androgens. British Journal of Psychiatry, 125, 310-315.

Bancroft, J., \& Vukadinovic, Z. (2004). Sexual addiction, sexual compulsivity, sexual impulsivity, or what? Toward a theoretical model. Journal of Sex Research, 41(3), 225-34. http://doi.org/10.1080/00224490409552230

Barth, R. J., \& Kinder, B. N. (1987). The mislabeling of sexual impulsivity. Journal of Sex \& Marital Therapy, 13(1), 15-23. http://doi.org/10.1080/00926238708403875

Basson, R. (2007). Sexual Desire / Arousal Disorders in Women. In S. R. Leiblum (Ed.), Principles And Practice of Sex Therapy (pp. 25-53). New York, NY: The Guilford Press.

Baum, M. D., \& Fishman, J. M. (1994). AIDS, sexual compulsivity, and gay men: A group treatment approach. In S. A. Cadwell \& R. A. Burnham (Eds.), Therapists on the front line: Psychotherapy with gay men in the age of AIDS (pp. 255-274). Washington, DC: American Psychiatric Publishing.

Beaglehole, R., Bonita, R., \& Kjellström, T. (2003). Epidemiología básica (2 ${ }^{\mathrm{a}}$ Edición). Organización Panamericana de la Salud.

Beck, A. T. (1967). Depression: clinical, experimental, and theoretical aspects. London: Staples press.

Beck, A. T. (1979). Cognitive Therapy of Depression. New York, NY: The Guilford Press.

Beck, A. T., Steer, R. A., \& Brown, G. K. (2011). BDI-II, Inventario de Depresión de Beck - II, Adaptación Española. Madrid: Pearson.

Beck, K. H., Thombs, D. L., Mahoney, C. A., \& Fingar, K. M. (1995). Social context and sensation 
seeking: gender differences in college student drinking motivations. The International Journal of the Addictions, 30(9), 1101-15.

Becker, M. A., \& Byrne, D. (1985). Self-regulated exposure to erotica, recall errors, and subjective reactions as a function of erotophobia and Type A coronary-prone behavior. Journal of Personality and Social Psychology, 48(3), 760-767. http://doi.org/10.1037/0022-3514.48.3.760

Benotsch, E. G., Kalichman, S. C., \& Kelly, J. A. (1999). Sexual compulsivity and substance use in HIV-seropositive men who have sex with men: prevalence and predictors of high-risk behaviors. Addictive Behaviors, 24(6), 857-68.

Bentler, P. M. (2006). EQS structural equations program manual. Encino, CA: Multivariate Software.

Berke, J. D., \& Hyman, S. E. (2000). Addiction, dopamine, and the review molecular mechanisms of memory. Neuron, $25,515-532$.

Berlin, F. (2008). Basic science and neurobiological research: potential relevance to sexual compulsivity. Psychiatric Clinics of North America, 31(4), 523-642.

Berlin, \& Hollander, E. (2008). Understanding the Differences Between Impulsivity and Compulsivity. Psychiatric Times, 25(8), 61.

Bjørkly, S. (2002). Psychotic symptoms and violence toward others - a literature review of some preliminary findings. Aggression and Violent Behavior, 7(6), 617-631. http://doi.org/10.1016/S1359-1789(01)00049-0

Bjornsson, A. S., Didie, E. R., \& Phillips, K. A. (2010). Body dysmorphic disorder. Dialogues in Clinical Neuroscience, 12(2), 221-32.

Black, D., Kehrberg, L., Flumerfelt, D., \& Scholosser, S. (1997). Characteristics of 36 subjects reporting compulsive sexual behavior. American Journal of Psychiatry, 152(2), 243-249.

Blankenship, R., \& Laarser, M. (2004). Sexual Addiction and ADHD: Is There A Connection? Sexual Addiction $\quad \& \quad$ Compulsivity, http://doi.org/10.1080/10720160490458184

Blashfield, R. K., Keeley, J. W., \& Burgess, D. R. (2008). Classification. In P. H. Blaney \& T. Millon (Eds.), Oxford Textbook of Psychopathology (pp. 3-28). New York, NY: Oxford University Press.

Blum, K., Braverman, E. R., Holder, J. M., Lubar, J., Monastra, V. J., Miller, D., ... Comings, D. E. 
(2000). Reward deficiency syndrome: A biogenetic model for the diagnosis and treatment of impulsive, addictive, and compulsive behaviors. Journal of Psychoactive Drugs, 32(suppl.), 1-12.

Bogaert, A. F., \& Sadava, S. (2002). Adult attachment and sexual behaviour. Personal Relationships, 9, 191-204.

Borgermans, L., Vrijhoef, B., Vandevoorde, J., De Maeseneer, J., Vansintejan, J., \& Devroey, D. (2013). Relevance of Hypersexual Disorder to Family Medicine and Primary Care as a Complex Multidimensional Chronic Disease Construct. International Journal of Family Medicine, 1, 1-5. http://doi.org/10.1155/2013/519265

Bostwick, J. M., Hecksel, K. A., Stevens, S. R., Bower, J. H., \& Ahlskog, J. E. (2009). Frequency of new-onset pathologic compulsive gambling or hypersexuality after drug treatment of idiopathic Parkinson disease. Mayo Clinic Proceedings, 84(4), 310-6. http://doi.org/10.1016/S0025-6196(11)60538-7

Bowlby, J. (1969). Attachment and loss: Vol.1. Attachment. New York, NY: Basic Books.

Bowlby, J. (1973). Attachment and loss: Vol. 2. Separation. New York, NY: Basic Books.

Bowlby, J. (1980). Attachment and loss: Vol. 3. Loss. New York, NY: Basic Books.

Boyer, C. B., Greenberg, L., Korelitz, J., Harper, G. W., Stewart-Campbell, R., Straub, D., ... Interventions, T. A. M. T. N. for H. (2016). Sexual Partner Characteristics, Relationship Type, and HIV Risk Among a Community Venue-Based Sample of Urban Adolescent and Young Adult Men Who Have Sex With Men. Youth \& Society, 20, 1-12. http://doi.org/10.1177/0044118X16669259

Bradford, J. M. (1999). The paraphilias, obsessive compulsive spectrum disorder, and the treatment of sexually deviant behaviour. The Psychiatric Quarterly, 70(3), 209-19.

Briken, P., Habermann, N., Berner, W., \& Hill, A. (2007). Diagnosis and treatment of sexual addiction: A survey among German sex therapists. Sexual Addiction \& Compulsivity, 13, 131-143.

Briken, P., Habermann, N., Kafka, M. P., Berner, W., \& Hill, A. (2006). The paraphilia-related disorders: An investigation of the relevance of the concept in sexual murderers. Journal of Forensic Sciences, 51(3), 683-688. http://doi.org/10.1111/j.1556-4029.2006.00105.x

Brotto, L. A. (2010). The DSM diagnostic criteria for hypoactive sexual desire disorder in women. Archives of Sexual Behavior, 39(2), 221-239. http://doi.org/10.1007/s10508- 
009-9543-1

Brotto, L. A., Heiman, J. R., \& Tolman, D. L. (2009). Narratives of desire in mid-age women with and without arousal difficulties. Journal of Sex Research, 46(5), 387-98. http://doi.org/10.1080/00224490902792624

Brown, A. R., Dargis, M. A., Mattern, A. C., Tsonis, M. A., \& Newman, J. P. (2015). Elevated Psychopathy Scores Among Mixed Sexual Offenders: Replication and Extension. Criminal Justice and Behavior, 0093854815575389-. http://doi.org/10.1177/0093854815575389

Byrne, D., Fisher, J. D., Lamberth, J., \& Mitchell, H. E. (1974). Evaluations of erotica: facts or feelings? Journal of Personality and Social Psychology, 29(1), 111-6.

Caldwell, J. D. (2002). A sexual arousability model involving steroid effects at the plasma membrane. Neuroscience and Biobehavioral Reviews, 26, 13-20.

Campbell, M. M., \& Stein, D. J. (2014). Hypersexual disorder in general practice. South Africa Medical Journal, 104(6), 9-10. http://doi.org/10.7196/SAMJ.8409

Campbell, W., \& Rohrbaugh, R. (2006). The Biopsychosocial Formulation Manual: A Guide for Mental Health Professionals. New York, NY: Routledge.

Cantor, J. M., Klein, C., Lykins, A., Rullo, J. E., Thaler, L., \& Walling, B. R. (2013). A treatmentoriented typology of self-identified hypersexuality referrals. Archives of Sexual Behavior, 42, 883-893. http://doi.org/10.1007/s10508-013-0085-1

Caparrós, B., Villar, E., Juan, J., \& Viñas, F. (2007). Symptom Check-List-90-R: fiabilidad, datos normativos y estructura factorial en estudiantes universitarios. International Journal of Clinical and Health Psychology, 7(3), 781-794.

Cardenal, V., \& Sánchez, M. P. (2007). Adaptación y baremación al español del Inventario Clínico Multiaxial de Millon-III (MCMI-III). Madrid: TEA Ediciones.

Cardo, E., \& Servera, M. (2008). Trastorno por déficit de atención/hiperactividad: estado de la cuestión y futuras líneas de investigación. Revista de Neurología, 46(6), 365-372.

Carey, J. W., Mejia, R., Bingham, T., Ciesielski, C., Gelaude, D., \& Herbst, J. H. (2008). Drug Use, High-Risk Sex Behaviors, and Increased Risk for Recent HIV Infection among Men who Have Sex with Men in Chicago and Los Angeles. AIDS and Behavior, (e-published ahead of print).

Carini, C., Granata, A. R. M., Bancroft, J., \& Marrama, P. (1995). The effects of testosterone replacement on nocturnal penile tumescence and rigidity and erectile response to visual 
erotic stimuli in hypogonadal men. Psychoneuroendocrinology, 20, 743-753.

Carnes, P. (1983). Out of the Shadows: Understanding Sexual Addiction. Minnesota: CompCare Publishers.

Carnes, P. (1991). Don't Call it Love: Recovery From Sexual Addiction. New York, NY: Bantam Books.

Carnes, P., Delmonico, D., \& Griffin, E. (2007). In the Shadows of the Net: Breaking Free of Compulsive Online Sexual Behavior. Minnesota: Hazelden.

Carnes, P., Green, B., \& Carnes, S. (2010). The Same Yet Different: Refocusing the Sexual Addiction Screening Test (SAST) to Reflect Orientation and Gender. Sexual Addiction \& Compulsivity, 17(1), 7-30.

Carnes, P., Green, B., Merlo, L., Polles, A., Carnes, S., \& Gold, M. (2012). PATHOS: A brief screening application for assessing sexual addiction. Journal of Addiction Medicine, 6(1), 29-34. http://doi.org/10.1097/ADM.0b013e3182251a28.PATHOS

Carnes, P., Murray, R. E., \& Charpentier, L. (2005). Bargains with chaos: Sex addicts and addiction interaction disorder. Sexual Addiction \& Compulsivity, 12(2-3), 79-120.

Carpenter, B. N., Reid, R. C., Garos, S., \& Najavits, L. M. (2013). Personality Disorder Comorbidity in Treatment-Seeking Men with Hypersexual Disorder. Sexual Addiction \& Compulsivity, 20, 79-90. http://doi.org/10.1080/10720162.2013.772873

Carvalho, J., Guerra, L., Neves, S., \& Nobre, P. J. (2014). Psychopathological Predictors Characterizing Sexual Compulsivity in a Nonclinical Sample of Women. Journal of Sex \& Marital Therapy, O(0), 1-14. http://doi.org/10.1080/0092623X.2014.920755

Cassidy, F., Murry, E., Forest, K., \& Carroll, B. J. (1998). Signs and symptoms of mania in pure and mixed episodes. Journal of Affective Disorders, 50(2-3), 187-201.

Castro-Calvo, J., Ballester-Arnal, R., \& Gil-Llario, M. D. (2015). Compulsividad Sexual: Convergencia y prevalencia entre medidas. Agora de Salut, 2, 205-213.

Castro-Calvo, J., Ballester-Arnal, R., \& Gil-Llario, M. D. (2017). Validación preliminar del Inventario de Hipersexualidad en jóvenes. Àgora de Salut.

Castro-Calvo, J., Ballester-Arnal, R., Gil-Llario, M. D., \& Giménez-García, C. (2016). Common etiological pathways between toxic substance use, Internet and cybersex addiction: The role of expectancies and antisocial deviance proneness. Computers in Human Behavior, 63, 383-391. http://doi.org/10.1016/j.chb.2016.05.066 
Castro-Calvo, J., Ballester-Arnal, R., Giménez-García, C., Salmerón-Sánchez, P., Ruiz-Palomino, E., \& Gil-Julià, B. (2016). Innovación docente en la formación en salud sexual: aplicación a una asignatura del grado en psicología. In J. L. Castejón (Ed.), Psicología y Educación: Presente y Futuro (pp. 523-531). Alicante: Ediciones Acipe.

Castro-Calvo, J., Ballester-Arnal, R., Salmerón-Sánchez, P., \& Gil-Llario, M. D. (2016). Traducción y validación preliminar del cuestionario de adicción al sexo en jóvenes. International Journal of Developmental and Educational Psychology, 2(1), 319-328.

Castro-Calvo, J., Gómez-Martínez, S., Gil-Julià, B., Giménez-García, C., \& Ballester-Arnal, R. (2015). Jóvenes y sexo en la red: reacción ante la exposición involuntaria a material $\begin{array}{llll}\text { sexual. } \quad \text { de } & \text { Salut, } 187-198 .\end{array}$ http://doi.org/http://dx.doi.org/10.6035/AgoraSalut.2015.1.14

Centers for Disease Control Prevention. (2008). HIV prevalence estimates (United States, 2006). Morbidity and Mortality Weekly Report, 57, 1073-1076.

Centro de Investigaciones Sociológicas. (2008). Actitudes y prácticas sexuales (estudio CIS $\left.n^{\circ} 2738\right)$. Madrid: Centro de Investigaciones Sociológicas.

Centro Nacional de Epidemiología. (2014). Vigilancia epidemiológica del VIH/SIDA en España: actualización 30 de Junio de 2014. Retrieved May 20, 2015, from http://www.msssi.gob.es/ciudadanos/enfLesiones/enfTransmisibles/sida/vigilancia/Infor meVIHSida_Junio2014.pdf

Centro Nacional de Epidemiología. (2015). Vigilancia epidemiológica del VIH/SIDA en España: actualización 30 de Junio de 2015.

Cespedes, C., Chahin, S., \& Coll, M. (2009). Trastornos de la diferenciación sexual: enfoque práctico. CCAP, $7(2), 45-51$.

Chaney, M. P., \& Burns, C. M. (2015). Examining Coming Out, Loneliness, and Self-esteem as Predictors of Sexual Compulsivity in Gay and Bisexual Men. Sexual Addiction \& Compulsivity, 22, 71-88. http://doi.org/10.1080/10720162.2014.1001543

Charnigo, R., Noar, S. M., Garnett, C., Crosby, R., Palmgreen, P., \& Zimmerman, R. S. (2013). Sensation seeking and impulsivity: combined associations with risky sexual behavior in a large sample of young adults. Journal of Sex Research, 50(5), 480-8. http://doi.org/10.1080/00224499.2011.652264

Choza, J. (1991). Antropología de la sexualidad. Madrid: Ediciones Rialp. 
Claes, L., Nederkoorn, C., Vandereycken, W., Guerrieri, R., \& Vertommen, H. (2006). Impulsiveness and lack of inhibitory control in eating disorders. Eating Behaviors, 7(3), 196-203. http://doi.org/10.1016/j.eatbeh.2006.05.001

Clayton, A. H., Segraves, R. T., Leiblum, S., Basson, R., Pyke, R., Cotton, D., ... Wunderlich, G. R. (2006). Reliability and validity of the Sexual Interest and Desire Inventory-Female (SIDI-F), a scale designed to measure severity of female hypoactive sexual desire disorder. Journal of Sex \& Marital Therapy, 32(2), 115-35. http://doi.org/10.1080/00926230500442300

Cochran, S. D., Ackerman, D., Mays, V. M., \& Ross, M. W. (2004). Prevalence of non-medical drug use and dependence among homosexually active men and women in the U.S. population. Addiction, 99, 989-998.

Codispoti, V. (2008). Pharmacology of sexuality compulsive behavior. Clinics in North America, 31(4), 671-679.

Cohen, J. (1988). Statistical Power Analysis for the Behavioral Sciences. L. Erlbaum Associates.

Coid, J., Yang, M., Tyrer, P., Roberts, A., \& Ullrich, S. (2006). Prevalence and correlates of personality disorder in Great Britain. The British Journal of Psychiatry, 188, 423-31. http://doi.org/10.1192/bjp.188.5.423

Coleman-Kennedy, C., \& Pendley, A. (2002). Assessment and diagnosis of sexual addiction. Journal of the American Psychiatric Nurses Association, 8(5), 143-151. http://doi.org/10.1067/mpn.2002.128827

Coleman, E. (1987). Sexual compulsivity: Definition, etiology, and treatment considerations. Journal of Chemical Dependency Treatment, 1, 189-204.

Coleman, E. (1990). The obsessive-compulsive model for describing compulsive sexual behavior. American Journal of Preventive Psychiatry and Neurology, 2, 9-14.

Coleman, E. (1991). Compulsive Sexual Behavior. Journal of Psychology \& Human Sexuality, $4(2), 37-52$.

Coleman, E. (1992). Is Your Patient Suffering from Compulsive Sexual Behavior? Psychiatric Annals, 22(6), 320-325. http://doi.org/10.3928/0048-5713-19920601-09

Coleman, E. (1995). Treatment of Compulsive Sexual Behavior. In R. Rosen \& S. Leiblum (Eds.), Case Studies in Sex Therapy (pp. 333-349). New York, NY: The Guilford Press.

Coleman, E. (2003). Compulsive sexual behavior: what to call it, how to treat it?: SIECUS Report, 31(5), 12-15. 
Coleman, E., Miner, M. H., Ohlerking, F., \& Raymond, N. (2001). Compulsive sexual behavior inventory: a preliminary study of reliability and validity. Journal of Sex \& Marital Therapy, 27(4), 325-32. http://doi.org/10.1080/009262301317081070

Coleman, E., Raymond, N., \& McBean, A. (2003). Assessment and treatment of compulsive sexual behavior. Minnesota Medicine, 86(7), 42-7.

Cooper, A., Delmonico, D. L., \& Burg, R. (2000). Cybersex users, abusers, and compulsives: New findings and implications. Sexual Addiction \& Compulsivity, 7(1-2), 5-29. http://doi.org/10.1080/10720160008400205

Cooper, Taylor, M. J., Cooper, Z., \& Fairbum, C. G. (1987). The development and validation of the body shape questionnaire. International Journal of Eating Disorders, 6(4), 485-494. http://doi.org/10.1002/1098-108X(198707)6:4<485::AID-EAT2260060405>3.0.CO;2-O

Copen, C. E., Chandra, A., \& Febo-Vazquez, I. (2016). Sexual Behavior, Sexual Attraction, and Sexual Orientation Among Adults Aged 18-44 in the United States: Data From the 20112013 National Survey of Family Growth. National Health Statistics Reports, (88), 1-14.

Costa, P. T., \& McCrae, R. R. (2002). Inventario de personalidad NEO revisado (NEO PI-R) e Inventario NEO reducido de cinco factores (NEO FFI). Manual profesional. Madrid: TEA Ediciones.

Courtois, C. (1979). Characteristics of a volunteer sample of adult women who experienced incest in child-hood and adolescence. Dissertation Abstracts International, 40A, 3194-A.

Craft, A. J. (2012). Love 2.0: a quantitative exploration of sex and relationships in the virtual world Second Life. Archives of Sexual Behavior, 41(4), 939-47. http://doi.org/10.1007/s10508-012-9933-7

Crockenberg, S. B., \& Soby, B. A. (1989). Selfesteem and teenage pregnancy. In A. M. Mecca, N. Smelser, \& J. Vasconcellos (Eds.), The Social Importance of Self Esteem (p. 127-155.). Berkeley, CA: Univesity of California Press.

Dailey, S. F., Gill, C. S., Karl, S. L., \& Barrio-Minton, C. A. (2014). Historical Underpinnings, Structural Alterations and Philosophical Changes: Counseling Practice Implications of the DSM-5. The Professional Counselor, 4(3), 166-178.

Dalby, J. T. (1988). Is Telephone Scatologia a Variant of Exhibitionism? International Journal of Offender Therapy and Comparative Criminology, 32(1), 45-49. http://doi.org/10.1177/0306624X8803200106 
Daneback, K., Månsson, S.-A., Ross, M. W., \& Markham, C. M. (2012). The Internet as a source of information about sexuality. Sex Education, 12(5), 583-598. http://doi.org/10.1080/14681811.2011.627739

De Cock, K. M., Jaffe, H. W., \& Curran, J. W. (2012). The evolving epidemiology of HIV/AIDS. AIDS (London, England), 26(10), 1205-13. http://doi.org/10.1097/QAD.0b013e328354622a

Del Rio-Olvera, F., López-Vega, D., \& Santamaría, F. C. (2013). Adaptación del cuestionario Sexual Opinion Survey: Encuesta Revisada de Opinión Sexual. Revista Internacional de Andrología, 11(1), 9-16. http://doi.org/10.1016/j.androl.2012.09.003

DelBello, M. P., Hanseman, D., Adler, C. M., Fleck, D. E., \& Strakowski, S. M. (2007). Twelvemonth outcome of adolescents with bipolar disorder following first hospitalization for a manic or mixed episode. The American Journal of Psychiatry, 164(4), 582-90. http://doi.org/10.1176/appi.ajp.164.4.582

Dennerstein, L., Burrows, G. D., Wood, C., \& Hyman, G. (1980). Hormones and sexuality: effect of estrogen and progestogen. Obstetrics and Gynecology, 56, 199-201.

Derbyshire, K. L., \& Grant, J. E. (2015). Compulsive sexual behavior: A review of the literature. Journal of Behavioral Addictions, 4(2), 37-47. http://doi.org/10.1556/2006.4.2015.003

DeYoung, M. (1982). The sexual victimization of children. Jefferson, NC: McFarland.

Dhuffar, M. K., \& Griffiths, M. D. (2016). Barriers to female sex addiction treatment in the UK. Journal of Behavioral Addictions, 1-6. http://doi.org/10.1556/2006.5.2016.072

Dodge, B., Reece, M., Cole, S. L., \& Sandfort, T. G. (2004). Sexual compulsivity among heterosexual college students. Journal of Sex Research, 41(4), 343-350. http://doi.org/10.1080/00224490409552241.Sexual

Döring, N., Daneback, K., Shaughnessy, K., Grov, C., \& Byers, E. S. (2015). Online Sexual Activity Experiences Among College Students: A Four-Country Comparison. Archives of Sexual Behavior, 1-12. http://doi.org/10.1007/s10508-015-0656-4

Earle, R., \& Crow, G. (1998). Lonely all the time: Recognizing, un- derstanding, and overcoming sex addiction of addicts and co- dependents. New York, NY: Pocket Books.

Edger, K. (2010). Evangelicalsim, sexual morality and sexual addiction: opposing views and continued conflict. Journal of Religion and Health, N.D., 1-15.

Edwards, W. (2012). Applying a Sexual Health Model to the Assessment and Treatment of 
Internet Sexual Compulsivity. Sexual Addiction \& Compulsivity, 19(October 2014), 3-15. http://doi.org/10.1080/10720162.2012.660433

El-Gabalawi, F., \& Johnson, R. A. (2007). Hypersexuality in inpatient children and adolescents: recognition, differential diagnosis, and evaluation. CNS Spectrums, 12(11), 821-7.

Elliott, R. (2003). Executive functions and their disorders. British Medical Bulletin, 65(1), 49-59. http://doi.org/10.1093/bmb/65.1.49

Ellis, P. D. (2010). The Essential Guide to Effect Sizes: Statistical Power, Meta-Analysis, and the Interpretation of Research Results. Cambridge, MA: Cambridge University Press. http://doi.org/10.1017/cbo9780511761676

Emler, N. (2001). Self-esteem: The costs and causes of low self-worth. New York, NY.

Engel, G. (1977). The Need for a New Medical Model: A Challenge for Biomedicine. Science, 196(4286), 129-139.

Eshbaugh, E. M., \& Gute, G. (2008). Hookups and Sexual Regret Among College Women. The Journal of Social Psychology, 148(1), 77-90. http://doi.org/10.3200/SOCP.148.1.77-90

Espada, J. P., Morales, A., Guillén-Riquelme, A., Ballester, R., \& Orgilés, M. (2016). Predicting condom use in adolescents: a test of three socio-cognitive models using a structural equation modeling approach. BMC Public Health, 16(35), 1-10. http://doi.org/10.1186/s12889-016-2702-0

Espada, J. P., Morales, A., \& Orgilés, M. (2013). Relación entre la edad de debut sexual y el sexo bajo los efectos de las drogas en la adolescencia. Revista Española de Drogodependencias, (1), 25-35.

Ferree, M. C. (2001). Females and Sex Addiction: Myths and Diagnostic Implications. Sexual Addiction \& Compulsivity, 8, 287-300.

Figueira, I., Possidente, E., Marques, C., \& Hayes, K. (2001). Sexual dysfunction: a neglected complication of panic disorder and social phobia. Archives of Sexual Behavior, 30(4), 36977.

Fineberg, N. A., Potenza, M. N., Chamberlain, S. R., Berlin, H. A., Menzies, L., Bechara, A., ... Hollander, E. (2010). Probing compulsive and impulsive behaviors, from animal models to endophenotypes: a narrative review. Neuropsychopharmacology : Official Publication of the American College of Neuropsychopharmacology, 35(3), 591-604. http://doi.org/10.1038/npp.2009.185 
Fineberg, N. A., Reghunandanan, S., Kolli, S., \& Atmaca, M. (2014). Obsessive-compulsive (anankastic) personality disorder: toward the ICD-11 classification. Revista Brasileira de Psiquiatria, 36(Suppl 1), 40-50.

Finlayson, A. J. R., Sealy, J., \& Martin, P. R. (2001). The Differential Diagnosis of Problematic Hypersexuality. Sexual Addiction \& Compulsivity, 8(3-4), 241-251. http://doi.org/10.1080/107201601753459946

Finney, S. J., \& DiStefano, C. (2013). Nonnormal and categorical data in structural equation models. In Structural Equation Modeling: A Second Course (2nd Editio, p. 703). Charlotte, NC: Information Age Publishing.

First, M. B., Gibbon, M., Spitzer, R. L., Williams, J. B., \& Benjamin, L. S. (1999). Guía del usuario para la Entrevista Clínica Estructurada para los Trastornos de la Personalidad del Eje II del DSM-IV. Barcelona: Masson.

First, M. B., Spitzer, R. L., Gibbon, M., \& Williams, J. B. (1999). Guía del usuario para la Entrevista Clínica Estructurada para los Trastornos del Eje I del DSM-IV. Barcelona: Masson.

Fisher, W. A., Moore, Z. T., \& Pittenger, M.-J. (2012). Sex on the brain?: an examination of frequency of sexual cognitions as a function of gender, erotophilia, and social desirability. Journal of Sex Research, 49(1), 69-77. http://doi.org/10.1080/00224499.2011.565429

Fisher, W. A., White, L. A., Byrne, D., \& Kelley, K. (1988). Erotophobia-erotophilia as a dimension of personality. Journal of Sex Research, 25(1), 123-151. http://doi.org/10.1080/00224498809551448

Flanders, C. E., Arakawa, D. R., \& Cardozo, A. C. (2013). Positive Implications for Sexual Sensation Seeking: An Exploratory Study. Electronic Journal of Human Sexuality, 16(21).

Foucault, M. (1990). The History of Sexuality: An Introduction (Vol. 1). New York, NY: Vintage Books Edition.

Franks, S., \& Jacobs, H. S. (1983). Hyperprolactinaemia. Clinics in Endocrinology and Metabolism, 12, 641-668.

Fugl-Meyer, A., \& Sjogren, K. (1999). Sexual disabilities, problems and satisfaction in 18-74 year old Swedes. Scandinavian Journal of Sexology, 2, 79-105.

Funahashi, S. (2001). Neuronal mechanisms of executive control by the prefrontal cortex. Neuroscience Research, 39(2), 147-65. 
Funder, D. C. (2001). Personality. Annual Review of Psychology, 52, 197-221. http://doi.org/10.1146/annurev.psych.52.1.197

G*Power. (2014). G*Power 3.1 manual. Retrieved from http://www.gpower.hhu.de/gpower/GPowerManual.pdf

Gagnon, J. H., \& Simon, W. (2009). Sexual Conduct: The Social Sources of Human Sexuality (2nd edition). New Brunswick: Transaction Publishers.

Gaither, G. A., \& Sellbom, M. (2003). The sexual sensation seeking scale: reliability and validity within a heterosexual college student sample. Journal of Personality Assessment, 81(2), 157-67. http://doi.org/10.1207/S15327752JPA8102_07

García-Figueras, R., Padhani, A. R., Vilanova, J. C., Goh, V., \& Villalba-Martín, C. (2010). Functional imaging of tumors. Radiología, 52(3), 208-20. http://doi.org/10.1016/j.rx.2009.12.011

Garton, S. (2004). Histories of Sexuality: Antiquity to Sexual Revolution (Critical Histories of Subjectivity \& Culture). New York, NY: Routledge.

Gentzler, A. L., \& Kerns, K. A. (2004). Associations between insecure attachment and sexual experiences. Personal Relationships, 11, 249-265.

Gil-Llario, M. D., Morell-Mengual, V., Ballester-Arnal, R., Giménez-García, C., \& Castro-Calvo, J. (2014). Sexual sensation seeking in spanish young men and women with different sexual orientations. Journal of Sex \& Marital Therapy, 41(5), 525-30. http://doi.org/10.1080/0092623X.2014.931316

Giles, J. (2006). No such thing as excessive levels of sexual behavior. Archives of Sexual Behavior, 35(6), 641-2-4. http://doi.org/10.1007/s10508-006-9098-3

Gilliland, R., South, M., Carpenter, B. N., \& Hardy, S. A. (2011). The roles of shame and guilt in hypersexual behavior. Sexual Addiction \& Compulsivity, 18(1), 12-29.

Gilliland, R., Star, J. B., Hansen, B., \& Carpenter, B. (2015). Relationship Attachment Styles in a Sample of Hypersexual Patients. Journal of Sex \& Marital Therapy, 0(0), 1-12. http://doi.org/10.1080/0092623X.2014.958787

Giménez-García, C., Ballester-Arnal, R., Ruiz-Palomino, E., Salmerón-Sánchez, P., \& CastroCalvo, J. (2016). Salusexsida: una experiencia de educación afectivo-sexual en el contexto universitario. In J. L. Castejón (Ed.), Psicología y Educación: Presente y Futuro (pp. 547554). Alicante: Ediciones Acipe. 
Giugliano, J. (2004). A Sociohistorical Perspective of Sexual Health: The Clinician's Role. Sexual Addiction \& Compulsivity, 11(1-2), 43-55. http://doi.org/10.1080/10720160490458238

Gold, S., \& Heffner, C. (1998). Sexual addiction: Many conceptions, minimal data. Clinical Psychology Review, 18(3), 367-381.

Goldstein, A. L., Barnett, N. P., Pedlow, C. T., \& Murphy, J. G. (2007). Drinking in conjunction with sexual experiences among at-risk college student drinkers. Journal of Studies on Alcohol and Drugs, 68(5), 697-705.

Goodman, A. (1992). Sexual addiction: designation and treatment. Journal of Sex \& Marital Therapy, 18(4), 303-14. http://doi.org/10.1080/00926239208412855

Goodman, A. (2001). What's in a Name? Terminology for Designating a Syndrome of Driven Sexual Behavior. Sexual Addiction \& Compulsivity, 8(3-4), 191-213. http://doi.org/10.1080/107201601753459919

Grant, J. E., \& Kim, S. W. (2003). Comorbidity of impulse control disorders in pathological gamblers. Acta Psychiatrica Scandinavica, 108(3), 203-7.

Grant, J. E., Levine, L., Kim, S. W., \& Potenza, M. N. (2005). Impulse control disorders in adult psychiatric inpatients. American Journal of Psychiatry, 162, 2184-2188.

Griffiths, M. D., Pontes, H., \& Kuss, D. (2015). Clinical psychology of Internet addiction: a review of its conceptualization, prevalence, neuronal processes, and implications for treatment. Neuroscience and Neuroeconomics, 4, 11-23. http://doi.org/10.2147/NAN.S60982

Griffiths, M. D., Pontes, H. M., \& Kuss, D. J. (2016). Online Addictions: Conceptualizations, Debates, and Controversies. Addicta: The Turkish Journal on Addictions, 3(2), 1-20. http://doi.org/10.15805/addicta.2016.3.0101

Grov, C., Parsons, J. T., \& Bimbi, D. S. (2010). Sexual Compulsivity and Sexual Risk in Gay and Bisexual Men. Archives of Sexual Behavior, 39(4), 940-949. http://doi.org/10.1007/s10508-009-9483-9.Sexual

Guasch, O. (1993). Para una sociología de la sexualidad. Reis: Revista Española de Investigaciones Sociológicas, 64, 105-121.

Guigliamo, J. (2006). Out of control sexual behavior: A qualitative investigation. Sexual Addiction \& Compulsivity, 13, 361-375.

Gullette, D. L., \& Lyons, M. a. (2005). Sexual sensation seeking, compulsivity, and HIV risk 
behaviors in college students. Journal of Community Health Nursing, 22(1), 47-60. http://doi.org/10.1207/s15327655jchn2201_5

Gullette, D. L., \& Lyons, M. A. (2006). Sensation seeking, self-esteem, and unprotected sex in college students. The Journal of the Association of Nurses in AIDS Care, 17(5), 23-31. http://doi.org/10.1016/j.jana.2006.07.001

Hagedorn, W. B. (2009a). Preparing Competent Clinicians: Curricular Applications Based on the Sexual Addiction Counseling Competencies. Sexual Addiction \& Compulsivity, 16(16), 341-360. http://doi.org/10.1080/10720160903399855

Hagedorn, W. B. (2009b). Sexual Addiction Counseling Competencies: Empirically-Based Tools for Preparing Clinicians to Recognize, Assess, and Treat Sexual Addiction. Sexual Addiction \& Compulsivity, 16(October 2014), 190-209. http://doi.org/10.1080/10720160903202604

Hall, P. (2011). A biopsychosocial view of sex addiction. Sexual and Relationship Therapy, 26(3), 217-228. http://doi.org/10.1080/14681994.2011.628310

Hall, P. (2013). A New Classification Model for Sex Addiction. Sexual Addiction \& Compulsivity, 20(4), 279-291. http://doi.org/10.1080/10720162.2013.807484

Halman, L., Luijkx, R., \& Van Zundert, M. (2005). Atlas of European values. Leiden: Brill Academic Publishers.

Halpern, A. L. (2011). The proposed diagnosis of hypersexual disorder for inclusion in DSM-5: unnecessary and harmful. Archives of Sexual Behavior, 40(3), 487-488. http://doi.org/10.1007/s10508-011-9727-3

Halpern, C. T., Udry, J. R., Campbell, B., \& Suchindran, C. (1993). Testosterone and pubertal development as predictors of sexual activity: a panel analysis of adolescent males. Psychosomatic Medicine, 55, 436-447.

Hamman, S., Herman, R., \& Nolan, C. (2004). Men and women differ in amygdala response to visual sexual stimuli. Natural Neuroscience, $7(4), 411-416$.

Harkness, J., Penell, B. E., \& Schoua-Glusberg, A. (2004). Survey questionnaire translation and assessment. In S. Presser, J. M. Rothgeb, M. P. Couper, J. T. Lessler, E. Martin, J. Martin, \& E. Singer (Eds.), Methods for Testing and Evaluating Survey Questionnaires (pp. 453-473). Hoboken, NJ, USA: John Wiley \& Sons, Inc. http://doi.org/10.1002/0471654728

Hartman, L. I., Ho, V., Arbour, S., Janice, M., \& Lawson, P. (2012). Sexual Addiction and 
Substance Addiction : Comparing Sexual Addiction Treatment Outcomes Among Clients With and Without Comorbid Substance Use Disorders. Sexual Addiction \& Compulsivity, 19(4), 284-309. http://doi.org/10.1080/10720162.2012.735515

Hedricks, C. A. (1994). Female sexual activity across the human menstrual cycle: a biopsychosocial approach. Annual Review of Sex Research, 5, 122-172.

Hendershot, C. S., Stoner, S. A., George, W. H., \& Norris, J. (2007). Alcohol use, expectancies, and sexual sensation seeking as correlates of HIV risk behavior in heterosexual young adults. Psychology of Addictive Behaviors: Journal of the Society of Psychologists in Addictive Behaviors, 21(3), 365-72. http://doi.org/10.1037/0893-164X.21.3.365

Henson, R. (2001). Understanding internal consistency reliability estimates: a conceptual primer on coefficient alpha. Measurement and Evaluation in Counseling and Development, 34(3), 177-189.

Herbenick, D., Reece, M., \& Hollub, A. (2009). Inside the ordering room: characteristics of women's in-home sex toy parties, facilitators and sexual communication. Sexual Health, 6(4), 318-27. http://doi.org/10.1071/SH08086

Herman, J. (1981). Father-Daughter incest. Cambridge, MA: Harvard University Press.

Higgins, A., Barker, P., \& Begley, C. M. (2004). Hypersexuality and dementia: dealing with inappropriate sexual expression. British Journal of Nursing, 13(22), 1330-4.

Homack, S., Lee, D., \& Riccio, C. A. (2005). Test review: Delis-Kaplan executive function system. Journal of Clinical and Experimental Neuropsychology, 27(5), 599-609. http://doi.org/10.1080/13803390490918444

Hook, J. N., Hook, J. P., Davis, D. E., Worthington, E. L., \& Penberthy, J. K. (2010). Measuring sexual addiction and compulsivity: a critical review of instruments. Journal of Sex \& Marital Therapy, 36, 227-260. http://doi.org/10.1080/00926231003719673

Hook, J. N., Hook, J. P., \& Hines, S. (2008). Reach Out or Act Out: Long-Term Group Therapy for Sexual Addiction. Sexual Addiction \& Compulsivity, 15(3), 217-232. http://doi.org/10.1080/10720160802288829

Hook, J. N., Reid, R. C., Penberthy, J. K., Davis, D. E., \& Jennings, D. J. (2014). Methodological review of treatments for nonparaphilic hypersexual behavior. Journal of Sex \& Marital Therapy, 40(4), 294-308. http://doi.org/10.1080/0092623X.2012.751075

Hooper, D., Coughlan, J., \& Mullen, M. R. (2008). Structural Equation Modeling: Guidelines for 
Determining Model Fit. Electronic Journal on Business Research Methods, 6(1), 53-60.

Hosmer, D. W., \& Lemeshow, S. (2004). Applied Logistic Regression. New York, NY: Oxford University Press.

Hudson-Allez, G. (2009). Infant losses; Adult searches: A neural and developmental perspective on psychopathology and sexual offending. London, UK: Karnac Books.

Hurlbert, D. F. (1993). Female sexuality: a comparative study between women in homosexual and heterosexual relationships. Journal of Sex \& Marital Therapy, 19(4), 315-27. http://doi.org/10.1080/00926239308404375

Hyde, J. S., \& DeLamater, J. (2000). Sexuality during pregnancy and the year postpartum. In C. B. Travis \& J. W. White (Eds.), Sexuality, Society, and Feminism (pp. 167-180). Washington, DC: American Psychological Association.

Janssen, E., Vorst, H., Finn, P., \& Bancroft, J. (2002). The Sexual Inhibition (SIS) and Sexual Excitation (SES) Scales: I. Measuring sexual inhibition and excitation proneness in men. Journal of Sex Research, 39(2), 114-26. http://doi.org/10.1080/00224490209552130

Johnson, J. G., Cohen, M., Kasen, S., Skodol, A. E., Hamagami, F., \& Brook, J. S. (2000). Agerelated change in personality disorder trait levels between early adolescence and adulthood: A community-based longitudinal investigation. Acta Psychiatrica Scandinavica, 102, 265-275.

Kafka, M. P. (1991). Successful antidepressant treatment of nonparaphilic sexual addictions and paraphilias in men. The Journal of Clinical Psychiatry, 52(2), 60-5.

Kafka, M. P. (1997). Hypersexual desire in males: An operational definition and clinical implications for males with paraphilias and paraphilia-related disorders. Archives of Sexual Behavior, 26(5), 505-526.

Kafka, M. P. (2001). The Paraphilia-Related Disorders: A Proposal for a Unified Classification of Nonparaphilic Hypersexuality Disorders. Sexual Addiction \& Compulsivity, 8(3-4), 227239. http://doi.org/10.1080/107201601753459937

Kafka, M. P. (2007). Paraphilia-related disorders. The evaluation and treatment of nonparaphilic hypersexuality. In S. Leiblum (Ed.), Principles And Practice of Sex Therapy (4th ed., pp. 442-476). New York, NY: Guilford.

Kafka, M. P. (2008). Neurobiological processes and comorbidity in sexual deviance. In D. R. Laws \& W. T. O’Donohue (Eds.), Sexual Deviance: Theory, Assessment, and Treatment (pp. 
571-593). New York, NY: The Guilford Press.

Kafka, M. P. (2010). Hypersexual disorder: a proposed diagnosis for DSM-V. Archives of Sexual Behavior, 39(2), 377-400. http://doi.org/10.1007/s10508-009-9574-7

Kafka, M. P. (2013). The Development and Evolution of the Criteria for a Newly Proposed Diagnosis for DSM-5: Hypersexual Disorder. Sexual Addiction \& Compulsivity, 20(1-2), 19-26.

Kafka, M. P. (2014). What happened to hypersexual disorder? Archives of Sexual Behavior, 43(7), 1259-61. http://doi.org/10.1007/s10508-014-0326-y

Kafka, M. P., \& Hennen, J. (1999). The paraphilia-related disorders: an empirical investigation of nonparaphilic hypersexuality disorders in outpatient males. Journal of Sex \& Marital Therapy, 25(4), 305-19. http://doi.org/10.1080/00926239908404008

Kafka, M. P., \& Hennen, J. (2000). Psychostimulant augmentation during treatment with selective serotonin reuptake inhibitors in men with paraphilias and paraphilia-related disorders: a case series. Journal of Clinical Psychiatry, 61, 664-670.

Kafka, M. P., \& Hennen, J. (2002). A DSM-IV Axis I Comorbidity Study of Males ( $n=120$ ) With Paraphilias and Paraphilia-Related Disorders. Sexual Abuse : A Journal of Research and Treatment, 14(4), 349-366.

Kafka, M. P., \& Hennen, J. (2003). Hypersexual desire in males: are males with paraphilias different from males with paraphilia-related disorders? Sexual Abuse: A Journal of Research and Treatment, 15(4), 307-21.

Kafka, M. P., \& Prentky, R. (1994). Preliminary observations of the DSM-III-R Axis I comorbidity in men with paraphilias and paraphilia-related disorders. Journal of Clinical psychiatry1, $55,481-487$.

Kafka, M. P., \& Prentky, R. (1998). Attention-deficit/hyperactivity disorder in males with paraphilias and paraphilia-related disorders: a comorbidity study. Journal of Clinical Psychiatry, 59, 388-396.

Kalichman, S. C., \& Cain, D. (2004). The relationship between indicators of sexual compulsivity and high risk sexual practices among men and women receiving services from a sexually transmitted infection clinic. Journal of Sex Research, 41(3), 235-41. http://doi.org/10.1080/00224490409552231

Kalichman, S. C., Heckman, T., \& Kelly, J. a. (1996). Sensation seeking as an explanation for the 
association between substance use ... Archives of Sexual Behavior, 25(2), 141-154.

Kalichman, S. C., Johnson, J. R., Adair, V., Rompa, D., Multhauf, K., \& Kelly, J. A. (1994). Sexual sensation seeking: scale development and predicting AIDS-risk behavior among homosexually active men. Journal of Personality Assessment, 62(3), 385-97. http://doi.org/10.1207/s15327752jpa6203_1

Kalichman, S. C., \& Rompa, D. (1995). Sexual sensation seeking and Sexual Compulsivity Scales: reliability, validity, and predicting HIV risk behavior. Journal of Personality Assessment, 65(3), 586-601. http://doi.org/10.1207/s15327752jpa6503_16

Kalichman, S. C., \& Rompa, D. (2001). The Sexual Compulsivity Scale: Further Development and Use With HIV-Positive Persons. Journal of Personality Assessment, 76(3), 379-395. http://doi.org/10.1207/S15327752JPA7603_02

Kandel, E. R. (1999). Biology and the Future of Psychoanalysis: A New Intellectual Framework for Psychiatry Revisited. The American Journal of Psychiatry, 156(4), 505-524.

Kaplan, H. S. (1979). Disorders of sexual Desire. New York, NY: Brunner/Mazel.

Kaplan, H. S. (1980). Deviant behavior and selfenhancement in adolescence. Journal of Youth and Adolescence, 7, 253-277.

Kaplan, H. S., \& Krueger, R. B. (2010). Diagnosis, assessment, and treatment of hypersexuality. Journal of Sex Research, 47(2), 181-98. http://doi.org/10.1080/00224491003592863

Kasl, C. (1998). Women, sex and addiction: A search for love and power. New York, NY: Harper \& Row.

Kasten, B. P. (1999). Self-Medication With Alcohol and Drugs by Persons With Severe Mental Illness. Journal of the American Psychiatric Nurses Association, 5(3), 80-87. http://doi.org/10.1177/107839039900500302

Kastner, R. M., \& Sellbom, M. (2012). Hypersexuality in college students: The role of psychopathy. Personality and Individual Differences, 1-6. http://doi.org/10.1016/j.paid.2012.05.005

Kelly, B. C., Bimbi, D. S., Nanin, J. E., Izienicki, H., Jeffrey, T., \& Kelly, B. C. (2009). Sexual Compulsivity and Sexual Behaviors Among Gay and Bisexual Men and Lesbian and Bisexual Women. Journal of Sex Research, 46(4), 301-308. http://doi.org/10.1080/00224490802666225

Kessler, R. C., Berglund, P., Demler, O., Jin, R., Koretz, D., Merikangas, K. R., ... Wang, P. S. 
(2003). The epidemiology of major depressive disorder: Results from the National Comorbidity Survey Replication (NCS-R). Journal of the American Medical Association, 289, 3095-3101.

King, M., Holt, V., \& Nazareth, I. (2007). Women's views of their sexual difficulties: agreement and disagreement with clinical diagnoses. Archives of Sexual Behavior, 36(2), 281-8. http://doi.org/10.1007/s10508-006-9090-y

Kingston, D. A., \& Bradford, J. M. (2013). Hypersexuality and Recidivism among Sexual Offenders. Sexual Addiction \& Compulsivity, 20(1-2), 91-105.

Kingston, D. A., \& Firestone, P. (2008). Problematic Hypersexuality: A Review of Conceptualization and Diagnosis. Sexual Addiction \& Compulsivity, 15(4), 284-310. http://doi.org/10.1080/10720160802289249

Kinsey, A. C., Pomeroy, W. B., \& Martin, C. E. (1948). Sexual Behavior in the Human Male. Philadelphia: Penn Saunders.

Kleinplatz, P. J. (2011). Arousal and desire problems: conceptual, research and clinical considerations or the more things change the more they stay the same. Sexual and Relationship Therapy, 26(1), 3-15. http://doi.org/10.1080/14681994.2010.521493

Kobayashi, T. (2004). Effect of haloperidol on a patient with hypersexuality following frontal lobe injury. Psychogeriatrics, 4(2), 49-52. http://doi.org/10.1111/j.14798301.2004.00060.x

Kohn, C. S. (2006). Conceptualization and Treatment of Kleptomania Behaviors Using Cognitive and Behavioral Strategies. International Journal of Behavioral Consultation and Therapy, 2(4), 553-559.

Kor, A., Fogel, Y., Reid, R. C., \& Potenza, M. N. (2013). Should Hypersexual Disorder be Classified as an Addiction? Sexual Addiction \& Compulsivity, 20(1-2). http://doi.org/10.1080/10720162.2013.768132

Koran, L. M., Abujaoude, E., Large, M. D., \& Serpe, R. T. (2008). The prevalence of body dysmorphic disorder in the United States adult population. CNS Spectrums, 13(4), 31622.

Krueger, T. H. C., Haake, P., Chereath, D., Knapp, W., Janssen, E., Exton, M. S., ... Hartmann, U. (2003). Specificity of the neuroendocrine response to orgasm during sexual arousal in men. Journal of Endocrinology, 177, 57-64. 
Kupfer, D. J., Frank, E., \& Phillips, M. L. (2012). Major depressive disorder: new clinical, neurobiological, and treatment perspectives. Lancet, 379(9820), 1045-1055. http://doi.org/10.1016/S0140-6736(11)60602-8

Kvalem, I. L., Træen, B., Lewin, B., \& Štulhofer, A. (2014). Self-perceived effects of Internet pornography use, genital appearance satisfaction, and sexual self-esteem among young Scandinavian adults. Cyberpsychology: Journal of Psychosocial Research on Cyberspace, 8(4). http://doi.org/10.5817/CP2014-4-4

Kwee, A. W., Domínguez, A. W., \& Ferrell, D. (2007). Sexual Addiction andd Christian College Men: Conceptual, Assessment, and Treatment Challenges. Journal of Psychology and Christianity, 26(1), 3-13.

Långström, N., \& Hanson, R. K. (2006a). High rates of sexual behavior in the general population: correlates and predictors. Archives of Sexual Behavior, 35(1), 37-52. http://doi.org/10.1007/s10508-006-8993-y

Långström, N., \& Hanson, R. K. (2006b). Population Correlates are Relevant to Understanding Hypersexuality: A Response to Giles. Archives of Sexual Behavior, 35(6), 643-644. http://doi.org/10.1007/s10508-006-9102-y

Laumann, E. O., Gagnon, J. H., Michael, R. T., \& Michaels, S. (1994). The Social Organization of Sexuality: Sexual Practices in the United States. Chicago, IL: University of Chicago Press.

Laws, R. D. (2009). Penile plethysmography: strengths, limitations, innovations. In D. Thornton \& R. D. Laws (Eds.), Cognitive approaches to the assessment of sexual interest in sexual offenders (pp. 7-30). New York, NY: Sage Publications.

Laws, \& O'Donohue, W. T. (2008). Sexual Deviance: Theory, Assessment, and Treatment. New York, NY: The Guilford Press.

Leary, M. R., \& Baumeister, R. F. (2000). The nature and function of self-esteem: Sociometer theory. In M. P. Zanna (Ed.), Advances in experimental social psychology (pp. 1-62). San Diego, CA: Academic Press.

Leedes, R. (1999). Theory and praxis: A heuristic for describing, evaluating, and intervening on sexual desire disorders when sexual expression interferes with humanistic expression. Sexual Addiction \& Compulsivity, 6, 289-310.

Leedes, R. (2001). The three most important criteria in diagnosing sexual addictions: Obsession, obsession, and obsession. Sexual Addiction \& Compulsivity, 8, 215-226. 
Leiblum, S. (2006). Principles and Practice of Sex Therapy (4th Edtion). Guilford Press.

Leventhal, A. M., \& Zvolensky, M. J. (2015). Anxiety, depression, and cigarette smoking: a transdiagnostic vulnerability framework to understanding emotion-smoking comorbidity. Psychological Bulletin, 141(1), 176-212. http://doi.org/10.1037/bul0000003

Levine, M. P., \& Troiden, R. R. (1988). The myth of sexual compulsivity. Journal of Sex Research, $25,347-363$.

Levine, S. B. (2002). Reexploring the concept of sexual desire. Journal of Sex \& Marital Therapy, 28(1), 39-51. http://doi.org/10.1080/009262302317251007

Levine, S. B. (2003). The nature of sexual desire: a clinician's perspective. Archives of Sexual Behavior, 32(3), 279-85.

Lezak, M. D. (2004). Neuropsychological Assessment. New York, NY: Oxford University Press.

Lindzey, J., \& Korach, K. S. (2003). Estrogen action in males: insights through mutations in aromatase and estrogen-receptor genes. In C. Bagatell \& W. Bremmer (Eds.), Androgens in Health and Disease (pp. 89-102). Totawa: Humana press.

Lizarraga, S., \& Ayarra, M. (2001). Entrevista motivacional. Anales Del Sistema Sanitario de Navarra, 24(2), 43-53.

Llópis, J. J. (2011). De las drogas y la sexualidad. In Conocimientos biomédicos y farmacológicos fundamentales para el estudio de la sexualidad (pp. 259-296). Madrid: Editorial Dykinson.

Lo Piccolo, L., \& Heiman, J. R. (1978). Sexual assessment and history interview. In J. Lo Piccolo \& L. Lo Piccolo (Eds.), Handbook of Sex Therapy (pp. 245-296). New York, NY: Plenum Press.

López, F., Carcedo, R., Fernández-Rouco, N., Blázquez, M. I., \& Kilani, A. (2011). Diferencias sexuales en la sexualidad adolescente: afectos y conductas. Anales de Psicología, 27(3), 791-799.

Luder, M.-T., Pittet, I., Berchtold, A., Akré, C., Michaud, P.-A., \& Surís, J.-C. (2011). Associations between online pornography and sexual behavior among adolescents: myth or reality? Archives of Sexual Behavior, 40(5), 1027-35. http://doi.org/10.1007/s10508-010-9714-0

Luef, G. J. (2008). Epilepsy and sexuality. Seizure, 17(2), 127-30. http://doi.org/10.1016/j.seizure.2007.11.009

Luker, K. (1975). Taking Chances: Abortion and the Decision not to Contracept. Berkeley, CA: 
Univesity of California Press.

Macapagal, K. R., \& Janssen, E. (2011). The valence of sex:Automatic affective associations in erotophilia and erotophobia. Personality and Individual Differences, 51(6), 699-703. http://doi.org/10.1016/j.paid.2011.06.008

MacLaughlin, D. T., \& Donahoe, P. K. (2004). Sex determination and differentiation. New England Journal of Medicine, 350(4), 367-378.

Marshall, L. E., \& Marshall, W. L. (2010). The Factorial Structure of The Sexual Addiction Screening Test in Sexual Offenders and Socio-Economically Matched Community NonOffenders. Sexual Addiction \& Compulsivity, 17(3), 210-218.

Martín-Albo, J., Núñez, J. L., Navarro, J. G., \& Grijalvo, F. (2007). The Rosenberg Self-Esteem Scale: Translation and Validation in University Students. The Spanish Journal of Psychology, 10(2), 458-467. http://doi.org/10.1017/S1138741600006727

Maser, J. D., Norman, S. B., Zisook, S., Everall, I. P., Stein, M. B., Schettler, P. J., \& Judd, L. L. (2009). Psychiatric Nosology Is Ready for a Paradigm Shift in DSM-V. Clinical Psychology: Science and Practice, 16(1), 24-40. http://doi.org/10.1111/j.1468-2850.2009.01140.x

Mashegoane, S., Moalusi, K. P., Ngoepe, M. A., \& Peltzer, K. (2002). Sexual sensation seekin and risky sexual behavior among south african university students. Social Behavior and

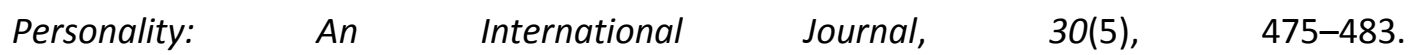
http://doi.org/10.2224/sbp.2002.30.5.475

Masters, W. H., \& Johnson, V. E. (1970). Human sexual inadequacy. Boston: Little Brown.

Mathew, R. J., \& Weinman, M. L. (1982). Sexual dysfunctions in depression. Archives of Sexual Behavior, 11(4), 323-328. http://doi.org/10.1007/BF01541593

Maurice, W. L. (2007). Sexual Desire Disorders in Men. In S. R. Leiblum (Ed.), Principles And Practice of Sex Therapy (pp. 181-211). New York, NY: The Guilford Press.

McBride, K. R., Reece, M., \& Dodge, B. (2011). Sexual behavior as an addictive or compulsive phenomenon. In B. A. Johnson (Ed.), Addiction Medicine: Science and Practice (pp. 661676). New York, NY: Springer New York. http://doi.org/10.1007/978-1-4419-0338-9

McBride, K. R., Reece, M., \& Sanders, S. A. (2008). Predicting Negative Outcomes of Sexuality Using the Compulsive Sexual Behavior Inventory. International Journal of Sexual Health, 19(4), 51-62. http://doi.org/10.1300/J514v19n04_06

McCarthy, B. (1994). Sexually Compulsive Men and Inhibited Sexual Desire. Journal of Sex \& 
Marital Therapy, 20, 200-209.

McCoul, M. D., \& Haslam, N. (2001). Predicting high risk sexual behaviour in heterosexual and homosexual men: the roles of impulsivity and sensation seeking. Personality and Individual Differences, 31(8), 1303-1310. http://doi.org/10.1016/S0191-8869(00)00222-1

McCrae, R. R., \& Costa, P. T. (2003). Personality in Adulthood: A Five-factor Theory Perspective (2nd editio). New York, NY: The Guilford Press.

McCrae, R. R., Löckenhoff, C. E., \& Costa, P. T. (2005). A step towardDSM-V: cataloguing personality-related problems in living. European Journal of Personality, 19(4), 269-286. http://doi.org/10.1002/per.564

McCrae, R. R., Terracciano, A., \& Al., E. (2005). Universal features of personality traits from the observer's perspective: data from 50 cultures. Journal of Personality and Social Psychology, 88(3), 547-61. http://doi.org/10.1037/0022-3514.88.3.547

McDaniel, K. (2008). Ready to heal: Women facing love, sex, and relationship addiction (2nd Editio). Carefree, AZ: Gentle Path Press.

McGee, R., \& Williams, S. (2000). Does low selfesteem predict health compromising behaviours among adolescents? Journal of Adolescence, 23, 568¡9-582.

McHorney, C. A., \& Tarlov, A. R. (1995). Individual-patient monitoring in clinical practice: are available health status surveys adequate? Quality of Life Research, 4(4), 293-307.

Mckeague, E. L. (2014). Differentiating the Female Sex Addict : A Literature Review Focused on Themes of Gender Difference Used to Inform Recommendations for Treating Women With Sex Addiction. Sexual Addiction \& Compulsivity, 21(3), 203-224. http://doi.org/10.1080/10720162.2014.931266

McNair, B. (2002). Striptease culture. London, UK: Routledge.

McNair, L. D., Carter, J. A., \& Williams, M. K. (1998). Self-esteem, gender and alcohol use: relationships with HIV risk perception and behaviors in college students. Journal of Sex \& Marital Therapy, 24, 29-36.

McNamara, D. (2002). Structured tool increases diagnosis of major depression in substance abusers. Clinical Psychiatry News, 30, 31-39.

Meston, C., \& Frolich, P. F. (2000). The neurobiology of sexual functioning. Archives of General Psychiatry, 57, 1012-1032.

Mick, T., \& Hollander, E. (2006). Impulsive-compulsive sexual behavior. CNS Spectrums, 11(12), 
944-955.

Milkman, H. B., \& Sunderwirth, S. G. (1987). Craving for ecstasy: the consciousness and chemistry of escape. New York, NY: Lexington books.

Miller, J. D., Lynam, D., Zimmerman, R. S., Logan, T. K., Leukefeld, C., \& Clayton, R. (2004). The utility of the Five Factor Model in understanding risky sexual behavior. Personality and Individual Differences, 36, 1611-1626.

Miner, M. H., \& Coleman, E. (2013). Compulsive Sexual Behavior and its Relationship to Risky Sexual Behavior. Sexual Addiction \& Compulsivity, 20(1-2), 127-138.

Miner, M. H., Coleman, E., Center, B. A., Ross, M. W., \& Rosser, B. R. S. (2007). The Compulsive Sexual Behavior Inventory: Psychometric Properties. Archives of Sexual Behavior, 36, 579-587. http://doi.org/10.1007/s10508-006-9127-2

Miner, M. H., Raymond, N., Mueller, B. a, Lloyd, M., \& Lim, K. O. (2009). Preliminary investigation of the impulsive and neuroanatomical characteristics of compulsive sexual $\begin{array}{llll}\text { behavior. } & \text { Psychiatry 174(2), }\end{array}$ http://doi.org/10.1016/j.pscychresns.2009.04.008

Ministerio de Educación. (2016). Panorama de la educación: indicadores de la OCDE 2016. Madrid. Retrieved from http://www.mecd.gob.es/dctm/inee/eag/panorama2016okkk.pdf?documentld=0901e72 b82236f $2 b$

Missildine, W., Feldstein, G., Punzalan, J. C., \& Parsons, J. T. (2005). S/he loves me, s/he loves me not: Questioning heterosexist assumptions of gender differences for romantic and sexually motivated behaviors. Sexual Addiction \& Compulsivity, 12, 65-74.

Moeller, F. G., Barratt, E. S., Dougherty, D. M., Schmitz, J. M., \& Swann, A. C. (2001). Psychiatric aspects of impulsivity. The American Journal of Psychiatry, 158(11), 1783-93.

Money, J. (1986). Lovemaps: Clinical Concepts of Sexual/erotic Health and Pathology, Paraphilia, and Gender Transposition of Childhood, Adolescence, and Maturity. New York, NY: Prometheus Books.

Money, J., \& Ehrhardt, A. (1986). Desarrollo de la sexualidad humana (diferenciación y dimorfismo de la identidad de género). Madrid: Ediciones Morata.

Montaldi, D. E. (2002). Understanding hypersexuality with an Axis II model. Journal of Psychology \& Human Sexuality, 14, 1-23. 
Morgenstern, J., Muench, F., Leary, A. O., Parsons, J. T., Hollander, E., \& Blain, L. (2012). NonParaphilic Compulsive Sexual Behavior and Psychiatric Co-morbidities in Gay and Bisexual Men. Sexual Addiction \& Compulsivity, 18(3), 114-134. http://doi.org/10.1080/10720162.2011.593420

Morgenstern, J., Muench, F., O'Leary, A., Parsons, J. T., \& Hollander, E. (2009). Assessing nonparaphilic compulsive sexual behavior and psychiatric co-morbidities in a community sample of gay and bisexual men. New York, NY: Columbia University.

Moser, C. (2011). Hypersexual disorder: just more muddled thinking. Archives of Sexual Behavior, 40(2), 227-229. http://doi.org/10.1007/s10508-010-9690-4

Muench, F., Morgenstern, J., Hollander, E., Irwin, T., O’Leary, A., Parsons, J. T., ... Lai, B. (2007). The Consequences of Compulsive Sexual Behavior: The Preliminary Reliability and Validity of the Compulsive Sexual Behavior Consequences Scale. Sexual Addiction \& Compulsivity, 14(3), 207-220. http://doi.org/10.1080/10720160701480493

Muench, F., \& Parsons, J. T. (2004). Sexual compulsivity and HIV: Identification and treatment. Focus: A Guide to AIDS Research and Counseling, 19, 1-3.

Muise, A., Milhausen, R. R., Cole, S. L., \& Graham, C. (2013). Sexual Compulsivity in Heterosexual Married Adults: The Role of Sexual Excitation and Sexual Inhibition in Individuals not Considered “ High-Risk ." Sexual Addiction \& Compulsivity, 20(3), 192-209. http://doi.org/10.1080/10720162.2013.786661

Nair, D., Pawar, A., Kalra, G., \& Shah, N. (2013). An Indian Study of Hypersexual Disorder in Patients with Anxiety and Mood Disorders. Sexual Addiction \& Compulsivity, 20(4), 292305. http://doi.org/10.1080/10720162.2013.814094

Nakken, C. (2013). The Addictive Personality: Understanding the Addictive Process and Compulsive Behavior (2nd editio). Minnesota: Hazelden.

Nanin, J. E., \& Parsons, J. T. (2006). Club drug use and risky sex among gay and bisexual men in New York City. Journal of Gay and Lesbian Psychotherapy, 10, 111-122.

Needell, N., \& Markowitz, J. (2004). Hypersexual behavior in Hasidic Jewish inpatients. The Journal of Nervous and Mental Disease, 192(3), 243-246.

Nelson, K. G., \& Oehlert, M. E. (2008). Psychometric Exploration of the Sexual Addiction Screening Test in Veterans. Sexual Addiction \& Compulsivity, 15(1), 39-58.

Nieto, J. A. (2003). Antropología de la sexualidad y diversidad cultural. Madrid: Talasa 
ediciones.

Nobre, P. J., Wiegel, M., Bach, A. K., Weisberg, R. B., Brown, T. A., Wincze, J. P., \& Barlow, D. H. (2004). Determinants of sexual arousal and accuracy of its self-estimation in sexually functional males. Journal of Sex Research, 41(4), 363-71. http://doi.org/10.1080/00224490409552243

O'Brien, C. (2011). Addiction and dependence in DSM-V. Addiction, 106(5), 866-7. http://doi.org/10.1111/j.1360-0443.2010.03144.x

Obegi, J. H., \& Berrant, E. (2009). Attachment theory and research in clinical work with adults. New York, NY: The Guilford Press.

Odlaug, B. L., \& Grant, J. E. (2010). Impulse-control disorders in a college sample: results from the self-administered Minnesota Impulse Disorders Interview (MIDI). Primary Care Companion to the Journal of Clinical Psychiatry, 12(2), 4-11. http://doi.org/10.4088/PCC.09m00842whi

Odlaug, B. L., Lust, K., Schreiber, L. R. N., Christenson, G., Derbyshire, K., Harvanko, A., ... Grant, J. E. (2013). Compulsive sexual behavior in young adults. Annals of Clinical Psychiatry, 25(3), 193-200.

Oldham, J. M., Skodol, A. E., Kellman, H. D., Hyler, S. D., Doidge, N., Rosnick, L., \& Gallaher, P. E. (1995). Comorbidity of Axis I and Axis II disorders. American Journal of Psychiatry, 152, 571-578.

Opitz, D. M., Tsytsarev, S. V, \& Froh, J. (2009). Women â€ $€^{\mathrm{TM}}$ S Sexual Addiction and Family Dynamics, Depression and Substance Abuse Women's Sexual Addiction and Family. Sexual Addiction \& Compulsivity, 16(4), 324-340. http://doi.org/10.1080/10720160903375749

Orford, J. (1978). Hypersexuality: Implications for a Theory of Dependence. Addiction, 73(3), 299-310. http://doi.org/10.1111/j.1360-0443.1978.tb00157.x

Orford, J. (2001). Excessive Appetites: A Psychological View of Addictions (2nd edn). Chichester, UK: John Wiley\& Sons. http://doi.org/10.1002/erv.489

Orth, U., Robins, R. W., \& Widaman, K. F. (2012). Life-span development of self-esteem and its effects on important life outcomes. Journal of Personality and Social Psychology, 102(6), 1271-88. http://doi.org/10.1037/a0025558

Orzack, M. H., Voluse, A. C., Wolf, D., \& Hennen, J. (2006). An ongoing study of group 
treatment for men involved in problematic Internet-enabled sexual behavior. Cyberpsychology \& Behavior, 9(3), 348-60. http://doi.org/10.1089/cpb.2006.9.348

Oswalt, S. B., \& Wyatt, T. J. (2013). Sexual Health Behaviors and Sexual Orientation in a U.S. National Sample of College Students. Archives of Sexual Behavior, 42, 1561-1572.

Pachankis, J. E., Rendina, H. J., Ventuneac, A., Grov, C., \& Parsons, J. T. (2014). The role of maladaptive cognitions in hypersexuality among highly sexually active gay and bisexual men. Archives of Sexual Behavior, 43(4), 669-683. http://doi.org/10.1007/s10508-0140261-y

Parmeggiana, P. L., \& Morrison, A. R. (1990). Alterations in autonomic functions during sleep. In A. D. Loewy \& K. M. Spyer (Eds.), Central Regulation of Autonomic Functions (pp. 367386). New York, NY: Oxford University Press.

Parsons, J. T. (2005). HIV-positive gay and bisexual men. In S. C. Kalichman (Ed.), Positive prevention: Reducing HIV transmission among people living with HIV/AIDS (pp. 99-133). New York, NY: Kluwer.

Parsons, J. T., Grov, C., \& Golub, S. a. (2012). Sexual compulsivity, co-occurring psychosocial health problems, and HIV risk among gay and bisexual men: further evidence of a syndemic. American Journal of Public Health, 102(1), 156-62. http://doi.org/10.2105/AJPH.2011.300284

Parsons, J. T., Kelly, AE. B. C., Bimbi, AE. D. S., Dimaria, L., Wainberg, 瓜. M. L., \& Morgenstern, $\mathbb{E}$. J. (2008). Explanations for the Origins of Sexual Compulsivity Among Gay and Bisexual Men. Archives of Sexual Behavior, 37, 817-826. http://doi.org/10.1007/s10508-0079218-8

Paul, E. L., McManus, B., \& Hayes, A. (2000). "Hookups": Characteristics and correlates of college students' spontaneous and anonymous sexual experiences. Journal of Sex Research, 37, 76-88.

Paulhus, D. L., \& Williams, K. M. (2002). The Dark Triad of personality: Narcissism, Machiavellianism, and psychopathy. Journal of Research in Personality, 36(6), 556-563. http://doi.org/10.1016/S0092-6566(02)00505-6

Paunović, N., \& Hallberg, J. (2014). Conceptualization of Hypersexual Disorder with the Behavioral-Cognitive Inhibition Theory. Psychology, 5(2), 151-159. http://doi.org/10.4236/psych.2014.52024

Pertusa, A., Fullana, M. A., Singh, S., Alonso, P., Menchón, J. M., \& Mataix-Cols, D. (2008). 
Compulsive hoarding: OCD symptom, distinct clinical syndrome, or both? The American Journal of Psychiatry, 165(10), 1289-98. http://doi.org/10.1176/appi.ajp.2008.07111730

Petersen, J. L., \& Hyde, J. S. (2010). A meta-analytic review of research on gender differences in sexuality, 1993-2007. Psychological Bulletin, 136(1), 21-38. http://doi.org/10.1037/a0017504

Petersen, J. L., \& Hyde, J. S. (2011). Gender Differences in Sexual Attitudes and Behaviors: A Review of Meta-Analytic Results and Large Datasets. Journal of Sex Research, 48(2-3), 149-165. http://doi.org/10.1080/00224499.2011.551851

Phillips, J., Frances, A., Cerullo, M. A., Chardavoyne, J., Decker, H. S., First, M. B., ... Zachar, P. (2012). The six most essential questions in psychiatric diagnosis: a pluralogue part 1 : conceptual and definitional issues in psychiatric diagnosis. Philosophy, Ethics, and Humanities in Medicine, 7(3), 1-29. http://doi.org/10.1186/1747-5341-7-3

Pinto, J., Carvalho, J., \& Nobre, P. J. (2013). The relationship between the FFM personality traits, state psychopathology, and sexual compulsivity in a sample of male college students. The Journal of Sexual Medicine, 10(7), 1773-82. http://doi.org/10.1111/jsm.12185

Plotnick, R. D. (1992). The effect of attitudes on teenage premarital pregnancy and its resolution. American Sociological Review, 57, 800-811.

Pollard, S. E., Hook, J. N., Corley, M. D., \& Schneider, J. P. (2014). Support utilization by partners of self-identified sex addicts. Journal of Sex \& Marital Therapy, 40(4), 339-48. http://doi.org/10.1080/0092623X.2012.751076

Prause, N., \& Graham, C. A. (2007). Asexuality: classification and characterization. Archives of Sexual Behavior, 36(3), 341-56. http://doi.org/10.1007/s10508-006-9142-3

Prause, N., Staley, C., \& Fong, T. (2013). No evidence of emotion dysregulation in "hypersexuals" reporting their emotions to a sexual film. Sexual Addiction \& Compulsivity, 20(1-2), 106-126. http://doi.org/10.1080/10720162.2013.772874

Quadland, M. C. (1985). Compulsive sexual behavior: definition of a problem and an approach to treatment. Journal of Sex \& Marital Therapy, 11(2), 121-32. http://doi.org/10.1080/00926238508406078

Raviv, M. (1993). Personality characteristics of sexual addicts and pathological gamblers. Journal of Gambling Studies, 9(1), 17-30. http://doi.org/10.1007/BF01019922 
Raykov, T., \& Marcoulides, G. A. (1999). On desirability of parsimony in structural equation model selection. Structural Equation Modeling: A Multidisciplinary Journal, 6(3), 292-300. http://doi.org/10.1080/10705519909540135

Raymond, N. C., Coleman, E., \& Miner, M. H. (2003). Psychiatric comorbidity and compulsive/impulsive traits in compulsive sexual behavior. Comprehensive Psychiatry, 44(5), 370-80. http://doi.org/10.1016/S0010-440X(03)00110-X

Reed, G. M. (2010). Toward ICD-11: Improving the Clinical Utility of WHO's International Classification of Mental Disorders. Professional Psychology: Research and Practice, 41(6), 457-464.

Reed, S. J. (2001). Shame and Hope in Sexual Addiction. Journal of Ministry in Addiction \& Recovery, 7(1), 9-17.

Regier, D. A., Kuhl, E. A., \& Kupfer, D. J. (2013). The DSM-5: Classification and criteria changes. World Psychiatry, 12(2), 92-8. http://doi.org/10.1002/wps.20050

Reid, R. C. (2007). Assessing Readiness to Change among Clients Seeking Help for Hypersexual Behavior. Sexual Addiction \& Compulsivity, 14(3), 167-186. http://doi.org/10.1080/10720160701480204

Reid, R. C. (2010). Differentiating Emotions in a Sample of Men in Treatment for Hypersexual Behavior. Journal of Social Work Practice in the Addictions, 10(2), 197-213. http://doi.org/10.1080/15332561003769369

Reid, R. C. (2013). Personal Perspectives on Hypersexual Disorder. Sexual Addiction \& Compulsivity, 20(1-2), 4-18. http://doi.org/10.1080/10720162.2013.772876

Reid, R. C., Berlin, H. A., \& Kingston, D. A. (2015). Sexual Impulsivity in Hypersexual Men. Current Behavioral Neuroscience Reports, 2(1), 1-8. http://doi.org/10.1007/s40473-0150034-5

Reid, R. C., Bramen, J. E., Anderson, A., \& Cohen, M. (2014). Mindfulness, emotional dysregulation, impulsivity, and stress proneness among hypersexual patients. Journal of Clinical Psychology, 70(4), 313-321. http://doi.org/10.1002/jclp.22027

Reid, R. C., \& Carpenter, B. N. (2009). Exploring Relationships of Psychopathology in Hypersexual Patients Using the MMPI-2. Journal of Sex \& Marital Therapy, 35(4), 294310. http://doi.org/10.1080/00926230902851298

Reid, R. C., Carpenter, B. N., Gilliland, R., \& Karim, R. (2011). Problems of self-concept in a 
patient sample of hypersexual men with attention-deficit disorder. Journal of Addiction Medicine, 5(2), 134-40. http://doi.org/10.1097/ADM.0b013e3181e6ad32

Reid, R. C., Carpenter, B. N., Hook, J. N., Garos, S., Manning, J. C., Gilliland, R., ... Fong, T. (2012). Report of findings in a DSM-5 field trial for hypersexual disorder. The Journal of Sexual Medicine, 9(11), 2868-77. http://doi.org/10.1111/j.1743-6109.2012.02936.x

Reid, R. C., Carpenter, B. N., \& Lloyd, T. Q. (2009). Assessing psychological symptom patterns of patients seeking help for hypersexual behavior. Sexual and Relationship Therapy, 24(1), 47-63. http://doi.org/10.1080/14681990802702141

Reid, R. C., Carpenter, B. N., Spackman, M., \& Willes, D. L. (2008). Alexithymia, emotional instability, and vulnerability to stress proneness in patients seeking help for hypersexual behavior. Journal of Sex \& Marital Therapy, 34(2), 133-49. http://doi.org/10.1080/00926230701636197

Reid, R. C., Cyders, M. A., Moghaddam, J. F., \& Fong, T. W. (2014). Psychometric properties of the Barratt Impulsiveness Scale in patients with gambling disorders, hypersexuality, and methamphetamine dependence. Addictive Behaviors, 39(11), 1640-5. http://doi.org/10.1016/j.addbeh.2013.11.008

Reid, R. C., Davtian, M., Lenartowicz, A., Torrevillas, R. M., \& Fong, T. W. (2013). Perspectives on the assessment and treatment of adult ADHD in hypersexual men. Neuropsychiatry, 3(3), 295-308. http://doi.org/10.2217/npy.13.31

Reid, R. C., Dhuffar, M. K., Parhami, I., \& Fong, T. W. (2012). Exploring facets of personality in a patient sample of hypersexual women compared with hypersexual men. Journal of Psychiatric Practice, 18(4), 262-8. http://doi.org/10.1097/01.pra.0000416016.37968.eb

Reid, R. C., Garos, S., \& Carpenter, B. N. (2011). Reliability, Validity, and Psychometric Development of the Hypersexual Behavior Inventory in an Outpatient Sample of Men. Sexual Addiction \& Compulsivity, 18(1), 30-51. http://doi.org/10.1080/10720162.2011.555709

Reid, R. C., Garos, S., Carpenter, B. N., \& Coleman, E. (2011). A surprising finding related to executive control in a patient sample of hypersexual men. The Journal of Sexual Medicine, 8(8), 2227-36. http://doi.org/10.1111/j.1743-6109.2011.02314.x

Reid, R. C., Garos, S., \& Fong, T. (2012). Psychometric development of the hypersexual behavior consequences scale. Journal of Behavioral Addictions, 1(3), 115-122. http://doi.org/10.1556/JBA.1.2012.001 
Reid, R. C., Harper, J. M., \& Anderson, E. H. (2009). Coping strategies used by hypersexual patients to defend against the painful effects of shame. Clinical Psychology \& Psychotherapy, 16(2), 125-138.

Reid, R. C., \& Kafka, M. P. (2014). Controversies About Hypersexual Disorder and the DSM-5. Current Sexual Health Reports, 6(4), 259-264. http://doi.org/10.1007/s11930-014-0031-9

Reid, R. C., Karim, R., McCrory, E., \& Carpenter, B. N. (2010). Self-reported differences on measures of executive function and hypersexual behavior in a patient and community sample of men. The International Journal of Neuroscience, 120(2), 120-7. http://doi.org/10.3109/00207450903165577

Reid, R. C., \& Meyer, M. D. (2016). Substance Use Disorders in Hypersexual Adults. Current Addiction Reports, 1-6. http://doi.org/10.1007/s40429-016-0124-9

Reid, R. C., Stein, J. A., \& Carpenter, B. N. (2011). Understanding the roles of shame and neuroticism in a patient sample of hypersexual men. The Journal of Nervous and Mental Disease, 199(4), 263-7. http://doi.org/10.1097/NMD.0b013e3182125b96

Rendina, H. J., Golub, S. A., Grov, C., \& Parsons, J. T. (2012). Stigma and sexual compulsivity in a community-based sample of HIV-positive gay and bisexual men. AIDS and Behavior, 16(3), 741-50. http://doi.org/10.1007/s10461-011-0048-2

Rettenberger, M., Klein, V., \& Briken, P. (2015). The Relationship Between Hypersexual Behavior, Sexual Excitation, Sexual Inhibition, and Personality Traits. Archives of Sexual Behavior, First Publ, 1-15. http://doi.org/10.1007/s10508-014-0399-7

Rice, E., Holloway, I., Winetrobe, H., Rhoades, H., Barman-Adhikari, A., Gibbs, J., ... Dunlap, S. (2012). Sex Risk among Young Men who have Sex with Men who use Grindr, a Smartphone Geosocial Networking Application. AIDS and Clinical Research, 84, 1-6.

Rickards, S., \& Laaser, M. (1999). Sexual acting-out in borderline women: Impulsive selfdestructiveness or sexual addiction/compulsivity? Sexual Addiction \& Compulsivity, 6, 3145.

Rief, W., Buhlmann, U., Wilhelm, S., Borkenhagen, A., \& Brähler, E. (2006). The prevalence of body dysmorphic disorder: a population-based survey. Psychological Medicine, 36(6), 877-85. http://doi.org/10.1017/S0033291706007264

Rinehart, N. J., \& McCabe, M. P. (1998). An empirical investigation of hypersexuality. Sexual and Marital Therapy, 13(4), 369-384. 
Robbins, T., \& Everitt, B. (2010). The neurobiology of addiction. Oxford: Oxford University Press.

Rodríguez-Shadow, M. J., \& López, M. (2009). Antropología y arqueología de la sexualidad: premisas teóricas y conceptuales. Coatepec, 16, 77-89.

Rosel, J., Jara, P., \& Herrero, F. (2014). Pronóstico con interacción de variables categóricas. Castellón de la Plana: Universitat Jaume I. http://doi.org/10.6035/Sapientia82

Rosen, R., Brown, C., Heiman, J., Leiblum, S., Meston, C., Shabsigh, R., ... D’Agostino, R. (2000). The Female Sexual Function Index (FSFI): a multidimensional self-report instrument for the assessment of female sexual function. Journal of Sex \& Marital Therapy, 26(2), 191208. http://doi.org/10.1080/009262300278597

Rosenberg, K. P., Carnes, P., \& O'Connor, S. (2014). Evaluation and treatment of sex addiction. Journal of Sex \& Marital Therapy, 40(2), 77-91. http://doi.org/10.1080/0092623X.2012.701268

Rosler, A., \& Wiztum, E. (1998). Treatment of men with paraphilia with a long-acting analogue of gonadotropin-releasing hormone. The New England Journal of Medicine, 338, 416422.

Rosler, A., \& Wiztum, E. (2009). One hundred men with severe paraphilia treated over a period of 15 years with a long-acting ana- logue of gonadotropin-releasing hormone: Effects and side effects. In 90th annual meeting of the Endocrine Society. San Francisco, CA.

Ross, M. W., Mansson, S. A., Daneback, K., Månsson, S.-A., \& Daneback, K. (2012). Prevalence, severity and correlates of problematic sexual Internet use in Swedish men and women. Archives of Sexual Behavior, 51(2), 459-66. http://doi.org/10.1007/s10508-011-9762-0

Ross, M. W., Rosser, B. R. S., McCurdy, S., \& Feldman, J. (2007). The Advantages and Limitations of Seeking Sex Online: A Comparison of Reasons Given for Online and Offline Sexual Liaisons by Men Who Have Sex With Men. Journal of Sex Research, 44(1), 59-71. http://doi.org/10.1080/00224490709336793

Rudden, M., Sweeney, J., Frances, A., \& Gilmore, M. (1983). A comparison of delusional disorders in women and men. The American Journal of Psychiatry, 140(12), 1575-8.

Ruiz, M. A., Pardo, A., \& San Martín, R. (2010). Modelos de ecuaciones estructurales. Papeles Del Psicólogo, 31(1), 34-45.

Rye, B. J. (2013). The Sexual Opinion Survey. In T. D. Fisher, C. M. Davis, W. L. Yarber, \& S. L. 
Davis (Eds.), Handbook of Sexuality-Related Measures (3rd editio, pp. 231-236). New York,: Routledge.

Rye, B. J., Meaney, G. J., Yessis, J., \& Mckay, A. (2012). Uses of the "Comfort with Sexual Matters for Young Adolescents" scale: A measure of erotophobia-erotophilia for youth. Canadian Journal of Human Sexuality, 21(2), 91-100.

Rye, B. J., Serafini, T., \& Bramberger, T. (2015). Erotophobic or erotophilic: What are young women's attitudes towards BDSM? Psychology \& Sexuality, 6(4), 340-356. http://doi.org/10.1080/19419899.2015.1012108

Safarinejad, M. R. (2009). Treatment of nonparaphilic hypersexuality in men with a long-acting analog of gonadotropin-releasing hormone. Journal of Sexual Medicine, 6, 1151-1164.

Samenow, C. P. (2010). A Biopsychosocial Model of Hypersexual Disorder/Sexual Addiction. Sexual Addiction \& Compulsivity, 17(2), 69-81. http://doi.org/10.1080/10720162.2010.481300

Samenow, C. P. (2011). What You Should Know about Hypersexual Disorder. Sexual Addiction \& Compulsivity, 18(October 2014), 107-113. http://doi.org/10.1080/10720162.2011.596762

Samenow, C. P. (2013). SASH Policy Statement (Revised): The Future of Problematic Sexual Behaviors/Sexual Addiction. Sexual Addiction \& Compulsivity, 20(October 2014), 255258. http://doi.org/10.1080/10720162.2013.847752

Samuels, J., Eaton, W. W., Bienvenu, O. J., Brown, C. H., Costa, P. T., \& Nestadt, G. (2002). Prevalence and correlates of personality disorders in a community sample. The British Journal of Psychiatry, 180, 536-42.

San Martín, C. (2011). Fármacos, drogas y sexualidad (efectos adversos). In Conocimientos biomédicos y farmacológicos fundamentales para el estudio de la sexualidad (pp. 183244). Madrid: Editorial Dykinson.

Sanders, S. A., Graham, C. A., Yarber, W. L., Crosby, R. A., Dodge, B., \& Milhausen, R. R. (2006). Women who put condoms on male partners: correlates of condom application. American Journal of Health Behavior, 30(5), 460-6. http://doi.org/10.5555/ajhb.2006.30.5.460

Sanders, S. A., Graham, C. M., Bass, J., \& Bancroft, J. (2001). Aprospective study of the effects of oral contraceptives on sexuality and well-being and their relationship to discontinuation. Contraception, 64, 51-58. 
Sansone, R. A., \& Sansone, L. A. (2011). Personality disorders: A nation-based perspective on prevalence. Innovations in Clinical Neuroscience, 8(4), 13-18.

Santamaría, F. C. (2010). Manual de sexología y terapia sexual. Madrid: Editorial Síntesis.

Satterwhite, C. L., Torrone, E., Meites, E., Dunne, E. F., Mahajan, R., Ocfemia, M. C. B., ... Weinstock, H. (2013). Sexually transmitted infections among US women and men: prevalence and incidence estimates, 2008. Sexually Transmitted Diseases, 40(3), 187-93. http://doi.org/10.1097/OLQ.0b013e318286bb53

Savaş, A., Efesoy, O., Cayan, F., \& Cayan, S. (2012). Sexual injuries during consensual sexual activity. Turkish journal of trauma \& emergency surgery, 18(6), 519-23. http://doi.org/10.5505/tjtes.2012.47347

Savin-Williams, R. C. (2014). An Exploratory Study of the Categorical Versus Spectrum Nature of Sexual Orientation. Journal of Sex Research, 51(4), 446-453.

Sbraga, T. P., \& O'Donohue, W. T. (2004). The Sex Addiction Workbook: Proven Strategies to Help You Regain Control of Your Life. Oakland, CA: New Harbinger publications.

Schiavi, R. C., Schreiner-Engel, P., Mandeh, J., Schanzer, H., \& Cohen, M. (1990). Healthy aging and male sexual function. American Journal of Psychiatry, 147, 766-771.

Schmitt, D. P. (2004). The big five related to risky sexual behaviour across 10 world regions: Differential personality associations of sexual promiscuity and relationship infidelity. European Journal of Personality, 18(4), 301-319. http://doi.org/10.1002/per.520

Schmitt, D. P., \& Buss, D. M. (2000). Sexual Dimensions of Person Description: Beyond or Subsumed by the Big Five? Journal of Research in Personality, 34(2), 141-177. http://doi.org/10.1006/jrpe.1999.2267

Schneider, J. P., \& Corley, M. D. (2002). Disclosure of Extramarital Sexual Activities by Persons with Addictive or Compulsive Sexual Disorders: Results of a Study and Implications for Therapists. In P. Carnes \& K. M. Adams (Eds.), The Clinical Management of Sex Addiction (pp. 137-161). New York, NY: Routledge.

Schneider, J. P., \& Schneider, B. H. (1996). Couple recovery from sexual addiction/coaddiction: Research of a survey of 88 marriages. Sexual Addiction \& Compulsivity, 3, 111-126.

Schneider, J. P., \& Weiss, D. (2001). Cybersex exposed: Simple fantasy or obsession? Center City, MN: Hazelden Publishing and Education.

Schreiner-Engel, P., \& Schiavi, R. C. (1986). Lifetime psychopathology in individuals with low 
sexual desire. The Journal of Nervous and Mental Disease, 174(11), 646-51.

Schultz, K., Hook, J. N., Davis, D. E., Penberthy, J. K., \& Reid, R. C. (2014). Nonparaphilic Hypersexual Behavior and Depressive Symptoms: A Meta-Analytic Review of the Literature. Journal of Sex \& Marital Therapy, 40(6), 477-487. http://doi.org/10.1080/0092623X.2013.772551

Schwartz, M. A. (1992). Sexual Compulsivity as Post-Traumatic Stress Disorder. Psychiatric Annals, 22(6), 333-338.

Schwartz, S. A., \& Abramowitz, J. S. (2003). Are nonparaphilic sexual addictions a variant of obsessive-compulsive disorder? A pilot study. Cognitive and Behavioral Practice, 10(4), 372-377. http://doi.org/10.1016/S1077-7229(03)80054-8

Schwartz, \& Abramowitz, J. S. (2005). Contrasting nonparaphilic sexual addictions and OCD. In Concepts and Controversies in Obsessive-Compulsive Disorder (pp. 117-184). New York, NY, NY: Springer New York.

Scott, W. A. (1958). Research definitions of mental health and mental illness. Psychological Bulletin, 55(1), 29-45.

Seegers, J. A. (2003). The Prevalence of Sexual Addiction Symptoms on the College Campus. Sexual Addiction $\quad \& \quad$ Compulsivity, 247-258. http://doi.org/10.1080/10720160390268942

Shepherd, L. (2009). Cognitive Behavior Therapy for Sexually Addictive Behavior. Clinical Case Studies, 9(1), 18-27. http://doi.org/10.1177/1534650109348582

Sherwin, B. B. (1991). The impact of different doses of estrogen and progestin on mood and sexual behavior in postmenopausal women. Journal of Clinical Endocrinology and Metabolism, 72(336-343).

Sheskin, D. (2007). Handbook of Parametric and Nonparametric Statistical Procedures. London, UK: Chapman \& Hall/ CRC Press.

Sierra, J. C., Ortega, V., \& Zubeidat, I. (2006). Confirmatory Factor Analysis of a Spanish Version of the Sex Fantasy Questionnaire: Assessing Gender Differences. Journal of Sex \& Marital Therapy, 32(2), 137-159. http://doi.org/10.1080/00926230500442318

Simon, L. E., Daneback, K., \& Ševčíková, A. (2015). The Educational Dimension of Pornography: Adolescents' Use of New Media for Sexual Purposes. In P. Lorentz, D. Smahel, M. Metykova, \& M. F. Wright (Eds.), Living in the digital age: self-presentation, networking, 
playing, and participating in politics (pp. 33-48). Brno: Muni Press.

Singh, A., Kandimala, G., Dewey, R. B., \& O'Suilleabhain, P. (2007). Risk factors for pathologic gambling and other compulsions among Parkinson's disease patients taking dopamine agonists. Journal of Clinical Neuroscience : Official Journal of the Neurosurgical Society of Australasia, 14(12), 1178-81. http://doi.org/10.1016/j.jocn.2007.01.009

Skegg, K., Nada-Raja, S., Dickson, N., \& Paul, C. (2010). Perceived "out of control" sexual behavior in a cohort of young adults from the Dunedin Multidisciplinary Health and Development Study. Archives of Sexual Behavior, 39(4), 968-78. http://doi.org/10.1007/s10508-009-9504-8

Soto, C. J., John, O. P., Gosling, S. D., \& Potter, J. (2011). Age differences in personality traits from 10 to 65: Big Five domains and facets in a large cross-sectional sample. Journal of Personality and Social Psychology, 100(2), 330-348. http://doi.org/10.1037/a0021717

Sowislo, J. F., \& Orth, U. (2013). Does low self-esteem predict depression and anxiety? A metaanalysis of longitudinal studies. Psychological Bulletin, 139(1), 213-40. http://doi.org/10.1037/a0028931

Spielberger, C. D., Gorsuch, R. L., \& Lushene, R. E. (2002). STAl: Cuestionario de Ansiedad Estado-Rasgo. Manual. (6 edición). Madrid: TEA Ediciones.

Spinella, M. (2004). Hypersexuality and dysexecutive syndrome after a thalamic infarct. The International Journal of Neuroscience, 114(12), 1581-90. http://doi.org/10.1080/00207450490509339

Spinella, M. (2005). Self-rated executive function: development of the executive function index. The International Journal of Neuroscience, 115(5), 649-67. http://doi.org/10.1080/00207450590524304

Sroufe, A. (2005). Attachment and development: A prospective, longitudinal study from birth to adulthood. Journal of Attachment and Human Development, 7, 349-367.

Stall, R., Paul, J., Greenwood, G., Pollack, L., Bein, E., \& Crosby, G. (2001). Alcohol use, drug use, and alcohol related problems among men who have sex with men: The Urban Men's Health Study. Addiction, 96, 1589-1601.

Starcevic, V., \& Brakoulias, V. (2016). Current understanding of the relationships between obsessive-compulsive disorder and personality disturbance. Current Opinion in Psychiatry, 29(0), 1-6. http://doi.org/10.1097/YCO.0000000000000291 
Stavro, K., Rizkallah, E., Dinh-williams, L., Stavro, K., Rizkallah, E., \& Dinh-williams, L. (2013). Hypersexuality among a Substance Use Disorder Population Hypersexuality among a Substance Use Disorder Population. Sexual Addiction \& Compulsivity, 20(3), 210-216. http://doi.org/10.1080/10720162.2013.787379

Steffens, B. A., \& Rennie, R. L. (2006). The Traumatic Nature of Disclosure for Wives of Sexual Addicts. Sexual Addiction \& Compulsivity, 13(2-3), 247-267. http://doi.org/10.1080/10720160600870802

Stein, D. (2008). Classifying hypersexual disorder: compulsive, impulsive and addic- tive models. Psychiatric Clinics of North America, 31(4), 587-591.

Stein, D. J., Hugo, F., Oosthuizen, P., Hawkridge, S. M., \& van Heerden, B. (2000). Neuropsychiatry of hypersexuality. CNS Spectrums, 5(1), 36-46.

Storholm, E. D., Fisher, D. G., Napper, L. E., Reynolds, L., \& Halkitis, P. N. (2011). A Psychometric Analysis of the Compulsive Sexual Behavior Inventory. Sexual Addiction \& Compulsivity, 18(2), 86-103. http://doi.org/10.1080/10720162.2011.584057

Štulhofer, A., \& Rimac, I. (2009). Determinants of Homonegativity in Europe. Journal of Sex Research, 46(1), 24-32.

Stupiansky, N. W., Reece, M., Middlestadt, S. E. S. E., Finn, P., Sherwood-Laughling, C., \& Sherwood-Laughlin, C. (2009). The Role of Sexual Compulsivity in Casual Sexual Partnerships among College Women. Sexual Addiction \& Compulsivity, 16(3), 241-252. http://doi.org/10.1080/10720160903202760

Suls, J., \& Rothman, A. (2004). Evolution of the biopsychosocial model: prospects and challenges for health psychology. Health Psychology: Official Journal of the Division of Health Psychology, American Psychological Association, 23(2), 119-25. http://doi.org/10.1037/0278-6133.23.2.119

Sutton, K. S., Stratton, N., Pytyck, J., Nathan, J., \& Cantor, J. M. (2014). Patient Characteristics by Type of Hypersexuality Referral : A Quantitative Chart Review of 115 Consecutive Male Cases. Journal of Sex \& Marital Therapy, (17), 1-18. http://doi.org/10.1080/0092623X.2014.935539

Swann, W. B., \& Bosson, J. K. (2010). Self and Identity. In S. T. Fiske, D. T. Gilbert, \& G. Lindzey (Eds.), Handbook of Social Psychology (pp. 589-628). Hoboken, NJ: John Wiley\& Sons. http://doi.org/10.1002/9780470561119.socpsy001016

Swanson, D. E. W., Polackwich, A. S., Helfand, B. T., Masson, P., Hwong, J., Dugi, D. D., ... 
McVary, K. T. (2014). Penile fracture: outcomes of early surgical intervention. Urology, 84(5), 1117-21. http://doi.org/10.1016/j.urology.2014.07.034

Tedesco, A., \& Bola, J. R. (1997). A pilot study of the relationship between childhood sexual abuse and compulsive sexual behaviors in adults. Sexual Addiction \& Compulsivity, 4, 147-157.

Teng, Y., \& Mak, W. W. S. (2011). The role of planning and self-efficacy in condom use among men who have sex with men: an application of the Health Action Process Approach model. Health Psychology, 30(1), 119-28. http://doi.org/10.1037/a0022023

Thompson, A., Nelson, B., McNab, C., Simmons, M., Leicester, S., McGorry, P. D., ... Yung, A. R. (2010). Psychotic symptoms with sexual content in the "ultra high risk" for psychosis population: frequency and association with sexual trauma. Psychiatry Research, 177(1-2), 84-91. http://doi.org/10.1016/j.psychres.2010.02.011

Thornton, D., \& Laws, R. D. (2009). Cognitive approaches to the assessment of sexual interest in sexual offenders. Hoboken, NJ: John Wiley \& Sons.

Tiefer, L. (2004). Sex Is Not a Natural Act: And Other Essays. Boulder: Westview Press.

Timms, R. J., \& Conners, P. (1992). Adult promiscuity following childhood sexual abuse: An introduction. Psychoterapy Patient, 8, 19-27.

Trickett, P. K., Noll, J. G., \& Putnam, F. W. (2011). The impact of sexual abuse on female development: Lessons from a multigenerational, longitudinal researchstudy. Developmental and Psychopathology, 23(2), 453-476.

Tripodi, F., Eleuteri, S., Giuliani, M., Rossi, R., Livi, S., Petruccelli, I., ... Simonelli, C. (2015). Unusual online sexual interests in heterosexual Swedish and Italian university students. Sexologies, 24(4), e84-e93. http://doi.org/10.1016/j.sexol.2015.03.003

Trobst, K. K., Herbst, J. H., Masters, H. L., \& Costa, P. T. (2002). Personality Pathways to Unsafe Sex: Personality, Condom Use, and HIV Risk Behaviors. Journal of Research in Personality, 36(2), 117-133. http://doi.org/10.1006/jrpe.2001.2334

Tsai, M., Feldman-Summers, S., \& Edgar, M. (1979). Childhood molestation:variables related to differential impact of psychosexual functioning in adult women. Journal of Abnormal Psychology, 88, 407-417.

Tsai, S. J., Hwang, J. P., Yang, C. H., Liu, K. M., \& Lirng, J. F. (1999). Inappropriate sexual behaviors in dementia: a preliminary report. Alzheimer Disease and Associated Disorders, 
13(1), 60-2.

Udry, J. R., Talbert, L. M., \& Morris, N. M. (1986). Biosocial foundations of adolescent female sexuality. Demography, 23, 217-229.

Vaillancourt-morel, M., Godbout, N., \& Labadie, C. (2015). Child Abuse \& Neglect Avoidant and compulsive sexual behaviors in male and female survivors of childhood sexual abuse. Child Abuse \& Neglect, 40, 48-59. http://doi.org/10.1016/j.chiabu.2014.10.024

Van Minnen, A., \& Kampman, M. (2000). The interaction between anxiety and sexual functioning: A controlled study of sexual functioning in women with anxiety disorders. Sexual and Relationship Therapy, 15(1), 47-57. http://doi.org/10.1080/14681990050001556

Ventegodt, S. (1998). Sex and the quality of life in Denmark. Archives of Sexual Behavior, 27(3), 295-307.

Voisin, D. R., Hotton, A., Tan, K., \& Diclemente, R. (2013). A Longitudinal Examination of Risk and Protective Factors Associated with Drug Use and Unsafe Sex among Young African American Females. Children and Youth Services Review, 35(9), 1440-1446. http://doi.org/10.1016/j.childyouth.2013.05.019

Voon, V., \& Fox, S. H. (2007). Medication-related impulse control and repetitive behaviors in Parkinson disease. Archives of Neurology, 64(8), 1089-96. http://doi.org/10.1001/archneur.64.8.1089

Voon, V., Mole, T. B., Banca, P., Porter, L., Morris, L., Mitchell, S., ... Irvine, M. (2014). Neural correlates of sexual cue reactivity in individuals with and without compulsive sexual behaviours. PloS One, 9(7), e102419. http://doi.org/10.1371/journal.pone.0102419

Wainberg, M. L., Muench, F., Morgenstern, J., Hollander, E., Irwin, T., \& Parsons, J. T. (2006). A double-blind study of citalopram versus placebo in the treatment of compulsive sexual behaviors in gay and bisexual men. Journal of Clinical Psychiatry, 67, 1968.

Wallace, M., \& Safer, M. (2009). Hypersexuality among cognitively impaired older adults. Geriatric Nursing, 30(4), 230-7. http://doi.org/10.1016/j.gerinurse.2008.09.001

Walters, G. D., Knight, R. a, \& Långström, N. (2011). Is hypersexuality dimensional? Evidence for the DSM-5 from general population and clinical samples. Archives of Sexual Behavior, 40(6), 1309-21. http://doi.org/10.1007/s10508-010-9719-8

Ware, M. R., Emmanuel, M. P., Johnson, M. R., Brawman-Mintzer, O., Knapp, R., Crawford- 
Harrison, M., \& Lydiard, R. B. (1996). Self-reported sexual dysfunctions in anxiety disorder patients. Psychopharmacology Bulletin, 32, 530.

Washton, A. M., \& Boundy, D. (2000). Willpower's not enough: understanding and recovering from addictions of every kind. New York, NY: HarperCollins.

Watson, D. (2003). Subtypes, Specifiers, Epicycles, and Eccentrics: Toward a More Parsimonious Taxonomy of Psychopathology. Clinical Psychology: Science and Practice, 10(2), 233-238. http://doi.org/10.1093/clipsy.bpg013

Watson, D., \& Clark, L. A. (2006). Clinical Diagnosis at the Crossroads. Clinical Psychology: Science and Practice, 13(3), 210-215. http://doi.org/10.1111/j.1468-2850.2006.00026.x

Weiss, D. (2004a). The Prevalence of Depression in Male Sex Addicts Residing in the United States. Sexual Addiction \& Compulsivity, 11(1-2), 57-69. http://doi.org/10.1080/10720160490458247

Weiss, D. (2004b). Treating sex addiction. In R. H. Coombs (Ed.), Handbook of Addictive Disorders: A Practical Guide to Diagnosis and Treatment (pp. 233-274). New York, NY: John Wiley\& Sons.

Widiger, T. A. (2001). social anxiety, social phobia, and avoidant personality disorder. In W. R. Corzier \& L. Alden (Eds.), International Handbook of Social Anxiety (pp. 335-356). New York, NY: Wiley.

Widiger, T. A., \& Costa, P. T. (2012). Integrating normal and abnormal personality structure: the Five-Factor Model. Journal of Personality, 80(6), 1471-506. http://doi.org/10.1111/j.1467-6494.2012.00776.x

Widman, L., Noar, S. M., Choukas-Bradley, S., \& Francis, D. B. (2014). Adolescent sexual health communication and condom use: a meta-analysis. Health Psychology, 33(10), 1113-24. http://doi.org/10.1037/hea0000112

Wilson, M. (2000). Creativity and Shame Reduction in Sex Addiction Treatment. Sexual Addiction \& Compulsivity, 7(4), 229-248. http://doi.org/10.1080/10720160008403699

Wines, D. (1997). Exploring the applicability of criteria for substance dependence to sexual addiction. Sexual Addiction \& Compulsivity, 4(3), 195-220. http://doi.org/10.1080/10720169708404228

Winters, J., Christoff, K., \& Gorzalka, B. B. (2010). Dysregulated sexuality and high sexual desire: distinct constructs? Archives of Sexual Behavior, 39(5), 1029-1043. 
http://doi.org/10.1007/s10508-009-9591-6

Witkiewitz, K., \& Marlatt, G. A. (2004). Relapse prevention for alcohol and drug problems: that was Zen, this is Tao. The American Psychologist, 59(4), 224-35. http://doi.org/10.1037/0003-066X.59.4.224

Womack, S., Hook, J., Ramos, M., Davis, D. E., \& Penberthy, J. K. (2013). Measuring hypersexual behavior. Sexual Addiction \& Compulsivity, 20(1-2), 65-78. http://doi.org/10.1080/10720162.2013.768126

Wright, P. J., Bae, S., \& Funk, M. (2013). United States women and pornography through four decades: exposure, attitudes, behaviors, individual differences. Archives of Sexual Behavior, 42(7), 1131-44. http://doi.org/10.1007/s10508-013-0116-y

Zapf, J. L., Greiner, J., \& Carroll, J. (2008). Attachment styles and male sex addiction. Sexual Addiction \& Compulsivity, 15, 158-175.

Zhao, J., Song, F., Ren, S., Wang, Y., Wang, L., Liu, W., ... Sun, Y. (2012). Predictors of condom use behaviors based on the Health Belief Model (HBM) among female sex workers: a cross-sectional study in Hubei Province, China. PloS One, 7(11), e49542. http://doi.org/10.1371/journal.pone.0049542

Zuckerman, M., \& Kuhlman, D. M. (2000). Personality and risk-taking: common biosocial factors. Journal of Personality, 68(6), 999-1029. 


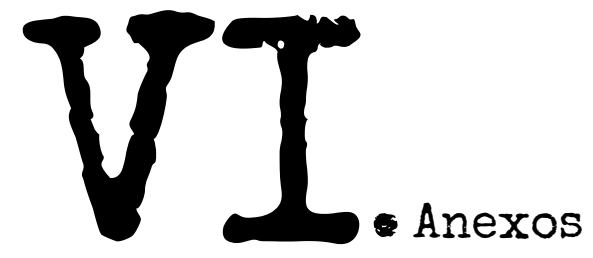



Anexo I. Trastornos del DSM-IV diagnosticables a partir de los módulos de la SCID-I y II empleados en esta investigación. 


\begin{tabular}{|c|c|}
\hline Trastornos del estado de ánimo & $\begin{array}{l}\text { Trastorno bipolar I (incluye trastorno bipolar I episodio más reciente hipomaníaco, } \\
\text { maníaco, mixto, depresivo, no especificado o episodio maníaco único, ) } \\
\text { Trastorno bipolar II } \\
\text { Trastorno ciclotímico } \\
\text { Trastorno depresivo mayor, episodio único } \\
\text { Trastorno depresivo mayor, recidivante } \\
\text { Trastorno depresivo no especificado } \\
\text { Trastorno del estado de ánimo debido a enfermedad médica } \\
\text { Trastorno del estado de ánimo inducido por alcohol u otras sustancias }\end{array}$ \\
\hline Trastornos relacionados con sustancias & $\begin{array}{l}\text { Abuso o dependencia del alcohol } \\
\text { Abuso o dependencia de alucinógenos } \\
\text { Abuso o dependencia de anfetaminas } \\
\text { Abuso o dependencia de cannabis } \\
\text { Abuso o dependencia de cocaína } \\
\text { Abuso o dependencia de fenciclidina } \\
\text { Abuso o dependencia de inhalantes } \\
\text { Abuso o dependencia de opiáceos } \\
\text { Abuso o dependencia de sedantes, hipnóticos o ansiolíticos } \\
\text { Abuso o dependencia de otras sustancias (o desconocidas) }\end{array}$ \\
\hline Trastornos de ansiedad & $\begin{array}{l}\text { Trastorno de angustia con agorafobia } \\
\text { Trastorno de angustia sin agorafobia } \\
\text { Agorafobia sin historia de trastorno de angustia } \\
\text { Fobia específica } \\
\text { Fobia social } \\
\text { Trastorno obsesivo-compulsivo } \\
\text { Trastorno por estrés postraumático } \\
\text { Trastorno de ansiedad no especificado } \\
\text { Trastorno de ansiedad debido a enfermedad médica } \\
\text { Trastorno de ansiedad inducido por alcohol u otras sustancias }\end{array}$ \\
\hline
\end{tabular}




\begin{tabular}{|c|c|}
\hline Trastornos somatomorfos & $\begin{array}{l}\text { Trastorno de somatización } \\
\text { Trastorno somatomorfo indiferenciado } \\
\text { Hipocondría } \\
\text { Trastorno dismórfico corporal }\end{array}$ \\
\hline Trastornos de la conducta alimentaria & $\begin{array}{l}\text { Anorexia nerviosa } \\
\text { Bulimia nerviosa }\end{array}$ \\
\hline Trastornos adaptativos & $\begin{array}{l}\text { Trastorno adaptativo (incluye trastorno adaptativo con estado de ánimo depresivo, con } \\
\text { ansiedad, con trastorno del comportamiento o mixto) } \\
\text { Trastorno adaptativo no especificado }\end{array}$ \\
\hline Trastornos parafílicos & $\begin{array}{l}\text { Exhibicionismo } \\
\text { Fetichismo } \\
\text { Froteurismo } \\
\text { Pedofilia } \\
\text { Masoquismo sexual } \\
\text { Sadismo sexual } \\
\text { Fetichismo transvestista (sólo varón heterosexual) } \\
\text { Voyeurismo }\end{array}$ \\
\hline Trastornos de la personalidad & $\begin{array}{l}\text { Trastorno obsesivo-compulsivo de la personalidad } \\
\text { Trastorno límite de la personalidad }\end{array}$ \\
\hline
\end{tabular}



Anexo II. Batería de evaluación de la primera fase de la investigación. El formato de los cuestionarios coincide con el empleado durante la recogida de datos. 


\section{COMPORTAMIENTO SEXUAL EN JÓVENES}

Los siguientes cuestionarios forman parte de una investigación más amplia que tiene por objeto el estudio del comportamiento sexual en jóvenes. Gracias a vuestra colaboración esperamos comprender algunos aspectos de vuestros hábitos sexuales.

La cumplimentación de los cuestionarios no te llevará más de 5 minutos. Lee con atención cada uno de los enunciados y trata de contestar a todas y cada una de las preguntas con sinceridad. Recuerda que los datos que se recojan son anónimos y su única finalidad es la investigación.

\section{Datos básicos}

Sexo: $\square$ Hombre $\quad \square$ Mujer

Edad:

Pareja estable: $\square \mathrm{Si} \quad \square$ No

Orientación sexual: $\square$ Heterosexual $\quad \square$ Bisexual $\quad \square$ Homosexual

Estudios que estás cursando:

Religión: $\square$ Creyente no practicante (Indicar religión):

$\square$ Creyente practicante (Indicar religión):

$\square$ Ateo o agnóstico

Los cuestionarios que incluimos a continuación forman parte de la primera fase de esta investigación. En una segunda fase, se seleccionarán en función de las respuestas a una serie de personas que participarán si así lo desean en una evaluación más extensa. La segunda fase se remunerará económicamente. Si en ese caso estuvieras dispuesto a participar, incluye tu email a continuación. Te recordamos de nuevo que estos datos son totalmente confidenciales.

E-Mail de contacto:

Muchas gracias por tu colaboración. 
A continuación se presentan una serie de afirmaciones sobre tu comportamiento sexual. Por favor, contesta con sinceridad, tus respuestas son anónimas y confidenciales.

\begin{tabular}{|c|c|c|c|c|}
\hline & 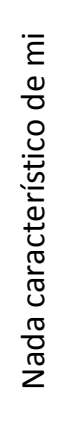 & 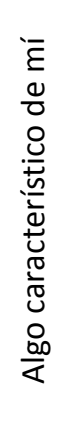 & 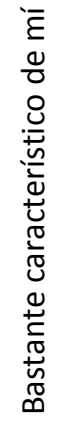 & 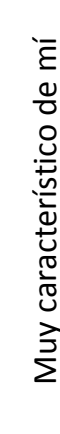 \\
\hline 1. Mi gran apetito sexual ha sido un obstáculo en mis relaciones. & $\square$ & $\square$ & $\square$ & $\square$ \\
\hline $\begin{array}{l}\text { 2. Mis pensamientos y comportamientos sexuales me están causando problemas } \\
\text { en la vida. }\end{array}$ & $\square$ & $\square$ & $\square$ & $\square$ \\
\hline 3. Mis deseos de tener sexo han afectado a mi vida cotidiana. & $\square$ & $\square$ & $\square$ & $\square$ \\
\hline $\begin{array}{l}\text { 4. A veces no consigo cumplir con compromisos y responsabilidades a causa de } \\
\text { mis comportamientos sexuales. }\end{array}$ & $\square$ & $\square$ & $\square$ & $\square$ \\
\hline 5. A veces llego a ponerme tan caliente que podría perder el control. & $\square$ & $\square$ & $\square$ & $\square$ \\
\hline 6. Me sorprendo a mí mismo pensando sobre sexo en el trabajo. & $\square$ & $\square$ & $\square$ & $\square$ \\
\hline 7. Siento que mis pensamientos y sensaciones sexuales son más fuertes que yo. & $\square$ & $\square$ & $\square$ & $\square$ \\
\hline $\begin{array}{l}\text { 8. Tengo que luchar para controlar mis pensamientos y comportamientos } \\
\text { sexuales. }\end{array}$ & $\square$ & $\square$ & $\square$ & $\square$ \\
\hline 9. Pienso en sexo más de lo que me gustaría. & $\square$ & $\square$ & $\square$ & $\square$ \\
\hline $\begin{array}{l}\text { 10. Me ha resultado difícil encontrar parejas sexuales que desearan tener sexo } \\
\text { tanto como yo. }\end{array}$ & $\square$ & $\square$ & $\square$ & $\square$ \\
\hline
\end{tabular}




\section{IH (Reid, Garos y Carpenter, 2011)}

A la hora de completar este cuestionario, recuerda que entendemos como sexo, cualquier actividad o conducta que estimula o excita a una persona con la intención de producir un orgasmo o placer sexual (por ejemplo, masturbación o sexo en solitario, uso de pornografía, relaciones sexuales con una pareja, sexo oral, sexo anal, etc.). Las conductas sexuales pueden o no implicar a una pareja.

\begin{tabular}{|ccccc|}
\hline 1 & 2 & 3 & 4 & 5 \\
\hline Nunca & Pocas veces & Algunas veces & Bastantes veces & Muchas veces \\
\hline
\end{tabular}

1. Uso el sexo para olvidarme de las preocupaciones cotidianas.

2. Aunque me he prometido no repetir cierta conducta sexual, me encuentro volviéndola a hacer una y otra vez.

3. Hacer cualquier cosa relacionada con el sexo me ayuda a sentirme menos solo/a.

4. Participo en actividades sexuales sabiendo que más tarde me arrepentiré.

5. Sacrifico cosas que realmente quiero en mi vida por el sexo.

\begin{tabular}{|l|l|l|l|l|l|l|l|}
\hline 1 & 2 & 3 & 4 & 5 \\
\hline
\end{tabular}

6. Recurro al sexo cuando experimento sentimientos desagradables (por ejemplo, frustración, tristeza, ira).

7. Fracaso en mis intentos por cambiar mi conducta sexual.

8. Cuando me siento inquieto, recurro al sexo para calmarme.

9. Mis pensamientos y fantasías sexuales me distraen de cumplir tareas importantes.

\begin{tabular}{l|l|l|l|l|}
\hline & 2 & 3 & 5 \\
\hline
\end{tabular}

10. Practico actividades sexuales que están en contra de mis valores y creencias.

\begin{tabular}{l|l|l|l|l|l|l|l}
\hline 1 & 2 & 3 & 4 & 5 \\
\hline
\end{tabular}

11. Aunque mi conducta sexual es irresponsable o imprudente, tengo dificultades para detenerla.

12. Siento como si mi conducta sexual me llevara en una dirección hacia la que no quiero ir.

13. Hacer cualquier cosa relacionada con el sexo me ayuda a manejar mi estrés.

14. Mi conducta sexual controla mi vida.

15. Siento que mis ansias y deseos sexuales son más fuertes que mi autodisciplina.

\begin{tabular}{l|l|l|l|l|l|l|l|l}
\hline 1 & 2 & 3 & 4 & 5 \\
\hline
\end{tabular}

16. El sexo es para mí una forma de manejar el malestar emocional que siento.

17. Sexualmente, me comporto de formas que creo que están mal.

18. Uso el sexo como una forma de ayudarme a afrontar mis problemas.

19. Mis actividades sexuales interfieren en aspectos de mi vida como el trabajo o los estudios. 
Por favor, contesta cada pregunta marcando con una cruz en la columna apropiada.

\begin{tabular}{|c|c|c|}
\hline Ítem & No & $\mathrm{Si}$ \\
\hline 1. ¿̇Has sufrido algún abuso sexual durante tu infancia y adolescencia? & & \\
\hline $\begin{array}{l}\text { 2. Frecuentemente, ¿has comprado revistas o explorado sitios en internet con } \\
\text { contenido sexual explícito? }\end{array}$ & & \\
\hline $\begin{array}{l}\text { 3. ¿Sabes si tus padres han tenido problemas derivados de la falta de control sobre } \\
\text { sus impulsos sexuales? }\end{array}$ & & \\
\hline 4. ¿A menudo te encuentras preocupado por pensamientos sexuales? & & \\
\hline 5. ¿Crees que tu conducta sexual se aleja de la normalidad? & & \\
\hline $\begin{array}{l}\text { 6. ¿Tu pareja o personas significativas de tu entorno se han preocupado o se han } \\
\text { quejado por tu conducta sexual desmedida? }\end{array}$ & & \\
\hline $\begin{array}{l}\text { 7. ¿Tienes problemas para detener tu conducta sexual cuando sabes que es } \\
\text { inapropiado? }\end{array}$ & & \\
\hline 8. ¿Alguna vez te has sentido mal por tu conducta sexual desmedida? & & \\
\hline 9. ¿Alguna vez tu conducta sexual te ha creado problemas a ti o a tu familia? & & \\
\hline 10. ¿Alguna vez has buscado ayuda por una conducta sexual que te desagradaba? & & \\
\hline 11. ¿Alguna vez te ha preocupado que alguien descubra tus actividades sexuales? & & \\
\hline 12. ¿'Has herido emocionalmente a alguien por tu conducta sexual? & & \\
\hline 13. ¿Alguna de tus actividades sexuales está en contra de la ley? & & \\
\hline 14. ¿Te has prometido a ti mismo eliminar algún aspecto de tu conducta sexual? & & \\
\hline 15. ¿'Te has esforzado sin éxito por abandonar algún tipo de actividad sexual? & & \\
\hline 16. ¿ ¿Ocultas a los demás algún aspecto de tu conducta sexual? & & \\
\hline 17. ¿Has intentado detener algún aspecto de tu actividad sexual? & & \\
\hline 18. ¿Alguna vez te has sentido humillado por tu conducta sexual? & & \\
\hline 19. ¿El sexo ha sido para ti una forma de escapar de los problemas? & & \\
\hline 20. ¿Te sientes deprimido después de tener sexo? & & \\
\hline 21. ¿HHas sentido la necesidad de abandonar ciertos tipos de actividad sexual? & & \\
\hline 22. ¿Tu actividad sexual ha interferido en tu vida familiar? & & \\
\hline 23. ¿Has llevado a cabo insinuaciones o contactos sexuales con menores? & & \\
\hline 24. ¿Te sientes controlado por tu deseo sexual? & & \\
\hline 25. ¿Alguna vez has pensado que tu deseo sexual es más fuerte que tú? & & \\
\hline
\end{tabular}



Anexo III. Batería de evaluación de la fase II de la investigación. El formato de los cuestionarios coincide con el empleado durante la recogida de datos. EI NEO PI-R se completaba con un cuadernillo de aplicación y respondiendo en una plantilla aparte, de modo que omitimos su inclusión en esta batería. Sí se incluye la hoja de respuestas empleada durante la administración de la SCID-I y II. 
Código del participante:

E-mail de contacto:

Número de teléfono:

Sexo: $\square$ Hombre $\quad \square$ Mujer

Modalidad: $\square$ Control $\quad \square$ Subclínico

Entrevista clínica estructurada para los trastornos del Eje I y II 
A. Cinco (o más)... durante un periodo de 2 semanas... uno de los síntomas debe ser (1) estado de ánimo depresivo o (2) pérdida de interés o de la capacidad para el placer

(1) Estado de ánimo depresivo

(2) Disminución acusada del interés o de la capacidad para el placer

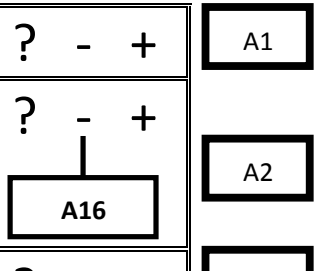

(3) Pérdida/aumento de peso; apetito reducido/aumentado

$?-+\frac{A 3}{3}$

(4) Insomnio o hipersomnia

(5) Agitación o enlentecimiento psicomotores

(6) Fatiga o pérdida de energía

(7) Sentimientos de inutilidad o de culpa excesivos o inapropiados

(8) Disminución de la capacidad de pensar o concentrarse

(9) Pensamientos de muerte; ideación, intento o plan suicidas

COMO MÍNIMO CINCO DE (A.1) A (A.9) SON CODIFICADOS «<+> Y COMO MíNIMO UNO DE ELLOS ES (A.1) O (A.2)

C. Deterioro o malestar clínicamente significativos

\begin{tabular}{lll|}
$?$ & - & + \\
$?$ & - & +
\end{tabular}

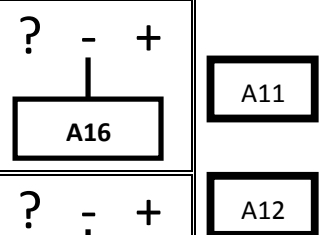

D. No debido a una sustancia o a una enfermedad médica (ver apartado de trastorno del estado de ánimo debido a enfermedad médica)

ATENCIÓN: Una respuesta AFIRMATIVA a la pregunta de la entrevista equivale a una puntuación negativa.

E. No se explica mejor por un duelo

ATENCIÓN: Una respuesta AFIRMATIVA a la pregunta de la entrevista equivale a una puntuación negativa.

\section{LOS CRITERIOS A, C, D Y E SON CODIFICADOS $<<+>>$}

Marcar aquí si los criterios se han cumplido durante el último mes 
A. Estado de ánimo anormal y persistentemente elevado, expansivo o irritable...

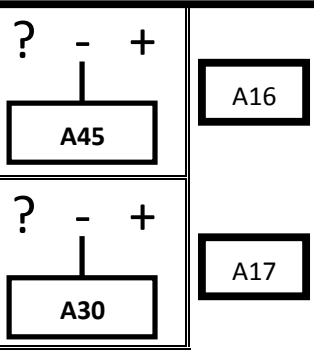

B. Durante el periodo de alteración del estado de ánimo han persistido tres (o más) de los siguientes síntomas (cuatro si el estado de ánimo es sólo irritable) y ha habido en un grado significativo:

(1) Autoestima exagerada o grandiosidad

(2) Disminución de la necesidad de dormir

(3) Más hablador de lo habitual o verborreico

(4) Fuga de ideas o experiencia subjetiva de que el pensamiento está acelerado

(5) Distraibilidad

COMO MÍNIMO TRES DE (B.1) A (B.7) SON CODIFICADOS <<+>> (O CUATRO SI EL ESTADO DE ÁNIMO ES IRRITABLE Y NO ELEVADO)

(6) Aumento de la actividad intencionada o agitación psicomotora

(7) Implicación excesiva en actividades placenteras

D. Alteración suficientemente grave como para provocar un marcado deterioro

E. No debido a una sustancia o a una enfermedad médica (ver apartado de trastorno del estado de ánimo debido a enfermedad médica)

ATENCIÓN: Una respuesta AFIRMATIVA a la pregunta de la entrevista equivale a una puntuación negativa si los criterios se han cumplido durante el último mes

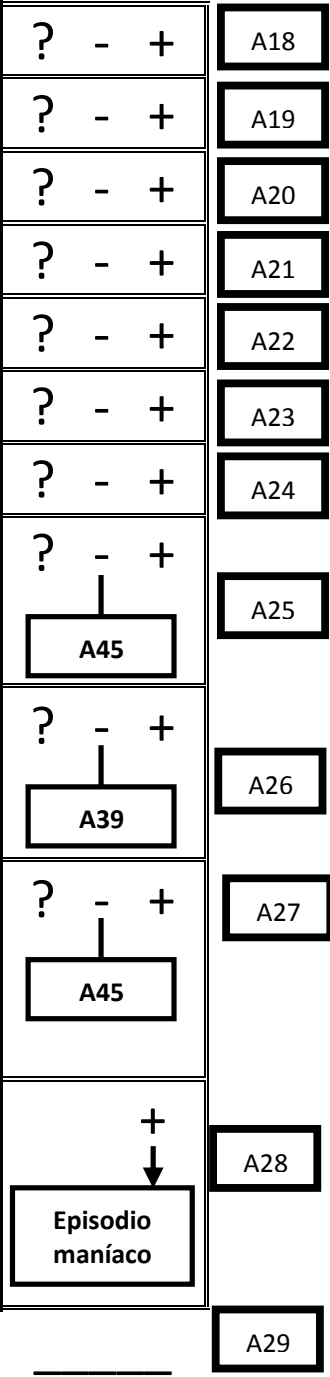


A. Estado de ánimo anormal y persistentemente elevado, expansivo o irritable que dura como mínimo durante 4 días

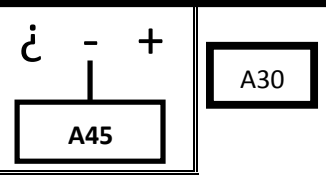

B. Durante el periodo de alteración del estado de ánimo, han persistido tres (o más) de los siguientes síntomas (cuatro si el estado de ánimo es sólo irritable) y ha habido en un grado significativo:

C. Cambio inequívoco de la actividad que no es característico

COMO MÍNIMO TRES DE (B1) A (B7) SON CODIFICADOS $<<+>>$ (0 CUATRO SI EL ESTADO DE ÁNIMO ES IRRITABLE Y NO ELEVADO)

(2) Disminución de la necesidad de dormir

(3) Más hablador de lo habitual o verborreico

(4) Fuga de ideas o experiencia subjetiva de que el pensamiento está acelerado

(5) Distraibilidad

(6) Aumento de la actividad intencionada o agitación psicomotora

(7) Implicación excesiva en actividades placenteras

A40 D. Cambio observable por los demás

\author{
(1)
}


A. Estado de ánimo depresivo la mayor parte del día de la mayoría de los días durante al

menos 2 años

B. Presencia de dos (o más) de los siguientes síntomas:

(1) Pérdida o aumento del apetito

(2) Insomnio o hipersomnia

(3) Falta de energía o fatiga

(4) Baja autoestima

(5) Dificultades para concentrarse o para tomar decisiones

(6) Sentimientos de desesperanza

COMO MÍNIMO DOS SÍNTOMAS <<B〉> SON CODIFICADOS <<+>>

C. No ha estado sin síntomas de los criterios A y B durante más de 2 meses seguidos

FIN SECCION

$?-+\quad$ A46

? - +

Edad de inicio del trastorno distímico actual

D. No ha habido ningún episodio Depresivo mayor durante los primeros 2 años de la alteración

E. Nunca ha habido un Episodio maníaco, mixto o hipomaníaco

F. No aparece exclusivamente en el transcurso de un Trastorno psicótico crónico

G. No debido a una sustancia o a una enfermedad médica (ver apartado de trastorno del estado de ánimo debido a enfermedad médica)

ATENCIÓN: Una respuesta AFIRMATIVA a la pregunta de la entrevista equivale a una puntuación negativa 
CRITERIOS PARA EL TRASTORNO DEL EST. DE ÁNIMO DEBIDO A ENFERMEDAD MÉDICA

A61

A62

A63

A64
A. Notable y persistente alteración del estado de ánimo

B / C. La alteración es la consecuencia fisiológica directa de una enfermedad, y no se explica mejor por la presencia de otro trastorno mental

E. Malestar o deterioro clínicamente significativos

LOS CRITERIOS A, B / C Y E SON CODIFICADOS 《<+>〉

Especificar la enfermedad médica etiológica:

Indicar el tipo de síntomas afectivos:

Con episodio similar al depresivo mayor

Con otros síntomas depresivos

Con síntomas maníacos

Con síntomas mixtos

Marcar aquí

si se han cumplido los criterios durante el último mes

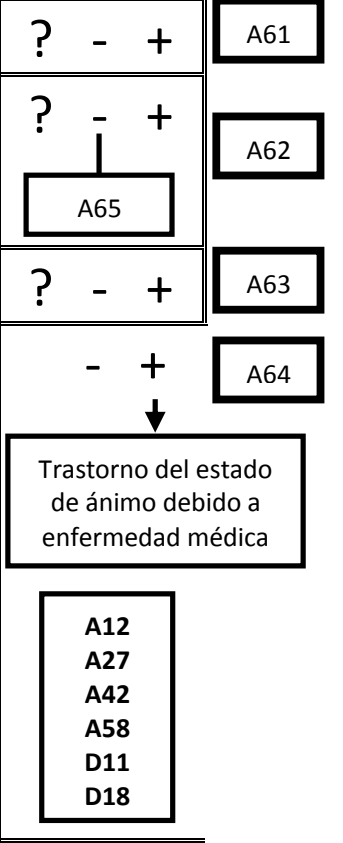

CRITERIOS PARA EL TRASTORNO DEL EST. DE ÁNIMO INDUCIDO POR SUSTANCIAS

A65

A66

A. Notable y persistente alteración del estado de ánimo

C. La alteración no se explica mejor por la presencia de un trastorno del estado de ánimo que no sea inducido por sustancias

B. O bien (1) los síntomas del criterio A aparecen durante o en el mes siguiente a una intoxicación o abstinencia, o (2) el empleo de un medicamento está etiológicamente relacionado con la alteración

?

\begin{tabular}{|ll|}
$?$ & $-\quad+$ \\
$?$ & -+ \\
\hline &
\end{tabular}

D18

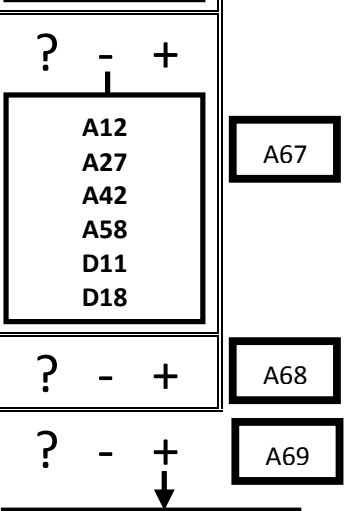

Codificar F10.8 para Alcohol y F19.8 para el resto de sustancias.

Especificar la sustancia:

Indicar el tipo de síntomas afectivos:

Con síntomas depresivos

Con síntomas maníacos

Con síntomas mixtos

Marcar aquí si se han cumplido los criterios durante el último mes
Trastorno del estado de ánimo inducido por sustancias

A12

A27

A42

A58

D11

D18 

si los criterios se han cumplido durante el último mes

Marcar un solo código:

F31.0 Episodio más reciente hipomaníaco

F30.x Episodio maníaco único *

F31.x Episodio más reciente maníaco **

F31.6 Episodio más reciente mixto

F31.x Episodio más reciente depresivo ***

* Marcar el cuarto dígito:

1 = Leve/moderado/grave sin síntomas psicóticos

2 = Grave con síntomas psicóticos

8 = En remisión parcial / en remisión total

** Marcar el cuarto dígito

$1=$ Leve $/$ moderado/grave sin síntomas psicóticos

2 = Grave con síntomas psicóticos

7 = En remisión parcial / en remisión total

$* * *$ Marcar el cuarto dígito:

$1=$ Leve $/$ moderado

$4=$ Grave sin síntomas psicóticos

5 = Grave con síntomas psicóticos

7 = En remisión parcial / en remisión total 
CRITERIOS PARA EL TRASTORNO BIPOLAR II

\begin{tabular}{|c|c|c|c|}
\hline D5 & $\begin{array}{l}\text { Como mínimo un Episodio hipomaníaco no es debido a una enfermedad médica ni al } \\
\text { consumo de sustancias (ver A43) }\end{array}$ & \begin{tabular}{|c|} 
No Si \\
D10
\end{tabular} & D5 \\
\hline D6 & $\begin{array}{l}\text { Como mínimo un Episodio depresivo mayor no es debido a una enfermedad médica ni al } \\
\text { consumo de sustancias (ver A14) }\end{array}$ & \begin{tabular}{|c|} 
No Si \\
D10
\end{tabular} & D6 \\
\hline D7 & Nunca se ha producido un Episodio maníaco o mixto & \begin{tabular}{|c|} 
No Si \\
D10
\end{tabular} & D7 \\
\hline D8 & $\begin{array}{l}\text { No se explica mejor por la presencia de un Trastorno esquizoafectivo y no está } \\
\text { superpuesto a una Esquizofrenia, un Trastorno esquizofreniforme, un Trastorno delirante o } \\
\text { un Trastorno psicótico no especificado }\end{array}$ & \begin{tabular}{|c|} 
No Si \\
D10
\end{tabular} & D8 \\
\hline D9 & $\begin{array}{l}\text { Marcar uno según el episodio actual (o el más reciente): } \\
\text { F31.8 Trastorno bipolar II, hipomaníaco } \\
\text { F31.8 Trastorno bipolar II, depresivo } \\
\text { Marcar aquí } \quad \text { si los criterios se han cumplido durante el último mes }\end{array}$ & E1 & D9 \\
\hline
\end{tabular}

\section{OTROS TRASTORNOS BIPOLARES}

\begin{tabular}{|c|c|c|c|}
\hline D10 & Síntomas maníacos o hipomaníacos clínicamente significativos & $\frac{\mathrm{N}_{\mathrm{L} 13} \mathrm{Si}}{\mathrm{N}^{\mathrm{N}}}$ & D10 \\
\hline D11 & $\begin{array}{l}\text { No se debe a una sustancia o a una enfermedad médica (ver apartado de trastorno del } \\
\text { estado de ánimo debido a enfermedad médica) }\end{array}$ & $\frac{\mathrm{N}_{\mathrm{D} 13} \mathrm{Si}}{\mathrm{N}}$ & D11 \\
\hline D12 & $\begin{array}{l}\text { Indicar el tipo: } \\
\begin{array}{r}\text { F34.0 Trastorno ciclotímico } \\
\text { F31.9 Trastorno bipolar no especificado } \\
\text { Marcar aquí } \quad \text { si los criterios se han cumplido durante el último mes }\end{array}\end{array}$ & E1 & D12 \\
\hline
\end{tabular}




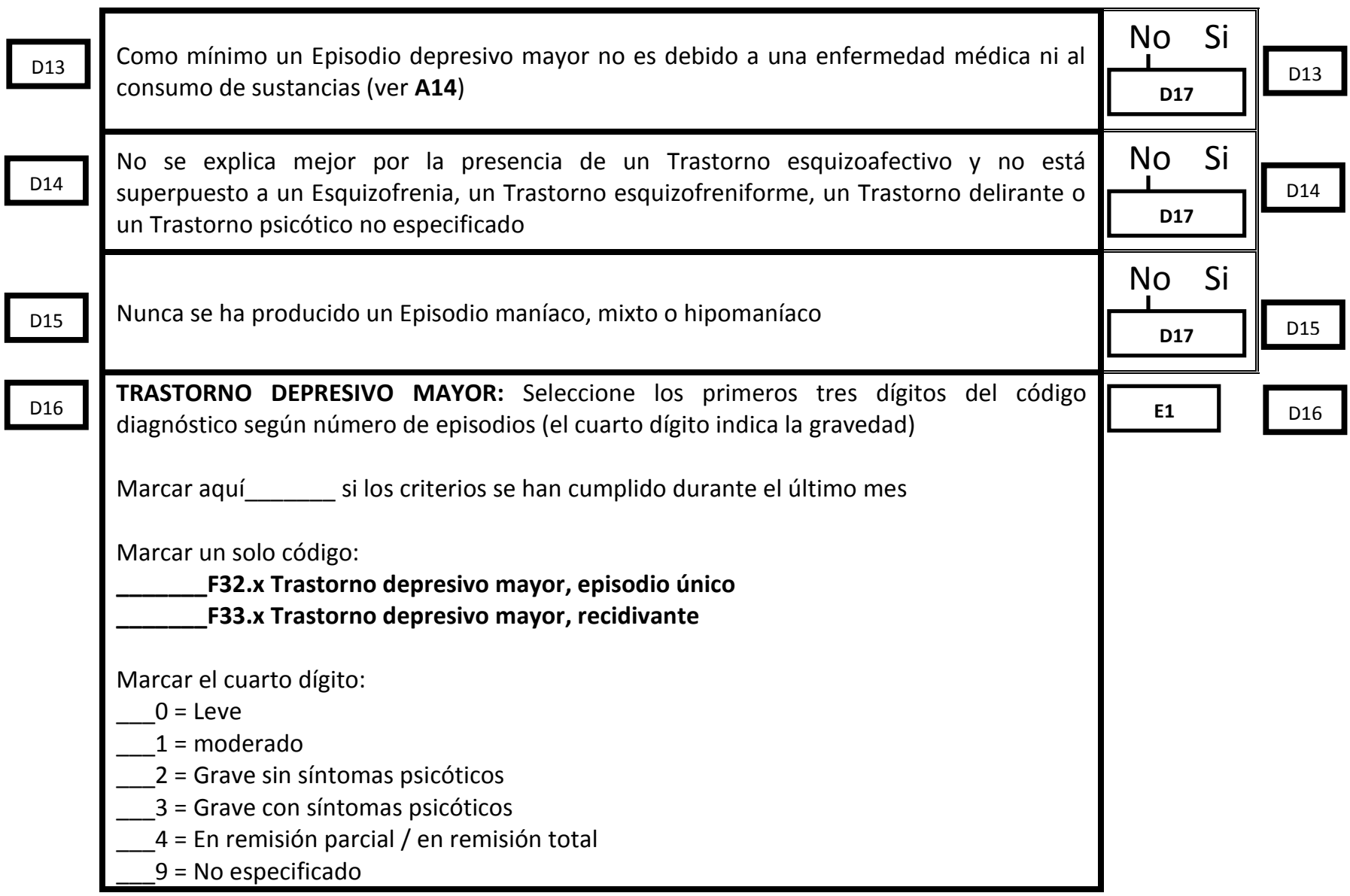

\section{TRASTORNO DEPRESIVO MAYOR NO ESPECIFICADO}

\begin{tabular}{|c|c|c|c|}
\hline & \multirow{2}{*}{ Síntomas depresivos clínicamente significativos } & No Si & \multirow[b]{2}{*}{ D17 } \\
\hline D17 & & E1 & \\
\hline D18 & $\begin{array}{l}\text { No es debido a una sustancia o a una enfermedad médica (ver apartado de trastorno del } \\
\text { estado de ánimo debido a enfermedad médica) }\end{array}$ & $\frac{\text { No Si }}{\text { E1 }}$ & D18 \\
\hline D19 & F32.9 Trastorno depresivo no especificado & E1 & D19 \\
\hline & Marcar aquí___ si los criterios se han cumplido durante el último mes & & \\
\hline
\end{tabular}




\section{CRITERIOS PARA EL ABUSO DE ALCOHOL}

A. Un patrón desadaptativo de consumo de alcohol que conlleva un deterioro o malestar clínicamente significativos, expresado por uno (o más) de los ítems siguientes durante un período de 12 meses:

(1) Incumplimiento de obligaciones en el trabajo, en los estudios o en casa

(2) Consumo en situaciones en que resulta físicamente peligroso

(3) Problemas legales repetidos con el alcohol

(4) Consumo continuado de alcohol a pesar de tener problemas causados o exacerbados por los efectos del alcohol

\begin{tabular}{|c|c|}
\hline$?-+$ & E2 \\
\hline$?-+$ & E3 \\
\hline$?-+$ & E4 \\
\hline ? - + & E5 \\
\hline$? \quad-\quad+$ & \\
\hline E17 & E6 \\
\hline
\end{tabular}

\section{CRITERIOS PARA LA DEPENDENCIA DEL ALCOHOL}

Un patrón desadaptativo de consumo de alcohol que conlleva un deterioro o malestar clínicamente significativos, expresado por uno (o más) de los ítems siguientes en algún momento de un periodo continuado de 12 meses:

(3) A menudo se toma alcohol en cantidades mayores o durante un período más largo de lo que inicialmente se pretendía

(4) Existe un deseo persistente o esfuerzos infructuosos de controlar o interrumpir el consumo de alcohol

(5) Se emplea mucho tiempo en actividades relacionadas con la obtención del alcohol, en el consumo de alcohol o en recuperarse de sus efectos

(6) Reducción de importantes actividades sociales, laborales o recreativas debido al consumo de alcohol

(7) Consumo continuado a pesar de tener conciencia de problemas psicológicos o físicos recidivantes o persistentes

(1) Tolerancia

(2) Abstinencia

COMO MÍNIMO TRES ÍTEMS DE DEPENDENCIA SON CODIFICADOS $<<+>$ Y OCURREN DURANTE EL MISMO PERÍODO DE 12 MESES

F10.2x Dependencia del alcohol

Marcar aquí si los criterios se han cumplido durante el último mes

F10.1 Abuso del alcohol

Marcar aquí si los criterios se han cumplido durante el último mes 

escribir el nombre si se trata de otros)

Sedantes-hipnóticos-ansiolíticos: Tranxilium, rohipnol, Valium, trankimazin, huberplex, barbitúricos, dapaz, orfidal, dormodor, halción u otros:

Cannabis: marihuana, hachís, THC u otros:

Estimulantes: Anfetaminas, speed, rubifen, dexadrina, katovit y otros:

Opiáceos: Heroína, morfina, opio, metadona, darvon, deprancol, buprex, codeína, metasedin, inespecíficos u otros:

Cocaína: Intranasal, intravenosa, <<coca >>, <<nieve >>, freebase, crack, speedball, inespecíficos u otros:

Alucinógenos/fenciclidina: LSD (<<ácido >>), mescalina, peyote, psilocibes, hongos, fenciclidina (PCP o <<Polvo de ángel $>>$ ), <<tripis >>, special K (ketamina), <<éxtasis >>, MDMA u otros:

Otros: esteroides, <<cola>>, pintura, inhalantes, óxido nitroso (<<gas de la risa>>), amil o butil nitrato (poppers), pastillas para dormir o para adelgazar sin receta, desconocidos $u$ otros:

Clase de droga más consumida / que causó mas problemas:

\section{CRITERIOS PARA EL ABUSO DE SUSTANCIAS NO ALCOHÓLICAS}

Un patrón desadaptativo de consumo de sustancias que conlleva un deterioro o malestar clínicamente significativos, expresado por uno (o más) de los ítems siguientes durante un período de 12 meses:

(1) Incumplimiento de obligaciones en el trabajo, en los estudios o en casa

(2) Consumo en situaciones en que resulta físicamente peligroso

(3) Problemas legales repetidos relacionados con la sustancia

(4) Consumo continuado de alcohol a pesar de tener problemas causados o exacerbados por los efectos de la sustancia

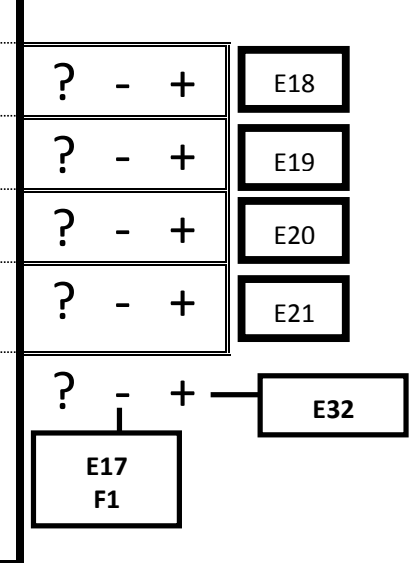


Un patrón desadaptativo de consumo de la sustancia que conlleva un deterioro o malestar clínicamente significativos, expresado por uno (o más) de los ítems siguientes en algún momento de un periodo continuado de 12 meses:

(3) La sustancia es tomada en cantidades mayores o durante un período más largo de lo que inicialmente se pretendía

(4) Existe un deseo persistente o esfuerzos infructuosos de controlar o interrumpir el consumo de la sustancia

(5) Se emplea mucho tiempo en actividades relacionadas con la obtención de la sustancia, en el consumo de la sustancia o en recuperarse de sus efectos

(6) Reducción de importantes actividades sociales, laborales o recreativas debido al consumo de la sustancia

(7) Consumo continuado de la sustancia pesar de tener conciencia de problemas psicológicos o físicos recidivantes o persistentes

(1) Tolerancia

(2) Abstinencia

COMO MÍNIMO TRES ÍTEMS DE DEPENDENCIA SON CODIFICADOS $<<+>$ Y SE HALLAN PRESENTES DURANTE UN MISMO PERÍODO DE 12 MESES

Marcar:

F16.2x Dependencia de alucinógenos

F15.2x Dependencia de anfetaminas

F12.2x Dependencia de cannabis

F14.2x Dependencia de cocaína

F19.2x Dependencia de fenciclidina

F18.2x Dependencia de inhalantes

$?-+$

E23

? - + E24

$?-+\quad E 25$

? $-+\quad$ E26

F11.2x Dependencia de opiáceos

F13.2x Dependencia de sedantes, hipnóticos o ansiolíticos

F19.2x Dependencia de otras sustancias (o desconocidas)

Marcar aquí

si los criterios se han cumplido durante el último mes

Marcar:

F16.1 Abuso de alucinógenos

F15.1 Abuso de anfetaminas

F12.1 Abuso de cannabis

F14.1 Abuso de cocaína

F19.1 Abuso de fenciclidina

F18.1 Abuso deinhalantes

F11.1 Abuso de opiáceos

F13.1 Abuso de sedantes, hipnóticos o ansiolíticos

F19.1 Abuso de otras sustancias (o desconocidas) 
F1

F2

F3

F4

F5

F6

F7

F8

F9

F10

F11

$\mathrm{F} 12$

F13

F14

F15

F16

F17

F18
A. (1) Crisis de angustia inesperadas y recidivantes

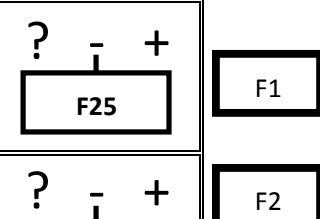

A. (2) Se presenta al menos uno de los siguientes síntomas: (b) preocupación por las implicaciones de la crisis; (a) inquietud persistente ante la posibilidad de tener mas crisis; (c) cambio significativo del comportamiento

Cuatro (o más) de los siguientes síntomas de crisis de angustia, que se inician bruscamente y alcanzan su máxima expresión en los primeros $10 \mathrm{~min}$ :

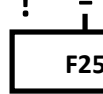

F25

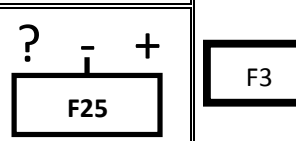

(1) Palpitaciones

(2) Sudoración

(3) Temblores o sacudidas

(4) Sensación de ahogo

(5) Sensación de atragantarse

(6) Opresión torácica

(7) Náuseas o molestias abdominales

(8) Mareo

(9) Desrealización o despersonalización

(10) Miedo a perder el control o volverse loco

(11) Miedo a morir

(12) Parestesias

(13) Escalofríos o sofocaciones

COMO MÍNIMO CUATRO DE (1) A (13) SON CODIFICADOS <<+>>

C. No es debido a unas sustancia o a una enfermedad médica (ver apartado de trastorno de ansiedad debido a enfermedad médica)

ATENCIÓN: Una respuesta AFIRMATIVA a la pregunta de la entrevista equivale a una puntuación negativa

D. No se explica mejor por otro trastorno mental

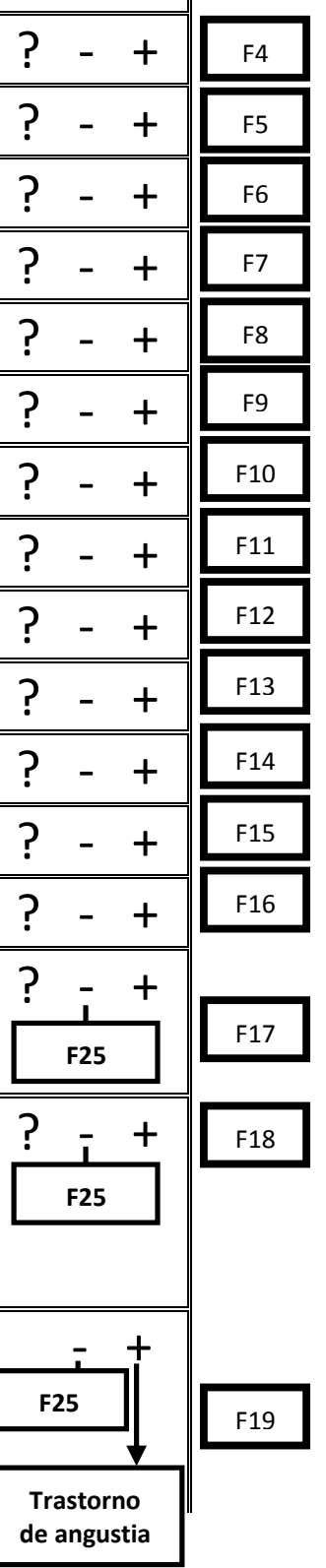


B. Presencia de agorafobia

B. (1) Aparición de ansiedad en lugares o situaciones donde escapar puede resultar difícil, en el caso de aparecer una crisis de angustia o bien síntomas similares a la angustia, o donde puede no disponerse de ayuda

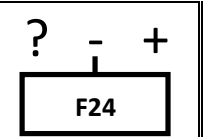

B. (2) Se evitan situaciones agorafóbicas, se resisten a cosa de un malestar o ansiedad significativos, o se requiere compañía

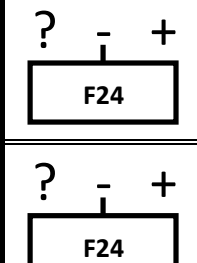

B. (3) La ansiedad o el comportamiento de evitación no pueden explicarse mejor por la presencia de otro trastorno mental

LA AGORAFOBIA ESTÁ PRESENTE si los criterios se han cumplido durante el último mes si los criterios se han cumplido durante el último mes 
Obsesiones:

F25

(1) Pensamientos, impulsos o imágenes recurrentes y persistentes

(2) No se trata de simples preocupaciones excesivas sobre problemas de la vida real

(3) La persona intenta ignorar, suprimir o neutralizar estos pensamientos

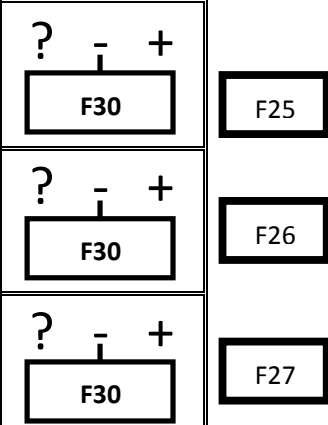

(4) La persona reconoce que son producto de su mente

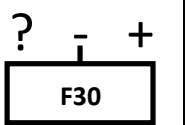

(1) Comportamientos o actos mentales de carácter repetitivo Compulsiones:

(2) El objetivo de estos comportamientos u operaciones mentales es la prevención o reducción del malestar

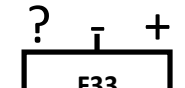

O F29 ES 《<+>> O F32 ES <<+>>; Es decir, obsesiones o compulsiones:

A. Se cumple para las obsesiones o las compulsiones

B. La persona ha reconocido que estas obsesiones o compulsiones resultan excesivas o irracionales

C. Las obsesiones o compulsiones son clínicamente significativas

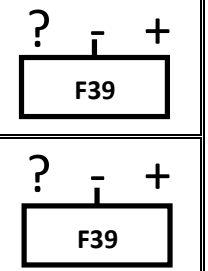

D. Si hay otro trastorno del Eje I, el contenido de las obsesiones o compulsiones no se limita a él

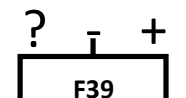

E. No debido a una sustancia o a una enfermedad médica (ver página 60).

ATENCIÓN: Una respuesta AFIRMATIVA a la pregunta de la entrevista equivale a una puntuación negativa

Marcar aquí si los criterios se han cumplido durante el último mes

LOS CRITERIOS A, B, C, D Y E DEL TRASTORNO OBSESIVO-COMPULSIVO SON CODIFICADOS $<<+>>$

Marcar aquí si los criterios se han cumplido durante el último mes 
A. La persona ha estado expuesta a un acontecimiento traumático en el que ha existido

(1) y (2):

(1) La persona ha experimentado, presenciado o le han explicado uno (o más) acontecimientos caracterizados por muertes o amenazas para su integridad física o la de los demás

(2) La persona ha respondido con un temor, una desesperanza o un horror intensos

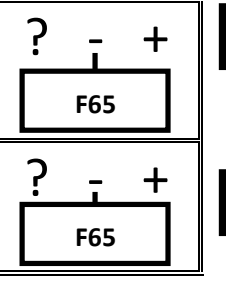

B. El acontecimiento traumático es reexperimentado persistentemente a través de una (o más) de las siguientes formas:

(1) Recuerdos del acontecimiento que provocan malestar

(2) Sueños sobre el acontecimiento

(3) Actuar o tener la sensación de que el acontecimiento traumático está ocurriendo

(4) Malestar psicológico intenso al exponerse a estímulos internos o externos

(5) Respuestas fisiológicas al exponerse a estímulos internos o externos

COMO MÍNIMO UN SÍNTOMA $<<B>>$ ES CODIFICADO $<<+>$

C. Evitación persistente de estímulos asociados al trauma y embotamiento de la reactividad general tal y como indican tres de los siguientes síntomas:

(1) Esfuerzos para evitar pensamientos, sentimientos o conversaciones

(2) Esfuerzos para evitar actividades, lugares o personas que motivan recuerdos del trauma

(3) Incapacidad para recordar un aspecto importante del trauma

(4) Reducción acusada del interés o la participación en actividades significativas

(5) Sensación de desapego o enajenación frente a los demás

(6) Restricción de la vida afectiva (p.e., incapacidad para tener sentimientos de amor)

(7) Sensación de un futuro limitado

COMO MÍNIMO TRES SÍNTOMAS $<<C>>$ SON CODIFICADOS $<<+>>$

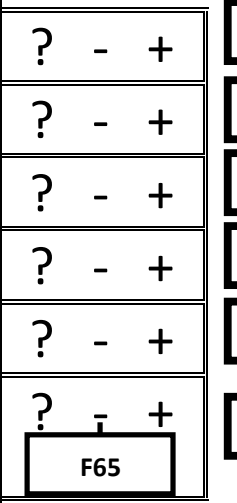

D. Síntomas persistentes de aumento de la activación (arousal) tal y como indican dos (o más) de los siguientes síntomas:

(1) Dificultades para conciliar o mantener el sueño

(2) Irritabilidad o ataques de ira

(3) Dificultades para concentrarse

\begin{tabular}{|lll|}
\hline$?$ & - & + \\
\hline$?$ & - & + \\
\hline$?$ & - & + \\
\hline$?$ & - & + \\
\hline$?$ & - & + \\
\hline$?$ & - & + \\
\hline$?$ & - & + \\
\hline$?$ & $-\quad+$ \\
\hline & F65 \\
\hline & \\
\hline$?$ & $-\quad+$ \\
\hline$?$ & $-\quad+$ \\
\hline$?$ & $-\quad+$ \\
\hline
\end{tabular}




\begin{tabular}{|c|c|c|c|}
\hline F59 & (4) Hipervigilancia & -+ & F59 \\
\hline F60 & (5) Respuestas exageradas de sobresalto & + & F60 \\
\hline F61 & COMO MÍNIMO DOS SÍNTOMAS <<D>> SON CODIFICADOS $<<+>>$ & 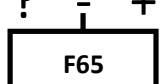 & F61 \\
\hline F62 & E. Las alteraciones se prolongan más de 1 mes & \begin{tabular}{|c|} 
\\
F65
\end{tabular} & $\mathrm{F} 62$ \\
\hline F63 & F. Malestar o deterioro clínicamente significativos & $\stackrel{?}{?+1}$ & F63 \\
\hline F64 & \multirow[t]{2}{*}{$\begin{array}{l}\text { LOS CRITERIOS A, B, C, D, E Y F DEL TRASTORNO POR ESTRÉS POSTRAUMÁTICO SON } \\
\text { CODIFICADOS «८+〉> }\end{array}$} & $?-+$ & F64 \\
\hline & & $\begin{array}{l}\text { Trastorno de } \\
\text { postraumá }\end{array}$ & \\
\hline
\end{tabular}

\section{OTROS TRASTORNOS DE ANSIEDAD}

F65

F66

F67

F68

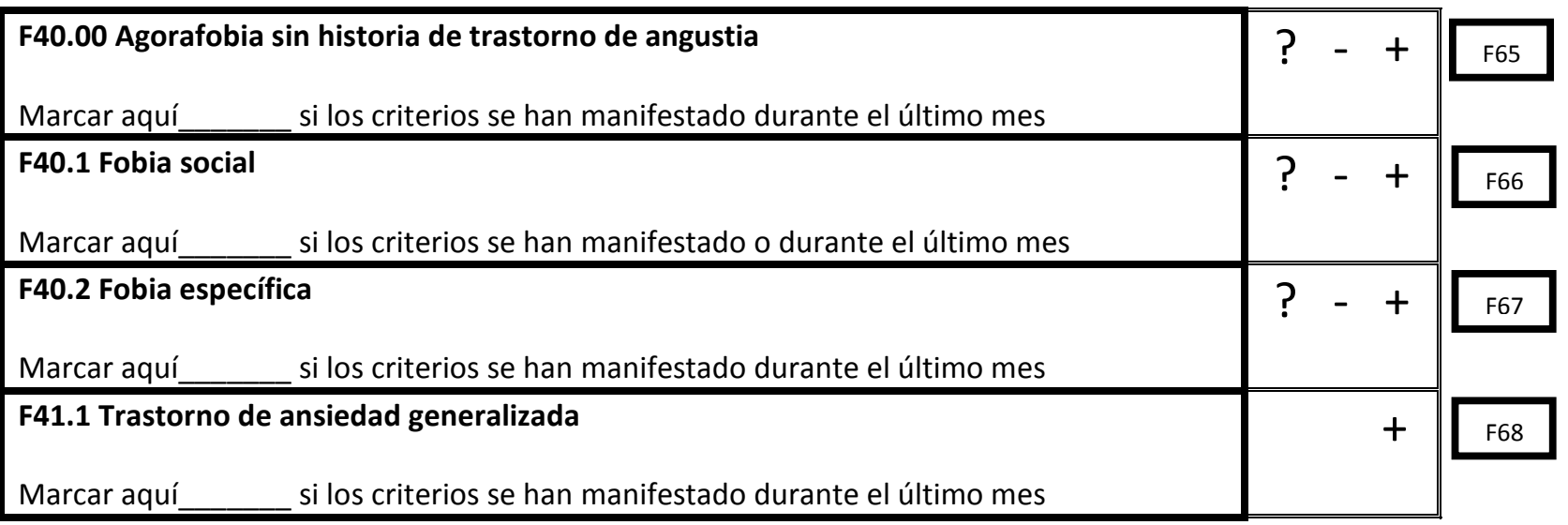

TRASTORNO DE ANSIEDAD NO ESPECIFICADO

Ansiedad o evitación fóbica clínicamente significativas

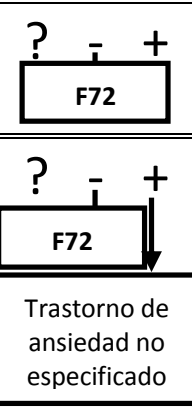

ATENCIÓN: Una respuesta AFIRMATIVA a la pregunta de la entrevista equivale a una puntuación negativa 
TRASTORNOS SOMATOMORFOS

F45.0 Trastorno de somatización O BIEN

F45.1 Trastorno somatomorfo indiferenciado

Marcar aquí

F45.2 Hipocondría

si se ha manifestado durante el último mes

Marcar aquí

si se ha manifestado durante el último mes

F45.2 Trastorno dismórfico corporal

Marcar aquí si se ha manifestado durante el último mes

TRASTORNOS DE LA CONDUCTA ALIMENTARIA

F75

F76

\begin{tabular}{|l|c|}
\hline F50.0 Anorexia nerviosa & $?-+$ \\
Marcar aquí__ si se ha manifestado durante el último mes & + \\
\hline F50.2 Bulimia nerviosa & -+ \\
Marcar aquí_ si se ha manifestado durante el último mes & + F76 \\
\hline
\end{tabular}

\section{CRITERIOS PARA LOS TRASTORNOS ADAPTATIVOS}

A. Aparición de síntomas emocionales o comportamentales en respuesta a un estresante identificable

B. Síntomas o comportamientos clínicamente significativos

C. No cumple los criterios de otro trastorno específico del Eje I y no constituye una simple exacerbación de un trastorno prexistente del Eje I o del Eje II

D. Los síntomas no responden a una reacción de duelo

ATENCIÓN: Una respuesta AFIRMATIVA a la pregunta de la entrevista equivale a una puntuación negativa

E. Una vez cesado el estresante (o sus consecuencias), los síntomas no persisten más de 6 meses.

Realizar un diagnóstico de Trastorno adaptativo según los síntomas predominantes:

F43.20 Trastorno adaptativo con estado de ánimo depresivo

F43.28 Trastorno adaptativo con ansiedad

F43.22 Trastorno adaptativo mixto con ansiedad y estado de ánimo depresivo

F43.24 Trastorno adaptativo con trastorno del comportamiento

F43.25 Trastorno adaptativo con alteración de emociones y comportamiento

F43.9 Trastorno adaptativo no especificado 
CRITERIOS PARA EL TRASTORNO DE ANSIEDAD DEBIDO A ENFERMEDAD MÉDICA

\begin{tabular}{|c|c|c|c|}
\hline F83 & A. Ansiedad prominente, crisis de angustia u obsesiones o compulsiones & $?-+$ & F83 \\
\hline F84 & $\begin{array}{l}\text { B / C. Las alteraciones son la consecuencia fisiológica directa de una enfermedad médica, y } \\
\text { no pueden explicarse mejor por la presencia de otro trastorno mental }\end{array}$ & $\stackrel{?+1}{\text { ? }}$ & F84 \\
\hline F85 & E. Las alteraciones provocan un malestar o deterioro clínicamente significativos & $?-+$ & F85 \\
\hline F86 & $\begin{array}{l}\text { LOS CRITERIOS A, B/C Y E SON CODIFICADOS }<<+>> \\
\text { Especificar la enfermedad médica etiológica: }\end{array}$ & $?-+$ & F86 \\
\hline & $\begin{array}{l}\text { Indicar el tipo de síntomas de ansiedad: } \\
\text { Con ansiedad generalizada } \\
\text { Con crisis de angustia } \\
\text { Con síntomas obsesivo-compulsivos }\end{array}$ & $\begin{array}{l}\text { Trastorno } \\
\text { de ansiedad } \\
\text { debido a } \\
\text { enfermeda } \\
\text { d médica }\end{array}$ & \\
\hline & Marcar aquí___ si se han cumplido los criterios durante el último mes & & \\
\hline
\end{tabular}

\section{CRITERIOS PARA EL TRASTORNO DE ANSIEDAD INDUCIDO POR SUSTANCIAS}

B. O bien: (1) los síntomas del criterio A aparecen durante o en el mes siguiente a una intoxicación o abstinencia de la sustancia, o (2) el empleo de un medicamento está etiológicamente relacionada con la alteración

C. La alteración no se explica mejor por la presencia de un trastorno de ansiedad no inducido por sustancias

Indicar el tipo de síntomas de ansiedad: Con ansiedad generalizada Con crisis de angustia Con síntomas obsesivo-compulsivos Con síntomas fóbicos 


\section{CRITERIOS PARA EXHIBICIONISMO}

F. Durante un período de por lo menos 6 meses, fantasías sexuales recurrentes y altamenteexcitantes, impulsos sexuales o comportamientos que implican la exposiciónde los propios genitales a un extraño que no lo espera.

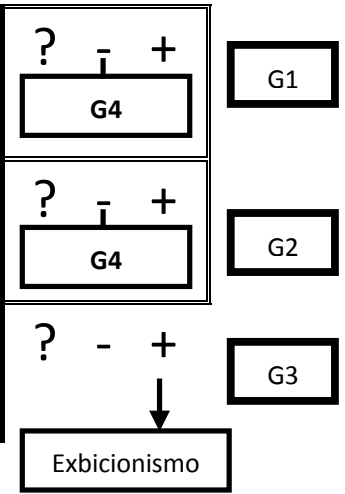

\section{CRITERIOS PARA FETICHISMO}

A. Durante un período de al menos 6 meses, fantasías sexuales recurrentes y altamenteexcitantes, impulsos sexuales o comportamientos ligados al uso de objetosno animados (p. ej., ropa interior femenina).

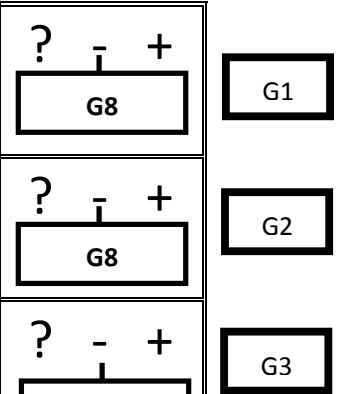

G6

B. Las fantasías, los impulsos sexuales o los comportamientos provocan malestar clínicamentesignificativo o deterioro social, laboral o de otras áreas importantes dela actividad del individuo.

C. Los fetiches no deben ser únicamente artículos de vestir femeninos como los utilizadospara transvestirse (fetichismo transvestista) o aparatos diseñados con elpropósito de estimular los genitales (p. ej., vibrador).

G8

ATENCIÓN: Una respuesta AFIRMATIVA a la pregunta de la entrevista equivale a una puntuación negativa

Marcar aquí si los criterios se han cumplido durante el último mes

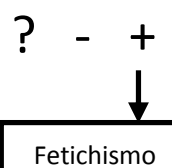

\section{CRITERIOS PARA FROTTEURISMO}

A. Durante un período de al menos 6 meses, fantasías sexuales recurrentes y altamenteexcitantes e impulsos sexuales o comportamientos ligados al hecho de tocary rozar una persona en contra de su voluntad.

B. Las fantasías, los impulsos sexuales o los comportamientos provocan malestar clínicamentesignificativo o deterioro social, laboral o de otras áreas importantes dela actividad del individuo.

\section{LOS CRITERIOS A Y B DE FROTTEURISMO SON CODIFICADOS $<<+>>$}

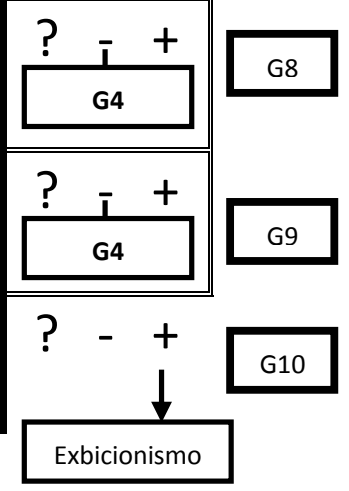


A. Durante un período de al menos 6 meses, fantasías sexuales recurrentes y altamenteexcitantes, impulsos sexuales o comportamientos que implican actividad sexualcon niños prepúberes o niños algo mayores (generalmente de 13 años o menos).

G11

G12

$\mathrm{G} 13$

Especificar si:

Con atracción sexual por los varones

Con atracción sexual por las mujeres

Con atracción sexual hacia ambos sexos

Especificar si:

Se limita al incesto

Especificar si:

Tipo exclusivo (atracción sólo por niños)

Tipo no exclusivo

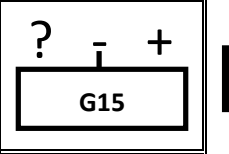

G11
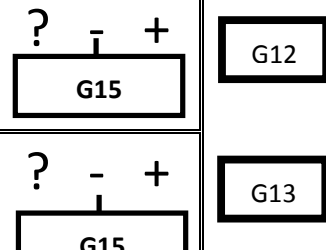

? -+

Pedofilia

Marcar aquí si los criterios se han cumplido durante el último mes

\section{CRITERIOS PARA MASOQUISMO SEXUAL}

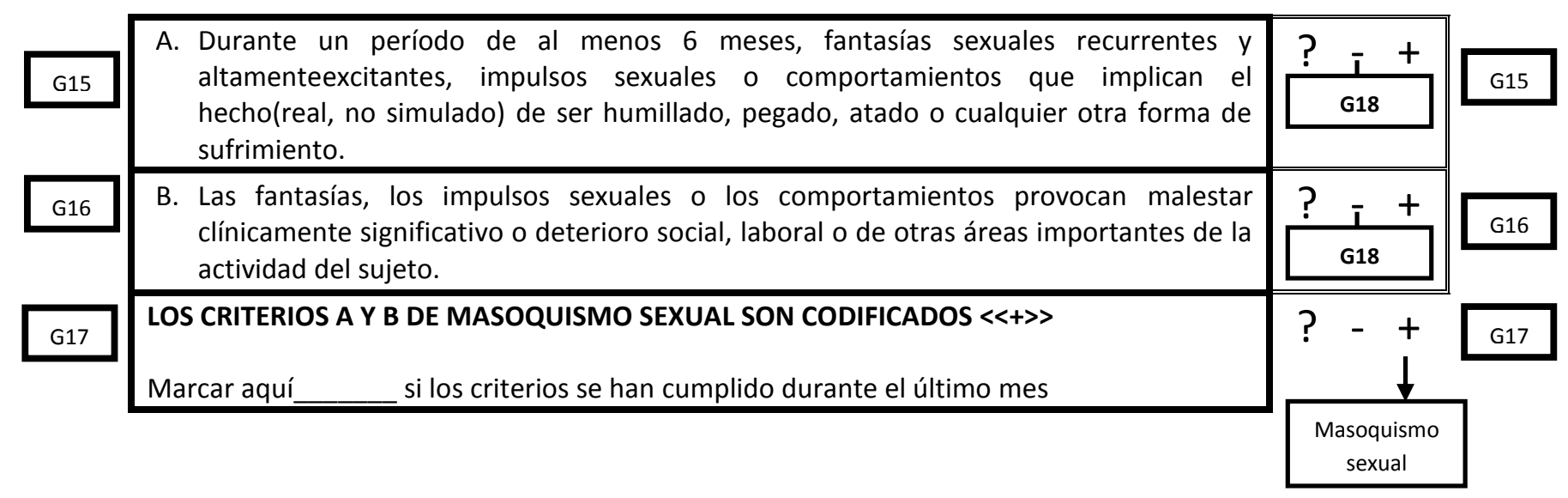

CRITERIOS PARA SADISMO SEXUAL

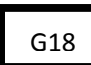

G19

G20
A. Durante un período de al menos 6 meses, fantasías sexuales recurrentes y altamenteexcitantes, impulsos sexuales o comportamientos que implican actos (reales, no simulados) en los que el sufrimiento psicológico o físico (incluyendo lahumillación) de la víctima es sexualmente excitante para el individuo.

B. Las fantasías, los impulsos sexuales o los comportamientos provocan malestar clínicamente significativo o deterioro social, laboral o de otras áreas importantes dela actividad del individuo.

LOS CRITERIOS A Y B DE SADISMO SEXUAL SON CODIFICADOS $<<+>>$

si los criterios se han cumplido durante el último mes
G18

G21

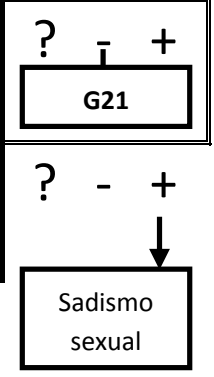




\section{CRITERIOS PARA FETICHISMO TRANSVESTISTA}

A. Durante un período de al menos 6 meses, fantasías sexuales recurrentes y altamente excitantes, impulsos sexuales o comportamientos que implican el acto de transvestirse, en un varón heterosexual.

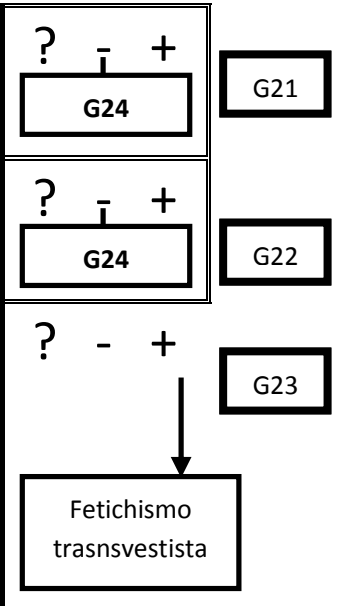

Marcar aquí si los criterios se han cumplido durante el último mes

\section{CRITERIOS PARA VOYEURISMO}

\begin{tabular}{|l|l|l|l|}
\hline A. Durante un período de al menos 6 meses, fantasías sexuales recurrentes y altamente \\
excitantes, impulsos sexuales o comportamientos que implican el hecho de observar \\
ocultamente a personas desnudas, desnudándose o que se encuentran en plena \\
actividad sexual.
\end{tabular}


TRASTORNO OBSESIVO-COMPULSIVO DE LA PERSONALIDAD

\begin{tabular}{|c|c|c|c|}
\hline 16 & 16. Se fija en los detalles & ? 123 & 16 \\
\hline 17 & 17. Dificultades a la hora de finalizar tareas & ? 123 & 17 \\
\hline 18 & 18. Creo pasar tanto tiempo trabajando que me queda poco tiempo para todo lo demás & ? 123 & 18 \\
\hline 19 & 19. Valores estrictos & ? 123 & 19 \\
\hline 20 & 20. Cuesta mucho tirar las cosas & ? 123 & 20 \\
\hline 21 & 21. Le cuesta que otras personas le ayuden & ? 123 & 21 \\
\hline 22 & 22. Le cuesta mucho gastar dinero & ? 123 & 22 \\
\hline 23 & 23. Seguro de tener razón & ? 123 & 23 \\
\hline 24 & 24. Tozudo y rígido & ? 123 & 24 \\
\hline
\end{tabular}

\section{TRASTORNO LÍMITE DE LA PERSONALIDAD}

\begin{tabular}{|c|c|c|c|}
\hline 90 & 90. Furioso cuando creen que van a abandonarle & ? 123 & 90 \\
\hline 91 & 91.Las relaciones con otras personas tienen altibajos & ? 123 & 91 \\
\hline 92 & 92. Cambia fácilmente como se ve o hacia donde va & ? 123 & 92 \\
\hline 93 & 93. Cambia dramáticamente la visión de sí mismo & ? 123 & 93 \\
\hline 94 & 94. Muy diferente con diferentes personas y diferentes situaciones & ? 123 & 94 \\
\hline 95 & 95. Cambios bruscos en metas, objetivos, creencias, etc. & ? 123 & 95 \\
\hline 96 & 96. Hace cosas impulsivamente & ? 123 & 96 \\
\hline 97 & 97. Amenazado con hacerse daño o intentado hacerlo & ? 123 & 97 \\
\hline 98 & 98. Autolisis & ? 123 & 98 \\
\hline 99 & 99. Cambios repentinos de estado de ánimo & ? 123 & 99 \\
\hline 100 & 100. Sentimiento de vacío por dentro & ? 123 & 100 \\
\hline 101 & 101. Arranques de cólera y pérdida del control & ? 123 & 101 \\
\hline 102 & 102. Cuando se enfada golpea o lanza objetos & ? 123 & 102 \\
\hline 103 & 103. Muy furioso incluso por cosas sin importancia & ? 123 & 103 \\
\hline 104 & 104.En situaciones de tensión, suspicaz y paranoide & ? 123 & 104 \\
\hline
\end{tabular}


RESUMEN DE LOS DIAGNÓSTICOS DE LA SCID-I

\title{
TRASTORNOS DEL ESTADO DE ÁNIMO
}

\author{
Prevalencia \\ a lo largo \\ Actual de la vida \\ Trastorno bipolar (D4, pág. 36) \\ F31.0 Trastorno bipolar I, episodio más reciente hipomaníaco \\ F31.x Trastorno bipolar I, episodio más reciente maníaco \\ Codificar el estado actual del episodio maníaco en el cuarto dígito: \\ - 1 = Leve, moderado o grave sin síntomas psicóticos \\ - 2 = Grave con síntomas psicóticos \\ $-7=$ En remisión parcial o total \\ F30.x Trastorno bipolar I, episodio maníaco único \\ Especificar si: Mixto \\ Codificar el estado actual del episodio maníaco en el cuarto dígito: \\ - $\mathbf{I}=$ Leve, moderado o grave sin síntomas psicóticos \\ - 2 = Grave con síntomas psicóticos \\ $-8=$ En remisión parcial o total \\ F31.6 Trastorno bipolar I, episodio más reciente mixto \\ F31.x Trastorno bipolar I, episodio más reciente depresivo \\ Codificar el estado actual del episodio maníaco en el cuarto dígito: \\ - 3 = Leve o moderado \\ - 4= Grave sin síntomas psicóticos \\ - $5=$ Grave con síntomas psicóticos \\ - 7 = En remisión parcial o total \\ F31.9 Trastorno bipolar I, episodio más reciente no especificado \\ Otros trastornos bipolares \\ F31.8 Trastorno bipolar II (D9, pág. 37) \\ Especificar: \\ - Hipomaníaco/Depresivo \\ F34.0 Trastorno ciclotímico (D12, pág. 37) \\ F31.9 Trastorno bipolar no especificado (D12, pág. 37) \\ Trastorno depresivo mayor (D16, pág. 38) \\ F32.x Trastorno depresivo mayor, episodio único \\ F33.x Trastorno depresivo mayor recidivante \\ Codificar el estado actual del episodio depresivo mayor en el cuarto dígito \\ $-0=$ Leve \\ - 1 = Moderado \\ - 2 = Grave sin síntomas psicóticos \\ - 3 = Grave con síntomas psicóticos \\ $-4=$ En remisión parcial \\ $-4=$ En remisión total \\ $-9=$ No especificado \\ Otros trastornos depresivos \\ F34.1 Trastorno distímico ( $A 60$, pág. 23) \\ F32.9 Trastorno depresivo no especificado (D19, pág. 39)
}

Prevalencia a lo largo

Otros trastornos del estado de ánimo

F06.xx Trastorno del estado de ánimo debido a enfermedad médica (A64, pág. 24) Indique la enfermedad médica:

Marque el especificador:

-.32 Con síntomas depresivos

-.32 Con síntomas de depresión mayor

-.30 Con síntomas maníacos

-.33 Con síntomas mixtos

F10.8 Trastorno del estado de ánimo inducido por alcohol (A69, pág. 25) Marque el especificador:

- Con síntomas depresivos

- Con síntomas maníacos

- Con síntomas mixtos

F19.8 Trastorno del estado de ánimo inducido por otras sustancias (o desconocidas) (A69, pág. 25)

Indique la sustancia:

Marque el especificador:

- Con síntomas depresivos

- Con síntomas maníacos

- Con síntomas mixtos 
TRASTORNOS RELACIONADOS CON SUSTANCIAS

\begin{tabular}{|c|c|c|c|}
\hline $\begin{array}{l}\text { Actual } \\
\square \\
\square\end{array}$ & $\begin{array}{c}\text { Prevalencia } \\
\text { a lo largo } \\
\text { de la vida } \\
\square \\
\square\end{array}$ & $\begin{array}{l}\text { Trastor } \\
\text { F10.2x } \\
\text { F10.1 }\end{array}$ & $\begin{array}{l}\text { nos relacionados con el alcohol } \\
\text { Dependencia del alcohol (E15, pág. 42) } \\
\text { Abuso de alcohol (E16, pág. 42) }\end{array}$ \\
\hline $\begin{array}{l}\square \\
\square \\
\square \\
\square \\
\square \\
\square \\
\square \\
\square \\
\square \\
\square \\
\square \\
\square \\
\square \\
\square\end{array}$ & $\begin{array}{l}\square \\
\square \\
\square \\
\square \\
\square \\
\square \\
\square \\
\square \\
\square \\
\square \\
\square \\
\square \\
\square \\
\square\end{array}$ & $\begin{array}{l}\text { Trastor } \\
\text { F16.2x } \\
\text { F15.2x } \\
\text { F12.2x } \\
\text { F14.2x } \\
\text { F19.2x } \\
\text { F18.2x } \\
\text { F11.2x } \\
\text { F13.2x } \\
\text { F19.2x } \\
\text { F16.1 } \\
\text { F15.1 } \\
\text { F12.1 } \\
\text { F14.1 } \\
\text { F19.1 } \\
\text { F18.1 } \\
\text { F11.1 } \\
\text { F13.1 } \\
\text { F19.1 }\end{array}$ & $\begin{array}{l}\text { nos relacionados con otras sustancias } \\
\text { Dependencia de alucinógenos (E31, pág. 46) } \\
\text { Dependencia de anfetamina (E31, pág. 46) } \\
\text { Dependencia de Cannabis (E31, pág. 46) } \\
\text { Dependencia de cocaína (E31, pág. 46) } \\
\text { Dependencia de fenciclidina (E31, pág. 46) } \\
\text { Dependencia de inhalantes (E31, pág. 46) } \\
\text { Dependencia de opiáceos (E31, pág. 46) } \\
\text { Dependencia de sedantes, hipnóticos y ansiolíticos (E31, pág. 46 } \\
\text { Dependencia de otras sustancias (o desconocidas) (E31, pág. 46) } \\
\text { Abuso de alucinógenos (E32, pág. 46) } \\
\text { Abuso de anfetamina (E32, pág. 46) } \\
\text { Abuso de Cannabis (E32, pág. 46) } \\
\text { Abuso de cocaína (E32, pág. } 46) \\
\text { Abuso de fenciclidina (E32, pág. } 46) \\
\text { Abuso de inhalantes (E32, pág. 46) } \\
\text { Abuso de opiáceos (E32, pág. } 46) \\
\text { Abuso de sedantes, hipnóticos y ansiolíticos (E32, pág. } 46) \\
\text { Abuso de otras sustancias (o desconocidas) (E32, pág. } 46)\end{array}$ \\
\hline
\end{tabular}

\section{TRASTORNOS DE ANSIEDAD}

$\begin{array}{ll}\square & \square \\ \square & \square \\ \square & \square \\ \square & \square\end{array}$

F40.01 Trastorno de angustia con agorafobia (F23, pág. 49)

F41.0 Trastorno de angustia sin agorafobia ( $F 24$, pág. 49)

F42.8 Trastorno obsesivo-compulsivo (F38, pág. 52)

F43.1 Trastorno por estrés postraumático (F64, pág. 56)

F41.9 Trastorno de ansiedad no especificado ( $F 71$, pág. 57$)$

F06.4 Trastorno de ansiedad debido a enfermedad médica (F86, pág. 60) Indique la enfermedad médica:

Marque el especificador:

- Con ansiedad generalizada

- Con crisis de angustia

- Con síntomas obsesivo-compulsivos

F10.8 Trastorno de ansiedad inducido por alcohol (F91, pág. 62)

Marque el especificador:

-Con ansiedad generalizada

- Con crisis de angustia

- Con síntomas obsesivo-compulsivos

- Con síntomas fóbicos

F19.8 Trastorno de ansiedad inducido por otras sustancias (o desconocidas) (F91, pág. 62)

Indique la sustancia:

Marque el especificador:

- Con ansiedad generalizada

- Con crisis de angustia

- Con síntomas obsesivo-compulsivos

- Con síntomas fóbicos

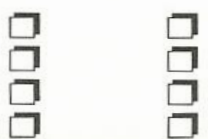

Otros trastornos de ansiedad

F40.00 Agorafobia sin historia de trastorno de angustia (F65, pág. 56)

F40.1 Fobia social (F66, pág. 56)

F40.2 Fobia específica (F67, pág. 56)

F41.1 Trastorno de ansiedad generalizada (F68, pág. 56)

\section{TRASTORNOS SOMATOMORFOS}

$\begin{array}{llll}\square & \square & \text { F45.0 } & \text { Trastorno de somatización (F72, pág. 58) } \\ \square & \square & \text { F45.1 } & \text { Trastorno somatomorfo indiferenciado (F72, pág. 58) } \\ \square & \square & \text { F45.2 } & \text { Hipocondría (F73, pág. 58) } \\ \square & \square & \text { F45.2 } & \text { Trastorno dismórfico corporal (F74, pág. 58) }\end{array}$

\section{TRASTORNOS DE LA CONDUCTA ALIMENTARIA}

$\begin{array}{llll}\square & \square & \text { F50.0 } & \text { Anorexia nerviosa (F75, pág. 58) } \\ \square & \square & \text { F50.2 } & \text { Bulimia nerviosa (F76, pág. 58) }\end{array}$

\section{TRASTORNOS ADAPTATIVOS}

F43.20 Trastorno adaptativo con estado de ánimo depresivo (F82, pág. 59)

F43.28 Trastorno adaptativo con ansiedad (F82, pág. 59)

F43.22 Trastorno adaptativo mixto con ansiedad y estado de ánimo depresivo (F82, pág. 59)

F43.24 Trastorno adaptativo con trastorno de comportamiento (F82, pág. 59)

F43.25 Trastorno adaptativo con alteración mixta de las emociones y el comportamiento (F82, pág. 59)

F43.9 Trastorno adaptativo no especificado (F82, pág. 59) 


\section{TRASTORNOS SEXUALES}

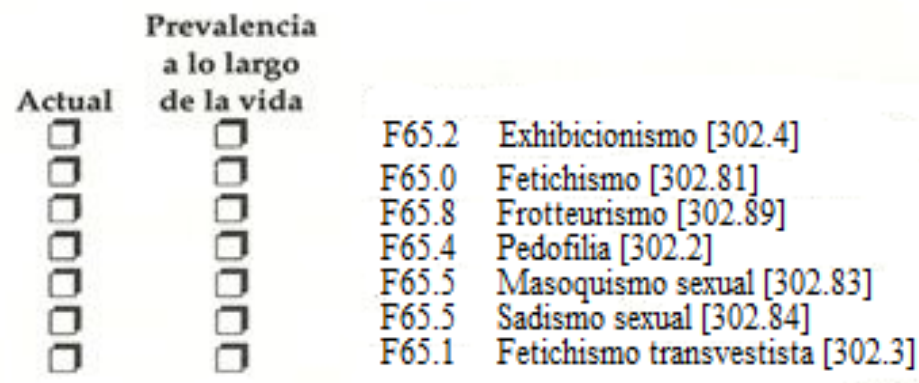

Trastorno de la personalidad

Número de ítems puntuados con un «3»» (Los números encasillados indican el umbral requerido para un diagnóstico)

01 Por evitación (págs. 3-4)

02 Por dependencia (págs. 5-7)

03 Obsesivo-compulsivo (págs. 8-10)

04 Pasivo-agresivo (págs. 11-12)

05 Depresivo (págs. 13-14)

06 Paranoide (págs. 15-16)

07 Esquizotípico (págs. 17-20)

08 Esquizoide (págs. 21-22)

09 Histriónico (págs. 23-24)

10 Narcisista (págs. 25-28)

11 Límite (págs. 29-32)

12 Antisocial (págs. 33-40)

13 No especificado (pág. 41)

\begin{tabular}{lllllllll|l}
1 & 2 & 3 & 4 & 5 & 6 & 7 & & & 11 \\
1 & 2 & 3 & 4 & 5 & 6 & 7 & 8 & & 12 \\
1 & 2 & 3 & 4 & 5 & 6 & 7 & 8 & & 13 \\
1 & 2 & 3 & 4 & 5 & 6 & 7 & & & 14 \\
1 & 2 & 3 & 4 & 5 & 6 & 7 & & & 15 \\
1 & 2 & 3 & 4 & 5 & 6 & 7 & & & 16 \\
1 & 2 & 3 & 4 & 5 & 6 & 7 & 8 & 9 & 17 \\
1 & 2 & 3 & 4 & 5 & 6 & 7 & & & 18 \\
1 & 2 & 3 & 4 & 5 & 6 & 7 & 8 & & 19 \\
1 & 2 & 3 & 4 & 5 & 6 & 7 & 8 & 9 & 20 \\
1 & 2 & 3 & 4 & 5 & 6 & 7 & 8 & 9 & 21 \\
1 & 2 & 3 & 4 & 5 & 6 & 7 & & & 22 \\
1 & & & & & & & & & 23
\end{tabular}

DIAGNÓSTICO PRINCTPAL DEL EJE II (esto es, el Trastorno de la personalidad que es -o debería ser-el centro principal de atención clínica).

Anótese el código situado a la izquierda del diagnóstico: Nota: Anótese 99 si no existe trastorno del Eje II. 


\section{Evaluación de la orientación del deseo sexual}

\section{(Ballester, 2013)}

- En cuanto a la orientación sexual te consideras:
$\square$ Heterosexual
$\bigcirc$ Bisexual
$\bigcirc$ Homosexual

- ¿Alguna vez has tenido deseo de mantener relaciones sexuales con personas de tu mismo sexo? ........

¿Alguna vez has tenido deseo de mantener relaciones sexuales con personas del otro sexo?

¿Alguna vez has fantaseado con personas de tu mismo sexo para excitarte?

¿Alguna vez has fantaseado con personas del otro sexo para excitarte?

- ¿Has mantenido relaciones sexuales con personas de tu mismo sexo?

¿ ¿Has mantenido relaciones sexuales con personas del otro sexo?

- Por favor, indica cuál de las siguientes afirmaciones describe mejor hacia quien te sientes atraído sexualmente:

Me siento atraído solo hacia el otro sexo

Me siento atraído casi siempre hacia el otro sexo y en muy contadas ocasiones hacia mi mismo sexo Me siento atraído algo más hacia el otro sexo que hacia mi mismo sexo Me siento igualmente atraído hacia los dos sexos

Me siento atraído algo más hacia mi mismo sexo que hacia el otro sexo

Me siento atraído casi siempre hacia mi mismo sexo y en muy contadas ocasiones hacia el otro sexo Me siento atraído solo hacia mi mismo sexo

- Por favor, señala con una X en la línea siguiente en función de tus preferencias sexuales:

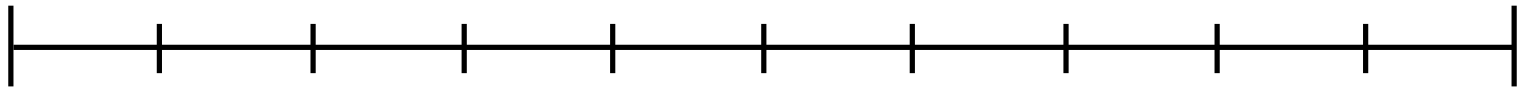




\section{Escala de Búsqueda de Sensaciones Sexuales}

\section{(Kalichman y Rompa, 1995)}

A continuación te presentamos una serie de afirmaciones sobre tu comportamiento sexual para que respondas en qué medida estos enunciados son característicos en ti. Por favor, contesta con sinceridad, tus respuestas son anónimas y confidenciales.

\begin{tabular}{|c|c|c|c|c|}
\hline & 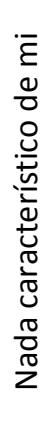 & 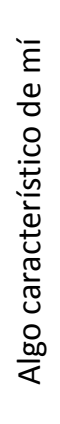 & 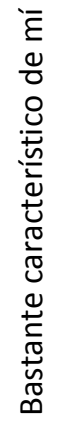 & 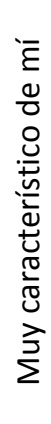 \\
\hline 1. Me gustan los encuentros sexuales salvajes y desinhibidos. & $\square$ & $\square$ & $\square$ & $\square$ \\
\hline 2. Las sensaciones físicas son lo más importante en el sexo. & $\square$ & $\square$ & $\square$ & $\square$ \\
\hline 3. Disfruto de la sensación que producen las relaciones sexuales sin condón. & $\square$ & $\square$ & $\square$ & $\square$ \\
\hline $\begin{array}{l}\text { 4. Seguramente, mis parejas sexuales piensan que soy una persona que corre } \\
\text { riesgos. }\end{array}$ & $\square$ & $\square$ & $\square$ & $\square$ \\
\hline $\begin{array}{l}\text { 5. En las relaciones sexuales, para mi es más importante la atracción física que } \\
\text { el grado de conocimiento que tengo de la persona. }\end{array}$ & $\square$ & $\square$ & $\square$ & $\square$ \\
\hline 6. Disfruto de la compañía de personas sensuales. & $\square$ & $\square$ & $\square$ & $\square$ \\
\hline 7. Disfruto al mirar vídeos clasificados " $\mathrm{X}$ ". & $\square$ & $\square$ & $\square$ & $\square$ \\
\hline $\begin{array}{l}\text { 8. He dicho cosas que no eran exactamente ciertas para conseguir que una } \\
\text { persona tuviera sexo conmigo. }\end{array}$ & $\square$ & $\square$ & $\square$ & $\square$ \\
\hline 9. Estoy interesado en probar nuevas experiencias sexuales. & $\square$ & $\square$ & $\square$ & $\square$ \\
\hline 10. Me apetece explorar mi sexualidad. & $\square$ & $\square$ & $\square$ & $\square$ \\
\hline 11. Me gusta tener nuevas y excitantes experiencias y sensaciones sexuales & $\square$ & $\square$ & $\square$ & $\square$ \\
\hline
\end{tabular}


En ocasiones, cuando utilizamos Internet para hacer trabajos, comunicarnos con amigos o para el ocio en general, nos podemos encontrar SIN QUERERLO (INVOLUNTARIAMENTE) con material sexual.

Vamos a plantearte ahora una serie de preguntas acerca de esta situación.

1. ¿Cuántas veces te has encontrado INVOLUNTARIAMENTE con material sexual en Internet?

\begin{tabular}{cccccc} 
Nunca & Casi nunca & Algunas veces & Bastantes veces & Muchas veces & Muchísimas veces \\
\hline$\square$ & $\square$ & $\square$ & $\square$ & $\square$ & $\square$ \\
\hline
\end{tabular}

2. ¿Sabrías decir cuántas veces te ha sucedido esto en el último año?

3. Aproximadamente, ¿̇a qué edad fue la primera vez que te sucedió?

4. En ese material, ¿Viste alguna de las escenas que te describimos a continuación? Puedes señalar tantas como creas conveniente:

Gente desnuda que no está teniendo relaciones sexuales Personas desnudas enseñando los genitales

Una relación sexual entre un hombre y una mujer Relaciones sexuales entre personas del mismo sexo Relaciones sexuales entre más de dos personas Uso de heces y orina durante las relaciones sexuales
Juegos sexuales que implican sometimiento Actividad sexual entre personas y animales Dibujos manga de contenido sexual Violación o violencia sexual Actividad sexual con adolescentes Actividad sexual con niños pequeños

5. ¿En qué tipo de páginas te has encontrado con contenido sexual DE FORMA INVOLUNTARIA?

Puedes señalar más de una opción:

En weblogs o blogs (blogger, liveJournal, Wordpress,...)

En webs de compra online

En redes sociales (Facebook, Twitter, Tuenti, MySpace, Habbo, etc.)

En motores de búsqueda (Google, Yahoo, Bing, etc.)

En Webs de descarga directa (Softonic, Torrent, Vagos, etc.)

En Webs educativas

En Webs de juegos Online (MSN Games, MiniJuegos, Pogo, etc.)

6. Ahora te proponemos una serie de situaciones que te han podido llevar a exponerte INVOLUNTARIAMENTE a dicho material. Marca la opción $\underline{\mathbf{V}}$ si consideras que es una afirmación verdadera y una $\underline{\mathbf{F}}$ si la consideras falsa. Presta atención ya que dependen de si la exposición a dicho material se produjo mientras navegabas por Internet o si fue otra persona (conocida o desconocida) quien te presentó este contenido:

\begin{tabular}{|c|c|c|}
\hline & $\mathrm{V}$ & \\
\hline Navegando por internet... & & \\
\hline He accedido a material sexual creyendo que era otro tipo de página Web. & & \\
\hline He tecleado mal la dirección de una página Web y he accedido a material sexual. & & \\
\hline He clickado involuntariamente sobre un pop-up o publicidad de una página web de contenido sexual. & & \\
\hline Una persona conocida... & & \\
\hline Me ha enviado e-mails con material sexual (fotos, vídeos, etc.). & & \\
\hline Me ha facilitado un link de una página web con material sexual. & & \\
\hline $\begin{array}{l}\text { Me ha hecho peticiones sexuales a través de Internet (Que le envíe fotografías sin ropa, que usemos la } \\
\text { Webcam para hacer algún tipo de juego sexual, etc.). }\end{array}$ & & \\
\hline Una persona desconocida... & & \\
\hline Me ha enviado e-mails con material sexual (fotos, vídeos, etc.). & & \\
\hline Me ha facilitado un link de una página web con material sexual. & & \\
\hline $\begin{array}{l}\text { Me ha hecho peticiones sexuales a través de Internet (Que le envíe fotografías sin ropa, que usemos la } \\
\text { Webcam para hacer algún tipo de juego sexual, etc.). }\end{array}$ & & \\
\hline
\end{tabular}


7. ¿Cómo reaccionaste cuando te encontraste con dicho material? Puedes señalar más de una opción:

Cerré inmediatamente la ventana

Eliminé dicho material y borré cualquier prueba

Avisé rápidamente a mis padres, profesores, etc.
Di un vistazo rápido por curiosidad

Me quedé un rato observando el contenido

Reenvié la información a otras personas.

8. Durante dicha exposición a material sexual, ¿qué sentiste? Marca las opciones de la lista que dicho contenido te provocó. Puedes seleccionar tantas como creas necesarias:
Preocupación
Culpabilidad
Vergüenza
Miedo
Sorpresa
Tristeza
Asco
Interés o distracción
Shock
Enfado
Excitación sexual
Confusión

9. Tras la exposición a este tipo de imágenes ¿Has experimentado alguna de las situaciones que describimos a continuación? Puedes señalar tantas opciones como creas convenientes.

A) Desde que me encontré involuntariamente con ese material sexual en Internet...

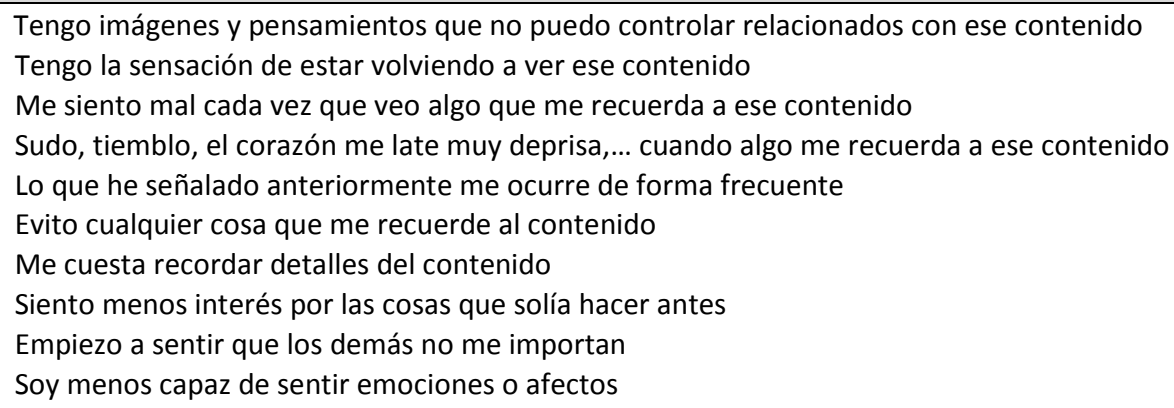

10. ¿Dirías que esta experiencia ha sido traumática para ti? Sí No

11. Por el contrario, ¿Dirías que esa experiencia te ha aportado algo positivo y que como consecuencia de ella tu vida sexual es mejor? Sí No

12. ¿En tu casa se utiliza algún tipo de programa de control de contenidos en Internet para protegerte de este tipo de situaciones? Sí No 
Ahora lee cada una de las siguientes afirmaciones. Marca con una cruz en la casilla $\mathrm{V}$ si consideras que es una afirmación verdadera o casi siempre verdadera y en la F si la consideras falsa o casi siempre falsa.

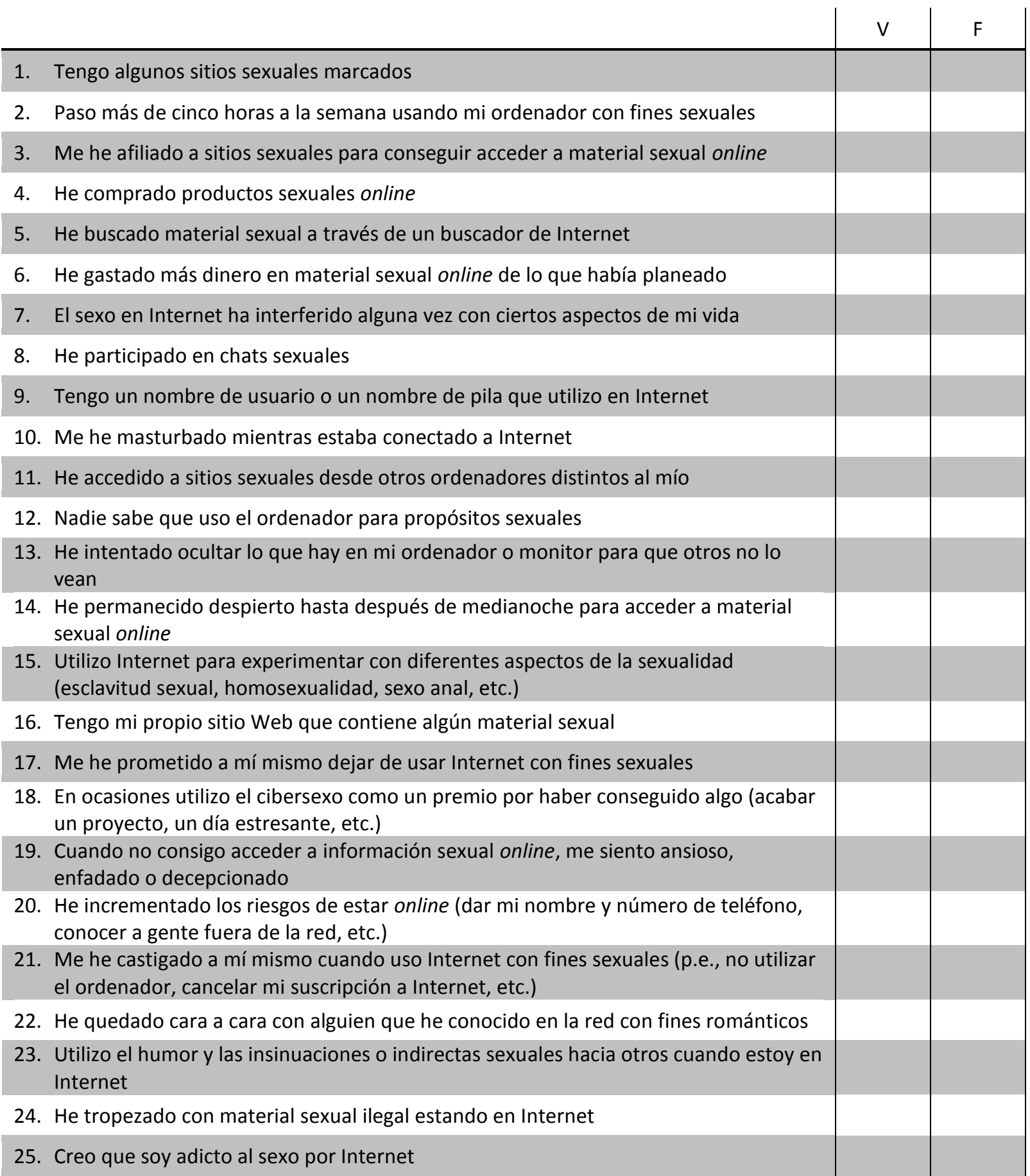




\section{Encuesta sobre el SIDA}

\section{(Ballester, Gil, Giménez y Castro, 2016)}

¿Has mantenido alguna vez relaciones sexuales de cualquier tipo con otra persona?

$\checkmark$ ¿Mantienes actualmente o has mantenido en los tres últimos meses relaciones sexuales?

$\checkmark$ ¿Con qué frecuencia sueles mantener relaciones sexuales?

$\square \quad$ Más de tres veces a la semana

Una vez al mes

$\square \quad$ Tres veces a la semana

$\square \quad$ Una vez a la semana

Cinco o seis veces al año

$\square \quad$ Dos o tres veces al mes

¿Qué tipo de prácticas sexuales has realizado hasta el momento? Puedes señalar varias

$\square \quad$ Masturbación

$\square \quad$ Masturbaciones mutuas

$\square \quad$ Coito o penetración vaginal
Sexo oral

Coito o penetración anal

Otras:

¿ ¿Has mantenido relaciones sexuales con personas de tu mismo sexo?

- En cuanto a la orientación sexual te consideras:
$\square$ Heterosexual
Bisexual
Homosexual

¿Mantienes relaciones con una pareja estable? Tiempo de relación (en meses):

- ¿Alguna vez has sido "infiel" a una pareja con la que tenías una relación estable?

- ¿Con cuántas personas aproximadamente has tenido relaciones sexuales en tu vida?

- De cada 100 personas afectadas por VIH (SIDA) ¿Cuántas crees que son toxicómanos? ¿Y homosexuales? ¿Y heterosexuales? Distribuye el $100 \%$ entre los tres grupos.

$\checkmark$ ¿Dirías que actualmente el SIDA es una enfermedad que tiene curación?

- ¿Con qué frecuencia utilizas el preservativo ante las siguientes situaciones? (Contesta sólo si te has encontrado ante alguna de ellas)

\begin{tabular}{lccc} 
& Nunca & Algunas veces & Bastantes veces \\
Coito vaginal & $\square$ & $\square$ & $\square$ \\
Sexo oral & $\square$ & $\square$ & $\square$ \\
Coito anal & $\square$ & $\square$ & $\square$ \\
Relaciones con pareja estable & $\square$ & $\square$ & $\square$ \\
Relaciones con pareja esporádica & $\square$ & $\square$ & $\square$ \\
Cuando has consumido alcohol o drogas & $\square$ & $\square$ \\
\hline
\end{tabular}

¿Utilizas algún otro método anticonceptivo distinto al preservativo? ¿Cuál? 
¿ ¿En tu última relación sexual, habías bebido alcohol?

¿ ¿En tu última relación sexual, habías consumido drogas?

- En el caso de que te surgiera la posibilidad de una relación sexual y no tuvieras un preservativo:

$\square$ Tendrías la relación exactamente igual

$\square$ Mantendrías la relación pero evitando prácticas de riesgo para a transmisión de VIH (SIDA)

$\square$ Te abstendrías de mantener relaciones sexuales

$\square$ Irías en busca de un preservativo, intentarías conseguirlo.

¿Hasta qué punto consideras que el preservativo es un método fiable de prevención sexual del SIDA?

\begin{tabular}{cccc} 
Nada & Algo & Bastante & Mucho \\
\hline$\square$ & $\square$ & $\square$ & $\square$ \\
\hline
\end{tabular}

- ¿Cuál es la principal dificultad o inconveniente que encuentras para usar el preservativo?

- Señala de 0 a 100 la probabilidad o el riesgo que percibes de un embarazo no deseado:

$\checkmark$ ¿Y de infectarte con el VIH (SIDA)?

- Señala de 0 a 100 el temor que te produce la posibilidad de un embarazo no deseado:

¿Y el temor de infectarte con el VIH (SIDA)?

- ¿Consideras que actualmente el SIDA es una enfermedad?
$\square \quad$ Leve
Grave
Moderada
Fatal

- ¿Alguna vez te has hecho las pruebas diagnósticas del VIH directamente o indirectamente (a través de una donación de sangre)? ............. En caso afirmativo, ¿cuántas veces? .............. ¿Y cuánto tiempo hace desde la última vez?

- Di hasta qué punto estás de acuerdo con las siguientes afirmaciones teniendo en cuenta esta escala:

1

2
3

4

5

Totalmente en desacuerdo Bastante en desacuerdo $\quad$ Algo en Desacuerdo $\quad$ Bastante de acuerdo Totalmente de acuerdo

Me siento/sentiría cómodo/a o seguro/a a la hora de comprar condones

Me resultaría cómodo hablar acerca del uso del condón con una pareja antes de comenzar la relación sexual

Si tengo que sugerir a una pareja que usemos el condón, tengo/tendría miedo a que me rechace \begin{tabular}{|l|l|l|l|l|l|l|}
\hline 1 & 3 & 4 & 5 \\
\hline
\end{tabular}

No me siento/sentiría seguro a la hora de sugerir el uso del condón a una nueva pareja ya que él/ella podría pensar que lo hago porque creo que tiene una enfermedad de transmisión sexual

Estoy seguro/a de que recordaría usar el condón aunque haya consumido alcohol u otras drogas

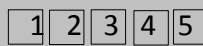
Me siento/sentiría incómodo/a a la hora de ponerme el condón o ponérselo a mi pareja \begin{tabular}{|l|l|l|l|l|l|l|l|l|}
\hline 1 & 2 & 3 & 4 & 5 \\
\hline
\end{tabular}

Estoy seguro/a de que podría parar aún en el momento de mayor excitación para ponerme el condón o ponérselo a mi pareja 


\section{(Spielberger, Gorsuch y Lushene, 2002)}

A continuación encontrarás unas frases que se utilizan corrientemente para describirse uno a sí mismo. Lee cada frase y señala la puntuación de 0 a 3 que indique mejor CóMO TE SIENTES AHORA MISMO, en este momento. No hay respuestas buenas ni malas. No emplees demasiado tiempo en cada frase y contesta señalando la respuesta que mejor describa tu situación presente.

\begin{tabular}{|c|c|c|c|c|}
\hline & $\begin{array}{l}\frac{\pi}{0} \\
\frac{\pi}{2}\end{array}$ & $\frac{\circ}{\mathbb{a}}$ & 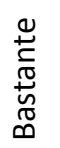 & $\begin{array}{l}\frac{O}{\mathrm{~L}} \\
\text { 일 }\end{array}$ \\
\hline 1. Me siento calmado. & $\square$ & $\square$ & $\square$ & $\square$ \\
\hline 2. Me siento seguro. & $\square$ & $\square$ & $\square$ & $\square$ \\
\hline 3. Estoy tenso. & $\square$ & $\square$ & $\square$ & $\square$ \\
\hline 4. Estoy contrariado. & $\square$ & $\square$ & $\square$ & $\square$ \\
\hline 5. Me siento cómodo (estoy a gusto). & $\square$ & $\square$ & $\square$ & $\square$ \\
\hline 6. Me siento alterado. & $\square$ & $\square$ & $\square$ & $\square$ \\
\hline 7. Estoy preocupado ahora por posibles desgracias futuras. & $\square$ & $\square$ & $\square$ & $\square$ \\
\hline 8. Me siento descansado. & $\square$ & $\square$ & $\square$ & $\square$ \\
\hline 9. Me siento angustiado. & $\square$ & $\square$ & $\square$ & $\square$ \\
\hline 10. Me siento confortable. & $\square$ & $\square$ & $\square$ & $\square$ \\
\hline 11. Tengo confianza en mí mismo. & $\square$ & $\square$ & $\square$ & $\square$ \\
\hline 12. Me siento nervioso. & $\square$ & $\square$ & $\square$ & $\square$ \\
\hline 13. Estoy desasosegado (intranquilo). & $\square$ & $\square$ & $\square$ & $\square$ \\
\hline 14. Me siento muy "atado" (como oprimido). & $\square$ & $\square$ & $\square$ & $\square$ \\
\hline 15. Estoy relajado. & $\square$ & $\square$ & $\square$ & $\square$ \\
\hline 16. Me siento satisfecho. & $\square$ & $\square$ & $\square$ & $\square$ \\
\hline 17. Estoy preocupado. & $\square$ & $\square$ & $\square$ & $\square$ \\
\hline 18. Me siento aturdido y sobrexcitado. & $\square$ & $\square$ & $\square$ & $\square$ \\
\hline 19. Me siento alegre. & $\square$ & $\square$ & $\square$ & $\square$ \\
\hline 20. En este momento me siento bien. & $\square$ & $\square$ & $\square$ & $\square$ \\
\hline
\end{tabular}


A continuación encontrarás unas frases que se utilizan corrientemente para describirse uno a sí mismo. Lee cada frase y señala la puntuación de 0 a 3 que indique mejor CóMO TE SIENTES EN GENERAL, en la mayoría de las ocasiones. No hay respuestas buenas ni malas. No emplees demasiado tiempo en cada frase y contesta señalando la respuesta que mejor describa cómo te sientes tú generalmente.

\begin{tabular}{|c|c|c|c|c|}
\hline & $\frac{\pi}{\frac{\pi}{\pi}}$ & $\frac{\mathrm{O}}{\mathrm{a0}}$ & 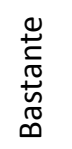 & $\frac{\text { 을 }}{\text { 을 }}$ \\
\hline 21. Me siento bien. & $\square$ & $\square$ & $\square$ & $\square$ \\
\hline 22. Me canso rápidamente. & $\square$ & $\square$ & $\square$ & $\square$ \\
\hline 23. Siento ganas de llorar. & $\square$ & $\square$ & $\square$ & $\square$ \\
\hline 24. Me gustaría ser tan feliz como otros. & $\square$ & $\square$ & $\square$ & $\square$ \\
\hline 25. Pierdo oportunidades por no decidirme pronto. & $\square$ & $\square$ & $\square$ & $\square$ \\
\hline 26. Me siento descansado. & $\square$ & $\square$ & $\square$ & $\square$ \\
\hline 27. Soy una persona tranquila, serena y sosegada. & $\square$ & $\square$ & $\square$ & $\square$ \\
\hline 28. Veo que las dificultades se amontonan y no puedo con ellas. & $\square$ & $\square$ & $\square$ & $\square$ \\
\hline 29. Me preocupo demasiado por cosas sin importancia. & $\square$ & $\square$ & $\square$ & $\square$ \\
\hline 30. Soy feliz. & $\square$ & $\square$ & $\square$ & $\square$ \\
\hline 31. Suelo tomar las cosas demasiado seriamente. & $\square$ & $\square$ & $\square$ & $\square$ \\
\hline 32. Me falta confianza en mí mismo. & $\square$ & $\square$ & $\square$ & $\square$ \\
\hline 33. Me siento seguro. & $\square$ & $\square$ & $\square$ & $\square$ \\
\hline 34. No puedo afrontar las crisis o dificultades. & $\square$ & $\square$ & $\square$ & $\square$ \\
\hline 35. Me siento triste (melancólico). & $\square$ & $\square$ & $\square$ & $\square$ \\
\hline 36. Estoy satisfecho. & $\square$ & $\square$ & $\square$ & $\square$ \\
\hline 37. Me rondan y molestan pensamientos sin importancia. & $\square$ & $\square$ & $\square$ & $\square$ \\
\hline 38. Me afectan tanto los engaños, que no puedo olvidarlos. & $\square$ & $\square$ & $\square$ & $\square$ \\
\hline 39. Soy una persona estable. & $\square$ & $\square$ & $\square$ & $\square$ \\
\hline $\begin{array}{l}\text { 40. Cuando pienso sobre asuntos y preocupaciones actuales, me } \\
\text { pongo tenso y agitado. }\end{array}$ & $\square$ & $\square$ & $\square$ & $\square$ \\
\hline
\end{tabular}


En este cuestionario aparecen 21 grupos de afirmaciones. Por favor, lee con atención cada uno de ellos y a continuación, señala la afirmación de cada grupo que describa mejor tus sentimientos durante las DOS ÚLTIMAS SEMANAS, INCLUÍDO EL DÍA DE HOY. Rodea con un círculo el número que esté a la izquierda de la afirmación que hayas elegido.

Asegúrate de haber leído todas las afirmaciones dentro de cada grupo antes de hacer la elección. Asegúrate también de no haber elegido más de una respuesta de cada grupo, sobre todo en los elementos 16 (cambios en el patrón de sueño) 18 (cambio en el apetito).

\section{Tristeza}

0 . No me siento triste.

1. Me siento triste gran parte del tiempo.

2. Me siento triste continuamente.

3. Me siento tan triste o tan desgraciado que no puedo soportarlo.

\section{Pesimismo}

0 . No estoy desanimado sobre mi futuro.

1. Me siento más desanimado sobre mi futuro que antes.

2. No espero que las cosas mejoren.

3. Siento que mi futuro es desesperanzador y que las cosas solo empeorarán.

\section{Sentimiento de fracaso}

0. No me siento fracasado.

1. He fracasado más de lo que debería.

2. Cuando miro atrás, veo fracaso tras fracaso.

3. Me siento una persona totalmente fracasada.

\section{Pérdida de placer}

0. Disfruto de las cosas que me gustan tanto como antes.

1. No disfruto de las cosas tanto como antes.

2. Obtengo muy poco placer de las cosas con las que antes disfrutaba.

3. No obtengo ningún placer de las cosas con las que antes disfrutaba.

\section{Sentimientos de culpa}

0 . No me siento especialmente culpable.

1. Me siento culpable de muchas cosas que he hecho o debería haber hecho.

2. Me siento bastante culpable la mayor parte del tiempo.

3. Me siento culpable constantemente.

\section{Sentimientos de castigo}

0 . No me siento que esté siendo castigado.

1. Siento puedo ser castigado.

2. Espero ser castigado.

3. Siento que estoy siendo castigado.

\section{Insatisfacción con uno mismo}

0. Siento lo mismo que antes sobre mí mismo.

1. He perdido la confianza en mí mismo.

2. Estoy decepcionado conmigo mismo.

3. No me gusto.

\section{Autocríticas}

0 . No me critico o me culpa más que antes.

1. Soy más crítico conmigo mismo de lo que solía ser.

2. Critico todos mis defectos.

3. Me culpo de todo lo malo que sucede.

\section{Pensamientos o deseos de suicidio}

0 . No tengo ningún pensamiento de suicidio.

1. Tengo pensamientos de suicidio, pero no los llevaría a cabo.

2. Me gustaría suicidarme.

3. Me suicidaría si tuviese la oportunidad.

\section{Llanto}

0. No lloro más de lo que lo solía hacer.

1. Lloro más de lo que lo solía hacer.

2. Lloro por cualquier cosa.

3. Tengo ganas de llorar continuamente, pero no puedo.

\section{Agitación}

0 . No estoy más inquieto o agitado que de costumbre.

1. Me siento más inquieto o agitado que de costumbre.

2. Estoy tan inquieto o agitado que me cuesta estarme quieto.

3. Estoy tan inquieto o agitado que tengo que estar moviéndome o haciendo algo.

\section{Pérdida de interés}

0 . No he perdido el interés por otras personas o actividades.

1. Estoy menos interesado que antes por otras personas o actividades.

2. He perdido la mayor parte de mi interés por los demás o por las cosas.

3. Me resulta difícil interesarme en algo. 


\section{Indecisión}

0 . Tomo decisiones más o menos como siempre.

1. Tomar decisiones me resulta más difícil que de costumbre.

2. Tengo mucha más dificultad en tomar decisiones que de costumbre.

3. Tengo problemas para tomar cualquier decisión.

\section{Inutilidad}

0. No me siento inútil.

1. No me considero tan valioso y útil como solía ser.

2. Me siento inútil en comparación con otras personas.

3. Me siento completamente inútil.

\section{Pérdida de energía}

0 . Tengo tanta energía como siempre.

1. Tengo menos energía de la que solía tener.

2. No tengo suficiente energía para hacer muchas cosas

3. No tengo suficiente energía para hacer nada

\section{Cambios en el patrón de sueño}

0 . No he experimentado ningún cambio en el sueño.

1.a Duermo algo más de lo habitual

1.b Duermo algo menos de lo habitual.

2.a Duermo mucho más de lo habitual

2.b Duermo mucho menos de lo habitual.

3.a Duermo la mayor parte del día.

3.b Me levante 1 o 2 horas más temprano y no puedo volver a dormirme.

\section{Irritabilidad}

0 . No estoy más irritable de lo habitual.

1. Estoy más irritable de lo habitual.

2. Estoy mucho más irritable de lo habitual.

3. Estoy irritable continuamente.
18. Cambios en el apetito

0 . No he experimentado ningún cambio en mi apetito.

1.a $\mathrm{Mi}$ apetito es algo menor de lo habitual.

1.b Mi apetito es algo mayor de lo habitual

2.a Mi apetito es mucho menor que antes.

2.b Mi apetito es mucho mayor que antes.

3.a He perdido completamente el apetito.

3.b Tengo ganas de comer continuamente.

\section{Dificultad de concentración}

0 . Puedo concentrarme tan bien como siempre.

1. No puedo concentrarme tan bien como habitualmente.

2. Me cuesta mantenerme concentrado en algo durante mucho tiempo.

3. No puedo concentrarme en nada.

\section{Cansancio o fatiga}

0 . No estoy más cansado o fatigado que de costumbre.

1. Me canso o fatigo más fácilmente que de costumbre.

2. Estoy demasiado cansado o fatigado para hacer muchas cosas que antes solía hacer.

3. Estoy demasiado cansado o fatigado para hacer la mayoría de las cosas que antes solía hacer.

\section{Pérdida de interés por el sexo}

0 . No he notado ningún cambio reciente en mi interés por el sexo.

1. Estoy menos interesado por el sexo de lo que solía estar.

2. Estoy mucho menos interesado por el sexo ahora.

3. He perdido completamente el interés por el sexo. 
La siguiente lista consiste en una serie de frases que se refieren a Ud. mismo y a su forma de pensar. De las cuatro alternativas, deberá elegir aquella con la que esté de acuerdo. Por favor, sea sincero.

\begin{tabular}{|c|c|c|c|c|}
\hline & 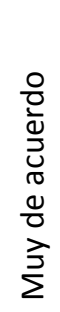 & 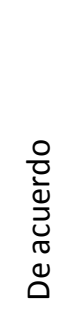 & 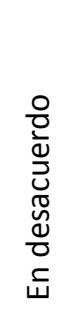 & 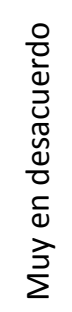 \\
\hline 1. En general, estoy satisfecho conmigo mismo. & & & & \\
\hline 2. A veces pienso que no soy bueno en nada. & & & & \\
\hline 3. Tengo la sensación de que poseo algunas buenas cualidades. & & & & \\
\hline 4. Soy capaz de hacer las cosas tan bien como la mayoría de las personas. & & & & \\
\hline 5. Siento que no tengo demasiadas cosas de las que sentirme orgulloso. & & & & \\
\hline 6. A veces me siento realmente inútil. & & & & \\
\hline $\begin{array}{l}\text { 7. Tengo la sensación de que soy una persona de valía, al menos igual que } \\
\text { la mayoría de la gente. }\end{array}$ & & & & \\
\hline 8. Ojalá me respetara más a mí mismo. & & & & \\
\hline 9. En definitiva, tiendo a pensar que soy un fracasado. & & & & \\
\hline 10. Tengo una actitud positiva hacia mí mismo. & & & & \\
\hline
\end{tabular}


Por favor, responde a cada una de las siguientes preguntas con sinceridad. Marca con un círculo el número que mejor exprese tu opinión o sentimiento según tu grado de acuerdo o desacuerdo.

\begin{tabular}{|c|c|c|c|c|c|c|c|c|}
\hline & \multirow[b]{2}{*}{$\begin{array}{l}\text { Pienso que ver una película o leer un libro con contenido } \\
\text { erótico/sexual podría ser entretenido. }\end{array}$} & \multicolumn{5}{|c|}{$\begin{array}{l}\text { Totalmente } \\
\text { en desacuerdo }\end{array}$} & \multicolumn{2}{|c|}{$\begin{array}{l}\text { Totalmente } \\
\text { de acuerdo }\end{array}$} \\
\hline & & 1 & 2 & 3 & 4 & 5 & 6 & 7 \\
\hline 2. & $\begin{array}{l}\text { El material erótico (libros y/o películas) de contenido sexual } \\
\text { es algo sucio y la gente no debería utilizarlo. }{ }^{*}\end{array}$ & 1 & 2 & 3 & 4 & 5 & 6 & 7 \\
\hline 3. & $\begin{array}{l}\text { Bañarse desnudo/a con una persona del mismo u otro sexo } \\
\text { podría ser una experiencia excitante. }\end{array}$ & 1 & 2 & 3 & 4 & 5 & 6 & 7 \\
\hline 4. & La masturbación puede ser una experiencia excitante. & 1 & 2 & 3 & 4 & 5 & 6 & 7 \\
\hline 5. & $\begin{array}{l}\text { Sería agobiante para mí que la gente pensara que tengo } \\
\text { interés por el sexo oral. * }\end{array}$ & 1 & 2 & 3 & 4 & 5 & 6 & 7 \\
\hline 6. & $\begin{array}{l}\text { Me atrae la idea de participar en una experiencia sexual en } \\
\text { grupo. }\end{array}$ & 1 & 2 & 3 & 4 & 5 & 6 & 7 \\
\hline 7. & $\begin{array}{l}\text { Me resulta excitante pensar en tener una relación sexual } \\
\text { con penetración. }\end{array}$ & 1 & 2 & 3 & 4 & 5 & 6 & 7 \\
\hline & $\begin{array}{l}\text { Me excitaría sexualmente viendo una película de contenido } \\
\text { sexual. }\end{array}$ & 1 & 2 & 3 & 4 & 5 & 6 & 7 \\
\hline 9. & $\begin{array}{l}\text { Pensar que puedo tener tendencias sexuales distintas a la } \\
\text { de mi propia orientación no me resultaría del todo } \\
\text { embarazoso. }\end{array}$ & 1 & 2 & 3 & 4 & 5 & 6 & 7 \\
\hline 10. & $\begin{array}{l}\text { No me resulta incómoda la idea de sentir atracción física } \\
\text { por personas de mi propio sexo. }\end{array}$ & 1 & 2 & 3 & 4 & 5 & 6 & 7 \\
\hline 11. & Casi todo el material erótico me produce incomodidad.. & 1 & 2 & 3 & 4 & 5 & 6 & 7 \\
\hline 12. & $\begin{array}{l}\text { Me sentiría emocionalmente mal viendo a alguien exhibirse } \\
\text { públicamente. }\end{array}$ & 1 & 2 & 3 & 4 & 5 & 6 & 7 \\
\hline & $\begin{array}{l}\text { No sería una experiencia muy excitante ver a una persona } \\
\text { desnuda. * }\end{array}$ & 1 & 2 & 3 & 4 & 5 & 6 & 7 \\
\hline 14. & No me agradaría ver una película erótica. ${ }^{*}$ & 1 & 2 & 3 & 4 & 5 & 6 & 7 \\
\hline 15. & $\begin{array}{l}\text { Me incomoda pensar que puedo ver una película en la que } \\
\text { aparezca masturbándose una persona. }{ }^{*}\end{array}$ & 1 & 2 & 3 & 4 & 5 & 6 & 7 \\
\hline 16. & $\begin{array}{l}\text { Es muy excitante imaginar prácticas sexuales poco } \\
\text { comunes. }\end{array}$ & 1 & 2 & 3 & 4 & 5 & 6 & 7 \\
\hline 17. & $\begin{array}{l}\text { Probablemente sería una experiencia excitante acariciar mis } \\
\text { propios genitales. }\end{array}$ & 1 & 2 & 3 & 4 & 5 & 6 & 7 \\
\hline 18. & No me agrada tener sueños sexuales. * & 1 & 2 & 3 & 4 & 5 & 6 & 7 \\
\hline 19. & $\begin{array}{l}\text { No siento ninguna curiosidad por el material de contenido } \\
\text { sexual (libros, revistas, películas, vídeos). }{ }^{*}\end{array}$ & 1 & 2 & 3 & 4 & 5 & 6 & 7 \\
\hline & $\begin{array}{l}\text { No me disgusta imaginar que tengo relaciones sexuales con } \\
\text { más de una persona. }\end{array}$ & 1 & 2 & 3 & 4 & 5 & 6 & 7 \\
\hline
\end{tabular}


Por favor, señala la respuesta que mejor describa tus comportamientos o experiencias:

\begin{tabular}{|c|c|c|c|c|c|}
\hline & 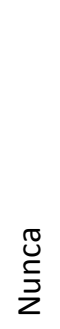 & 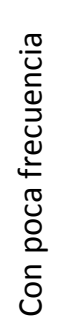 & 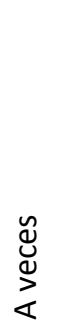 & 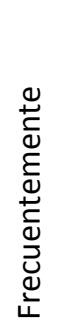 & 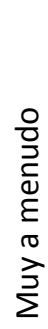 \\
\hline $\begin{array}{l}\text { ¿Con qué frecuencia has tenido problemas para controlar tus impulsos } \\
\text { sexuales? }\end{array}$ & 1 & 2 & 3 & 4 & 5 \\
\hline ¿Te has sentido incapaz de controlar tu comportamiento sexual? & 1 & 2 & 3 & 4 & 5 \\
\hline $\begin{array}{l}\text { ¿Con qué frecuencia has usado el sexo para sobrellevar tus } \\
\text { preocupaciones o los problemas de tu vida? }\end{array}$ & 1 & 2 & 3 & 4 & 5 \\
\hline $\begin{array}{l}\text { ¿Con qué frecuencia te has sentido culpable o avergonzado sobre } \\
\text { aspectos de tu comportamiento sexual? }\end{array}$ & 1 & 2 & 3 & 4 & 5 \\
\hline $\begin{array}{l}\text { ¿Con qué frecuencia has ocultado o escondido tu comportamiento } \\
\text { sexual a los demás? }\end{array}$ & 1 & 2 & 3 & 4 & 5 \\
\hline ¿Con qué frecuencia has sido incapaz de controlar tus deseos sexuales? & 1 & 2 & 3 & 4 & 5 \\
\hline $\begin{array}{l}\text { ¿Con qué frecuencia has hecho el propósito o te has prometido a ti } \\
\text { mismo cambiar tu comportamiento sexual? }\end{array}$ & 1 & 2 & 3 & 4 & 5 \\
\hline $\begin{array}{l}\text { ¿Con qué frecuencia tus pensamientos o comportamientos sexuales te } \\
\text { han interferido para hacer amistades? }\end{array}$ & 1 & 2 & 3 & 4 & 5 \\
\hline $\begin{array}{l}\text { ¿Con qué frecuencia has inventado excusas y razones para justificar tu } \\
\text { comportamiento sexual? }\end{array}$ & 1 & 2 & 3 & 4 & 5 \\
\hline $\begin{array}{l}\text { ¿Con qué frecuencia has perdido oportunidades para realizar e } \\
\text { incrementar actividades debido a tu comportamiento sexual? }\end{array}$ & 1 & 2 & 3 & 4 & 5 \\
\hline $\begin{array}{l}\text { ¿Con qué frecuencia tus actividades sexuales te han provocado } \\
\text { problemas económicos? }\end{array}$ & 1 & 2 & 3 & 4 & 5 \\
\hline $\begin{array}{l}\text { ¿Con qué frecuencia te has sentido emocionalmente distante mientras } \\
\text { mantenías relaciones sexuales con otras personas? }\end{array}$ & 1 & 2 & 3 & 4 & 5 \\
\hline $\begin{array}{l}\text { ¿Con qué frecuencia has tenido relaciones sexuales o te has } \\
\text { masturbado más de lo que querías? }\end{array}$ & 1 & 2 & 3 & 4 & 5 \\
\hline ¿Has sufrido abusos sexuales en la infancia? & 1 & 2 & 3 & 4 & 5 \\
\hline ¿Has sufrido maltrato físico en la infancia? & 1 & 2 & 3 & 4 & 5 \\
\hline $\begin{array}{l}\text { Sin contar a tus padres o hermanos, ¿tuviste experiencias sexuales } \\
\text { durante tu infancia con alguien que tuviera al menos } 4 \text { años más que } \\
\text { tú? }\end{array}$ & 1 & 2 & 3 & 4 & 5 \\
\hline ¿Has tenido experiencias sexuales con alguno de tus hermanos? & 1 & 2 & 3 & 4 & 5 \\
\hline $\begin{array}{l}\text { ¿Has sido forzado a tener relaciones sexuales con un extraño, un } \\
\text { conocido o un amigo? }\end{array}$ & 1 & 2 & 3 & 4 & 5 \\
\hline
\end{tabular}




\begin{tabular}{|c|c|c|c|c|c|}
\hline $\begin{array}{l}\text { ¿Con qué frecuencia has sido arrestado o detenido por tu } \\
\text { comportamiento sexual? }\end{array}$ & 1 & 2 & 3 & 4 & 5 \\
\hline $\begin{array}{l}\text { ¿Has obligado a alguien a mantener relaciones sexuales en contra de su } \\
\text { voluntad? }\end{array}$ & 1 & 2 & 3 & 4 & 5 \\
\hline ¿Has tenido relaciones sexuales con alguno de tus padres? & 1 & 2 & 3 & 4 & 5 \\
\hline $\begin{array}{l}\text { ¿Alguna vez has golpeado, pateado, abofeteado, lanzado, inmovilizado, } \\
\text { retenido o mordido a alguna de tus parejas sexuales? }\end{array}$ & 1 & 2 & 3 & 4 & 5 \\
\hline ¿Has producido dolor físico por placer? & 1 & 2 & 3 & 4 & 5 \\
\hline $\begin{array}{l}\text { ¿Durante una pelea, has sido golpeado, pateado, abofeteado, lanzado, } \\
\text { inmovilizado, retenido o mordido por tu pareja actual o la más reciente? }\end{array}$ & 1 & 2 & 3 & 4 & 5 \\
\hline ¿Has recibido dolor físico por placer? & 1 & 2 & 3 & 4 & 5 \\
\hline ¿Has recibido dinero por mantener relaciones sexuales? & 1 & 2 & 3 & 4 & 5 \\
\hline ¿Has sido forzado a tener sexo con tu marido, mujer o amante? & 1 & 2 & 3 & 4 & 5 \\
\hline $\begin{array}{l}\text { ¿Has sido visto masturbándote o manteniendo relaciones sexuales sin } \\
\text { que hayas dado tu permiso? }\end{array}$ & 1 & 2 & 3 & 4 & 5 \\
\hline
\end{tabular}




\section{(McBride, Reece y Sanders, 2008)}

\section{Consecuencias cognitivas:}

A continuación se muestra una lista de cosas por las que algunas personas se preocupan como resultado de sus actividades sexuales (incluyendo cosas que la gente hace sola y cosas que hace con otras personas). Por favor, indica en qué medida las siguientes son aplicables a ti.

Me preocupa que las cosas que he hecho sexualmente:

1. Me hayan puesto a mí o a mis parejas sexuales en riesgo de embarazo.

2. Hayan podido ponerme a mí o a alguna de mis parejas sexuales en riesgo de contraer una infección de transmisión sexual (como herpes, gonorrea o ladillas).

3. Pudieran haberme puesto a mí o a mis parejas sexuales en riesgo de infección por el VIH.

4. Pudieran haber causado a alguna de mis parejas sexuales dolor, lesiones u otros problemas.

5. Pudieran haberme causado dolor, lesiones u otros problemas a mí mismo.

6. Pudieran provocar potencialmente lesiones físicas graves o la muerte.

7. Pudieran llevarme a problemas con mis amigos.

8. Pudieran llevarme a problemas con miembros de mi familia.

9. Pudieran llevarme a problemas con mi pareja.

10. Pudieran haberme puesto en riesgo de ser arrestado/a.

11. Pudieran haber ido en contra de la ley.

12. Pudieran haberme provocado problemas financieros.

13. Pudieran haberme hecho gastar dinero.

14. Estuvieran interfiriendo con mi capacidad para realizar las tareas del trabajo o los estudios.

15. Pudieran hacerme perder el trabajo.

16. Podrían llevarme a problemas escolares, como mayor vigilancia, expulsiones u otras sanciones.

17. Estuvieran en contra de mis creencias espirituales.

18. Estuvieran en contra de mis valores religiosos.

19. Me estuvieran haciendo sentir culpable.

20. Me estuvieran haciendo sentir avergonzado de mí mismo/a.

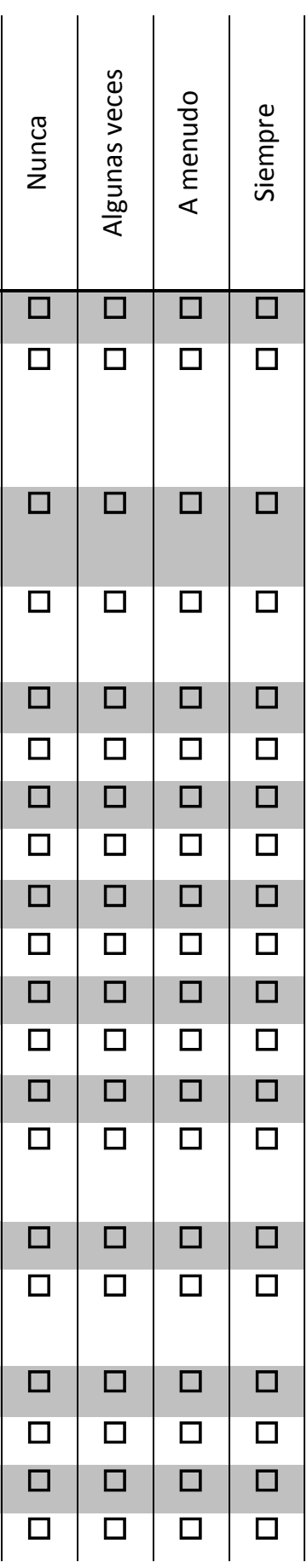




\section{Consecuencias conductuales:}

A continuación se muestra una lista de cosas que a veces les sucede a las personas como consecuencia de sus actividades sexuales (incluyendo aquellas que hace sólo y las que hace con otros). Por favor, indica si estas cosas te han sucedido durante el último año como resultado de tu actividad sexual (Sí/No).

De las siguientes, ¿cuáles te han sucedido en el último año como resultado de las cosas que has hecho sexualmente?:

1. Yo o mis parejas sexuales se han quedado embarazadas.

2. Contraje una infección de transmisión sexual.

3. Contraje el VIH.

4. Transmití a alguien una infección de transmisión sexual.

5. Trasmití a alguien el VIH.

6. Me causé dolor, lesiones u otros problemas físicos.

7. Causé dolor, lesiones y otros problemas físicos a alguna de mis parejas sexuales.

8. Mis relaciones con amigos y/o familiares se vieron dañadas.

9. Mis relaciones con mi esposo/a o con mi pareja se vieron dañadas.

10. Fui arrestado.

11. Experimenté problemas económicos.

12. Experimenté problemas en la escuela.

13. Experimenté problemas en el trabajo.

14. Experimenté malestar espiritual.

15. Me sentí turbado o avergonzado de mí mismo/a.

16. Me sentí culpable. 
Anexo IV. Modelos de e-mail para la participación en la segunda fase de la investigación, cartel para difusión de la investigación y captura de pantalla de su publicación en Facebook. 
VERSIÓN: Chicos control y subclínicos

ASUNTO: Propuesta de participación en investigación remunerada de UNISEXSIDA

Buenos días,

Desde UNISEXSIDA (Universitat Jaume I), estamos realizando actualmente una investigación sobre conducta sexual en jóvenes. A propósito de esta investigación, el año pasado preparamos mesas informativas en el Hall de tu facultad. Allí rellenaste uno de nuestros cuestionarios y facilitaste tu mail de contacto para que pudiéramos contactar contigo durante la segunda fase de esta misma investigación.

En este momento estamos comenzando con la segunda fase de esta misma investigación. Las personas que participen en esta fase tan sólo deberán acudir a nuestro laboratorio de investigación (facultad de ciencias humanas y sociales, HC2256DL) y:

1- Completar una entrevista clínica general.

2- Cumplimentar una batería de cuestionarios dirigidos a evaluar tu personalidad, autoestima, ciertos aspectos de tu conducta sexual, etc.

3- A parte, existe la posibilidad de participar también en la aplicación de una prueba fisiológica de medida de la respuesta sexual, el pletismógrafo. Esta prueba es opcional y se remunera aparte.

La participación en la entrevista y en la batería de cuestionarios se remunerará con 10 euros. Si además decides participar en la prueba del pletismógrafo, se remunerará con 10 euros más.

El horario para la realización de la investigación es muy flexible. En todo momento trataremos de acoplarnos a tu disponibilidad.

Si estás interesado, puedes responder a este mismo e-mail con tu nombre y tu número de contacto y nosotros mismos te llamaremos.

Un saludo y gracias por tú atención,

Jesús Castro Calvo,

Personal Investigador en Unisexsida

Unisexsida (Unidad de Investigación en Sexualidad y SIDA)

Facultad de Ciencias Humanas y Sociales, 2a planta, HC2256DL 
VERSIÓN: Chicas control y subclínicas

ASUNTO: Propuesta de participación en investigación remunerada de UNISEXSIDA

Buenos días,

Desde UNISEXSIDA (Universitat Jaume I), estamos realizando actualmente una investigación sobre conducta sexual en jóvenes. A propósito de esta investigación, el año pasado preparamos mesas informativas en el Hall de tu facultad. Allí rellenaste uno de nuestros cuestionarios y facilitaste tu mail de contacto para que pudiéramos contactar contigo durante la segunda fase de esta misma investigación.

En este momento estamos comenzando con la segunda fase de esta misma investigación. Las personas que participen en esta fase tan sólo deberán acudir a nuestro laboratorio de investigación (facultad de ciencias humanas y sociales, HC2256DL) y:

1- Completar una entrevista clínica general.

2- Cumplimentar una batería de cuestionarios dirigidos a evaluar tu personalidad, autoestima, ciertos aspectos de tu conducta sexual, etc.

La participación se remunerará con 10 euros.

El horario para la realización de la investigación es muy flexible. En todo momento trataremos de acoplarnos a tu disponibilidad.

Si estás interesada, puedes responder a este mismo e-mail con tu nombre y tu número de contacto y nosotros mismos te llamaremos.

Si algún amigo o amiga está interesado en participar, también puede hacerlo.

Un saludo y gracias por tú atención,

Jesús Castro Calvo,

Personal Investigador en Unisexsida

Unisexsida (Unidad de Investigación en Sexualidad y SIDA)

Facultad de Ciencias Humanas y Sociales, 2a planta, HC2256DL

Personal Investigador en Unisexsida. 


\section{¿Alguna vez...}

... Has perdido el control de tu conducta sexual?

... Has pensado que tu conducta sexual era excesiva?

... Te has arrepentido de aspectos de tu vida sexual?

... Has utilizado el sexo como válvula de escape?

Si es así, quizás te interese colaborar en una investigación sobre conducta sexual organizada por UNISEXSIDA. Participar no te llevará más de 3 horas y tu colaboración se remunera con entre 10-20 EUROS. NO IMPORTA NI TU SEXO NI TU EDAD.

Si te interesa, llámanos o pásate por nuestro despacho. También puedes escribirnos un e-mail con tu nombre y tu número de contacto y nosotros mismos te llamaremos. Tu participación es totalmente ANÓNIMA.

\section{Teléfono: 964729719 \\ E-mail: unisexsida@uji.es}

Despacho: facultad de ciencias humanas y sociales, 2a planta, HC2256DL 
Desde UNISEXSIDA (UJI) estamos organizando una investigación REMUNERADA sobre conducta sexual en jóvenes estudiantes de esta universidad. Si estáis interesados chicos, incluimos una imagen con más información y el enlace siguiente para inscribiros: https://docs.google.com/ .../1wuF-7s1_jooweo3eqqoM1rT.../viewform

Desde UNISEXSIDA (Universitat Jaume 1). estamos realizando actualmente una investigación sobre conducta sexual en jovenes. Para participar tan solo debtis acudir a nuestro laberatorio de investigacion (facultad de ciencias humanas y sociales, $\mathrm{HC22560L}$ ) y.

1. Complatar una entrevista clinica genera!

2. Cumplimentar una bateria de cuestionarios dingidos a evaluat tu personalidad, autoestima, cientos aspectos de tu conducta sexual, etc.

La participación no suele llevar más de 2 horas y se remunera con 10 quros

Los chicos pueden ganar 10 euros adicionales realizando una segunda parte de la investigación (en total 20 euros). Esta segunda parte es totalmente opcional y su duración es tambietn de aproximadamente 2 horas.

El horario para la realización de la investigación es muy flexible (podera ser tanto por la maḱana como por la tarde). En todo momento trataremos de acoplarnos a tu disponitidad

Ahora os preguntaremos algunos datos para poder ponernos en contacto y concertar la cita Os pediremos que nos indiaueis que dia de la semana y a que hora dispondriais de dos horas liter para poder acudir a nuestro laboratorio y realizar la investigación.

Finalmente, pasartis a otra hoja donde completartis una encuesta de 10 preguntas. Una vez finalizada y segün si westras respuestas se ajustan a un perfil concreto, nos pondremos en

\section{Investigación sobre conducta sexual en jóvenes}

Desde UNISEXSIDA (Universitat Jaume I), estamos realizando actualmente una investigación sobre conducta sexual en jóvenes. Para participar tan sólo debéis acudir a nuestro laboratorio de investigación (facultad de ciencias humanas y...

DOCS.GOOGLE.COM

Me gusta Comentar $\Rightarrow$ Compartir



Has visto el fuego temporal y el eterno, hijo mío, y has llegado a un sitio donde no puedo ver nada más por mí mismo. Con ingenio y con arte te he conducido hasta aquí; en adelante sirva de guía tu voluntad; fuera estás de los caminos escarpados y las estrechuras; mira el sol que brilla en tu frente; mira la hierba, las flores, los arbustos, que se producen solamente en esta tierra (...). No esperes ya mis palabras, ni mis consejos: tu albedrío es ya libre, recto y sano, y sería una falta no obrar según lo que él te dicte. Así, pues, ensalzándote sobre ti mismo, te corono y te mitro.

Virgilio a Dante, canto vigésimo séptimo de la divina comedia, Purgatorio, edición de 1979. 
